\title{
Verena Dohrn
}

\section{Die Literaturfabrik}

\section{Die frühe autobiographische Prosa V. B. Šklovskijs - ein Versuch zur Bewältigung der Krise der Avantgarde}

Verlag Otto Sagner München · Berlin · Washington D.C.

Digitalisiert im Rahmen der Kooperation mit dem DFG-Projekt „Digi20“

der Bayerischen Staatsbibliothek, München. OCR-Bearbeitung und Erstellung des eBooks durch den Verlag Otto Sagner:

http://verlag.kubon-sagner.de

(C) bei Verlag Otto Sagner. Eine Verwertung oder Weitergabe der Texte und Abbildungen, insbesondere durch Vervielfältigung, ist ohne vorherige schriftliche Genehmigung des Verlages unzulässig. 


\title{
SLAVISTISCHE BEITRÄGE
}

\author{
BEGRÜNDET VON \\ ALOIS SCHMAUS \\ HERAUSGEGEBEN VON \\ HEINRICH KUNSTMANN \\ PETER REHDER - JOSEF SCHRENK \\ REDAKTION \\ PETER REHDER
}

Band 216

\section{VERLAG OTTO SAGNER \\ MÏNCHEN}




\section{VERENA DOHRN}

\section{DIE LITERATURFABRIK}

Die frühe autobiographische Prosa V. B. Šklovskijs Ein Versuch zur Bewältigung der Krise der Avantgarde

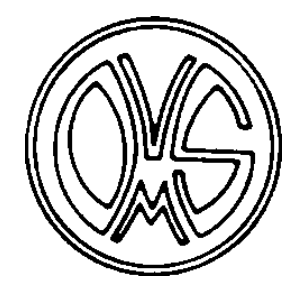

VERLAG OTTO SAGNER · MÜNCHEN 1987 


$$
\begin{aligned}
& \text { Biyc-a'? } \\
& \text { Sian: } n \text { l' } \therefore \text {. ck } \\
& \text { R.:._.:? ! }
\end{aligned}
$$

ISBN 3.87690-384.X

(C) Verlag Otto Sagner, München 1987

Abteilung der Firrina Kubon \& Sagner, München

$$
p 8812449
$$




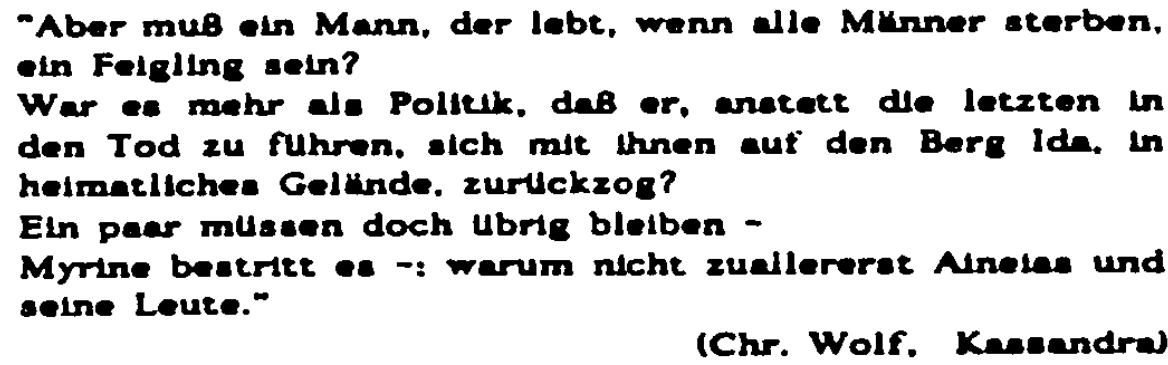

Vorbemerkung

Um die lange Geschichte dieser Arbeit kurz 2u skizzieren: Der Plan, uber Viktor Šklovskij zu schreiben, entstand bereits Ende der 70er Jahre. Das ev. Studienwerk Villigst unterstützte meinen Plan nicht nur finanziell, sondern auch durch guten Rat: Man emptiahl mir Hans Günther, damals noch Protessor in Bochum. als Spezialisten fü die sowjetische Avantgarde der 20er Jahre. Hans Günther erklärte sich bereit, die Dissertation zu betreuen. Im Laute des Jahres 1980 schrieb ich die Rohfassung des 1. Teils der Arbeit. Im Herbst 1982 fuhr ich nach Moskau und besuchte Viktor Šklorskij. Er war beinahe 90 Jahre alt. Ich sah ihn damals zum ersten und zum letzten Mal. Im Jahr darauf, im Winter 1983/84, erhielt ich ein Forschungsstipendium von der Deutschen Forschungsgemeinschaft (DFG): Ich konnte ein Vierteljahr in der Leninbibliothek und in der Bibliothek des Instituts fur Weltliteratur (IMLL) in Moskau arbeiten. In Januar 1985 erhielt ich noch einmal ein solches Stipendium fir einen Monat Arbeit im Zentralarchiv fur Literatur und Kunst (CGALI) in Moskau. Danach bot mir das Bielefelder Doktorandencolloquium. das Hans Günther organisiert hatte. einen kontinuierlichen Diskussionszusammenhang. Im Frühjahr 1986 reichte ich die Dissertation bei der Fakultät für Linguistik und Literaturwissenschaft der Universität Bielefeld ein. Professor Hans Ginther, Dr. Bernd Ublenbruch und Protessor Wilhelm VoBkamp begutachteten die Arbeit. Am 2S. Juni 1986 schloB ich das Promotionsverfahren mit einer Disputation ab.

Für ihre Hilfe danke ich auBer denen, die ich bereits erwähnt habe. Fritz Mierau. Prof. Dr. Aage A. Hansen-Löve, dem Osterreichischen Filmmuseum in Wien, Varvara V. Šklovskaja, Marietta O. Čudakova, E. Levin, Gabriele Leupold. Gesine Böttcher, Anna, Milena und Henning Dohrn.

Hannover/Bielefeld, im Dezember 1987

Verena Dohrn 


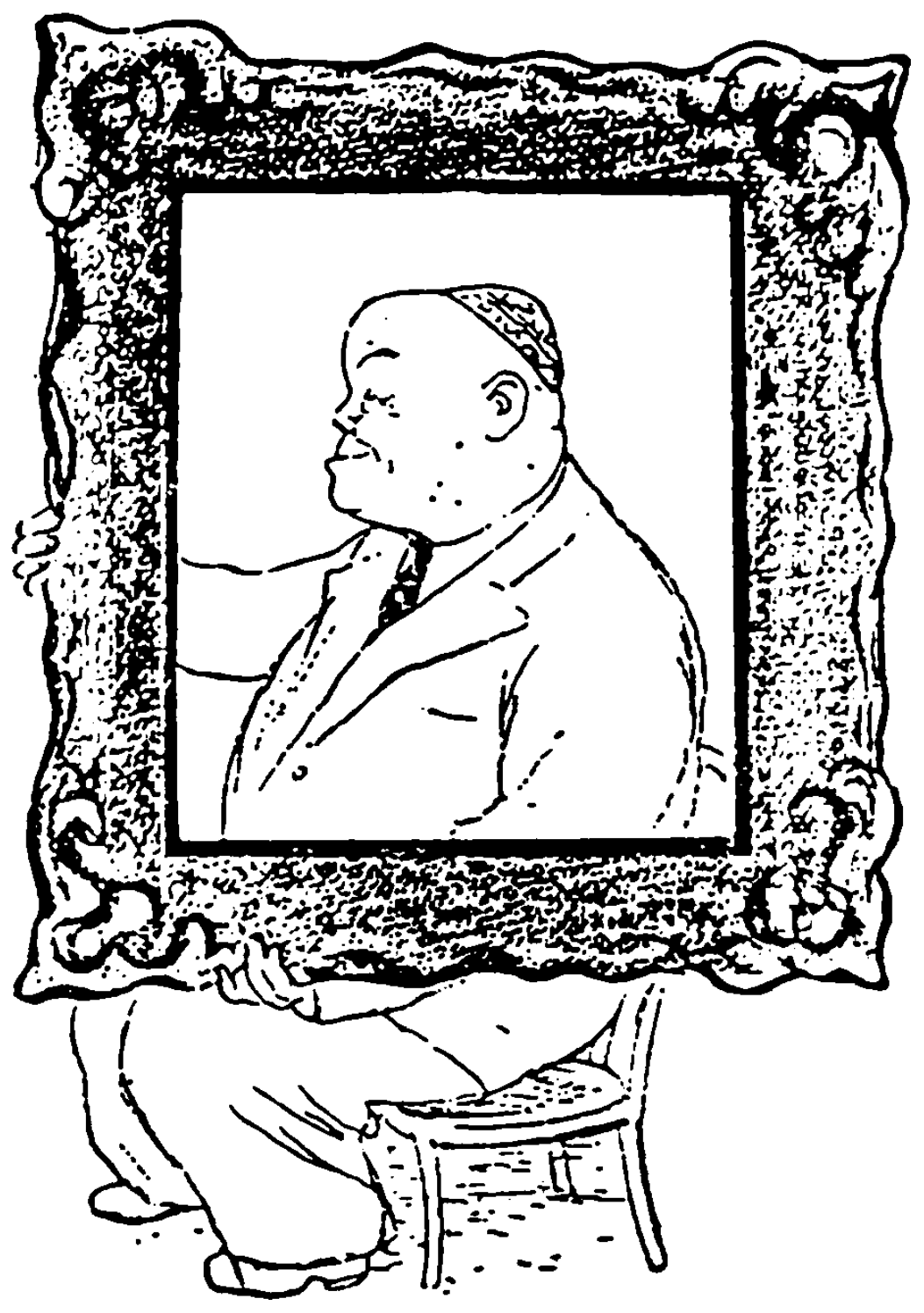




\section{Inhalt}

Einleitung: Nach dem Ende der Kunst ................................... 1

I. Teil : Das Subjekt in der Literaturfabrik ................................. 11

Kap. 1: Die fruhe autobiographische Prosa Šklorskijs und der Formalismus ....................................................................... 12

1. Die "literarische Persönlichkeit" - Zur Herausbildung literatursoziologischer Kategorien im russischen Formalismus

2. Von der Eigengesetzlichkeit der Literatur

Kap. 2: Die frühe autobiographische Prosa Šklorskijs und die Konzeption einer faktographischen Literatur

1. Das Programm der literatura fakta

2. Autobiographie als Selbstreflexion - Šklovskijs Version der literatura fakta

3. Die Verlebendigung der Dinge - ein Kunstgriff der Verfremdung

4. Šklovskijs Teilnahme am Kollektirprojekt WeiBmeer kanalbau"

Kap. 3: Die fragmentarisch-essayistische Form der friihen autobiographischen Prosa Šklovskijs

1. Der Dialog zwischen Tradition und Gegenwart und seine subversive Funktion

2. Šklovskijs Prosa im Verhaltnis zur Essaytradition in Westeuropa

II. Teil: Textanalyse "Dritte Fabrik"

Kap. 1.:

Viktor Šklorskij - der Held der "Dritten Fabrik"

Kap. 2:

Die Stimme des Schriftstellers

1. Die Maske des deplacierten Menschen

Material aus der literarischen Gegenwart

Vorbilder aus der literarischen Vergangenheit

2. Der Experimentator

Ist Šklovskij ein Imitator oder ein Erfinder?

Das Recht auf eine spezielle Kultur

Der Revolutionär und Abenteurer Šklorskij

Kap. 3:

Die Stimme des OPOJAZ-Mitarbeiters

1. Die Maske des Technikers 
2. Der Experimentator im OPOJAZ ................................... 148

Erinnerungen an den OPOJAZ ..................................... 148

Die Fortsetzung der Arbeit ........................................... 153

Unfreiheiten verschiedener Art ...................................... 155

Der Experimentator tanzt mit der Wissenschaft ......... 160

Die Briefe an die Freunde im OPOJAZ - eine Erfin-

Kap. 4: $\quad$ Die Stimme des Kinoarbeiters …........................................ 185

1. Der deplacierte Mensch im Kinoalltag ......................... 185

2. Der Filmtheoretiker Šklovskij ...................................... 200

3. Šklovskijs Montagekonzeption und ihre Literarisierung in "Dritte Fabrik" ......................................................... 205

Schlußbemerkungen: Šklovskijs Literaturfabrik .... 226

Literaturverzeichnis ..................................................................................... 230

Bibliographische Abkürzungen:

CGALI Central'nyj gosudarstrennyj archiv. Moskva

IMILI Institut mirovoj literatury, Moskra

L Leningrad

LEF Levyj front iskusstva

M Moskva

NL Novyj LEF

OPOJAZ Obsčestro izučenija poetučeskogo jazyka

TdF Texte der russischen Formalisten

Literatur im russischen Originaltext wird. sofern sie in deutscher Ubersetzung vorliegt, in gegebener Reihenfolge (russisch/deutsch) nachgewiesen. 
Переписка A. Фадевеа C B. Wкnовскиm-

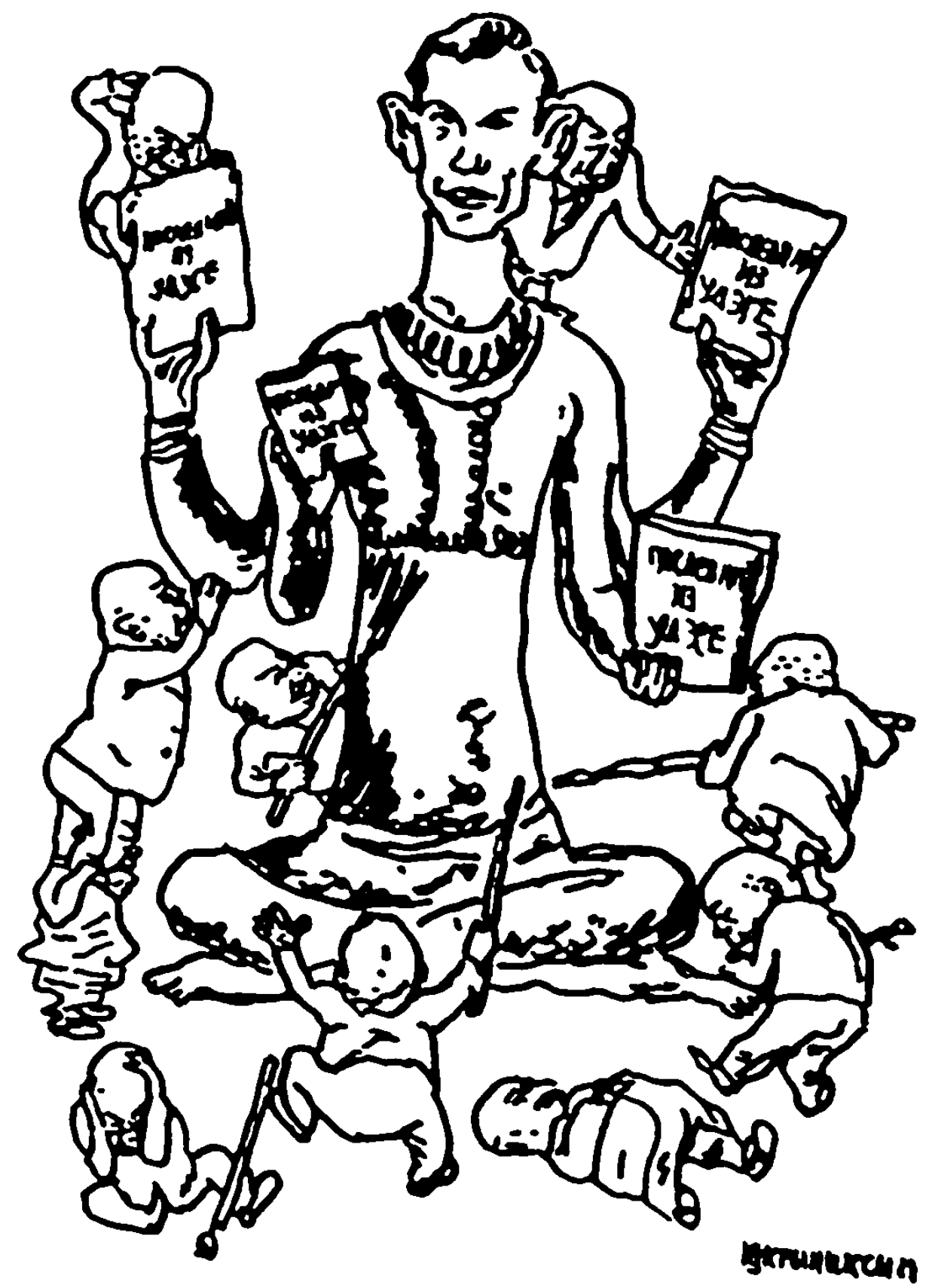



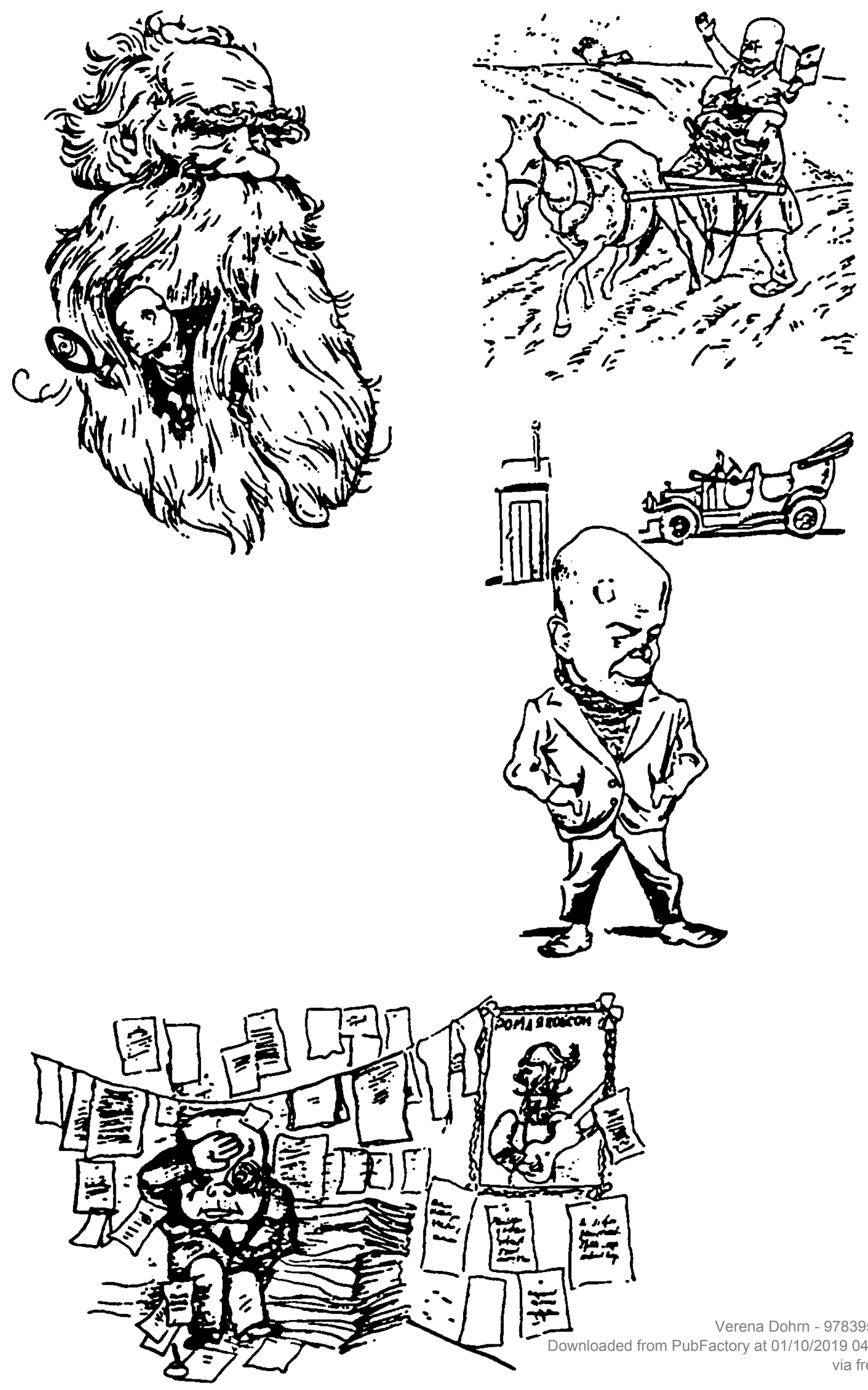
"Du selber muBt an deine Zeit Fragen stellen können,
muBt dem friher Getanen einen neuen Sinn geben.
Friher aB man von der Rübe das Grin, später kam
man dahinter, daB sie eine Hackfrucht ist." (Šklovskij, Žill byli, 1964)

Der Plan, sich heute in der Bundesrepublik Deutschland noch einmal mit der historischen Avantgardebewegung in der Sowjetunion der 20er/30er Jahre zu befassen. obwohl das gesellschaftliche Interesse an diesem Gegenstand längst nachgelassen hat, verlangt nach einer Neubestimmung des Erkenntnisinteresses. Zwanzig Jahre nachdem die Studentenbewegung die sowjetische Avantgarde in der Kunst neu $2 u$ entdecken und euphorisch $2 u$ rezipieren begann, lassen sich Unzulänglichkeiten jener Rezeption unschwer erkennen. Die Hochachtung vor dem politischen Engagement der Studentenbewegung. die die kulturrevolutionären Programme des Proletkul't. des Konstruktivismus. des Formalismus, der Linken Front der Künste (LEF) in die verstaubten Bibliotheken und Hörsäle unserer Universitäten trug. darf nicht den Blick dafir verstellen, daB das Bild von der sowjetischen Avantgarde in der Kunst, wie man es zunächst entwarf, in mancher Hinsicht eher eine Projektion eigener utopischer Vorstellungen war als eine kritische Rekonstruktion. Die Sehnsucht nach einer gesellschaftlichen Identität verleitet nur allzu leicht dazu, vorschnell Ähnlichkeiten zu behaupten, um den Weg nach Utopia abzukürzen.

In dem Bemuihen, dem Verlust der Aura dieser ungebrochen kämpferischkulturrevolutionären Konzeption zu begegnen, entdeckte ich, daB sich innerhalb der sowjetischen Avantgarde ein unglückliches, mehr noch, ein kritisches Bewubtsein dem gesellschaftlichen Leben und dem avantgardistischen Selbstverständnis gegenüber herauszubilden begonnen hatte. Dem nachzugehen. erschien $\mathrm{mir}$ in zweifacher Hinsicht sinnvoll: zum einen, um die eigene Betroffenheit über den Verlust der GewiBheit. man könne die kulturrevolutionären Konzeptionen der linken Avantgarde in der Sowjetunion ohne groBe Probleme auf die eigenen Verhälnisse ibertragen, kritisch 24 bearbeiten. zum anderen, um verschiedene Aspekte des Verhälnnisses von Theorie und Praxis in der Avantgardebewegung in der Sowjetunion der 20er/30er Jahre kritisch zu reflektieren.

Die Emphase, die Dichte der auf Aktion und Radikalität dringenden Zeit der Revolution, des Burgerkriegs und der 20er Jahre, die durch die Suche nach einem Weg der sozio-ökonomischen Stabilisienung und durch politische Machtkämpfe gekennzeichnet sind, produzierte in ihrer Spitze eine Avantgarde. deren Selbstverständnis nicht nur in ihrer Selbstauflösung, sondern in der Auflösung der Kunst im Leben gipfelte. Angesichts dieser das Autonomiepostulat der burgerlichen Kunst radikal in Frage stellenden Forderung 
vermochten sich differenzierte Vorstellungen über die Evolution der Kunst. über mögliche Veränderungen von künstlerischen Formen und Funktionen nicht durchzusetzen. Wo sich die Avantgarde auf die Geschichte von Literatur bezieht, wo sie die Spezifik der Literatur zu begreifen und zur gesellschaftlichen Wirklichkeit in Beziehung zu setzen versucht, verharrt sie in Polemik und Programmatik. Erst in der Krise, in der Zuriicknahme ihrer kulturrevolutionären Konzeption unter dem Druck der politischen Verhältnisse entwickelte sie gegen die verordnete Linie der offiziellen Literaturpolitik ein Interesse an der Spezifität künstlerischer Formen und Funktionen und ein Bewubtsein von der Bedeutung der literarischen Tradition für die Literatur der Gegenwart. Zunächst aber waren die programmatischen Postulate der Avantgarde weder mit der literarischen Tradition noch mit der eigenen Arbeit. noch mit der gesellschaftlichen Realität der Sowjetunion während und nach der Oktoberrevolution dialektisch vermittelt.

Obwohl es in ihren Kreisen - zum Beispiel bei den Formalisten - differenziertere Einschätzungen gab. behandelte der Proletkul't. der Futurismus und der LEF, von dem im folgenden in der Hauptsache die Rede sein soll. die kanonisierte Kunst als das überlebte Alte. das man "vom Dampfer der Gegenwart zu werfen" gedachte." In der eigenen Literaturproduktion gerieten Konzeption und Praxis in Widerspruch zueinander. Vladimir Majakovskij gibt dafür ein schlagendes Beispiel: Seine letzte Ausstellung "Majakorskij 20 Jahre Arbeit" trieb die Unvereinbarkeit von maximalistischem Anspruch und gesellschaftlicher, postrevolutionärer Forderung nach Pragmatisierung des linken Kunstprogramms als Paradoxon auf die Spitze, indem er mit seiner Ausstellung "gegen Denkmäler stritt", die "in Wirklichkeit das originellste seiner Denkmäler wurde". ${ }^{2}$ - Immerhin hat er diesen Widerspruch an sich selbst wahrgenommen und reflektiert.

Der LEF unterschätzte das sozio-ökonomische Ungleichgewicht $z$ wischen Stadt und Land und die daraus resultierende Spannung. Er arbeitete in den GroBstädten Moskau und Leningrad. orientierte sich an der Kunstentwicklung Westeuropas. während auf dem Land der Kampf gegen den Analphabetismus. die Durchsetzung elementarer Kenntrisse der Zivilisation und die Probleme der materiellen Versorgung eindeutig Vorrang hatten vor der Vermittlung von Kunst. Die Radikalität der Avantgardekonzeption erstarte zu einem eindimensionalen Extremismus. Der Anspruch auf Souveränität der Revolution der Kunst gegeniber der sozialen Revolution verkehrte sich zur Isolation der avantgardistischen Kunstproduktion. Der Zwang zur Gemeinschaftswohnung im Alltag stand in einem ebenso krassen Gegensatz zu der euphorischen Kommunekonzeption des LEF wie der Analphabetismus der bäuerlichen Bevölkerung zum Programm von der Schaffung des neuen Menschen. der auf seinen Namen verzichten kann. der allseitig entwickelt und qualifiziert ist und ein befreites Verhältnis zu seiner Arbeit hat.

Die Forderung nach einer historischen Betrachtungsweise der Konstruktionsprinzipien von Kunst verengte sich zu einem Schematismus der Klassifikation: 
der Roman wurde mit Psychologismus und Individualismus, mit einem fiktionalen Sujet und mit der bïrgerlichen Gesellschaft gleichgesetzt; die Reportage, die Skizze, die Faktographie, die Fotographie und der Film dagegen mit kollektiver, technisch fortschrittlicher, am gesellschaftlichen Faktum orientierter Kunstproduktion in der Revolution fur den Sozialismus. Auf diese Weise begann die Avantgarde ihre eigenen Kunstformen zu kanonisieren. Aus der Bestimmung der Kunst als Produktion wurde in Extrem ein technizistisches, rationalistisches Produktionsverständnis im engen Sinne der Industrietechnik, wodurch die Kunst in jeder Hinsicht enorm eingeschränkt wurde. Der LEF entwickelte kaum ein systematisches Interesse an der Rezeptionsseite der Kunst. Die Differenzierung nach individueller und kollektiver Rezeption verfestigte sich zu der illusionären und schablonenhaften Vorstellung, daB letztere - Kunst der StraBen und Plätze - im Sozialismus den absoluten Vorrang erhalten und in der Sowjetunion bedingungslos durchgesetzt werden solle.

In dieser Situation der inneren Widersprüche und Schwierigkeiten wirkte sich die Herrschaft Stalins für die künstlerische Avantgarde verheerend aus. Während der LEF sich international. vor allem an Westeuropa, orientierte. forderte der Stalinismus auch im Bereich der Kunst "die Entwicklung des Sozialismus in einem Lande". Im Unterschied 24 der leninistischen Parteielite konstituierte sich die Führungsschicht unter Stalin nicht mehr aus dem Typus eines von der westeuropäischen Kultur gebildeten Intellektuellen. sondern entstammte den in RuBland geschulten mittleren Funktionärskadern der kommunistischen Partei. Der Intellektualismus der Avantgarde wurde zum Stein des öffentlichen AnstoBes.

Avantgarde-Positionen durften nicht mehr offentlich vertreten werden. Die klassische Literatur murde nun zum "kulturellen Erbe”, zum Vorbild deklariert. Die Kulturfunktionäre problematisierten ihre Rezeption allenfalls unter dem Aspekt der Ressourcen (Papier), der Produktion und der Vertellung. Produktions- und Rezeptionsweisen von Kunst wurden traditionallsiert. künstlerische Experimente tabuisiert, das literaturtheoretische Interesse an der künstlerischen Form diffamiert. Die offentliche Kritik am "Formalismus" bzw. an der "Fetischisierung des Fakts" wurde 1936 als Diskussion um "Naturalismus und Formalismus" in der Literatur bzw. in der Photographie wieder aufgegriffen. Auch die "Expressionismus-Debatte" in der Exilzeitschrift "Das Wort" nahm die Auseinandersetzung mit der Avantgarde-Problematik, wenn auch nur implizit, wieder auf. ${ }^{3}$

So richtig die methodische Trennung der Bedingungen der Krise nach externen und internen Faktoren ist, so problematisch wird sie, wenn es darum geht. die Krise zu interpretieren bzw. die unterschiedlichen Tendenzen ihrer Bewältigung zu begreifen. Da der Schwerpunkt meiner Arbeit nicht auf der historischen Beschreibung von Verlaufsformen liegt, sondern in der exemplarischen Herausarbeitung von spezifischen Problemen einer kïnstlerischen Avantgarde in einer historischen Umbruchsituation bzw. in einer nachrevolutio- 
nären Situation der Restitution des Altags, müssen die immanenten Krisenmomente als Angriffsflächen für externe Einwirkungen begriffen werden. Da die Sowjetunion bis in die 30er Jahre hinein zumindest dem Anspruch nach eine revolutionäre Gesellschaft war, die vorgab. der literarischen Produktion konkrete Praxisfelder zu eröffnen, bleibt zu fragen, ob und, wenn ja, welche Möglichkeiten die sowjetische Avantgarde hatte, um ihr Dilemma - einerseits die Kunstproduktion gesellschaftlich zu isolieren (Gefahr der gesellschaftlichen Irrelevanz), andererseits die Trennung von Kunst und Leben aufzugeben (Gefahr der Pragmatisierung) - zu bewäligen.

Viktor Borisovič Šklovskij (1893-1984) gehörte zum konservativen Flügel der Avantgarde. Diese Bestimmung bezieht sich sowohl auf seine sozialrevolutionäre Interpretation der Oktoberrevolution als auch auf seine Prosakonzeption. Seine Theorie der Prosa, die er, als Hunger, Kälte und Bürgerkrieg herrschten, zusammen mit den Freunden Lev Jakubinskij. Roman Jakobson, Jurij Tymanov. Boris Ejchenbaum u.a. in der Gesellschaft zur Erforschung der poetischen Sprache (OPOJAZ) in Petersburg diskutierte und niederschrieb. gehört zu den Standardwerken der Literaturwissenschaft. Sie ist eine Vorschule fur strukturalistisches und semiotisches Denken. $\mathfrak{S}_{k l o v s k i j}$ bestimmte die Kunst provokativ als "Summe von Kunstgriffen". Er richtete sein Augenmerk auf die Eigengesetzlichkeit, auf die Formensprache der Literatur. In erster Linie interessierte ihn ihre Emeuerung mit dem Ziel. die asthetische Wahrnehmung zu revolutionieren. Doch sollte diese Umwertung der Literatur keineswegs in einer Auflösung der Kunst ins gesellschaftliche Leben münden. Vielmehr lag ihm daran, die Spannung $z$ wischen Alltags- und Literatursprache zum Motor für die Erneuerung der Kunst zu machen. Während die Nlltagssprache nach dem Gesetz der Einsparung geistiger Energien, nach dem Gesetz der algebraischen Denkmethode funktioniere, die de Dinge durch Symbole ersetze, sie als Zahl und Raum begreife, so daB die Gegenstände gleichsam in einer Verpackung an uns voribergingen. sollte die bewuBte Konstruktion der literarischen Sprache, die Verfremdung der Dinge und die Komplizierung der Form, die lebendige Wahrnehmung der Welt wiederherstellen."

Er miBtraute der Vorstellung von der Oktoberrevolution als einer radikalen Befreiung der Gesellschaft von jeglicher Unterdrilckung frither als viele andere und 208 sich dennoch nicht in den Elfenbeinturm der Wissenschaft oder gar ins Exil zurick, sondem kehrte, nachdem er das Jahr 1922 im Berliner Exil verbracht hatte. nach Moskau zurück, verdiente sich seinen Lebensunterhalt als Filmdrehbuchschreiber und arbeitete in der Avantgardeorganisation der Linken Front der Künste, wo er seine Prosakonzeption engagiert vertrat. Es entsprach nicht seinen Vorstellungen von avantgardistischer Literatur. diese vorschnell aus der experimentellen Arbeit zu entlassen und neue. revolutionäre Inhalte in alte, abgelebte Formen zu pressen. Er sah die Unzulänglichkeit von Avantgardepositionen und distanzierte sich ironisch von der Naivität der programmatischen, vom hohlen Klang der pathetischen und vom labilen Gleichgewicht der pragmatischen Positionen. Er sparte nicht mit 
Kritik und Selbstkritik, aber er sah das Kritisierte nicht so sehr als Fehler oder Abweichungen, sondern als experimentelle Schritte, die erprobt, diskutiert, korrigiert oder verworfen werden sollten. In der Zusammenarbeit mit den Schriftstellern des LEF erkannte Šklovskij die Bedeutung der gesellschaftlichen Wirklichkeit für die Literatur. Gemeinsam entwarfen sie einen theoretisch-programmatischen Rahmen für die ästhetische Verarbeitung der Auseinandersetzung $\mathbf{z w i s c h e n ~ K u n s t ~ u n d ~ L e b e n ~ i n ~ F o r m ~ d e r ~ F a k t o g r a p h i e - K o n z e p t i o n . ~}$ einer auf Eingriff in die Welt ausgerichteten Konzeption von Dokumentarliteratur.

Die autobiographische Prosa $̌$ klovskijs stellt eine besondere, eine außergewöhnliche Form von faktographischer Literatur dar. Das Subjekt, die "literarische Persönlichkeit" als Schnittpunkt unterschiedlicher semantischer Reihen im kulturellen Text seiner Zeit ernennt sich zum Gegenstand der Literatur und schaut auf sich selbst. Es sucht nach einem gangbaren Weg für eine experimentelle, engagierte Kunst und Literatur in der revolutionären Sowjetgesellschaft - in einer Zeit, die durch heftige Fraktionskämpfe innerhalb der linken Avantgarde. mehr aber noch durch die ideologischen Auseinandersetzungen 2 wischen den verschiedenen Gruppierungen um die Anerkennung durch die Bolschewiki, d.h. um die Vormachtstellung im Kultursystem. gekennzeichnet ist.

Ohne die ästhetische Konzeption der linken Kunstfront aus dem Auge zu verlieren. entschied sich Šklovskij für die literarische Form der Selbstreflexion. um gegen die beilende Kritik und das naive Unverständnis der sogenannten proletarischen Schriftsteller und gegen den im Laufe der 20er Jahre stäker werdenden Ansturm der offiziellen sowjetischen Kulturdoktrinen zur Einschüchterung der Linken bestehen zu können. Es ging Šklovskij um die Möglichkeit. weiterhin experimentieren, offen und neugierig sein $2 u$ können ftir die Entwicklung kulturrevolutionärer Kunstformen, für die Fortsetzung der vom Leningrader OPOJAZ begonnenen Forschungsarbeiten zur Begrilndung einer formalistischen Literatursoziologie. Unter dem Deckmantel der Narrenfreiheit des Schriftstellers balancierte er auf dem Seil der Selbstreflexion. den Himmel der Kunst, die ihn beflügelte, über sich und doch rom Gesetz der Schwerkraft, vom Leben in gesellschaftlicher Verantwortung unter sich, magnetisch angezogen. Dieser Balanceakt der subjektiven Auseinandersetzung formierte sich zu einer spezifischen Prosa, zu einem eigenen Stll. dem von Sklovskij selbst so genannten barocken, romantisch- ironischen, essayistischfragmentarischen und faktographischen Stil einer autobiographischen Prosa. In der Besprechung des Buches "Sentimentale Reise" schreibt Walter Benjamin uber den Autor:

"Das Genie seiner Beobachtung kommt aus der tiefsten skeptischen Besonnenheit, aus einer Selbstkontrolle ohne alle Eitelkeit. Und wenn er recht hat und die Energie, der Mut, die Liebe, die er dem Chaos gegeniber einsetzt, nichts gewirkt haben, so ist die klare. iberzeugte Geste dieses Mannes sein Buch: eine unvergeBliche Geste voll rücksichtsloser Trauer und voll herrischer Zartheit."5 
Die Prosa Šklovskijs ist weder - im Negativen - Kompensation politischer Ohnmacht bzw. gesellschaftlicher Handlungsunfähigkeit noch - im Positiven Kompensation der HäBlichkeit und Luge des Lebens. 6 Vielmehr bewahrt die ästhetische Transformation der politischen Auseinandersetzung die Authentizität des streitbaren Dialogs zwischen Kunst und Leben, wie er sich in einem Schriftstellersubjekt in der Sowjetunion der 20er/30er Jahre abspielte. Die Auseinandersetzung fand statt. Šklovskij wich ihr nicht aus, er kämpfte sich sein Terrain frel, bestimmte die Kampfart und wähte die Mittel selbst - um den Preis unmittelbarer politischer Folgenlosigkeit, mit dem Ergebnis, daB er noch heute lesbar und wirksam ist.

"Du wirst gewiB sagen, das sei Romantik. Für mich besteht dieses Wort auch heute noch. Es hat seine Verdienste. In alten Zeiten nannten die Russen einen an Ketten hängenden eisenbeschlagenen Balken, mit dem sie die festen Mauern feindlicher Städte brachen. 'roman'. Roman - das war damals ein Mauerbrecher. Später ist er immer mehr gesunken und schlieBlich ein Buch geworden. Und jetzt ist es Zeit. ihm die urspruingliche Bedeutung wiederzugeben. Romantik! Glaub mir. mein Lieber. dieser Mauerbrecher taugt immer noch zum Kampf gegen den Verfall der Ehre. gegen Heuchelei. Gemeinheit und Langweiligkeit." 7

Ich stelle die frühe autobiographische Prosa des Avantgarde-Schriftstellers Šklovskij als einen Versuch vor, die Krise der sowjetischen Avantgarde. ihre eigene Handlungsunfahigkeit und ihre Ohnmacht zu bearbeiten und zu iuberwinden angesichts einer diktatorischen Staatspolitik, die im Namen aller Unterdruickten und Ausgebeuteten Kulturrevolution in politische Indienstnahme der Kunst verwandelt, wobei sie ihre Stellvertreterschaft wissenschaftlich begriindet. Ins Zentrum der Darstellung rücke ich den 1926 veröffentlichten Prosatext "Dritte Fabrik", denn er kann als das Krisenbuch Šklovskijs gelten. ${ }^{8}$ Der Text, seine Konstruktion, sein Wortmaterial - Šklovskijs Marier, es zu bearbeiten und zu formen - bietet Angriffsfläche genug, um von hier aus die anderen frühen autobiographischen Prosatexte - "Sentimentale Reise". "Zoo oder Briefe nicht uber die Liebe" und "Suche nach dem Optimismus"9 ins Blickfeld zu ricken und in die Interpretation einzubeziehen. Von hier aus lassen sich auch die mannigfaltigen Praxisfelder Šklovskijs erschlieBen. Dariber hinaus läBt die Palimpseststruktur des Textes "Dritte Fabrik" die Herkunft des Materials so klar durchscheinen, dab eine von der Textanalyse ausgehende Rekonstruktion kontextueller Zusammenhänge und literaturgeschichtlicher Bezugsfelder möglich ist. Im Vorfeld der Textanalyse möchte ich dem Leser zwar keine systematischen Begriffe, aber doch Bestimmungen an die Hand geben. um methodische Implikationen offenzulegen und um einer Standortbestimmung der Prosa Šklovskijs im kulturellen Kontext der Sowjetunion der 20er Jahre den Weg zu ebnen.

In der Sowjetunion gilt Šklovskij heute als Klassiker der Avantgarde. Zeit seines Lebens muBte er um Anerkennung kämpfen, unter der Herrschaft 
Stalins sich gar den Vorwurf gefallen lassen, er sei ein dekadenter, prinzipienloser Formalist. Sein Erinnerungsbuch Uiber Majakovskij $(1940)^{10}$ brachte ihn vollends in Verruf. Danach war es lange Zeit still um ihn, bis er nach Stalins Tod zu Beginn der 60er Jahre wieder in der Offentlichkeit auftreten und publizieren konnte. Seitdem gewahrte man ihm Auslandsreisen, organisierte Auftritte im sowjetischen Fernsehen. Das Gor'kij-Institut fur Literatur in Moskau unterstlitzte seine Arbeit an einer materialreichen Tolstoj-Monographie. Als Dozent des Instituts lehrte er junge Poeten das Schriftstellerhandwerk. Trotzdem blieb er bis zu seinem Lebensende ein enfant terrible im sowjetischen Kulturbetrieb. Bis ins hohe Alter galt $\$$ klovskij als unermuldicher und unverbesserlicher Kritiker, der sich niemals von literarischen oder wissenschaftlichen Modetrends vor den Karren spannen lieB, sondern beharrlich seinen eigenwilligen Zickzackkurs, zu dem er sich selbstironisch bereits 1921 literarisch bekannt hatte, verfolgte.

Seine schwer faBbare politische Haltung brachte ihm halufig den Ruf eines Feiglings und den Vorwurf der Prinzipienlosigkeit ein. Und es gibt sicherlich Indizien genug, um ihn im Zusammenhang mit brisanten Diskussionen, beispielsweise in Verbindung mit der Debatte um die Veröffentlichung von Boris Pasternaks "Doktor Żivago", der nicht stattgegeben wurde, einer an Selbstverrat grenzenden affirmativen Haltung zu bezichtigen. Aber es gibt ebensoviele denkwuirdige Gelegenheiten, wo er Zivilcourage bewies, zum Beispiel als er. wie Nadežda Mandel'štam in ihren Erinnerungen bezeugt, den verfolgten und verbannten Dichter Osip Mandel'క̌tam in seiner Wohnung aufnahm', oder als er in der Tradition seines eigenen Schutzherm Maksim Gor'kij junge Schriftsteller wie zum Beispiel den auch bei uns in Ubersetzungen bekannten Lyriker Genadij Ajgi förderte, der bis heute in der Sowjetunion Publikationsschwierigkeiten hat.

In der Sowjetunion liegen bis heute vor allen Dingen die seit der Tauwetterperiode verfaBten Texte Sklorskijs ror. Von den frühen Texten sind dem sowjetischen Leser nur die Schriften zum Film in zwei umfangreichen Textsammlungen, ${ }^{12}$ Auszüge aus der "Theorie der Prosa". ${ }^{13}$ der Briefroman "Zoo..." und "Erinnerungen an Majakovskij"14 bekannt. Viele seiner fruihen Arbeiten sind dort bis heute nicht wieder publiziert worden - weder "Sentimentale Reise" (abgesehen von der tibersetzung ins Estnische: Tallin 1969) ${ }^{\mathbf{1 5}}$ noch Theorie der Prosa", weder "Dritte Fabrik" noch "Hamburger Vergleich" oder "Suche nach dem Optimismus" - abgesehen von zahlreichen anderen Texten. publizistischen. literarischen und literaturtheoretischen. Es heiBt, daB eine umfangreiche Edition literaturkritischer Texte Šklovskijs, vor allem solcher aus den fruhen 20er Jahren, in Moskau in Vorbereitung sei.

Bisher sind keine nennenswerten gröBeren Arbeiten uber $\mathbf{S}_{k}$ klovskij in der Sowjetunion erschienen. Dagegen liegen aus den USA zwei Dissertationen iber ihn vor. Richard Sheldons Arbeit von 1966 mit dem Titel "Viktor Borisovic Shklorsky: Literary Theory and Practice 1914-1930-16 setzt sich sowohl mit dem Schriftsteller als auch mit dem Kritiker und Literaturtheoretiker Sklovskif auseinander. Sheldon begreift Theorie und Praxis Šlovskijs als ineinander- 
greifende, einander bedingende Teile eines komplizierten dialektischen Prozesses von Aneignung und EntäuBerung in Auseinandersetzung mit der sowjetischen Gesellschaft jener Zeit. Er spricht ron einer "Evolution" der Grundkonzeption Šklovskijs in den späten 20er Jahren, die in dem Verzicht auf formale Komplexität zugunsten einer formalen Einfachheit zum Ausdruck komme, und hat dabei die Arbeiten Šklovskijs im Rahmen des Novyj LEF vor Augen. Seiner Meinung nach ist die Entwicklung Šklovskijs keineswegs allein als ein Resultat externen Drucks zu verstehen und ebensowenig als eine völlige Abkehr von den Positionen der Gesellschaft zur Erforschung der poetischen Sprache (OPOJAZ).

"Although Shklovsky finally recognized in principle the relevance of social norms to literature. he continued to study literature primarily as form. ${ }^{-16}$

Des weiteren hat sich Sheldon mit seiner Bibliographie der Schriften von und uber Šklorskij, der bisher umfangreichsten und systematischsten Sammlung aller Schriften bis 1976, die es gibt, um Šklovskij verdient gemacht. Diese Bibliographie hat mir meine Arbeit sehr erleichtert. Die andere Dissertation im amerikanischen Sprachraum schrieb eine Schullerin von Sheldon. Malgorzata Munk, uber die Prosa Šklovskijs: "Fragmentation and Unity In the Prose of V.B. Šklovskij, 1923-1963." Ihr Interesse gilt - und darin liegt ihr besonderes Verdienst - dem Schriftsteller Šklovskij, dessen Entwicklung sie weit uber die 20er Jahre hinaus verfolgt.

"In comparison with his recognition as a literary theoretician and critic. Sklovskij the writer has been virtually neglected by Soviet and Western critics alike. There is not a single scholarly work dealing with the body of Śklovskij's other writings in the Soviet Union and only one such work has appeared in the West." 17

Munk bezieht sich in ihrer Ausgangsposition stark auf Sheldon und zielt in ihrer Arbeit darauf $a b$, die These der traditionellen Slavistik in den USA - die Victor Erlich repräsentativ vertritt - zu widerlegen. daB Šklovskijs Entwicklung als eine Kapitulation vor der Zeit und als Niedergang der Konzeption einer experimentellen Literatur zu begreifen sei. ${ }^{18}$

In Frankreich entstand unlängst eine umfangreiche Arbeit ebenfalls über die literarische Praxis Šklovskijs von 1914 bis 1930, die dessen Entwicklung. ahnlich wie Sheldon und Munk, als Evolution verstanden wissen will. ${ }^{19}$

Der Formalist und Schriftsteller $\zeta_{k}$ klovskij ist in der Bundesrepublik Deutschland nicht nur den Slavisten bekannt. Er hat hierzulande $\mathrm{zwar}$ keine breite Leserschaft, aber es gibt doch einen Kreis bibliophiler Kenner, die den immer seltener werdenden Exemplaren seiner ins Deutsche libersetzten Bucher antiquarisch nachspüren und sich neugierig nach Neuauflagen erkundigen. 
Die bekanntesten seiner fruihen Texte - "Sentimentale Reise", "Zoo oder Briefe nicht liber die Liebe". "Theorie der Prosa" und "Erinnerungen an Majakovskij" - liegen seit ungefähr 20 Jahren in deutscher Sprache vor. Nicht Ubersetzt sind bisher die Texte "Rösselsprung", "Dritte Fabrik" und "Hamburger Vergleich" aus den 20er Jahren. "Suche nach dem Optimismus" (1931), zahlreiche literaturgeschichtliche Texte und die Drehbuicher, die Šklovskij verfaßte. Von den Arbeiten, die Šklovskij seit der Tauwetterperiode in den 60er Jahren publizierte, erschienen bei uns in deutscher Übersetzung eine Auswahl der Schriften zum Film, das Erinnerungsbuch "Kindheit und Jugend", die Essaysammlung "Von der Ungleichheit des Ähnlichen in der Kunst" und zwei Monographien - die eine über Ejzenštejn, die andere über Lev Tolstoj.

Die Auseinandersetzung mit Šklovskij im deutschsprachigen Raum beschränkt sich bisher im groBen und ganzen auf den Formalisten, d.h. den Literaturund Filmtheoretiker. ${ }^{20}$ In diesem Zusammenhang ist vor allen Dingen die Dissertation von Aage Hansen-Löve über den russischen Formalismus zu nennen. ${ }^{21}$ In seiner "methodologischen Rekonstruktion der Entwicklung des russischen Formalismus aus dem Prinzip der Verfremdung" räumt der Wiener Slavist Šklovskijs Prosakonzeption eine besondere Bedeutung ein. Aber eine Auseinandersetzung mit dem Avantgarde-Schriftsteller Šklovskij gibt es in deutscher Sprache bisher noch nicht. 


\section{Anmerkungen zur Elnleitung:}

1 VI. Majakoraklf. Vel. Chlebnikor, D. Burljuk. A. KruXenych. PołXaX̌lna objZeatrennomu vikusu. In: Manfesty I programmy rusakich futurtetov. mit. e. Vorwort v. V1. Markov, Sleviache Propylien 27. Munchen 1967. S.50/51

2 F. Mlerau. Majekovakifa Ausstellung und Tod. In: Majakovakif. 20 Jahre Arbelt. Katalog zur Ausatellung im Kunstlerhaua Bethanien vom 12.2. bla 27.3.1978. NGBK Berlin 1978. S.S4

3 vgl. Die Expressionlemuadebate. Metertalen zu einer marxlatschen Realiamuskonxeption. (Hrsg.) H.-J. Schmite. Ffm 1973: vel. de Diskussion mit und Uber A.RodXenko, In: Soretskoe foto S-6 (1936)

4 V.Sklovakl). O teorll prozy. M.1925. $1929^{2}$. reprint: (Zentralantiquartat der DDR Lelpzig 1977. S.12: deutsch (In elner Auswahl): Theorle der Prose. U.: G.Drohla. Ffm. 1966. S.13/14

5 W.Benjamin, Kritiken und Rezensionen. Gesammelte Schriften. Bd.I-V. (Hrsg.) R.Tledemann, H.Schweppenhäuser, Ffm. 1972-1982, Bd.111. S.109

6 vgl. O.Marquard. Kunst als Kompensetion thres Endes. In: Kolloqulum Kunst und Phllosophle 1, Kathetiache Erfahrung. (Hrag.) W. Oelmuller. Paderborn. Munchen. Wien. Zurich 1981. S.160 f. und Chr. Enzeneberzer. Literatur und Interesse. Bd.1. Munchen/Wien 1977. S.15S ff.

7 V.Kevertn. Chudokntk nelzveecen. In: ders., Chudoznik netzvesten I drugle prolzvedenija. Jerusalem 1982. S.160; deutach: Unbekannter Melater. U.: G.Drohla. Ffm. 1961. S.11

8 V.Sklorsklj. Tretja fabrika. M. 1926. reprint: Letchworth-Herta.. England 1978

9 dera.. Sentimentel'noe putexeste. Berlin/M. 1923: deutech: Sentimentale Relse. U.: E.Rledt unter Mitwirkung von G.Drohle. Ffm. 1964: dera.. Zoo 111 plaima ne o ljubvi lll Tretja Elolze. Berlin 1923: deutsch: Zoo oder Briefe nlcht Uber dle Liebe. U.: A.Kaempfe. Ffm. 1965. 1980; ders.. Polakl optimizme. M. 1931

10 dere.. O Majakorakom. M. 1940

11 N. Mandelstam. Dae Jahrhundert der Wolfe. desch. U.: E.Mahler. 1973. S.345 f.

12 V.Sklovakl). Za sorok let. M. 1965, ders.. Za 60 let. M. 1985

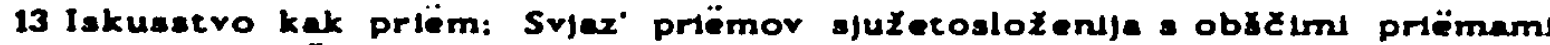
atilje. In: V.Sklorakll. O teorll prozy. M. 1983

14 ders.. Zoo .... ders.. O Majakovskom. In: ders.. Zlll byll. M. 1964. $1966^{2}$

15 vgl. RSheldon. V.B.Shklovaky: An International Blbllography of Worka by and bbout hlm. Ardle/Ann Arbor 1977. S.10

16 RSSheldon. Viktor Bortsovid Shklovaky: Literary Theory and Practice. 1914-1930. Univeratiy of Mlchlgan 1966. S.2

17 M. Munk. Fragmentation and Unity in the Prose of V.B.Sklovakif 1923-1964. New York Univeralty 1974. S.29

18 vgl. V. Erlich. Rusalscher Formalismus. U.: Mariene Lohner. Munchen 1973. S.132 ff.

19 M. Lalle-Waller. Les Romans de V.Sklovaklj, Geapes dune Grolution: 1914-1930. Universit Sorbonne Parla - IV. 1983-84

20 R.lechmarn. Dle Verfremdung und dae Neue Sehen bel Viktor Sklovaklj. In: Poetice H.1. 1970

21 A.Henaen-Löve. Der ruseleche Fomelismua. Wlen 1978 


\section{I. $T \in 11$}

Das Subjekt in der Llteraturfabrlk 
Kap. 1: Die fruhe autobiographische Prose Sklovskifs und der Formallsmus

1. Die "literarische Persönlichkeit" - Zur Herausbildung literatursoziologischer Kategorien im russischen Formalismus

Im Vorwort zu dem Buch "Literatur und Kommerz" (die Buchhandlung A.F.Smirdins) seiner Schuiler im OPOJAZ T.Gric, V.Trenin und M.Nikitin weist Šklovskij auf die Relevanz der Analyse der "literarischen Persönlichkeit" (literatumaja ličnost') als eines das "literarische Leben" (literatumyj byt) wesentlich strukturierenden Elementes für die Bestimmung der Veränderung der Funktion von Literatur hin.

"Schriftsteller. Autor. Dichter - das sind Bestimmungen. die einer Präzisierung bedürfen ... Auch Begriffe wie Schriftsteller. Autor. Dichter, künstlerisches Schaffen (tvorčestvol und literarische Arbeit (literaturnyj trud) verändern sich im Laufe der Zeit ständig ... Wie ein fließender Begriff danach drängt. sich in einem Wort zu verfestigen, so fühlt sich die literarische Evolution zu Familien. zu bestimmten Zeichen hingezogen. die $2 u$ Legenden werden. ${ }^{-1}$

Die literatursoziologischen Studien der Autoren Gric/Trenin/Nikitin über das Verlagshaus Smirdin der 20er/30er Jahre des 19. Jahrhunderts zu Fragen der Professionalisierung des Schriftstellers. zum Problem der Literatur als Handelsware und zu dem der literarischen und gesellschaftlichen Funktion nichtkanonisierter Literatur (Trivial- und Dokumentarliteratur) für die literarische Erolution realisieren am historischen Beispiel die programmatischen Erkenntnisse Ejchenbaums über die Bedeutung des "literarischen Lebens" für die Bestimmung dessen. was Literacur im gesellschaftlichen Kontext ist und leisten kann. ${ }^{2}$ Sie beziehen sich in diesem Zusammenhang gleichermaBen auf Tynjanovs Definition der "literarischen Persönlichkeit" als literarisches Faktum ${ }^{3}$ und auf die Literarisierung desselben Problems in "Dritte Fabrik" von Šklovskij." Die Situation der sowjetischen Literatur am Ende der 20er Jahre zwang die Formalisten zu der Einsicht. daB die Betrachtung der Literatur allein nach dem Gesichtspunkt der Evolution ihrer Technologie und Thematik einer materialistischen Bestimmung nicht genügte, daß so zwar die innere Dialektik der Stile und Genres, aber nicht die Geschichte der Literatur im eigentlichen Sinne dieses Wortes erhellt wurde. Während sich die Formale Schule zunächst gegenuiber Fragen. die das Verhältnis von Literatur und Leben betrafen. weder gegen den Druck des zur Macht gelangten Marxismus noch in Anpassung an ihn. sondern als Konsequenz aus der eigenen Methode und ihrer Diskussion innerhalb der Schule allmählich geöffnet hatte, reagierte sie nun eher auf den Druck der seit Mitte der 20er Jahre politisch gestiutzten marxistischen Kritik. die immer radikaler ein Bekenntnis der Formalisten zur gesellschaftspolitischen Bedingtheit der Literatur forderte. In seinem Aufsatz "Das literarische Leben" antwortete Ejchenbaum auf solche Repressionen 
dezidiert sachlich und scharfsinnig mit einer kritischen Analyse der derzeitigen Situation der sowjetischen Literatur.

"Der literarische Kampf hat seinen früheren spezifischen Charakter verloren: verschwunden ist die fruhere rein literarische Polemik. es fehlen die deutlichen Gruppierungen der Zeitschriften, es mangelt an scharf profilierten literarischen Schulen, und schlieBlich gibt es keine führende Kritik und keinen behartichen Leser ... Die Frage 'wie soll man schreiben' wurde abgelöst oder zumindest durch die andere Frage 'wie soll man Schriftsteller sein' kompliziert. Mit anderen Worten. das Problem der Literatur als solcher wurde durch das Problem des Schriftstellers verdrängt."

Der revolutionäre Anspruch des Sowjetsystems auf Sozialismus und Befreiung der Gesellschaft brachte die russische Literatur - ihrem Selbstverständnis nach souveräner, revolutionärer Faktor im gesellschaftlichen Befreiungskampf - sogar um die Möglichkeit, gegen den zunehmenden Druck der stalinistischen Kulturpolitik aufzubegehren. Sie geriet folglich in die miBliche Lage, 2 war vom Antagonismus des bürgerlichen Autonomiepostulats befreit. dafür aber einem neuen manifesten Abhängigkeitsverhälenis ausgeliefert zu sein. Der Schriftsteller wurde in den Augen Ejchenbaums zum Staatsdiener degradiert.

-Die Lage des Schriftstellers kam der Lage des Handwerkers nahe. der im Auftrag arbeitete oder sich verdingte. Der Begriff des literarischen 'Auftrags' selbst blieb indes unbestimmt und widersprach den Vorstellungen des Schriftstellers von seinen literarischen Rechten und Pflichten." 6

Die Diskussionen um den sozialen Auftrag innerhalb des LEF, in der Zeitschrift Pečat' i revol'jucija etc., finden hierin eine Erklärung. Auf der einen Seite demonstrieren sie den Versuch, die autoritäre Indienstnahme der Literatur durch die sowjetische Kulturpolitik ideologisch zu untermauem, auf der anderen Seite zeigen sie das Bemühen, die Eigengesetzlichkeit der Literatur zu behaupten. Den Formalisten wurde deutlich gemacht. dab die Entwicklung der Literatur und ihrer Funktionen nicht allein durch die Fakten der Evolution. sondern auch durch die Tatsachen des literarischen Lebens, der Genesis. bestimmt wird. - ein Zugeständnis Ejchenbaums an die marxistische Terminologie. Die Literaturwissenschaft werde somit vor ein neues Problem gestellt. vor "das Problem der Beziehung 2 wischen den Fakten der literarischen Evolution und des literarischen Lebens." 7 In Abgrenzung gegen die Soziologisten unter den marxistisch-leninistischen Literaturtheoretikern bestimmt Ejchenbaum die Hinwendung zum Material des literarischen Lebens keineswegs als eine Abkehr vom literarischen Faktum. Es geht ihm weder um die Betrachtung literarischer Werke vom Standpunkt der Klassenzugehörigkeit des Autors noch um eine ökonomistische Ableitung des Literarischen aus sozialen und wirtschaftlichen Faktoren, denn die Beziehungen zwischen den Fakten der literarischen Reihe und denen. die auBerhalb ihrer liegen, - so Ejchenbaum sind keineswegs kausale, "sie beruhen vielmehr auf Entsprechungen, Wechsel- 
wirkungen, Abhängigkeiten oder Bedingtheiten. ${ }^{8}$ Hinwendung zum Material heiBt fur thn dialektische Verknijpfung formalistischer Prosatheorie mit literatursoziologischen Kategorien für die Analyse der Genesis.

Die Bestimmung der "literarischen Persönlichkeit" geht auf Tynjanov zurück. In seinem Aufsatz "Das literarische Faktum" aus dem Jahre 1924, den er ک̌klovskij widmete. weist Tynjanov auf die Bedeutung der "literarischen Persönlichkeit" als "literarischem Faktum" hin. Gegen einen Biographismus und Psychologismus in der Literaturbetrachtung wendet er ein, daB die Frage nach der "literarischen Individualität" häufig mit der Frage nach der "Individualität des Literaten" vertauscht werde. 9 Er hingegen will die "literarische Persönlichkeit" als Konstruktionsprinzip verstanden wissen, "dem es im rein literarischen Material zu eng wird" und das auf "auBerliterarische Erscheinungen ibergeht." ${ }^{\text {10 }}$ Diesen Gedanken führt Tynjanov drei Jahre später in dem programmatischen Aufsatz "tber die literarische Evolution" unter dem Gesichtspunkt der "Expansion der Literatur in das auBerliterarische Leben" näher aus.

'Die 'literarische Persönlichkeit', die 'Dichterpersönlichkeit', der 'Held' erscheinen $\mathrm{zu}$ verschiedenen Zeiten als sprachliche Intention der Literatur und gelangen von dort ins auBerliterarische Leben."11

Diesen ProzeB begreift Tynjanov als eine der literarischen Reihe immanente Emeuerung von Konstruktionsprinzipien. die einer Kanonisierung der Literatur entgegenwirken soll. Er zeigt, wie auBerliterarische Groben gewissermaßen ein Reservoir für die Literatur bilden und in das System des Literarischen aufgenommen werden. aber er weicht der Frage. inwieweit die soziale Reihe die Literatur in ihren Funktionen bestimmt und welche Rolle die "literarische Persönlichkeit" in diesem Zusammenhang spielt. aus, auch wenn er zugesteht. daB für die "Expansion der Literatur in das auBerliterarische Leben ... selbstverstandlich besondere auBerliterarische Bedingungen erforderlich" sind. ${ }^{12}$ In dieser Hinsicht ist ihm Ejchenbaum weit überlegen, denn ihm ist es gelungen, die Bedeutung der Frage nach der sozialen Stellung der Kunst und der Frage "wie soll man Schriftsteller sein?" für die Literatur zu erkennen und sie nicht den Soziologisten zu überlassen. sondern sie in Form der Bestimmung des "literarischen Lebens" in das System literaturwissenschaftlicher Begrifflichkeit 24 iberfuhren. ${ }^{13}$

Die Autoren Gric/Trenin/Niktin erheben in ihrer Studie uber Literatur und Kommerz die Vermittlung dieser Erkenntnis mit Tynjanovs Bestimmung der "literarischen Persönlichkeit" als Faktum der literarischen Reihe zum Programm. Sie gehen von der Arbeitshypothese aus, daB

"die Konstruktion einer wahrhaft wissenschaftlichen Geschichte der Literatur als einem dynamischen System der literarischen Evolution (...) 
unmöglich (ist) ohne die Lösung des Problems des literarischen Lebens und in erster Linie der Frage nach der Position des Schriftstellers." 14

So verstanden kann auch die Biographie zu einem aktiven Faktor für die Herausbildung eines bestimmten Stils oder Genres werden und eine "literarische Persönlichkeit" konstituieren, die in einer Gegenbewegung wiederum. literarisch vermittelt, konstruktiv auf das "literarische Leben" einwirkt.

Die methodologische Bedeutung der Entwicklung des Formalismus hin zu einer soziologisch fundierten Literaturtheorie hat Hansen-Löve in seiner Arbeit uber den russischen Formalismus detailliert beschrieben und nachgewiesen. Seiner Meinung nach darf die letzte methodologische Phase des Formalismus nicht als Bruch mit dem urspringlichen Konzept, nicht als ideologisches Scheinmanöver oder opportunistische Haltung gegeniber der stalinistischen Kulturpolitik kritisiert. sondern muB als konsequente methodologische Entfaltung des Formalismus begriffen werden.

Wenn Ejchenbaum eine Modifizierung der Theorie fur notwendig erachtete. weil die Fakten sich gegen eine Interpretation im System der bisherigen formalistischen Evolutionstheorie sperrten -

"Jede Theorie aber ist eine Arbeitshypothese, die vom Interesse an den Fakten selbst bestimmt wird ... Das Bedürfnis aber gerade nach diesen oder jenen Fakten. das Erfordernis des einen oder anderen Bedeutungsvorzeichens wird von der Gegenwart diktiert, von Problemen, die gerade aktuell sind." ${ }^{-15}$

- dann ist dies. mehr als eine passive Reaktion, eine gegen die politische Zensur durch List getarnte aktive wissenschaftliche Auseinandersetzung mit der eigenen Zeit. In diesem Sinne argumentiert auch Hansen-Löve:

"Es ist daher die formalistische Interpretation der Falsifizierbarkeit theoretischer Positionen unter dem Druck des synchronen Interesses und der Faktizität von den Formalisten selbst bewuBt einseitig und untertreibend vollzogen worden. da es ihnen auf diese Weise möglich schien, ihre eigene synchrone Position als Theoretiker und mitoder selbstschaffende Künstler zu legitimieren und durch den Rekurs auf die Eigengesetzlichkeit des 'literaturnyj byt' in diesen all jene Instanzen zu integrieren. die - jenseits der immanenten 'Evolution der Verfahren' - aus der Position der Macht das Verlagswesen. die Zensur, die gesamten materiellen und existentiellen Bedingungen der Arbeit des Schriftstellers (und Theoretikers) beherrschten. ${ }^{-16}$

Die Auseinandersetzung mit dem "literarischen Leben" richtet sich zugleich auf Vergangenheit. Gegenwart und Zukunft. Ejchenbaum versteht "Geschichte als besondere Methode zur Erforschung der Gegenwart mit Hilfe von Fakten der Vergangenheit. ${ }^{-17}$

Im System des "literarischen Lebens" der 20er/30er Jahre verkörpert Šklovskij das Paradigma einer "literarischen Persönlichkeit". Es entspricht seinem 
Selbstverständnis als Avantgarde-Schriftsteller, diese Rolle nicht nur zu spielen, sondern sie zugleich auch im Sinne der literatursoziologischen Methode des Formalismus zu reflektieren: Wie soll man Schriftsteller sein? Wie kann man seine Position künstlerisch, moralisch. sozial, kommunikativ legitimieren?

In seinem Aufsatz "Zur Verteidigung der soziologischen Methode" radikalisiert $\zeta_{k l o v s k i j}$ das Prinzip, die Theorie müsse sich durch gesellschaftliche Tatsachen veriflzleren lassen, nach dem Motto "Die Fakten existieren unterdessen veiter" in einer für die Wissenschaft provokanten Art und Weise.

"Die Formalisten (OPOJAZ) wollen sich zugleich dem wissenschaftlichen Faktum nicht widersetzen. Wenn die Fakten die Theorie zerstören. um so besser für die Theorie. Wir haben sie selbst geschaffen, sie wurde uns nicht zur Aufbewahrung anvertraut.

Die Veränderung des ästhetischen Materials ist ein soziales Faktum ..."18

Ähnlich wie Ejchenbaums Konstruktion des "literarischen Lebens" ist hier der Versuch der Selbstlegitimation, der aus diesen Worten spricht, keineswegs als eine Kapitulation vor der gesellschaftlichen Wirklichkeit zu verstehen; er entspringt vielmehr einer "vitalistischen Tendenz". die - so Hansen-Löve durchaus die Kontinuität des frihen Formalismus wahre und auf ein existentielles Interesse an einer permanenten Auseinandersetzung mit dieser Wirklichkeit hinweise. ${ }^{19}$ Im Unterschied zu Éjchenbaum findet bei Šklovskij dieser Dialog nicht in erster Linie in der wissenschaftlichen Arbeit. sondern in der Literarisierung seinen stärksten Ausdruck. Šklovski\} macht sich selbst zu einem literarischen Thema.

"Als Sprachrohr dienten Viktor Šklovskij seine bloßen Handflächen. well ihm kein anderes Material unter die Finger kam ...20

schreibe Tynjanov. Seine Absicht. ein Buch Uber Šklovskij als einen neuen Typus des Schriftstellers $z u$ verfassen, blieb ein unvollendetes Projekt. Im Tynjanov-Archiv fanden sich Fragmente einer Beschreibung: Šklovskij sei ein scharfsinniger und witziger Schriftsteller (ostroumec), der stark der literarischen Tradition (Karamzin. Sterne, Rozanov etc.) verhaftet und mehr als nur ein sentimentaler Ironiker sei. Er konstituiere einen neuen Schriftstellertypus, weil er mit Material arbeite, das ihm sehr nahe stehe. das in seinen Händen llege und während der Arbeit auf ihn zu trete. Im Zweifel an sich selbst, in der Unsicherheit dariber, was man mit einem unbekannten Gegenstand machen solle. liege Šklovskijs Stärke. In dieser Hinsicht unterscheide er sich von einem Possenreißer, der die Fakten nur flüchtig berühre und sie schnell wieder vergesse. Tynjanov deutet hier bereits an, was sich in der Untersuchung der autobiographischen Prosa noch erweisen soll, wie Šklovskijs vom Sensualismus und von der Lebensphilosophie geprägte Schreibweise, die in seiner Prosatheorie ein konzeptionelles Fundament erhält, den 
autobiographischen Schriftsteller vor einer oberflachlich anekdotischen Verarbeitung des Materials bewahrt. Die Selbstthematisierung des Schriftstellers erfüllt hier eine doppelte Funktion: zum einen, die Literatur durch die Einführung auBerliterarischen Materials vor der Erstarrung, vor Automatisierung und Kanonisierung, zu bewahren, zum anderen. ihr die Aura des Autonomiepostulats zu nehmen und die Auseinandersetzung der Schriftstellerpersönlichkeit liber die Zerrissenheit von Kunst und Leben in die Literatur selbst zu verlagern. Šklovskijs spezifische literarische Verarbeitung dieses Problems - vor allem in der "Dritten Fabrik" - war nicht nur für die Literaturwissenschaftler des OPOJAZ wegweisend: sie konstituierte eine neue Form von Literatur, die jener literatursoziologischen Methode künstlerisch entspricht und nur in Zusammenhang mit ihr angemessen erfaBt und beurteilt werden kann.

Auch Ejchenbaum schildert seinen Freund und Mitstreiter im OPOJAZ als einen ganz besonderen Typ von Schriftsteller. Nicht nur seine Ideen, sein Stil oder seine Theorie seien der sowjetischen Literaturkritik ein Dorn im Auge. sondern vor allen Dingen sein Auftreten, sein Ton, seine Anspielungen, seine Marier.

"Er verkörpert nicht nur einen Autor. sondern eher eine literarische Personage, den Helden irgendeines ungeschriebenen Romans, und zwar eines Problemromans. ${ }^{-21}$.

schreibt Ejchenbaum und knujpft damit an Tynjanors Bestimmung der "literarischen Persönlichkeit" an. Man könnte meinen, die Formale Schule hätte Šlovski\} ihre literatursozlologische Konzeption auf den Leib geschneidert. Šklovskij verkörpert das Paradigma einer "literarischen Persönlichkeit" als Schnittpunkt - oder wie Hansen-Löve sagt - als Träger" zweier Systeme. des literarischen und des sozialen Systems. 22

"Nls 'Meister des Wortes' findet seine Manier nicht nur Eingang in die Literatur, sondern auch in den Brief, in die Lebensform, ins Gespräch, in studentische Referate." 23

Ejchenbaum erkennt, daB Šklovskif es nicht bloB verstand. revolutionär auf die Kunst, sondern in der umgekehrten Bewegung auch auf das Allagsleben einzuwirken. Damit rittelt er von der entgegengesetzten Seite an demselben Tabu, das auch die marxistisch-leninistischen Kulturtheoretiker sprengen wollten - an der Trennung zwischen Kunst und Leben. Aber während diese die empirische politische Wirklichkeit der Sowjetunion als wahrgewordene Utopie einer befreiten Gesellschaft uber die Kunst stellten -

"Potentiell hat diese (die sowjetische, d.V.) Intelligenz alle Voraussetzungen in sich fir die Entwicklung einer Kunst, die bedeutende (Hervorhebung V.D.) Erlebnisse ausdrickt und dadurch 'ansteckt'."24 -

hät Šklorskij an der Konzeption einer Literatur fest, die der fortwährenden 
Anarchie des Lebens exemplarisch eine Form gibt - und sei es auch eine widersprüchliche, gebrochene, elliptische.

"Er ist professionell bis in die Knochen ... Literatur ist für ihn wie das Atmen, wie das Gehen. In die Zusammensetzung seines Appetits geht die Literatur ein. Er probiert sie auf ihren Geschmack hin, weiB, woraus sie hergestellt werden muB und liebt es, sie selbst zuzubereiten und verschiedenartig zu gestalten. Deshalb liest er professionell Buicher. unterhält sich professionell mit Leuten. lebt professionell." 25

Nur während er schlafe. sei er nicht professionell, bemerkt Ejchenbaum scharfzüngig mit einem Seitenhieb gegen Šklovskijs humorvolle Gelassenheit und Souveränität angesichts der politischen Repressionen des Alltags. Trotz des "Knirschens der Rezensentenfedern" schlafe er tief und fest. Vielleicht so meint er - ertrugen Leute, die keine "professionelle oder historische Freundschaft" mit ihm verband, seine Anwesenheit in der Literatur deshalb so schlecht. 26

Šklovskij macht sich - wie er selbst nicht ohne Ironie zugibt - zum Helden seiner literarischen Produktionen. Aber nicht hierin liegt der Unterschied zu anderen Schriftstellern, die alle in irgendeiner Weise durch Helden sprechen und sich in Helden verkörpern. sondern darin. daB er den ProzeB der komplizierten Verknipfung von auBerliterarischem sozialem und literarischem Material in der "literarischen Persönlichkeit" durch EntblöBung des Kunstgriffs als Konstruktionsprinzip kenntlich macht, aber dadurch nicht etwa "Literarizität" einer Vortäuschung von Welthaftigkeit uberführt. sondern ihr in der spezifischen Verarbeitung des sozialen Materials eine Eigengesetzlichkeit attestiert, so daß sie fähig wird. in Verschiedenverstehbarkeit kodifiziert Botschaften zu transportieren. die uber eine Widerspiegelung der Wirklichkeit weit hinausreichen. So wie der Held im Roman sich von seinem Schöpfer löst. lebendig wird und eine gewisse Eigenständigkeit erhält, so distanziert sich der Schriftsteller von seiner literarischen Figur Šklovskij. Aus der Reflexion dieser Distanzierung entsteht das künstlerische Verfahren der Verdoppelung der "literarischen Persönlichkeit" zu einer dialogischen Figur. Mit diesem Verfahren versetzt Šklovskij vor allen Dingen den sog. proletarischen Schriftstellem der RAPP einen ironisch-kritischen Seitenhieb, die in jenen Jahren, sich gegen das faktographische Konzept der LEF-Avantgardisten ereifernd, den psychologischen Roman, die Bedeutung des Helden im Roman verhertlichten, eine Diskussion, die in der Auseinandersetzung um Libedinskijs Roman "Geburt eines Helden" (1930) ihren Höhepunkt fand.

Die "literarische Persönlichkeit" Šklovskij stand immer wieder im Feuergefecht der Auseinandersetzungen des "literarischen Lebens" der 20er Jahre. Ejchenbaum schreibt:

"Jeden Tag, in jeder beliebigen Zeitungsnotiz oder Zeitschrift 'beschimpft' man Śklovskij. Es kommt noch soweit, daB man bei Šklovskij studiert, ihn beschimpfen zu lemen. ${ }^{-27}$ 
Šklovskij ging auf diese Attacken, die gegen ihn gefuhrt wurden, nicht jenseits. sondern gerade und ausschlieBlich innerhalb seiner literarischen Praxis ein und verwandelte diese Auseinandersetzung in literarische Konstruktionen. Er entzog sich damit der Diskussion auf ideologisch-politischer Ebene und wurde erst für den greifbar, der sich auf die Immanenz des Literarischen einlieB. Die "literarische Persönlichkeit" - der Held seiner Prosa - entstehe auBerhalb des Schriftstellers, sie entlaste ihn in seiner Verantwortung und erzeuge jene politische Unverständlichkeit, die sich unter Umständen in einen intuitiven Gedanken verwandeln könne, erläutert Šklovskij die Funktion dieses Kunstgriffs. ${ }^{28}$ Auch ein programmatisch-politisch deklarierter Aufsatz wie "Denkmal für einen wissenschaftlichen Irrtum" muB deshalb nach den Kriterien eines Kunstwerks beurteilt werden. Die "literarische Persönlichkeit" Šklovskijs verweigert sich einer moralisch-politischen Zuordnung auf der Basis eigener transitiver Aussagen.

"Das Schwanken zwischen Literarisierung und Existentialisierung des Identitätsverlusts relativiert auf der einen Seite alle transitiven Aussagen Šklovskijs hinsichtlich ihrer 'moralischen Zuverlässigkeit' und verleiht auf der anderen Seite der EntblöBung der literatumost' und uslornost' Intentionen, die über die asthetischen weit hinausgehen." 29

Hansen-Löve erkennt hier, dab die Intentionen der literarischen Praxis Sklorskijs weit über rein ästhetische hinausreichen. Er rekurriert in diesem Zusammenhang auf Šklorskijs Lebensphilosophie und auf seine Kritik an den Bolschewiki in der "Sentimentalen Reise". Um so mehr mundert es, wenn er an Ende die Entwicklung der Positionen Sklorskijs 2 war nicht in Abrede stelle, aber doch so relativiert, dab nichts anderes als ein rein ästhetischer Immanentismus ibrigbleibt. "Das in sich ruhende Gliick der totalen Sensibilität, die gleichzeitig zu einer freudigen Aufgabe der (monoperspektivischen) Idencität führen muibte". 30 sei sein letztes Ziel. Der Kïnstler-Theoretiker, der gleichzeitig zwei heterogenen Reihen angehöre - der der Kunst und der des Lebens -. könne die heterogenen Kräfte, die sich in seiner Person uber schnitten, nur "formal", "struktural", "wie der Kalauer oder die Metapher die heterogenen semantischen Reihen". aber nicht "kausal-genetisch" verbinden. Deshalb muinde seine Identitätssuche in eine "Existentialisierung der Intransivität des Ästhetischen". in einen "asthetischen Augenblick" im doppelten Sinne des Wortes, der nicht Uberschritten werden wolle. Dem möchte ich entgegenhalten. daB der ästhetische Augenblick in Šklorskijs autobiographischer Prosa nur Inseln, Abweichungen im ambivalenten System der Auseinandersetzungen. Abseiten zur Aufbewahrung fülbarer Worte sind, die Sklovskij, in literarische Form gebracht, wieder ans Tagesilicht der Diskussion zerrt. um sie lebendig zu erhalten. Die literarische Konstruktion verhindert die Erstarrung des "ästhetischen Augenblicks" und durchbricht die asthetische Immanenz. Seine literarischen Konstruktionen leben 2 war von den Abweichungen. diesem Netz von Verschiebungen und Anekdoten, die aber - 
umgekehrt - ohne die Konstruktion nichts wären.

Die über das Ästhetische hinausweisende Bedeutung der Konstruktion in der Theorie wie in der literarischen Produktion Šklorskijs unterschlägt HansenLöve in seinen SchluBbemerkungen ibber den russischen Formalismus. "In der Bearbeitung des Gegenstands (Literatur. V.D.) erlebte ich den Gedanken an die Freiheit" sagt Šklovskij in der "Dritten Fabrik". ${ }^{31}$ An einer anderen Stelle: "Wir muissen Methoden suchen. Einen Weg finden. um Unfreiheiten verschiedener Art zu begreifen. ${ }^{-32}$

Für Šklovskij ist die literarische Konstruktion solch eine Methode, an der die "Grenzen der Freiheit" und die "Deformationen des Materials" aufgezeigt und im literarischen Entwurf einer eigenen. eine neue Fiktionalität konstituierenden Formgebung exemplarisch überschritten werden.

In der Figur der "literarischen Persönlichkeit" hat sich die sowjetische Avantgarde ein Medium zur Verarbeitung der eigenen Krise geschaffen. Nicht nur die Anhänger der Formalen Schule. Ejchenbaum. Tynjanov, Šklovskij u.a.. haben im BewuBtsein ihrer Rolle als Träger des literarischen Lebens die Verantwortung für die Entwicklung der Literatur ubernommen. indem sie Theorie und Praxis auf ihre gesellschaftliche Funktion hin reflektierten, auch Avantgardeschriftsteller wie Majakorskij (2.B. "Die Wanze". "Das Schwitzbad"). Venjamin Kaverin ("Skandalist". "Unbekannter Meister"), Jurij Oleša ("Vieid) u.a. Literarisierten auf der Suche nach einer gesellschaftlichen Identität als Schriftsteller die existentiellen Probleme der Literatur in einer ihrem Anspruch nach befreiten. de facto aber einer zum autoritären Herrschaftssystem erstarrenden Gesellschaft. Auch ihnen eröffnete die literarische Verarbeitung der Selbstreflexion die Möglichkeit, der Krise der Avantgarde nicht auszuweichen und sich ihr zu stellen. ohne das Gesicht 24 verlieren.

\section{Von der Eigengesetzlichkeit der Literatur}

Ich betrachte Šklovskij nicht in erster Linie als einenTheoretiker der Formalen Schule, sondern als eine "literarısche Persönlichkeit" in der Sowjetunion der 20er/30er Jahre und zugleich als einen Schriftsteller der LEF-Avantgarde. Dementsprechend verwahre ich mich dagegen. Theoretiker und Schriftsteller getrennt zu betrachten. Gleichwohl ist es unter methodischen Gesichtspunkten von Bedeutung, die jeweiligen Formen der Vermischung verschiedener Verfahren, derer sich Šklovskij bedient, zu studieren und sie $2 u$ diesem Zweck voneinander $z u$ sondern, d.h. zu untersuchen, mit welchen Intentionen und in welchen Funktionen beispielsweise Erinnerungen an die eigene Kindheit neben einen literaturtheoretischen Essay iber den Zusammenhang 2 wischen dem Kunstgriff der mündlichen Erzählung (skaz) und der Sujetkonstruktion montiert sind. oder aber in welchem Verhältnis die konzeptionellen und kritischen Arbeiten. die Schriftstellerbiographien. die Kinderbuicher und die Kinoarbeit zu der autobiographischen Prosa stehen. 
Seit etwa fünfzehn Jahren haben die programmatischen Konzeptionen der sowjetischen Avantgarde und auch die Theorie und Geschichte des russischen Formalismus ihren festen Platz in den literaturwissenschaftlichen Diskussionen zumindest der westlichen Welt. Eine kritische Auseinandersetzung mit ihnen ist gleichsam die Basis, von der die Analyse der avantgardistischen Prosa Sklovskijs abhebt und zu der sie, um sich $z u$ vergewissern, immer wieder zurückkehrt, ebenso wie die Avantgardekonzeptionen der damaligen Zeit selbst Ausgangspunkt. Material und methodische Voraussetzung für die literarische bzw. kulturrevolutionäre Praxis waren und vice versa zum Gegenstand neuer, alte Positionen modifizierender literaturtheoretischer Diskurse wurden. Die Prosa Šklovskijs amalgamiert formalistische Prosatheorie und faktographische LEF-Konzeption, ohne daB sie auf deren Theoreme und programmatische Forderungen reduziert werden kann. In der literarischen Verarbeitung erfahren die Konzeptionen eine ästhetische Umwertung, in der künstlerischen Formung werden sie umfunktioniert und neu gebildet, so daB sie nicht wie ein Echo. sondern als Stimmen - thematische und konstruktive - aus dem polyphonen und verschiedenverstehbaren Prosawerk tönen.

Šklovskijs literaturtheoretische Uberlegungen kristallisieren sich um 2 wei Zentren - um die Arbeiten des OPOJAZ, die im wesentlichen in der Theorie der Prosa" zusammengefaBt sind, und um die Autsätze zur Konzeption einer faktographischen Literatur, die zum groBen Teil im Noryj LEF erschienen und später in dem Sammelband "Literatura fakta" abgedruckt wurden. ${ }^{33}$ '̌klovskijs spezifische Methode der Vermischung theoretischer und literarischer Thematik und Schreibweise produziert vielfätige Genreformen, die nur schwer den klassischen Gattungen zuzuordnen sind. Hansen-Löve versucht. die Mischgattungen im Prosawerk Šklovskijs systematisch in Form einer Tabelle zusammenzustellen. ${ }^{34}$ Zunächst unterscheidet er 2 wei groBe Gruppen voneinander - die wissenschaftliche literatura fakta und die literarische literatura fakta, die er noch einmal in je $z$ wei. insgesamt vier Prosatypen unterteilt. Der ersten Gruppe ordnet er zum einen die theoretischen Genres (z.B. Theorie der Prosal zu. in ihnen finde sich die poetische Realisierung der Konzeption nur punktuell als Verfremdungseffekt und die Einstellung auf den theoretischen Diskurs sei dominant. zum anderen die Montage literaturkritischer Texte (z.B. "Hamburger Vergleich". "Lohnarbeit im Tagewerk". "Rösselsprung"). in denen die poetische Realisierung als verfremdender Kommentar in illustrativer, dienender Funktion eingesetzt sei. Der 2 weiten groBen Gruppe der literarischen literatura fakta ordnet er zum einen theoretisch-literarische Mischgenres wie "Dritte Fabrik" und "Suche nach dem Optimismus" zu. Hier wiirden theoretisch-wissenschaftliche Motive leitmotivisch entwickelt, die eng stilistisch, perspektivisch und semantisch zu einer Einheit verflochten seien, und in denen so ein Gleichgewicht 2 wischen theoretischer und literarischer Einstellung herrsche, wodurch eine Gleichberechtigung 2 wischen Theoretisierung und poetischer Realisierung hergestellt sei. Zum anderen ordnet er der Gruppe der literarischen literatura fakta die sujetlose Prosamontage ("Sentimentale Reise", "Zoo oder Briefe nicht iber die Liebe") $z u$, in der die Theoretisierung 
als Verfremdungssignal z.B. in Form der Abschweifung fungiere, und die in erster Linie ein literarisch-fiktionales Genre sei.

Die tabellarische Systematisierung gibt einen ersten Uberblick uber das komplizierte System der theoretischen, kritischen und literarischen Komponenten des Prosawerks und scheint als Fundament für die These geeignet zu sein, daB $\mathfrak{S}_{k}$ lovskij qua Literarisierung des theoretisch-wissenschaftlichen Diskurses bzw. Theoretisierung des Literarischen die historisch gewordene Trennung von literarisch-praktischer und theoretischer Arbeit in einem 'Kunstgriff aufhebt.

"Es entsteht der Eindruck" - schreibt Hansen-Löve -, "als würden beide Aktivitäten auf eine gemeinsame Metaebene rekurrieren. die auf einer Ebene liegt. wo es keine Unterschiede mehr gibt $z$ wischen Theorie und Praxis, wissenschaftlichem und künstlerischem Denken."3S

Form. Funktion und Bedeutung der Repräsentanz des Lebens bzw. der Kunst in der autobiographischen Prosa Šklovskijs lassen sich erst auf dem Hintergrund der Diskussion um die Eigengesetzlichkeit der Literatur angemessen beschreiben. Zu jeder Zeit seiner Arbeit vertrat Šklovskij den Standpunkt. daB die Kunst als ein eigengesetzlicher Bereich im gesellschaftlichen Leben anzusehen sei. In den frühen Arbeiten des OPOJAZ - in dem programmatischen formalistisch-futuristischen Aufsatz "Die Auferweckung des Wortes" (1914) sowie in den $1925 \mathrm{zu}$ einem Sammelband zusammengefaBten Abhandlungen zur Theorie der Prosa legte Šklovskij zum ersten Mal sein Verständnis von der Kunst als Kunstgriff dar:

"Die heutigen Literaturtheoretiker sehen die sogenannte Form eines literarischen Werkes als eine Art Huille an. durch die man in das literarische Werk eindringen muB: und sie setzen sich aufs hohe RoB und springen uiber die Form hinweg.

Aber ein literarisches Werk ist reine Form. es ist kein Ding. kein Material. sondern ein Verhältnis von Materialien. Und wie jedes Verhältnis ist es unabhängig von jeglicher Dimension. ${ }^{-36}$

Immer wieder zitieren seine Kritiker die programmatisch überspitzte Formel

"Der Inhalt (daher die 'Seele') eines literarischen Werkes ist die Summe aller darin angewandten stilistischen Kunstgriffe. ${ }^{-37}$

und verkennen damit die Funktion der methodischen Reduktion des Erkenntnisinteresses des friihen Formalismus an der Spezifik des Literarischen.

Sklovskij konzentrierte sich in dieser Phase ganz auf die Herausarbeitung dieser Eigengesetzlichkeit der Kunst. Er trennt die poetische Sprache scharf von der praktischen und nennt sie eine "konstruierte", eine "gebremste". Wahrnehmung erschwerende Sparche ${ }^{38}$ im Gegensatz zur Alltagssprache, die sich wie alle gewohnheitsmäBigen Handlungen automatisiert - 
"Alle unsere Gewohnheiten ziehen sich in den Bereich des UnbewuBten und Automatischen zurück."39

und so in ihrer Form nicht mehr spürbar ist.

"Man muB den Gegenstand aus der Reihe der gewohnten Assoziationen herausreißen, in der er sich befindet, und ihn umdrehen wie ein Holzscheit im Feuer." ${ }^{-10}$.

schreibt Šklovskij. An der Literatur Sternes, an Cervantes "Don Quijote”, an Mark Twain, Rozanov und an Märchen erprobte er seine Kunst-als-KunstgriffTheorie und entwickelte stilistische und kompositioneile Bestimmungen. ohne sie in wissenschaftlicher Grundlichkeit zu systematisieren. Diese Theoreme gehen sowohl als Konstruktionsprinzip als auch als Thematisierung (EntblöBung des Kunstgriffs) in seine Prosa ein. Im Vorwort zur ersten Ausgabe von "Zoo ..." entblöBt Šklovskij den Kunstgriff der Motivierung in der Form einer Erklärung über den Entstehungszusammenhang des Buches.

"Urspriinglich hatte ich einige Skizzen iber das russische Berlin im Sinn: dann kam mir der Gedanke, die Skizzen durch irgendein allgemeines Thema zu verbinden. Ich nahm das 'Tiergehege' (den 'Zoo'). schon war der Buchtitel geboren, aber er verknipfte die Stuicke nicht. Da fiel mir ein. aus ihnen so etwas wie einen Roman in Briefen zu machen. Ein Roman in Briefen bedarf einer Motivierung: einer Ursache des Briefwechsels.

Die gewöhnliche Motivierung ist die Liebe und das, was die Liebenden trennt. Ich wählte einen Sonderfall: die Briefe schreibt ein Liebender an eine Frau, die keine Zeit für inn hat. Hier brauchte ich ein neues Detail: da das Grundmaterial des Buches nichts mit Liebe zu tun hat, führte ich ein Verbot ein, über die Liebe zu schreiben. So kam das heraus, was ich im Untertitel ausgedrickt habe Briefe nicht iber die Liebe. ${ }^{-41}$

Dieser Kunst-als-Kunstgriff-Gedanke durchzieht den ganzen Briefroman. Er motiviert ihn in ähnlicher Weise wie die Liebe oder das Emigrantendasein.

Wir haben aus dem Bedürfnis nach neuem Material in der Kunst in unsere Arbeit das Intime aufgenommen, das beim Namen und Vaternamen Genannte. ${ }^{-42}$,

erklärt Šklovskij in "Zoo..." ähnlich wie Tynjanov in dem Aufsatz "Literatumyj fakt", analog auch zu seinen eigenen Studien uber Rozanov. So wie "sich alle Beschreibungen als Metaphern der Liebe entpuppten". 43 so fungiert umgekehrt die Liebe zu Alia als ein Bild fur die Liebe Šklovskijs zum Kunstgriff, zur Literatur.

"Ich schwöre es dir: mein Roman ist bald fertig.

Die Frau, die mir nicht antwortet! 
Du hast meine Liebe in einen Telefonhörer gejagt ... Der Art jedoch sagt, ich hätte einen normalen Blutdruck und meine Halluzinationen seien rein literarischer Natur. ${ }^{-44}$

In der Einleitung zum neunzehnten Brief thematisiert Šklovskij das Problem der Automatisierung der Alltagssprache und löst es im Kunstgriff der Verfremdung in der Absicht, ästhetische Wahrnehmung durch Verhinderung zu erneuem, konstruktiv auf, indem er dem Leser ein Leseverbot erteilt, wodurch die Neugier auf das Verbotene gesteigert und Lust am Lesen erst recht geschulut wird.

"Ich bin taub. Ich habe in meinem Leben Kessel genietet. indem ich mit der Zange die Nietnägel von innen festkniff. In meinen Ohren donnert es. Ich sehe, wie sich die Lippen der Menschen bewegen. doch ich höre nichts. Das Leben hat mich taub gemacht; Taube sind sehr verschlossen ... Also liebe Freunde. lest diesen Brief nicht. Ich streiche ihn absichtlich mit dem Rotstift durch. Um jeden Irrtum auszuschließen. Wie soll man diesen Brief kompositionsmäBig auffassen? Er wurde ja immerhin aufgenommen.

Aber wozu in Teufels Namen beduirfen Sie der Komposition? Sollten Sie ihrer dennoch bediurfen, dann bitte sehr!

Der Ironie des Werkes wegen ist eine zweifache Enträtselung der Handlung vonnöten ...

Ich bin taub. ${ }^{-45}$

Auf die Kritik Trockijs. die Formale Schule verabsolutiere das Wort, es sei vielmehr nur der Schatten eines Gegenstandes, entgegnet Šklovskij, daß das Wort für sich selbst ein Gegenstand, richtiger gesagt, ein Gegenstand mit zwei Seiten sei: er habe

"eine Schattenseite, die Seite der Beziehung zu den Dingen und eine sprachliche. eigenständige. den Wortimpuls. seine Trägheit. Dies prägt sich auch den literarischen Formen ein. ${ }^{-46}$

Es ist wohl kein Zufall, daß Šklovskij der denotativen Seite des Wortes den bedeutsamen Namen "Schattenseite" gibt, der weniger ein wissenschaftlicher Begriff denn ein poetisches Bild für das Uneigentliche. Abseitige und Obskure dieses Aspekts ist und ein Schlaglicht auf sein Verhältnis zu ihm wirft. Der Wortaspekt der Beziehung zu den Dingen verweist auf den sozialen Auftrag der Kunst, den die sowjetische Kulturpolitik einklagt, verweist auf die Forderung nach gesellschaftlichem Engagement, das für Šklovskij, den Meister der Wortkunst, unter den gegebenen Bedingungen so schwer zu realisieren ist. Aber er weiB. daB die den Dingen zugewandte Seite des Wortes für die Literatur eine wichtige Funktion erfullt. weil sie die Trägheit der Sprache bzw. der literarischen Form aufhebt und sie zur Veränderung zwingt - nicht. damit sich jene ans Leben anpasse, sondern damit man sie in der Auseinandersetzung mit der Zeit als lebendige literarische Form wahrnehme. Die Eigen- 
gesetzlichkeit der Sprache prägt sich den literarischen Formen als Möglichkeit zu mimetischer Erfahrung von utopischen Augenblicken ein, die die Evolution der Kunst bewahrt. Dem denotativen, uber die Sprache als System hinausweisenden Aspekt des Wortes, den Šklovskij so schwer sehen kann, fällt hingegen die Aufgabe zu, in der konstruktiven Perspektive auf das Faktum die Beziehung zwischen Wortgegenstand und Leben zu realisieren, d.h. sie ständig aufs neue herzustellen und von dem einen auf das andere zu verweisen. "Ich fürchte mich nicht vor der Gegenwart", erklärt Šklovskij noch 1930 in seinem Buch iber die Kinoarbeit "Lohnarbeit im Tagewerk".47

Mehr als alle anderen Bücher repräsentiert dle "Dritte Fabrik" Šklovskijs Auseinandersetzung mit der Konzeption der Kunst als einem eigengesetzlichen Verfahren. Sein Schüler Gric liest das Buch ausschlieBlich in diesem Sinne: es sei eine literarische Abhandlung uber die Theorie der Prosa Das Revolutionäre" bei Šklovskij liege im besonderen Thema, in der Thematisierung des Auberliterarischen. Nichtkanonisierten, in der Literarisierung wissenschaftlicher Probleme. Auf ein und derselben "emotionalen Ebene" seien anerkannte literarische Topoi, Motive des Romans, des Feuilleton mit denen wissenschaftlicher Reflexion entwickelt und miteinander verflochten.

"Darin liegt das Neue, Revolutionäre des Materials, aus denen Šklovskij seine Produktionen baut. ${ }^{-48}$

Autobiographische Erinnerungen und Reflexionen transformieren sich qua Selbststulisierung des Erzählers zu einem literarischen Faktum, das die poetische Realisierung der formalistischen Konzeption motiviert, die - ahnlich wie in dem Briefroman Zoo ..." nur mit der Verlagerung des Schwerpunkts vom Gegenstand Liebe auf das Material Theorie - in dem Medium der literarischen Persönlichkeit die Intimität eines existentiellen Verhältnisses erheischt. Sowohl in der Funktion der Personage (Brik. Tynjanov, Jakubinskij. Ejchenbaum. Jakobson (.a.), in der spezifischen Form ihrer Einfuhrung - zum Teil spricht Šklovskij sie nur mit ihren Vomamen an und setzt damit eine Vertrautheit des Lesers mit diesen Figuren voraus - und in der kinstlerischen Konstruktion der dialogischen Auseinandersetzung der "literarischen Persönlichkeit" Šklovski] mit ihnen, als auch in der stilistisch wie kompositionell engen Verknipfung der Wunsche und Ängste des Erzählers mit theoretischen Uberlegungen und literarischen Konstruktionsspielen findet die Intimitat der Auseinandersetzung mit der formalistischen Prosatheorie ihren Ausdruck. Aber das revolutionäre Potential der "Dritten Fabrik" Šklovskijs liegt ebensowenig wie in seinen anderen fruhen autobiographischen Prosatexten in der Einführung von irgendwelchem beliebigen, neuen, literarisch unverbrauchtem Material in die Literatur, sondern in der literarischen Verarbeitung von konkretem, gesellschaftlich tabuisiertem und deshalb brisantem Material, in der Erörterung der Frage: "Wie soll man schreiben in literarischer und gesellschaftlicher Verantwortung?" Nicht Parteilichkeit, sondern technische Meisterschaft entscheide uber die Qualität von Literatur, erklărt Šklovskij $\mathbf{z u}$ einer Zeit, in der der LEF - stark 
beeindruckt von der Massenbewegung der Arbeiter- und Bauernkorrespondenten (Rabkory) - dazu neigte, die Konzeption einer engagierten Literatur in diesen Korrespondenzen bereits verwirklicht zu sehen.

\begin{abstract}
Wenn ihr lernen wollt, wie man schreibt, muiBt ihr vor allem euren Beruf gut kennen" - belehrt er die Rabkory. - "Lemt mit den Augen eines Meisters auf fremde Berufe zu schauen und versteht, wie die Dinge gemacht sind. Glaubt nicht an die gewohnte ZweckmäBigkeit der Dinge." 49
\end{abstract}

Šklovskij macht keinen Unterschied - "die Technik der Produktion ist uberall ein und dieselbe" -. Deshalb solle der Literaturarbeiter nicht vor der professionellen Arbeit uberhaupt davonlaufen, er müsse vielmehr lernen, in die Zukunft hineinzuarbeiten - auf jene Formen hin. die er selbst entwickeln muisse. ${ }^{50}$ In der literaturpädagogischen Broschüre "Die Technik des Schriftstellerhand-

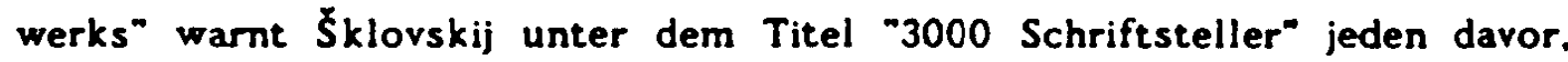
sich ausschlieblich für den Schriftstellerberuf $2 u$ entscheiden, bevor er in allen Einzelheiten die Technik des Schriftstellerhandwerks erläutert. Das Herzenhaus - Haus der Schriftsteller in Moskau - sei vollkommen überfulltt. aber das sei immer noch besser, als spezielle Kasernen für Schriftsteller zu bauen und ihnen eine paramilitärische Ausbildung zu erteilen. Unter dem Vorwand, gegen den massenhaften Andrang junger Schiftstelleradepten ins Herzenhaus zu agitieren, der ihm zugleich noch die Gelegenheit gibt, eine ironische Attacke gegen kulturpolitische Bestrebungen der staatlichen Lenkung und Vereinheitlichung der Ausbildung zum Schriftsteller zu reiten. weist \klovskij ählich wie in dem Aufsatz "Uber den Schriftsteller und die Produktion" darauf hin. daß erst der Schriftsteller, der noch einen anderen Beruf habe, über die Dinge auf seine eigene Weise schreiben könne. ${ }^{51}$ Seine Forderung nach einer Zweitprofession antwortet auf dasselbe Problem. das Ejchenbaum in dem Aufsatz "Literarisches Leben" als Ausgangspunkt seiner literatursoziologischen Überlegungen dient. auf das Problem. das in der Situation der sowjetischen Literatur der 20er Jahre die Frage "Wie soll man schreiben?" von der Frage "Wie soll man Schriftsteller sein?" in den Hintergrund gedrängt wurde. In der paradox erscheinenden Verknuipfung der Forderung nach einem zweiten Beruf mit der literaturpädagogischen Einführung in die Technik des Schriftstellerhandwerks gibt Šklovskij als professioneller Schriftsteller. Theoretiker und Kritiker eine doppelsinnige Antwort auf die tagespolitische Vermischung von Fragen der Literaturkonzeption mit den diktatorischen Forderungen einer staatlichen Kulturpolitik - "Die Produktionstechnik ist uberall ein und dieselbe." In dem Prosawerk "Suche nach dem Optimismus". der vorläufig letzten autobiographisch-faktographischen Produktion zu Beginn der 30er Jahre, variert Sklovskij diese doppelsinnige Antwort, indem er die Technik des Schriftstellerhandwerks mit der Organisationstechnik des gesellschaftlichen Lebens thematisch - als Motivierung -, kompositorisch - als Abschweifung . EntblöBung - und stilistisch - als Metapher - ineinssetzt. 
Das Technikverständnis der Formalen Schule kann in vieler Hinsicht als der theoretische Ausdruck der futuristischen Technikgläubigkeit gewertet werden. und die Faszination, die die Technik auf die sowjetische Avantgarde ausibte. geht auch in Form und Sprache in die Literatur Šklovskijs ein. Beispielsweise literarisiert er, sei es als Thema, sei es als Kompositionsmethode oder Stilmittel immer wieder seine Tätigkeit als Fahrlehrer oder seine Arbeit am Coskino und an der Zeitung. Solange das Technikverständnis des LEF-Futurismus dem Anspruch einer Utopie genügte, antwortete es in groBen Zügen auch der Hoffnung Šklovskijs auf gesellschaftliche Befreiung. Aber seine Schwierigkeiten, die bolschewistische Politik als konsequente Fortsetzung der russischen Revolution 24 akzeptieren. hinderten ihn stets erneut daran, die Utopie von der Befreiung der Technik, von der selbstbewuBten Aneignung der Methode des Lebenbauens auf der Grundlage einer nicht länger in eindimensionalem Zweckrationalismus befangenen Beziehung zu den Gegenständen verwirklicht zu sehen. Dementsprechend vermochte $\mathbf{S} k l o v s k i j$ das Verhälnis von Technik in der Kunst und Technik im gesellschaftlichen Leben nur als eine Analogie, als einen Parallelismus dazustellen, der auf der einen Seite die Relevanz der literarischen Konstruktion fur die Literatur analog zu der Bedeutung, die der Technik für das Leben zukommt, hervorhebt und auf der anderen Seite der Hoffnung Ausdruck gibt, daB Kunsttechnik und die Technik im Leben einmal in einem Ziel - in der gesellschaftlichen Befreiung des Menschen zusammengehen werden. Nicht zuletzt verleiht der Kunstgriff des Parallelismus mit List der Einschätzung Ausdruck, daB die Zeit noch nicht gekommen ist, da bewuBte Konstruktion von Kunst- und Lebensformen eins sein werden und sich die Kunst ihrer doppelten Funktion als Huterin der Utopie der Freiheit und zugleich als Schleifstein fur die Wahrnehmung von Widersprüchen und Differenzen enthoben sehen und sich selbst aurheben kann. 
1 T.Gric/V.Trenin/M.Nikitin, Slovesnost i kommercifa. M. 1929. S.7

2 B.Ejchenbaum. Llteraturnyl byt/Dae llterartache Leben, In: TdF. Bd.I. S.462-481

3 vgl. Ju.Tynjanov, Literaturnyt fakt/Das literarlache Faktum. In: TdF. (Hrag.) J.Striedter, Munchen 1969. 19712. Bd.1. S.392-431: vel. dera.. 0 literaturnol evolfucll/uber die literarlache Evolution. obd. S.432-461

4 vel.T.Gric/V.Trenin/M.Nikitin. S.9

5 B.Ejchenbaum. S.466/S.467

6 ebd.

7 ebd.. S.468/S.469

8 ebd.. S.474/S.475

9 Ju. Tynjanor. Literatumyt fakt. S.404/405

10 ebd.. S.426/S.427

11 ebd.. S.454/S.455

12 bbd.: rgl. A. Hanaen-Love. Der rusalsche Formalismus. S.401/402: Wryrend in der fruhen Evolucionscheorte des Fil < de dricte Phase dea rusalachen Formallamua, pregmatseches Modell. V.D. ) (v.e. in der Konzeption Tynjanova) der auBerllterartache 'byt' (mellteratumyl byt) ala "Reserrotr" poteneleller. noch nlcht (oder nicht mehr) dechetiacher Fakten der allgemelnen eprachlichen Kommuniketion gllc. bestmme nun Ejchenbeum dlesen auBerliterarischen 'byt' al Bestandtell dea 'llteraturnyt byt'. ale Reglon. de niche auberhalb der klinetlerischen Kommunikation llegt. sondem den Ort bezelchnet. wo de iathetische Kommunlkation ala soztaler Nkt eteeffindet. Dleser wesentllche Unterachled $x$ wischen Tymjenove Konzeption des 'vneliteracumyl byt'... und der fast glelchieltig von Ejchenbaum entwickelten Auffasaung des 'llteraturnyl byt' lat sowohl von den zeltgendselschen ale euch ron den apiteron interpraten des Formallamus unbeachtet geblieben."

13 Zu fregen blelbe. Inwlewelt in dem Begriff des -literarischen Lebens" Ejchenbeume in nuce der epitere Begrtff des Strukturaliemus "kultureller Kontext" zugletch euch "kultureller Text" schon enthaleen lat: vgl. Ju. Lotman. Text und Funktion. in: J.K-latera, U.Eco, M.Bachtin U.e., Textsembotk al Ideologiekritlk. Ffm. 1977. S.149-164

14 T.Gric/V.Tronln/M.Nikith. S.10

15 B.Ejchenbaum. Literaturnyf byt. S.462/S.463

16 A.Hensen-Love. S.400

17 B.Ejchenbaum. S.462/S.463

18 V.Jklorakif, Gamburgaklf sket, L.1928, S.30

19 A. Hanaen-Löre. S.400/401

20 Ju. Tymjenov. Poitlke. Iatortje literatury. Kino. M. 1977. S.569

21 B. Ėjchenbaum. Mof vromennlk. L. 1929. S.131

22 A. Hansen-Love. S.404

23 B. Ejchenbaum. S.131

24 A. Lunacarakif. Der Formaliemus in der Kunetwiesenschaft, In: Marxlemus und Formaliamus. (Hrag.) H.Gunther, U.: K. Hielacher, H. Gunther. Munchen 1973. S.94

B. Ejchenbaum. S.132 .

ebd.. S.131 
27 ebd.

28 V.Skloraklf, Gamburgaklj .... S.104

29 A. Hanaen-Love, $\mathbf{5 . 5 8 3}$

30 ebd.. S.586

31 V.Sklovaklj. Tret'je .... 5.52

32 ebd.. S.69

33 Llteratura fakte. (Hrag.) N. Cučak. M. 1929; raprint: Munchen 1972 mit einer Einleltung von H. Gunther

34 A. Hansen-Lbve. Wiasenachaftlche Theoretialerung kUnatlerlacher Modelle und kunstleriache Realisterung (Literafialerung) theoretischer Modelle dargestellt am Belsplel des russischen Formaliamus. In: Wiener Slaviatiaches Jahrbuch Bd.24. Beltedge der österrelchlschen Sleviaten zumvill. Internationalen SleviatenkongreB. Zegreb-Ljubljane 1978. S.103

35 bd.. 5.102

36 V. Sklovaklf. Llteratura vne afuzeta. In: O teorll prozy (1929), S.226/S.163

37 ebd., S.228/S.165

38 dera., Iakuastro kak priëm. ebd.. S.22/S.26

39 ebd.. S.11-12/S.12

40 dera., Stroente rasekeze I romene. In: O teort prozy (1929). S.79/S.75

41 ders.. Zoo .... S.9/S.7

42 ebd.. S.29/S.34

43 ebd.. $5.9 / 5.7$

44 obd. In der nee. Aungebe (1923) fohlt dleae Paraege/5.11s

45 ebd.. S.74-75/5.83-84

46 ders.. Metertal I ecll' $\checkmark$ romene L've Tolatogo -Vojne I mir". M. 1928. S.237

47 dere., Podenxzina. L. 1930. S.228

48 T. Gric. Trorteatro Viktora Sklovakogo (O tret'ef fobrike). Baku 1927. S.11

49 V.Šklovekif. O plancele I prolzrodetre. In: Llteratura fakte. S.194

so ebd.

51 dera.. Technlka plactel'akogo romesia. M.-L. 1930. roprint: (ZentralentiquaHat der DDR Lelpzig 1977. S.3 


\section{Kap. 2: Dle fruhe autoblographlsche Prose Sklovskijs und dle Konzep- tion einer faktographischen Literatur}

Šklovskij geht stets davon aus, daß sich die Literatur eigengesetzlich gegenuber der gesellschaftlichen Wirklichkeit oder - in der Terminologie der Formalisten - gegenuiber der sozialen Reihe entwickelt. Dabei hat er die Bedeutung der auBerliterarischen Wirklichkeit - nicht nur in ihrer Funktion als Reservoir zur Erneuerung der Kunst, sondern auch in ihrer die Literatur bedrängenden und verändernden Funktion - niemals geleugnet. Zunächst kam die Dialektik der Beziehungen zwischen Kunst und Leben in seinen Arbeiten sehr implizit zur Erscheinung, so als habe sie sich mehr hinter seinem Ruicken als mit BewuBtsein in seine Schriften hineingearbeitet. Aber die Auseinandersetzungen mit seiner Zeit, mit der Literaturpolitik und dem Soziologismus der Marxisten-Leninisten forderten Šklovskij mehr und mehr zu einer expliziten Stellungnahme zu diesem Problem heraus. Die methodische Reduktion des frühen Formalismus scheint mir in seiner Literatur theoretisch wie praktisch uberwunden zugunsten einer die gesellschaftliche Funktion der Kunst bewuBt reflektierenden Konzeption. die in dem kulturrevolutionären Programm der literatura fakta und in ihrer spezifischen Auslegung durch Šklovskij eine engagierte produktionsästhetische Ausrichtung erhält und als solche operationalisierbar wird.

Schon in der Schrift "Die Auferweckung des Wortes" von 1914 stellt Šklovskij die Literatur programmatisch vor die Aufgabe, das Wort zu neuem Leben zu erwecken. um die gesellschaftliche Entfremdung der sinnlichen Wahrnehmung der Welt in der Literatur exemplarisch aufzuheben. Die Gewohnheit. der Alltag habe das Leben des Wortes - diese oszillierende Beziehung zwischen innerer (bildlicher) und äuBerer (lautlicher) Form - erstickt und an seine Stelle algebraische Zeichen gesetzt. die wir nicht sinnlich erfahren, sondern nur noch wiedererkennen können. Aber Šklovskij spricht nicht nur vom Tod des Wortes in der Kunst, sondern auch vom Tod der Dinge, d.h. von der Erstarrung und Automatisierung unserer Wahmehmung von Welt.

"Heute ist die alte Kunst tot, eine neue noch nicht geboren: tot sind auch die Dinge. wir haben das Gefühl für die Welt verloren: wir gleichen einem Geiger, der den Bogen und die Saiten nicht mehr fühlt, im alltäglichen Leben sind wir nicht mehr Künstler, wir lieben unsere Häuser und Kleider nicht mehr und trennen uns leicht von einem Leben, das wir nicht empfinden. Nur das Schaffen neuer Formen in der Kunst kann dem Menschen das Erleben der Welt zurïckgewinnen, die Dinge auferwecken und den Pessimismus töten."

Konstruktiv gewendet, durchzieht dieser Gedanke einige Jahre später క̌klovskijs Arbeiten zur Theorie der Prosa. Hier bildet er gleichsam das programmatische Fundament des Prinzips der Verfremdung in der Kunst. In dem ersten Aufsatz zur Theorie der Prosa "Kunst als Kunstgriff" will Šklovskij die Bedeutung 
des bildlichen Wortes für die Wahmehmung der Sprache wie der Dinge auf dem Hintergrund der Erkenntnis, daB wir Sprache in ihrer doppelten. der inneren/äuBeren Form nicht mehr wahmehmen können, da sie sich automatisiert und abgenutzt habe, in ihre revolutionären Rechte einsetzen.

"Es ist nicht der Sinn des Bildes, seine Bedeutung unserem Verständnis näherzubringen, sondern eine besondere Wahmehmung des

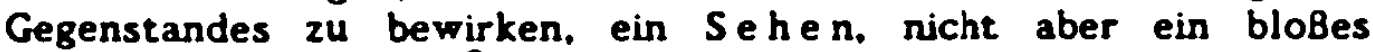
Wiedererkennen."

Es geht Šklovskij keineswegs darum. der Bildlichkeit ihre Bedeutung für die Literatur abzusprechen. Vielmehr kritisiert er die Vorstellung von der Kunst als Denken in Bildern unter dem ökonomischen Gesichtspunkt der Einsparung geistiger Kräfte, die selbst Ausdruck einer entfremdeten Wahmehmung. eines entfremdeten Verständnisses von Kunst in ihrem Verhälnis zur Welt und 2u deren Entsprechung auf sprachlicher Ebene - der inneren Form, des Bildlichen - ist. Dagegen sei Kunst eine Methode, ein konstruktives Verfahren, um auf dem Umweg der Erschwerung und Verhinderung - und nichts anderes meint das Prinzip der Verfremdung - durch Bilder. d.h. durch semantische Verschiebungen, die Kunst des Sehens zu lehren. ${ }^{3}$

\begin{abstract}
"Um flir uns die Wahrnehmung des Lebens wiederherzustellen, die Dinge fuhlbar, den Stein steinig zu machen. gibt es das, was wir Kunst nennen. Das Ziel der Kunst ist, uns ein Empfinden für das Ding 24 geben, ein Empfinden. das Sehen und nicht Wiedererkennen ist. Dabei benutzt die Kunst zwei Kunstgriffe: die Verfremdung der Dinge und die Komplizierung der Form. um die Wahmehmung zu erschweren und ihre Dauer zu verlängern. Denn in der Kunst ist der WahmehmungsprozeB ein Ziel in sich und muB verlängert werden. Die Kunst ist ein Mittel, das Werden eines Dings zu erleben, das schon Gewordene ist für die Kunst unwichtig. ${ }^{-4}$
\end{abstract}

\title{
1. Das Programm der literatura fakta
}

Innerhalb des Novyj LEF bildete sich eine Konzeption von Literatur heraus. die den Anspruch formulierte, künstlerische Arbeit in kulturrevolutionäre Praxis zu überführen. Diese Konzeption nannte sich Literatur des Fakts (literatura fakta). Unter dem gleichlautenden Titel veröffentlichten einige der Novy LEF-Avantgardisten (Brik. Gric, Neznamor, Percov, Trenin. Tret'jakov, Cužak und Šklovskij) unter der Redaktion Čužaks 1929 nach der Auflösung der Gruppe Novyj LEF eine Sammlung von Aufsätzen, die vordem in der Zeitschrift Novyj LEF verstreut bereits abgedruckt worden waren. 5

Die literatura fakta darf - was das Konzept anbelangt - nicht mit Dokumentarliteratur verwechselt werden. Denn sie will nicht nur dokumentieren, sondern operativ in den ProzeB gesellschaftlicher Veränderung eingreifen. In der 
Konzeption der literatura fakta verbinden sich verschiedene Programme der Avantgarde miteinander: die Produktionskunstkonzeption insbesondere Arvatovs, die formalistische Prosakonzeption und Čužaks Konzeption der lebenbauenden Kunst (ziznestroenie). Alle genannten Konzeptionen beziehen sich praktisch-politisch auf die Bewegung der Arbeiter- und Bauernkortespondentenliteratur. 6

Im Verständnis der Formalisten - vor allen Dingen nach der Evolutionstheorie Tynjanovs - ist die Literatur ein instabiles, kontextbedingtes Phänomen, das sich der statischen Fixierung entzieht. Dadurch wird es denkbar, die Funktion des Literarischen an Formen ubergehen zu lassen, die bisher nicht als literarisch gegolten haben. Die Theoretiker der literatura fakta ibernehmen diesen Gedanken. Für sie ist zum Beispiel die Zeitung eine der revolutionärsten Formen im evolutionierenden System der Literatur. Sowohl die skaz-Theorie Ejchenbaums als auch die Sujettheorie Šklovskijs haben, auch wenn sie von Arvatov dem konservativen Flijgel zugerechnet wurden, die literatura faktaKonzeption mit geprägt.

Ejchenbaum bemulht sich in seiner Theorie um eine Form von Literatur. die "die Möglichkeit zur Auferweckung einer in ihrer 'Schriftlichkeit' erstarrten Prosa durch die Mündlichkeit des Erzählens" gibt. Renate Lachmann begreift die "ormamentale Prosa" der "Weggenossen"/"Mitläufer"-Literatur als eine mit dieser Theorie "korrespondierende" Literatur, auch wenn sie sich nicht der Theorie gemäß konsequent in Mindlichkeit auföst. ${ }^{7}$ Die "ornamentale Prosa" zeichnet sich dadurch aus, daB sie statt der klassisch-realistischen Romanform offene Erzählformen verwendet und dabei auf die psychologische Motivierung, auf den literarischen Helden und die traditionelle Fabel verzichtet. Zamjatin. Pil'njak. Érenburg sind bekannte Vertreter dieser Richtung, von denen sich der LEF aber zu jeder Zeit klar abgegrenzt hat.

Die Sujettheorie Šklovskijs ist ein anderer Erneuerungsstrang, der die literatura fakta mitkonstituiert. Šklovskijs Uuberlegungen zu einer Prosatheorie, die die literarische Konstruktion ins Zentrum der Literaturbetrachtung ruickt und das Sujet als eine Ansammlung von Kunstgriffen entlarvt, intendieren eine "Entliterarisierung um des Ästhetischen willen" - wie Renate Lachmann es nennt - nicht als Selbstzweck. sondern im Sinne einer "Revolutionierung der Sehweise (Sensibilisierung). ${ }^{-8}$ Šklovskij entlarve die Konventionalität des Sujets in der bürgerlichen Literatur, indem er die Nichtkorrespondenz des Sujets zu einer wie-immer-gearteten Wirklichkeit und die Korrespondenz allein zu den übrigen Elementen des Kunstwerks nachweise. Daraus ergebe sich für ihn eine doppelte Möglickeit, mit dem Sujet zu verfahren: zum einen, es aus der Literatur zu entfernen; die Folge sei eine Literatur ohne Sujet: zum anderen. "das Sujet als ein Verfahren der BewuBtmachung von Handlungs- und Ereignisstrukturen einzusetzen, als Faktor, der die Realität organisiert und Mechanismen aufdeckt." 9

Für den Theoretiker der Produktionskonzeption, Arvatov, der sich selbst als "Soziologe-Formalist" bezeichnet. gehört Šklovskij zu jenen "rechten Forma- 
listen", die die Strukturen der Kunst allein in ihrer immanenten Spezifik betrachten und jeglichen EinfluB gesellschaftlicher Faktoren auf den Bereich der Kunst leugnen. Er besteht darauf, die Literatur sowohl hinsichtlich ihrer Analyse als auch hinsichtlich ihrer Produktion in einen sozialen Kontext zu stellen. Von den soziologisch orientierten Formalisten haben die Theoretiker der Faktographie das "Primat der strukturell-evolutionären Auffassung" vor der "Betrachtung unter genetischem Aspekt" ibernommen. Sie betrachten die Kunst als ein "evolutionsimmanentes Mittel, das zu einer Entliterarisierung. also Aufhebung der Konventionalität und Kanongläubigkeit, führt." ${ }^{10}$ Sie intendieren eine Verminderung der herkömmlich behaupteten Distanz der Kunst zum Leben und übertragen ihr die Rolle einer gesellschaftlich nuitzlichen Produktivkraft. "In dem Maße, wie die Kollektivierung der Gesellschaft voranschreitet." prognostiziert Arvatov, werden "das künstlerische und das sozial-utilitäre Schaffen zusammenflieBen."11 Für ihn bedeutet "künstlerisch tätig sein ... bewuBt verändem." 12 Revolutionierung der Literatur heiBt für ihn Revolutionierung ihrer sozialen Funktion und nicht, wie für Šklovskij. Revolutionierung ihrer Formen. Er übergeht diesen Aspekt bzw. stellt die Frage nach den kunstlerischen Formen unmittelbar in den Kontext der sozialen Wirksamkeit der Kunst. Für den Theoretiker der Produktionskunstkonzeption Arvatov ist die Suspendierung des Ästhetischen die Voraussetzung für die Revolutionierung der Kunst. ${ }^{13}$

Tret'jakov, einer der führenden Theoretiker der literatura fakta der so wie Arvatov der extremen Fraktion der "Utilitaristen" zuzurechnen ist. geht davon aus, daB die Wirklichkeit erkennbar geworden ist. Die Revolution habe den Warenschleier, der die bürgerliche Gesellschaft umhullt und blind gemacht hat, von den Dingen gezogen, so dab sie jetzt 24 Gegenständen bewubter menschlicher Produktion werden könnten. Das Konstruktionsprinzip der Geschichte - Tret'jakov nennt es "die Methodik des Aufbauens" ${ }^{\text {14 }}$ sei greifbar geworden. Aufgabe der Faktographie sei es, die revolutionären Möglichkeiten ins BewuBtsein $z u$ bringen, sie sich anzueignen und $z u$ lehren. von ihnen Gebrauch zu machen. Tret'jakor schreibt eine "Biographie des Dings" und provoziert schon im Titel den Widerspruch: Lebensgeschichte wurde bis dahin nur dem Menschen zuerkannt, ein Ding hingegen galt als etwas Totes und Statisches. BewuBt lenkt er den Blick weg vom Menschen, hin zu den Dingen. die in der traditionellen Literatur nur als Dekoration der Handlung um die Helden herumgruppiert wurden.

"Die Biographie des Dings ist eine sehr nuitzliche, die Seelen der Literaten abkuihlende Dusche ... und, was das Wichtigste ist, die Biographie des Dings hat den Nutzen, daB sie der vom Roman aufgeblasenen menschlichen Gestalt ihren Platz zuweist." ${ }^{-15}$

Ding ist für Tret'jakov zunächst alles Gegenständliche: das Brot, der Wald, der Betrieb, die Tasche etc.. Der Welt der Dinge als der "objektiven Welt" 
stellt er die "Welt der Emotionen und Erlebnisse" als die subjektive Welt gegenüber, die im psychologischen Roman dominiert. Dort bestimmte das "Schicksal" die Beziehungen der Menschen zum Leben, die durch die Liebe. die Eifersucht und das Nervenleiden geknüpft seien. Dagegen sei hier die auf Wissen und "technisch-organisatorische Erfahrung" begrüindete Beziehung zu den Dingen konstitutiv. 16

Wenn Lukács die "Biographie des Dings" als Herrschaft der Dinge über den Menschen interpretiert, in der die Menschen "in ihrer Lebendigkeit miBachtet". an die Wand gedrickt und platt schematisch abgebildet werden. ${ }^{17}$ so miBversteht er Tret'jakov, denn die Faktographie rückt zwar die Dingwelt ins Zentrum der Darstellung, nicht jedoch als eine verdinglichte und fetischisierte, sondern als Projektion einer Welt der Gegenstände der menschlichen Arbeit.

"Die Kompositionsstruktur der Biographie des Dinges stellt gleichsam ein Fliebband dar, auf dem sich der Rohstoff fortbewegt. der durch die Anstrengungen der Menschen in ein nützliches Produkt verwandelt wird." 18

Die literatura fakta handelt - obwohl das Gegenteil der Fall zu sein scheint zentral rom Menschen. da sie ihn in seiner Arbeit an der Gesellschaft ernst nimmt und die Menschen aus der Perspektive der Produktion. "mit ihrer sozialen Seite, mit ihren Produktionsgewohnheiten"19 als einer primär ihr Verhältnis zum Leben konstituierenden Dimension schildert. (Produktion ist hier als utopische Projektion auf freie. gesellschaftliche Arbeit zu verstehen. nicht als ein gesellschaftlich bestimmtes Produktionsverhältnis.) Der Vorwurf der Literaturnaja ènciklopedija (1932), der LEF gehe in der Konzeption der literatura fakta "in metaphysischer Manier von der materiellen Welt als von einer mechanischen Summe schon in sich abgeschlossener. fertiger. unbeweglicher Fakten "20 aus, muB strikt zurickgewiesen werden. Im Gegenteil betonen die Theoretiker der Faktographie immer wieder die Notwendigkeit, das ProzeBhafte. Dynamische herauszustellen.

"Aber die sozialen Prozesse, das Wachstum von Menschen und Lebensformen, der Wandel der Funktionen von Dingen ist für uns das Interessanteste. ${ }^{-21}$.

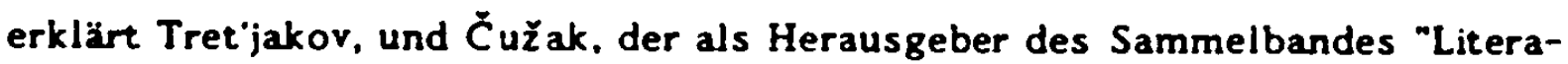
tura fakta" verantwortlich zeichnet, fordert von der Faktographie, daB sie dynamisch sein müsse, wenn sie eine soziale Funktion in der proletarischen Revolution, in einer sich revolutionierenden Gesellschaft haben wolle. ${ }^{22}$ Ihrer Konzeption nach ist die literatura fakta eine Literatur des Weitertreibens. der Voranbewegung des Faktums.

"die sowohl den Vorgang der Rezeption als auch den der Produktion dynamisiert. weil dieser nicht mehr die Erzeugung unvergänglicher 
Kunstwerke, sondern das Schreiben als Handlung meint, die Teil der Realität (učastok Żizni) ist und diese nicht abbildet, sondern mitbildet. ${ }^{* 23}$

Dementsprechend begreift Tret'jakov das Faktum auch in seiner Immanenz nicht als etwas Statisches, sondern immer als etwas in der Zeit Gewordenes, von der Gesellschaft Erarbeitetes.

"Die Fixierung des Faktums in eine zeitliche Koordinate eingespannt. ergibt die Fixierung eines Prozesses, ohne die es ibberhaupt unmöglich ist. unser Denken aus der Logik in die Dialektik zu überführen. ${ }^{-24}$

Dieses Verständnis Tret'jakovs von einem Faktum als einem WerdensprozeB des Dings im Sinne des dialektischen Materialismus verbietet jegliche Typisierung und Verallgemeinerung. wie wir sie im klassisch-bürgerlichen Roman finden. Die Theoretiker der Faktographie setzen dem "Typ" das "Modell" entgegen. Es gibt zwei Arten von Dingen, erklärt Čužak, im Sinne der Organisationstheorie Bogdanovs: materielle Gegenstände und Modelle von Dingen (Ideen). Er warnt davor. aus der Vorstellung des Dings die Vorstellung der Idee zu eliminieren. da die Idee als Modell notwendige Voraussetzung jedes realen Bauens sei, wie K. Marx es ausschlieBlich der menschlichen Arbeit unterstelle. 25

Gegen den Einwand. die Literatur des Fakts miisse notwendig zu einer "ïbertriebenen Austrocknung der Prosa" führen, da sie eine wissenschaftliche Arbeit vom Autor und Rationalitat von den Rezipienten erwarte. argumentiert Tret'jakov, indem er darauf hinweist, dab die Forderung nach Exaktheit und Uberprifbarkeit der Fakten und nach einer dementsprechend klaren und genauen Ubertragung in die literarische Form nicht zugleich der bildlichen Ausdrucksweise das Verbot ausspricht. ${ }^{26}$ An diesem Punkt, an dem Problem der Ubertragung der Fakten in die literarische Form. werden die bereits angedeuteten Differenzen 2 wischen den Fraktionen innerhalb des Novyi LEF deutlich.

In dem programmatischen literatura fakta-Buch bleiben die Meinungsverschiedenheiten - wohl um eine Geschlossenheit der Konzeption zu demonstrieren 27 - im Hintergrund. Aber in einzelnen Diskussionsbejträgen 2.B. im Novyj LEF sind sie von Anfang an virulent, und nachdem der Novyj LEF aufgelöst war und die literatura fakta-Konzeption keine neue kollektive Arbeit in Gang setzen konnte, traten sie offen zutage. Während Čužak, Arvatov, Brik und Tret'jakov ihre Vorstellung von der literarischen Form dem Aspekt der sozialen Funktion unterordneten und sich weniger die Frage des wie als des was stellten. konzentrierte sich Šklovskijs Aufmerksamkeit auf das Problem der Erneuerung der literarischen Form, um sie fur die Auseinandersetzung mit den gesellschaftlichen Fakten, die die Literatur bedrängten, zu wappnen. Er kritisierte den "operativen Schriftsteller" Tret'jakov:

"Du bist sehr begabt, aber du wirst niemals verstehen, was du siehst. Du hast so teuer fir den Zugang zum Faktum bezahlt. daB es dir zu schade ist, es $z u$ verändern, zu schade, es $z u$ bearbeiten. ${ }^{-28}$ 
Šklovskij kritisiert die Realisten, die es zu jeder Zeit und in jeder Kunst gebe. fur ihre Naivität, zu glauben, man könne Ideen ohne Worte zum Ausdruck bringen, und zu denken, daB damit der Widerstand der Formen gebrochen sei. Inhalt könne sich nur als Form realisieren.

"Inhalt" - sagt er - "das ist die Verwandlung der Form in Inhalt, ohne diese Verwandlung entsteht kein Inhalt. ${ }^{-29}$

Umgekehrt realisiere sich die Form nicht qua Verwandlung in Inhalt, sondern qua Aufhebung durch den Inhalt, um dann zu einer neuen Form zu gerinnen.

"Form, das ist wahrscheinlich nicht die Verwandlung der Form in Inhalt, sondern die Überwindung der Form durch den Inhalt, d.h. die Nichtkongruenz der früher existierenden mit einer neuen, sich noch keine Erscheinung gebenden Form. Die Formen existieren auBerhalb unser, und manchmal stiurzen sie auf uns ein ...."30

Das literarische Faktum sei dem Faktum des Lebens in keiner Weise an Eigenständigkeit unterlegen. Šklovskij will der Gestajt des Siamesen aus einer fiktiven Geschichte nicht weniger Realität zugebilligt wissen als dem Chinesen Tret'jakovs, der Hauptfigur des faktographischen Biointerviews "Den $\zeta_{j}$-Chua". Er sei genauso aus Dokumenten, und $\mathbf{z w a r}$ aus literarischen Dokumenten gemactrt: er leite sich von Bunin her und sei auf dem Schiff zusammen mit dem Herm aus San Francisco gefahren. Šklovskij zitiert Platon: "Was wird aus den Wachtruppen. wenn sie ihre Wachsamkeit verlieren?", um 2u zeigen. daB Tret'jakov den Anspruch auf Eigengesetzlichkeit der Literatur gegeniber der Politik verletzt hat.

"Die Fakten lassen dich am Thema kleben. Du hast die Mobglichkeit des literarischen Schrittes verloren. Du hast das Moment der Umgestaltung eingebüBt. Freund. du hast die Wachsamkeit verloren. ${ }^{31}$

Während Renate Lachmann die literatura fakta-Konzeption als "revolutionäres Kulturmodell" begreift, bestimmt Hans Günther sie als "literarische Evolution". die im Bedingungsgeflecht von kulturrevolutionärem Anspruch und politischer Anforderung in Utilitarisierung und Pragmatisierung der Literatur mündete. ${ }^{32}$ Martin Schneiders Untersuchungen über die "Operative Skizze S. Tret'jakovs" bestätigen Hans Günthers Thesen. Sie zeigen am Beispiel der Skizzen-Literatur Tret'jakovs, daB die praktische Umsetzung der Konzeption Anpassung der Kunst ans Leben, d.h. tendenziell Entliterarisierung der Literatur und Entprofessionalisierung des Schriftstellers hieB. Er kommt zu dem SchluB, daB die Tendenz zu dokumentarischen Verfahren nicht allein durch den fortlaufenden UtilitarisierungsprozeB der Avantgardekonzeptionen begrindet, sondern auch durch die veränderte Kommunikationssituation des I. Fünfjahresplans gefördert worden ist. ${ }^{33}$ 
Der Verlauf der Geschichte, insbesondere der Geschichte der sowjetischen Literatur, scheint Günther, seiner Interpretation der Avantgardekonzeption der literatura fakta, wie er sie in der Einleitung zum Sammelband "Literatura fakta" 1971 und sieben Jahre später. 1978, noch einmal schärfer in seinem Beitrag zum Internationalen SlavistenkongreB in Zagreb formulierte, recht zu geben. Im Klima staatlicher Anfeindungen und Sanktionierungen verwandelten sich sachbezogene, literaturtheoretische Auseinandersetzungen zwischen den Protagonisten der literatura fakta in kulturpolitische Debatten, so daB eine Entwicklung der Konzeption unmöglich und der Spielraum, sie zu konkretisieren und mit dieser Form $z u$ experimentieren, nicht gegeben war. Begreift man die literatura fakta als ein in sich kontroverses Modell von Literatur. das sich seines Standorts im ProzeB der literarischen Evolution bewuBt ist und gleichzeitig aktiv nach einer operativen gesellschaftlichen Standortbestimmung sucht. dann läßt sich diese Konzeption ohne weiteres auf die frihe autobiographische Prosa Šklovskijs beziehen und - darüber hinaus - in die Zukunft fortschreiben.

2. Autobiographie als Selbstreflexion - $\breve{S} k$ lovskijs Version der literatura fakta

Šklovskij gehörte zu denen, die innerhalb der Noyj LEF-Avantgarde die literatura fakta mitkonzipierten. Von ihm stammen zwar nicht die politisch programmatischen, aber doch die wichtigsten literaturtheoretisch programmatischen und auch die meisten Texte im Sammelband "Literatura fakta". Er war der einzige aus dem ehemaligen OPOJAZ, der an dieser Konzeption mitarbeitete. AuBer ihm zeichneten nur Gric und Trenin aus der zweiten Generation der Formalisten als Autoren in dem Buch verantwortlich. Aber seine Haitung zu dieser Konzeption - sei es seine theoretische oder literarischpraktische, sei es seine kulturpolitische - blieb umstritten.

Zahlreiche Kritiker. zeitgenössische und solche von heute (Tynjanov, Ejchenbaum. Gric, Hansen-Löve), lesen seine Texte einzig unter dem Aspekt der Realisierung der formalistischen Prosatheorie. Hansen-Löve begreift die Literatur Šklovskijs darüber hinaus als Bestandteil einer nicht affirmativen Kultur. ${ }^{34}$ Viele lesen seine Prosa - insbesondere "Sentimentale Reise" und "Zoo..." - wie andere Romane der bürgerlichen Kultur, die einen affirmativ, die anderen kritisch als Residuum bürgerlich dekadenter Kultur. Die Gegner der Kulturpolitik des sowjetischen Staatssozialismus - sowohl diejenigen, die ein konservatives Kulturmodell vor Augen haben, z.B. Struve, Erlich und Stepun, als auch Kritiker der Linken - differenzieren $z$ wischen "fruihen" und "späten" Texten. Sie machen einen Schnitt $z$ wischen "Dritte Fabrik" und "Hamburger Vergleich" und halten sich im Zweifelsfall an den "frühen" Šklovskij der experimentellen Phase. Die späteren Arbeiten, seien es die Texte, die im Zusammenhang mit der literatura fakta entstanden, seien es die literatursoziologisch essayistischen und die literaturtheoretischen Arbeiten oder seine 
Literaturkritik, stehen bei solchen Kritikem im Verruf, nichts mehr als eine kulturpolitisch gereinigte Wiederholung alter Positonen und eine Anpassungsleistung Šklovskijs an die dogmatischen und normativen Anforderungen einer autoritären Kulturpolitik zu sein. Die sowjetischen Kritiker sind einer literaturwissenschaftlichen Untersuchung und Bestimmung der autobiographischen Prosatexte bisher aus dem Wege gegangen.

Der Herausgeber des Sammelbandes "Literatura fakta", der Linkskommunist und Theoretiker der Faktographie, Čužak, ist wohl der einzige. der die Prosa Šklovskijs $z u$ jener Zeit als literatura fakta $z u$ kategorisieren und $z u$ beschreiben versuchte. In dem programmatischen Aufsatz "Merkbuch für Schriftsteller", gedacht als Leitfaden für junge Literaten. insbesondere für Arbeiter- und Bauernkorrespondenten, der allen anderen Aufsätzen vorangestellt war. preist Č užak die faktographische Prosa Šklovskijs. Sie sei eine "Gelehrtenprosa", die mehr errege als bestimmte Lyrik.

-Der Faktist Šklorskij ('Sentimentale Reise') spricht davon, wie er sich mit Autos abplagt. mit der Theorie des Sujets. mit Dreck. mit Holzhacken, mit der Umwertung Sternes und mit Läusen. ${ }^{-35}$

Cużak begreift die Vermischung ron Theoriefragmenten und literaturtheoretischen Exkursen mit der Erinnerung an Erlebnisse im Revolutionsalltag in der Prosa "Sentimentale Reise" im Rahmen der LEF-Konzeption der literatura fakta. Šklovskijs Prosa stellt für ihn eine neue Sujetform dar, die die Fabel als traditionelle Form der Verklammerung der Literatur ablöst. Čužak kontrastiert das "kiinstliche Sujet" der Fabel mit dem "nichterfundenen Sujet" (nevydumannyj sjužet) oder, wie er es auch nennt. mit dem "natürlichen Sujet" (natural'nyj sjužet: estestvennaja sjužetnost') der faktographischen Prosa, in der nicht die Literatur, sondern das Leben der Erfinder sei. ${ }^{36}$

In bezug auf Šklovskijs Prosa macht Čužak keinen Unterschied zwischen Fakten der empirisch erfahrbaren Altagswelt und Fakten der Literatur bzw. ihrer Theorie. Er nennt beide Kategorien von Fakten in einem Atemzug und wiederholt damit das analoge Prinzip der literarischen Sprache Šklovskijs. ohne seine ästhetische Funktion zu berijcksichtigen, vielmehr um die Fakten in der literarischen Darstellung bei Šklovskij sodann mit immanenter Argumentationslogik auf seine eigene Literaturkonzeption beziehen zu können, die das Problem der literarischen Form ibergeht und statt dessen eine unmittelbare Ubertragung der Fakten des Lebens sowie der Formen ihrer Darstellung in die Literatur behauptet. Čužak weicht auf diese Weise der Kontroverse zwischen formalistischer Prosatheorie und Faktographie aus. Das zeigt sich noch einmal besonders deutlich daran, wie unspezifisch er \$̌klovskijs "produktionsmäBigen Zugang" zu den Dingen, ihrer "Spezifik" entsprechend, lobt.

"Fïr ihn ist 'jeder Floh ein Floh', und es gibt keine 'uninteressanten' Dinge. Er möge es nicht als Kränkung auffassen, wenn wir sagen, 
er beschnuppert die ganze Welt wie ein junger Hund, der gerade anfägt $z u$ sehen ... Sterne ist fur ihn ebenso interessant wie ein vorsätzlich von jemandem beschädigtes Auto. Sowohl Steme als auch das Auto repariert er auf der Stelle. Sogar über die Läuse an der Front äuBert sich Šklovskij als großer Spezialist. Im Scherz wie im Ernst ist er ein Meister des produktiven Zugangs ..."37

Auf der einen Seite paßt Čužak die Prosa Šklovskijs in seine Kunst des "Lebenbauens" eln, auf der anderen Seite läBt er dessen spezifisches Interesse an literarischen Problemen nicht unerwähnt. Indem er von Šklovskijs Interesse an Sterne in unmittelbarem Zusammenhang mit den Fakten des Revolutionsalltags spricht, ohne diese Dinge zu hierarchisieren, d.h. die der empirischen Wirklichkeit über die der Kunst zu stellen, wertet er zugleich auch den Literaten Šklovskij auf, und indem er Šklovskijs sensualistisches Weltempfinden positiv hervorhebt, redet er, ohne daB er näher darauf einginge, einer Subjektivität das Wort, die unter einem Faktum das Erlebnis, die subjektive Aneignung eines Dings versteht. In diesem Zusammenhang erfährt der Begriff "produktionsmäBiger Zugang zu den Dingen" eine Erweiterung, die uber den Horizont der produktionsrationalistischen Einstellung der Bolschewiki, uber eine ökonomische Perspektive auf die Kunst hinausreicht.

So flüchtig und formelhaft ČuZaks Bestimmung der faktographischen Prosa Šklovskijs ist, so sehr sie auch die kontroversen Standpunkte unterschlägt - als der einzigen authentischen Belegstelle dafïr. nach welchen Kriterien ein Theoretiker der Faktographie die Prosa Šklovskijs der literatura fakta zuordnet. aber auch dafur, wie weit bzw. wie konkret die literatura fakta-Konzeption auslegbar ist, kommt ihr eine unersetzliche und nicht zu unterschätzende Bedeutung zu. Čužak nennt Šklovskijs Prosa eine faktographische Prosa. Er spezifiziert sie als "Gelehrtenprose", als "Prose ohne Sujet". er lobt Šklovskijs kenntnisreiche Aufmerksamkeit für die Spezifik der Dinge und seine Meister schaft im produktionsmäBigen Zugang zu den Dingen. Er bezieht seine ÄuBerung explizit nur auf einen Prosatext Šklovskijs - auf die "Sentimentale Reise", die nicht unter dem Vorzeichen der literatura fakta geschrieben. sondern im nachhinein dazu deklariert wurde. Unerwähnt bleibt der autobiographische Text "Zoo...", der beinahe zur gleichen Zeit entstand und veröffentlicht wurde, unerwähnt bleibt auch der Text "Dritte Fabrik", den Šklovskif 2wei Jahre vor der literatura fakta-Konzeption verfaBt hatte. Es ist wohl mehr politisches Kalkuil als literaturtheoretische Uberlegung, daß Čužak sich nur auf diesen einen Text Šklovskijs beruft. Indem er so verfährt, macht er indirekt eine Aussage uber die kulturrevolutionäre Intention der Konzeption: daB sie eine operative Agitationskunst begrinden sollte. Denn die "Sentimentale Reise" ist das Revolutionsbuch Šklovskijs - wenn auch nicht unbedingt im Sinne der Parteipolitik der Bolschewiki -, während sowohl "Zoo ..." als auch "Dritte Fabrik" jeweils aus verschiedenen Perspektiven eher als Buicher der Krise und der Selbstreflexion zu bezeichnen sind.

Keiner der autobiographischen Prosatexte - auch keiner der späteren - ist 
von Šklovskij als literatura fakta veröffentlicht worden. Der Essayband "Hamburger Vergleich", der während der Arbeit am Novy LEF unter dem unmittelbaren EinfluB der literatura fakta-Konzeption entstanden ist. kann vielleicht als der exponierteste Versuch Šklovskijs gelten. seine Version der Konzeption zu realisieren, aber dieses Buch erwähnt ¿užak nicht.

Seit seiner Rückkehr aus dem Exil hatte Šklovskij zahlreiche Reportagen verfaBt, die der Form nach eher ins Konzept der Faktographie passen als die autobiographische Prosa. Ohne daB er auf diese namentlich verweist, hat Cužak möglicherweise auch sie im Sinn, wenn er uber die literatura fakta Sklovskijs spricht.

Vergleicht man die programmatischen ÄuBerungen Čužaks uber die Prosa Šklovskijs mit ihrer Interpretation von seiten der Formalistenfreunde Tynjanov, Ejchenbaum und Gric, die Šklovskijs Orientierung auf das Faktum des Alltagslebens genauso wie die Literarisierung und Verwissenschaftlichung existentieller Probleme (das Problem der Professionalisierung, der "literarischen Persönlichkeit ${ }^{-1}$ in seiner Prosa als Erneuerung der literarischen Sprache im Rahmen der literarischen Evolution begreifen, so werden bei aller Verschiedenheit der politischen Perspektive doch Berührungspunkte sichtbar. Sowohl ČuŽak als auch Tynjanov, Ejchenbaum und Gric heben Šklovskijs besondere Aufmerksamkeit für die Dinge hervor, wobei Ding für die Formalisten das Wort-Ding. für Cužak hingegen das auBerliterarische Ding in der empirischen Wirklichkeit oder aber seine Idee bedeutet. Sie alle betonen Šklovskijs produktionsmäBigen Zugang zu diesen Dingen - worunter die Formalisten den ProduktionsprozeB der literarischen Arbeit verstehen, in den selbst das Leben des Schriftstellers als Produktionsfaktor einzubeziehen ist. während Čužak den unmittelbaren Bezug der literarischen Arbeit zur gesellschaftlichen Wirtschaftsproduktion meint Aber Cužak schlieBt die formalistische Interpretation nicht ous. Er setzt die Schwerpunkte anders, bezieht aber die literarischen Fakten (Sterne. Sujettheoriel in die literatura fakta ein und baut auf diese Weise eine Bricke 2wischen formalistischer Prosatheorie und Faktographie, die Šklovskij annimmt und ausbaut. Dessen autobiographische Prosa darf nicht mit der literatura fakta Tret'jakovs. Arvatovs u.a. gleichgesetzt werden und auch nicht mit jener Skizzenliteratur, die im Namen der Konzeption im Rahmen des I. Fünfjahresplans entstand. Versteht man aber unter dem Faktum sowohl das Wort-Ding als auch das Ding im Leben und begreift man die Bestimmung "produktionsmäBiger Zugang $2 u$ den Dingen" als zentrales Kriterium der Konzeption und faBt sie im Sinne Šklovskijs doppeldeutig auf - sowohl als Indiz fur die Emeuerung der literarischen Sprache und fur die Revolutionierung des Formbegriffs in der Literatur als auch als Hinweis auf die veränderte Einstellung des Schriftstellers zur literarischen Produktion in gesellschafticher Verantwortung - dann kann man sie wohl als literatura fakta begreifen.

Gesellschaftliche Wirklichkeit erscheint in seiner Prosa als Alltag (Arbeitsalltag. Lebensalltag, einfaches Leben) auch in vermeintlich ganz unalltäglichen Situationen, in Revolution. Krieg und Abenteuer, in der Welt der Künstler 
und Intellektuellen und in der Schilderung des Emigrantendaseins, das weder die Sicherheiten des Gewohnten garantiert noch Abenteuer oder Experiment ist. Alltag - in der Prosa $\mathbf{S} k$ lorskijs ein schillernder Begriff - markiert den Kontrapunkt 24 euphorischem existentiellem Erleben in Situationen des Aufbruchs und trägt doch die widersprijchlichen Züge eines Gedoppelten, eines Janusköpfigen in sich. Elan vital. Spontaneität. die Wïnsche und Träume des UnbewuBten, ein geringes $\mathrm{MaB}$ an Organisation und Rationalitat als Schutz vor Ubbergriffen von politischen und ökonomischen Systemzwängen haben dort Platz neben, ja sogar in dem Ewiggleichen, zur Gewohnheit Gewordenen und deshalb nicht mehr Wahrnehmbaren oder noch nicht ins BewuBtsein Gelangten, neben Pragmatismus. Ökonomismus und auf Wahrscheinlichkeit Berechnetem.

Šklovskij betrachtet den Alltag aus der Perspektive des Literaturspezialisten. der es sich zur Aufgabe macht, die ästhetische Wahmehmung zu revolutionieren. In der "Sentimentalen Reise" formuliert er seine Kritik am Revolutionsbzw. Alltagsverständnis der Bolschewiki.

"Das Leben treibt in abgerissenen Bruchstiucken dahin, die verschiedenen Systemen angehören.

Einzig unsere Kleidung, nicht unsere Körper, verbindet die voneinander isolierten Augenblicke des Lebens.

Das BewuBtsein beleuchtet das Band der nur durch das Licht miteinander verbundenen einzelnen Abschnitte. wie ein Scheinwerfer ein Stuick von einer Wolke, das Meer, ein Stiuck Ufer beleuchtet. ohne sich um ethnograhische Grenzen zu kümmern. Aber der Wahnsinn ist systematisch. und im Schlaf ist alles zusammenhängend.

Und nun stehe ich mit den Splittern meines Lebens vor dem konsequenten BewuBtsein der Kommunisten ... Man kann ein Volk organisieren. Die Bolschewisten glaubten, daB es nicht auf das Material ankäme. sondern nur darauf, was man daraus mache ... Sie wollten alles organisieren. die Sonne sollte fahrplanmäBig aufgehen. und das Wetter sollte in ihrer Kanzlei gemacht werden.

Der Anarchismus des Lebens, die Tatsache. daß es sich im UnterbewuBtsein abspielt, und daB der Baum selber an besten weiB, wie er wachsen soll, das alles ist ihnen unbegreiflich. Die Projektion der Welt auf ein Stuick Papier ist kein zufälliger Irrtum der Bolschewisten.

Sie haben anfangs geglaubt, daB ihre Formel mit dem Leben ubereinstimme. daB das Leben sich aus der 'Eigeninitiative der Massen' zusammensetze, aber immer ihrer Formel gemäB. Wie verendete Nashömer oder Mammuts liegen diese Worte jetzt in RuBland herum, eine Unmenge von Worten wie: 'Eigeninitiative der Massen'. die 'örtliche Macht' oder der Ichtiosaurier 'Frieden ohne Annexionen und Kontributionen', und die Kinder lachen iber die verendeten und noch nicht verwesten Ungetuime. ${ }^{-38}$

Šklovskij sieht Revolutionierung von Altag nicht dadurch verwirklicht, daB Alltag in ein rational durchschaubares und dementsprechend wirtschaftlich und sozial kalkulierbares System neuer Lebensformen transformiert wird. Die 
Herrschaft der Bolschewiki, ihre bornierte und biirokratische Sozial- und Wirtschaftspolitik schien ihm die Aufhebung entfremdeter Lebensweise in keiner Weise zu gewährleisten. Seiner Meinung nach hatten die Bolschewiki RuBland vielmehr um die Revolution - ja um die Weltrevolution betrogen. Der Festcharakter des Februar 1917 als spontaner und darin chaotischer Auftakt der Revolution versprach - so Sklovskij - das Kontinuum der Geschichte aufzusprengen, revolutionäre Kräfte im Altag wie in der Politik, in der Kunst wie in der Wissenschaft freizusetzen und in einem Ziel miteinander zu verknijpfen. doch der Sieg der Bolschewiki zerschiug diese Hoffnungen.

Šklovskij hat weder einen exakt soziologischen noch einen im engen Sinne des Wortes politischen Begriff von Alltag. Sehr häufig spricht er einfach von "Leben" (Zizn' oder bytie) oder "Alltag" (byt). "Ich bin kein Sozialist, ich bin Freudianer." 39 , bemerkt er selbstironisch und weist damit auf Freud und die Psychoanalyse hin, nimmt sie wie andere Dinge, wie zu anderen Gelegenheiten auch fragmentarisch. scheinbar unmotiviert, aphoristisch literarisch in Gebrauch und gibt damit doch immerhin einen Anhaltspunkt filr die Herkunft seiner Bestimmung von Alltag als Domäne des Un- und UnterbewuBten, das das wahre Antlitz des Lebens nur im Wahnsinn oder im Traum offenbart. $\$ 0$

Subjektivität, Befangenheit und existentielle Betroffenheit des 'Ich' im Allag der Arbeit und des Lebens prïgen $\zeta_{k}$ klovskijs literarische Perspektive und geben der Selbstreflexion ihre thematische Orientierung und eine kompositionelle wie stilistische Struktur.

Nur selten - vor allen Dingen im Film - geht er auf das Problem des Alltags. z.B. auf den Kleinbuirger-byt, jenseits einer unmittelbar auf die eigene Subjektivität bezogenen Auseinandersetzung ein $\$ 1$

Die -Sentimentale Reise" - eine Reise der Erinnerung an Situationen des Aufbruchs in Revolution und Abenteuer, die dem Subjekt die utopische Möglichkeit. strukturierend und selbstbestimmt die Geschicke der eigenen Geschichte in die Hand nehmen zu können, dicht vor Augen rückt - schreibt solche Situationen in der literarischen Konstruktion fest und konfrontiert sie zugleich mit dem Pragmatismus und der Ohnmacht des Subjekts angesichts der Restitution von Alltag Im RuBland der 20er Jahre ohne, wie es vielleicht scheinen mag, sie gegen diesen Alltag auszuspielen. Worte wie "es tut mir leid, dab ich versucht habe, den Dingen eine neue Richtung zu geben. denn es lief alles im alten Gleis weiter" kommen aus dem Munde des in den Alltag Zurickkehrenden. $\$ 2$ Der Kunstgriffcharakter der Negation des revolutionären Aufbruchs an der Schwelle des Ubergangs von Revolution und Abenteuer zum Alltag wird angesichts der politisches Engagement und subjektive Betroffenheit signalisierenden ersten Teile des Buches of fensichtlich. Die nachzeitige Negation bedeutet nicht Abkehr von den urspringlichen Vorstellungen. sondern ist nichts anderes als der literarische Ausdruck der Reproduktion des Alltagsmenschen Šklorskij - ein "fallender Stein". der in der Selbstreflexion, in der künstlerischen Beleuchtung seiner eigenen Person die Naturwilchsigkeit von Altag ins Bewubtsein hebt, um sie sich im literarischen 
Augenblick anzueignen. Aber das Bild des "fallenden Steines", in dem sich Sklovskijs resignierte Vorstellung von der Naturwiichsigkeit des Lebens nach dem Scheitern der Revolution kristallisiert, bleibt nicht unwidersprochen stehen.

"Natürlich tut es mir nicht leid, daB ich gekïbt habe und gegessen und die Sonne gesehen ..."

Šklovskij stellt ihm eine sensible und vitale Lebenshaltung an die Seite:

"Es ist schön, zu leben und den Weg des Lebens mit der Scinnauze zu spiren.

SüB ist das letzte Stuickchen Zucker. Sorgsam in ein Papierchen eingewickelt.

Schön ist die Liebe.

DrauBen. jenseits der Mauer, ist der Abgrund und ein Strom von Autos und im Winter der Schneesturm.

Wir treiben dahin auf unserem FloB. ${ }^{-43}$

- und zwischen dem "fallenden Stein" und dem élan vital entspannt sich ein nicht endenwollender Dialog.

In der Emigration kommt Šklovskij Alltag in einer doppelten Entfremdung zu BewuBtsein. Dem Emigrantendasein, dem Leben in Konfrontation mit einer fremden Lebensweise (westliche Mode. Sitten und Umgangsformen auch in der Liebe. westeuropäischer Kunstgeschmack) fügt sich die Erfahrung des Alltags im kapitalistischen System hinzu (Berlin - Glanz und Elend einer kapitalistischen GroBstadt). Hier wird ihm besonder klar, daB

-... die Dinge. besonders die Maschine. den Menschen verwandelt (haben). Der Mensch versteht sich heute nur darauf, sie aufzuziehen; dann laufen sie von allein. Sie laufen und laufen und erdricken den Menschen ....44

Den Zustand der Heimatlosigkeit, der Heimatlosigkeit seiner Revolutionserfahrungen und der Erinnerungen an die eigene Geschichte erfahrt Šklovskij schmerzhafter als die Enttäuschung über die Geschicke der Revolution unter der Regie der Bolschewiki als Nicht-Leben und Nicht-Sehen der Dinge.

"Rettet mich vor den Schattenmenschen, vor den Menschen, die man von der Deichsel losgespannt hat: vor dem Rost; vor diesem ganzen Leben, das immerzu nur das eine wiederholt:

Lebe, aber nimm mir weder Zeit noch Raum weg!"

Und das auBerdem noch wiederholt:

'Das ist der Tag, und das ist die Nacht: du aber lebe dazwischen.

Am Morgen und am Abend darfst du jedoch nicht kommen! ${ }^{n 45}$

Šklovskij entschied sich gegen das Leben in der Emigration. Er wollte sich bewruBt dem Alltag des Schriftstellers in gesellschaftlicher Verantwortung 
aussetzen und sich mit dem Sozialismus der Bolschewiki im Aufbau konfrontieren.

Die Auseinandersetzung mit diesem Schriftstelleralltag führt Šklovskij in "Dritte Fabrik". Hier schildert er den auch im Sozialismus sowjetischer Machart fortexistierenden Doppelcharakter von Alltag aus der Perspektive subjektiver Befangenheit. Er schildert die Dialektik der Lebensunmittelbarkeit - ihren "spontanen Materialismus". wie G. Lukács es nennt ${ }^{46}$ - und ihre Anfälligkeit fur Entfremdung durch Automatisierung. Ökonomisierung und Pragmatisierung von Sprechen und Handeln. Er konfrontiert die Blindheit der Alltagsroutine, wie er sie in der Kinoarbeit im Unterschied zur experimentellen Forschungsarbeit des OPOJAZ erfährt. mit dem GenuB sinnlichen Erlebens ganz banaler Dinge. z.B. des Geruchs des Filmklebers. Im Bild der Liebe symbolisiert er zugleich die den Menschen beherrschende Naturwichsigkeit - Tripper/Syphilis - und die Utopie hedonistischer Beziehungen. Den Marxschen Satz "Das Sein bestimmt das BewuBtsein" wendet er mit List gegen die naive Interpretation der Bolschewiki. indem er die kritische. subversibe und utopische Funktion des UnterbewuBten zeigt. Die alltägliche Beziehung des Schriftstellersubjekts zur sowjetischen Wirklichkeit. dargestellt im varierenden Gebrauch der Redewendung "im Gleichschritt" bzw. "mit beiden Beinen auf der Erde stehen". ist nicht nur ein zentrales Thema der "Dritten Fabrik". sondern auch seiner theoretischen Arbeiten jener Zeit. So hebt die Konzeption der Faktographie die kritisch materialistische Einsicht, daß die Revolution auch die Perpektive auf die Dinge verschoben habe und daB die Schriftsteller nicht ungebrochen von den Meistern der Klassik lemen könnten. da sich die Evolution der literarischen Reihe nicht allein aus sich selbst speise. gerade auch in der Forderung nach einer Zweitprofession des Schriftstellers auf die Ebene einer engagierten Produktionskunst. $\$ 7$

Diese Forderung hat eben eine doppelte Funktion. Neben der Aufgabe. den Formalismus. seine literatursoziologische Konzeption 24 legitimieren und auf diesem Wege der Technik des Schriftstellerhandwerks als verarbeitender. verfremdender, die Eigengesetzlichkeit der Kunst gegeniber dem Leben zum Ausdruck bringender Instanz eine besondere Bedeutung beizumessen. hat sie auch die Funktion. den Schriftsteller mit seiner Zeit. mit seiner Verantwortung gegeniber der gesellschaftlichen Wirklichkeit. in der er lebt, zu konfrontieren. nicht damit er vor ihr kapituliere und sich anpasse, sondern damit er wirklich Kunst produziere. Der Schriftsteller soll nicht vor dem Druck seiner Zeit fliehen. sondern sie so ausfüllen, wie ein Schiff seine Segel mit Gegenwind fullt, um seinen eigenen Kurs zu halten. Er soll die Dinge wie noch nicht beschrieben neu sehen.

"Glaubt nicht an die gewöhnlichen Beziehungen zu den Dingen. glaubt nicht an die gewohnte ZweckmäBigkeit der Dinge ..."

Die soziale Revolution machte es dem Schriftsteller hierbei leicht und schwer zugleich. Auf der einen Seite erleichterte das revolutionäre Postulat der 
radikalen Umwertung aller Werte es dem Künstler, eine neue, den Kunstkanon sprengende Einstellung $z u$ den Dingen zu gewinnen, aber auf der anderen Seite erschwerte sie die künstlerische Produktion, denn sie hatte die Verbindung zur Tradition durchschnitten, so daB es dem sowjetischen Schriftsteller nicht vergönnt schien, bei der alten Kunst in die Schule zu gehen.

"Sie (die Schriftsteller, d.V.) sind in eine Fabrik mit verlassenen Werkzeugmaschinen geraten und wissen nicht. welche Maschine hobelt, welche bohrt." 49

Šklovskij versteht die Konzeption der Faktographie als Versuch. den Anspruch der Revolution, die russische Gesellschaft vom Joch kapitalistischer Unterdrickung zu befreien, noch einmal beim Wort 24 nehmen und ihn auf die kinstlerische Produktion zu beziehen.

"... es ist notwendig zu lernen, in die Zukunft hineinzuarbeiten, auf jene Formen hin, die ihr selbst entwickeln mübt. Die Menschen einfach literarische Formen lehren. d.h. sie Aufgaben richtig lösen lehren, aber nicht die Mathematik - das heiBt die Zukunft bestehlen und Banalitäten züchten." ${ }^{m 0}$

Mit diesem programmatisch in die Zukunft engagierter künstlerischer Produktion weisenden Worten beschlieBt Šklovskij den Aufsatz "Der Schriftsteller und die Produktion". der als einer der wichtigsten Texte im Rahmen des Entwurfs der literatura fakta-Konzeption gelten kann.

So avanciert und engagiert der Plan einer faktographischen, d.h. einer nicht nur dokumentierenden, sondern in den ProzeB des gesellschaftlichen Lebens auch eingreifenden, einer operativen Literatur zunächst einmal erscheint. so abstrakt und naiv muBte diese Konzeption angesichts zunehmender Repressionen der stalinistischen Kulturpolitik, aber auch infolge von Divergenzen innerhalb des LEF $\mathbf{z w i s c h e n ~ d e n ~ e i n z e l n e n ~ F r a k t i o n e n ~ b l e i b e n . ~ A u f ~ d e r ~ e i n e n ~}$ Seite stand Tret'jakovs Programm einer utilitaristischen Faktographie, auf der anderen die formalistische Konzeption der literatura fakta als eine neue Form von Fiktion. Eine Fortsetzung der Arbeit der Linken Kunstfront war in einer Zeit, die literaturtheoretische Kontroversen und Experimente nicht dulden konnte, nach der Auflösung der Zeitschrift Novy LEF endgiiltig vereitelt.

Nachdem der Plan gescheitert war, einen Moskauer OPOJAZ zu gründen.

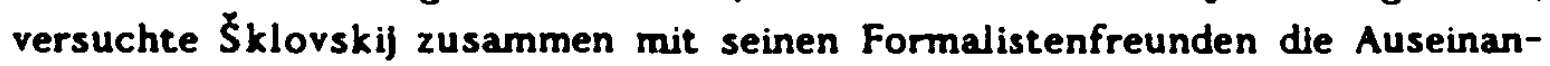
dersetzung iber die realen Anforderungen des Lebens an die Schriftsteller nun auf dem Fundament literatursoziologischer Prämissen weiterzuführen. Unter seiner Hand nahm dieser Diskurs uber den Widerstreit von künstlerischer Freiheit und realer Unfreiheit angesichts der Professionalisierung der Schriftstellerpraxis, uber den Kampf zwischen Vergangenheit und Gegenwart im Schriftstellersubjekt selbst, iber die Suche nach einer künstlerischen und gesellschaftlichen Identität in einer von Ungleichzeitigkeiten und Verschieden- 
artigkeiten geprägten Kultur, den er am historisch-biographischen Material entwickelte, weniger eine wissenschaftliche als eine literarische form an. So entstanden die Bücher "Matvej Komarov". "Der Höfling Bolotov". "Čulkov und Lovక̌in" und "Marco Polo".51

Mehr als jene ironisch getönte politische Programmschrift "Denkmal für einen wissenschaftlichen Irrtum".52 deren Stärke eher darin liegt, die agitatorischen oder gar repressiv terroristischen MaBnahmen der Staatsmacht. den Schriftsteller bzw. Literaturwissenschaftler zum Gehorsam gegenuiber der Obrigkeit zu zwingen, ad absurdum zu führen. als darin. Selbstkritik und Veränderung der formalistischen Theorie anzuzeigen. geben diese Arbeiten einen deutlichen Hinweis auf die existentielle Bedeutung des Bemuihens. sich die Zeit und die eigene Gesellschaftlichkeit gegen den Strom autoritärer Reglementierungen stalinistischer Literaturpolitik anzueignen. Auch wenn es Šklovskij letztlich nicht gelang, sich als engagierter Schriftsteller - als Produktionskünstler - gesellschaftlich nützlich zu machen. wozu die Entwicklung der russischen Revolution das Ihrige beitug. so gelang es ihm doch. die Gefangenschaft im privaten, zwischen fensterlosen Mauern eingeschlossenen Leben $\mathbf{5 3}$ in der Literarisierung dieser Auseinandersetzung und in der Existentialisierung des Literarischen aufzuheben.

Wie ein kleiner, heiBe Luft durch die Münder seiner trichterförmigen Schornsteine atmender Dampfer schwimmt unser Haus.

Es schwimmt unter dem Himmel.

In der Schiffahrt nennt man das wahrscheinlich abdriften.

Das Haus treibt auf der Erde.

Nichts ist gelöst. Ein Weg ist nicht gefunden.

Meine Schliussel öffnen nicht alle Türen meiner Zeit.

Es ist notwendig. $z u$ neuem Leben $z u$ erwachen, sich $z u$ verändem. Auf einer Tafel, auf einem Schachbrett. acht mal acht. inszeniere ich meine Erzählungen. Weiß. Schwarz. Liebe, Verrat. Tod.

...ich weiB nicht. wie ich über das, was ich sah. schreiben soll ... Ein Wohnungsleben.

Wie schwer ist es. Leser. aus seinem unbeweglichen Haus zu schwimmen. Wie schwer ist es, die Bitterkeit. die Verworrenheit zu vergessen. Vom Maßstab der Wohnung zur Weltkarte uberzugehen."5\$

Der produktionsmäßige Zugang zu den Dingen kommt in der Prosa Šklovskijs als spezifische Form und Funktion der autobiographischen Erzählung zum Ausdruck. der fragmentarisch aphoristischen Erzählung des Literaten. der sich selbst thematisiert, sich erinnert, reflektiert und parodiert. Auch wenn die einzelnen Texte allein schon durch den Zeitpunkt ihres Entstehens unterschiedliche Perspektiven auf das literatura fakta-Programm einnehmen, so zeigen sie doch eine so groBe strukturelle Ähnlichkeit. daB es methodisch sinnvoll ist, den Zusammenhang zu betonen und die Unterschiede als Veränderungen einer sich im Grundsatz gleichbleibenden Konzeption der Revolutionierung der Literatur in Verbindung mit der gesellschaftlichen Revolution zu betrachten. die sich im ProzeB der Auseinandersetzung mit dem Oktober, mit 
den Jahren des Bürgerkriegs, der NEP und der Politik des I. Fünfjahresplans modifizierte.

Allen autobiographischen Prosatexten der fraglichen Zeit ("Sentimentale Reise". "Zoo...". "Dritte Fabrik" und "Suche nach dem Optimismus") liegt gleichermaBen auBerliterarisches Faktenmaterial zugrunde: jedesmal macht sich der Autor selbst zum Gegenstand der Darstellung - Šklovskij, der etwas erlebt, der sich erinnert, der beobachtet, der vom Hörensagen etwas weiB. Šklovskij, der besonders informierte Spezialist und Šklovskij, der Geschichtenerzähler. 55 Er nimmt verschiedene Rollen an: In der "Sentimentalen Reise" erzählt der Anarchist, der Fahrlehrer, der OPOJAZ-Mitarbeiter, der Soldat und Sprengmeister und der Schriftsteller Šklovskij. In "Zno..." ühernimmt. er die Rolle des unglücklichen Liebhabers, des Exilianten, des Literaturtheoretikers und Schriftstellers. In der "Dritten Fabrik" erinnert sich Šklovskij an seine Kindheit, reflektiert seine Existenz als politisch verantwortlicher Schriftsteller. Kritiker und Theoretiker der Literatur und als Kinoarbeiter (Montagetechniker und Drehbuchautor) am staatlichen Kino in Moskau; er ist der Faktograph, aber auch der Geschichtenerzähler. In "Suche nach dem Optimismus" ist er - ähnlich wie in "Dritte Fabrik" - der Schriftsteller, der Geschichtenerzähler, der Faktograph und der Theoretiker und Kritiker der Literatur.

Jede dieser Rollen basiert auf auBerliterarischem Faktenmaterial. selbst die des Anarchisten. der ein Attentat auf Lenin mitorganisiert, oder de des unglilcklichen Liebhabers, der sich in die Schriftstellerin Elsa Triolet, die Schwester Lilja Briks und spätere Frau Louis Aragons, verliebt. Die knappe Skizzierung der verschiedenen Rollenbilder zeigt, daB sich eine Form der Selbstdarstellung, die zunächst eine unter anderen ist. im Laufe der Zeit in den Vordergrund schiebt, die Rolle des Literaten. Während in der "Sentimentalen Reise" der anarchistische Abenteurer in der Revolution die Handlung entscheidend vorantreibe und in "Zoo..." der ungllickliche Liebhaber bzw. der einsame Emigrant eine dominante Motivation des Sujets bildet. tritt in der "Dritten Fabrik" der Literat, der in den beiden vorausgegangenen Titeln jeweils auch keine unbeträchtliche Rolle innehatte. in den Vordergrund. Diesen Status behält er auch in "Suche nach dem Optimismus" bei. Die allmähliche Veränderung der Konstellation der Rollenbilder des autobiographischen Erzählers, die zu einer Dominanz der Rolle des Literaten führt, korrespondiert mit einer Veränderung in der Methode der Selbstdarstellung. Die Form der autobiographischen Prosa modifiziert sich von der Selbstdarstellung zur Selbstreflexion des Faktenmaterials. Der Beginn des zweiten Teils der "Sentimentalen Reise" markiert den Beginn dieser Wende.

"Ich schreibe weiter. Heute ist der 22. Mai. ich bin in Raivola in Finnland. Natürlich tut es mir nicht leid, daB ich gekuibt habe und gegessen und die Sonne gesehen; es tut mir leid. daB ich versucht habe, den Dingen eine neue Richtung zu geben, denn alles lief im alten Gleis weiter. Es tut mir leid, daB ich in Galizien gekämpft 
habe, daß ich mich in Petersburg mit den Panzerwagen abgeplagt habe, daB ich am Dnepr gekämpft habe. Ich habe nichts geändert. Und während ich hier am Fenster sitze und in den Frihling hinausschaue. der an mir vorübergeht, ohne zu fragen, was für Wetter er morgen bringen soll, der meine Erlaubnis nicht braucht, vielleicht. weil ich nicht von hier bin, denke ich: 'Vielleicht hätte ich auch die Revolution einfach voribergehen lassen sollen.'

Wenn man fallt wie ein Stein, darf man nicht denken; wenn man denkt. darf man nicht fallen. Ich habe $z$ wei verschiedene Gewerbe durcheinandergebracht. Die Ursachen. die mich antreiben. lagen nicht in mir. Die Ursachen, die die anderen antreiben, lagen nicht in ihnen.

Ich bin nur ein fallender Stein.

Eis Stein. der fältt und gleichzejtig eine Lateme anzünden kann. um seine Bahn zu beobachten." (Hervorhebung V.D.)

Das Bild vom Stein, der fält, beim Fallen in die Tiefe schaut und die Bahn seines Fallens beleuchtet. steht für die Rolle des sich selbst reflektierenden Schriftstellersubjekts. Šklovskij verwendet es hier zum ersten Mal und überträgt ihm eine leitmotivische Funktion der "Sentimentalen Reise". 57 Schon der Titel des zweiten Teils des Buches "Am Schrebtisch" - im Kontrast zum Titel des ersten Teils "Revolution und Front" - signalisiert eine Veränderung der Perspektive des Schriftstellers auf die gesellschaftliche Wirklichkeit. Der Held der autobiographischen Prosa beginnt den ProzeB dieser Veränderung der Perspektive auf die russische Revolution zu schildem. Er stellt ihn als einen Wandel seines politischen Handlungsspielraums dar. Da Šklovskij die Erinnerungen in Etappen niederschrieb, wurden sie nicht nur durch die Distanz zwischen Erleben und Beschreiben, sondern auch durch den Fortlauf der Ereignisse während des Schreibens in ein anderes Licht getaucht. Den ersten Teil "Revolution und Front" verfaßte er während des Bürgerkriegs 1919 in Petrograd - allerdings ohne ihn gleich zu veröffentlichen -. in der Zeit der experimentellen Arbeit im OPOJAZ und im Kreis der Serapionsbrider. Den zweiten Teil schrieb er im Exil in Finnland und Berlin, da ihm seine Machenschaften gegen die Bolschewiki erneut zur Last gelegt worden waren. im Jahre 1922. dem zweiten Jahr der NEP, als sich die Herrschaft der Bolschewiki gefestigt hatte und der revolutionäre UmwälzungsprozeB zu einem vorläufigen Ende gekommen war. Zwischen dem Anfang und dem Ende der Aufzeichnungen lagen demnach drei Jahre epochemachender Ereignisse und einschneidender persönlicher Erlebnisse. In dem Maße, wie sich Šklovskijs Spielraum für gesellschaftliche Handlungsmöglichkeiten verengte, verändert sich die Perspektive des Subjekts der autobiographischen Darstellung: der in der gesellschaftlichen Wirklichkeit Agierende hält inne und nimmt die Position des Sinnenden und Reflektierenden ein. Das Material, aus dem seine autobiographische Prosa seither verfertigt wird. sind nicht so sehr empirisch dingfest machbare Erlebnisse des Subjekts oder gar operative Eingriffe des Subjekts in den Ablauf der Dinge, wie die Konzeption der literatura fakta es in ihrer extremen. pragmatischen Formulierung fordert, sondern der widersprichlich verlaufende 
ProzeB der Selbstreflexion des Schriftstellers, seine Erinnerungen an die Kindheit, an die Revolution und Majakovskij und an die Literatur.

Während der anarchistische Revolutionär und der experimentierende Literat ein aktives und praktisches Verhältnis zum gesellschaftlichen RevolutionsprozeB eingehen konnte, das der literatura fakta-Konzeption, ihrer Forderung nach einer positiv gestimmten und 24 konkretem politischen Handeln aufgelegten Grundposition des Subjekts der literarischen Darstellung entsprach, stellt der Literat im zweiten Teil seinen Schreibtisch als sein Aktionsfeld vor. Zum zweiten Mal exiliert. ist er in eigenen Land ohne politische Handhabe und ohne Ambitionen im fremden. Er reflektiert seine Existenz- und Arbeitsform und wird in diesem Sinn literarisch produktiv.

Selbstreflexion des Schriftstellers stellt sich in der autobiographischen Prosa Šklovskijs nicht als einsame Reflexion eines in seinen Gedanken und Gefuhlen befangenen Subjekts und auch nicht als Bekenntnis oder sentimentale Erinnerung dar. sondern als unaufhörliche Auseinandersetzung der "literarischen Persönlichkeit" zwischen den sich verändernden Systemen dem der Kunst und dem des gesellschaftlichen Lebens. Sie hat zur Voraussetzung. daB sich das Schriftstellersubjekt nicht als privates Individuum, sondem als Individualisierung der "literarischen Persönlichkeit" versteht.

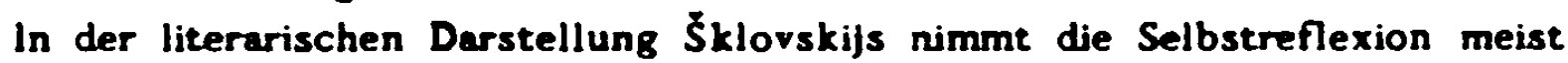
die Form eines Spiels 2 wischen den semantischen Ebenen (Sprache des Alltagslebens/Sprache der Kunst/Sprache der Wissenschaft) an oder sie erscheint als Dialog der Masken der Selbststilisierung und als Dialog der Texte. In seinem Exil-Buch "Zoo..." thematisiert Šklovskij das Prinzip der Selbstreflexion. Einmal spricht er von einer Unterhaltung mit seinem Leid:

"Du Frau, die mir nicht antwortet!

Du hast meine Liebe in einen Telefonhörer gejagt.

Mein Leid kommt zu mir und setzt sich an meinen Tisch.

Ich unterhalte mich mit ihm."S8

Ein anderes $\mathrm{Mal}$ erläutert er die kleinste Einheit der literarischen Form, in der sich die Selbstreflexion Gestalt gibt, die Anekdote:

"Wir lösen das geronnene Leben in Anekdoten auf.

Wir errichten 2 wischen der Welt und uns kleine Eigenbestiarien.

Wir wollen Freiheit.

Remisow lebt sein Leben nach den Methoden der Kunst.

Ich schlieBe, ich muB in die Konditorei eine Torte abholen ....59

Die gedankliche Vermittlung der Welt der Literatur und der des Lebens gelingt ihm einzig in der literarischen Konstruktion der ironischen Selbstreflexion bzw. in der fragmentarischen, elliptischen Aneinanderreihung solcher Konstruktionen. Indem Čužak Šklovskijs fragmentarischen Stil als "innere Sujethaftigkeit" bezeichnet, die die verborgene Sujethaftigkeit des Lebens 
aufdecke und das Leben in seiner inneren dialektischen Verknijpfung darstelle, verhält er sich 2 war empathisch $2 u$ diesem Stil, umgeht es aber gleichzeitig. die dieser Schreibweise immanente Gesellschaftskritik zu explizieren. Auf diese Weise neutralisiert er den fragmentarischen, ironischen Stil ふ̌klovskijs zu einer Spezifik des Verfahrens.

"Sind die Genossen (Šklovskij u.a., V.D.) nicht deshalb lesbar und ron innen her sujethaft, weil sie die Spezifik nicht füchten?" ${ }^{m 0}$

"Dritte Fabrik" kann - wie die Textanalyse noch zeigen soll - als das Buch der Selbstreflexion des Schriftstellers in gesellschaftlicher Verantwortung gelten. Es ist noch mehr als "Zoo..." ein Buch der Krise. Aus dem Berliner Exil, aus der fremden Kultur gab es einen Ausweg, einen Weg nach Hause. Aus der "Dritten Fabrik" gibt es keinen. Hier erzählt der Schriftsteller davon, wie fremd er sich in seiner eigenen Kultur und Gesellschaft fühlt. Šklovskij veröffentlichte dieses Buch bei den "Mitläufern" - bei Voronskij. Dafür muBte Majakorskij ihn später im Namen des Novyj LEF gegen Angriffe von Averbach (RAPP) in Schutz nehmen.

Wir wissen uber Šklovskij viele unangenehme Dinge ... Niemand macht einen Hehl daraus. Doch worin besteht unsere Aufgabe? Die bedeutenderen wissenschaftlichen Kräte wie auch die bedeutenderen technischen Kräfte abspenstig zu machen. Wenn Šklovskij es fertigbringt. sich umzustellen und seine Energie umzuschalten. sagen wir. hundertprozent ein Soziologe zu werden. so heiBt das. daB unsere Arbeit Erfolg gehabt hat. Wir missen uns darum bemihen. ihn zu erobern. Was aber tut Voronskij? Der nimmt ihn in Beschlag für alte, dekadente Tendenzen. Und Averbach weiB, daB Voronskij ihn attackiert. Darum haben wir genau vermerkt. daB es Voronskij war, der '̌klovskijs 'Dritte Fabrik' herausbrachte. Wir hätten Šklovskij dazu iberredet. Textänderungen vorzunehmen. Darin besteht ja unsere politische Aufgabe: Aus dem Gleichgewicht geratene Leute auf unser Gleis heruberzurollen. ${ }^{.61}$

Der prominenteste marxistische Kritiker der Krasnaja nov'. Ležnev, fand in der "Dritzen Fabrik" nichts "Ausgedachtes", keinen Erfindungsgeist.

Ts ist das Buch eines Menschen, der seine Zielrichtung verloren hat. Das Leben geht mit schwerem, unbarmherzigen Schritt. Der fribere Theoretiker und Forscher muB nun Feuilletons schreiben und am Kino arbeiten. Die Biicher bleiben halb geschrieben liegen. ${ }^{.62}$

Wie Gor'kij, Majakovskij und andere kritisiert er Šklorskijs Ironie, sein Schbnreden. das Ausdruck mangelnder politischer Ethik sei, und miBversteht den Text. da er ihn ais die Klage eines Individuums begreift und nicht als Selbstreflexion der "literarischen Persönlichkeit". "Dritte Fabrik" bearbeitet - wie drei Jahre später Ejchenbaums Aufsatz "Das literarische Leben" - die Frage: wie soll man Schriftsteller sein. Šklovskij unternimmt hier den Versuch, die 
Revolution in der Kunst mit der kritischen Frage nach den Möglichkeiten der literarischen Produktionsbedingungen zu verknuipfen. Der Text ist weder schlichte Dokumentation des Lebens und der Arbeit des Literaten. noch eine Literarisierung der formalistischen Prosatheorie, d.h. ein formales Experiment im schlechten Sinne des Wortes, sondern der Versuch, mit experimentellen Mitteln das Subjekt des Schriftstellers zu einem literarischen Faktum. die literarische Arbeit zu einer Fabrik mit spezifischer Technik und besonderem Instrumentarium und die literarische Form zu einem Forum der Selbstreflexion zu machen, um das konkrete und allgemeine Problem, wie man in der Sowjetgesellschaft der ausgehenden 20er Jahre Schriftsteller und Literaturwissenschaftler sein kann, zu bearbeiten und um der Literatur zu einem kritischen Selbstbewubtsein zu verhelfen. Die Auseinandersetzung der -literarischen Persönlichkeit" Šklovskij mit sich selbst, der vielfaltig perspektivierte Dialog zwischen dem Schriftsteller, dem OPOJAZ-Mitarbeiter und dem Kinoarbeiter Šklovskij, zwischen Literaturtradition und kulturpolitischer Gegenwart. zwischen Kunst und Leben. zwischen ihm. Šklovskij, und den Futuristen, den Formalisten und dem Typus des sozial engagierten Literaten Platonov ist ein literarisches Verfahren und keine ikonographische Uibertragung personlicher Probleme in die Literatur, und in diesem Sinne ist sie eine literatura fakta. "Dritte Fabrik" stellt die Arbeit am Schriftstellersubjekt, an seiner Dualität als gesellschaftliches und als literarisches Faktum dar. Schon der Titel des Buches. noch deutlicher aber die Erklärungen zum Titel ${ }^{63}$ und solche Kapiteluberschriften wie -

"Was man aus mir macht." 64 -

bringen in ironischer Anspielung auf den Soziologismus des sowjetischen Marxismus den produktionsmäBigen Zugang zum Schriftstellersubjekt zum Ausdruck. Dagegen ist der vorläufig letzte seiner autobiographischen Prosatexte jener Zeit. "Suche nach dem Optimismus", eher die ironische Darstellung eines vorab erreichten Standorts der Erfahrung, der Erfahrung von einer uniberwindlich erscheinenden Getrenntheit von Leben und Literatur. Die Utopie verbleibt in den bereits geschriebenen Blichern. in den Versen Majakovskijs, im Marsian Chlebnikovs. Man kann sie allenfalls zitieren. Der autobiographische Erzähler gibt vor, die Meisterschaft in der Literatur verloren zu haben: er findet keine Formen mehr, um die Fakten der gesellschaftlichen Wirklichkeit literarisch zu verarbeiten. Die Skizze, vordem zum Prototyp der literatura fakta erhoben. erwies sich für ihn als untauglich. ${ }^{6}$ Auf der einen Seite tritt er als geistreicher Erzahler rätsel- oder parabelhafter Novellen uber die Naturwichsigkeit des Lebens, uber die Willkür, die Banalität und die Tragik alltäglicher Ereignisse auf, oder als Schriftsteller Šklovskij, der sich angesichts des Selbstmords seines Freundes Majakovskij an die Geschichte der Bewegung der linken Avantgarde erinnert, der weiterhin gegen die Pragmatiker unter ihnen polemisiert und insgeheim die kritische Position des Statthalters einer dem Leben gegenüber eigengesetzlichen Literatur behäl. Auf 
der anderen Seite werden diese Reminiszenzen an revolutionäre Experimente in der Kunst von dem Eingeständnis der "literarischen Persönlichkeit", dem ProzeB gesellschaftlicher Veränderungen ohnmächtig gegenüberzustehen, eingerahmt.

\section{Die Verlebendigung der Dinge - ein Kunstgriff der Verfremdung}

Von der Hypothese der Theorie der Prosa ausgehend, daB Literatursprache keine das Verstehen erleichternde Bildersprache, sondern eine konstruierte, die Wahmehmung erschwerende Sprache ist, in der Metaphern als Kunstgriff der Verfremdung fungieren, kann Šklovskij die Konzeption der literatura fakta fü sich als Möglichkeit, die Metaphorik der Literatursprache zu erneuern. nutzen. Das auBerliterarische Faktum wird in der Prosa Šklovskijs zu einem Wortding, das die konventionellen Wort-bzw. Wort/Ding-Relationen verwirt und neue, ungewohnte Zeichenrelationen erprobt. Zum Beispiel fungieren häufig technische Begriffe als Metaphern für literaturtheoretische oder existentielle Probleme - anders als bei Tret'jakov, der den Kunstgriff des literarischen Vergleichs als ein Modell verstanden wissen will. das wie eine technische Gebrauchsanweisung an den praktischen Verstand des Menschen apellieren und die Spezifik des Gegenstandes aufdecken soll.66 \$̌klorskij kann sich selbst in seinen Reportagen, die scheinbar ganz der Schilderung gesellschaftlicher Fakten verpflichtet sind, nicht enthaiten, literarische Reflexionen über den Kunstgriff des literarischen Vergleichs anzustellen, die sein Interesse an einer Emeuerung der Literatursprache verraten. In dem Artikel "60 Tage ohne Arbeit" setzt er sich zum Beispiel kritisch mit Fedor Gladkovs Roman "Zement" auseinander und bemängelt die konventionelle Form des psychologischen Romans und die traditionelle Metaphorik des Buches, die der Schilderung des Aufbaus einer Fabrik in der Rekonstruktionsphase der Sowjetunion nicht angemessen sei:

\footnotetext{
Tch bin des Vergleichs so müde, daß ich das rächste Mal. wenn ich eine Wolke beschreiben soll, sie so beschreibe: 'Und über den Zementfabriken, über Novorossijskoe, zogen die schon friiher beschriebener Wolken.'
}

Der Terek in der Darjalsker Schlucht ähnelt nicht einer Löwin mit langer, dichtbepelzter Mähne auf dem Rücken, aber Vergleiche sind nicht dezu verpflichtet, ähnlich 24 sein ..."67

Šklovskijs Uberlegungen drehen skch dabei nicht um ein schlicht literaturimmanentes Problem. sondern darum. seine Beziehung zu den gesellschaftichen Fakten literarisch $2 u$ bearbeiten. Die metaphorische Sprache dient ihm hierbei is ein Kunstgriff der Verrätselung und als Ausdruck dafür, daB seine Beziehung zur gesellschaftlichen Wirklichkeit eine vermittelte und $z u$ vermittelnde bleibt. 
Eine Form der Transformation von auBerliterarischem Material in literarische Metaphern ist der Kunstgriff der Vermenschlichung der Dingwelt. Šklovskijs Version des produktionsmäBigen Zugangs zu den Dingen hat in seinen Prosatexten trotz kontroverser literaturpolitischer Positionen einen ähnlichen Anspruch wie Tret'jakovs "Biographie des Dings", die jener 2.B. in der Modellerzählung "Die Tasche" realisierte, einer Aufforderung an Jugendliche, die jeweilige Geschichte der Gegenstände aufzuschreiben, die sich in ihren Hosentaschen befinden. 68 Aber ihre kontroversen gesellschaftspolitischen und literarischen Positionen heben die Gemeinsamkeit dieses Anspruchs in der Orientierung der literarischen Produktion auf das Faktum auf, sobald es um seine Realisierung und Konkretisierung geht.

Während Tret'jakov von einer rationalen und objektiven Verfligbarkeit der Dingwelt und von der produktiv-pragmatischen Funktion der Literatur im ProzeB der Planung der Dinge hin zum Aufbau des Sozialismus uberzeugt war, ging Šklovskij davon aus, daß es weiterhin Unfreiheit und Entfremdung des Menschen ron sich selbst und von den Dingen geben werde, gegen die man kämpfen müsse. Als Kunstgriff gegen automatisierte und entfremdete Wahrnehmungsstrukturen setzte er u.a das Verfahren der Vermenschlichung der Dingwelt ein, um in der Umkehrung der Verhälenisse auf die Verdinglichung des Menschen hinzuweisen. Während sich Tretjakov an die sowjetische Wirklichkeit hielt, orientierte sich \$klovskij an literarischen Vorbildern, um sie mit dieser Wirklichkeit zu konfrontieren. Eines dieser Vorbilder ist der dänische Märchendichter Hans Christian Andersen, in dessen Geschichten die Vermenschlichung der Dingwelt einen besonders ausgeprägten Kunstgriff der Verfremdung darstellt. ${ }^{69}$ An ihn erinnert Sklovskij explizit in dem Bild ron der alten Laterne in der "Dritten Fabrik": 70 von ihm lieB er sich wohl auch zu der leitmotivischen Flachsmetapher in demselben Buch inspirleren. ${ }^{71}$

Im achtundzwanzigsten Brief des Briefromans "Zoo...". der in der russischen

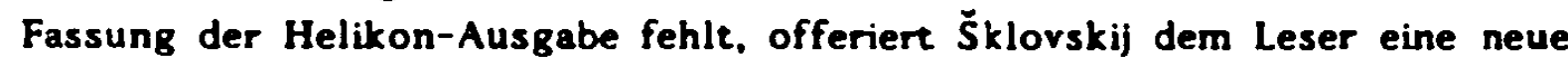
Variante des bekannten Märchens "Der Schweinehirt" von Andersen als mögliche Lösung des Buches. Auch hier arbeitet er den Kunstgriff der Vermenschlichung der Dinge ein: der Bratfisch in der Pfanne erwacht zu neuem Leben und macht sich iber die blinde Verliebtheit des Prinzen lustig, der sich bei Šklovskij weigert. den Schweinehirten zu spielen und statt dessen mit Shimmyrasseln und anderen Spielzeuggeschenken um die Liebe der launischen Prinzessin wirbt, so wie man um Besitz wirbt. Denn der Prinz bei Šklorskij ist den Vorstellungen von Liebe, Glück und Schönheit, wie sie die kapitalistische Großstadt produziert, am Ende genauso verfallen wie Nia. Er sieht in der Erfullung dieser Liebe sein Lebensglück. Der Bratfisch erkennt das SelbstmiBverständnis des Prinzen, der glaubt, sein Herz fur immer gegen die Liebe der Prinzessin eintauschen zu können.

"Er (der Bratfisch, V.D.) lacht, wenn er sieht, daB jemand sein Herz statt einer Rassel verschenkt hat.

Diesmal lachte er bis zum Umfallen. fuchtelte mit dem Schwanz. 
und verspritzte die Sauce.

'Prinz', sagte der Bratfisch, 'weshalb verdirbst du fremde Märchen?'

'Andersen hat mich verleumdet', erwiderte der Prinz.

'Mein Haus und mein Herz gehören der Prinzessin!

Der, den man liebt, ist niemals schuld.

Du aber bleib hübsch brav liegen und verspritz die Sauce nicht. denn die Prinzessin wird dich gleich aufessen."

'Du selbst bist aufgegessen. o Bratprinz', sagte der Fisch. So sprach er und starb ein zweites Mal. aus Langeweile; er liebte die Prinzessin nicht. ${ }^{-72}$

Auch der Dialog zwischen Alias Hausschuhen und dem Wasser und das Märchen vom Einsiedler, der sich in eine Maus verliebt und sie in ein Mädchen verwandelt, in "Zoo..." haben Ähnlichkeit mit Märchen von Andersen in bezug auf diesen Kunstgriff. ${ }^{73}$ Dinge werden lebendig, beginnen zu reden und sich miteinander zu unterhalten. Aus ihrem Munde werden die Worte wieder lebendig und hörbar, die bei den Menschen hohl und abgegriffen oder gar verlogen klingen.

In Šklovskijs Prosa werden sie zu Statthaltern des autobiographischen Erzählers und geben ihm jeweils eine konkrete und plastische Gestalt. Mit ihrer Hilfe gelingt es ihm. sich literarisch wirklich darzustellen und seine Rede bedeutsam zu machen. Mit ihren Stimmen spricht er von und mit sich selbst: er spricht aus dem Wasser, das die Sturmflut, an Petersburg, an die Revolution und den OPOJAZ erinnernd. bis an Alias Zimmerschwelle hat steigen lassen und das die Hausschuhe um EinlaB bittet, und er spricht aus den Hausschuhen. die dem Wasser den Eintritt zu Alia verwehren und die den Lebensstil Alias bzw. des russischen Emigranten verkörpern. der sich in der westlichen Kultur der kapitalistischen Großstadt Berlin einzubürgern versucht. 74

Im Unterschied zu Andersen fabuliert Šklovskij nur in vom literarischen Vorbild abweichenden Variationen. Im allgemeinen ist die fabelhafte Metapher bei ihm Zitat - sei es ein verrätseltes, sei es ein offen kenntlich gemachtes. - das er in die literarische Konstruktion seiner. der realen Erfahrung verpflichteten Prosa montiert. 
4. Sklorskijs Teilnahme am Kollektivprojekt "WeiBmeerkanalbau"

Eine ganz andere Form der faktographischen Literatur $\mathbf{S} k l o v s k i j s$ als die autobiographischen Texte sind seine Reportagen. Sie entsprechen weniger seinen Vorstellungen von Literatur, sondern stellen in seinen Augen eher "vorliterarisches Material" dar. 75

Auch in öffentlichen Diskussionen forderte er immer wieder, daB man von dem Schriftsteller nicht nur politische, sondern auch kinstlerische Verantwortung fordern solle: man muisse sich dem Gewissen des Schriftstellers behutsam nähern. ${ }^{76}$ Aber die Arbeit. als Feluilletonist und Joumalist. die er sowoh! :m literarischen wie im Kinobereich leistete, brachte ihm zum einen gesellschaftliche Anerkennung ein und bedeutete ihm zum anderen praktische Auseinandersetzung mit der gesellschaftlichen Realität. die wiederum für seine literarische Arbeit unabdingbar war. Ohne auf die Reportagen im einzelnen einzugehen, möchte ich als besonders exponiertes Beispiel Šklovskijs Mitarbeit am Buchprojekt WeiBmeerkanalbau" im Rahmen der Aktion "Geschichte der Fabriken und Werke" vorstellen und diskutieren.

Die Aktion "Geschichte der Fabriken und Werke" kann nur bedingt als Verwirklichung der literatura-fakta-Konzeption betrachtet werden. Sie lag ganz in den Händen von Literaturpolitikern und Schriftstellern. die der kommunistischen Partei loyal gesonnen waren. Leonid Averbach fungierte als literarischer Politkommissar und Maksim Gorkij als Repräsentant der sowjetrussischen Literatur und als einheitsstiftende Mittlerfigur zwischen den verschiedenen Fraktionen. Die literatura fakta-Theoretiker waren allenfalls Teilnehmer (wie Šklovskij, Percov u.a.) und spielten eine völlig untergeordnete Rolle. Aber diese Aktion bot zumindest der Form nach die Möglichkeit, sich an einer Literaturproduktion zu beteiligen. die dokumentarisch, operativ und kollektiv sein sollte. Ungeachtet seiner Kritik an der utilitaristischen Tendenz der engagierten sowjetischen Literatur beteiligte sich Šklorskij an dieser Aktion.

Das Buchprobjekt "Weißmeerkanalbau". das Aleksandr Solženicyn später wertvolles Faktenmaterial für den "Archipel Gulag" liefern sollte und das er als "jenes schändliche Werk" bezeichnete, "in dem zum ersten $M a l$ in der russischen Literatur der Sklavenarbeit Ruhm gesungen wurde", 77 dokumentiert Šklovskijs Mitarbeit innerhalb dieser Aktion.

Im Herbst 1931 begann die kulturpolitische Aktion"Geschichte der Fabriken und Werke" damit, daB unter literaturpolitischer Anleitung, vor allen Dingen von Averbach und Gor'kij, in Zeitungsartikeln der Pravada dazu aufgerufen wurde. die Geschichte der Fabriken. des Arbeiterlebens in der alten kapitalistischen, zaristischen Gesellschaft und der Arbeitsbedingungen damals zu schreiben und die Revolutionierung der Sowjetwirtschaft darzustellen. ${ }^{78}$ Einzelne Fabrikkollektive sollten zusammen uber ihre Arbeitsstätte und ubber deren Geschichte schreiben. Vor allem sollte von den groBen Projekten - 
vom Bau des Kraftwerks und Staudamms Dnepostroj, von der Grïndung der Industriestadt Magnitogorsk (Stahl- und Hüttenwerke) und vom Bau des Kanals vom Baltischen zum WeiBen Meer - berichtet werden. Es sollten Bïcher, nicht nur Zeitungsartikel verfaßt und die Skizze (očerk) sollte von ihrem schlechten Ruf befreit werden. ${ }^{79}$ Man wollte die Darstellung der Gegenwart mit der Aufarbeitung der Vergangenheit verbinden, um den technischen und zivilisatorischen Fortschritt festzuhalten und zu zeigen. Nach Gor'kijs Vorstellungen sollten die jungen Schriftsteller durch das Schreiben die Möglichkeit erhalten. eine literarisch-technische Qualifikation zu erlangen und gleichzeitig in der Auseinandersetzung mit ihren GroBvätern und Vätern ihr KlassenbewuBtsein stärken. In zahlreichen Artikeln gibt er genaue Schreibanweisungen und listet all die seiner Meinung nach wichtigen Themengebiete auf, um die es gehen soll. Sein Interesse gilt vornehmlich sozialökonomischen Fragestellungen (den Lebens- und Arbeitsbedingungen der Arbeiter. ihre Familien einbezogen, und ihren politischen Mitbestimmungsmöglichkeiten). Wesentlich stärker als Gorkij betont Averbach die Notwendigkeit. die politische Perspektive des Aufbaus einer sozialistischen Wirtschaft darzustellen. Er fordert eine neue Ästhetik: die Ästhetik des Aufbaus des Sozialismus. die so wie der Sozialismus selbst eine wissenschaftliche Form annehmen miusse. ${ }^{80}$

Abgesehen von zahllosen jungen Arbeiterschriftstellern nahmen auch bekannte sowjetische Schriftsteller und Publizisten als sogenannte Spezialisten und Vorreiter an einzelnen Projekten dieser Aktion teil. wie zum Beispiel Viktor Percov. Aleksej Tolstoj. Boris Kušner. Michail Kol'cov. Jurij Tynjanov, Konstantin Fedin. Michail Zoščenko. Valentin Kataev. Vera Inber. Vsevolod Ivanov, Viktor Šklovskij u.a. Es erschienen mehrere Aufsatzsammlungen und Bücher in der Reihe "Geschichte der Fabriken". Das Buch "Die Arbeiter schreiben die Geschichte der Fabriken" unter der Redaktion von Gor'kij veröffentlicht in Moskau im Jahre 1933, aus dem oben bereits referiert wurde, gab sozusagen das Programm aus. Schon im Jahre 1932 waren drei Sammelbände. im nächsten wurden drei weitere ediert. Es gab auch eine Serie von Broschüren unter dem Titel "Zur Hilfe für das Autorenkollektiv". in denen Arbeitsanleitungen für den Umgang mit historischem Archivmaterial (z.B. "Uiber die Arbeit an der Geschichte der Fabriken in Leningrads Archiven") und für die kollektive Schreibarbeit gegeben wurden. Einzelne gröBere Industrieprojekte bzw. regionale Bezirke bildeten gröBere Redaktionskollektive und gaben eigene Publikationen heraus. ${ }^{81}$ Das Buch "Weißmeerkanalbau" war wohl die letzte groBe Veröffentlichung in der Reihe der Bücher, die kollektiv geschrieben wurden und die die Militarisierung der Arbeit im Rahmen der Industrialisierung der Sowjetwirtschaft mit Emphase schilderten. Es wurde so bekannt. daB es gleich ein Jahr nach seinem Erscheinen ins Amerikanische ibersetzt. nach Stalins Tod verboten und angeblich von der Geheimpolizei aus den einzelnen Haushalten eingezogen wurde. Seither ist es in der Sowjetunion tabu. ${ }^{82}$ Geplante Publikationen uiber die Projekte "Geschichte von Magnitogorsk" und "Geschichte des Metrobaus" sind meines Wissens nicht mehr erschienen. ${ }^{83}$ 
Der Weißmeerkanal, auch Stalinkanal genannt, der sich von der Ostsee bis zum Weißen Meer erstreckt, wurde in der ersten Hälfte der 30er Jahre vor allen Dingen von Zwangsarbeitern, politischen Häftlingen, die "umerzogen" werden sollten, gebaut. Das staatlich angeordnete Projekt. daB vierunddreiBig, darunter renommierte sowjetische Schriftsteller den Bau des Kanais und die ideologische Umerziehung der Zwangsarbeiter dokumentieren sollten, kann als der endgültige Verfall der literatura fakta-Konzeption gelten, denn hier war der Punkt erreicht, an dem die Avantgarde ihre kulturrevolutionären Vorstellungen allenfalls noch als Schutzschild, um die Kapitulation vor der stalinistischen Kulturpolitik zu verbrämen, behaupten konnte.

گ̌klovskijs Beitrag zu dem Buch ist, da es sich um eine Kollektivarbeit handelt. in der die Autorenschaft der einzelnen nicht angegeben wird. schwer zu ermessen. Seine Position dazu bzw. seine Position innerhalb dieses Projekts läBt sich eher an ÄuBerungen darüber von ihm selbst, von anderen Teilnehmern, von Freunden oder Verwandten rekonstruieren als am Text des Buches. Er war nicht nur einer unter vierunddreiBig Autoren, sondern auch einer, der - wie er selbst glaubhaft versichert und we ein anderer Tellnehmer - G.Gauzner - es bestätigt. nicht mit politischer Entscheidungskompetenz an dem Plan zu dem Buch beteiligt war. sondern in der Gruppe die Rolle des Literaturtheoretikers mit allgemeiner technischer Kompetenz spielte. ${ }^{84}$

Šklovskij hatte mit dem Projekt enorme politische Schwierigkeiten, nicht nur. weil er selbst als Formalist und Linksfrontler permanent den Angriffen der Literaturideologen, insbesondere auch des Projektleiters Averbach, ausgeliefert war, sondern auch, weil sein Bruder, der Philologe Vladimir Šklovskij, mit dem ihn nicht nur das Interesse an der Literatur, sondern auch ein loser Arbeitszusammenhang verband. ${ }^{85}$ unter den zur Zwangsarbeit am WeiBmeerkanalbau verpflichteten Häftlingen war. Šklovskij hatte sich nach Aussagen seiner Tochter Varvara Viktorovna nur deshalb an diesem Projekt beteiligt, um seinem Bruder das Leben zu retten, was ihm nicht gelingen sollte. Es kursiert das Geriicht, daB er, von der Lagerleitung befragt, wie er sich beim "WeiBmeerkanalbau" fühle, mit dem Scherz geantwortet habe. "Wie ein Biber im Pelzgeschäft". Šklovskijs existentiellen Ängste angesichts der ersten Säuberungskampagnen unter den Intellektuellen, denen auch sein Bruder zum Opfer fiel, schlagen sich literarisch insbesondere in 2 wei bisher unbekannten. einander recht ähnlichen Filmszenarien ("Angst" und "Totenhaus") nieder, die er zu Beginn der 30er Jahre schrieb und von denen nur eines - das literarisch verrätselte - filmisch realisiert wurde. ${ }^{86}$

Šklovskij selbst außerte sich an verschiedenen Stellen Uber seine Mitarbeit an diesem Projekt. Er gehört zu jenen Autoren, die in dem Sammelband "Die Geschichte der Fabriken". Bd.3-4 (11-12) 1934 von ihren Erfahrungen beim Buchprojekt "WeiBmeerkanalbau" berichten und auf diese Weise anderen Schriftstellern bzw. schreibenden Mitarbeitern ihre Hilfe anbieten. Hier stellt er sich als Fachmann fur technische Fragen dar und versteckt seine politischen Schwierigkeiten hinter seinem sehr allgemein gefaBten Technikbegriff, dessen 
konkrete Doppelsinnigkeit (Industrietechnik als Metapher für literarische Technik) inn vor der Denunziation als "bürgerlicher Spezialist" bewahren sollte. Er diskutierte mit den Ingenieuren über Baukonstruktionen. über die Beschaffenheit von Beton und war zugleich für die erste Durchsicht und den Rohbau. die Rohmontage, des Faktenmaterials verantwortlich. Er habe sich bemuiht zu verstehen, schreibt er, daB, so, wie die Technik den Menschen verändere, der Mensch sich selbst verändere, indem er die Methoden seiner Arbeit erfinde, modifiziere und rationalisiere; Šklovskij benutzt diese Überlegung als Argument gegen die literarische Form des historischen Romans und für die Montage dokumentarischer Kunstformen mit der Warnung vor einer naiven Ineinssetzung von Dokument und Faktum.

Man dürfe nicht, wie das bei den Abhandlungen über die lžursker Fabrik der Fall sei, das Dokument für die Wirklichkeit nehmen. sondern müsse es hinterfragen, ubberlegen. zu welchem Zweck, unter welchen Bedingungen und von wem es verfabt worden sei. Sonst könne man es nicht zum Sprechen bringen. und der Leser könne das Material in seiner Wirklichkeitshaltigkeit nicht fühlen. ${ }^{87}$

In einer Variante zu einem Zeitungsartikel, den er für die Literatumaja gazeta verfaBte. klingen ähnlich kritische Töne in bezug auf das "Weißmeerkanalbau"Buch an.

Das ganze Buch - mit Ausnahme des Beitrags von Zoščenko - sei nach der Methode der direkten Aussage geschrieben. "Wir machten bei der Arbeit an 'Weißmeerkanalbau', an der Arbeit, die grundsätzlich gelungen ist, folgende Fehler: erstens erzählten wir direkt von den Dingen. $z$ weitens wollten wir alles über die Dinge erzählen. wir kamen von einem Thema auf das andere und produzierten damit für den Leser langweilige Passagen."

Seine Berichterstattung über das Prinzip der kollektiven Arbeit am WeiBmeerkanalbau"-Buch knupft ebenfalls an einen von ihm schon fruher begonnen Diskurs an. Sie erschöpft sich nicht in Formeln apologetischer Zustimmungsbekundungen zu diesem Arbeitsprinzip. wenngleich sie es positiv schildert. sondern verfügt über einen Hintersinn, der sich dem Leser aber erst erschliebt. wenn er Šklovskijs früheren Uberlegungen dazu und die von ihm favorisierte Form der kollektiven Arbeitspraxis kennt.

Šklovskijs Mitarbeit am "Weißmeerkanalbauprojekt" kann nicht zum Maßstab flir seine Prosa gemacht werden und auch unter dem Gesichtspunkt der literatura fakta nur bedingt beurteilt werden. Sie demonstriert. wie der Schriftsteller Šklovskij in einer lebensbedrohlichen Situation versuchte, den Balanceakt 2 wischen Anpassung an staatspolitische Forderungen und Behauptung seiner eigenen Position - sei es der lebensphilosophischen, sei es der literarischen - auszuhalten, und zeigt, daB die Konzeption der faktographischen Literatur in sich noch so divergent und abstrakt war, daB genug Spielraum blieb, um in ihrem Namen Literatur zu produzieren. die sich nur allzu leichtfertig auf die Gesetze einer Realität festschreiben lieB, in der unter dem Anspruch des Aufbaus des Sozialismus in einem Lande die Barbarei herrschte. 
1 V.Skloveklf. Voskrotenle slova. Peteraburg 1914, roprtnt (mit deutecher U.) In: TdV, B.2. S.12/S.13

2 dera.. lakuactro kak prï̈m. In: O teorl prozy (1929), S.18/S.21

3 Dem Verauch R.Lachmanne. das Prinxip der Vorfremdung ale ein Spazifikum der Kunat-de-Kunatgetff-Konzepelon Sklovakijs zu begrelfen und damit gerade das Verhilitnle zwechen Literatur und Leben in selnen fruhen Schriften zu thematlaleren und zu problematlaleren. kommt fur de Rehabilltleming Sklovsklfs dn elnem Menn der Literatur. der atch der gesellechaftIlchen Verantwortung der Kunat zunehmend bemubt wid, etre zentrale Bedeutung zu. Im Verglelch der fruhen ("Auferweckung des Wortes". "Theorte der Prose") mit den literaturtheoreclechen Arbelten der 60er Jahre ("Kunstleriache Prosa". "Novellen Uber die Prose") erbeltet Lechrann de Entwicklung und Veranderung des Verfremdungebegriffe in der Konzeptlon Sklovaklls heraus: Das Verfahren der Verfremdung zur Emeuerung der anehetlechon Wahmehmung mit dem Zwock in elch eelbet. dem or in den frthen Arbetien elne zentrale Stellung belmesee. werde zunehmend von dem Verfahren dee Selteam-machene der Dinge (oetranenle velzel) uberlagert.

Lechmann welat in desem Zusammenhang uberzeugend darauf hin. das Sklovakif kaurs d. Reprisentant und Wortfuhrer des ruselachen Formallemue gelten könne. und dab or "Im Grunde in barug auf de formalletleche Bewegung nur ein Eklektlker" zu nennen sel. Ander ala in der Konzepelan Sklovakly: komme dem Begriff der Verfremdung in der formallaclechen Theorte kelnerlet Bedeutung zu. Im Laufe selner Arbelt habe or dar Verfahren der Verfremdung usegeweltet. berelchert, verschleden motiviert und

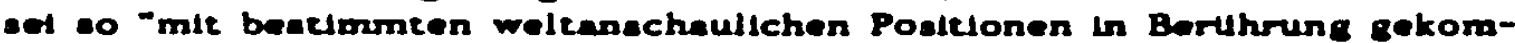
men". vermuket Lachmann. Sle deutet auf eine Affinitit zu Brocht, zu deseen Verfremdungekonzeption fur das Epieche Theater hle.

4 v.Šklorakif. lakuatetro kak prëm. ebd. S.13/S.14

5 ral. l.Tell. Kap.1., Anm 33

6 vel. Trat'jakor. Rabkor 1 etroltel'atvo. In: Literatura fakta. a.e.O. S.213-216; dtach.: Arbelterkorrespondent und Aufbau, In: Lyrk. Dramattk. Prose. (Hres.) F. Mlerau. Lelpzig 1972, S.216 ff.: ders.. Des Wort lat zur Tat gewor den. In: Unsere Zelt. H 9 (1933): reprint in: Dte Arbelt des Schriftetellers. (Hraz.) H.Boahncke. Ralnbek b. Hamburg 1972: Vel. B.Ejchenbaum. Kak adelana "ZInel'- Gogolja Wie Gogola Mantel' gemacht lat: dera., IIIJuxija akaxa Die Illusion des a $k$ a beldes In: TdF. Bd.1. S.122/123 ff. und $160 / 161$ ff.

7 R.Lachmann. Faktographle und formalisteche Prosathoorte. In: Xathotlk und Kommuntkatlon. 12 (1973), S.79:

8 ebd., S. 80

9 ebd., S.82

10 ebd.. S.79

11 B.Arrator. Poetlache und prakelache Sprache - zur Methodologle der Kunstwisenschaft, in: Marxiemus und Fomnalismus. S.99

12 ebd.. S.114

13 R.Lachmann, S.80

14 S.Tret'jakor. Feld-Herran. Der Kampf um elne Kollektimirtachaft. U., R.Selke. Berlin 1931. roprint: Amsterdam 1972. S.179 
15 dere.. Blograflja vexzl. In: Lleeratura fakte. S.66 f.: deutech: Dle Blographle dea Dinge, U.: K.Hlelecher. In: Die Arbelt des Schrlfesellere. (Hrag.) H.Bonhncke. Reinbek b. Hamburg 1972. S.83

16 dere.. Blograflja .... S.82

17 G.Luktce. Erzuhlen oder Beschrelben, in: Intermationale Literntur 12 (1936). $\mathbf{S . 1 1 8}$

18 S. Tret'jekov, 5.83

19 ebd.

20 Lleeratumaja enclklopedije (1932). Stichwort: Lery front lakuatera

21 S.Tretjakor. $\mathbf{S . 8 0}$

22 N. CuŽk. Pleatel'akaja pamjacke. In: Literature fakta, S.23

23 R. Lachmann. S.81: vel. N.CuZak. Piaetel'akafa .... S.1S; dera.: Literatura Zizneatroenija. In: Llterature fakta. S.60

24 S.Tretjakov, Llteraturnoe mnogopolle. In: $\mathrm{NL} 12$ (1928). S.43. drutech: Literertache Vielfelderwirtechaft. In: Die Arbelt .... S.80

25 N. CuZak. K zadąam dnje. In: LEF 2 (1923), S.14s f.: rgl. K.Marx. Dan Kapleal. Bd.1. MEW 23. S.193: WWIr unterecellen die Arbelt in elnar Form. wortn ele dem Menschen ausechlleblich angehort. Etne Splnne rertichtet Operationen. dle denen des Webere uhneln. und elso Blene berchilmt durch den Bau threr Wachezellen manchen mentchlichea Baumelater. Wan aber ron vormherain den echlechtesten Beumelecer vor der beeten Blene auezelchnet. let. dab or dle Zelle In selnem Kopf gebaut het. bevor er alo in Wache beut. Am Ende des Arbelesprozesese korme eln Reaultat heraus. dae beim Beginn deacelben echon in der Voracellung dea Arbeltere. aleo echon Ideell vorhanden war."

26 S.Tratjakor. Obrazoborzentro, in: NL 12 (1928). S.43

27 rgl. M.Schnelder. Dle operative Skbze Sergel Tretjakora. Bochum 1983. S.52

28 V.Sklovaklj. Polaki .... S. 62

29 ebd.. 5.63

30 ebd.. S.115

31 ebd.. 5.63

32 val. Rlachmann. S.77 f.: val. H.Gunther. Elnleteung zu: Literature fakea. S.VI

33 vel. M.Schrelder. S.57. S.272

34 A. Hansen-Löve. Der mesleche Formallemue. S.21

35 N. Cuxak. Plsatel'skaja .... S.23

36 ebd.. 5.22

37 ebd.. 5.24

38 V. Skloreklf. Sentimental'noe .... S.260: 266/254: 260-61

39 •bd.. S.85/S.86

40 rgl. ebd.. S.260: 266/254: 260-61: vel. dere., Tretje .... S.86: rel. dere.. Andref Bely. In: Pjat' Zelovek znakomych. TIfle 1927. S.14.16

41 zum Beinplel handeln de Filme: "Tret'je mexxanskeje". Ucheby" und "Dom Trubnol". 24 denen Sklovaklj de Drehbucher echrleb. rom sowjetachen Alteg der 20er/30er Jahre. Vel. euch des erse Kapleel dea Buchea "Polekl optintzma".

$\$ 2$ V. Sklorakl). Sentimental'noe .... S.187/S.191

43 ebd.. S.270/5.264

44 V.క̌klorakl). Zoo .... S.40-41/S.42-43

45 ebd.. S.58/S.62 
46 G.Lukfes. Xethotlk 1. Darmatedt \& Nuwled. 1972. S. 20

47 V. Skloraklf. O pleatele .... S.1983

48 ebd.. 5.194

49 ebd., 5.193

50 ebd.. S.194

51 V. Sklorekl\}. Metref Komaror. Zitel' eorode Moakvy. L. 1929; ders.. Kratkaje no dostovernaja povest o drorjanine Bolotove. L. 1930: dera.. Marko Polo rezredXlk. M. 1931

52 dera.. Pamjetnlk naucnoj ollbke. In: Llteratumaje gazeta 4 (1930). deutach: Denkmal fur elnen wiaeenechaftlichen Irrtum. in: Formaliamua. Strukturallemua und Geachlchte. (Hrag.) A. Flaker, V. Żmegax. U.: W. Kruae. Kronberg/Ta. 1974. $5.74-80$

53 vel. V. Skklovaklf, O fakture 1 kontr-rel'efach, In: Chod konja, knlge atatef. M.-Berlen 1923, S.102/103: vel. dera.. Polakl .... S.113

54 V. Sklorakl\}. Polakl .... S.4

55 vgl. de eyetematieche Unterauchung dazu ron M. Munk. S.67-94

$56 \mathrm{~V}$. Sklorakif, Sentimental'noe .... S.187/S.191; rgl. euch $5.200 / 5.208$ und S.203/S.210

57 vel. ebd.. S.252/S.317: S.248/S.312. Der Theoretlker dea Pereval und Krttlkar der Kreaneja nov'. A.Z. Leznev, etellt in der Beaprechung des Buchee "Drtete Febrlk- (Sorremennlkl, M. 1927. S.133-138: zuerat in: Patat' I revoljuclje. 8 (1926)) einen Zueammenhang 2 wlachen der Stein-Metapher. wie Sklorakif ale eabraucht. und der Philosophie Splnozen her. "Wenn eln fallender Stein eln Bemubtaetn beatizen wirde. age Splnoza. dann wirde or beetitigen. deb er deshalb rult. well or es to mobhte. Sklovakif wiederholt diese Ubarlegungen dea Splnozlatinchen Stelne." (133) So intereseant der Gedanke. Sklovaklf mit der Phllosophle Splnozen zu interpretieren. Iat - zumal Baruch Splnoze in der SU der 20 er Jahre intenatr reziplert wurde CA.Debortn. Die Weltanachauung Spinozan. 1928; L.1.Akselrod.Splnoza und der Materiallemua. 1925: I.-P. Razumorakif. Splnoze und der Stant. 1927. In: Texte zur Geschlchte dea Splnoziamue. (Hrag.) N.Altwicker. Darmatedt 1971) - 10 wenle lieB elch eln konkreter Hinwele dereuf. daB Sklovekly Splnoze rezlplert und rerarbeitet het. finden.

58 ders.. Zoo .... Pasage fehle in der ruse. Ausgabe (1923)/S.115; vgl. ders.. PodenxZina. L. 1930. S.227

59 ebd.. S.30/5.35

60 N.Cufak. Plaeteliekaje .... S.24

61 V1. Majakorakif. Vyatuplente na depute "Lef ll blef?". Poln. sobr. act.. M. 1957-59. t.12 (1959), S.345

62 A. Ležner. S.134

6.3 V. Sklorakly. Trat'je .... S.16

64 ebd.. 5.93

65 dere., Polekl .... S.5

66 Tretjakor let der literatechen Umeetzung eelnes Programme letzellch nlcht gewacheen und quilt elch. aus lauter Anget. In elne traditionelle Literatureprache zu verfallen. ron elnem programmetiachen Bekenntnis zum anderen. wodurch alch eelne Literaturaprache genauso abnutzt wie polltische Parolen. rgl. S.Tret'jakor, Skrox noprotertye otkl. In: Literature fakte. S.227 ff.; deutech: Durch die trube Brlle, in: Feld-Herren, S.24 ff.

67 V.Sklorak1f. 60 dnef bez sluzby, in: NL. 6 (1927), 5.22

68 S.Tretjakov, Die Tasche. In: Uneere Zelt 3 (1933); reprint in: Die Arbelt dea des Schriftetellera. S.86 f. 
69 H. Chr. Andersen. Murchen in 3 Bänden, U.: E.-M. Bluhm. Ffm. 1975; man denke z.B. an de Geschlchten "Vom standhuften Zlnnsoldaten". "Der Tannenbeum". "Der Buchwelzen". "Dle Hirtin und der Schomaceinfeger" uaw.

70 V.Sklovaklj. Tretje .... S.102; Vgl. Andersena Murchen "Die alte Strabenleterne"

71 ebd.. S.39 ff.; rel. Andersens Marchen "Der Flachs"

72 dera.. Zoo ...., -/S.118

73 ebd.. S.43-45/S.46-48 und S.100-102/S.112-114

74 ebd.. S.19/S.24; S.43-45/S.46-58

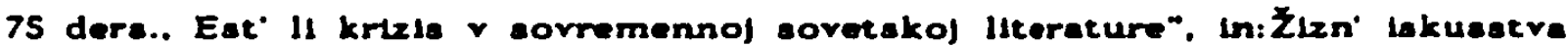
8 (1929). S.15

76 Plactel I pollgramote. Diakusalon Im Ravolutionatheater. Oke. 1929: Bertcht In: Llteraturnaja gazeta. 14. Okt. 1929: vel. auch Redebelerag V. Sklovaklja auf dem 2. Plenum des Vorstanda des Sowjetlachen Schriftsellerverbandea der SSSR. Marz 1935. Stenogr. Berlche. M. 1935. S.305-308

77 A. Solzenteyn. Der Archipel Guleg. U.: A. Peturndg. Bern 1974.5 .12

78 M.Gorkij. Napixem latorlju borby rabozego kleasa!. In: Pravda. 7. Sept. 1931: dera.. Zn rabotu!. In: Pravda. 23. Nov. 1931; dera.. Kakaje knlen nam nużna. in: Pravda. 1. Apr. 1932

79 dera.. NapiJem letorfu, abgedrucke in: Rabocle plaxut latorifu zarodor. (Hrag.) M. Gor'kl]. M. 1933. S.21

80 L. Arerbach. Nauznaje I chudozeatrennaje lacortje zarodor, in: Rabozle plat .... $\$ .43$ ff.

81 z.B. Sozdadim lacortju zerodor!. 1933. S.112: Zarod Imenl Lenlne 1857-1918. (Hrsg.) P.S. Kudelll i drugle. M.. L. 1933

82 Belomorako-bale1jakif kanal. (Hrag.) M. Gor'klj. L.Avarbech. S.G. Firin. M.1934; amerikenlache Ausgabe: Belomor. (Hrsg.) H. Smilh.R Hea. U.: A. WilliamsEll1s. New York 1935. reprint: Weseport. Connectlcue 1977

83 Diese Titel murden in den letzten Bunden der "latortja zarodor" angekundlgt. in Bd. 4-3 (11, 12) und Bd. 7-8, belde M. 1934 erachienen.

84 vel. V. Skloraklf. O avoel rabote ned knigol 'Belomoratrof'. In: Iatorlfa zavodor. Bd. 3-4. S.114-117; rel. auch G.Gauznera Daracellung ron Sklorakl) in demaelben Buch. S.111

85 VI. Yklovaklf erbeltete Im lockeren Zusammenhang mit den Formalnten: sowohl in der NL ala auch in dem Sammelband "Fel'eton" achrteb er Uber den Esacy: Literacumy) opye (esad) $v$ ego formalinom okruzenll. In: NL 6 (1927), S.39-47: Fel'eton l esae. In: Fel'eton, abornik atece). (Hrse.) Ju. Trnjanov. B. Kazansklf, L. 1927. S.72-79

86 V. Sklovaklf. 1.Strach. 2. Mertvy dom u.e.. Llteraturnye scenari: maschineneeachrtebene Manuakripte in der Blbllothek dea IMLI in Moskau; vgl. auch de Fllmographle in: V.Skloraklj. Zn sorok let

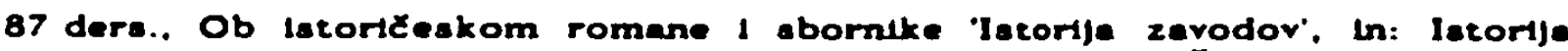
zerodor. S.158/159: rel. G. Gauzner, S.109, 111: rgl. V. Skloraklf. O aroej rabote nad kndgof 'Belomorstrof'. S. 114 ff.

88 V. Skloraklf, Varlante, opla' No.1. ed. chr. No.9. Fond 562 CGAll. S.14. zu: Noryl oterk. In: Literaturnaje gexete. 26.6.1934 
Kap. 3: Die fragmentarlach-easejiatlache Form der frllbea autoblographlschen Proea Šklorakijs

Šklovskijs frihe autobiographische Prosa ist eine fragmentarisch-essayistische Prosa. Sie revolutioniert die Form der Autobiographie, indem sie sie aus dem Zwang zur psychologischen Motivierung und zur kausal verknupfenden und chronologisch verlaufenden Kontinuität und Einheitlichkeit der Darstellung des Lebens eines Menschen entläBt und eine Form der Darstellung erprobt. die der Dissoziiertheit und der Entfremdung des Subjekts in der bürgerlichkapitalistischen Gesellschaft, die auch der sowjetische Staatssozialismus nicht aufzuheben vermochte. gererht zu werden versucht: die Form dar Montage von Textfragmenten, die Erinnerungen an. Reflexionen uber und subjektive Wahmehmungen von unterschiedlichen Seins- und Arbeitsformen unmittelbar verknüpft darstellt, wobei - um mit Šklovskij zu reden - "die Umstellung der Teile das Geheimnis des Romans ersetzt und die Erzählung statt durch eine gegenläufige Intrige durch die Aufnahme von neutralem Material gebremst wird. ${ }^{1}$

Šklovskij kennt keinen Respekt vor den Regelsystemen der politischen oder der Wissenschaftssprache. Er durchbricht sie spielerisch und schafft auf diese Weise einen unkonventionellen, experimentellen Dialog zwischen den Disziplinen, der für Entdeckungen und Erfindungen in der literarischen Sprache und dariber hinaus in der Wahmehmung und im Denken des Menschen neuen Raum eröffnet. Die fragmentarisch-essayistische Prosa క̌klorskijs erfindet keine asthetische Welt des Ausgedachten, sondern eine spezifische Methode der Verarbeitung heterogener, einander fremder Texte, die in mancher Hinsicht an die literarische Tradition des Essays in Westeuropa erinnert.

1. Der Dialog zwischen Tradition und Gegenwart und seine subversive Funktion

Insbesondere eine Literatur, die sich selbst als Produktion von Literatur aus literarischen, vor oder auBerliterarischen Fakten versteht. - und als solche begreift sich die autobiographische Prosa des Formalisten und Faktographen Šklovskij - hat Anspruch darauf, im Zusammenhang mit den in ihr bewuBt rezipierten und verarbeiteten Texten interpretiert $z u$ werden. Denn hier setzt ein ProzeB der Sinnkomplexion ein, der sich aus der Interferenz der Texte ergibt und deren konkretes Korpus voraussetzt. ${ }^{2}$

Zitat heiBt in diesem Zusammenhang nicht nur die wörtlich zitierte Rede. sondern jegliche als fremde intendierte und identifizierbare Rede im Text. Es kann sowohl der Geschichte der Literatur als auch dem kulturellen Milieu der Entstehungszeit des fraglichen Textes entnommen sein. Die in den Text eingearbeiteten fremden Texte - seien es literarische, seien es nichtliterarische -, die ich im folgenden auch als Text-Vorbilder bezeichnen möchte. 
entfalten ihre Sinnkomplexität vollends erst dann, wenn man ihr Beziehungsgefüge im Text auf das kulturelle Milieu reflektiert, in dem sich die pragmatische Funktion des Textes realisiert.

Die Aufnahme von auBerliterarischen Texten - ein in der Geschichte der Literatur durchaus geläufiges Phänomen - galt den Formalisten Tynjanor und Šklovskij, die es iberhaupt zu einem literaturtheoretischen Problem erhoben, als ein Verfahren, die Literatur zu erneuern und die Wahrnehmung der Wirklichkeit zu revolutionieren. Insbesondere die Aufnahme nichtliterarischer, d.h. wissenschaftlicher. literaturkritischer, alltäglicher und privater Äußerungen sollte den dekanonisierenden und innovierenden Effekt garantieren. ${ }^{3}$

Šklovskij bedient sich dieses Kunstgriffs in verwirtendem Wechsel. Er zitiert die unterschiedlichsten Texte herbei und verknüpft sie scheinbar willkürlich auf ungewöhnliche Weise.

Den Titel der Erinnerungen an seine Revolutionsabenteuer "Sentimentale Reise" leiht er von dem englischen Schriftsteller Sterne, den er in Arbeiten zur Theorie der Prosa aus der Zeit des OPOJAZ neu interpretiert, so daB sowohl die Erinnerung an den Sterneschen Sentimentalismus. an Sternes gleichnamiges Reisebuch, als auch die literaturcheoretischen Studien des Formalisten S̈klorskij den Leser bei der Lektuire des Erinnerungsbuches begleiten - mehr noch - herausfordern. scheinbar Unzusammenhängendes zusammenzubringen. zumindest miteinander zu vergleichen und möglicherweise den Mur aufzubringen, auf der Ungleichartigkeit der Texte zu bestehen. Dem Autor Šklovskij kommt dabei die Aufgabe zu. mit den Texten so zu jonglieren. d.h. durch Anspielungen und Abschweifungen sie immer wieder in Erinnerung zu bringen. daB die Aufmerksankeit und das Interesse des Lesers an der Auseinandersetzung mit ihnen nicht erlahmt. In dem Untertitel zu "Zoo...". der "oder die dritte Heloise" lautet und nur in der Helikon-Ausgabe (Berlin 1923) in auffallig dick gedruckten Lettern auf der Titelseite in Erscheinung tritt. weckt Šklovskij die Erinnerung an Rousseau und wiederum den von diesem adaptierten Abaelard. Dariber hinaus verweist er auf die literarische Tradition des Liebesromans in der Form des Briefwechsels $\mathbf{z w i s c h e n ~ d e n ~}$ Liebenden. Sein "Zoo..." sollte als die "Dritte Heloise" gelesen werden. Die Heloise des Abaelards (Anfang des 12. Jahrhunderts) war die erste und die "Nouvelle Heloise" Rousseaus (1761) die $\mathbf{z w e i t e . ~ M i t ~ d i e s e n ~ b e i d e n ~ T i t e l n ~ h a t ~}$ Sklovskij die bekanntesten Beispiele für die Literarisierung des Briefes in der Literaturgeschichte benannt. Dem kann man noch die Briefromane des Sentimentalisten Richardson - "Pamela" (1740) und "Clarissa Harlow" (1748) hinzufügen. die auch Šklovskij im Rahmen seiner Sentimentalismusstudien (Sterne u.a.) zur Kenntnis genommen hat."

Während in dem Briefwechsel $z$ wischen Heloise und Abaelard die Innovation darin liegt, daB die Literarisierung des Briefes die öffentliche Thematisierung eines bis dahin tabuisierten Problems, des Konflikts zwischen der irdisch leiblichen und der religiös-spirituellen Liebe, möglich machte. kommt das 
Revolutionäre der "Nouvelle Heloise" darin zum Ausdruck, daB Rousseau die literarisierte Form des Briefwechsels dazu benutzt, um das Recht der natijlichen Liebe gegenïber den Ketten der Konventionen zu verteidigen.

Die Erfindung Šklovskijs in "Zoo..." liegt darin. daß er qua Literarisierung des Briefwechsels $\mathbf{z w i s c h e n}$ einem Liebenden und einer die Liebe nicht Erwidernden die Struktur der sehnsiichtigen Liebe seziert, wobei er in einem Verwechselspiel die Analogie der Struktur der Liebe zu einer Frau, zur Heimat und zur Literatur darstellt. Er riickt sie auf diese Weise in die Nähe der formalistischen Theorie der Prosa und motiviert das Verfahren mit der Fabel seiner unglucklichen Liebe zu einer Russin in Berlin. Hinter der Geliebten verbirgt sich die Schriftstellerin Elsa Triolet. Ihre Briefe benutzt Šklovskij zum einen dazu, um seinem Leid im Berliner Exil beziehungsweise in dem Verhältnis 24 Nin einen unsentimentalen und doch eindringlichen Ausdruck zu verleihen, und zum anderen, um hinter einer fremden Rede geschitzt einen naiv realistischen Stil zu Worte kommen zu lassen, gegen den er seine eigene Literaturkonzeption abgrenzen kann. Diese beiden Funktionen bedingen einander und sind austauschbar. 5

Am Ende zitjert er aus Andersens Märchen und erzählt den "Schweinehirten" in einer eigenen, tragikomischen, autobiographischen Version, um die einzig mögliche Entscheidung metaphorisch vorwegzunehmen. die den unglücklich liebenden Emigranten aus dem Zwiespalt befreien kann, ob er sich nun für das Leben im Berliner Exil und fir die Liebe zu Nlia oder fïr das Leben in der Sowjetunion ohne Alia, wo ihn politische Schwierigkeiten, aber auch die mit den Freunden begonnene Arbeit erwarteten. und wo er sich in der Öffentlichkeit sprachlich verstïndlich machen konnte, entscheiden solle. Er ersetzt das Ende des altbekannten Märchens durch $\mathrm{z}$ wei variable alternative Abschlusse. die jeweils die Lächerlichkeit und das SelbstmiBverständnis der Liebe des Prinzen so deutlich hervorkehren, daB sie in der Negation besonders prononciert auf die einzig mögliche Lösung, die Lösung bei Andersen. hinweisen: sich von der unglücklichen Liebe zu trennen und nach Hause zurickzukehren.

Die Zusammenschau all dieser Texte findet auf dem Hintergrund der Darstellung der Szene der russischen Emigranten im Berlin der Jahre 1922/23 statt. zu deren Schilderung als Metapher wiederum ein fremder Text herhalten muB: Chlebnikovs Tiergehege", dem Šklosvkij vor Rousseau und Abaelard im Titel des Buches ein Denkmal setzt, wie sich herausstellt, wenn man das Epigraph gelesen hat.

Jedesmal spannt der Autor semantische Linien in verschiedene Richtungen und auf verschiedene Ebenen aus: in die literarische, in die autobiographische Vergangenheit und zurick in die Gegenwart existentieller Probleme, gesellschaftlicher Ereignisse und literarischer kulturpolitischer oder wissenschaftlicher Diskussionen.

Anders als in "Sentimentale Reise" und "Zoo..." verfährt Sklovskij in "Drtte Fabrik". In jenen beiden Prosatexten signalisiert er bereits im Titel, auf 
welche literarische Tradition er sich zu beziehen, an welcher er sich abzuarbeiten beabsichtigt. In "Dritte Fabrik" spielt der Titel nicht auf eine literarische Tradition, sondern auf Texte des kulturellen sowjetischen Kontexts der 20er Jahre an, in erster Linie auf solche Texte, die den Standpunkt des MarxismusLeninismus vertreten - zum Beispiel von Lunačarskij und Trockij, um nur die renommiertesten zu nennen. Der Bezug auf die literarische Tradition zeigt sich erst im Text selbst. Zum Beispiel tritt der Bezug auf Rozanovs aphoristische Bekenntnisprosa, der Šklovskij bereits, ähnlich wie der Literatur Sternes. in seinen prosatheoretischen Untersuchungen beachtliche Aufmerksamkeit gezollt hatte. ${ }^{6}$ nicht als of fenes $Z$ itat, sondern vorwiegend in der stilistischen Struktur zutage, was in Anbetracht jener theoretischen Arbeiten Šklovskijs ibber den katholischen Publizisten und Schriftsteller, der ketzerisch die Kirche beschimpfte und im RuBland der Jahrhundertwende eine dubiose und skandalumwitterte Rolle spielte, doppelt ins Auge fält. Rozanovs Stimme bedient sich Šklovskij in "Dritte Fabrik" verrätselt: er galt auch in der sowjetischen Kultur nicht als gesellschaftsfähig. Auf dem Hintergrund der fortwährenden heimlichen Erinnerung an die "Verwehten Blätter" und an "Solitaria" erhält die Präsentation von Briefen an seine Freunde im Leningrader OPOJAZ und - im kontrastiven Zusammenhang damit - die Darstellung seiner Arbeit am sowjetischen $K$ ino in Moskau eine spezifische, eine ironische Funktion.

Im Gegensatz dazu leiht sich Šklovskij das Wort des in der Sowjetunion allgemein anerkannten russischen Schriftstellers Lev Tolstoj an vielen Stellen ganz demonstrativ - insbesondere dann. wenn er seinen eigenen umstrittenen Standpunkt als Schriftsteller der linken Avantgarde und als Mitarbeiter des OPOJAZ zu verteidigen hat. Auch Cervantes' "Don Quijote" - ähnlich wie Rozanov und Tolstoj Objekt seiner prosatheoretischen Untersuchungen fungiert als ein zentrales literarisches Vorbild der autobiographischen Erzählung in "Dritte Fabrik". An dieses Buch, das sich in der Sowjetunion seit jeher und bis auf den heutigen Tag großer Beliebtheit erfreut, erinnert Šklovskij direkt, allerdings ohne seine Zitate zu erläutern. Er setzt. wie auch in allen anderen Fällen, die Kenntnis des Ursprungstextes voraus. Von "Don Quijote" leiht er sich die Stimme des 'hellen Wahns' im Konflikt der Bücherwelt mit der empirischen Realität. Daneben hat Šklovskij - ähnlich wie in "Zoo..." Märchenbilder Andersens in den Text hineingearbeitet: die leitmotivischen Metaphern, der Flachs und die Straßenlaterne, gehen, die erste verrätselt, die zweite als Zitat kenntlich gemacht. auf Andersens Märchen zurück.

An die Rede des amerikanischen Schriftstellers E.A. Poe über den Fortschritt und die Zukunft erinnert Šklovskij in "Dritte Fabrik" beinahe wie an einen apokryphen Text. ${ }^{7}$ Von einer Kindergeschichte des indisch-englischen Schriftstellers Rudyard Kipling lieB er sich zu einem weiteren Bild, der Selbststilisierungsfigur der "Katze, die ihren eigenen Weg geht", inspirieren. ${ }^{8}$ Es gelingt inm sogar, die antike Kultur in Gestalt einer Anspielung auf den Schöpfungsmythos, wie Aristophanes ihn in Platons Gastmahl erzählt, in den Text der 
"Dritten Fabrik" einzubinden." Die Konfrontation dieser so ungleichartigen Arbeiten in den verschiedenen Etappen seiner Lebensgeschichte in einander so fremden Städten - Leningrad/Moskau - provoziert einen Dialog vor und mit dem Leser über existentielle Entscheidungen, in den auch die Erinnerungen an Kindheit und Jugend im selben Buch einbezogen werden.

"Suche nach dem Optimismus", eine Auseinandersetzung mit der gesellschaftsfähig gewordenen literatura fakta in der Form der Skizzenliteratur nach dem praktischen Vorbild der Arbeiter- und Bauernkorrespondenten-Bewegung vereinigt die unterschiedlichsten Texte: Skizzen aus dem Alltagsleben, über technische Errungenschaften, liber Industrialisierung und Kollektivierung, quasi-theoretische Erörterungen über die Rote Armee. Erinnerungen an Majakovskij, eine historische Skizze über den Weltreisenden Marco Polo, uber den er später ein Buch schreiben sollte. Šklovskij bringt Chlebnikov und Majakovskij in Erinnerung, um deren utopische Poesie mit der Realität des sowjetischen Lebens im I. Fünfjahresplan so, wie er in der faktograhischen Literatur dokumentiert wird, zu konfrontieren. Das Feuilleton steht neben einer lyrischen Passage. In einen Brief wird eine literaturtheoretische Abhandlung eingelassen. Die ironische Rede des Autors löst die Skizze oder die anekdotische Erzählung unmittelbar ab. Šklovskij schreibt nicht nur unterschiedliche literarische Gattungen, nicht nur literarische mit nichtliterarischen Texten zusammen, sondern er montiert auch Texte zeitlich und räumlich verschiedener Kulturen aneinander. Er bringt die italienische Renaissancekultur (Marco Polo in "Suche nach dem Optimismus") oder die Kultur des friihen Futurismus (Chlebnikov in eben dem Buch) in unvermittelten Zusammenhang mit der politischen Kultur der Sowjetgesellschaft im I. Fünfjahresplan, was den Denkgewohnheiten des Lesers nicht eben entgegenkommt. Solche Verbindungen erscheinen eher als metaphorische Kollisionen, die nicht auf literarische Konventionen bauen können, sondern erst als Dialog verschiedener Stimmen - im Sinne Bachtins - miteinander im ProzeB der Rezeption, d.h. des Dialogs mit dem Leser. Bedeutung gewinnen. ${ }^{10}$

Die Struktur der Aufnahme und Verarbeitung sowie das Potential fremder Texte scheint in der frühen autobiographischen Prosa Šklovskijs jeweils sehr ahnlich, ja, beinahe schematisch zu sein. Und doch zeigen sich - nach dem Prinzip der "Unähnlichkeit des Ähnlichen" - neben dem gleichbleibend Präsenten auch Abwandlungen, die ich jedoch nicht unbedingt mit dem am Fortschrittsdenken orientierten Ausdruck Evolution belegen möchte. Die Veränderungen im Schema der Verarbeitung fremder Texte signalisieren sowohl im Stil als auch in der Erzählstruktur jedesmal den Versuch Šklovskijs, am gesellschaftlichen ProzeB der Veränderungen in jenen Jahren teilzunehmen von Revolution und Bürgerkrieg bis hin zum 1. Fünfjahresplan, von dem OPOJAZ, dem Futurismus, dem Kreis der Serapionsbruider bis hin zur Diskussion um die "Skizzen". zur "Bewegung der Schriftsteller in die Fabriken, in die Kolchosen!". während gleichbleibende Strukturen - wie zum Beispiel Einschübe von Texten Chlebnikovs. Erinnerungen an Majakovskij, an die 
formale Theorie der Prosa - die Funktion von Kontrapunkten zukommt. Sie zeigen das Festhalten am Konzept einer Literatur. die eine gewisse Eigenständigkeit gegenuiber der empirischen Wirklichkeit behauptet, die eine eigene Sprache spricht. Die Selbstdarstellung des Schriftstellers Šklovskij. die Darstellung seiner Arbeitsmethode in dem Sammelband Wie wir schreiben" gibt einen Eindruck davon, wie er aus Literatur Literatur machte.

"Ich beginne eine Arbeit mit der Lektüre. Während ich lese, versuche ich. ganz entspannt zu sein. Richtiger: ich bemuihe mich. mir nichts zu merken. Anspannung. Aufmerksamkeit. sie stören. Man muB in aller Ruhe lesen, einem Buch in die Augen blicken.

Ich lese viel ...

Ich lese entspannt. Ich benutze verschiedenfarbige Lesezeichen oder solche von verschiedener Breite. Für den Fall, daß diese Lesezeichen herausfallen, wäre es gut, die Seitenzahl anzumerken, was ich jedoch unterlasse. Dann sehe ich die Lesezeichen durch und fertige Notizen an. Eine Stenotypistin. dieselbe, die jetzt diesen Artikel schreibt, tippt Auszüge mit dem Seitenvermerk ab. Diese Zettel. manchmal sind es ziemlich viele. hänge ich an den Wänden meines Zimmers auf. Leider ist mein Zimmer klein und mir wird eng.

Es ist sehr wichtig. ein Zitat 24 erfassen. es umzukehren und mit anderen $2 u$ verbinden.

Die Auszüge hängen lange an der Wand. Ich gruppiere sie, ordne sie nebeneinander und formuliere dann. sehr knapp. verbindende Uiber gänge. ${ }^{-11}$

Aus diesen Zeilen geht deutlich hervor. was in den Passagen zuvor noch miBverständlich erscheint. Wenn $\zeta_{k l o v s k i j}$ behauptet "Ich schreibe, ausgehend von einem Fakt" 12 so meint Fakt in erster Linie ein Textfaktum. ein Zitat. Aus dem Dialog des Textmaterials entsteht, zum Teil hinter dem Rucken des Autors, ein neuer Text.

"Fast immer ändert sich im Arbeitsproze日 der Plan. sehr häufig sogar das Thema. Der Gehalt einer Arbeit erweist sich als nicht vorhersehbar. Und da. auf den Trümmern der künftigen Arbeit. erlebt man jenes Gefühl der Geschlossenheit des Materials. findet man die Möglichkeıt einer neuen Komposition. während sich im UnterbewuBtsein die algebraische Zusammensetzung des Materials vollzieht - all das, was man Inspiration nennt."13

Eine Wahrheit wird einer anderen gegenubergestellt. So verwandeln sie sich in Aussagen aus unterschiedlichen Perspektiven: "Ambivalenz wird als Wert positiviert. ${ }^{-14}$

Šklovskij zitiert in verrätselten Anspielungen oder demonstrativ, je nachdem. ob die Rede eines verpönten Schriftstellers hörbar gemacht werden soll, oder ob der Name eines angesehenen Literaten für eine miBliebige Meinung herhalten muB. Er zitiert scheinbar zerstreut, abrupt und ohne besondere einleitende Bemerkungen vorauszuschicken. Er stellt Zitat und Text scheinbar unvermittelt nebeneinander und konstruiert auf diese Weise einen fragmentarisch essayisti- 
schen Schreibstil, den er selbst in "Suche nach dem Optimismus" einen elliptischen oder barocken Stil nennt. ${ }^{15}$

Der Kunstgriff, dem Text der autobiographischen Prosa fremde Texte ganz heterogener Art einzuschreiben, erfüllt bei Šklovskij mehrere Funktionen. Zum einen demonstriert er, daB eine moderne Literatur ohne Verarbeitung der Literaturtradition undenkbar ist, und daB der radikale Bruch mit dieser Tradition, wie ihn die russische Avantgarde in der ersten Euphorie mit Emphase behauptete ("Puškin. Dostoevskij, Tolstoj usw. sind vom Dampfer der Gegenwart zu werfen. ${ }^{16}$ ), in erster Linie als Dekanonisierung aufzufassen ist. Zum anderen zeigt er, daB Literatur nach der Revolution jedoch nicht kontinuierlich und linear fortgeschrieben werden und nicht länger die auratische, nach Autonomie vom gesellschaftlichen Leben strebende bürgerliche Romankultur sein konnte, sondern daB sie nun - ob sie wollte oder nicht - auf Politik fundiert war. Das Zitat tradierter Literatur macht den Tod ihrer vormaligen Funktion und Bedeutung, aber auch die Trauer um ihren Verlust deutlich. In dem Bild von der kiinstlichen Nachtigall aus Andersens Märchen "Die Nachtigall" hat Olga Forక̌ in ihrem Schliusselroman "Das Narrenschiff", der von dem Leben im "Haus der Künste" in Petrograd am Anfang der 20er Jahre erzählt, diese Funktion der Zitatmontage Šklovskijs Prosa anschaulich und treffend beschrieben.

-Seine (ک̌klovskijs, V.D.) Prototypen sind die Ersatzproduktionen der berihmten Andersenschen Mandarine für die entflogene Waldnachtigall - kiinstliche Nachtigallen." ${ }^{-17}$

Šklovskij wendet die Erkenntnis von der bürgerlichen Romankultur zu einer konstruktiven Möglichkeit der Umfunktionierung der Literaturtradition. Als Zitat weist Šklovskij ihr einen entfernten Ort an, der ihm die nötige Distanz gibt, um sich kritisch mit ihr auseinanderzusetzen, und ihm aber doch die Möglichkeit läßt. sie in dem Status einer Erinnerung genieBen zu können. Dariber hinaus vermag das Zitat tradierter Literatur ihre von kanonisierten Lesarten verdeckten und weiterhin lebendigen und gültigen Aussagen freizulegen und herauszustellen. In diesem Sinne fungiert es als ein Kunstgriff der Verfremdung: das Wort wird aus seinem gewohnten Zusammenhang gerissen. in einen neuen. ungewohnten eingefügt und dadurch sinnlich wahmehmbar. Um die fortgesetzte Auseinandersetzung der Kunstformen mit der gesellschaftlichen Realität literarisch manifest werden zu lassen, gilt ふ̌klovskij der Ruickgriff auf das Alte in Sinne eines Kunstgriffs als erlaubt. Denn auf diese Weise läBt sich die Dialektik der Revolution als radikale Loslösung auf der einen und als Möglichkeit der kritischen Verarbeitung und Aneignung der Vergangenheit auf der anderen Seite deutlich machen. Das Zitat, das manch ein Kritiker in Šklovskijs Prosa schlicht als ein Zeichen der Gelehrsamkeit des Autors auffaßt - ein Image, mit dem Šklovskij zuweilen kokettiert fungiert in seiner Prosa als ein Kontrapunkt, um auf Anachronismen und zugleich historische Ankniupfungspunkte hinzuweisen. In der "Dritten Fabrik" 
kommt dieser Gedanke in den Sätzen "Sterne, den ich wiedererweckte, verwirt mich. Ich mache nicht nur andere zu Schriftstellern, ich bin selbst einer

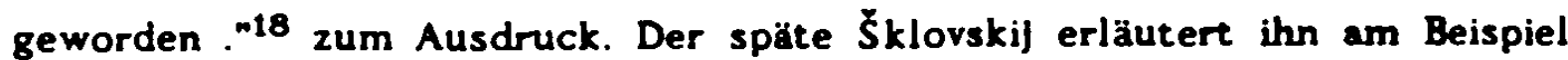
von Lev Tolstojs Sterne- und Rousseaurezeption.

"Als Kind las er bereits Rousseau ...

Werke von Steme ibersetzte Tolstoj in Starogladkovskaja als Ubung im Englischen Kapitel um Kapitel.

Wenn ein Schriftsteller einen anderen studiert. bedeutet das nicht, daB er ihn kopiert, daB er sich ins künstlerische Dasein des anderen einmengen will, wie Entladungen der Obusleitung sich ins Fernsehgeschehen einblenden.

Rousseau und Sterne jedöch setzten Ruchtpunkte für eine Zeit, als bei den Menschen das Interesse für ihr Innenleben erwachte und sie ihre häuslichen Gespräche, kommerziellen Interessen. Erbschaftsangelegenheiten, eheliche Zerwuirfnisse als das Alpha und Omega der Welt betrachteten.

Die Emotion war erschlossen und wurde mit dem Staat, der veralteten mittelalterlichen Gelehrsamkeit, dem Nachhall der Feudalzeit konfrontiert ...

Während Tolstoj zur Herbst- und Winterszeit in einer bunt ausgemalten Kosakenkate in der Staniza saß und Sterne ibersetzte, wurde ihm sein eigenes Anliegen bewuBt. ${ }^{-19}$

Eine andere Funktion erfüllt das Zitat nichtliterarischer Texte aus dem kulturellen Kontext der Entstehungszeit der autobiographischen Prosa Śklovskijs. Es hat zum einen die Funktion, die literarische Sprache durch Aufnahme von auBerliterarischem Material zu emeuern, zum anderen zeigt es Šklovskijs Art, sich auf literarischer Ebene mit der ihn umgebenden. ihm zumeist feindlich gesonnenen sowjetischen Kultur auseinanderzusetzen.

Die dominante Funktion beider Arten von Zitatmontagen - der aus der Literaturtradition und der von Texten aus dem zeitgenóssischen kulturellen Kontext - ist es, eine subversive Methode zu konstituieren, um mittels gesellschaftlich anerkannter und kanonisierter Rede (kenntlich gemachtes Zitat) - sei es in der Literatur (z.B. Lev Tolstoj), sei es in der sowjetischen Kultur (2.B. LunaCarskij) - provozierende oder zumindest unliebsame Dinge sagen zu können oder um in verrätselter Form (nicht kenntlich gemachtes Zitat) unliebsame Autoren (z.B. Rozanov) und Meinungen (Formale Methode) zu Wort kommen zu lassen.

Die fragmentarisch-essayistische Prosa Šklovskijs ist Teil einer Gegenkultur. der als einer nicht affirmativen in einer sich selbst entfremdeten Kultur "wenn auch verschleiert, ein (...) ideologiekritischer Impetus" unterstellt werden kann - wie inn Lachmann und ebenso Giinther fiir die Literaturkonzeption Bachtins bzw. für seinen "Aufweis einer literarischen Tradition mit gegenkultureller Funktion - der Kamevalsliteratur ${ }^{\mathbf{2 0}}$ behaupten. Gleich zu Beginn seines Artikels in "Wie wir schreiben" formuliert Šklovskij scheinbar naiv und doch treffend eine grundlegende Einsicht uber die Produktion einer 
fragmentarischen Prosa.

"Vor fünfzehn Jahren fiel es (das Schreiben, V.D.) $\mathrm{mir}$ besonders schwer, weil ich nie wuBte, wie ich beginnen sollte. Beim Schreiben schien mir immer, alles sei schon einmal gesagt. Die einzelnen Stücke fügten sich nicht zusammen. Beispiele standen nur für sich selbst. Im Grunde genommen ist es auch so geblieben. Das Schreiben fällt mir immer noch schwer, wenngleich auf andere Art. Ein Teilstuick entwickelt sich bei mir zu einer selbständigen Produktion, doch das Wichtigste steht, wie in der Kinematographie, zwischen den Teilen. ${ }^{-21}$

Der Kunstgriffcharakter dieser scheinbar naiven Gedanken iber die Schwierigkeiten, einen kohärenten Text zu schreiben, deutet sich in dieser Textpassage bereits durch ihre Widersprüchlichkeit in der Aussage an - vor fünfzehn Jahren fiel es (das Schreiben) mir besonders schwer ... Im Grunde genommen ist es auch so geblieben ... doch das Wichtigste steht, wie in der Kinematographie. zwischen den Teilen." Dieser Widerspruch weist auf, daB es sich hier nicht um die Probleme eines Anfängers. sondem um eine konkrete Methode handelt, die sich für Šklovskij als sinnvoll und notwendig erwiesen hat: die Methode, einzelne Textfragmente zu einer Textkonstruktion zu montieren.

Vor der Frage nach der Einheit und Geschlossenheit eines literarischen Werkes geht er dem Problem der Isoliertheit der Formen nach. Seine eigene fragmentarische Rede verrät seine Vorliebe für das je Einzelne. Uber "Dritte Fabrik" schreibt er in "Hamburger Vergleich":

"Was ich an meiner nicht theoretischen, sondern literarischen Arbeit für wichtig halte?

Wichtig ist das Gefuihl für die Getrenntheit der Formen und der freie Umgang mit ihnen.

Die Vorstellung von der Einheit eines literarischen Werkes wird bei mir durch das Gefühl für die Bedeutung des je einzelnen Stuicks ersetzt. mehr als die Verschmelzung der Stuicke interessiert mich ihre Widerspriichlichkeit.

Und weil das wahrscheinlich für den heutigen Augenblick der Literaturentwicklung notwendig ist. wurde diese meine persönliche Eigenart nicht aus der Literatur verdrängt, sondern von mir in sie hineingetragen. ${ }^{-22}$

Auf die Frage nach der Einheit des Textes "Suche nach dem Optimismus" antwortet er:

-Die Einheit. Leser, liegt hier in dem Menschen, der auf sein sich veränderndes Land blickt und neue Kunstformen baut, damit sie Leben wiedergeben. Was die Einheit eines Buchs angeht. so ist sie oft Illusion. ebenso wie die Einheit eines Landschaftsgemäldes. Spaziert an den Dingen entlang. findet einen Standpunkt und genieBt die Einheit. wenn ihr sie findet. Ich habe sie nicht gefunden." ${ }^{-23}$ 
Auf der einen Seite erkennt Šklovskij die Unfreiheit des Materials, die Unfreiheit des Schriftstellers, seine eigene Unfreiheit, die sich in der Zerrissenheit der Formen eine Gestalt gibt. -

"Ich bin abgeschweift, aber alles, was den Menschen organisiert. liegt auberhalb seiner selbst. Er selbst ist nur ein Schnittpunkt von Kräften. ${ }^{-24}$ -

auf der anderen Seite hält er die Freiheit der künstlerischen Konstruktion hoch und setzt ihre Souveränität gegeniber dem Material der Unfreiheit entgegen, zwar ohne sie abzuschaffen - dies liegt weder in der Macht der Kunst noch ist es ihr Bestreben, denn die Unfreiheit des Materials macht ihre Verbindung zum Leben aus, sie gewährleistet die Lebendigkeit der Literatur -, aber um sie im $\mathrm{Nu}$ der künstlerischen Illusion aufzuheben und dann in der Zerstörung dieser Illusion - "mehr als die Verschmelzung der Stuicke interessiert mich ihre Widersprilchlichkeit" - wieder auf sie hinzuweisen. Diese Differenzerfahrung ${ }^{25}$ - Freiheit der Konstruktion auf der einen und Unfreiheit des Materials auf der anderen Seite - ist zugleich vor allem anderen Basis und Motor der literarischen Arbeit und - auf der Ebene der Kunstproduktion - selbst ein künstlerisches Verfahren. Sie verweist keineswegs auf einen sich immer gleichbleibenden Dualismus von Material und Konstruktion. sondern auf einen dialektischen Widerspruch: die Freiheit der küstlerischen Konstruktion kommt nur in der ästhetischen Aufhebung der Unfreiheit des Materials zu sich selbst. gleichzeitig muB der Unfreiheit des Materials als solcher im Kunstwerk Gestalt verliehen werden, um sie ästhetisch wahmehmbar und lebendig zu machen. d.h. sie realisiert sich allein in der Negation der unumschränkten Herrschaft der Freiheit der kiinstlerischen Konstruktion. Diese Differenzerfahrung verhilft Šklovskij zu der Einsicht, daB Kunst so lange zu gesellschaftlicher Folgenlosigkeit verurteilt ist, wie sie in ihrer Borniertheit die Aufnahme des Materials, der gesellschaftlichen Fakten verweigert. aber daB sie auf der anderen Seite ihre Souveränität verliert. wenn sie sich diesen Fakten ausliefert und die Freiheit der Konstruktion aufgibt. In dem Bild des "literarischen Schrittes" verleiht Šklovskij diesem Prinzip der Differenzerfahrung einen metaphorischen Ausdruck.

"Ich will die Freiheit.

Aber wenn ich sie erhalte, dann suche ich sofort, die Unfreiheit gegenuiber einer Frau und meinem Verleger.

Doch zwei Schritte Spielraum. die Illusion einer Wahl braucht der Schriftsteller wie der Boxer. um schlagkräftig zu sein.

Die Illusion ist ihm ein ausreichend solides Material." 26

Später nimmt er dieses Bild noch einmal auf. Tret'jakov wirft er vor, "die Möglichkeit des literarischen Schrittes verloren" zu haben. Der "literarische Schritt" bezeichnet den Spielraum zwischen 2 wei Schritten, der die Illusion von Freiheit nicht nur suggeriert, sondern ihr auch einen Raum gibt. Hierin erhält das Literarische, so, wie Šklovskij es auffaßt und in die Praxis umsetzt. 
seinen eigenen Ausdruck und seine spezifische Bedeutung. Er nimmt die Fähigkeit der Literatur, zu illusionieren, mittels der lllusion das Reich der Notwendigkeit zu entgrenzen, ernst und durchschaut doch gleichzeitig den affirmativen Kern dieser Fähigkeit zur lllusion, kraft derer die Kunst Jahrhunderte lang die Möglichkeit hatte, von einer schlechten Wirklichkeit abzulenken. ihre Mängel zu kompensieren und den Leser/Betrachter fernab aller realen Unbilden in eine Welt des schönen Scheins zu versenken. Für den Schriftsteller Šklovskij ist die Illusion Material und Kunstgriff. Als Kunstgriff verleiht sie dem Werk eine Aura und hütet die Eigengesetzlichkeit des Ästhetischen, aber als Material, als Thema entblöBt er sie und stellt sie in Frage. denn auf den ersten Schritt folgt - mag der Spielraum auch auf die vermeintliche Chance des ganz Anderen, des Zufalls, der Utopie hoffen lassen unweigerlich der nächste: die Entlarvung der Freiheit der Konstruktion als eines begrenzten Spielraums, eines Zwischen-raums zwischen dem einen und dem nächsten Schritt, an dem sich die Standfestigkeit der Literatur auf dem Boden der Realität erweist. Auf den folgt erneut ein Spielraum und - ein Schritt.

Angesichts einer zunehmend repressiven Kulturpolitik, die die Künste aufforderte, eine harmonische Sowjetwirklichkeit abzubilden. setzt sich Šklovskij in "Suche nach dem Optimismus" thematisch mit dem fragmentarischen Stil auseinander. Er behauptet. daß die besseren sowjetischen Dichter mit diesem Stil ringen würden. der kein "Laster" sei. sondern "eine Eigenschaft unserer Zeit". Majakovskij habe mit diesem Stil gerungen.

"Die Menschen unserer Zeit. die Menschen des intensiven Details, das sind die Menschen des Barock. ${ }^{-27}$

Šklovskij führt den Nichtzusammenhang der Kunstformen auf die Dissoziiertheit der Lebensformen zuruick. Die Formen - behauptet er - existieren auBerhalb unserer Vorstellungen und fallen manchmal über uns her, weil die Methode, nach der sie konstruiert werden. "jetzt auf eigene Faust lebt."28 Sie sind gleichsam ein Resultat des Zusammenstoßes der semantischen Reihen Kunst und Leben.

"Jahrzehnt um Jahrzehnt machen die Kritiker den Poeten den Vorwurf der Auslassung (propusk).

Die Ellipse ist Auslassung, die fundamentale Trope, die fundamentale Figur der Poesie.

Die Ellipse ist das Bild.

Wenn man den Abstand zwischen dem zu vergleichenden und dem Vergleich mit Erklärungen füllt, dann ist das Bild begrifflich und unbildlich. ${ }^{-29}$

Šklovskij vergleicht die fragmentarische Kunstform der Ellipse mit einer "Auslassung". Aber die Mehrdeutigkeit des Wortes "propusk"30 kompliziert den Sinn dieses Vergleichs und macht ihn verschieden verstehbar. 
In dem Wortspiel stellt Šklovskij die Ellipse erstens als einen besonderen metaphorischen Stil vor, spielt zweitens iber diese literaturtheoretische Zuordnung hinausweisend auf das "Fermbleiben" des Dichters vom gesellschaftlichen Leben an und läßt drittens den Leser die in der Sowjetunion geläufigste Bedeutung des Wortes "propusk" assoziieren, seine Bedeutung 'Passierschein', die die im Staatssozialismus allgegenwärtige Instanz der gesellschaftlichen Kontrolle und den Weg, sie zu umgehen, bezeichnet.

Die literarische Redefigur der Ellipse, die bedeutsame Auslassung in Text. gibt dem Dichter die Möglichkeit, sich dem direkten Zugriff des gesellschaftlichen Lebens zu entziehen. Denn er kann für das, was er nicht zu Ende gesprochen hat, nicht zur Rede gestellt werden.

Šklovskijs Deutung der elliptischen Schreibweise in "Suche nach dem Optimismus" als Passierschein für den Dichter. um sowohl in der Kunst als auch im Leben Grenzen und Regeln zu überspringen. steht nicht allein. Sie knüpft an die metaphorische Selbstdarstellung im "Rösselsprung" an, wo der Schriftsteller Šklovskij seine Methode zu schreiben mit dem Bewegungsmuster des Springers im Schachspiel vergleicht. der sich quer zur Anordnung der Spielfelder bewegt und nicht von Feld zu Feld zieht. sondern springen kann (Rösselsprung ${ }^{31}$ ) - ein Bild, das der Erzähler in "Dritte Fabrik" in dem Kapitel "Bucht des Neids" wieder auf nimmt. 32

Auch wenn S̈klorskij in dem Aufsatz "Ende des Barocks" (1936) ${ }^{33}$ Ejzenštejns klassisch realistischen Formen das Wort redet und in verschiedenen Artikeln den ormamentalen Stil der Odessaer Schule fachmännisch kritisiert ("Süd-West". "Sujet und Bild" u.a.) ${ }^{34}$. so bleibt er selbst doch bei seiner fragmentarischessayistischen Schreibweise und verteidigt sie auch weiterhin. ${ }^{35}$

\section{2. Šklorskijs Prosa im Verhältnis zur Essaytradition in Westeuropa}

Die frühe autobiographische Prosa Šklovskijs ist eine essayistische Prosa, die sich in mancher Hinsicht in Zusammenhang mit der westeuropäischen Essaytradition betrachten läBt. Denn sie weist die grundsätzlich dem Essay als asthetische Form eigenen und von kontroversen Interpretationen gleichermaßen hervorgehobenen Merkmale auf. Šklovskijs Prosa - von Čužak "Gelehrtenprosa" genannt - versucht sich in der Gratwanderung zwischen Kunst. Moral und Wissenschaft genauso wie Musil in "Der Mann ohne Eigenschaften", wie Adorno oder Lukács es dem Essay nachsagen. "Wie ein Schritt. der nach allen Seiten frei ist, aber von einem Gleichgewicht zum nächsten und immer vorwärts führt".36 jongliert die frühe autobiographische Prosa Šklovskijs zwischen den Sprachsystemen. Sie nimmt einen Wortgegenstand aus verschiedenen Perspektiven. die im Nu wechseln, sich uberblenden und parallel zueinander stehen bleiben können, so daB das Wort verschieden verstehbar wird und ein im wissenschaftlichen Diskurs stehendes z.B. plötzlich einen 
existentiellen Sinn oder eine literarische Sentenz eine literaturtheoretische Bedeutung erhält. Sie berührt zahllose Themen und führt keines aus -

"wie ein Essay in der Folge seiner Abschnitte ein Ding von vielen Seiten nimmt, ohne es ganz zu erfassen, - denn ein gefaßtes Ding verliert mit einem Male seinen Umfang und schmilzt zu einem Begriff ein. ${ }^{37}$

In diesem Sinne ist sie ein Versuch, ein Experiment, das die Institut gewordene Arbeitsteilung zwischen den Disziplinen symbolisch in Frage stellt. Ihre Intellektualität und Begrifflichkeit erscheinen als "sentimentales Erlebnis. als unmittelbare Wirklichkeit, als spontanes Daseinsprinzip". 38 Sie weiB. daB die Trennung von Kunst und Wissenschaft in der Geschichte vollzogen wurde und "mit keinem Zauberschlag wiederherstellbar" ist, aber dab die individuelle Erfahrung manches einfangen kann, was dem Netz der wissenschaftlichen Begrifflichkeit entgeht. 39

"Der Essay kündigt wortlos die Illusion, der Gedanke vermöchte aus dem. was thesei. Kultur ist, ausbrechen in das. was physei, von Natur sei." $\$ 0$

Šklovskijs Prosa hält die so verschiedenen Gegenstände ihrer Betrachtung wie der Essay in der Beschreibung von Adorno. Lukács und Musil allein durch das subjektive Erlebnis bzw. die subjektive Entscheidung des Erzählers zusammen und ist doch frei von Subjektivismus. Die subjektive Anstrengung der fragmentarischen Verknüpfung heterogener Sprachsysteme im Essay vermag es, die scheinbare Objektivität und Geschlossenheit, die sie jeweils fur sich genommen suggerieren, als bloB subjektive Veranstaltung zu entlarven. ${ }^{41}$ Musils Gedanke, daß der Essay "einmalige und unabänderliche Gestalt" sei. "die das innere Leben eines Menschen in einem entscheidenden Gedanken annimmt, (...) dem (nichts) fremder (ist) als die Unverantwortlichkeit und Habfertigkeit der Einfäle, die man Subjektivität nennt”.42 trifft auch auf Šklovskijs frühe Prosa zu. deren subjektive Willkür und Flüchtigkeit ein Kunstgriff der Verfremdung und Verrätselung ist. Deshalb erheischt sie ein asthetisches Urteil, auch wenn sich ihr Telegrammstil ein feuilletonistisches Ansehen gibt. Ihre Originalität liegt - wie die des Essay - nicht im Erfindungsreichtum, was ihre Gegenstände anbetrifft, sondern in der Art ihrer Darstellung - in der unvermittelten Verknüpfung "von etwas bereits Geformtem oder bestenfalls von etwas schon einmal Dagewesenem"43 und von einander nicht unbedingt ebenbiurtig. einander fremd erscheinenden Gegenständen. Ihre Form "kommt dem kritischen Gedanken nach, daB der Mensch kein Schöpfer, daB nichts Menschliches Schöpfung sei".44 aber sie gibt sich 2 ugleich die Gestalt einer "bewubten Lebenshaltung" (Musil), die in der symbolischen Geste der unvermittelten Zusammenschau des Dissoziierten und vorgegeben Geformtem die gesellschaftliche Handlungsfähigkeit des Subjekts behauptet. 
Mehr als andere Gattungen besitzt der Essay die Fähigkeit zur Selbstreflexion. ${ }^{45}$ In der frühen autobiographischen Prosa Šklovskijs verarbeitet die Selbstreflexion die Erkenntnis der Unzulänglichkeit des Seienden, der, gemessen an den mannigfaltigen Projektionen menschlicher Sehnsucht, fortwährenden Diskrepanz zwischen Anspruch (Utopie) und Wirklichkeit, zu einem Humor, der diese Diskrepanz als Defizit zu erkennen gibt. ${ }^{46}$

So zahlreich die Parallelen zwischen dem westeuropäischen Essay und der essayistischen Prosa Šklovskijs im einzelnen sein mögen. so verschieden und schwer miteinander vergleichbar sind die Formen, betrachtet man sie in ihrem jeweiligen historischen und gesellschaftlichen Zusammenhang. Dies wird insbesondere an den verschiedenen Interpretationen der westeuropäischen Essaytradition deutlich.

Karl-Heinz Bohrers theoretische Bestimmung des Essay in seiner "Theorie der Plötzlichkeit" ${ }^{\$ 7}$, aber auch Hannelore Schlaffers Untersuchung iber die Evolution dieses Genres $\$ 8$ läBt die Unvergleichlichkeit des westeuropäischen Essay mit der essayistischen Prosa des sowjetischen Schriftstellers auf unmittelbarer Ebene evident werden. Schlaffer argumentiert literatursoziologisch, sie geht von der Evolution des Genres analog zu der Entwicklung der bürgerlichen Gesellschaft aus. Ihr Untersuchungsmaterial ist die westeuropäische Essaykultur. Sie unterscheidet 2 wischen dem dialogischen, experimentellen. perspektivisch auf die Zukunft gerichteten und in die öffentlich-politische Diskussion miteinbezogenen Essay des fruhen Bürgertums (Montaigne. Schlegel) und dem auratischen, von solipsistischer, ohnmächtig raisonierender Selbstreflexion und rückwärs gewandter Gesellschaftsutopie getragenen kulturkonservativen Essay des 20. Jahrhunderts (Hofmannsthal. Benn u.a.).

Bohrer differenziert ebenfalls zwischen einer riickwärtsgewandten. vorwiegend interpretierenden Essaykultur und einer auf die Zukunft. auf spontanes Denken orientierten, aber er kommt, da er nicht von einer kritisch-historischen Gesellschaftstheorie ausgeht. zu einer anderen Zuordnung und $2 u$ anderen Schlubfolgerungen als Schlaffer. Er unterscheidet 2 wischen einem "romantischen Essayismus", wobei er eine Verwandtschaft 2 wischen der romantischen und der surrealistischen Essayform konstatiert, und dem kulturkonservativen Essay, den Adorno und Lukács stiutzen. In seiner Theorie der Plötzlichkeit spricht er dem romantischen Essay eine utopische Dimension dergestalt zu. daB hier "Erkenntnis" plötzlich aufflammt "mit einer zuckenden Bewegung". Er nennt den Essay Erkenntnisprosa. die "genau 2 wischen festgelegtem Begriff und gerade gefundenem Zeichen steht. die noch zukinftig ist und daher utopisch. "\$9 Der Essay sei spontane Erkenntnis im Dialog des scheinbar Unvereinbaren vermittelt durchs Subjekt. Bohrer beruft sich u.a. auf Schlegel ("Ubber die Unverständlichkeit") und Kleist ("Über die allmähliche Verfertigung des Gedankens beim Reden") und zitiert Musils Essaykonzeption ("Essay als utopische Lebenshaltung") als positives Beispiel für seine Bestimmung, wobei er auf eine literatursoziologische und gesellschaftskritische Fundierung seiner Bestimmung des Essays als Erkenntnisprosa verzichtet. 
Šklovskijs essayistische Prosa spertr sich einer eindeutigen Zuordnung innerhalb des dichotomischen Bestimmungssystems kulturkonservativer und auf die Zukunft gerichteter, monologischer, politisch ohnmächtiger Essay auf der einen Seite und dialogischer, an der öffentlich-politischen Diskussion teilhabender auf der anderen sowohl im Sinne Schlaffers als auch im Sinne von Bohrers "Theorie der Plötzlichkeit". Šklovskijs frlihe autobiographische Prosa ist beides: sie trägt utopisches Potential in sich, das sich - auf der Suche nach einem kritischen Korrektiv zu der zur Herrschaft gekommenen marxistischleninistischen Gesellschaftsutopie - positiv auf die Erinnerungen an die europäische Kulturtradition bezieht. ohne ein "Utopia" in der Vergangenheit zu bauen. Vielmehr verarbeitet sie Gegenwartserleben im Zusammenhang mit der vergangenen Kultur zu neuen Erfahrungen und zu neuen Kunstformen. Sie hat eine kritisch-ironische und im Sinne des romantischen Ironiebegriffs eine dialogische Form. die sich auf dem Hintergrund realer gesellschaftlicher Erfahrung selbst verändert: die Erfahrung der mit gesellschaftsutopischen Projektionen befrachteten, schnell und radikal sich verändernden Zeit. die der Literatur zunächst die Möglichkeit zum Experiment und zur Einmischung ins gesellschaftliche Leben bot. sie ihr gegen Ende der 20er Jahre aber wieder entzog, machte aus einer gesellschaftliche Entfremdungszusammenhänge und traditionelle Arbeitsteilung aufbrechenden Prosa eine sich in diesem ProzeB selbst reflektierende. essayistische. Die frühe autobiographische Prosa Šklovskijs ist keine einsame Selbstreflexion, kein selbstgefalliger Monolog eines bomierten Intellektuellen. sondern eine kunstvolle Form des literarisierten Dialogs eines Intellektuellen in der Sowjetunion der 20er/30er Jahre mit sich selbst bzw. mit den Rollen. die die Gesellschaft auf ihn projizierte.

Während Musil - ungeachtet seiner konzeptionellen Überlegungen über den Essay - nach einer Vollendung des Romanzyklus "Der Mann ohne Eigenschaften" suchte, ihm die gewiunschte Geschlossenheit aber nicht zu geben vermochte, verwirklichte Šklovskij seine Prosatheorie in den frühen autobiographischen Schriften gegen die Kritik in der sowjetischen Öffentlichkeit und schrieb eine Literatur ohne Anfang und ohne Ende. 
Anmerkungen zu Tell 1, Kap. 3: Die fragmentarlach-essaylatische Form der fruben atoblographlschen Prose Sklovikij:

1 V.Sklovaklf, Orlbki 1 kobretenlje. In: Za sorok let. S.100: deutsche Erfindungen und Irrtumer. in: Schriften zum Fum. S.102/S.103

2 In throm Aufaetz "Intertextualitit als Sinnkonaticution" Uber A.Belyje "Petersburg" (R.Lechmann. Intertextualitit als Sinnkonstitution. Andrel Belyjs "Petersburg" und dle -fremden" Texte. Poetice 1-2 (1983). S.66-107) entwirft Renate Lachmann euf dem Hintergrund der Auseinanderaetzung mit dem rusalachen Strukturalismus Lotmana und Bechtins und mit den franzbalachen Semlotikem Kriateve. Derride und anderen dae Konzept elner Textinterpretation. de - Uber die Analyse von Mlkroatrukturen elnes Textes bxw. Uber die Analyse von Strukturen elnes kulturellen Feldes hineus - intertextuelle Relationen innerhalb elnes literariachen Textes sufapuren will, der sich per se da eln "gemachter" verateht.

-Bekannte Verfahren. die zwischentextliche Bezlehungen heratellen. wie die Elnlagerung fremder Texte in elnen Text ale Zitat oder Anaplelung. die Kontamination elner Vielzahl heterogener Texte oder die Wider und Gegenschrift etnes bekannten Textes ale Parodie oder Kontrafaktur. werden unter dem Gesichtspunkt des semantischen Mehrwerta'. den sle Im konkreten Text erbringen. neu geschen. Es geht um dle Bestimmung der in den Text elngesplelicen semantschen und dathetschen Differenx. wle sie durch die 'Uaurpation' fremder Texte. Textkonventionen und Gatungsechemete erzeugt wird bel Autoren wie Rabelass. Sterne. Belyl. Jamea Joyce oder Amo Schmid." (68)

Da sich um den Begriff der Intertextualitit beretes elne lebhafte Diskussion entwickelt het. mochte ich thn fur melne Fregestellung in deser Arbelt alnnvoll elnschranken. mlch Wolf Schmld anachlleben und von elner Intertextuellen Rieletion nur dann aprechen. -wenn de Bezlehung des spdteren Textes (T) zum fruhen oder fremden Text. dem $P$ $A-T e x t$ (PT). als eln vom Autor intendlertes semantlaches Faktum im Bedeutungeaußou von $T$ identifizierbar let." Schmld bexieht alch in seiner Definition suf das Didoglzititsmodell Bachelns. Selnem Veratindnla nach manfestere sich elne intertextuelle Reletion im mehrstmmigen Wort elnes Textes. Wolf Schmid. Sinnpotentlale der diegetsachen Nluaton. Alexander Puxklns Posthaltemovelle und thre Pritexte. In: Dialog der Texte. Hemburger Kolloqulum zur Interextualitut. (Hrag.) W. Schmid und W.-D. Stempel. Wlener Slaviatiecher Almanach. Sonderbd. 11. Wien 1983, S.143)

3 vgl. Ju.Tynjanov, Literaturnyl fakt. S.392 ff.

4 V. Sklovakll. Togda I sejcas. Den' smert Klarleay Garlor. In: Literatura fakte. S.122

S In dem 21. Brief dea Brlefromana "Zoo" (S.80 f./S.89 ff.) entizlplert Sklovakl) Ironisch das zwel Jahre sputer erschelsende Relseerinnerungs-Buch von Elsa Triolet: E.Trole. Talt. L. 1925.

6 V.Skloraklf. Rozanov: lz knlgl "Sjufet kak javlenlje etllja". In: Sbornlkl po teorl poeticeskogo jaxyka. Petrograd 1921: abgedruckt mit Ausnahme der letxten seche Selten ale "Llterature vne ajuzete". ebd., S.162 ff./S.163 ff.: Sklovakif bezleht alch auf: V.V.Roxanov. Uedinennoe. St.Peteraburg 1912; dera.. Operale llat'ja. St.Peteraburg 1913-1915: reprint in: Ixbrannoe. (Hrag.) E.Zigleve. Munchen 1970; deutsch: Solltarla. Auagewihlte Schriften. (Hrag.) J.v.Guenther, U.: H.Stammler. Hamburg U. Munchen 1963

7 V.Sklorgkil. Tret'ja .... S.89: vgl.: E.A.Poe. Houroke. Eln Esaly uber dae meterielle a epirituelle Univeraum. Das Gesamte Wark in zehn Bunden. (Hrag.) K.Schumenn. H.-D.Muller, U.: Arno Schmid, H.Wollechluger. Olten 1966. Bd. II (5), S.896 ff.

8 V.Sklovakil, ebd.. S.108: vgl.: RKIpling. Die Katze geht thro elgenen Wege. Gesemmelte Werke in drel Binden. Munchen 1965. Bd.3. S.595 ff.

9 V.Sklorakif. ebd.. S.129: Vgl: Platon. Dea Gatmahl. Hamburg 1960 
rel. M. Bechtin. Problemy poetlkt Dostoerakozo. M. 1963: deutach: Probleme der Poetlk Doetoerakelje, U.: A.Schramm. in der Rethe: Literntur ale Kunet. (Hrag.) W.Hollerer. MUnchen 1971

11 V. Skloraklf in: Kak my plxam. L. 1930; reprint: Benaon. Vermont 1983. S.212

12 bd.. 5.211

13 bod.. 5.212

14 rel. J.Lehmann. Ambivalenz und Dialoglzitut. Zur Theorle der Rede bel $M$. Bacheln. In: Urazenen. (Hrag.) F.A.Kiteler. H.Turk. Ffm. 1977; zit. nach: R Lachmann. Intertextuelitit. $\mathbf{S . 7 0}$

15 V. Sklorakif. Polaki .... S.115

16 VI.Mejakorakif. Vel. Chlebnikor, D. Burljuk. A. Krucenych, Pokzežne obzZeetrennomu rkueu. S.SO/S1

17 O. Forl. SumanedXIj korabl. L. 1930; raprint: Weahington 1964. S.92; ral. Skloveklfs Hinwele auf den Uneerschled zwischen dem Brohmschen und dem Gummleplelzeug-Elefancen in: Tracje .... S.13

18 V. Skloraklf. Tret'ja .... S.93

19 dera.. Lev Toleto). Sobr. sox.. M. 1973-1974. tom 2. S.161; deutech: Leo Toletol. U.: E.Panzid. Berlin 1980. S.169/170

20 R Lechmann. Intertextudielit, S.70; vel. H.GUnther, Mlchall Bachtine Konzepe ale Altemetive zum Soztalietischen Realiemue, In: Semloesce and Dinlectice. Ideology and Texe. (Hrag.) P.V.Zime. in der Ratha: Linguinesc and Literary Studien in Eantern Europe. S. Ameterdam 1921, S.137 ff.

21 V. Skloraklf in: Kak my plyem. S.211

22 dere.. Gamburgeklj .... S.107

23 dera.. Polakl .... S.64

24 dere.. Sentimentalinoe .... S.266/S.260

25 Skloveklj deutet den Begriff der -Differenzerfahrung- berelte in der Theorte der Prose" (S.31-32/5.35-37). Er Ubernimme die Beselmmune eue B.Chrtetineene "Philosophle der Kunet de Konetruktonoprtnzip der Verfremdung. um sein Modell der literartechen Evolueton zu entwickeln. ohne nther zu beetimmen. wortn dle Differenz zwachen Norm und Abwalchung konkret llege (rgl. A.Haneen-Love, S.223), und welcher Grad an Bewubtedis notg ist. um te wahrzunchmen. bzw. thr Wahmehmung zu verarbetien. Die methodleche Reduktion des fruhen Formallemus bat noch keinen Begriff fur dle uber de Werkimmanenz hineuaweleenden Aepekte der Differenzerfahrung.

27 dera.. Polakl .... S.11s

28 dere.. Zoo .... S.40/S.\$2: TWelle beechretbe da Leben Immer 00 . das man eleht. wie die Dinge den Menechen lenken. Die Diage. beeondere die Maschine, haben den Menachen verwandele.

Der Menech veretehe ekch houte nur darauf, ale eufzuzlehen: dann laufen ale ron allein. Sle laufen und leufen und erdrucken den Menechen.

Der Zuetand der Wlesenechaft lat Uberaue ermat.

Die Notwendigkelt der Vermunft und de Notwendlgkete in der Natur haben elch roneinender getrennt.

Ea gab ein Oben und Unten. es gab dle Zeit. ea gab dle Materte.

Jetze let nichte dn In der Welt herseht die Methode.

Der Menech hat die Methode erfunden.

D I M e hode.

Die Methode het thr Haus rerleseen und lebt jetzt auf elgene Fause.

Die Spelee der Goteer wurde entdeckt, aber wir eseen nlcht davon.

Die Dinge. euch die kompliztertesen aller Dinge: die Wiesenechafien. wandern nach elgenem Gutdunken Uber die Erde. Wla kónnen wir ele zwingen, fur une zu arbelten?

Und let ea Uberhaupe notiz?

Wir wollen lleber nuezlose und absehbare, aber neue Dinge bauen.

Auch in der Kunet geht de Methode fremd.- (nech der deutechen Auegabe) 

verałumnis. Fermblelben. Nichtbeauch. 3. frot-, ausgelasane stelle. Lucke. Auslasaung (im Text)

31 vel. V. Sklorakil. Chod konja. S.9-11

32 V. Kklorakl]. Tretje.... S. 121: Dle Freunde, de im Hinterzimmer dea Trudelladene "Der frobliche Elngeborene" der Ezzhlung Soloveje laushen. heben dartiber die Zelt vergessen und stellen plotzlich feat. deb es schon 1 Uhr naches lat und ale kelnen Pasalerachetn haben. um legal an den Wachen rorbel nach Hause gehen zu kobnen De mache elner ron thren den Vorachleg: "Am beeten geht men echrikg uber das Ela."

33 V. Skloraklf. O lfudjech. kotorye Idut po odnol 1 tof te doroge 1 ob jetom ne znajut. Konec barokko. Literaturnaje gazete. 32 (17. Jull) 1932: Im Auszug in: ders.. Za sorok let. S.118/119. unter dem Titel: Konec barokko. Pla'mo Ejzenziejnu.

34 ders.. Sjulet I obraz. Llteraturnaje gezete. 37 (17. Aug.) 1932: ders. Jugozepad. Llteraturnaje gazete. I (S. Jan.) 1933; deucach: "Sud-Weaten". In: Konzepte. (Hrag. U. U.) F.Mlerau. Lelpzle 1979. S.89; dera.. Razgovor a druz'jaml. 1938. In: dera.. Ze sorok let. S.132 ff.

35 Zum Belapiel achrelbe Sklovakil in den Erinnerungen an Majakorakj)" S.386-387/S.175: "Hufig zeratorten wir mit dem Ornament auch dle Konatruktion. Ale wir im Theater nackte Winde verwendeten. verachwammen die Tone. Rosale Omamentik befestgte glelcheam den $\mathrm{Kleng}$ an dle architektonsachen Formen. hilt dle Tüne zuasmmer. Er war wirklich koneerukelv ...

Stellen sle aich eber de elnmal den Dicheer vor. Er glbe elne Zeltachrift heraue. die Zeltachrfit aber lat gegen die Dichtung.

Mejakovakif war ohne Stellung-- Eln anderes Beleplel: Sklorekifa Redebeltrag ouf dem 1. SchriftecellerkongreB 1934. deutech in: Sozlalietsche Realiamuakonzeptionen. Dokumente zum 1. Allunionakongreb der Sowjetachriftateller. (Hrag.) H.-J.Schmite u. G.Schramm. U.: G.Schramm. Ffm. 1974. S.94-96: hier hale er etn Pludoyer fur da Ornmment im Nemen elner neuen Senalbilitie. de offizlelle Tendenz hin zu etnem pproletarichen Humanismua" auenutzend: "An unseron Husem jedoch Uberwlegt zuwellen das Unwesentiche. Wir haben des Gealme vergesaen. Wir. und in der Mehrzahl wir ehemellgenLEF-Leute, haben rom Leben dan Nutzliche genommen. denkend. des sel schon dle Xachetlk: wir. de Erwecker der Konstruktiviaten. machten solche Konetruktomen. das ate zu Unkonatruktionen wurden." (95)

36 R Musll. Der Mann ohne Elgenechaften. Geammelie Werke in 9 Bden.. (Hrag.) A.Frtat. Relnbek b. Hamburg 1978. Bd.1. S.250

37 ebd.

38 G.Lukfica. Uber Weaen und Form dea Easays: Eln Brief an Leo Popper. In: Die Seele und de Formen. Neuwled und Beriln 1971. S.15

39 T.W.Adorno. Der Easey al Form. In: Noten zur Literatur I. Ffm. 1971, S.18

40 ebd.. S. 26

41 rgl. ebd.. 5.48

42 R.Murll. 5.253

$\$ 3$ G.Lukaca. S.20

44 T.W.Adorno. S.37

45 rgl. dera.. 5.47

46 vel. G.Lukíce. S.19

47 K.-H. Bohrer. Plotzllchkelt. Zum Augenbllck dea urehetachen Schelna. Ffm. 1981

48 H. Schlaffer. Der kulturkoneervative Esany In 20. Jahrhundert. In: Studten zum bethetlachen Hatoriamua. (Hrag.) H. U. H.Schlaffer. Ffm. 1975. S.140-173

49 K.-H. Bohrer. S.20 
II. TEIL

Textanalyae "Dritte Fabrik" 


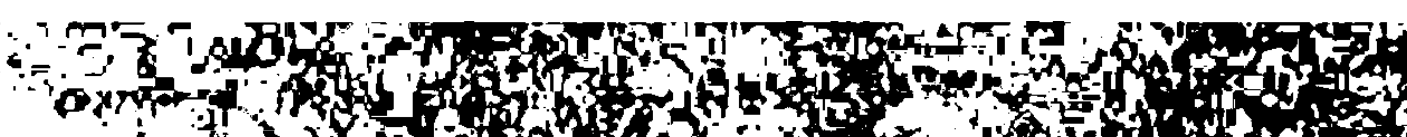

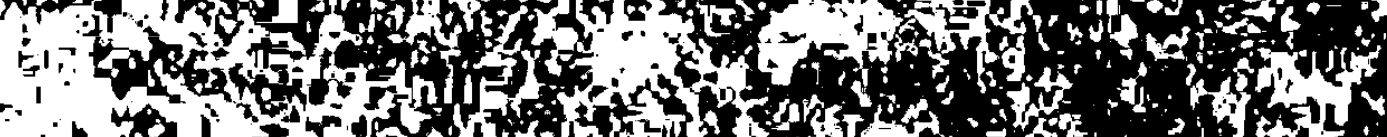

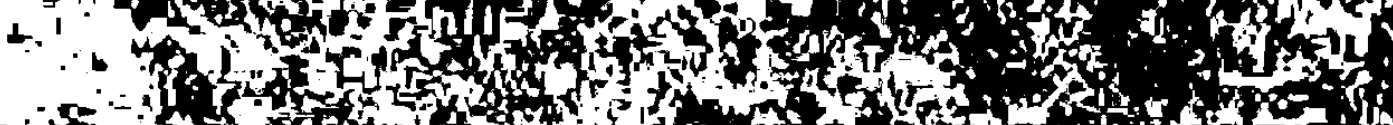

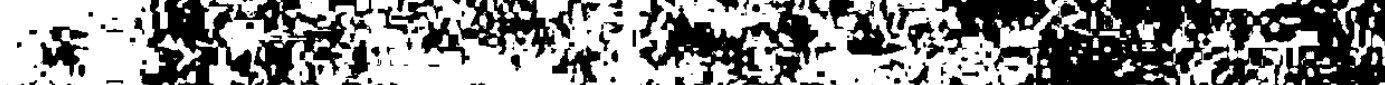

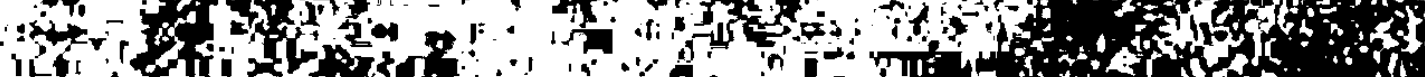

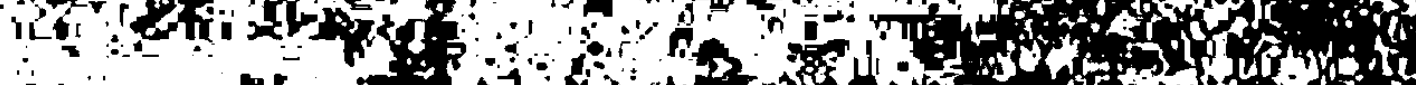
$1=8-0$ of

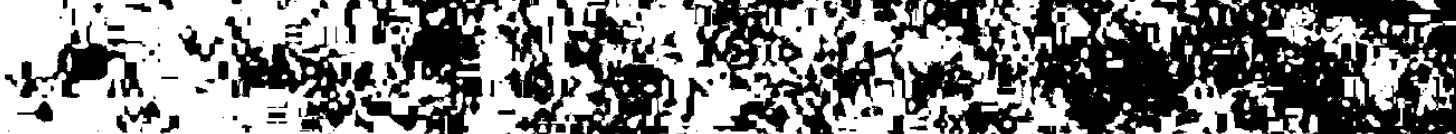

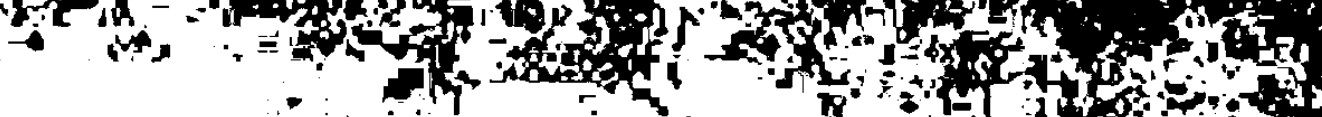

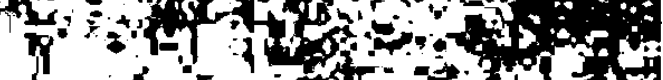

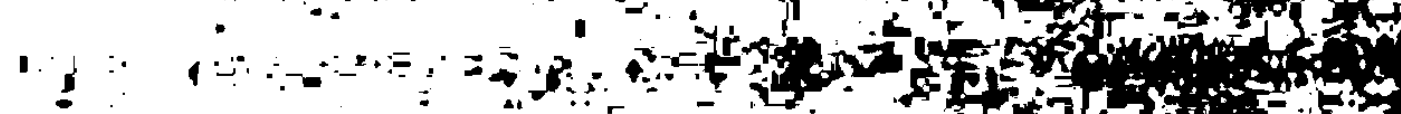

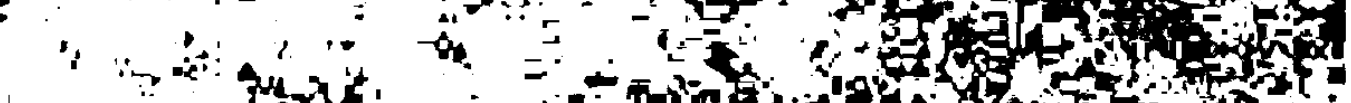

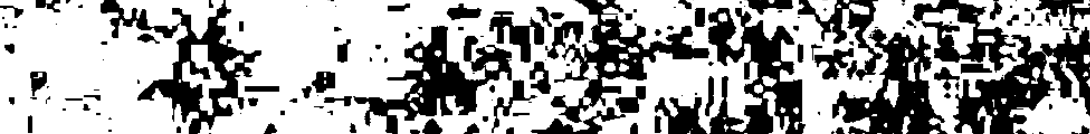
$-\quad \therefore=1$.

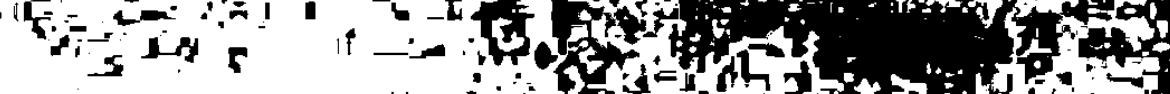

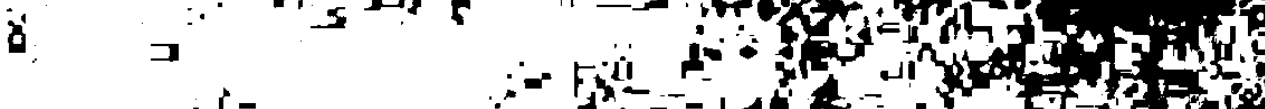

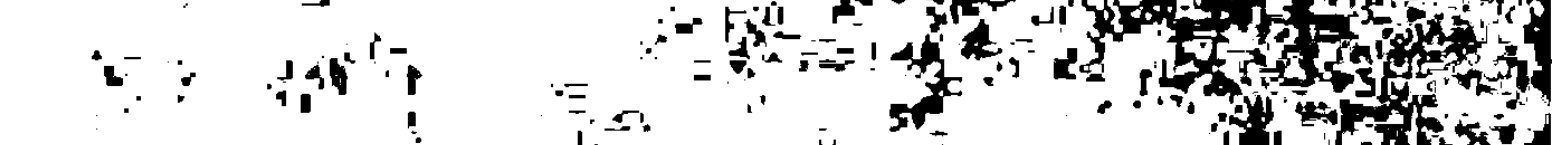

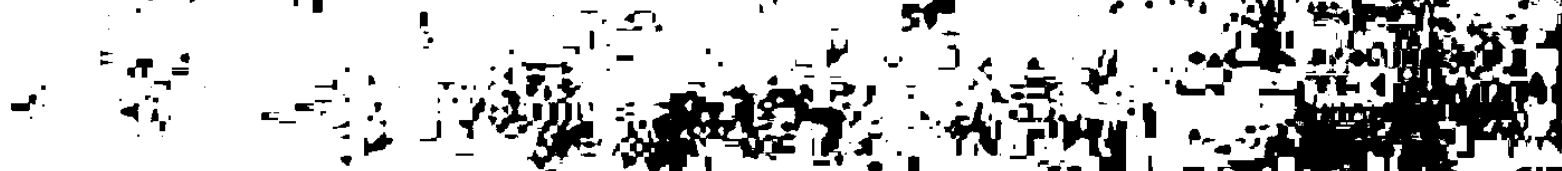

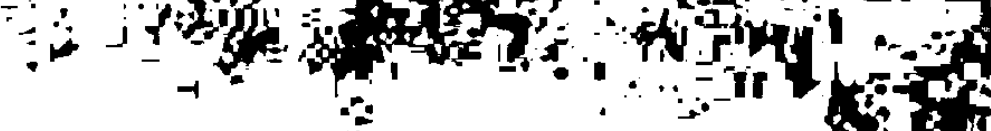

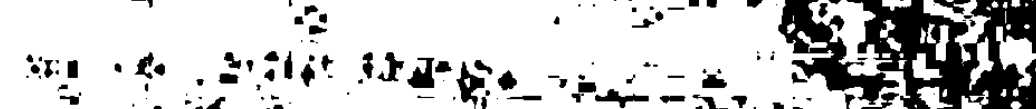

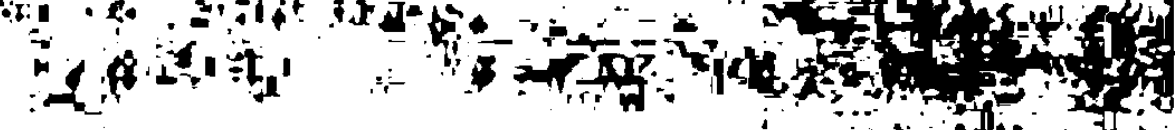

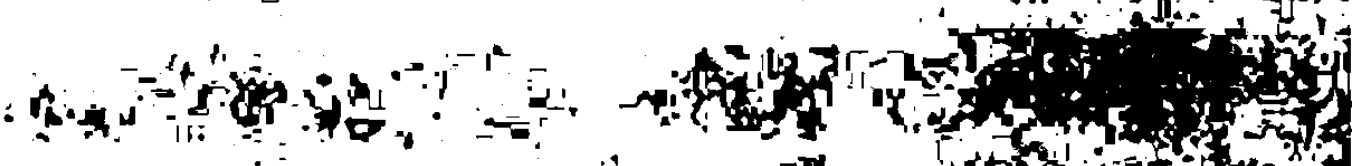

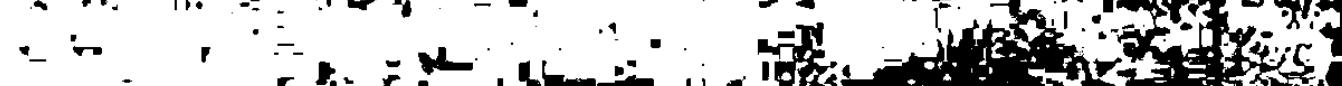
- .

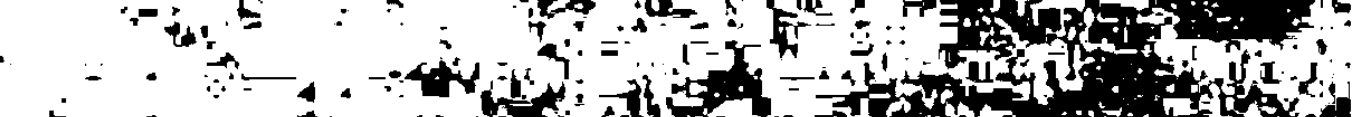

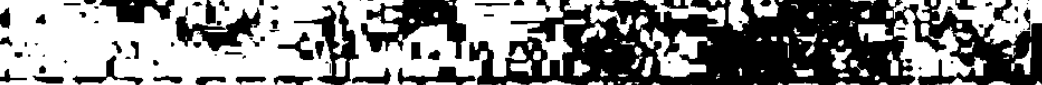

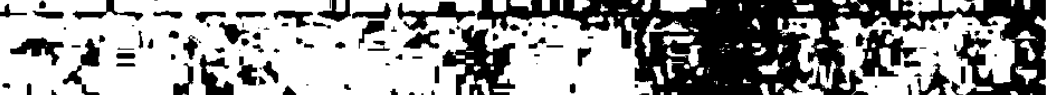
ind r-

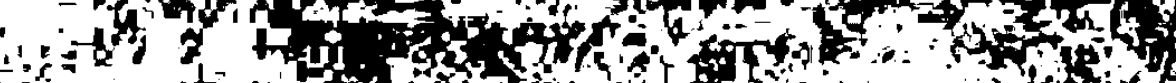

3 - 15 trits

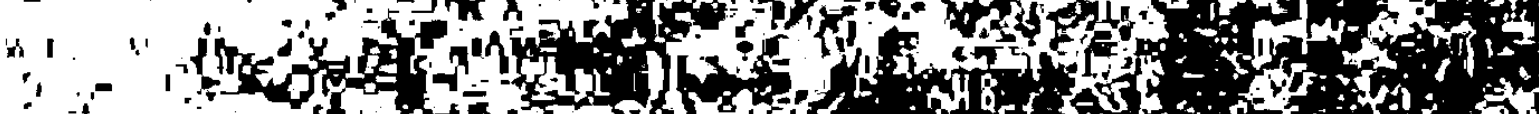
$\because \therefore \quad 1$. : 


\section{Kap. 1: Viktor Šklorakl\} - der Held der "Dritten Fabrik"}

"In meinen belletristischen Produktionen schrieb ich immer über mich selbst und war der Held meiner Buicher." 1

Šklovskij bekennt sich ohne Zögern zur autobiographischen Schreibweise, denn er konzipierte den Helden der "Dritten Fabrik" in vollem Bewustsein der konstruktiven Möglichkeiten dieses Verfahrens.

- Er (der Held) tritt aus dem Schriftsteller heraus. entlastet ihn von Verantwortung und verleiht ihm jene politische Uneindeutigkeit, die sich manchmal in einen intuitiven Gedanken verwandeln kann. Der Held ist aus Material gemacht; er besteht daraus wie eine Bibliothek aus Buichern ...

Deshalb werfe ich mir nicht vor. daß ich immer von meiner Person aus schreibe, um so mehr. als man nur das so eben Geschriebene durchsehen muB, um sich zu vergewissern, daB ich von mir ausgehend. aber nicht für mich spreche.

Schließlich. jener Viktor $\check{S} k \mid$ ovs $k i j$, von dem irh schreibe, ist wahrscheinlich nicht ganz und gar ich, und wenn wir uns träfen und anfingen, uns $z u$ unterhalten, dann wären $z$ wischen uns sogar Meinung sverschiedenheiten möglich. ${ }^{2}$

Der autobiographische Erzähler in der "Dritten Fabrik" ist nicht bloB das Sprachrohr der weltanschaulichen und literarischen Positionen Šklovskijs und auch nicht einfach die Form, um uber sich persönlich zu sprechen, sondern ein Kunstgnff, um die Lebens- und Arbeitssituation des Avantgarde-Schritistellers zu literarisieren und seine Prosakonzeption zu existentialisieren. ${ }^{3}$ Der Formalist Sklovskij hatte diese Methode - wie fragmentarisch und hyputhetisch auch immer -, bevor er "Dritte Fabrik" schrieb, an Texten von Anna Achmatova" und Andrej Belyj' studiert. Später, in der Zeit der Arbeit am Novyj LEF, sollte er sie im Rahmen seiner Studie über Lev Tulstojs "Krieg und Frieden" 6 literatursoziologisch fundieren und kritisch-analytisch ausführen. Genauso wie die Definition der "literarischen Persönlichkeit" den Schnittpunkt verschiedener semantischer Reihen - innerliterarischer und solcher, die das Leben bezeichnen - markiert und auf einen strukturalen Zusammenhang zwischen ihnen verweist, ohne eine einheitliche Figur zu demonstrieren, so versammeln sich unter dem Namen des autobiographischen Helden - der Realisierung dieser Definition - verschiedene Masken der "literarischen Persönlichkeit" Sklovskij, die sich miteinander unterhalten, sich streiten und gegeneinander ausspielen, aber einander auch den Rücken decken und den Weg freihalten.

Der programmatische Autsatz Ilja Gruzdevs im ausländischen Almanach der Serapionsbrijder ${ }^{\prime}$ mit dem Titel "Gesicht und Maske" vermag einen Eindruck von dem Stand der Diskussion über den literarischen Helden als Kunstgriff im Kreise der von Šklovskij inspirierten und angeleiteten Petersburger Avantgarde jener Jahre zu geben. ${ }^{8}$ Die provozierenden Hypothesen "Der Künstler 
ist immer Maske" und "Ein ausgesprochener Gedanke ist eine Lïge ... nur ein solch verlogenes und vielfältig gebrochenes Leben lebt die Kunst"9 bilden das Fundament seiner Úberlegungen zu einer Literaturkonzeption, die Kunst nicht als Spiegelung, sondern als prismatische Brechung der Ideen und der Seele des Kïnstlers in der Form des Werkes betrachtet.

'Eine 'unmaskierte' Ehrlichkeit nennen wir in der Kunst Tendenz. Ein literarisches Werk. das nicht zur Maske gemacht wurde. ist entweder schlechte oder überhaupt keine Kunst." ${ }^{-10}$

Der Ironie, verstanden im Sinne des Romantikers Friedrich Schlegel als

"ewiger Widerspruch zwischen dem Absoluten und dem Relativen. zwischen dem unendlichen Reichtum der schöpferischen Phantasie und den höchst begrenzten. dürtigen Möglichkeiten ihrer Verwirklichung""11

komme dabei die konstruktive Rolle zu. das Inkommensurable miteinander zu verknuipfen: "setze eine Maske auf. parodiere dich selbst." 12

"Die Unaufrichtigkeit der Kunst, ihre 'unvermeidliche Lïge"- - so Gruzder - "besteht darin. daB das 'Aussprechen', die Form. sich den Gedanken unterordnet. ${ }^{-13}$

DaB die Kunst zumeist doch als Weg zur Seele des Autors gelesen wird. führt Gruzdev aut ihre Kraft zur Illusion zurick, auf ihre Fähigkeit. Masken so glaubhaft darzustellen, dab sie real erscheinen. Hierbei spiele insbesondere die Figur des Erzählers. seine mannigfaltigen Kunstgriffe, die Personage zu zeichnen. den Gang der Handlung zu steuern und seine eigene Meinung ins Spiel zu bringen, eine zentrale Rolle. Selbst der Schritisteller, der sich die Maske vom Gesicht reiße und mit dem Impetus unverhüllter Ehrlichkeit zum Leser spreche. wie 2.B. Belyj in seinem Autsatz "Ich", tue nichts anderes als die dem gelungenen Kunstwerk eigene Krati zur Illusion zur Illusion gröBter Aufrichtigkeit zu perfektionieren. ${ }^{14}$

In der "Dritten Fabrik" spielt Šklovskij ironisch auf den Versuch des Schriftstellers an. unmasklert von sich selbst zu schreiben. indem er Brik zu Ėjchenbaum sagen läbt:

"Wenn der Schauspieler sich die Maske herunterreiBt, ist darunter die Schminke."

Dabei verweist er auf die Machart von Gogols Erzählung "Der Mantel". In "Suche nach dem Optimismus" literarisiert Šklovskij den Vorgang, wie sich der Schrifsteller, der von sich reden möchte, maskiert.

"Es ist leichter, durch einen Helden $z u$ sprechen.

Das fängt so an - du sitzt selbst vor dir. unterhältst dich. Bemitleidest dich. daB du gealtert bist. Hier an den Ohren haben trockene 
Falten die Haut straftigezogen.

Morgens weiBt du. wie du den gestrigen Tag verbracht hast.

Allgemein ist es nicht egal, was friiher war ...

Und so sitzt du vor dir und beginnst. jenen anderen umzugestalten.

Du gibst ihm einen charakteristischen Gang, verbindest ihn mit einem anderen. den du beleidigen möchtest. Du läBt ihm Haare wachsen.

Sein Gesichtsausdruck ändert sich. So manche Tendenzen treten in Erscheinung. Er kann eine Frau werden.

Die Frauentypen in der Literatur sind von besonderer Art. Sie ähneln mehr einander als den Mit-Helden beim selben Schriftsteller. Sie sind standardisierte Wunschvorstellungen.

Und so ist das Herz in der Brust eines anderen Menschen verborgen. schon tut man sich nicht mehr leid.

Er steht aut. Geht durch das Zimmer. Tut schon unerwartete Schritte.

An ihm zeigen sich Zutälligkeiten.

Du sprichst zu ihm.

Nun. Sie gehen heute von mir fort. sozusagen in eine andere Welt.

Nehmen Sie die Dinge. tragen Sie sie fort. Nun ja. es gibt ungeklärte Verhältnisse. Auf daB diese Verhältnisse die lhren werden.

Sehen Sie dem Zeitungsmann richtig in die Augen. wenn Sie die Zeitung kaufen. bemerken Sie Ihre Nachbarn in der StraBenbahn?

Welch eine ermuidende Sache ist doch die Literatur.

Lieber Passant. ich habe Angst vor dir. wenn du mein Buch in der StraBenbahn liest.

So einfach ist es. am Morgen seinen Mantel anzuziehen. Irgendetwas zu tun.

Wir durchleben das Leben in tausenden von Schicksalen haushäterisch mit uns selbst.

Den Menschen stehen Jahrhunderte in den Augen geschrieben, aber wenn sie schauen, dann schauen sie, daB sie nicht unter die Strabenbahn geraten.

Aber schubsen Sie den Menschen mit dem lebenden Vogel in den Händen (den Schriftsteller. V.D.) nicht.

Freuen Sie sich nicht dariber, daB er stark, lustig, groB oder rundlich ist. daß er selbst drängeln kann.

Sehen Sie, er lebt. ohne das Leben auszuschlieBen. Er hat keine Schutzhülle zu seiner Verteidigung.

Wahr ist. daB der Reim. die Phrase den Menschen verteidigt. Wahr ist. daB im Weizen nicht der Geschmack des Schweißes liegt.

Das Ding geht von dir fort. es schiitzt dich sogar.

Es existiert wie deine Freunde. Zu ihm kannst du kommen, um dich zu beklagen.

Es ist wie die jüdische Unsterblichkeit in den Kindern. Doch es schïzt die Verletzlichkeit. ${ }^{-16}$

So dicht und eindringlich erzăhlt Šklovskij sonst an keiner Stelle von dem ProzeB der Literarisierung autobiographischen Materials. Er beschreibt die Funktion, die die durch Helden maskierte Rede ubernehmen kann, als Möglichkeit. sich von sich selbst zu distanzieren und einen Dialog mit den aus sich herausgestellten anderen Stimmen 24 beginnen. Auf diese Weise gelingt es ihm, eine literarische Form $z u$ denken, die die eigene Position in verschiedene 
Aspekte zerlegen und dadurch relativieren kann: sie kann sowohl aus der Perpektive des Jetzt, die der Zeitungsmann, die Leute, die Nachbarn in der StraBenbahn repräsentieren, als auch aus der des Damals, die die Geschichte - vor allem in der Tradition der Literatur aufgehoben - bietet, betrachten. sowohl in der Introspektion - sich bemitleiden, mit sich rechten - als auch den Blick auf die AuBenwelt, auf die Leute in der StraBenbahn, auf den Zeitungsmann, gerichtet. Der Schriftsteller der sowjetischen Avantgarde rechtfertigt den uralten Kunstgriff, durch Helden zu sprechen, nicht, um sich - auch wenn er mit diesem Gedanken kokettiert - seiner politischen Verantwortung zu entziehen. sondern um sich gegen die staatspolitische Forderung. er muisse engagierte. d.h. gesellschaftlich nuitzliche, eindeutige und politisch zielgerichtete Agitationskunst produzieren, zu wehren.

In dem Maße, wie Śklovskij die Funktion des Helden in der Literatur reflektiert und durchschaut, kompliziert sich die Heldenkonstruktion in "Dritte Fabnk", denn das Wissen um Konstruktion und Funktion. um das 'Gemachtsein' des Helden, verbietet einen naiven Gebrauch des Kunstgriffs. Šklovskij löst dieses Problem, indem er das Verfahren entblöBt, um es dann. sozusagen geläutert, auf seine Weise erneut als Spiel mit verschiedenen Masken, in dem der Demaskierung eine neue Maskierung folgt. ins Werk zu setzen. So gibt es in seiner autobiographischen Prosa nicht den Helden. der - eingesperrt in ein Koordinatensystem von fixierten Eigenschaften. Lastern und Tugenden in einem bestimmten Verhältnis zum Autor der Erählung steht. sondern mannigfaltige Selbststilisierungen. die ihr Spiel miteinander treiben. Aber die Relativierung der Positionen des Helden in der autobiographischen Prosa Šklovskijs heißt nicht Verzicht auf den Helden und bedeutet keineswegs, daB das Subjekt - sei es das darstellende oder das dargestellte - sich in der Zersplitterung auflösen und verschwinden wirde. sondern sie eröffnet neue. konstruktive Möglichkeiten seiner Darstellung, wie im folgenden noch $2 \mathrm{u}$ zeigen sein wird. Daß es Šklovskij dabei nicht in erster Linie um eine formale Erneuerung der Literatur ging, sondern um die Revolutionierung der ästhetischen Wahrnehmung, bezeugen auch zwei seiner Zeitgenossen. Die Schriftstellerin Olga Forš schreibt:

"Jedoch war sein lautes Lachen. sein Witz. die GroBzügigkeit 'des muiBigen Bummlers', mit der er sein Talent unterschlug. nur ein 'Kunstgriff und der Zuhörer nur ein 'Experimentierfeld'. Jedes Glitzern, jedes Geräusch, jede Geste war eine Projektion seiner besonderen Ansicht von der literarischen Arbeit auf Sitten und Gebräuche. Und es war möglicherweise auch noch eine Selbstverteidigung. ähnlich wie bei dem Meerestier. der Sepia. die. um ihren wahren Weg noch besser zu sichern oder zu verbergen. das Wasser mit einer Farbe, die sie ausstöBt. trubt und in die Tiefe schwimmt. wo es für sie ungefährlich ist. Ein kluger Mensch. ein Analytiker war er, auch im Hinblick darauf, wie er seine Möglichkeiten abwog. um sich von ihnen mehr Kupons abzuschneiden - ein Apotheker." ${ }^{17}$ 
Und Belyj skizziert den Non-Formalisten Šklovskij als einen

'Menschlen) ohne 'Verfahren'. ohne 'Form': er ist durch und durch Inhalt. Thema: und der Inhalt ist immer spannend: die von ihm erfundene 'formale Methode' ist spannend, weil die Analyse der Verfahren. das Zurickführen auf Verfahren bei ihm Geste ist. Pantomime und Symbol: wenn er Verfahren sagt, glaube ich ihm nicht: dieses 'Verfahren' ist ein Erraten: seine Intuition: seine 'formale Methode' ist so etwas wie die bekannte 'Psycho-Analyse': sein Verbrechen ist. daB er Formalisten zuichtet und ihnen Lehrstuihle verschafft: die 'Protessoren' des Schklovismus sind fad. akademisch. von tödlicher Langeweile. ${ }^{-18}$

Um die Verschiedenverstehbarkeit des Helden der autobiographischen Prosa "Dritte Fabrik" beschreiben zu können, ist es notwendig, die Verknotung der semantischen Reihen in Gestalt der "literarischen Persönlichkeit" analytisch aufzulösen und sie als je einzelne zu sezieren, bevor man sie in ihren zum Teil komplizierten Bewegungen aufeinander zu. miteinander analgamierend. sich voneinander abstoBend oder parallel nebeneinander herlautend usf. schildert. die den KonstitutionsprozeB des Helden ausmachen. Der Held der "Dritten Fabrik" spricht mit verschiedenen Stimmen - mit der des Schrittstellers. der des Kinoarbeiters und der des OPOJAZ-Mitarbeiters Śklovskij. Jede dieser Stimmen repräsentiert eine Form seiner Realitatserianrung bzw. eine spezıfische Arbeitstorm. Die Stimmen relativieren. korrigieren. widersprechen. ergänzen und bestärken einander. Vor allen anderen dirigiert die Stimme des Schiftstellers seine Rede. Sie hat gewissermaßen die Diskussionsleitung im Diskurs iber die existentielle Bedingtheit der literarischen Arbeit inne. Die Stimme des Kinoarbeiters behauptet daneben zäh ihren Platz. so wie im Leben der Alltag unerbittlich seinen Platz behauptet. Die Stimme des OPOJAZ-Mitarbeiters bezieht ihre Lebendigkeit vorwiegend aus der Erinnerung an die experimentelle Arbeit im Petrograder OPOJAZ.

Die Stimmen haben jeweils eine dominante Funktion. aber aus jeder von ihnen spricht dennoch ein und dieselbe janusgesichtige Maske, die der Perspektive der jeweiligen Stimme entsprechend jedesmal einen in Nuancen anderen Ausdruck annimmt. Es ist die Maske des deplacierten Menschen. die wie ein Vexierbild auf den zweiten Blick den Experimentator und Erfinder zeigt.

Die Rede der Helden-Stimmen bezieht ihr Material auf der einen Seite aus Diskussionen uber den Publizisten. den Formalisten. Kinoarbeiter und Schriftsteller Šklorskij in der kulturellen Öffentlichkeit - sei es in den Zeitungen als Feuilleton oder als Karikatur, sei es in literaturtheoretischen Abhandlungen. sei es im von der Erinnerungsliteratur uberbrachten AlltagsbewuBtsein zeitgenössischer Intellektueller oder sei es in Romanen jener Zeit lauch wenn diese Diskussionen in "Dritte Fabrik" nicht explizit thematisiert werden). Auf der anderen Seite bezieht sie ihr Material von literarischen Vorbildern. zum Teil von den gleichen, die Šklovskij auch in seinen theoretischen Schriften immer wieder zum Objekt seiner Studien machte - wie Lev Tolstoj, Cervantes' 
Don Quijote, Rozanov. Sterne. Charly Chaplin - zum Teil von solchen, die auch in anderen fruihen autobiographischen Prosatexten von ihm Prätexte bilden - wie Chlebnikov, Andersen und Kipling - um nur die wichtigsten zu nennen. Die Rede des Helden setzt sich aus dem leicht und rätselhaft wie ein Spiel erscheinenden literarisierten Diskurs mit und uber diese verschiedenartigen Vorbilder zusammen, wobei sie wie in einem Mosaik die einzelnen Bestandteile, die zusammengelegt ein ganzes Bild ergeben, zu einem neuen. eigens den Autor stilisierenden Bild gerinnen. das sich in verschiedenen Metaphern - häufig in der Funktion von Leitmotiven - Gestalt gibt.

Die "literarische Persönlichkeit" Šklovskijs kann als exemplarisches Beispiel für den komplizierten und dynamischen ProzeB der Wechselwirkungen, der Erzeugung gegenseitiger Bedingtheiten und Funktionszuweisungen von kuinstlerischer Existenz und literarischer Produktion im kulturellen Text der frihsowjetischen Gesellschaft gelten, nicht nur weil Śklovskij viel von sich reden machte. sondern weil er dieses Phänomen in den Stand eines zu analysierenden Gegenstandes und eines literarischen Themas erhob.

Es sei dahingestellt. ob die Unperson Šklovskij oder seine Literatur den Anfang des Geredes über ihn in der kulturellen Öffentlichkeit bildete. S̆klovskijs stete Anwesenheit und sein provokantes Auftreten als Verteidiger der Formalen Schule in öffentlichen Diskussionen. dazu sein bissig-ironischer. aphoristischer Stil. sich in der "Sentimentalen Reise" als abenteuernder Held $z$ wischen den Fronten und in "Zoo" als sehnsüchtig in Richtung Heimat blickender. ungliicklich liebender Emigrant darzustellen. setzte ein Gerede über inn in Gang. daB weder als persönlicher Klatsch noch als Ausdruck kulturpolitischer Streitigkeiten interessiert, sondern als ein beredtes Zeugnis der Auseinandersetzung uiber einen spezifischen Typus von literarischer Produktion. die dem einen prinzipienlos und bürgerlich dekadent. dem anderen als literarische Form der Zukunft. dem einen als banales Geschwätz und dem anderen als geniale. faszinierende und rätselhafte Literatur der Moderne erscheint.

Die "literarische Persönlichkeit" Šklovskij war nicht nur bei den FormalistenFreunden. die ihn als literarische Innovation feierten. ein Gesprächsthema. sondern auch in literarischen Texten von Venjamin Kaverin. ${ }^{19}$ Olga Forš 20 und Michail Zoščenko, ${ }^{21}$ die ihn aus Petrograd kannten, von Michail Bulgakov, 22 der ihn während des Buirgerkriegs in Kiev erlebt hatte, von Ilja Ėrenburg. ${ }^{23}$ Andrej Belyj ${ }^{24}$ und anderen. Sie alle nahmen mit freundschaftlich-fachmännischem Interesse an dem Gerede über Šklovskij teil, das von Faszination uber belustigte Anerkennung bis zu kritischer Begutachtung reicht. Auch Gor'kij ${ }^{25}$ und Trockij 26. Protagonisten des Sowjetsystems in den ersten Jahren nach der Revolution, äuBerten sich solidarisch und sachverständig urteilend uiber Šklovskij, obgleich sie in Fragen der Kunst zumeist anderer Meinung waren als er. Dagegen stieben sich die Verteidiger der sogenannten proletarischen Literatur und später die des "Sozialistischen Realismus" in der Presse immer wieder an der "literarischen Persönlichkeit" Šklovskij - an ihrer "Prinzipienlosig- 
keit", an ihrer "selbstgefälligen Koketterie" und "Eigenliebe", an ihrer "bürgerlichen Dekadenz", ihrem "Individualismus" und "Irrationalismus".27 Auch wenn diese Kritiken Šklovskij nur schablonenhaft zeichnen und sich vor allen Dingen durch Unverständnis seiner Selbstdarstellung gegenüber auszeichnen. so bilden sie doch ebenso den Hintergrund und zum Teil auch das Material fur seine Heldenkonstruktion in der autobiographischen Prosa wie die theoretisch fundierte und differenzierte Beschreibung der "literarischen Persönlichkeit" '̌klovskij durch die Formalisten, da sie einen Aspekt seines "literarischen Lebens" beleuchten und damit einen Pol im Kraftfeld der Arbeit des Schriftstellers markieren.

Neben kurzlebigen. auf kulturpolitische Aktualität setzenden Auseinandersetzungen nahmen sich auch umfangreichere und dauerhaftere Genres - die Erinnerungsliteratur und der Roman - der skandalumwitterten "literarischen Persönlichkeit" Šklovskij an. Venjamin Kaverin, Olga Forš und Lidija Ginzburg erinnern an den Šklovskij der Petrograder Zeit, an den Mitarbeiter im OPOJAZ. im Kreis der Serapionsbriuder und an das Leben im "Haus der Künste". Ėsfir Šub. Aleksandra Chochlova und Lev Kulešov erinnern an die Anfänge der Kinoarbeit in Moskau. Sie erweitern das Bild von Šklovskij für den Leser von heute, lassen jedoch die Brisanz der aktuellen Auseinandersetzung vermissen. Denn die zeitliche Distanz zum erinnerten Geschehen ruickt manche Anschauung. manches Ereignis gerade. Sie stellen ihn als eine anerkannte Autorität in Künstlerkreisen (Ginzburg. Kaverin. Šub. Chochlova) dar. der eine Aura des Komischen und des Geheimnisvollen um sich aufbaut (Kaverin. Ginzburg). Sie zeigen ihn als solidarischen Berater (Kulešov/Chochlova) und Lehrer (Šub). der auch mit den praktischen Seiten des Lebens - seien es Fragen der Technik. des Alltagslebens oder des kulturpolitischen Lebens - umzugehen weiß. ohne $z$ wangsläufig als Pragmatiker angesehen $z u$ werden. 28

Aber weitaus aufschluBreicher als die Erinnerungsliteratur spaterer Jahre ist für uns die zeitgenössische Literatur der 20er/30er Jahre, in denen Šklovskij eine Rolle spielt. Denn sie konstituiert den kulturellen Text. in den die "literarische Persönlichkeit" eingeschrieben ist bzw. - vice versa - der in sie eingeschrieben ist und der das Material für die literarische Selbstreflexion Šklovskijs liefert. Sowohl in Bulgakovs erstem Roman "Die weiBe Garde". der im Jahre 1924 in Fortsetzungen in der Zeitschrift Rossija erschien. ${ }^{29}$ als auch in Kaverins Roman "Der Skandalmacher oder ein Abend auf der Vasil'evskijInsel". der im Jahre 1928 ebenfalls in Fortsetzungen in der Zeitschrift Zvezda und ein Jahr später als Buch veröffentlicht wurde. ist Šklovskij der Prototyp für eine der Romanfiguren - für den "Verderber" Špoljanskij bei Bulgakov und für den "Skandalisten" Nekrylov bei Kaverin. ${ }^{30}$ Auch in der Novelle von Forక̌ "Das Narrenschiff". die 1930 in Leningrad zum ersten Mal erschien und die als eine Mischform zwischen dokumentarischer Erinnerung und fiktionaler Literatur gelten kann, ist von Šklovskij in verrätselter Form als von einem der verriuckten Bewohner des "Narrenschiffs" "Haus der Künste" in Petrograd die Rede. 
Kaverins "Skandalist" und Foršs "Narrenschiff" sollen im Zusammenhang dieser Arbeit nur am Rande Erwähnung finden, da sie im Unterschied zu Bulgakovs "Weißer Garde" nicht als Prätexte zu "Dritte Fabrik" fungierten. sondern als solche nur für spätere autobiographische Produktionen Šklovskijs in Frage kommen.

Einen anschaulichen Eindruck von der Diskussion um die "literarische Persönlichkeit" Šklovskij im kulturellen Text der Sowjetunion der 20er/30er Jahre geben auch Bilder - seien es literarische, seien es Karikaturen - seiner Person. Was ŠkJovskijs Physiognomie anbetrifft, so hatte sein kahler, sich rund und hoch wölbender Schädel eine entsprechende Wirkung wie sein rhetorisches Talent. Šklovskij selbst hält es für wert, seinen "glänzenden Schädel" in der "Dritten Fabrik" zu erwähnen. ${ }^{31}$ Mandel'štam schimpft freundschaftlich auf den "Gurkenkopf" Šklovskij. ${ }^{32}$ Kornaj Zelinskij vergleicht ihn mit dem Kopf eines ägyptischen Feldherm, aus dem sich unerwartete Ideen wie ein Sprïhregen aus einer GieBkanne auf das ornamentale Blumenbeet der russischen Literatur ergieBen. ${ }^{33}$ Forš stellt ihn im "Narrenschiff" als einen "bemerkenswerten Kopf vor, den sie mit verschiedenen Bildern vergleicht: aus seinem Kopf sei die "chinesische Methode" entsprungen wie aus dem Kopfe des Zeus die Göttin Athene in voller Rüstung entsprang. und er sähe dem stupsnasigen Zwerg des Imperator Pavel und dem zweiflerischen Sklaven in der Mitte des Gemäldes "Christus erscheint dem Volk" von Ivanov ähnlich. ${ }^{34}$ Ėjenstejn zeichnet in einer freundschaftlichen Karikatur, die er Šklovskij per Post zukommen läßt. seinen Kopf als ein im Verhältnis zum Körper überdimensional großes Goldfischaquarium. aus dem Šklovskij, selbstverständlich blind, einen Helden seiner Bucher (den Maler Fedotov) angelt. ${ }^{35}$ In allen diesen Beschreibungen der Person Šklovskij wird die Ganzheit seiner Physiognomie auBer Acht gelassen. sein Kopf ubbermäBig betont und pars pro toto betrachtet. so, wie Henri Bergson es in seiner Theorie des Komischen als Kunstgriff der Karikatur beschreıbt. ${ }^{36}$ Der Schädel Šklovskijs bleibt nicht bloß ein äuBeres Erkennungszeichen. sondern verdichtet sich zu einer Metonymie. Er wird zu einem Symbol für die "Kopflastigkeit". für das Geniale. Phantastische und Subjektive, aber auch für das Theoretische und Artifizielle seiner literarischen Konzeption im Positiven wie im Negativen - je nachdem. ob man ihn aus freundschaftlicher oder aus feindlicher Perspektive betrachtet.

Auch in den Karikaturen der Kukryniksy, des wohl bekanntesten Teams sowjetischer Karikaturisten jener Zeit, ist es der kahle Schädel, an dem man Šklovskij sofort erkennt. ${ }^{37}$ Sie zeichnen ihn häufig als kleinen teuflischen Gnom mit uberdimensional großem Kopf, der andere Schriftsteller traktiert und der sich angesichts der chaotischen Zettel- und Zitatensammlung, aus der er seine Bücher zusammenschreibt, verzweifelt die gewaltige Stirn wischt. Sie zeichnen den Schriftsteller Šklovskij, dessen Haupt ein orientatlisches Käppchen ziert und der selbstironisch den prächtigen Rahmen seines eigenen Portraits hält, und den technikbegeisterten Fahrlehrer Šklovskij mit einem Pflaster auf der Stirn. 
Bilden die im kulturellen Text der Sowjetunion der Zwanziger Jahre schriftlich fixierten Auseinandersetzungen um die "literarische Persönlichkeit" Šklovskij den einen Pol der Materialbasis zur Konstruktion des Helden der autobiographischen Prosa, so stellen literarische Vorbilder wie Tolstoj, Gogol, Cervantes' Don Quijote, Märchengestaiten Andersens und Kiplings, Charly Chaplin. Rousseau. Sterne. E.A. Poe, Rozanov und Platon den Gegenpol dazu dar. Die konzeptionelle Voraussetzung flir das Zitat der literarischen Vorbilder liegt in der Prosatheorie Šklovskijs, die Literatur als etwas Gemachtes, als evolutionären ProzeB der Kanonisierung und Dekanonisierung bzw. Emeuerung begreift, begrindet.

Die literarischen Vorbilder fungieren zum einen als thematischer Hintergrund. d.h. sie werden selten direkt zitiert, sondern mehr durch Anspielungen des Autors - 2.B. dadurch, daB ihnen dieselben Attribute und Charaktereigenschaften. Verhaltensweisen auf den Leib geschrieben werden - dem Leser. den $\grave{S} k$ lovskij immer als einen Eingeweihten konzipiert, in Erinnerung gerufen, zum anderen gehen sie als Konstruktionsprinzipien (im Status von Material, das erneut umgeformt wird) - z.B. als ironische Rede des Autors (Rozanov). als sentimentale Selbstreflexion (Tolstoj, Rousseau. Steme), als Abschweifung (Rozanov, Steme) usw. - in die autobiographische Prosa ein. Um die literarischen Vorbilder mit der "literarischen Persönlichkeit" Šklovskij, wie sie im kulturellen Text besprochen wird bzw. wie sie sich selbst empfindet, ins Gespräch zu bringen, setzt Šklovskij die Maske des Komikers auf, der die Rolle des Vielgesichtigen spielt - eine Rolle, die ihm einige seiner literarischen Vorbilder (Don Quijote und Charly Chaplin) nahelegen. Daruber hinaus findet er im Bereich des Komischen konstruktive und stilistische Möglichkeiten. literarische Tradition aufzunehmen und in der Erinnerung an sie die Semantik seiner autobiographischen Darstellung zu erweitern, um sich sodann wieder von ihr abzustoBen und neue, eigene literarische Formen zu bilden.

Die Unähnlichkeit der Ähnlichkeit des Autors Šklovskij mit dem Helden seiner autobiographischen Prosa, des Autors mit der "literarischen Persönlichkeit" im Gerede der kulturellen Öffentlichkeit, des Helden mit seinen literarischen Vorbildern und die Unähnlichkeit der Ähnlichkeit der verschiedenen Stimmen: der des Literaturtheoretikers, des Kinoarbeiters und des Schriftstellers und ihrer Masken - der des deplacierten Menschen und der des Experimentators - gibt sich auf stilistischer Ebene zunächst die Erscheinung der semantischen Verschiebung in Gestalt der Anekdote. des Kalauers und der Parodie, in der die Ironie als Bindeglied zwischen den einzelnen Teilen fungiert. um sich im 2 weiten Schritt als EntblöBung, als selbstironische Reflexion des Kunstgriffs der Ironie und ihrer stilistischen Erscheinungsformen darustellen. ${ }^{38}$ 
Anmerkungen zu Tell II, Kap. 1: Viktor Sklovsklf - der Held der "Dritten Fabrik"

1 V.Šklovak1). Gamburgak1f .... S.104

2 ebd.. S.104. 106

3 A.Hensen-Löve. Der rusalsche Formalismus. S.s75 ff.

- V.Šklovakly. Anna Achmatove Anno Dominl MCXXI. In: Petersburg 2 (1922). S.18; her beachrelbe or die konkrete Intimitä der poetischen Sprache der Dichterin ala Kunstgriff.

5 dera., Andrel Belyl. In: Pjat' Zelovek znakomych. S.3-141: Sklovaklf schlldert de asthetische Tranaformation der Weltanschauung. d.h. fur Belyj der Anthroposophle. in der literarischen Produktion.

6 ders.. Material I atil" V romene L'va Tolstogo "Vojna $1 \mathrm{mir}$

7 Il.Gruzdev. Gesicht und Maske. zit. nach der deutschen Ausgabe: Die Seraplonsbruder von Petrograd. (Hrsg. U. U.) G.Drohla. Ffm. 1963. 1982. S.273 ff.

8 Vgl. A. Hansen-Love. S.276 ff.: Vgl. auch II. Erenburg. Die russische Dichter kolonie im Cafo "Prager Diele" (1922-1923). In: Literarische Welt 2 (1926). S.5-6: reprint in: Dle Lachkuche. (Hrsg.) F. Mlerau. Lelpzlg u. Weimar 1981. S.40-42: Erenburg achildert den Kunsegrtffcharakeer von Žklovskifa unglucklicher Llebe xu Alle und Berlin: -... der Formalise Vikeor Schklowskl. das Caft mit Tschechowachen Pausen. Ja sogar mit Uhricken. Ja sogar mit dem Raschein elnes sterbenden Obstgartens fullend, die ganze Seele. dsa ganze Innere, den ganzen verfluchten 'Inhalt' aus atch herausblies: 'Nlemand llebt mich!' - Das war selbatverstandlich eine Metapher, denn Schklowskl wurde von vielen gellebe." (S.S1)

9 Il.Gruzdev. S.272: Gruxdev Ubemimmt hler - wie er S.275 dess. Textes offenlegt - else Strophe aus elnem Gedicht TjuXevs

10 ebd.. 5.273

11 ebd.. 5.275

12 ebd.

13 ebd.. S.275/276

14 Il.Gruzder, S.288

is V.Sklovakil. Tret'ja .... S.70

16 V.Sklorsklf. Polakl optimlxma. S.148-150

17 O. ForX. Sumasiedxly korabl'. S.92

18 A.Belyj. Veter a Karkaza. Vpetatlenjfa. M. 1928. S.181. Ubersetze nach F.Mlerau. V.B. Sklovikif (unveröffentlichtes Manuskript)

19 V.Kaverin. Skandallst 111 vezera na Vallevskom ostrove. L. 1929. lat ein Schlusaelroman Uber Sklovakll: vgl. auch ders. In: Kak my pixem. S. 59 ff.; ders.. Zdravatvul brat. Plaat ocen' trudno .... M. 1965, S.168 f.

20 O.ForX. SumasłedXII ...: dies.. Š apoklfak (1930). sobr. soZ.. t. 4. S.455-458

21 M.Zoxzenko. Družeskle parodu. I. V.B. Sklovakil. In: Literatumye zaplakl. 2 (1922). S.58; ders.. O sebe. O kritlkach 1 o svoef rabote. L. 1928. S.11

22 rgl. M.Bulgakov, Belaja Grardja (1924), In: Belaja grardlja. Teatral'nyj roman. Master 1 Margarita. 1978, S.13-270; deutsch: WelBe Garde (U: Larlasa Roblne). Berlin (DDR), 1969

23 Vgl. Il.Ërenburg. Dle rusalsche Dichterkolonle ...: ders.. Ljudl, gody. Zirn:. Moskra 1966-67; deutsch: Menschen - Jahre - Leben. 3 Bde.. (Hrag. u. U.) H. Burck. F. Mierau: Berlin (DDR) 1978. $1982^{2}$

vel. A. Belyj. Veter ... 
25 M.Gor'klf. Sovetakeje pazat 11. Archir Gorkogo tom X.2. 1965; ders. Pleimo K.Fedinu ot 30 go marte 1925g.. In: Gorklj. Sovetakle plaetell. Nelzdannaje pereplaka, tom LXX. Literaturnoe nasledetro. M. 1963. S.492

26 L. Trocklf. Literature I revoljuclja. M. 1924. deutach: Literatur und Revoluuon (U.: E. Scheefer. H.Y.Rlesen). Munchen 1972.S.136-154

27 vel. z.B. die melaten zeltgenobs. Rezensionen zu Skloraklje Prose: M. Osorgin, Rex. zu ZZoo...”. In: Sorremennye zaplek1. 17 (1923). S.486-488; zu "Sentimentale Retae": F.Zlc. In: Krannaje nov, 2 (192s), S.283-284: Rez. In: Molodaje grardije. 2-3 (1925). S.266-267: zu "Tratje fabrika": O. Beakin. Kuetarneje masterakeje literaturnol reakcll. In: Ne literaturnom postu. 7 (1927).S.18-20: V. Żlc. In: Krasnaja nor'. 11 (1926), S.246-247: A. Leżner. in: Sorremennikl. M. 1927. S.133-138 (aus der Position der 'Mitldufer'): 2u -Polekl optimlzma": A. Lejtea. Pravo na optimlzm. in: Literaturnaja gazeta 10.9.1931. S.3

28 Vel. V.Kavern. Zdrevetruj .... S.168/69: L. Ginzburg, O atarom I novom, L. 1982. S.352 ff.: E. Šub. Kupnym plenom. M. 1959. S.73 ff.: A. Chochlova L. Kulexor. so let $\checkmark$ kino. M. 1975. S.97 ff.

29 G. Struve. Geachlchte der Sowfellteretur. S.204

30 Uber die Prototypen in Kevertne Roman -Skandaliat ..." haben M. Cudakove und E. Toddes elnen achr informativen Aufaetz geschrieben: Prototipy odnogo romane, In: Al'manach blbllofilie, rypusk X. M. 1981, S.172-190: Die Autoran gehen im Detall der Hypothese nach. Skloraklf eel der Prototyp des Nekrylor und belegen ale ausuhrilch.

31 V.Sklovakif. Trat'ja .... S.135, vel. auch S.24. 45

32 O. Mandel'yeam. Je pixu ecenarlf. In: Soratakif ekran. 25 (1927). S.4

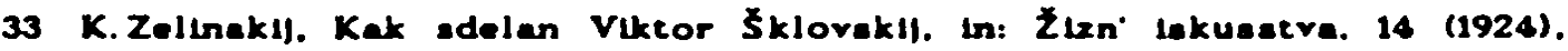
S.13-14

O. Forz. SumasiedXif .... S.92

35 S. Ejzentefn. Druteaklf Xerz, 1936, CGALI. Fond 562, ople' Nr.1. ed.chr.Nr. 971

36 H. Bergaon. Den Lechen. U.: R. Planchevel-Walter. ZUrch 1972, S.25/26

37 Kartkaturen der Kukrynikey, in: LechkUche. S.45. 144. 145. 147. 204

38 Skloveklf lieB elch - wae de Komlk der Heldenkonetruktion in aelner Prose und die Reflexionen uber des Komlache in enderen Schriften anbelangt - von Bergaons lebenaphllosophlsch geatimmtem Beltrag zu elner Theorle dee Komischen. eber auch von der Wieztheorle Freuds, auf de auch Bergeon rokurriert. Insplrteren. Daruber hinaus geben thm die Diakuselonen im OPOJAZ Uber den parodietiachen Roman. Uber die Literatur der Romantlk und Uber das Groteake bel Gogol und die Geepriche im Kreta der Seraplonabruder Uber die romantiache Ironte und uber die funktion der llterartachen Illusion fur des Verwechelsplel zwischen Autor und Erzahler Anregungen, elne eelnem elgenen Stll und eelner Prosatheorle encemesene Kunstom des Komlechen in Gesealt des Helden eetner autoblographiachen Prosa - Je. man könnte fant genelge seln, zu angen selner autoblographischen Schrabwelee in all eelnen Schrifen zu entwickeln. Abgesehen ron Il. Gruzdera Aufaecz "Gesicht und Marke" labe elch deaer Diakuasionazuaemmenhang z.B. an A.Slonimskife Arbelt Technike komleekogo u Gogolja". Petrograd 1923 (rgl. dazu A. Haneen-Love. S.161-168. S.201-206) nachrollzlehen. 


\section{Kap. 2: Die Stlmme des Schrlftatellers}

1. Die Maske des deplacierten Menschen

\section{Material aus der literarischen Gegenwart}

Die dominante Form der Selbststilisierung in "Dritte Fabrik" ist die des deplacierten Menschen - desjenigen, der in der Gesellschaft seinen Platz nicht gefunden hat bzw. der den für ihn vorgesehenen Platz nicht einnimmt. In der Pose eines solchen ver-rïckten Menschen - eines, wie Šklovskij weiB. in der Literatur sich ewig wiederholenden Kunstgriffs' - kontert er sinnbildlich gegen die Tendenz in der sowjetischen Kunst, ihre kritische Dimension zugunsten eines pragmatischen und utilitaristischen Standpunkts innerhalb der politischen Kultur der Sowjetunion aufzugeben.

\footnotetext{
"Man schlägt jetzt vor. davon $z u$ singen, daß alles an seinem Platze steht, oder daß es zumindest einen Platz gibt, wohin man alles stellen kann." $[84]^{2}$
}

Die Stimme des Schriftstellers schreibt die Maske des deplacierten Menschen zunächst aus den verschiedenen, einander zum Teil heftig widersprechenden und deshalb besonders laut tönenden Kritikerstimmen des literarischen Lebens zusammen. Auf diese Weise gibt er sich den Anschein, gelehrig und reuig zu sein. Aber da er seine Kniefälle mal in die eine Richtung, in die seiner Freunde im OPOJAZ, und $\mathrm{mal}$ in die andere, in die der marxistischleninistischen Kritiker, macht, führen sie sich gegenseitig ad absurdum. Die Stimme des Helden parodiert die Stimmen des "literarischen Lebens".

Śklovskij genoB zu Beginn der 20er Jahre ohne Zweifel eine gewisse allgemeine spektakuläre Publizität. Während er in den Kreisen der künstlerischen Avantgarde als literarisches Kuriosum verehrt, gefeiert. belächelt und gefürchtet wurde. machte er in der politischen Kultur als eigensinniger Intellektueller von sich reden, der nicht gewillt war, sich ohne weiteres in das kulturpolitische System einzupassen. Sogar Lenin und Trockij beschäftigten sich mit Šklovskij. Wir wissen, daB Lenin seine Bücher für wichtig genug hielt, um sie sich kommen zu lassen. Im April 1922 bestellte er sich "Revolution und Front". den ersten Teil der "Sentimentalen Reise". und im Januar 1923 lieB er sich aus Berlin neben Belyjs "Aufzeichnungen eines Sonderlings", Erenburgs "Dreizehn Pfeifen" und anderen Büchern die Berliner Ausgabe des "Rösselsprungs" und der "Sentimentalen Reise" beschaffen, die erste vollständige Publikation der Revolutionserinnerungen. Beide Male standen Šklovskijs Bücher gleich obenan auf der Bestelliste. ${ }^{3}$ Trockij hatte den "Rösselsprung" gelesen. Die Lektüre dieses Büchleins gab ihm den AnlaB. uber seine materialistische Kritik an der Formalen Theorie hinaus in den Schriften liber Literatur und Revolution aus dem Jahre 1924 gegen den Autor Šklovskij ad personam 
einige besondere Attacken zu reiten. Er spricht von dem Autor des"Rösselsprungs", der "nit gröBter Ungezwungenheit zwischen dem sprachlichen Ragout des Formalismus und den allersubjektivsten Bewertungen hin und her flattert" und fügt ironisch hinzu, daB "die Kürze jedenfalls der grundlegende und unbestreitbare Vorzug Šklovskijs" sei. Seine Worte seien "leeres Stroh"," Šklovskij selbst "das überaus malerische Produkt einer bestimmten sozialen Schicht und einer bestimmten Zeit" ${ }^{\text {"S }}$ und seine Theorie "eine sozial bedingte Extravaganz: Das ist asthetischer Größenwahn, in dem unsere rauhe Wirklichkeit auf den Kopf gestellt wird." ${ }^{6}$

In der Diskussion um das Verhältnis von Formalismus und Marxismus im Jahre 1924 prägte der erste Sekretär des sowjetischen Volkskommissariats für Bildung Lunačarskij, um seine Kritik an der Formalen Schule auf den Punkt zu bringen, nicht speziell für Šklovskij, sondern fur den vorrevolutionären Formalismus als solchen den bildlichen Ausdruck "Saisongemiuse". Als l'art pour l'art im Modetrend der Zeit vor der Oktoberrevolution sei er jetzt. in den 20er Jahren ein "lebendiger Uberrest des Alten". Er sei ein Palladium. um das herum die Verteidigung der bürgerlich-europäisch denkenden Intelligenz geführt werde.?

Im Gefolge der tonangebenden Bolschewiki warfen Šklovskij viele Rezensenten seiner autobiographischen Prosa "Sentimentale Reise" und "Zoo", die 1924 auch in der Sowjetunion erschienen. "Prinzipienlosigkeit" (Molodaja gvardija. 192S. Osorgin. Percov), "Koketterie". "Eitelkeit" und "Selbstliebe" (Osorgin. Percov, Żic). "Seichtheit" in der literarischen Verarbeitung des Materials (Žic) und eine arrogante "Unverständlichkeit" (Zvezda, 1925) vor. Dem Literaturkritiker und Vertreter der sog. proletarischen Literatur Lelevič galt Šklovskij als ein bourgeoiser Literaturtheoretiker, der - so Lelevič - die dem Tode geweihte Literatur der bürgerlichen Dekadenz (Pil'njak. Pasternak. Zamjatin u.a.) legitimiere, die der VAPP-Apologet im Bild des "Hippokratischen Gesichts" drastisch metaphorisiert. "In dem Urteil, die Prosa Šklovskijs sei "prinzipienlos" und "eitel", treffen sich aber auch Kritiker aus einander diametral entgegengesetzten Lagern - der zur Emigration gezwungene Fedor Stepun, der den Symbolisten nahestand, und der sowjetische Literaturkritiker Viktor Percov, der aus dem Umkreis der Futuristen kam. Beide wissen, differenzierter und fachkundiger als manch anderer Rezensent. die literarische Qualität, das Innovatorische und Revolutionäre der Form der Prosa zu schätzen. Stepun lobt die scharfsichtigen und erfahrungsklugen Metaphern und das Tempo in dem Buch. Percor die Leichtigkeit des Stils und die spielerische Leichtigkeit der Radikalität. mit der Šklovskij verstaubtes Bildungsgut umwerte und philiströse Philologie auBer kraft setze. ${ }^{9}$ Aber beide kritisieren, daB Šklovskij eine ethische Grundhaltung fehle. Stepun beklagt, daB Sklovskij sich in der "Sentimentalen Reise" von sich selbst abgewandt habe: Percov, daß Šklovskij sich immer noch nicht zu einer prosowjetischen Haltung habe entscheiden können.

"Er ist ein utopischer Formalist und wilnscht es deshalb nicht. den elektrischen Starkstromschalter auf sozialen Kontakt zu schaiten." 
Eine weitere Stimme im kulturellen Text der Sowjetunion, die aus einer antibolschewistischen Position heraus kritisch zu $\mathbf{S}$ klovskijs ethisch-politischer Grundhaltung Stellung nahm, ist der Roman "Die WeiBe Garde" von Bulgakov. Es ist höchst wahrscheinlich, daB Šklovskij den Roman zur Kenntnis nahm. bevor der "Dritte Fabrik" verfaBte.

Der Roman "Die WeiBe Garde" schildert das wechselhafte politische Geschehen im Winter 1918/1919 in Kiew. Bulgakovs Heimatstadt. Er schildert die Ablösung der deutschfreundlichen Hetmansregierung Skoropadskijs durch die ukrainische Nationalregierung Petljuras und zuletzt die Besetzung der Stadt durch die Bolschewiki aus der stark autobiographisch geprägten Perspektive zweier Brider, Alexej und Nikolaj Turbin, beide Offiziere der WeiBen Garde der Skoropadskij-Regierung. Ungefähr in der Mitte des Buches erscheint vor dem Leser Michail Semenovič Špoljanskij, ein futuristischer Dichter, ein eleganter Salonlöwe im Kiewer Nachtleben und ein charmanter Verführer der Frauen. Aber Şpoljanskij ist nicht einfach ein Bohemien, sondern im Gegensatz zu seinem Dichterkollegen I.Russakov, einem depressiven und völlig verunsicherten Syphilitiker, eine starke Persönlichkeit mit "gesundem Menschenverstand". schlitzohrig und praktisch veranlagt. Von einem auf den anderen Tag meldet er sich freiwillig in die Hetmansarmee, ist nun ein Fähnrich. der in Soldatenmontur mit Käppi und ölverschmiertem Gesicht kaum wiederzuerkennen ist. Er beginnt dort subversiv gegen die Hetmansregierung zu arbeiten. Er agitiert die Soldaten seiner Abteilung, verhindert. daB die seinem Befehl anvertrauten Panzerwagen in den Kampf fahren können. dadurch, daB er Zucker in ihre Benzintanks schuittet und damit die Düsen verstopft. SchlieBlich desertiert er und läuft zu den Bolschewiki uiber.

Der Erzähler bezieht auf verschiedene Weise indirekt Stellung gegen Špoljanskij. aber nicht ohne seiner Erscheinung eine gewisse Bewunderung zu zollen. Er verleiht ihm den Namen Špoljanskij, dessen Herkunft (von dem lateinischen Wort spoliare - verderben) der zwischen $\mathrm{HaB}$ und Bewunderung für ihn hinund hergerissene Dichterkollege Russakov, ohne direkt auf diese Wortwurzel zu verweisen, mit geheimnisvollen Erklärungen andeutet.

"Der böse Geist meines Lebens, der Vorbote des Antichrist, ist in die Stadt des Teufels gefahren ... Ich spreche von seinem Vorboten. Michail Semenovič Śpolanskij, einem Menschen mit den Augen einer Schlange und einem schwarzen Backenbart. Er ist ins Reich des Antichrist gefahren, nach Moskau, um ein Signal zu geben und der bösen Engel Horden in diese Stadt zu führen um der Suinden ihrer Bewohner willen. Wie damals Sodom und Gomorrha ... Er ist noch jung. Aber Abscheulichkeit steckt in ihm wie in einem tausendjährigen Teufel. Er verfuihrt Ehefrauen zur Unzucht, Jünglinge zum Laster. Schon schmettern die Trompeten der suindigen Horden, und über die Felder schwebt das Antlitz des Satans, der ihnen folgt ... Sein Name heiBt auf hebräisch Abaddon und auf griechisch Apollyon, was bedeutet - der Verderber. ${ }^{-11}$ 
Der Erzähler, der selbst in Hintergrund bleibt, schildert die Ereignisse vor allen Dingen aus der Perspektive des weiBgardistischen Offiziers und Arztes Alexej Turbin, dessen Biographie der des Autors Bulgakov stark ähnelt. Er überläBt es Turbin, die Wahnvorstellungen Russakovs als Angst vor der Herrschaft Trockijs und der Bolschewiki zu entschlüsseln, die er mit ihm gemeinsam hat. Dagegen läßt er in der Gestalt des Špolanskij die Macht der Bolschewiki aufscheinen: Špolanskijs Rede präsentiert Argumente für die historische Notwendigkeit der Herrschaft der Bolschewiki.

"WiBt ihr, Freunde, eigentlich ist es noch sehr die Frage, ob wir richtig tun, diesen Hetman $2 u$ verteidigen. In seinen Händen sind wir nichts als ein teures und gefährliches Spielzeug, mit dessen Hilfe er die finsterste Reaktion einführt. Wer weiB, vielleicht ist der ZusammenstoB Petljuras mit dem Hetman historisch vorbestimmt. und aus diesem ZusammenstoB wird eine dritte historische Krati entstehen, die vielleicht die einzig richtige ist. ${ }^{\text {I2 }}$

Es gibt eine indirekte, sehr intime Berührung zwischen Alexej Turbin und Špoljanskij. deren Tragweite, uber das Gefüge der fiktionalen Geschichte hinaus, für die autobiographischen Erlebnisse des Autors in diesem Zusammenhang nicht $z u$ ermessen ist: sie lieben dieselbe Frau, die geheimnisvolle Julia Reiss, die Turbin das Leben rettet und mit Špoljanskij - wie der Erzahler diskret andeutet ${ }^{13}$ - wohl ein Verhälnis hat. As Turbin Špoljanskijs Bild auf dem Tisch in Julias Zimmer stehen sieht und fragt, wer dieser Mann sei. antwortet ihm Julia: "mein Cousin". Der Leser weiß, daB sie lugt, denn er war ja Zeuge des Stelldicheins zwischen ihnen. Das Geheimnis um Julia Reiss. Spolanskij und Alexej Turbin wird bis zum Ende des Romans nicht geluiftet.

Es gibt mehrere Indizien dafür, daß sich hinter der Romanfigur ふ̌poljanskjj die "literarische Persönlichkeit" Šklovskij verbirgt. Šklovskij war zur fraglichen Zeit tatsächlich in Kiew. Er hatte sich auf der Flucht vor den Bolschewiki. die ihn als Sozialrevolutionär verfolgten, weil er an einem Putsch gegen sie beteiligt war, nach Kiew gerettet. Šklovskijs eigene Schilderungen in der "Sentimentalen Reise" weisen in einiger Hinsicht Ähnlichkeit mit den Schilderungen Bulgakovs auf, auch wenn Motivation und Bewertung der Figur Špoljanskij/Šklovskij andere sind. Während Bulgakov der Figur eine skandal- und geheimnisumwitterte Aura verleiht, tritt der autobiographische Held Šklovskij in der "Sentimentalen Reise" als ein $z$ wischen den Lagern aus Not mit List hin und her pendelnder Abenteurer auf, der den politischen Unruhen zum Trotz auch in Kiew seiner Profession, seinen literaturtheoretischen Studien und seinen literarischen Experimenten nachgeht. ${ }^{14}$

Abgesehen von diesen Parallelen, die das erzählte Geschehen betreffen, sind Anajogien in der konkreten Zeichnung der Figur Špoljanskij zu der "literari-

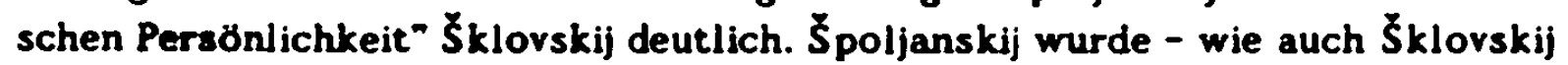
- Im Fruhjahr 1917 von der Kerenskij-Regierung das Georgskreuz verliehen. ${ }^{15}$ Er meldete sich wie $\zeta_{k l o v s k i j}$ als Freiwilliger in die Armee Skoropadskijs. ${ }^{16}$

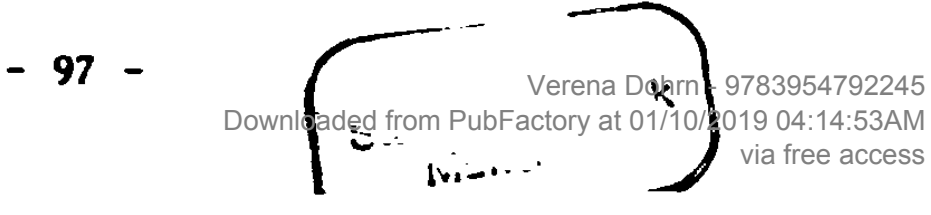


Russakov spricht Špoljanskij Ähnlichkeit mit dem Puškinhelden Evgenij Onegin zu. Šklovskijs Spitzname unter Freunden war Puškin. ${ }^{17}$ Špoljanskijs spektakulärer Ruf, sein Rednertalent, seine Vorliebe für Autos und seine technischen Kenntnisse, vor allem was das Auto betrifft, deuten auf Šklovskij hin, wie er sich selbst darstellt bzw. wie er in der Erinnerungsliteratur dargestellt ist.

Das gleiche gilt für Špoljanskijs Mitgliedschaft im futuristischen Dichterclub -Das magnetische Trolett", dessen Name wohl eine Anspielung auf das pathetisch-programmatische Technikverständnis der Avantgarde im allgemeinen. möglicherweise aber auch eine Anspielung auf den Prototyp der geliebten Alia in Šklovskijs "Zoo". Elsa Triolet ist, ferner für die Zusammenkunft von Dichtertalent und literaturtheoretischem Interesse in seiner Person - "im Morgengrauen schrieb er an seiner wissenschaftlichen Arbeit Das Intuitive bei Gogol'."18 - und nicht zuletzt für seinen Sprachduktus:

"Alle sind Schurken. Der Hetman und auch Petljura. Petljura ist obendrein Pogromstifter. Aber das ist nicht das Wichtigste. Ich langweile mich. weil ich schon lange keine Bomben geworfen habe." ${ }^{19}$

Bulgakov war sowohl in Fragen der Literatur als auch in seiner Weltanschauung anderer Meinung als Šklovskij. Dennoch setzte er ihm ein literarisches Denkmal, das sein zwielichtiges Image in der Revolutions- und Bürgerkriegszeit wirkungsvoll beleuchtet.

"Špoljanskij, du bist der stärkste von uns allen in dieser Stadt. die genauso im Verwesen begriffen ist wie ich. Du bist so schön daB man dir sogar die gruselige Ähnlichkeit mit Onegin verzeiht." 20

Der autobiographische Held in "Dritte Fabrik" nimmt die Stimmen Trockijs. Lunąarskijs. Percovs. Bulgakovs und anderer aus dem kulturellen Kontext seiner Zeit auf und arbeitet sie als Material für die Konstruktion des unglucklichen Schriftstellers in den Text ein, der nach seinem politischen Standort in der sowjetischen Kultur sucht.

Der deplacierte Mensch tritt dem Leser in der "Dritten Fabrik" zuallererst in der metaphorischen Gestalt eines roten Gummielefanten entgegen.

"Kleiner roter Elefant. Spielzeug meines Sohnes. Ich lasse dich als ersten in mein Buch ein, damit andere sich nicht damit briisten." [13]

Im Wortspiel - der Elefant quietscht (pił̌ et) und der Schriftsteller schreibt (pišet) - realisiert der Erzähler den Vergleich:

"Wir sind in verschiedene Formen gestanzt, aber wir haben nur eine Stimme, wenn man uns presst." [ebd.]

Hinter der Maske des mechanisch piepsenden Gummielefanten beschwört der 
Erzähler die Gefahr, daß die gesellschaftlichen Repressionen seine Rede in Wortschablonen pressen könnten, um in einer zweiten Geste diese Maske wieder ron sich $\mathrm{zu}$ schieben:

Kleiner roter Elefant, geh beiseite, ich möchte das Leben ohne Scherz sehen und ihm etwas mit meiner Stimme und nicht durch Piepsen sagen." [14]

Das Verwirrspiel der Masken beginnt. Das Bild der mechanischen Stimme des Gummielefanten wiederholt sich im Text leitmotivisch.

"Das sage ich mit meiner eigenen, nicht mit der Stimme des Elefanten." [16]

"Ich vermag nicht mit Elefantenpiepsen zu reden." [17]

"Der kleine Elefant spricht ziemlich träge. Er möchte Uber die Liebe sprechen." [24]

Im Spiel mit der Maske bedient sich Šklovskij des Kunstgriffs, im Wechsel von Negation und Position die unter dem Zwang der Verhältnisse mechanisch tönende Stimme seiner Zeit ins Gespräch zu bringen, wobei nicht so sehr die Pole plus, d.h. die Identifikation mit dieser Stimme, und minus. d.h. Ablehnung dieser Stimme. Beharren auf einer individuellen, eigenen. die Autmerksamkeit fesseln. sondern die Spannung, die zwischen ihnen entsteht. ${ }^{21}$ Derselbe Kunstgriff begegnet dem Leser in der ebenfalls leitmotivisch sich wiederholenden Redewendung vom Fähnrich. der nicht im Gleichschritt geht.

"Es ist nicht richtig zu sagen: 'Die ganze Kompanie geht nicht im Gleichschritt, allein der Fähnrich geht im Gleichschritt." [16]

Durch das russische Wortspiel "im Gleichschritt"/"mit FüBen" (v nogu/s nogamil verschiebt sich ihr Bedeutungsfeld:

Wenn man Brik die FüBe abschneidet, wird er zu beweisen suchen, daB es so bequemer ist ... Brik. ich habe das ganze Leben Fehler gemacht, aber ich habe gearbeitet ... Brechen wir auf. Mit Füen ist es besser. Es ist besser. Fehler zu machen. Du möchtest die Last verbrennen. die du nicht tragen kannst." [62]

Während die Gleichschrittmetapher den Konformitätsdruck, dem der Held der "Dritten Fabrik" ausgesetzt ist, thematisiert, meint die Variation dieser Metapher ein realistisches, d.h. ein die Wirklichkeit als so seiende emstnehmendes In-der-Welt-Stehen. ${ }^{-22}$

Mehr als alle anderen leitmotivisch fungierenden Bilder prägt die Metapher vom Flachs auf der Schutte die Selbststilisierung des deplacierten Menschen. die auf Šklovskijs Arbeitserfahrungen im Flachszentrum - wahrscheinlich eine MaBnahme zur ideologischen Umerziehung des eigensinnigen Intellektuellen nach seiner Ruckkehr aus dem Exil ${ }^{23}$ - verweist.

TWir sind Flachs auf der Schutte. So wrd das Feld genannt, auf dem man den Flachs ausbreitet. Wir liegen in flachen Streifen. Uns 
bearbeiten die Sonne und Bakterien." [39] "Der Flachs schreit nicht. wenn er gebrochen wird." [40] "Ich bin Flachs auf der Schütte. Ich schaue in den Himmel und fühle den Himmel und den Schmerz." [68] "Ich arbeitete im Flachszentrum. Die Faser läBt sich nicht raufen, sie rollt sich zu einer "33" ein. Der Nummer meines Alters ... Sind wir zur Faser oder zum Samen bestimmt? [70/71] "Der Flachs braucht die Unterdrilckung. Man zupft ihn. Man breitet ihn auf Feldern aus (in einigen Gegenden) oder wässert ihn in Gruben und FlüBchen. - Die FlüBchen, in denen man den Flachs wäscht. sind verflucht - in ihnen gibt es keine Fische mehr. Dann knickt man den Flachs und bricht ihn." [82]

In der Metapher des Flachs auf der Schütte zeichnet der Erzähler die schonungslose psychische Bearbeitung des avantgardistischen Künstlers in der Sowjetunion der 20er/30er Jahre so nach, daB sie in Worten wie "den Flachs brechen, zupfen, in Gruben wässern" sinnlich spürbar wird, ohne daß der Erzähler die Emotionen des Lesers durch die Schilderung dramatischer Ereignisse schürt. Der Schriftstellers Šklovskij sieht sich einer vergleichbaren Bearbeitung ausgesetzt: die Kritik schmäht ihn und bezichtigt ihn, ein Intellektueller ohne politischen Standort zu sein. Der deplacierte Schriftsteller durchlebt diese Bearbeitung zäh und unsentimental wie die Flachsfaser nach seiner Beschreibung so bewuBt. daB er sie literarisch verarbeiten kann. Andere leitmotivische Metaphern - die der Schwerkraft und der Zeit sowie das Bild vom Stein -. die eng mit der Flachsmetapher verwoben sind. erhellen und verstärken die Reflexion dariber, wie der Held $\mathbf{S} k l o v s k i j$ bearbeitet wurde.

-Die Äpfel fallen sogar in den Tagen revolutionärer Feste nach den Gesetzen der Schwerkraft auf die Erde ... Wir sind die Steine, an denen man die Wahrheit schleift ... Das Leben gelingt nicht, wenn du denkst. daB es für dich ist ... Ich lehne meine Zeit nicht ab. Ich möchte sie verstehen. - wozu braucht sie mich und was bedeutet sie für meine Arbeit? - Leben." [70]

Diese Bilder, die im Text eng miteinander verknüpft sind, ohne daB sie nach unseren landläufigen Vorstellungen in Zusammenhang miteinander ständen. bezeichnen das Lebensgefühl des deplacierten Helden in der "Dritten Fabrik". Der Leser kennt sie zum Teil aus fruheren, zum Teil aus späteren Prosawerken Šklovskijs. Es sind keine - wie es scheinen mag - aus einer Laune heraus flüchtig hingeworfenen Zeilen, sondern Bildsequenzen, die in Variationen in die jeweiligen Texte hineinmontiert worden sind. Das Wort "Zeit". gleichbedeutend mit dem Wort "Leben". meint in der "Dritten Fabrik" Lebenszeit - im Sinne einer zu erlebenden Zeit. Der Held spricht sie an "Nimm mich an. dritte Fabrik des Lebens!" [139] und redet von "meiner" bzw. "unserer Zeit" [70. 96. 13]. Aber seine Zeit verweigert sich ihm. Er erfährt sie als taub [63]. als Schicksal, das man durchleben muB wie ein Naturgesetz und das vom Zufall regiert wird [16, 86, 93, 97] - ebenso wie in der bürgerlich-kapitalistischen Gesellschaft. 
"Wir sind alle Ware vor dem Antlitz unserer Zeit, wir dürfen nicht sterben: Weggenossen werden sich schon finden." [138]

Syphilis und Tripper fungieren im Text als Metaphem für die Herrschaft des Zufalls und der Naturgesetze. Denn diese Geschlechtskrankheiten sind im Alltagsleben der Sowjetunion mehr als einfach nur Krankheiten. Sie sind ein Indiz für das Paradox, daB sich die Befreiung der Sexualität unter den gegebenen Verhältnissen als massenhaft wie eine Seuche um sich greifende Krankheit niederschlug. [50, 86, 127, 129] Hier forderten die materielle Not als Folge des Welt- und des Bürgerkriegs, die Unaufgeklärtheit weiter Teile der Bevölkerung, die enormen Unterschiede der Kulturen des Vielvölkerstaates und die kulturellen Differenzen zwischen Stadt und Land, die sämtlich zur Legitimation autoritärer Herrschaftsformen mit Ideologemen überdeckt statt bearbeitet wurden. ihren Tribut. Auch die Anspielungen auf die Herkunft aus dem Judentum. dem der Erzähler keineswegs religiös dogmatisch nachtrauert, aber dessen Weltbürgertum er verkörpert und mit dessen Leidensgeschichte er sich identifiziert, versinnbildlichen in der "Dritten Fabrik" wie auch in anderen Prosatexten den Standort des deplacierten Menschen.

"Der Fleischwolf vermag mich nicht zu zermalmen.

Die Juden stehen jedes Jahr einen Tag am Amtsschalter. den Wanderstab in der Hand zum Zeichen ihrer Bereitschaft aufzubrechen. Vergessen wir die Juden.

Brechen wir auf." [62]

Nur selten finden sich im Text beim Namen genannte Stellungnahmen Šklovskijs zur kulturpolitischen Lage in der Sowjetunion der frihen 20er Jahre bzw. zur Kritik an seiner Literatur. Begegnen dem Leser ideologische Reizworte der damaligen Zeit. dann sind sie im Sprachgebrauch des Erzählers so ver-rückt, daB er sich, sofern er sie erkennt, ihre Semantik erst erarbeiten mus.

"Besser ein Brand der Bücherläden, ein Verbot. Bücher zu drucken als eine rote Restauration ... Der Rohstoff der Schokolade ist nicht suiB. Erz klingt nicht. Elektrizität in Leitungen leuchtet nicht." [89]

Sheldon erkannte, daß $\mathfrak{S}_{k}$ lovskij in die Rede seines Erzählers in der "Dritten Fabrik" Lunačarskijs Schimpfwort "Saisongemuise" für den Formalismus ironisch aufgenommen hat. ${ }^{24}$

"Das Erdbeben ist vorbei. Man nahm den Deckel ab. Die Suppe kochte. Die Löffel sind ausgeteilt, - iB.

Wir haben das Recht, die Löfel nicht zu nehmen.

Wir sind bloB der ideologische Uuberbau.

Wir haben mit der Suppe ein kompliziertes nichtfunktionales Verhältnis ... [63]

Die Menschen haben sich verändert. Wahrscheinlich muB das so sein. Gemise. zum Beispiel, kocht man in der Suppe, aber iBt es nachher nicht. 
Man muB nur verstehen, was in diesem ProduktionsprozeB vor sich geht. Sonst verwechselt man möglicherweise in der Geschichte die Arbeit mit dem Lärm.

Lärm - das ist Arbeit für ein Orchester, aber nicht für das PutilovWerk. Im großen und ganzen ist es wahrscheinlich, daB wir Gemüse waren.

Aber nicht in bezug auf unseren Meridian." $[64)^{25}$

In der ironischen Replik schlägt der Erzähler den marxistischen Kulturpolitiker mit den eigenen Mitteln - mit den Mitteln einer dialektisch-materialistischen Beweisführung hinter der Maske des Spaßmachers: Zuerst setzt er sich mit den Bolschewiki an einen Tisch, um gemeinsam zu genieBen, was sich in der Revolution, die er mit einem Erdbeben vergleicht, zusammengebraut hat. Dann ibernimmt er mit parodistischer Geste die ihm von den Bolschewiki angetragene Rolle - "Wir sind bloB der ideologische Überbau. Wir haben mit der Suppe ein kompliziertes, nichtfunktionales Verhälnis" - und verweigert nun mit gutem Grund die Teilnahme an diesem gemeinsamen Essen. Ein neues Kapitel beginnt. Die Perspektive wechselt. Der Erzähler sitzt nicht mehr unter den Essenden. er ist vielmehr ein Bestandteil der Suppe: das Gemüse, das - wie man weiB. wenn man die Herstellungsweise von Suppe kennt. notwendig dazugehört, auch wenn es im Resultat als solches nicht erscheint. Der SpaBmacher erteilt dem Marxisten eine Lektion, indem er die mechanische Verkniipfung von wirtschaftlicher Produktion und Kunst. die Wesen und Erscheinung nicht unterscheiden kann, kritisiert und ihm eine naive Vorstellung von revolutionärer Kunst attestiert. Im Gegenzug zeichnet er - und das macht die subversive semantische Ebene seiner Worte aus - die Umrisse der dialektischen Evolution des Formalismus und seiner Literatur unter den politischen Bedingungen der russischen Revolution. nicht ohne mit ironischem Augenzwinkem die schmerzhafte Erfahrung von Zwang und Unterdrückung von Entwicklungsmöglichkeiten der Formalen Schule durch die bolschewistische Kulturpolitik im Bild des in der Suppe siedenden Gemuises anklingen zu lassen.

Als Gegenfigur zum deplacierten Menschen läBt der Autor den Schriftsteller Andrej Platonov auftreten. den der Erzähler um sein Engagement für die gesellschaftlich nützliche Arbeit als Meliorationsingenieur in der Landwirtschaft beneidet.

"Platonov verstand das Land. Ich flog mit dem Flugzeug dariber hinweg. Irgendetwas gelang uns nicht ... [130]

Aber die Felder brauchen meine Ironie nicht. Ich brauche Felder, ich brauche reale Dinge. Wenn ich sie nicht zu sehen vermag, dann sterbe ich." [132]

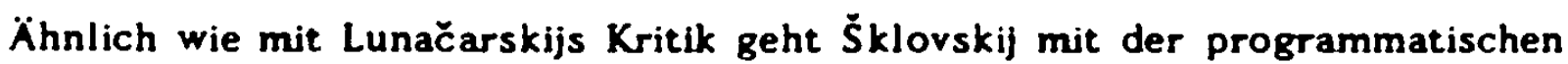
Forderung um, die Kunst habe einen "sozialen Auftrag" zu erfüllen, die in den Diskussionen um Marxismus und Formalismus im Jahre 1924 bereits anklang. ${ }^{26}$ Er stilisiert ausgerechnet Platonov, der weder zu den Linksavant- 
gardisten noch 24 den proletarischen Schriftstellem gehört, die sich in jenen Jahren als Apologeten der Parteipolitik im Bereich der Kunst aufspielten. zum Schriftsteller, der seinen gesellschaftlichen Standort als Künstler gefunden hat. Er nimmt ihn sowohl als Ingenieur als auch als Schriftsteller ernst, der sich auf sein Handwerk versteht.

"Platonor sprach uber Literatur, Uber Rozanov, dariber, daB man den Sonnenuntergang nicht beschreiben und keine Erzählungen verfassen soll." [129] -

Platonov genügt Šklovskijs Anspruch, daB der Schriftsteller zwei Berufe haben muisse, um aus einer lebendigen, produktiven Beziehung heraus über die Dinge schreiben zu können. Der Held der "Dritten Fabrik" greift die Parole vom "sozialen Auftrag" auf, um ihr eine andere Bedeutung zu geben.

"Ich stelle mir die Sache schematisch so vor: die Veränderung der Kunstproduktion kann aus nichtästhetischen Grïnden entstehen und entsteht auch so, zum Beispiel, weil eine andere Sprache auf die betreffende Sprache Eintlub hat, oder weil sich ein neuer sozialer Auftrag entwickelt hat." [95]

Sozialer Auftrag erscheint ihm als gesellschaftliche Gegebenheit. als Material, das in die Kunst Eingang findet. und nicht als pragmatische Aufforderung an den Künstler, in seinen Werken den Fortschritt des Sozialismus zu preisen. Er antwortet auf die kulturpolitische Forderung mit einer Abweichung. Denn der Leser von heute weiB. Platonovs Romane "Die Baugrube" und "ĆCevengur" zeichnen die ersten Jahre des "Aufbaus des Sozialismus in einem Land" kritisch und skeptisch in dunklen Farben. ${ }^{27}$

Auch die Unähnlichkeit des Ähnlichen 2 wischen Šklovskijs Reportagen über seine Reisen auts Land in Sommer und Herbst 1925 und der literarischen Darstellung dieser Erlebnisse in der "Dritten Fabrik". die dem aufmerksamen sowjetischen Leser jener Zeit nicht entgangen sein kann, da die meisten Reportagen bereits vor Veröffentlichung des Prosatextes in verschiedenen Zeitschriften zu lesen waren. ${ }^{28}$ ist als Kritik am "sozialen Auftrag" der Literatur zu verstehen. Der Šklovskij der "Dritten Fabrik" erzählt beinahe von denselben Dingen wie der Skizzenschreiber Šklovskij: von der Reise im Agitationsflugzeug "Das Gesicht zum Dorf!” über Voroneż, Liski. Bogučar nach Astrachan. Gur'ev und zuriuck nach Moskau; von der Reaktion der Bauern auf das Flugzeug: Uber die Sehnsucht der Bauern nach der Stadt und uber die Anfänge der Elektrifizierung. Maschinisierung und Rationalisierung der Landwirtschaft; von der Arbeit in Flachszentrum, Uber die Bauern und ihr Wirtschaften im Voronežer im Unterschied zumTversker Gouvernement. Er benutzt zum Teil dieselben Worte wie der Skizzenschreiber, aber er entreibt sie dem dokumentierenden Erzählzusammenhang der Reportage und funktioniert sie fur die autobiographische Prosa so um, daB sie Mosaiksteine für die Zeichnung des Bildes vom deplacierten Menschen werden. Die Worte verändern 
nicht deshalb ihre Bedeutung, weil sich Šklovskij in "Dritte Fabrik" als prinzipienloser Schriftsteller ausgibt, sondern weil er den Blickwinkel veränderte: während in den Reportagen das erlebte Objekt im Zentrum der Darstellung steht, schiebt sich in der Autobiographie das erlebende Subjekt in den Vordergrand. Die Worte verändern ihre Bedeutung in dem MaBe, wie die Autobiographie der Reportage als Kunstform iberlegen ist.

Die gesamte Konstruktion der "Dritten Fabrik" wird entscheidend von der Selbststilisierung des autobiographischen Erzählers zum deplacierten Menschen im "Aufbau des Sozialismus" getragen. Die Einteilung des Buches in drei als erste, zweite und dritte Fabrik bezeichnete Teile und einige Kapiteluiberschriften wie -

"Ich schreibe davon, daB das Alltagsleben das BewuBtsein bestimmt. aber das Gewissen unstrukturiert bleibt." [1S]

"Die Stimme des Halbfabrikats" [39]

"Was man aus mir macht" [93]

entsprechen seiner Selbstdarstellung als Material, das in drei Fabriken: in Familie und Schule, im OPOJAZ und im sowjetischen Kino deformiert wurde. Wieder versucht der Erzähler seine Gegner mit ihren eigenen Mittein zu schlagen: er parodiert die von den Bolschewiki mechanistisch als Handlungsanweisung statt als Kritik aufgefaBte marxistische Erkenntnis. daB der Mensch ein Produkt seiner Verhälnisse sei, mimt den bourgeoisen. dekadenten Intellektuellen, wie er von der "Diktatur des Proletariats" ideologisch bearbeitet wird und verwandelt das existentielle Problem: "Wie kann man in der Sowjetunion Schriftsteller sein?" in ein literarisches Thema. das in das System der Literatur aufgenommen und mit anderen Kunstwerken ins Verhältnis gesetzt wird.

\section{Vorbilder aus der literarischen Vergangenheit}

Lev Tolstoj. Der kritische, aber handlungsunfähige Außenseiter.

Um der Maske des deplacierten Menschen eine Geschichte. Kontur und Farbe zu verleihen, entlieh sich Šklovskij Stimmen aus der Literatur - vor allen anderen die Stimme Lev Tolstojs.

"Von mir aus zur Rechten steht ein Buicherregal mit Tolstoj. Bei mir auf der Schiitte liegt seit etwa zehn Jahren nur sein Werk." [39]

Šklovskij ubernimmt Tolstoj so in die "Dritte Fabrik", wie sein Freund Ejchenbaum und er inn im OPOJAZ gelesen haben: als literarisches Vorbild in bezug auf den Kunstgriff der Verfremdung sowie im Hinblick auf das Problem der Literarisierung einer AuBenseiterposition. ${ }^{29}$ Die Tatsache, daB $\zeta_{k}$ klovskij die Selbststilisierung des deplacierten Menschen explizit zuallererst 
an Tolstoj knüpft, birgt eine doppelte Ironie in sich. Er beruft sich auf einen in der Sowjetunion von Anfang an kanonisierten Schriftsteller, einen Schriftsteller ersten Ranges, der die Kontinuität der Entwicklung von der russischen zur sowjetischen Kunst verkörpern soll, um seine eigene desolate Situation und seine Schwierigkeit, eine gesellschaftliche Identität zu finden, zu legitimieren. Aber da er sich einer anderen Lesart Tolstojs befleiBigt, als die offizielle sowjetische Version es nahelegt, und ihn auf den deplacierten Menschen projiziert, iberträgt er ihm die von der kanonisierten Interpretation abweichende Funktion und Bedeutung, die Eindimensionalităt der utilitaristischen Perspektive auf die Welt durch den Kunstgriff der Verfremdung, in diesem Falle in der Spielart der Deplacierung, modellhaft aufzuzeigen.

Šklovskijs Auseinandersetzung mit dem russischen Schriftsteller schlechthin sollte ihn bis ins hohe Alter begleiten. Die neunzigbändige Jubiläumsausgabe der Werke Tolstojs nahm später allein schon eine Wand seines Arbeitszimmers ein. In der "Dritten Fabrik" bringt der Erzähler Tolstoj zunächst mit der Anekdote vom Schlachter ins Gespräch, der am Bordstein sein Messer schleift. ohne ibber die Steine nachzudenken oder sie als solche wahrzunehmen, und nur einen bestimmten Zweck verfolgt, der seine Perspektive bestimmt: das Messer zu schärfen. um damit Fleisch zu schneiden. Diese Anekdote fuhrt den Leser hin zur Flachsmetapher, sie wird in variierenden Anspielungen vom Erzähler immer wieder im Zusammenhang mit den leitmotivisch fungierenden Bildern in Erinnerung gerufen und so selbst in den Stand eines Leitmotivs gesetzt. $^{30}$ Indem er die Tolstoj-Anekdote wiedererzählt, weist der Erzähler nicht nur auf seine Leidensposition als AuBenseiter hin. sondern rïckt die Einstellung des AuBenseiters in den Blickpunkt: ein Spaziergänger in Moskau sieht von weitem den jungen Mann iber den Steinen hocken und findet dessen Verhalten absonderlich, da er aus der Ferne den Zweck des Tuns nicht erkennen kann; er beginnt es zu hinterfragen. Aus dem Blickwinkel des deplacierten Menschen à la Tolstoj weitet sich die Perspektive auf die sowjetische Kultur der 20er Jahre mit ihrem Normen- und Sittenkodex; als AuBenseiter kann der Erzähler sie hinterfragen. Dadurch, daß er die alltägliche Perspektive des Leidens an der Zeit entgrenzt und reflektiert. gewinnt der Held der "Dritten Fabrik" Spielraum, um sich andere, neue Perspektiven - die einer anderen Kultur - zu eröffnen und um sich selbst neu zu definieren. Doch die Kehrseite der Moral der Anekdote - die Erkenntnis, daß man, um den Zweck des Tuns genau erkennen zu können, nahe an das Geschehen herantreten muB - 2 wingt ihn zur Teilnahme am Geschehen des literarischen Lebens - am "Messerschleifen in der Kunst", damit ihm selbst nicht "die FiiBe abgeschnitten werden" und damit er nicht "durch den Fleischwolf gedreht" wird.

"Ich beginne nicht. mit dem toten Tolstoj zu streiten. Ich nehme ihn als Kunst - vorbei." [40] 
Die kokette Geste, mit der ک̌klovskij das literarische Vorbild Tolstoj wieder in seine Schranken weist, bezeichnet weniger seine Position speziell ihm gegenüber, sondern vielmehr Šklovskijs Umgang mit der Literaturtradition im allgemeinen: er verfügt uber sie, indem er sie neu liest, ihre jeweilige Bedeutung für sich als Subjekt seiner Zeit sucht und ihre Form als Theoretiker der Formalen Schule deutet. Sie ist zugleich ein ironisches Zugeständnis an das Primat des gesellschaftlichen Faktums vor dem literarischen im kulturellen Text jener Jahre. Aber sie ist auch als eine Ohrfeige für all diejenigen zu verstehen, die Tolstoj unkritisch und unhistorisch feiern und zur Nachahmung empfehlen und damit einer - wie Šklovskij es nennt - "roten Restauration" das Wort reden - einer Tendenz, die insbesondere unter fuhrenden sowjetischen Kulturideologen schon der 20er, mehr noch der $30 \mathrm{er}$ Jahre ausgeprägt

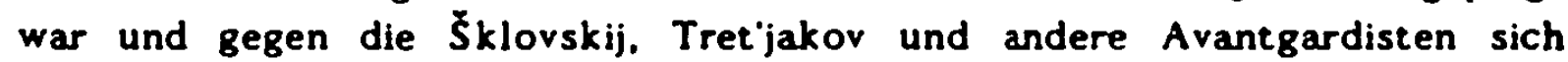
vielfach wandten. ${ }^{31}$

Abgesehen davon, daß Šklovskij Tolstoj namentlich erwähnt und auch zitiert. spielt er - wieder im Zusammenhang mit den metaphorischen Leitmotiven auf Texte von ihm an, ohne sie zu kennzeichnen, so daß nur der eingeweihte, literarisch versierte Leser sie erkennt und in seine Assoziatiunen zum Helden šklovskij einbezieht. In dem Kapitel "Die Felder anderer Gouvernements" fügt er in kurzen Passagen Worte. Informationen zusammen, die nicht nur an seine Reportagen über Reisen ins Voronežer Gebiet bzw. an die Diskussion iber den sozialen Auftrag erinnern. sondern die in der Erinnerung desjenigen. der Tolstojs frühe Erzählung "Der Schneesturm" gelesen und ihre thematische Verwandtschaft zu Puškins Erzählung "Die Hauptmannstochter" erkannt hat. mehr noch desjenigen, der die Diskussionen im OPOJAZ über Tolstoj und Šklovskijs Tolstojmonographie kennt. das Bild jener Winternacht heraufbeschwören, in der der Held der Puškin-Erzählung Grinev und nach ihm der junge Graf Tolstoj von einem Schneesturm iberrascht wurden. Die Passage in dem Kapitel "Die Felder anderer Gouvernements" lautet:

"Friedliches Leben. Ruhig pflügt der Bauer im Voronežer Gouvernement sein Feld. Mit vier Kühen. Das hiesige Vieh hält das aus. Kalmückische Rinder. Die Pferde haben im Bürgerkrieg stärker gelitten als die Kühe.

Man braucht die Kühe auf dem Acker. Sie fürchten nur die Hitze. Doch die Felder brauchen meine Ironie nicht.

Ich aber brauche die Felder. ich brauche reale Dinge. Wenn ich sie nicht zu sehen vermag, dann sterbe ich.

Im Tversker Gouvernement sind die Felder anders. Sie sind umzäunt. Es gibt Dörfer mit Zwölffelderwirtschaft. In einem solchen Dorf steht ein Haus. mit der Aufschrift 'UdSSR-ständiges Museum des Dorfes Kutuzovo'.

Kutuzovo liegt mitten in der UdSSR, das heiBt in der Welt. Es ist elektrifiziert. An den Wänden der Hütten sind Tapeten, die nicht verräuchert sind.

'Dieses Kartoffelfeld ist bereits eine Stadt', sagte man mir in Lichoslavl'. Die Stadt war zwei Wochen alt. Aber hier strickt man Strumpfe. Es gibt Maschinen und Geld. Und Ehrerbietung den 
Frauen gegeniber, die die Struimpfe stricken.

Und man singt anders.

Bei Krasnyj Cholm war ich vom Flachszentrum aus. Es fiel und schmolz der Schnee. Das unbeschlagene Pferd fürchtete das Kitzeln und ging nicht die Chaussee entlang ... wir fuhren am Wegesrand. Es schlingerte dermaBen, daB wir, als das rechte Rad verlorenging. es erst nach drei Werst merkten. Schnee auf den Feldern wie zerrissene Hasenfelle.

Aber auf den Feldern lag in flachen Rechtecken, eingezeichnet wiederum in Rechtecke, der Flachs auf der Scniutte. Die Ecken der Rechtecke sind abgerundet. Schnee legte sich auf den Flachs.

Wir sind Flachs auf der Schiitte. Ihr wiBt das schon.

Mein persönliches Schicksal fand in diesem Buichlein nicht Platz. Es endete in der Kindheit. Das Leben wurde durch die Ritzen geblasen. Die benachbarten Zimmer waren nicht geheizt.

Die verborgene und verschwiegene liebe ist nicht gegliickt. Es scheint, daB es so ausging. daB ich das Recht auf eine spezielle Kultur besitze.

Ich wiinsche mir. auf der Schuitte zu liegen." [132/133]

Šklovskij erzählt nicht, er montiert verrätselte Wortfetzen. Wie in einem Rätsel bewubt deplacierte Worte reihen sich die Namenszeichen, die die Erzählung assoziieren lassen. aneinander.

"Voronežer Gouvernement ... kalmückisches Vieh ... Es fiel und schmolz der Schnee. Das unbeschlagene Pferd ... ging nicht die Chaussee entlang. Wir fuhren am Wegesrand. Es schlingerte dermaßen, daB wir. als das rechte Rad verlorenging. es erst nach drei Werst merkten. Schnee auf den Feldern wie zerrissene Hasenfelle".

Um der vagen Assoziation ein solides Fundament zu verleihen, erscheint mir eine Abschweifung hin zur Tolstoj-Erzählung "Der Schneesturm", von dort zu Šklovskijs später Interpretation dieser Erzählung. wie sie in der Tolstoj-Monographie dargelegt ist, und zurick in die 20er Jahre und zur "Dritten Fabrik" sinnvoll.

\section{Tolstojs Erzählung "Der Schneesturm" ${ }^{32}$}

Auf der Heimreise vom Kaukasus, wo der junge Graf Tolstoj als gemeiner Soldat, ohne zu militärischen Ehren gelangt zu sein, seinen Militärdienst abgeleistet hatte. nach Jasnaja Poljana raubte ein Schneesturm ihm, seinem Diener und den Kutschern, die sie fuhren, die Orientierung.

"Mir kam es so vor, als ob wir uns auf einer sehr kleinen Fläche immer im Kreise drehten. Es konnte übrigens auch eine Sinnestäuschung sein. wie es mir zuweilen auch vorkam. als ob die vorderste Troika bald bergauf, bald den Abhang entlang und bald bergab fahre, während die Steppe nach allen Seiten vollkommen eben war. 
Nachdem wir noch einige Zeit so gefahren waren, glaubte ich fern am Horizont einen langen, schwarzen, sich fortbewegenden Streifen zu sehen; doch schon im nächsten Augenblick wurde mir klar, daß es dieselben Lastfuhren waren, die wir schon einem iberholt hatten. ${ }^{33}$

Die Kälte, der Sturm und die Glöckchen des Pferdeschlittens wiegten ihn in den Schlaf und ihm träumte von einem heißen Sommertag auf Jasnaja Poljana. wie er einem ertrunkenen Bauem das Leben retten will, dann aber doch nicht ins Wasser springt, sondern zuschaut, wie der leibeigene Koch die Leiche des Ertrunkenen birgt. In der Fortsetzung des Traumes nehmen die Traumfiguren aus Jasnaja Poljana die Gestalt der realen Figuren aus der Winternacht an: einer der Kutscher, der "Ratgeber". gleicht plötzlich dem leibeigenen Koch. Er will Tolstoj ausrauben und ihn im Schnee verrecken lassen. Da kiBBt Tolstoj einem anderen Kutscher, dem Alten, "mit unsagbarer Wonne die Hand". Doch als sich ihm der Koch/Ratgeber drohend naht, läuft Tolstoj fort. $^{34}$ Am Ende gelangte die Kutsche wohlbehalten bei der Poststation an.

Die Deutung der Erzählung in $\breve{S}_{k}$ lovskijs Tolstoj-Monographie

Der Schneesturm figuriert als Symbol für die Orientierungslosigkeit Tolstojs bzw. seine Suche nach Orientierung im Leben. ${ }^{35}$ Šklovskij deutet Tolstoj grundsätzlich unter dem Gesichtspunkt der Literarisierung des existentiell politischen Zwiespalts und Zweifels eines 2 wischen der höfischen Kulturtradition der Adelsgesellschaft und der Utopie einer klassenlosen, freien Bauerngesellschaft hin- und hergerissenen Adligen. Die Bauern/Kutscher aus der Gegend. wo der Bauernrebell Pugačev sein Unwesen getrieben hatte, halfen ihm, den Weg zu finden, nachdem er sich einsichtig gezeigt und sich ihnen gefügt hatte. ${ }^{36}$ Dem Traumgesicht, wie Tolstoj einem Bauern die Hand küBt. widmet Šklovskij in seiner Deutung besondere Aufmerksamkeit. Es wiederhole sich in den Erzählungen Tolstojs. ${ }^{37}$ Es entbehre jeglicher Erotik, hänge vielmehr mit der gesellschaftlichen Position Tolstojs auf Jasnaja Poljana zusammen. Šklovskij verweist auf Parallelen zu Puškins "Hauptmannstochter". wo Pugačev von dem jungen Grinev verlangt, ihm die Hand zu küssen. ${ }^{38}$

-Jahre und Generationen sind seither vergangen, neue Wege wurden gesucht, aber eine Bauernhand kiiBt Tolstoj vorerst nur im Traum ... Der Mensch entspricht durchaus nicht dem Bilde, das er von sich selber hat, häufig ist er derart verlogen und sucht nach Rechtfertigungen, daB er gleichsam aus sich, aus seinem Verstand heraustritt ... Das Thema Traum und Fieberwahn im Dienste des Umdenkens der Wirklichkeit beschäftigt den Schriftsteller auch später. ${ }^{-39}$ 
Nun reist der junge Sklovskij, Held der autobiographischen Prosa, durch dieselbe Gegend wie seinerzeit Tolstoj und vordem Grinev. An Tolstoj und dessen Vermittlerrolle 2 wischen Stadt und Land fuhlt er sich auf jener Reise durch eine Handschrift erinnert, die er als einziges Relikt der Kulturgeschichte des Dorfes in einem ländlichen Museum fand. ${ }^{40}$ An Grinev erinnert nicht nur der Šklovskij der Tolstoj-Monographie, sondern auch der der "Dritten Fabrik" in diesem Kapitel, indem er den Schnee "wie zerrissene Hasenfelle" erscheinen läßt - eine Metapher, die den Hasenfellmantel Grinevs ins Gedächtnis ruft. den jener Pugačev schenkte, als er ihn noch nicht kannte und für einen Landstreicher hielt. Da Pugažev der Mantel zu klein war, riB er die Năhte auf. um ihn passend zu machen. ${ }^{\text {I }}$

Grinev, Tolstoj und nun auch $\zeta_{k}$ lovskij geraten in die Hände der Bauernmacht. Aber während sie in der "Hauptmannstochter" besiegt wird und im "Schneesturm" ein Traum bleibt, ist sie in der "Dritten Fabrik" real. Der Schriftsteller erhält den "sozialen Auftrag", in die Dörfer zu gehen und den "Fortschritt des Sozialismus" zu schildern und voranzutreiben. Doch die literarische Darstellung der Reiseerfahrungen des Erzählers entspricht keineswegs den Anforderungen an einen sowjetischen Schriftsteller mit "sozialem Auttrag". Statt ausführlich, leicht verständlich und optimistisch $2 u$ dokumentieren. stottert der Erzähler kärgliche Informationen zusammen, die kaum zueinander zu passen scheinen. Er unternimmt - scheinbar systematisch und formal einen Strukturvergleich verschiedender "Felder" - der im Tversker, der im Voronežer Gouvernement, der Felder, auf denen der Flachs ausliegt und der Felder der Ironie, spielt dabei auf die Schneefelder im "Schneesturm" und in der "Hauptmannstochter" an und montiert auf diese Weise ein Mosaik. ein inneres Bild rom deplacierten Menschen.

Šklovskij hat, wie Tolstoj im Krieg, seinen gesellschaftlichen Dienst im Flachszentrum abgeleistet, ohne eine politische Identität zu finden. Ihre gesellschaftliche Orientierungslosigkeit und der permanente Versuch, ihr in der Selbstanalyse (Literarisierung des Traumes, des inneren Monologs, das Verfahren der Verfremdungl sowie in der intensiven Hingabe an das Leben (wie sie sich im Material ihrer Arbeit niederschlägt) zu begegnen, verbindet sie.

"Ich bin glücklich, daB man Dich mit Tolstoj herausgebracht hat, genauer. daß Tolstoj das Buch iber das literarische Leben erötfnet. ${ }^{-\$ 2}$.

schrieb گ̌klovskij 1928 an Ejchenbaum, als der erste Band von dessen zweiter groBer Arbeit über Tolstoj erschien.

"Du empfindest den Druck der Zeit und spannst alle Deine Kräfte an, auf sie einzuwirken - in gewisser Weise ähnlich wie Tolstoj. ${ }^{\text {t3 }}$. 
heiBt es in einem Brief von Ejchenbaum im Jahre 1929 an Šklorskij. Nicht formalistische Koketterie trieb Šklovskij dazu, sich, was seine literarische Selbstdarstellung anbetrifft, an Tolstoj abzuarbeiten. vielmehr identifizierte er sich ein stückweit mit dem Schriftsteller, der mit seiner politischen Moral haderte, ohne ihm blind nachzueifern und ihn nachzuahmen. Es gilt für ihn selbst, was er iber die Beziehungen Sternes und Franklins zu Tolstoj und insbesondere, was er über Tolstoj sagt.

"Lev Nikolaevič selbst ist Sterne auffallend unähnlich. obwohl sie miteinander verbunden sind. und Franklin ist er nicht ähnlich. denn Franklin gruindete den amerikanischen Staat. Tolstoj aber wollte jeden Staat zerstören, den russischen wie den amerikanischen. ${ }^{464}$

Er bedient sich der Rede des anerkannten Schriftstellers. um vor der sowjetischen Öffentlichkeit die Position des kritischen AuBenseiters zu rechtfertigen. Er stellt ihr Tolstoj als seinen Verbuindeten und Leidensgenossen vor.

Vasilij V. Rozanov. Der respektlose Kritiker

Aber Šklovskij leiht sich. um den deplacierten Menschen zu zeichnen. nicht nur die Stimme des Protagonisten der in der Sowjetunion offiziell gewürdigten russischen Literatur. Lev Tolstoj, sondern genauso die Stimme des Schriftstellers und Publizisten Vasilij Rozanov, der dort lange Zeit keine Anerkennung fand. ${ }^{4 S}$ dessen Schriften Šklovskij ebenso wie die Tolstojs vordem als Objekt seiner theoretischen Studien gedient hatten. ${ }^{46} \mathrm{Er}$ erwähnt Rozanov in der "Dritten Fabrik" nur einmal namentlich im Zusammenhang mit Platonor und dem Verbot. den Sonnenuntergang zu beschreiben und Erzählungen zu verfassen [129]. im Unterschied zu Tolstoj, den er namentlich nennen und auch zitieren kann. ohne mit der herrschenden kulturpolitischen Meinung in Streit zu geraten. Während Šklovskij die sowjetische Lesart Tolstojs dadurch. daß er dessen Texte neu deutet, parodiert und ihn, indem er ihn mit Don Quijote und Rozanov in eine Reihe stellt, vor den Augen des sowjetischen Lesers erniedrigt. erhebt er Rozanov in den Stand eines zu "beerbenden" russischen Schriftstellers. Tolstoj oder Gogol' vergleichbar, und erhöht ihn. nicht indem er ihn zitiert. sondern imitiert. Er ahmt seine ironische Rede nach. Denn in dieser Form ist ihm eine Variante der literarischen Methode. Werte umzuwerten. das GroBe klein und das Kleine groB zu machen, vorgegeben. Ihre Originalität erhält die Imitation dadurch. daß sie vor einem neuen Hintergrund erscheint. Sie hebt sich vom kulturellen Text der Sowjetunion der 20er Jahre ab. der der verschiedenverstehbaren Rede des Autors eine neue Funktion und Bedeutung gibt.

Šklovskij imitiert den Bekenner, den häuslichen Privatier, den Ketzer, den Zyniker und den Buffo ${ }^{47}$ aus den "Gefallenen Blättern" und aus "Solitaria", um den deplacierten Menschen zu kostümieren. Analog zu Rozanov, der sich in jenen Schriften in der bewubt fragmentarischen Form einer losen Sammlung 
von Aphorismen, die das Subjekt als vielstimmiges, widerspriichliches Dasein. Denken und Fühlen eines Einzelnen in seiner Gesellschaft begreift, kritisch mit der Religion der Staatskirche, den Sitten und Gewohnheiten in der buirgerlichen Gesellschaft im zaristischen RuBland und in Europa auseinandersetzt, streitet Šklovskij in der "Dritten Fabrik" mit dem Marxismus, mit der marxistisch-leninistischen Weltanschauung und den Gebräuchen im Alltagsleben der Sowjetunion der 20er Jahre. Nimmt man den Šklovskij der Prosatheorle betm Wort, dann erschlieBt sich dem Leser die Methode, die der Formalist zunächst Rozanov unterstellt und in der Folge selbst in seine eigene Prosakonzeption ubernimmt.

"Die Bücher Rozanovs waren ein heroischer Versuch, der Literatur den Rücken zu kehren, 'sich ohne Worte. ohne Form zu äuBern'. Das Ergebnis war ein ausgezeichnetes Werk, die Schaffung einer neuen Literatur, einer neuen Form.

Rozanov führte neue Themen in die Literatur ein. Küchenthemen. Familienthemen waren bereits bekannt - die brotschneidende Lotte im 'Werther' war für die damalige Zeit eine ebenso revolutionäre Erscheinung wie der Name Tatjana in Puškins 'Onegin' - doch über Dinge wie die Steppdecke, die Küche und ihren Geruch (njcht satirisch dargestellt) hatte bisher noch niemand geschrieben. Rozanov hat diese Themen in einer ganzen Reihe von Fragmenten behandelt, manchmal ohne jede Motivierung.

Es folgen Beispiele aus den "Gefallenen Blättern", von denen manche, zum Beispiel der "Morgentee" oder die Liebe zu ganz alltäglichen, banalen Dingen. die die Aufmerksamkeit des Lesers um so mehr fesseln, als sie mit groBen. erhabenen Themen konfrontiert werden. ganz konkret an metaphorische Wendungen in der "Dritten Fabrik" erinnern. Sie erinnern an den Morgentee im Brief an Ejchenbaum. den der Autor der literarischen Arbeit vorzuziehen vorgibe [103], an den Geruch des Klebers aus Birnenessenz in den Montageräumen der Kinofabrik, den er dem Schicksal und der Schicksalsgläubigkeit des Menschen gegeniberstellt [97], an den Geruch der Aptelsinen im kalten. feuchten und verräucherten Zimmer, in dem Šklovskij während des ersten Winters in Moskau mit seiner schwangeren Frau wohnte, und der seine Arbeit über zeitgenössische russische Literatur begleitete [79], und an den Nachsatz im Brief an Tynjanov: "Mein persönliches Leben erinnert mich an die Anstrengungen, eine Portion Eis zum Schmelzen zu bringen" [100].

Šklovskij entlarvt die Aufnahme des Konkreten und Intimen bei Rozanov als einen bewubten Kunstgriff, dessen Funktion auf stilistischer Ebene die Stilfigur des Oxymorons entspreche: Widersprilche in einer Redefigur zu vereinen, ohne sie aufzulösen.

' 'Ja' und 'nein' stehen nun auf demselben Blatt - ein biographisches Faktum wurde in den Rang eines stilistischen Faktums erhoben. Der 'schwarze' und der 'rote' Rozanor schaffen einen künstlerischen 
Kontrast, ebenso wie der 'schmutzige' und der 'göttliche' Rozanov zueinander stehen. Sogar der Ton seiner 'Prophezeiungen' hat sich geändert, sie sind keine Verkündigungen mehr, sondern eine rein private Angelegenheit, an niemanden gerichtet."

Dle Beteuerungen Šklovskijs, daß es ihm allein um die Analyse oder Form der Literatur Rozanovs gehe, durfen keineswegs dahingehend miBverstanden werden. daB ihn die politische und existentielle Dimension dieser Literatur nicht interessierte. Im Gegenteil: Šklovskij fesselten gerade solche Probleme. die die gesellschaftliche Identität des Künstles betrafen. Aber sie interessierten ihn nur als literarisch gestaltete, als stilisierte. Insbesondere die letzten Seiten des Rozanov-Aufsatzes, die in die nach 1921 erschienenen Ausgaben der "Theorie der Prosa" nicht aufgenommen wurden, weisen auf das eminent politische Interesse Šklovskijs an Rozanov, mehr noch auf eine Identifikation mit ihm hin, was seine respektlose Methode der politischen Reflexion und ihre Literarisierung angeht.

Von Rozanov übernimmt Šklovskij die Forderung, daß der Schriftsteller, so wie die Kinder es in ihrer alltäglichen Wahrnehmung urbewuBt tun. die Dinge aus ihrem kategorialen Zusammenhang reiBen. sie erhöhen oder erniedrigen solle, und setzt sie fraglos als fundierendes Theorem in seine eigene Prosakonzeption (Theorie der Verfremdung) ein, um hinter einer literaturwissenschaftlichen Argumentation geschuitzt Kritik nicht nur an der traditionellen Philologie, sondern auch am Marxismus-Leninismus üben zu können. Versteckt hinter Zitaten aus den "Gefallenen Blättern", die er angeblich für seine philologische Beweisführung benötigt, legt Šklovskij seine politische Haltung dar, kaschiert seine politische Respektlosigkeit vor den geltenden Dogmen des Marxismus-Leninismus mit literaturtheoretischen Uberlegungen und reflektiert die formalen Möglichkeiten, sie zu literarisieren. In einem Zitatbeispiel ist es der "Berg der Lichter", ein "hoher Berg. von dem das Licht ausgeht und die Welt erhellt", den Rozanov als Konstruktion auf vier hölzernen Beinchen entblöBt: "Eisen und hartes Metall lassen wir hier nicht zu, so wie auch verletzende Nägel nicht zugelassen sind. ${ }^{50}$ Hier verwandle sich ein technisches in ein symbolisches Detail, kommentiert Šklovskij lakonisch. In einem anderen Zitatbeispiel ist es Rozanovs obszöner Vergleich der Enthaltsamkeit mit Verstopfung.

"Ich möchte alles unter unsagbaren Tränen einfach und grob vermitteln, wobei ich den lieben Gegenstand erniedrige: obwohl der Vergleich. im Sinne eines ungestümen Dranges, genau ist: der Mund ist übervoll mit Speichel, es ist verboten, auszuspucken. Man könnte unter die Mönche fallen. Der Mensch iBt Tage. Wochen. Monate: es ist verboten, auf ein 'gewisses Örtchen' $z u$ gehen, man muB alles an sich halten. Er trank, er trinkt - und wiederum ist es verboten irgendwohin 'auszutreten'. Das ist der Jungfernstand. Ich ersticke. Es zerreiBt mich. "Verboten'. Das ist Mönchstum."s1

Indem Šklovskij dies zitiert und in Nachfolge von Rozanov das Obszöne als 
eine Variation des Intimen in seine autobiographische Prosa aufnimmt, um den deplacierten Menschen zu zeichnen -

"... ich lecke wie ein abgenutzter Gummischlauch ..." [16]

"... wie eine durchlöcherte Röhre ..." [67]

"Ich lebe stumpf wie in einem Präservativ:" [93] -

rüht er in mehrfacher Hinsicht an Tabus, die, wenn er Enthaltsamkeit iben und sie nicht brechen wiirde, ihn ersticken wïrden. Er riburt an dem Tabu Rozanov, denn er wiurdigt ihn und reiht ihn in die russische Literaturtradition ein. Er verletzt das Tabu der Unantastbarkeit der marxistisch-leninistischen Ideologie und verstöBt gegen das Verbot, iber Obszönität offen zu sprechen. Mit den Bildern der Boa, die ein Zicklein verschlingt. Gottes, der die Erde umfangen hält und eines Glacéhandschuhs, der erst über die Hand gestülpt sich zu seiner vollen GröBe entfaltet. setzt Šklovskij die Zitatreihe der obszönen Vergleiche bei Rozanov fort, die nicht nur als eine literarische Innovation zu begreifen sind. sondern dem lebensphilosophischen und politischen Gedanken Ausdruck verleihen, daB in einer dehnbaren Materie, auch wenn sie unscheinbar erscheint. mehr Kraft steckt a's in einer festen und starren. In den Bildern vom Flachs auf der Schiitte, vom roten Spielzeugelefanten, in den Zeit-Metaphern und den Bildern vom Gesetz der Schwerkraft. am deutlichsten aber im Symbol der Muschel, die den Druck auf ihre beiden Hälften braucht, um am Leben $z u$ bleiben [40], gestaltet der Autor der "Dritten Fabrik" Rozanovs Gedanken von der Stärke der Flexibilität zum deplacierten Menschen. der - wie sein literarisches Vorbild - versteckt hinter den typisierenden Masken des Bekenners. des Ketzers, des Zynikers und des Hans Wurst sich gewandt zwischen den Polen des "ja" und "nein" zum Sowjetsystem bewegt. und der dieses Spannungsverhältnis zwischen Freiheit und Unfreiheit für sein Leben, d.h. für die Lebendigkeit seiner Literatur, braucht.

"In festem Umfangen hält Gott die Welt und alles strebt nicht nur zur Freiheit und zur Lockerung, sondern es gibt auch einen völlig entgegengesetzten Appetit, einen 'engen Weg' zu gehen, einen beschwerlichen Weg. ${ }^{.52}$

\section{Cervantes Don Quijote. Der weise Narr}

Auch von Cervantes Helden Don Quijote leiht sich der Autor der "Dritten Fabrik" eine Stimme für die Rede seines deplacierten Helden. Im Kapitel "Die Zeit nahm ihren Lauf". in dem er seinen ersten Herbst und Winter in Moskau schildert, vergleicht er das Haus, in dem er wohnt. mit der von Don Quijote imaginierten Burg, die eigentlich nur ein Wirtshaus war. Vor jener Burg wollte Don Quijote, um den Preis, vom Wirt zum Ritter geschlagen zu werden, eine Nacht Wache stehen. Als er anfing, unschuldige Männer zusammenzuschlagen, weil er sie für feindliche Eindringlinge hielt, gegen die er die 
Festung verteidigen wollte, willigte der Wirt, um weitere Unruhe zu vermeiden und um den Verriuckten loszuwerden, tatsächlich in das Spiel ein und schlug ihn unverzüglich zum Ritter. ${ }^{53}$

"Das Haus ist von der letzten Besitzerin durch Bretteraufbauten wie eine Burg gestaltet worden. Wenn der Mond ihm auf den Rücken scheint, dann ähnelt es einer Burg.

Ein Brunnen.

Hier mag Don Quijote Wache stehen. Welch ein merkwürdiges und niemals wirklich gewesenes Leben." $[79]^{54}$

Der Erzähler der "Dritten Fabrik" erinnert. um den deplacierten Menschen zu skizzieren, an den Ritter von der traurigen Gestalt. der sich vor seiner Welt zum Narren machte, da er sie mit der Welt der Ritterromane verwechselte. Er erinnert an die literarische Figur des Don Quijote, indem er - wie jener die Grenze zwischen Literatur und Leben verwischt: Don Quijote tritt in die sowjetische Gegenwart, die sich in der Wahrnehmung des Helden der "Dritten Fabrik" nicht nur als Gegenwart, sondern auch als literarische Vergangenheit zeigt. die es zu bewachen gilt. Von Cervantes ubernimmt der Autor der "Dritten Fabrik" vor allen Dingen das Verwirtspiel der zwiegesichtigen Maske des Verruickten und des Weisen in einer Gestalt, das dadurch entsteht. daB er seinem Helden "seine eigene Weisheit auflud." Narren, der, in die Welt der Bücher eingesponnen, abenteuerliche Reisen unternimmt. kämpft er als Beschützer der Armen und Geknechteten für Gerechtigkeit und Liebe, während seine Zeitgenossen ihn zum Narren halten und ihr grausames Spiel desto mehr mit ihm treiben. je klarer Don Quijote sich selbst erkennt. Je deutlicher er die Diskrepanz sieht $z$ wischen seinen Idealen und der Wirklichkeit, in der er lebt, und die Differenz zwischen der Eigen- und der Fremdwahmehmung seiner Person. und je mehr er die Literarizität seiner eigenen Person erkennt (noch während er im zweiten Teil als Held agiert, erschien bereits ein gefäschter Teil des Romans, und Don Quijote unterhält sich im zweiten Teil mit Leuten. die den gefälschten bereits gelesen haben, uiber sich selbst), desto qualvoller wird sein Leben.

"Don Quijote weiB viel und richtet gut. Er richtet über sein zeitgenössisches Spanien nicht nur mit der Kraft seiner Dummheit, sondern auch mit der Kraft dessen, der die Dummheit des damaligen Lebens. dem er die Legende über das gerechte Goldene Zeitalter gegenüberstellt, versteht."

So wie im "Don Quijote" bildet sich auch in der "Dritten Fabrik" das Sujet aus dem Aufeinanderprall zweier Wirklichkeiten: der der literarisch imaginierten und der empirisch erfahrbaren Wirklichkeit. So wie der "Don Quijote" mehr als eine Parodie auf den Ritterroman - eine Satire auf die spanische Gesellschaft des 16./17. Jahrhunderts ist. so ist die "Dritte Fabrik" - mehr als die Realisierung der formalen Methode - die subversive Rede des Avantgardeschriftstellers Šklovskij, der gegen die herrschende Ideologie, die seine 
Arbeitsmöglichkeiten und die Beweglichkeit seiner Gedanken einschränken will. kämpft wie Don Quijote gegen die Windmuihlenflügel.

In einem Aufsatz von 1921 "Wie Don Quijote gemacht ist" untersucht Šklorskij das Verwirtspiel der Maske des Don Quijote zum einen am Beispiel seiner Reden, die den "dumm konzipierten Don Quijote" als in den verschiedensten Bereichen - vor allem in literarischen - bewanderten, weisen Mann ausweisen. zum anderen an den "Schaltnovellen". die die Handlung, den Fortgang der Abenteuer, bremsen und das Verwirrspie! komplizieren. 57 . Die Form der weisen Reden aus dem Munde des deplacierten Helden begegnet dem Leser der "Dritten Fabrik" insbesondere in Gestalt der literaturtheoretischen Passagen wieder, die verschiedentlich, vor allem in die Briefe an seine Freunde aus dem OPOJAZ - Tynjanov, Ejchenbaum. Jakobson und Jakubinskij - und in das Kapitel "Utber die Freiheit der Kunst" eingearbeitet sind. Damit greift Šklovskij in der "Dritten Fabrik" als konstruktives Verfahren auf, was er am Don Quijote studierte: die Möglichkeit. im Spiel mit der Narrenmaske die im Ansehen der Gesellschaft amoralischen Ansichten des Autors zu verbergen und sie dennoch 24 präsentieren.

Andersens Märchen: "Der Flachs". Uiber die ideologische Bearbeitung des Menschen

Das Bild rom Flachs, das auf die gesellschaftliche Bearbeitung des Helden der "Dritten Fabrik" anspielt. hat nicht nur im kulturellen Kontext. konkret

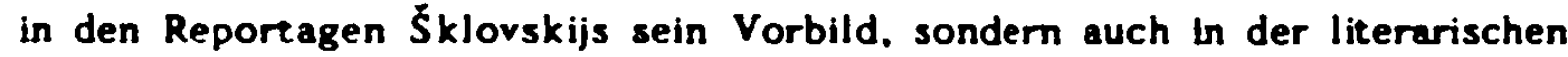
Tradition: in dem Märchen "Der Flachs" von Andersen. Andersen realisiert. wie nach ihm Šklovskij, in diesem Märchen den Kunstgriff der Verlebendigung eines Dings. des Flachses, um so verfremdet den schmerzvollen ProzeB der gesellschaftlichen Bearbeitung der menschlichen Existenz und die Selbsttäuschungen des Menschen ubber diesen Vorgang, die seine Ohnmacht und sein Ausgeliefertsein verbrämen und beschönigen, 24 schildern. Der Flachs im Märchen erlebte seinen Lebensweg nicht nur ergeben als einen schicksalhaften Naturzusammenhang, er nahm die Schläge. die man ihm erteilte, das Wässern und Trocknen iber dem Feuer, das AufgespieBtwerden auf dem Rocken als Werg, das Gebleicht- und Zerschnittenwerden als Leintuch u.s.f. nicht nur selbstverständlich hin. sondern gewann all der Pein obendrein jeweils noch eine gute Seite ab. Andersen schildert den ProzeB der Flachsbearbeitung mit ähnlich drastischen Worten wie Šklorskij in der "Dritten Fabrik". Je gröBer das Leid wurde, desto jubelnder nahm der Flachs es als seine Bestimmung an. Als er arn Ende in der Form von Altpapier verbrannt wurde. sprach er: "Nun gehe ich gerade zur Sonne hinaut?" Und als die Kinder bei der toten Asche sangen: "Schnipp-Schnapp-Schnurre, Baselurre, aus ist das Lied!". da antworteten thnen die Aschestaubchen, die einmal der Flachs gewesen waren: "Das Lied ist nie aus. das ist das schönste von allem! Ich weiB es, und deswegen bin ich der allerglucklichste!" 58 
Die immer gröBer werdende Diskrepanz 2 wischen dem Leid, das der Flachs erfuhr, und der Deutung des Leids durch den Flachs selbst, macht die Ironie des Märchens aus, die $\mathbf{S} k$ lovskij von Andersen in die "Dritte Fabrik" übernommen hat: er läßt den deplacierten Menschen mit der Stimme des Flachses seine ideologische Bearbeitung hochloben, während der Schmerz der Bearbeitung doch offensichtlich ist. Aber im Unterschied 24 Andersen fuhrt die Anpassung an diesen ProzeB der Knechtung und Brechung in Šklovskijs -Dritte Pabrik" nicht zur Selbstverleugnung. Šklovskij weist nur mit einer Stimme in Anspielung auf Andersen auf die Möglichkeit hin, daB bei fortdauernder und eskalierender "Bearbeitung" die Selbsttäuschungen zur Selbstverleugnung ausarten könnten.

Platons "Gastmahl". Wie die Zerrissenheit des Menschen ihren Anfang nahm.

Šklovskij läBt es sich nicht nehmen. in einer völlig deplaciert erscheinenden Abschweifung im Kapitel "Billige Antriebsmotoren", in dem von der Arbeit des Meliorationsingenieurs Platonov, von Bewässerungssystemen und von den nach Feierabend feiernden und tanzenden Dorfbewohnern die Rede ist. an einen Schöpfungsmythos zu erinnern. den der gnechische Komödiendichter Aristophanes im "Gastmahl" des Platon erzählt und in dem berichtet wird. wie die Zerrissenheit des Menschen ihren Anfang nahm.

"Es tanzten 2 wei: der junge Mann mit dem Tamburin und eine Frau im Kattunkleid mit Streifen.

Der junge Mann sang Ċastuški unglaublichsten Inhalts. Wie von Platon her bekannt ist. war der ganze Mensch irgendwann einmal in einen Mann und eine Frau entzweit worden. Jeder Teil wurde mit Kennzeichen versehen. Diese Kennzeichen wurden im Lied auch erwähnt ... Sie vereinigten sich zu bizarren Verbindungen." [129].

heiBt es in der "Dritten Fabrik".

Im "Gastmahl" erzählt Aristophanes die Geschichte, wie die Menschen ursprünglich kugelförmige Wesen waren, von denen es statt 2 wei drei Geschlechter gab: das männliche. das weibliche und das weiblichmännliche. Sie hatten jeweils einen gemeinsamen Kopf mit zwei Gesichtern und vier Ohren. Sie hatten zwei Schamglieder, vier Arme und Beine. Die Gesichter und GlieBmaBen waren nach auBen gerichtet. Sie bewegten sich im Kreisschwung rasch vorwärs. Als diese Menschen daran gingen. voll SelbstbewuBtsein und Übermut die Götter zu stürzen, beschioß Zeus, um sie zu zügeln und gleichzeitig das Fortbestehen der Menschen zu sichern, die Kugeln in zwei Hältten zu zerschneiden. Er teilte sie in der Mitte und befahl Apollon, ihnen die Gesichter. die Arme und die Beine nach innen zu drehen, "auf daß der Mensch angesichts der vollzogenen Zerschneidung sittsamer wirde. ${ }^{\text {.59 }}$ Als sie nun gespalten waren, begannen die einzelnen Hälften einander voller Sehnsucht zu suchen und. damit sie sich vermehren konnten und nicht ineinander verschlungen 
verhungern und sterben muBten, versetzte Zeus auch ihre Schamteile nach innen.

"Seit so langer Zeit also ist die Liebe zueinander den Menschen eingeboren. Sie fuhrt das urspringliche Wesen zusammen und int bestrebt, aus Zweien Eins zu machen und der menschlichen Natur Heilung zu schaffen.

Sklovskij arbeitet hier mit Kontrasten: er konfrontiert die Rede uber den Altag im sowjetischen Dorf, wo liber Rationalisierung und Technifizierung der Landwirtschaft gesprochen wird, mit der fragmentarischen Erzählung eines antiken Mythos. Er spricht iber die Zerrissenheit des Menschen, dariber. wie die Liebe diese 24 heilen sucht, und iber die Melioration des Ackerlandes in einem Atemzug. Die Anspielung auf den Schöpfungsmythos, wie Aristophanes ihn erzählt, ist zugleich drastisch und unscheinbar: ein Unwissender oder ein fluchtiger Leser kann sie ohne weiteres ubersehen. Die Möglichkeit einer Verschiedenverstehbarkeit ist kalkuliert, denn so können sich die verschiedenen Stimmen gegenseitig decken. Die Rede das faktographischen Schriftstellers uber die Antriebsmotoren deckt die Rede des deplacierten Menschen. der eine mythologische Deutung des Ursprungs seiner Zerrissenheit gibt; die Rede des deplacierten Menschen deckt die Rede des Formalisten, der sich für das Thema Liebe in der literarischen Evolution interessiert und Motive des Gassenhauers (einer sogenannten niederen Kunstform) in unmittelbaren Zusammenhang mit Motiven des antiken Mythos (der humanistischen Bildungstradition par excellence) bringt: umgekehrt schuitzt aber auch die quasi "wissenschaftliche" Argumentation des Formalisten die Klage des deplacierten Menschen, die in der sowjetischen Kultur nicht statthaft ist. Die Montagekonstruktion aus Material der antiken Kulturtradition und aus Material der sowjetischen Gegenwart zeigt, daB nicht nur das literarische Motiv der Liebe, sondern auch das des deplacierten Menschen auf eine lange Geschichte zurickblicken kann, daB diese beiden Motive miteinander verknuipft und auch weiterhin literarisch brauchbar sind.

\section{Der Komiker Charly Chaplin}

Die Maske des deplacierten Menschen Šklovskij bewegt sich in der -Dritten Fabrik" nach dem Muster des amerikanischen Filmkomikers Charly Chaplin. dem der Kinotheoretiker Šklovskij an anderer Stelle Interesse und viel Aufmerksamkeit zollte und den er selbst als deplacierten Menschen (čelovek ne na sroem meste) bezeichnete. ${ }^{61}$ Šklovskij vergleicht Chaplin mit den Figuren des italienischen Volkstheaters der comedia dell'arte. Ähnlich wie diese Figuren und wie auch Chaplin zeigt die Maske des deplacierten Menschen einen typisierten Šklovskij. Sie mimt die Grimasse des reumuitig vor der Sowjetmacht katzbuckelnden Intellektuellen ebenso wie die des amoralischen und eitlen Schwätzers. Ihre Stimme klingt so mechanisch wie der stumme Chaplin sich 
auf der Leinwand bewegt: sie reproduziert abgehackt und, ohne auf einen Zusammenhang $\mathrm{zu}$ achten, verschiedene fremde Stimmen, die beim eingeweihten Leser automatisch ablaufende Assoziationsketten in Gang setzen, sie jedoch auch wieder unterbrechen und irritieren, ehe der Leser das Angedeutete zu Ende denken kann. Wie in Chaplinfilmen unerwartete Wendungen im Verlauf der Bildsequenzen den Zuschauer aus einer gespannten Haltung zum Lachen befreien. so lösen sich plötzlich und unerwartet semantische Verknotungen, die durch das Stimmgewir in der Rede entstanden sind, und bringen den Leser, der iberrascht ist und plotzlich versteht, zum Lachen. Die Maske des deplacierten Menschen ist deshalb genauso eine komische Maske wie Chaplin eine komische Figur ist. Denn ihre mechanische Typisierung ist hier wie dort ein Kunstgriff der Verfremdung: hinter der Maske blinzelt der sehnsüchtig nach gesellschaftlicher Identitat suchende sowjetische Intellektuelle, der durch die Welt abenteuernde weise Nart, dem Leser verschmitzt und verschwörerisch zu.

\section{Der Experimentator}

\section{Ist Sklovskij ein Imitator oder ein Erfinder?}

Der Erzähler der "Dritten Fabrik" setzt sich die Maske des deplacierten Menschen auf und entfaltet das Verwirspiel: Bin ich wohl ein Erfinder oder ein Imitator? Seiner Absichtserklärung getreu -

"Ich werde Uber Dinge und Gedanken schreiben. - Wie eine Sammlung aus Zitaten." [8] -

nimmt er unvermittelt Textpassagen aus anderen Zusammenhängen auf, spielt auf Stimmen im kulturellen Text seiner Zeit an, auf die recht unterschiedlichen Texte der Litaturgeschichte, nimmt Briefe an Freunde, die wie private verfaBt sind und von denen einer bereits die Variante eines bereits friher publizierten Briefes ist, ${ }^{62}$ in die autobiographische Prosa auf. Wie Schablonen benutzt er auch sonst manche Wortwendung und manches metaphorische Bild erneut, das dem Leser aus friheren Schriften geläufig ist und ihm in späteren Texten wiederbegegnen wird.

Seine Kritik an R.Jakobson -

"Aber Du bist ein Imitator. Du, Rotblonder, sag doch, warum muBt Du ein Akademiker sein? Sie sind langweilig, sie sind dreihundert Jahre alt. Ununterbrochene, Unsterbliche." [69] -

bezieht Šklovskij in gewisser Weise auch auf sich selbst. Denn er weiB. daB sie sich miteinander im OPOJAZ eng verbunden fühlten und daB sie derselben Kultur angehörten. "Ich und Du, wir waren wie zwei Kolben in einem Zylinder." [66] Aber im Unterschied zum "rotblonden" Jakobson, der emigrierte, um in 
Ruhe und mit Erfolg Wissenschaft betreiben zu können und auf diese Weise die Auseinandersetzung mit der gesellschaftlichen Wirklichkeit der Sowjetunion floh, ist Šklovskij aus der Emigration nach Moskau zurückgekehrt und kein Akademiker geworden.

"Du kennst meine Fieberphantasie. Ich handele nicht. Ich tanze mit der Wissenschaft. Richte mich. Romka. Aber weder nasche ich an ihr, noch trage ich sie wie ein Halstuch, und ich richte Dich, Romka." [68]

Um die Tragweite und Bedeutung des Schimpfwortes "Imitator" in der "Dritten Fabrik" ermessen zu können, ist es sinnvoll, zum Vergleich andere autobiographische Prosatexte Šklovskijs hinzuziehen; denn auch hier gehört es zum sich wiederholenden Wortinventar. Mit seiner Hilfe klassifiziert Šklovskij Freunde und Schriftsteller, aber auch sich selbst. Der Imitator ist wohl am genauesten durch seinen Gegentyp zu beschreiben: durch den originellen, authentischen Schriftsteller-Erfinder, der mit der alten Gesellschaft gebrochen hat und utopische Perspektiven eröffnet.

Während Šklovskij Érenburg. Jakobson und zuweilen sich selbst ${ }^{63}$ als Imitator beschimpft. stellt er Chlebnikov und Majakovskij an die Spitze der Erfinder seiner Zeit. ${ }^{64}$ Aber unter der Hand verkehrt sich die kritische. negative Bedeutungsdimension der Bezeichnung "Imitator" in bezug auf ihn selbst in die positive. jedoch keineswegs programmatische Beschreibung eines neuen Typs von Literatur - einer Literatur. die ihren Standort in der Gesellschaft wie in der literarischen Evolution reflektiert, diese verschiedenen Ebenen miteinander in Beziehung setzt und ihr so gewonnenes Selbstbewubtsein zu einem subjektiven Standpunkt gestaltet. Die Selbstreflexion der "literarischen Persönlichkeit" bewerkstelligt eine Vereinigung dieser beiden einander eigentlich kontrastiven Stilisierungen: der Imitator wird zum Erfinder in der Kunst.

Šklovskij erzählt in der "Dritten Fabrik" Andersens Märchen von der alten Straßenlaterne nach; dabei arbeitet er ein Zitat aus Gogol's Erzählung "Nevskij Prospekt" in den Text ein. um dann anhand der romantischen Metapher der alten Laterne das Erfindertum seines Helden vorzustellen:

"In Dänemark gibt es die Stadt Kopenhagen. Dort lebte Andersen. Das Land ist so klein, daB man wahrscheinlich auf der Eisenbahn nur Billetts zum halben Preis ausgibt.

Einst wechselte man dort die Waltranlaternen gegen Gaslatemen aus. 'Weg, um Gottes willen, weg von der Laterne!' schrieb Gogol in seiner klassischen Novelle 'Nevskij Prospekt', 'und geht schnell, so schnell ihr könnt, an ihr vorbei. Ihr könnt noch von Glibck reden. wenn ihr damit davonkommt. daB sie euch den stutzerhaften Rock mit ihrem duftenden Öl beträufelt."

Doch andererseits zeigte die Laterne, wie man sieht. romantische Züge. Besonders als man sie gegen eine Gaslaterne auswechselte. 
Der ausrangierten Laterne machten die Sterne ein Geschenk. Wenn man in ihr ein Wachslicht anzündete, dann verwandelte sie sich in eine Zauberlaterne (in eine Art Kinematograph).

Und der Regen machte ein anderes Geschenk ... "Wenn du alles satt hast". sagte er. "dann wiinsche es dir und du zerfällst zu Staub." Die Laterne erhielt ein Wächter - ein Held der Arbeit in Rente. Die Laterne liebte den Wächter und wiinschte sich, sein Kinematograph zu sein. Der Wächter liebte die Laterne und goB manchmal Waltran in sie hinein. Aber wozu in einer StraBenlaterne eine Kerze anzỉnden?

Die Laterne ging von Redaktion zu Redaktion ...

Sie sprach: 'Nein, ich bin kein Kinematograph, ich bin ein Projektor.' Ich vermag es nicht, ein Zimmer zu erleuchten, ich bin Forscher ... Ich habe meinen Witz satt. Der Witz, das ist die Annäherung des Unähnlichen. Ich bin ein Erfinder in der Kunst ...

Ich habe keinen Ort, wo ich leuchten könnte! Und so zünde ich mir mitten im Buch ein Licht an." [102]

Šklovskij rekurriert auf Gogol' und Andersen, um seiner Selbststilisierung als Erfinder in der Kunst Farbe zu verleihen. Er zitiert und erzählt nach, aber er verschweigt in beiden Fälen die Pointe der jeweiligen Geschichte, die man kennen muB, um die in den Text montierten Andeutungen $2 u$ verstehen. Erst wenn der Leser das namentlich kenntlich gemachte, aber dennoch verrätselte Zitat und die Passage der Nacherzählung im Kontext der Novelle bzw. des Märchens, d.h. des jeweiligen Erzählzusammenhangs, in den sie ursprünglich eingebettet waren. zu entschlüsseln vermag, erschlieBt sich ihm ihre Funktion für die Darstellung des Erfinders in der Kunst.

Das Andersen-Märchen von der alten Stadtlateme ${ }^{65}$ erzählt nicht nur von der Angst der Laterne, nutzlos zu sein und ausrangiert zu werden, sondern auch von ihrer Angst, im Falle, daB sie umgeschmolzen wird, ihr Gedächtnis zu verlieren.

Nachdem sie nun vom Regen und von den Sternen, aber auch vom Wind ler verlieh ihr die Kraft der inneren Vorstellung) beschenkt und in die Obhut des Wächters genommen worden war, wartete sie sehnlichst darauf, daB man ein Wachslicht in ihr anzünde, damit sie ihre Zauberkräfte entfalten könne. Aber niemand, auch nicht der alte Wächter, kam auf die Idee, dies zu tun. So begann sie, ihre Vorstellungskraft nur für sich in Träumen zu entfalten und thr träumte, daB sie zu einem Leuchter in Gestalt eines Engels umgeschmolzen worden sei, der einen BlumenstrauB in Händen hält, in dessen Mitte man ein Wachslicht stellte. Von der Möglichkeit, sich selbst den Tod $2 u$ wiunschen. vermochte sie selbst im Traum keinen Gebrauch 24 machen. Im Traum stand sie in einem behaglichen Zimmer mit vielen Büchern und Bildern an den Wänden auf einem grünen Schreibtisch.

"Es war die Wohnung eines Dichters, und alles, was er sagte und schrieb. zeigte sich ringsherum. Das Zimmer wurde zu tiefen, dunklen Wäldern, zu sonnenbeleuchteten Wiesen, wo der Storch herumstolzierte, und zum Schiffsverdeck hoch auf dem wogenden Meere! -

Als die Laterne im Aufwachen den Wunsch verspürte, sich umschmelzen zu lassen, fielen ihr die fursorglichen Wärtersleute ein, die sie ihrer Person und nicht ihrer Zauberkraft wegen, von der sie nichts ahnten, liebten, und sie be- 
schloB - innerlich zur Ruhe gekommen - den Lebensabend in der Stube der Wärtersleute zu verbringen zusammen mit den zwei Blumentöpfen in Gestalt von Elefanten, einem Souvenir aus Indien, einer Schwarzwälder Uhr und einem "schönen bunten Bild" mit dem Titel "Die Fürstenversammlung zu Wien".

In Gogol's Novelle "Nevskij Prospekt" 67 beleuchten die Laternen das nächtliche Treiben auf der Hauptstraße Petersburgs, auf dem Nevskij Prospekt. Der Erzahler warnt vor ihrem Licht, da sie "allem und jeglichem einen verlockenden, wunderbaren Schein verleihen. ${ }^{-68}$ In ihr Licht getaucht. erschienen zwei jungen Männern zwei Frauengestalten so faszinierend, daB sie sich jeweils - der eine in eine Briinette. der andere in eine Blonde - so heftig verliebten, daB sie ihnen wie hypnotisiert nachstiegen. Beide wurden von der Realität der Frauen tief enttäuscht. Aber während der eine von thnen, der Künstler, der Imagination, die sich für ihn zu einer wahnwitzigen Leidenschaft auswuchs, zum Opfer fiel, kam der andere, ein Leutnant, mit einem blauen Auge davon, um sich alsbald emeut in Vergnügungen zu stürzen. "Oh, traut diesem Nevskii Prospekt nicht! ... Alles Trug, alles Traum, alles nicht das, was es scheint! ${ }^{69}$ heißt es bei Gogol'. Nicht das Öl der Laterne, das den Passanten die Kleider beschmutzt, sondern ihr Licht, das das nächtliche Treiben der Gesellschaft illuminiert, - "wenn der Dämon selber die Lampen anzundet - einzig deshalb, um alles nicht in seiner wahren Gestalt zu zeigen." ${ }^{\text {70 }}$, erweist sich als Gefahr für die Menschen.

Der Erfinder in der Kunst, wie Šklorskij ihn zeichnet, ist der Künstler, der die dämonische Kraft der Imagination kennt, der sie lieben und fürchten gelernt hat. aber der ihr nicht zum Opfer fält, sondern sie als eine Spielart der "Unfreiheit" studiert. sie in Form von Anspielungen und autblitzenden Buldmontagen in Erinnerung bringt und ihr wohl auch eine literarische Funktion zukommen läBt, die er aber als solche kenntlich macht. Im Unterschied zu den naiv fabulierenden und imaginierenden Künstlem ist sein Verhältnis zur Imagination kompliziert und widersprichlich. ${ }^{71} \mathrm{lhm}$ wird es nicht so ergehen wie dem Künstler auf dem Nevskij Prospekt, der Illusion und Wirklichkeit miteinander verwechselt. Denn er ist ein radikaler Kritiker der Auffassung. daB die Kunst die Aufgabe habe, eine schlechte Wirklichkeit zu beschönigen. Andererseits leidet er, wie die alte Straßenlaterne, am Unverständnis seiner Zeitgenossen fü die überlieferte Kunst und deren Fähigkeit zur Imagination und zur Illusion. denn er begreiti sich als Teil der Vergangenheit und als Nachkomme der alten Kunst - so wie man die Herkunft der Gaslaterne von der mit Waltran gespeisten Laterne nicht leugnen kann. Aber er leidet auch an der Unmöglichkeit, die von seiner Zeit geforderte Imaginationskraft zur Darstellung der sowjetischen Gesellschaft und ihrer Perspektiven aufzubringen.

Der Erfinder in der Kunst lehnt es ab, "die Kunst zu bewahren". "Wir haben nicht denselben Weg wie der in Goldschnitt gebundene Abram Efros," [17] heiBt es iber den Philologen und Wahrer der Tradition in der "Dritten Fabrik". Die Tendenz in der zeitgenössischen sowjetischen Literatur "von Gogor und zurick zu Gogol' bezeichnet er als Restauration in der Kunst. [89] Ihm geht 
es dagegen darum, die Bedingtheit der Literatur der Gegenwart nicht nur im Rahmen ihrer gesellschaftlichen Existenz. sondern auch im System der Evolution der Kunst zu erkennen und in der produktiven Erinnerung an die literarische Tradition $2 u$ bearbeiten.

Das Kapitel "Die Bucht des Neids" - möglicherweise in memoriam der Diskussionen und Lesungen im Kreis der Serapionsbrüder geschrieben - demonstriert ganz explizit das Problem des zeitgenössischen sowjetischen Erzählers, daB seine Lust $z u$ fabulieren und in phantastische Welten zu entfliehen. von zwei Seiten begrenzt wird: von dem kulturrevolutionären Anspruch der Avantgarde. operativ ins gesellschaftliche Leben einzugreifen und es mit umzugestalten. und von dem Verbot. bestimmte, im uberlieferten Literaturkanon abgenutzte Worte und Formen zu verwenden. damit seine Kunst lebendig wahrgenommen und nicht bloB als Schablone wiedererkannt werde. - ein Problem. auf das der Held des Briefromans "Zoo" ausführlich eingeht, wenn er gegen Alias naiven realistischen Schreibstil seine eigene, fragmentarisch-essayistische Literaturkonzeption setzt.

"Du warst auf Tahiti, und auBerdem fält dir das Schreiben leichter. Du weiBt nicht - und es ist gut so -. daB viele Worte verboten sind. Verboten sind Worte über Blumen. Verboten ist der Fruhling. Alle guten Worte verharren in Ohnmacht. ${ }^{-72}$

In "Bucht des Neids" kontrastiert der Erzähler der "Dritten Fabrik" die damalige gesellschaftliche Realität - die Käle, den Hunger und den Bürgerkrieg in Petrograd - mit einer Erzählung von der exotischen Idylle in Polynesien. Nach dem Klischee utopischer Abenteuerliteratur wird darin geschildert. wie sich russische Seefahrer, die ursprünglich auf Welteroberung aus waren. in das friedliche und muibige Leben dort eingliederten, eingeborene Frauen nahmen und dariber ihre Pläne vergaßen. Gleichzeitig deckt der Erzähler die Funktion der Imagination der exotischen Idylle. den Kontrast zur eigenen Realität darzustellen, auf verschiedenen Ebenen auf. Zum einen ruickt er. verlangsamt durch Abschweifungen. die die Abschweifung als literarischen Kunstgriff legitimieren und der Selbststilisierung des Erfinders in der Kunst Vorschub leisten. den selbst in gewisser Weise exotischen Schauplatz der Erzählung ins Blickfeld und schildert ihn: Das Treffen der Freunde findet im Hinterzimmer des Trödelladens "Der fröhliche Eingeborene" statt. wo man sich hinter einem Vorhang auf einer Ottomane sitzend und in einen Hirschpelz gewickelt vor der eisigen Käle $z u$ schützen sucht und sich gegenseitig Geschichten erzählt. ${ }^{73}$ Zum anderen unterbricht. erganzt und kommentiert der Erzähler der "Dritten Fabrik" den Erzähler jener Geschichte, seinen Freund Solov'ev, sei es, um auf die imperialistischen Interessen der russischen Seefahrer hinzuweisen, sei es, um zu beweisen, daB die Vorstellung einer exotischen Idylle eine Wunschprojektion der Nordländer sei. Indem er den kontrastierenden Vergleich konsequent weiterführt, weist er auf kulturelle und zivilisatorische Unterschiede so hin. daB nicht nur die paradiesischen Eigen- 
schaften, sondern auch Mängel beleuchtet werden: in Polynesien gibt es keine Bucher und keine ergiebige Bodenbewirtschaftung. Die Durchkreuzung des illusionären Erzählraums durch Hinweise auf die Erzählsituation. wobei semantische Analogien deutlich werden, schwächt den magischen Effekt der Erzählung von der exotischen Idylle und verlagert die Spannung auf das Verhältnis der Pole Realität - Fiktion.

Die Sehnsucht nach Inspiration. de dem Erzähler eine literarische Imagination seiner eigenen Zeit eingeben soll, kommt in der "Dritten Fabrik" nicht nur in den Anrufen an die Zeit zum Ausdruck, sondern sie nimmt, ähnlich wie in anderen autobiographischen Texten Šklovskijs. auch die metaphorische Gestalt eines Vogels an, der $z u$ ihm in sein Arbeitszimmer geflogen kommt -

"Und ich schreibe in meinem hohen Nest uiber dem Arbat.

Ein seltener Vogel wird zu mir gelangen. Er ist nicht auBer Atem.

Ich habe mir in meinem Nest den langen Atem abgewöhnt." [13] -

den er - wie Prometheus - mit seinem eigenen Fleisch futtert und dem er sein Herz überläBt.

"Der Vogel trägt mich. Du fütterst ihn mit deinem eigenen Fleisch. Es ist schon eine Gewohnheit. Lende. Brust, Kamm. Ich gebe dir das Herz. Vogel. Sage nicht 'Danke'." [97]

Der Vogel, der sich milhelos in den Himmel erheben kann, ohne atemlos zu werden, erinnert an die Fähigkeit zur Imagination, wie Šklorskij sie in seiner Jugend bei der Lektiure von Jules Verne, Mark Twain. Andersen u.a empfunden und kennengelernt haben mag. Diese Phantasien trugen den Menschen - wie es, die Kindheitserinnerungen in "Dritte Fabrik" ergänzend, in "Kindheit und Jugend" heiBt - "aus elenden Wohnungen, aus Hüten, aus Gefängnissen ${ }^{74}$ fort. Denn

"ein Mensch kann sich nicht von allein erheben. Er bittet die Menschen. die vor ihm dachten, träumten, haBten. Zu ihnen spricht er. übers Buch gebeugt: 'Nehmt mich mit!'m75

Aber der Vogel der Inspiration, der ihn in seiner Jugend emportrug, nagt nun an ihm. 3o, wie der Adler an dem gefesselten Prometheus nagte. Auch der hatte hochfliegende Ideen und wollte die Herrschaft der Götter über die Menschen stürzen. Dafür straften ihn die Götter. Der Erzähler der "Dritten Fabrik” uberlabt dem Vogel sein Herz.

"Das Ding (das Buch "Dritte Fabrik". V.D.) wird ganz und gar trocken werden. Das macht der Husten meines Herzens. ${ }^{76}$,

heiBt es im Manuskript zur "Dritten Fabrik". Im gedruckten Text ist der Zusatz "meines Herzens" gestrichen. [7] 
Während Šklovskij der Sehnsucht nach Inspiration in der "Dritten Fabrik" nur in spärlichen, fragmentarischen Andeutungen Ausdruck verleiht, spricht er in anderen autobiographischen Texten offener und ausfuhrlicher über sie.

In "Zoo" erscheint sie als der Neid. nicht so naiv fabulieren. nicht von der Liebe reden, nicht so flieBend und im Zusammenhang Erinnerungen niederschreiben zu können wie Alia.

"Ich habe das Gescheite und die Ironie satt.

Dein Brief hat meinen Neid geweckt.

Wie gern möchte ich einfach die Gegenstände beschreiben. als hätte es nie eine Literatur gegeben. als könnte man 'literarisch' schreiben. Schön wäre es auch, in langen Sätzen etwas in der Art von: 'Herrlich ist der Dnjepr bei ruhigem Wetter' zu schreiben.

Auch ich möchte gern rom niemals welkenden, nein. noch lieber: vom nimmerwelken Kranz schreiben. ${ }^{\text {77 }}$

In der "Sentimentalen Reise" kleidet er den Gedanken iuber seine Unfähigkeit. sich von der Inspiration beflügeln zu lassen, in einen Schwall von Metaphern.

Ich schreibe, aber das Ufer weicht nicht zurïck vor mir, ich kann mich nicht wie ein Wolf in einem Wald von Gedanken verirren, im Wald der von mir geschaffenen Worte. Die Ufer verschwinden nicht. ringsum ist Leben und nicht ein Meer von Worten, und seine Grenzen biegen sich nicht nach oben. Der Gedanke läuft und läuft über die Erde und kann sich doch nicht von ihr abheben wie ein falsch konstruiertes Flugzeug.

Und der Sturm der Inspiration will meine Gedanken nicht emporwirbeln, und der Gott hebt den Schamanen nicht von der Erde empor. Ich fahre mit der Zunge iber meine Lippen, es ist kein Schaum darauf. ${ }^{m 8}$

In "Suche nach dem Optimismus" verwandelt sich der Phantasievogel in der Hand des Schriftstellers in ein Huhn, das er im Gedränge der Straßenbahn schützend im Arm hält.

"Der Schriftsteller trägt einen lebendigen Vogel - das Herz in den Händen. Vielleicht ist es keine Taube. Vielleicht ist es ein Huhn.

Aber es ist lebendig.

Er fährt mit der Straßenbahn. Man drängelt sich.

Er verteidigt das Herz mit den Ellenbogen.

Alle drängeln sich, sogar die Alten."

Selbst in der Zeit der beginnenden 30er Jahre, als die staatlichen Repressionen gegen den einzelnen Bürger begannen und die Massen für die forcierte Industrialisierung und Kollektivierung mobilisiert wurden, beschuitzt der Erfinder in der Kunst den "Vogel der Inspiration", der sich den Anforderungen jener Zeit entsprechend kein phantastisches, sondern ein überaus prosaisches Aussehen gibt. Da es den LEF nicht mehr gab und die Neugrindung des OPOJAZ innerhalb der Föderation der sowjetischen Schriftsteller (FOSP) 
fehlgeschlagen war, stand der Erfinder und Experimentator nun ohne Schutz im "Gedränge" des gesellschaftlichen Lebens. Die metaphorische Verknüpfung: Vogel, Prometheus, Herz des Erzählers, von der in "Dritte Fabrik" die Rede ist, verweist auf die von Šklovskij so gesehene Zusammengehörigkeit von Inspiration, Literatur und gesellschaftlicher Bedingtheit. Die Gleichsetzung von Vogel, Prometheus und Herz, die sich hier ankündigt ("Ich gebe dir das Herz. Vogel") und die sich in "Suche nach dem Optimisus" vollzieht, ist als Steigerung des Verknuipfungsgedankens zu verstehen: die Inspiration ist das Herz der in der "literarischen Persönlichkeit" verkörperten Literatur in der Krise. In "Kindheit und Jugend" illustriert Šklovskij die Sehnsucht nach Inspiration mit der Erinnerung an ein russisches Märchen, in dem ein kleiner Junge, vor der Hexe Baba Jaga fliehend, vorïberfliegende Gänse und Schwäne bittet: "Nehmt mich auf eure Flügel!", aber diese ihm antworten: "Sollen dich die Hinteren nehmen." Bis ihn der letzte Schwarm tatsächlich autnahm und nach Hause brachte. ${ }^{80}$ Der Erfinder in der Kunst begnilgt sich scheinbar damit, alte Geschichten neu zu erzählen. Aber in Wirklichkeit entwickelt er auf diese Weise einen für die sowjetische Avantgarde neuartigen Typus von Literatur. In der Gestalt des Imitators, der sich unter der Feder des Autors der "Dritten Fabrik" in den Erfinder in der Kunst verwandelt. fordert der deplacierte Mensch wie Don Quijote die Anerkennung seiner Andersartigkeit - die Anerkennung der Spezifität seiner Literatur.

\section{Das Recht auf eine spezielle Kultur}

"Und laBt mich mit speziellen Kulturen arbeiten. Es ist nicht richtig. wenn alle Weizen säen. Ich vermag nicht mit der Piepsstimme eines Elefanten zu sprechen." [17]

Mit diesen Worten klagt der Held in einem der ersten Kapitel der "Dritten Fabrik" deutlich sein Recht auf einen Sonderstatus in der sowjetischen Kultur ein, den er in erster Linie aus seiner Arbeit im OPOJAZ ableitet $[65 ; 133$ ]. Die sich in Variationen wiederholende Getreide-Metapher $[17 ; 88]$ und die Metapher vom Suppengemuise [63-64], von der unter einem anderen Gesichtspunkt bereits die Rede war. illustrieren seinen Anspruch auf eine spezielle Kultur. Die kulturelle Tradition der weltoffenen GroBstadt Petersburg ist die Heimat des Helden der "Dritten Fabrik". Er erzählt von seiner Kindheit dort und davon. daB seine Angehörigen GroBstädter waren [20; 91]. Es muBte wie eine Provokation wirken, wenn Šklovskij sich in jener Zeit als Städter bezeichnete. in der die kommunistische Partei nicht nur für eine forcierte Verknüpfung von Stadt und Land eintrat. sondern auch das Zentrum der revolutionären Bewegung von der Stadt aufs Land zu verlagern begann. Indem sie ganze Bataillone von Arbeitern und auch Schriftstellem in die Dörfer schickte. Der Kritiker Percov bemerkt diese Provokation auch in den journalistischen Schriften Šklovskijs und geht scheinbar humorvoll, aber kritisch darauf ein. 
um diese Haltung moralisch zu verwerfen.

"Zürnen Sie nicht, Šklovskij! Wir sind keine Dorfbewohner. Wir fühlen hier ... die Ironie ... gegenuiber dem Leser. Doch aus diesen Zeilen spricht eine derartige kokette Selbstliebe, eine derartige Hoffahrt (grassirovanie) junger Leute aus 'gutem Hause', daB es quälend wird. ${ }^{81}$

Möglicherweise kann Šklovskijs Abschweifung uber revolutionäre Prozesse in der Sprache [93/94] als Antwort auf den prominenten Kritiker Percov gelesen werden, auch wenn jener nicht namentlich genannt ist. Šklovskij geht hier auf die Mode, das " $r$ " nach franzözischer Art zu sprechen (grassirovanie), ein. Unter dem Vorwand, das Phänomen begriffsgeschichtlich erforschen zu wollen. legitimiert Šklovskij seine eigene Schweibweise. Denn der Hintersinn seiner Uberlegungen liegt weniger in der Frage nach den Wurzeln des "grassirovanie" als in der Subsumtion dieser Mode unter dem Sammelbegriff "undeutliche Aussprache" (nevnjatnoe proiznošenie). den man als eine Variation der Bestimmung von Šklovskijs Konzeption der Verfremdung betrachten kann.

In jenen Kapiteln. in denen von Šklovskijs Reisen ibber Land und von seinem Treffen mit Platonov die Rede ist, realisiert der Autor sein Selbstbewußtsein als Städter und Protagonist einer städtischen Kultur. indem er dem Leser zu verstehen gibe. wie wenig er vom sowjetischen Dorf begreift, und daB er sich beim Anblick tanzender Bauern an Platons Gastmahl erinnert fühlt und mit Platonov uber Rozanov und die Literatur diskutiert. statt Probleme aus der Arbeit des Meliorationsingenieurs zu besprechen.

Šklovskij war in der Bildungstradition verschiedener Kulturen herangewachsen. Er war von seines Vaters Seite her juidischer Abkunft, worauf der "Held" in der "Dritten Fabrik" indirekt mehrfach anspielt 162.44$)$. und hatte von seiner Mutter Seite deutsche Vorfahren, an die er sich ebentalls in der "Dritten Fabrik" erinnert.

"Mein GroBvater war Gärtner im Smol'nyj. Ein grauhaariger, hochgewachsener Deutscher." [19]

Diese Erinnerungen komplettleren das Selbstbild des Städters.

In einem Brief äuBert der Freund Ejchenbaum in Anbetracht der für den OPOJAZ schwierigen Zeit seine Besorgnis ubber diese brisante Mischung verschiedener Kulturen in der "literarischen Persönlichkeit" Šklovskij. “.. du bist ein Fanatiker und nicht nur ein russischer Jude, sondern
auch ein russischer Deutscher. In dir brodelt das Blut ...

Das Milieu der Petersburger Intelligencija, in das Šklovskij hineinwuchs, war stark von internationalen, besonders von westeuropäischen Einflüssen geprägt. 
Der Erzähler der "Dritten Fabrik" legt viel Wert darauf, sie hervorzuheben.

"Ich erinnere mich an den Buren-Krieg und an ein gedrucktes Bild: der Bure schlägt den Engländer. Die Ankunft der Franzosen in Petersburg. Den Beginn des zwanzigsten Jahrhunderts ..." [19]

Er erinnert daran, daB sein Onkel bereits ein Telefon besaB [20, vgl. 18]. Vor allen Dingen aber läBt er das kulturelle Leben der vorrevolutionären Zeit und der Jahre des Bürgerkriegs am Leser Revue passieren: die Petersburger Universität mit Baudoin de Courtenay [42], die Symbolisten. die er nicht gekannt haben will [43], den Skulpteur Sherwood [44], die Futuristen Burljuk. Majakovskij, Čukovskij und Kručenych [42, 44], den Künstler Kul'bin und den Dichter Blok [50 f., 53], die Treffen in der Wohnung der Briks [56 ff.] und nicht zuletzt den OPOJAZ. Von den Serapionsbrïdern erzählt er nicht. Aber das Kapitel "Bucht des Neids" kann - wie ich in einem anderen Zusammenhang bereits andeutete - als eine Widmung an diesen Diskussionszusammenhang aufgefaBt werden, um so mehr, als in dieses Kapitel eine Anspielung eingelassen ist, die nicht nur in der "Dritten Fabrik". sondern auch in anderen autobiographischen Prosatexten als leitmotivische Metapher der Selbststilisierung des Sonderlings fungiert, der das Recht auf eine spezielle Kultur für sich geltend macht: die Anspielung auf Kiplings Geschichte von der Katze. die ihre eigenen Wege geht.

-Für Katzen. so heiBt es in jenem Kapitel. "lieB man in den alten Häusem in Frankreich Durchgänge in den Wänden. Diese Durchgänge führten von Zimmer zu Zimmer und von Etage zu Etage. Im Namen einer kleinen Gruppe von Menschen, die nicht in den Mensen zu Mittag essen können und die es iberhaupt nicht verstehen. das Geld für Nutzliches auszugeben und die deshalb Brötchen auf der StraBe essen oder (wenn sie keine Familie haben) ihren Hunger mit fremden Piroggen stillen (wonach es ihnen jeden Tag von der sauren geschlagenen Sahne ein biBchen ibel wird), wende ich mich an die Menschheit, auf daB man ihnen die Erlaubnis erteile, solche Durchgänge (für Katzen) zu benutzen." [108]

Von dieser Anekdote aus läBt sich ein Zusammenhang zu einer Bemerkung zwei Seiten zuvor, am Ende des Kapitels "Brief an Lev Jakubinskij" herstellen.

-Lev, mein Lieber, ich wohne auch in der achten Etage und die Komsomolzen, die zu mir kommen, sind außer Atem. Die Katze fiel. als sie aus meinem Fenster nach unten schaute, auf das StraBenpflaster, weil ihr schwindelte." [106]

In seinem Erinnerungsbuch über Majakovskij weiB Šklovskij zu berichten. daB sich die Serapionsbruider für Kipling begeisterten. ${ }^{83}$ In "Zoo" heiBt es:

-Unser groBes Affenheer (die russischen Emigranten in Berlin. V.D.) lebt wie Kiplings Katze auf dem Dach: fur sich allein." ${ }^{* 6}$ 
Und zwei Seiten später uiber ihn selbst:

"Ich gebe mein Gewerbe als Schriftsteller, meinen freien Weg über die Dächer nicht preis: nicht für einen europäischen Anzug, nicht für blankpolierte Schuhe, nicht für hohe Valute, nicht einmal tür Alia. ${ }^{-85}$

Auch wenn der Erzähler der "Dritten Fabrik" den Schriftsteller Kipling nicht namentlich erwähnt. so liegt es doch nahe, daß er mit der Rede ron der Katze und von den für sie bestimmten Durchgängen in den alten französischen Häusern nicht nur die für Katzen sprichwörtliche Eigenwilligkeit und Selbständigkeit, sondern auch die auf diese Eigenschaften rekurrierende Geschichte "Die Katze geht ihre eigenen Wege" von Kipling im Sinn hat. die er in verrätselter Form in "Zoo" erwähnt.

Kiplings Geschichte "Die Katze geht ihre ejgenen Wege" erzählt von dem legendären Ursprung der Auffassung. daB die Katze im Unterschied zu den anderen Haustieren ein eigenwilliges und wildes Tier geblieben ist.

$\mathrm{Zu}$ jener Zeit, als die Menschen ihr wildes Leben autgaben und häuslich zu leben begannen, zähmte die Frau, die Betreiberin der Zivilisation, die wilden Tiere des Waldes und machte sie sich dienstbar. Nur die Katze weigerte sich standhatt: "Ich bin kein Freund, ich bin kein Diener, ich bin die Katze und ich gehe meine eigenen Wege, und ich winsche in der Höhle gelassen zu werden." 80 Sie begann mit der Frau 7.4 feilschen, mimte die Traunge und schmeichelte der weiblichen Eitelkeit, so daB jene sich das Versprechen abnehmen lieb: wenn sie dreimal etwas Gutes iber die Katze sagen wirde, diurfe diese. wann immer sie wolle, in der Höhle am Feuer sitzen und Milch trinken. ohne ihren Status als eigenständiges und wildes Tier aufgeben zu missen. Mit einiger List brachte die Katze die Frau dreimal dazu. sie zu loben. Damit hatte sie sich das Recht erworben, am menschlichen Leben teilzunehmen, ohne sich domestizieren zu lassen. Aber der Mann, der ihr nichts versprochen hatte und der ihr zu nichts verptlichtet war, jagte sie wieder aus der Höhle. Seither darf die Katze nur dann bei den Menschen in der Höhle leben, wenn der Mann nicht zu Hause ist. "Aber danach und auch $z$ wischendrin, und wenn der Mond aufgeht und wenn die Nacht kommt, dann geht die Katze auf ihren eigenen Wegen. Dann wandelt sie hinaus in den nassen wilden Wald oder klettert auf nasse wilde Bäume oder auf nasse wilde Dächer und schwenkt ihren wilden Schwanz auf einsam-wilden Pfaden." Mit diesen Worten endet die Geschichte für Kinder von Kipling.

Wieder erschlieBt sich dem Kenner der literarischen Vorlage der Anspielung in der "Dritten Fabrik" - in diesem Falle der Anspielung auf Kiplings Geschichte "Die Katze geht ihre eigenen Wege" - eine zusätzliche Bedeutungsdimension. In Erinnerung an die märchenhafte Erzählung reichert der Autor seine literarische Selbstdarstellung durch die metamorphe Gestalt der eigenwilligen Katze an, deren Schicksal der Leser nun an den verschiedensten Punkten mit dem des Helden der autobiographischen Prosa verknüpft sieht: 
Die Katze wird mit dem Menschen konfrontiert.

Die Katze, die sich den anderen Tieren nicht anschliebt. als diese naiv und neugierig zu den Menschen gehen.

Die Katze, die den Zauber der Frau durchschaut, weil sie den Tieren heimilch zur Hohle folgt.

Die Katze, die es dennoch zur Höhle und zu den Menschen treibt.

Die Katze, die, um ihre Eigenständigkeit zu bewahren und dennoch in den GenuB häuslicher Verguinstigungen zu kommen. mit der Frau feilscht. ihr schmeichelt und sie betört und bezaubert.

Die Katze, die $z$ war von der Frau akzeptiert, aber vom Mann und rom Hund verjagt wird.

Die Katze, die weiterhin wild bleibt und ihrer eigenen Wege geht. §klovskij ist mit der Kultur der Sowjetmacht konfrontiert.

Šklovskij, der - anders als die meisten Künstler der linken Avantgarde - sich nicht bedingungslos der neuen Sowjetmacht zur Verfügung stellt.

Šklovskij, der sich nicht scheut, sich in Gefahr zu begeben, um "verschiedene Methoden der Unfreiheit zu studleren". d.h. der den Kontakt und die Auseinandersetzung mit den Trägern der offiziellen Kulturpolitik sucht.

Šklovskij, der sich nicht ins Private oder gar ins Exil zurickzieht, sondern in die Sowjetunion zurückkehrt und stets am öffentlichen Leben teil hat.

Šklovskij, der mit seiner Redekunst. mit seinem Witz die kulturelle Öffentlichkeit der Sowjetunion so betört. das es niemandem gelingt. inn ideologisch festzulegen und er sich aut diese Weise einen künstlerischen Spielraum sichern kann. ohne in Ästhetizismus zu verfallen.

Sklovskij, der von einigen maßgeblichen Trägern der Kulturpolitik whe LunaCarskij. Gor'kij und anderen akzeptiert wird. aber sich auBerhalb des EinfluBbereichs dieser Protektoren nicht sicher weib.

Šklovskij, der weiterhin den Status eines "Hotidichters" erfolgreich abwehrt und auch nach seiner Ruickkehr aus dem Exil seiner eigenen Wege geht.

Für den Erzähler in der "Dritten Fabrik" liegt - wie es in "Zoo" noch scheinen mag - das entscheidende Problem nicht in der Frage. welcher politischen Kultur, ob der westeuropäisch kapitalistischen oder der sowjetrussischen. der Schriftsteller sich beugen soll. Sein Problem ist vielmehr - und hierin trifft er sich mit Kipling - daB er zwischen verschiedenen Kulturen steht. Kipling, von Geburt ein Inder, seiner Budung nech ein Engländer, stand zwischen der Kultur der Kolonialherren seines Landes und der des kolonisierten Indien. Der Konflikt zwischen dem indischen Leben und der englischen Zivilisation. der sich dem Europäer als Konflikt zwischen dem Wilden und der Zivilisation darstellt, ist ein immer wiederkehrendes Thema seiner Geschichten. Sklovskij stand 2 wischen verschiedenen Kulturen - 2 wischen der jüdischen, der deutschen und der russischen, $z$ wischen der vortevolutionären russischen und der sowjetischen und $z$ wischen der revolutionären sowjetischen und der westeuropäisch kapitalistischen Kultur. Die Erfahrung so vielfaltig verschiedener Kulturen hinderte ihn daran, sich bedingungslos 24 der sowjetischen Kultur zu bekennen, die sich - ihrer Unerfahrenheit zum Trotz - gegen 
Ende der 20er Jahre anschickte, die selbstherrliche und bornierte Parole vom "Aufbau des Sozialismus in einem Lande" zu propagieren und Internationalismus jeglicher Art zu verfemen. Vor die Alternative gestellt. "wild". d.h. anarchistischer Revolutionär im Untergrund, zu bleiben oder sich domestizieren zu lassen. was soviel heiBt wie: entweder den Verlockungen des glamour der kapitalistischen GroBstadt zu erliegen oder aber zum Hofdichter der sowjetischen Kultur zu werden. entschied er sich zu einem eigenwilligen Zickzackkurs zwischen den Kulturen - in der Hoffnung, daB die russische Revolution in besonderem MaBe das Recht auf eine spezielle Kultur gewähren könne, die die Sehnsucht nach Imagination von Menschheitsträumen nicht aufgibt, aber ihre eigene Bedingtheit erkennt.

\section{Der Revolutionär und Abenteurer Šklovskij}

Der Held der "Dritten Fabrik" hat keinen utopischen Gesellschaftsentwurf und kein utopisches Menschenbild im Sinne eines auberhalb von erfahrbarer Zeit und erfahrbarem Raum liegenden geschlossenen und idealen Gebildes vor Augen. ${ }^{88}$

Im SchluBkapitel seines Buches "Lohnarbeit im Tagewerk" verrät der Erzähler Šklovskij dem Leser unter dem Vorwand eines Dialogs mit seinem Gewissen. das ihn in der Nacht heimsucht, daB er weder eine Papierrolle mit sich herumtrage. noch mit ihm, dem Gewissen, so spreche wie Griboedov in Tynjanovs historischem Roman "Der Tod des Wesir Muchtar", da er, Šklovskij, das Igorlied weder kenne noch liebe. ${ }^{89}$ Die Papierrolle Griboedovs enthielt einen Gesellschaftsentwurf, einen geheimen Plan zur Erneuerung der russischen Gesellschaft. Aber der Erzähler in "Lohnarbeit im Tagewerk" ist kein Patriot. er hat keine Utopie im Sinne eines politischen Entwurfs. Er sagt, daB sein Gewissen nur ihm selbst ähnlich sei.

"Es ist mir ähnlich, es arbeitet nur für einen Beunruhigten, Unzufriedenen, Begehrenden. Es sitzt am Tisch und raschelt mit den Seiten." 90

Šklovskij vertritt weder eine programmatische Theorie, noch beansprucht er für seine Konzeption absolute Gültigkeit oder Wahrheit. Er ist ein Revolutionär. ein Abenteurer in Revolution und Alltag. Sein Freund Tynjanov aus dem Leningrader OPOJAZ plante, ein Buch über ihn als "Schriftsteller neuen Typs" zu schreiben:

Šklovskij arbeite mit Material seiner unmittelbaren Umgebung, das ihm zu Füen liege und das während der Arbeit auf ihn zu trete. Deshalb kämen ihm Zweifel, wenn er nicht wisse. was er mit einem unbekannten Ding machen solle, und darin liege seine Stärke." 91

Seine vom Sensualismus und von der Lebensphilosophie geprägte Prosakonzeption bewahrt ihn sowohl vor einer programmatisch politischen, als auch vor einer oberflächlich anekdotischen Verarbeitung des Wortmaterials. Das Spiel 
mit den Worten, mit der Sujetkonstruktion und mit dem Leser verweist auf eine Sehnsucht - auf die Sehnsucht nach einer nicht von eindimensional ausbeuterischem Zweckrationalismus verstellten Wahmehmung und Beziehung $\mathbf{z}$ wischen Menschen. Worten und Dingen. Die Rede des Helden in der "Dritten Fabrik" eröffnet in diesem Sinne eine utopische Dimension, d.h. eine die unmittelbare Erfahrung der Realität entgrenzende Tendenz mit der Funktion. ästhetische Wahmehmungsstrukturen zu revolutionieren. In "Die Erweckung des Wortes" und in "Die Kunst als Verfahren" sprach der Formalist Šklovskij bereits davon.

Herbert Marcuse stuitzt sich in seiner Theorie von der "neuen Sensibilität" auf diese utopische Tendenz in der Konzeption der Formalisten, insbesondere Šklovskijs, allerdings ohne auf die "literarische Persönlichkeit" des Schriftstellers im kulturellen Kontext der Sowjetunion genauer einzugehen. Sein Rekurs auf Šklovskij dient in erster Linie der Beweisführung und Illustration seines eigenen utopischen Konzepts, das in kritischer Auseinandersetzung und Nachfolge der gescheiterten klassischen kommunistischen Revolutionskonzeption steht und insofern auch nur einen Teilaspekt von Šklovskijs Prosakonzeption zu erfassen vermag, nämlich die Rebellion gegen die Entfremdung und Eindimensionalität des Zweckrationalismus repressiver Gesellschaften in Gestalt der Forderung nach Entautomatisierung und Revolutionierung der sinnlichen Wahrnehmung in der Kunst. ${ }^{92}$ In allem Uibrigen unterstellt er den Formalisten bzw. Šklovskij eher ein Einverständnis mit seiner von dem Marx der "Deutschen Ideologie" inspirierten und an den antiautoritären Protestbewegungen unterschiedlicher Provenienz in Europa und in den USA der 60er Jahre entwickelten Utopie einer repressionsfreien Gesellschaft. als daB er ihnen gerecht wuirde. Denn eine tiefe "skeptische Besonnenheit" (Benjamin) hält Šklovskij davon ab, an die reale Möglichkejt der Verwirklichung einer solchen Utopie zu glauben.

Hansen-Löve bezeichnet die utopische Dimension in S̆klovskijs Konzeption als "Vitalismus" und "Neo-Primitivismus", in dem die Sehnsucht des "iberinformierten. mit Kultur und Bildung gesättigten BewuBtseins einer hochentwickelten intelligencija” zu Worte komme 93 - eine Tendenz, die, von Westeuropa kommend, auf die Formalisten in RuBland eine "viel tiefere Wirkung ... (hatte), weil sie hier unmittelbar an jene archaischen 'primitiven Denkstrukturen' anschlieBen konnte. die auBerhalb der Stadtkultur - wenn auch peripher - noch reich erhalten waren." 94 Hansen-Löve rekonstruiert die Evolution dieser Tendenz von der symbolistischen Kunst des ersten Jahrzehnts über die Kunst der Futuristen (Larionov, Gončarova, Kamenskij, Burljuk. Chlebnikov u.a.) bis hin zu den Formalisten. Seine Auffassung, daB sie in direkter Linie von Šklovskij zum artifiziellen Kunstprogramm Nabokovs führe, in dem die Utopie des "Primitivismus" ganz im ästhetischen Erleben des Kunstwerks aufgehoben ist, scheint mir ebenfalls eher eine spekulative Projektion des Autors zu sein, die sich durch die Textanalyse der "Dritten Fabrik" falsifizieren läbt.

Die Rede des revolutionären Šklovskij entzündet sich immer wieder an der 
Kritik an der Gesellschaft. Er redet gegen die Dichotomisierung von Öffentlichkeit und Privatsphäre, die sich gerade in der Sowjetunion mit der Restitution des Alltags nach der Revolution entgegen allen Behauptungen. daB das gesellschaftliche Leben die Privatsphäre abgeschafft hätte, wieder zu etablieren begann. gegen eine naive Vorstellung von kollektiver Arbeit auf der einen und von Individualismus auf der anderen Seite. ${ }^{95}$ Er kritisiert die Erstarrung von Herrschaftsstrukturen, wie sie sich für ihn insbesondere in der Kulturpolitik (gegen die rote Restauration, gegen die Entmuindigung der Künstler, gegen taylorisierte Arbeit im Kinobereich) bemerkbar machte. Gegen all das setzt er seine literarische Rede, die Hierarchien und ritualisierte Strukturen aufbrechen. Privates veröffentlichen und Öffentliches privatisieren und Begriff und Emotion miteinander verknüpfen will.

Den revolutionären Abenteurer der "Sentimentalen Reise" bezeichnen Sätze wie:

"Es ist schön, zu leben und den Weg des Lebens mit der Schnauze zu spüren. SüB ist das letzte Stückchen Zucker. Sorgsam in ein Papierchen eingewickelt. Schön ist die Liebe.

Ihn bezeichnet ebenso die Anekdote, daß er. Šklovskij, auf eine einsame Insel verschlagen, nicht Robinson, sondern ein Affe werden würde 97 - wie seine Kritik an der "wissenschaftlichen Utopie" der Bolschewiki. ${ }^{98}$ In "Zoo" präsentiert er sich als ungluicklich Liebender - als russischer Emigrant in ungebiugelten Hosen, der die Tischsitten und die Methode. eine Frau zu verführen. in der westlichen Kultur nicht beherrscht. ${ }^{49}$

In der "Dritten Fabrik" verkörpert der deplacierte Mensch, der die Zeit und das Leben anruft, auf daB es sich ihm erötfne und er es sinnlich erfahren könne, den revolutionären Sensualisten, der bei Rousseau und Sterne in die Schule ging. Der Geruch des Klebers in den Montageräumen des sowjetischen Kinos, der nach Bimenessenz duftet, versiibt ihm die Alltagsarbeit [97]. Die Erinnerung an den ersten Winter in Moskau verquickt sich mit der Erinnerung an den Geruch von Apfelsinen und Rauch [79]. Den Morgentee liebt er genauso wie die Frau und die Literatur $[37,103]$. In der Rede des deplacierten Menschen spürt Kklovskij sinnlichen Beziehungen zu elementaren und banalen Dingen des Alltags nach. Die Bilder der Liebe setzen das Verwechselspiel, das Šklovskij in "Zoo ..." entfaltete, fort. In jenem Text fungiert die geliebte Alia als "Realisierung einer Metapher".

"Ich bin völlig verwirtt. Alia! Gleichzeitig mit den Briefen an dich schreibe ich nämlich an einem Buch. Was im Buch ist. und was im Leben ist, hat sich völlig verwirrt. Erinnerst du dich, daB ich dir von Andrej Belyj berichtete und von der Methode? Die Liebe hat ihre Methoden, eine Logik der Bewegungen, die ohne mich und uns festgelegt wurde. Ich sprach das Wort Liebe aus und setzte den Ablauf ins Werk. Das Spiel begann. Wo die Liebe, wo das Buch ist. weiB ich nicht mehr. Das Spiel entfaltete sich. Aut dem dritten oder vierten Druckbogen wird mir Schach und Matt geboten werden. Der Anfang ljegt bereits hinter uns. Niemand vermag das Ende zu korrigieren." 
Während sich der Held in "Zoo ..." der Schwerkraft der imaginierten Liebe überläBt. sie thematisch gestaltet und literarisch ausschöpft - man erinnere sich in diesem Zusammenhang auch daran, daB Šklovskij das Buch qua Titel in die Tradition des Liebes-Brief-Romans stellt -. geht er in der "Dritten Fabrik" zurückhaltend und sparsam mit solchen Imaginationen um. Er assoziiert sie eher flüchtig und abrupt - zum Beispiel in Form eines Mottos. das er dem Kapitel "Der Sommer nach dem Gymnasium" voranstellt.

"Die Frau hat die Liebe und 24 der Liebe sucht sie sich Liebhaber.

Bleib hier stehen. Satz, und bewache die Dinge, während ich andere Worte herbeibringe." [37]

Liebe, nicht als statische Fixierung auf ein Ideal, sondern als emotionale Energie verstanden, wirke - so heiBt es hier - $z$ wischen den Worten so wie zwischen Mann und Frau ein Beziehungsgeflecht, das ihre Semantik konstituiere. Solche Bilder zeigen. daB Šklovskijs Prosakonzeption nicht nur als Programm einer artifiziellen Kunst, die sich in Ästhetizismus erschöpft (Hansen-Löve), verstanden werden darf, sondern auch als eine revolutionäre Konzeption, da sie die Sehnsucht nach sinnlichen Beziehungen zu den Dingen - wobei Sprache nicht bloB als Medium. sondern eben auch als Ding zu betrachten ist - modellhaft realisiert.

In den Erinnerungen an seine eigene Kindheit in der "Ersten Fabrik" und in den Erzählungen von seinem Sohn verleiht der Held der "Dritten Fabrik" der Sehnsucht nach dem naiven Zustand des Kindseins Ausdruck. Er stellt sich dem Leser in der Maske des roten Spielzeug-Elefanten seines Sohnes vor nicht nur. um als deplacierter Mensch auf die Gefahr hinzuweisen, daB seine Stimme schablonenhaft wie das Piepsen eines Gummitieres klingen könnte. sondern auch. um durch die Autnahme auBerliterarischen Materials den Bannkreis der für die literarische Darstellung als würdig befundenen Gegenstände zu sprengen und die kindliche Wahmehmung der Welt, die noch keine Gattungsbegriffe kennt bzw. diese von der Bezeichnung konkreter Einzelgegenstände noch nicht unterscheiden kann und deshalb unbewuBt die hierarchisch geordneten Wahmehmungen und Bezeichnungen der Erwachsenenwelt durcheinanderbringt. als Kunstgriff zu übernehmen.

"Mein Sohn lacht.

Er fing an zu lachen, als er zum ersten Mal ein Pferd sah, er dachte. daB es im Scherz vier Fiibe machte und eine lange Schnauze." [13].

erzählt der Held, um im nächsten Satz die eigene Maskierung als Gummielefant vorzubereiten. DaB der Held der "Dritten Fabrik" die Distanz zwischen dem Kind und dem Schriftsteller dariber nicht vergiBt, zeigt sich in dem Kapitel "Zweite Kindheit", in dem er sich als liebevoller, beobachtender Vater präsentiert.

"Er ist jetzt anderthalb Jahre. Er ist rosig. rund und warm. Er hat weit auseinanderstehende ovalgeformte Augen. Dunkle. Er geht 
noch nicht, er rennt. Sein Leben verläuft noch ohne Unterbrechungen. Es besteht nicht aus einzelnen Tropfen. Man fühlt das Ganze. Er rennt, indem er die FüBchen seitlich hochhebt.

Als wir ihn im Sommer mit aufs Land nahmen. beugte er sich von meinen Armen herab. Betrachtete das Gras.

Betrachtete die Wände, den Himmel betrachtete er nicht. Er wuchs. An den Wänden Werg. In der Stadt erkannte er in einer Puppe einen Menschen. Setzte sie in einen Korb mit dem Kopf nach unten und $z 0 \mathrm{~g}$ sie durch das Zimmer.

Er wollte auf den Tisch klettern. Der Tisch ist höher als er. Der Junge schleppte den Korb zum Tisch, kletterte hinein und wurde nicht gröBer. Der Korb war oben offen.

Dann drehte er den Korb um. Stellte sich auf allen Vieren rückwärts vor ihm auf und kletterte mit den Hinterbeinen hinauf. Es kam nichts dabei heraus: er kam nicht hoch. Nach einigen Tagen lernte er es. auf den Korb und von dort auf den Tisch zu klettern ... An mir gefällt ihm meine glänzende Glatze ..

Die Zeit wird kommen ... [134/135]

Auch durch seine literarischen Vorbilder - Kiplings Geschichte von der eigenwilligen Katze. Andersens Märchen ("Die StraBenlaterne". "Der Flachs") und Don Quijote - bringt der Erzähler der "Dritten Fabrik" Kindheit ins Gespräch. denn diese Bücher zählen allesamt zur klassischen Kinder- und Jugendliteratur. Šklovskij verfaßte selbst zahlreiche Kinder- und Jugendbücher und wahrscheinlich nicht allein deshalb, weil es leicht zu beschaffende Auftragsarbeit war. sondern weil inm bei dieser Arbeit seine Vorstellungen von der kindlichen Wahrnehmung auch als Schutz vor der Zensur zugute kamen.

Während der Held der "Sentimentalen Reise" in erster Linie den Abenteurer verkörpert, der Revolution und Bürgerkrieg wie ein exotisches Fest feiert. ironisiert der Held der "Dritten Fabrik" die Idealisierung des Exotischen und erwähnt dabei namentlich auch Rousseau und dessen Projektion des Ideals vom natürlichen Menschen auf den Naiven und Wilden. ${ }^{101}$ Sein revolutionärer Sensualismus ist komplizierterer, widerspruichlicher Art. Er fixiert sich nicht auf ästhetische Ideale und gesellschaftliche Utopien. seine Sehnsucht ist vielmehr die Aufhebung solch statischer - seien es transzendentale. seien es positivistische - Fixierungen. Seine Rede verkniupft Lebens- und Denkräume. die im BewuBtsein der Moderne von den Mechanismen der Arbeitsteilung und den Machtstrukturen einer hierarchisch geordneten Gesellschaft dichotomisiert und einander entfremdet sind. und schafft auf diese Weise eine neue Synthese des zerrissenen Subjekts. Die Rede des Helden der "Dritten Fabrik" evoziert eine erhöhte Sensibilität für Methoden zur Verknuipfung des sich selbst fremd gewordenen Einzelnen, wie sie in der subjektiven Wahrnehmung unbewubt ohnehin vonstatten geht, und literarisiert somit modellhaft seine Sehnsucht.

Der Held der "Dritten Fabrik" nimmt ironisch, wenngleich wesentlich verrätselter als der Held der "Sentimentalen Reise". zur "wissenschaftlichen Utopie" des Marxismus-Leninismus Stellung. Er erinnert an Edgar Allan Poe und dessen science fiction-Vision rom mit schwimmenden Telegraphenstationen 
Uberzogenen Ozean in der phantastischen Erzählung "Mellonta Tauta", 102 einer Welt im Jahre 2848, in der es keine unerforschten Regionen mehr gibt.

-Edgar Poe stellte sich den zukuinftigen Ozean vor, der ganz von Kabeln auf schwimmenden Bojen bedeckt ist. Die Menschen träumen von der Zukunft, als einer Verbesserung, als einer Fortsetzung." [89]

Die Geschichte "Mellonta Tauta" erweist sich bei genauerer Betrachtung weniger als Zukunftsvision denn als Satire auf die amerikansiche Gesellschaft seiner Zeit, als Kritik an der Wissenschaftsgläubigkeit und als Kritik an der Vermassung der Menschen bzw. an der Herabwürdigung des Individuums in der modernen Industriegsellschaft. ${ }^{103}$ Indem Šklovskij Poe zitiert. setzt er dessen negative Utopie und Gesellschaftskritik zur Technikgläubigkeit des Marxismus-Leninismus analog.

Poe präsentiert die Erzählung als Botschaft aus einer Flaschenpost. die die Verfasserin auf einer Vergnïgungsfahrt im Ballon durch die Atmosphäre ins Meer wirft, als der Ballon platzt. wie der Leser aus der Botschaft selbst erfährt. Pandita verfaBte sie als Brief an einen Freund, um - wie sie sagt sich die Langeweile zu vertreiben. Dann und wann schildert sie ihre äuBere Befindlichkeit, aber vorwiegend raisoniert sie uber die "Antike", d.h. iber die alten Philosophen von Aristoteles bis zu Poes Gegenwartszeit (bis zu der Zeit "vor tausend Jahren").

In ihrer Erzählung präsentiert sich dem Leser die Zukuntit als "Verbesserung" in Sinne einer ununterbrochenen Fortsetzung des Lebens der "Antike", in der der Fortschritt der Technik mit der Tendenz der Vermassung einhergeht. Die Eisenbahnen erreichen eine Geschwindigkeit von 300 Meilen pro Stunde, ihr Schienennetz durchzieht vielgleisig die Erde. der Ozean ist mit Telegraphenstationen überzogen. Ballons gelten als öffentliche Verkehrsmittel, sie schweben zuhauf am Himmel. Pandita fliegt durch die Milchstraße, an den Trabanten des Neptun und am Mond vorbei. Schiffe und Ballons haben gigantische AusmaBe, sie transportieren jeweils hunderte von Menschen. Das Leben des Einzelnen zählt nicht viel: als einer uiber Bord eines Schiffes geht. wird er nicht wieder aufgenommen. "Ich finde es herrlich. mein lieber Freund. daB wir in einem Zeitalter leben. welches erleuchtet genug ist. um sich mit einer Bagatelle wie dem Individuum nicht mehr abzugeben. Die Masse ist es, worum sich die wahre Humanitat zu kümmern hat."10'

Der "Humanismus der Masse" diktiert, daB Krieg und Pest der "vernunftigen" Dezimierung der Masse dienen. "Waren sie (die Menschen der früheren Zeit, V.D.) so blind, nicht zu erkennen, daB die Vernichtung einer Myriade von Individuen doch für die Masse nur von Vorteil ist?!"

Die Vorstellung von der Zukunft als "Verbesserung" und "Fortschritt" - von Poe scharf kritisiert - hat in Anlehnung an jenen Autor auch Šklovskijs Widerspruch provoziert. Denn er ibernimmt sie in einem Satz beinahe wörtlich. unmittelbar nach dem expliziten Hinweis auf Poes Vision vom "verkabelten Ozean" aus einem anderen Text Poes. der in unmittelbarem thematischen Zusammenhang mit der Zukunftsgeschichte "Mellonta Tauta" steht, aus dem philosophisch-literarischen Dialog 2 wischen Monos und Una. Monos sagt: 
"Du wirst dich entsinnen, daB einer oder zwei der Weisen unter unseren Vorvätern - Weisen in Wahrheit, ob schon auch nicht in den Augen der Welt - es gewagt hatten, die Berechtigung des Begriffs "Verbesserung" in Zweifel zu ziehen, wo er auf das Fortschreiten unserer Zivilisation angewendet ward." 106

Als Motto dieses Dialogs fungieren die Worte "Méllonta taata (Zukünftig ist all dies)", die acht Jahre später den Titel der oben genannten phantastischen Geschichte bilden sollten. Poe hat sie sich von Sophokles aus der "Antigone" geliehen und dann als ironisches Zitat eingesetzt.

Mit der Kritik am Gegenwärtigen korrespondiert in Poes science fiction "Mellonta Tauta" das Bekenntnis zur intuitiven Erfindung. d.h. zur literarischen Imagination in Analogie zu naturwissenschaftlichen Entdeckungen. Hiermit setzt Poe den Philosophen der Vergangenheit, den Transzendentalphilosophen und den technikgläubigen Positivisten seine eigene "Erkenntnistheorie" entgegen.

"... die Unterdruickung der Imagination war ein übel, das keine noch so aufgeplusterte Zuversicht, ja GewiBheit bei den alten Methoden der Wahrheitssuche aufzuwiegen vermochte. ${ }^{.107}$ Kepler gab zu. daß seine drei Gesetze (die Gesetze der Gravitation. V.D.) durch Erraten zustande gekommen seien. diese drei obersten Gesetze, welche den groBen eng-ländischen Mathematiker (Newton. V.D.) zu seinem Prinzip führten, dem Grundprinzip aller Physik dem mit unserem Verstande $z u$ folgen wir das Reich der Metaphysik betreten missen. Kepler riet, das soll heißen. er lieB seiner Imagination freies Spiel. ${ }^{\text {108 } 8}$

Der Ausruf des griechischen Mathematikers Archimedes bei der Entdeckung hydrostatischer GesetzmäBigkeiten "Heureka", der im Laufe der Zeit zu einem geflügelten Wort geworden ist und den Pandita in "Mellonta Tauta" im Zusammenhang mit Entdeckungen über das Leben in dem "antiken" New York ausstöBt, verdichtet sich im Werk Poes zu einem Symbol dafür. daß die Naturwissenschaft als objektives Korrelat seiner intuitiven GewiBheit fungiert. Denn auch sein philosophischer Essaypoem "Heureka" ist nach dem legendären Ausruf des Archimedes benannt. in dem Poe seine Lebensphilosophie von der Zerrissenheit der ursprünglichen Einheit des Universums darstellt. Poe setzt die naturwissenschaftliche Entdeckung in seiner science fiction nicht so sehr als Thema in Szene - in "Mellonta Tauta" spielt sie als solche kaum eine Rolle -. sondern als Kunstgriff, Wahrscheinliches glaubhatt zu machen und Urbilder von Menschheitsphantasien zu mobilisieren (der Flug in der Atmosphärel. Auf diese Weise entwarf er gegen die Utopie des technischen und zivilisatorischen Fortschritts seine Kunsttorm, in neue Welten vorzudringen.

Der Held der "Dritten Fabrik" folgt Poe weiter, als es die beiden in Anlehnung an den amerikanischen Schriftsteller formulierten Sätze vermuten lassen. Nicht nur in ihrer Gesellschaftskritik, sondern auch in ihrer Utopie von der Macht der Worte, von der Korrelation 2 wischen naturwissenschaftlichen und literarischen Erfindungen zeigen sich Affinitäten, die bis in die Metaphorik der Sprache des Helden in Šklovskijs autobiographischer Prosa hineinreichen. Das in Variationen wiederkehrende Bild von dem Gesetz der Schwerkraft (mit den Füßen auf der Erde stehen: die Äpfel, die auch in Zeiten der Revolution vom Baum fallen; der Stein, der vom Himmel auf die Erde fält; die Zimmerdecke. die den Bewohnern auf den Kopf fält), das energetische Modell der Muschel, die den Druck aus beiden Richtungen auf ihren Häften braucht, um lebendig zu bleiben, und der Vergleich aus der Physik. daß die literarische 
Produktion ein ProzeB sei, in dem es darum gehe, die Kunstgriffe zu konzentrieren, da er sich nicht danach bemesse, daB es Materie und Energie, sondern danach, daß es ein Wärmeäquivalent für die Maßeinheit der Arbeit gebe [102], weisen auf solche Affinitäten zwischen Šklovskij und Poe hin. Auf dem Hintergrund der Interpretation der utopiekritischen Passage in der "Dritten Fabrik" im Zusammenhang mit Poes Zukunftsvision in "Mellonta Tauta" erhaiten auch die dieser Passage folgenden Sätze eine zusätzliche Bedeutungsdimension:

"Die Zukunft - das ist Revolution. In der Zukunft wird man nicht Uber die Miete streiten.

Lieber ein Brand im Buchladen, ein Verbot. Bücher zu drucken, als eine rote Restauration." [89]

Sie besagen, daB Revolution, verstanden als Unterbrechung der sich in die Zukunft verlängemden schlechten Realität. Kunst und Gesellschaft in gleichem MaBe betreffen soll. Indem sich der Held der "Dritten Fabrik" in diesem Sinne gegen das Verständnis von Utopie als "Fortschritt" und für die Revolution als Unterbrechung automatisierter und kanonisierter Gesellschafts- und Kunstformen ausspricht. nenne ich ihn einen Revolutionär.

Das Bild von der Blüte des Faulbeerbaums - eine in Šklovskijs Prosa ebenfalls häufig in Variationen sich wiederholende Metapher - bezeichnet nicht nur die zähe Beharrlichkeit, mit der Šklovskij gegen den Widerstand seiner Zeit der Hoffnung auf Anerkennung seiner Konzeption Ausdruck verleiht. sondern gibe auch seiner "Utopie" Gestalt. Šklovskij lieh sich das Bild des in der winterlichen Kälte der ersten Frühlingstage schon blühenden Faulbeerbaums von zwei völlig verschiedenen russischen Schriftstellem - von Velemir Chlebnikov und Lev Tolstoj. In sein Buch "Suche nach dem Optimismus" ubernimmt er Teile aus Chlebnikovs Manifest "Die Trompete der Marsianer", worin es heiBt:

"Wir rufen ins Land, wo die Bäume reden. wo es Wissenschaftsbünde gibt, die den Wellen gleichen, wo die Frilhlingsheere der Liebe stehn, wo die Zeit wie ein Faulbeerbaum bliht und in Bewegung setzt. wie ein Kolben. wo der Mensch im Zimmermannsschutz die Zeit zu Brettern zersägt und wie ein Drechsler mit seinem Morgen verkehrt."

Und in seinem im gleichen Jahr wie "Dritte Fabrik" erschienenen Buch "Die Erfolge und Niederlagen Maksim Gor'kijs" erläutert er die Metapher, indem er sie auf eine Erzahlung Tolstojs zuribkfuhrt, ehe er sie auf Gor'kij bezieht.

"Es gibt bei Lev Tolstoj im Lesebuch fur Kinder eine Erzahlung uber den Faulbeerbaum. Diesen Faulbeerbaum fallte man und trat ihn nieder, aber er trieb heimlich wieder aus und bluhte. Als einer. 
der gefällt wurde, der in Mißerfolgen stürzte, jäh zum Schweigen gebracht wird, der es nicht versteht. seine Sachen zu Ende zu bringen. der die Fingerabdruicke seiner Lehrer trägt. der an allen Leiden der russischen Literatur krankt: an Sujetlosigkeit. Gleichgültigkeit. Lehrerhaftigkeit - als solch einer bluiht Gor'kij wie der Faulbeerbaum. ${ }^{110}$

Viel später entschlüsselt Šklovskij diese Metapher. Indem er eine ausführIIchere Nacherzahlung der Geschichte in seine Ejzenštejn-Monographie montiert. dort, wo der Leser ein SchluBwort erwartet.

"Der Faulbeerbaum wächst iberall in unserem Land - vom Weißen bis zum Schwarzen Meer.

Der Faulbeerbaum wächst gern an den Ufern kleine FlüBchen. er liebt den Wald - das Dickicht. Er blüht zu Beginn des Frihlings mit langen, weißen. bisweilen fast rosatarbenen Bischeln. Der Faulbeerbaum blüht zu Beginn des Fruhlings. Es heiBt. da es in dieser Zeit noch friert: wenn die Eiche Knospen treibt. friert es auch noch. der Frühling kommt bei uns immer mit Unterbrechungen.

Im Garten von Jasnaja Poljana sind noch Teile des alten Zaseka erhalten geblieben ...

Lev Nikolaevič war ein Reschätiger Hausherr: eines Tages hatte er bemerkt. daB ein Faulbeerbaum auf dem Weg gewachsen war und einen NuAstrauch uberwuchert hatte.

Dieser Faulbeerbaum wuchs nicht als Strauch, sondern als Baum von, wie Lev Nikolaevǐ̌ notiert hatte, etwa vier Sažen' Höhe. Er war krausköptig. gabelförmig und von wohlriechenden hellen Bliten ubersät. Noch weit von ihm entfernt konnte man seinen Duft riechen. Man befahl. den Faulbeerbaum abzuholzen.

Ein Arbeiter fing an. mit der Axt zu hauen. Der Hausherr kam hinzu und sah, dab man den Faulbeerbaum auf dem Weg abholzte.

Der Saft gluckste nur so unter der $A x t$ und floB in die Kerbe nach. und der Faulbeerbaum erzitterte mit den Trauben seiner Bluiten.

Offenbar ist es Schicksal, dachte Tolstoj, und begann zusammen mit dem Bauem zu hauen.

Jede Arbeit ist fröhlich - fröhlich ist auch das Abholzen.

Der Haushert vergaB den Faulbeerbaum und seine Bliuten. Er dachte nur noch daran. ihn so schnell wie möglich abzuholzen.

Tolstoj geriet auBer Atem. legte die Axt beiseite. stemmte sich mit dem Bauern gegen den Baum - der Baum war so dick. daB man den Stamm mit zwei Händen umtassen muBte.

Sie bewegten ihn hin und her. die Blatter des Baumes fingen an zu zittern. Tautropfen fielen herab: die weiBen, wohlriechenden Bluitenblätter rieselten nieder.

Noch einmal stemmten sie sich dagegen.

Es schien. als schrie jemand in dem Baum auf.

Dort. im Innern des Baumes, schien etwas aufzuweinen.

Es fing in der Mitte an zu krachen; der Baum fiel zu Boden. Er riB an der angehauenen Kerbe auseinander und blieb, mit Ästen und Bluiten ins Gras stoBend. liegen; Blätter und Bluiten zitterten eine Zeitlang.

"Schade". sagte der Bauer.

Tolstoj tat es auch leid.

Jahre vergingen. Man säuberte erneut den zugewachsenen Weg. Man 
holzte die wilde Rose und eine Weide ab. Sie hatten sich auf einen Faulbeerbaum gestiutzt.

Der groBe, dicke Faulbeerbaum war unter einer Linde aufgewachsen. Man holzte ihn mit Leichtigkeit, genau an der Wurzel, ab: die Wurzel war verfault.

Man wollte den Faulbeerbaum zur Seite schleppen. er war aber wie festgeklebt, und man uberlegte, wo er wohl hängengeblieben ist. Ein Arbeiter fand eine andere Wurzel auf dem Weg: der Faulbeerbaum hatte gespiurt, daB er nicht unter der Linde leben konnte und hatte sich mit einem Zweig an der Erde festgeklammert und den Zweig in eine Wurzel verwandelt. Die alte Wurzel hatte er aufgegeben.

Damals begriff Tolstoj, wie jener, der erste Faulbeerbaum, auf dem Weg gewachsen war.

Schön blüht der Faulbeerbaum. schön duftet er im Frühling, und man holzt ihn ab. ohne seinen Wert zu erkennen. Doch der Baum. der blühende. lebendige Baum wechselt von einem Ort zum andern über ... Wie ein Faulbeerbaum blühte Sergej Michajlovič Ejzenštein bei uns in Moskau ....111

In die "Dritte Fabrik" fügt Šklovskij die Metapher vom blühenden Faulbeerbaum ein. um den Neubeginn seines Lebens in der Sowjetunion. in Moskau nach der Rückkehr aus dem Berliner Exil, zu schildern.

Im Jahre '20 in Piter litt ich unter der Menschenleere der Stadt ... Diesen Frühling gibt es in Moskau nicht.

Auf dem Meridian von Pokrovskoe Strešnevo kommt er so: der Schnee taut. Die Erde kommt heraus.

Dann fält noch einmal Schnee.

Ostern glückte es mir kaum. Efeublätter zu sammeln, und der Winter schlug noch einmal zu. Dennoch nahmen wir die gewaltigen Vorsatzfenster heraus. Die Fenster lagen bei uns oberhalb der Zimmer, sie verschwinden nach oben, in besondere Abseiten.

An den Bäumen gelb-grüne Knospenbällchen.

Im Wald, richtiger, unter den Bäumen bewegt das Gras die Blätter des Vorjahres leicht. Es wächst.

Dann blüht der Faulbeerbaum in neuer Käte.

Ich weiB nicht. was ich über den Flieder sagen soll. Er ist dick. Die Nachtigallen begannen so gewaltig zu schlagen. daB man im Dunkeln nach dem Gehör aus den Bergen auf sie hätte schieBen können. Belaubte Bäume teilen den Park in Nischen. Menschen gehen umher. flüstern. schlagen sich den dicken Flieder ins Gesicht. Mücken.

Ganz Moskau kommt in StraBenbahnen zu uns gefahren.

Es herrscht schon stickige Hitze. Menschenschlangen auf dem Strastnaja Platz. Die Eisverkäufer sind da. Radfahrer, ein Restaurant. Ein Blasorchester direkt vor dem Fenster.

Das Publikum bleibt stehen und liest die Inschrift am Zentralmuseum vor uns. Mit verschiedenen Stimmen ...

Zum Abend hin zilndet man die Laterne an. Das Grin bei der Laterne sieht sehr dick aus.

Nachts fährt ein Automobil die Alleen entlang zum Restaurant." [91/92]

So banal die Schilderung der Frihlingsidylle in Moskau auch erscheinen mag. so ist sie doch weniger ein schlichtes Stimmungsbild als die kunstvolle 
Konstruktion der Selbststilisierung des Autors zum optimistisch in die Welt blickenden und beinahe schwärmerisch den Beginn des Frühlings erlebenden Schriftsteller im Kontrast zum sich selbst anklagenden deplacierten Menschen. In diesem Frühlingskapitel gibt sich der Held mit seinem neuen Dasein versöhnt. indem er sich die Perspektive eines ganz alltäglichen, aber angesichts des Ausnahmezustands der Revolutions- und Bürgerkriegszeit doch neuen. friedlich und festlich gestimmten Lebens- und Sprachgefühls eröffnet. Die Blüte des Faulbeerbaums weist auf seine Hoffnung hin, daB sich ihm nach der winterlichen Kälte des Exils und der "roten Restauration" die Aussicht auf einen sinnvollen Lebens- und Arbeitszusammenhang in Moskau eröffnen möge.

Während das Bild des blühenden Faulbeerbaums in Chlebnikovs Manifest "Die Trompete der Marsianer" utopische. Zeit und Raum entgrenzende Perspektiven eröffnet. in denen sich die gesellschaftliche Revolution und die Revolution in der Kunst miteinander verschmelzen - ein Entwurf, an dem der junge S̆klovskij als Bewunderer und Schüler des futuristischen Dichters ${ }^{112}$ partizipierte und an den der Autor der autobiographischen Prosa Šklovskij nun erinnert - beschwört es in Tolstojs Erzählung eine Vision ganz anderer. beinahe diametral entgegengesetzter Art: hier fasziniert die Vorstellung von der zähen, anspruchslosen Lebendigkeit der Natur, die sich beharrlich und erfolgreich gegen den Versuch des Menschen, sie einzuschränken und zu vernichten, wehrt.

Die Verbindung dieser inkommensurablen Konnotationen verleiht der Metapher in der Prosa Šklovskijs eine neue. eigene Semantik. Auf der einen Seite transportiert sie die utopische Vision der konstruktiven Verschmelzung der gesellschaftlichen Revolution und der Revolution in der Kunst. Denn sie erinnert an einige der groBen Revolutionäre in der Kunst - an Chlebnikov. Gor'kij und Ejzenštejn - und bringt den Helden der autobiographischen Prosa. sein Leben und seine Arbeit (den OPOJAZ), in Zusammenhang mit ihnen bzw. ihren Konzeptionen. Auf der anderen Seite erzählt sie aber auch von dem Tribut. den die gesellschaftliche Realität Šklovskij abverlangt, und davon, daß er sich erst dann als Revolutionär in der Kunst erweist. wenn seine Kunst, dem Widerstand der Zeit zum Trotz, zäh, behartich und flexibel in einer subversiven Rede ihre Lebendigkeit behauptet. so wie der Faulbeerbaum mit dem labyrinthischen System seines Wurzelwerks unter der Erde. d.h. unsichtbar für seinen Feind, den Menschen, der ihn roden will, zäh sein Leben verteidigt.

Der revolutionäre Abenteurer Šklovskij - das ist der Erfinder in der Kunst. wie er sich in den Flugmetaphern darstellt, das ist der Schriftsteller und Literaturkritiker, der mit geliehenen Stimmen spricht und sie anscheinend zusammenhanglos aneinanderreiht: der mit der Schreibfeder raschelt, anstatt mit starkem Flügelschlag in den Himmel von Utopia aufzusteigen. Er kennt und akzeptiert die Differenz zwischen der imaginierten Welt der Bücher. deren Sprache das BewuBtsein der Menschheit zum Ausdruck bringt, und der gesellschaftlichen Realität, deren Sprache sich dem BewuBtsein des Menschen 
zumeist erst im nachhinein entschlüsselt. zwischen den Menschheitsphantasien und dem Altag des Menschen, und er setzt alles daran, diese Differenzerfahrung zum "élan vital" für die Literatur und für das Leben zu machen.

Der endgültige Zerfall der linksavantgardistischen Künstlergruppe LEF und der Tod des Freundes, des Zukunftsdichters Majakovskij, den er ironisch als "Arbeitsunfall" bezeichnet, ${ }^{113}$ stellen ihn vor die Zerreißprobe, denn während der Staat eine zunehmende Annäherung von Utopie und Wirklichkeit behauptet. verschärft sich in dieser Situation aus seiner Perspektive die Differenzerfahrung zu einer extremen Kontrasterfahrung, in der ein Dialog zwischen den Polen kaum mehr möglich scheint. Angesichts dieser Ereignisse bestimmt weniger Ironie als trauriges Pathos die bekenntnishafte Rede Šklovskijs in "Suche nach dem Optimismus".

"Oh Jugend - schreie ich jetzt.

Und ich schlage mit den Flügeln an den Tisch.

Sie flogen dorthin in den Norden. wo es den FüBen auf den Steinen nicht heißt ist. die Gänse aus dem Süden.

Sie flogen und brachten die Luft mit den Flügeln in Bewegung ... und gaben sich gegenseitig Halt.

Oh Jugend. Futurismus!

Lef!

Ein Schrei fliegender Gänse.

Eine graue Hausgans. sie hört den Schrei.

Sie läuft am Meeresufer entlang wie ein Passagier auf dem Deck eines sinkenden Schiffes.

Sie schreit.

Oh verflogene. nicht aufgeflogene Jugend!

Ich schreie aus einer roten Kehle, mit einer Stimme von Gänsekupfer.

Mit der Stimme eines Leiterwagens.

Und schlage mit grauen Flügeln auf dem Papier.

Sie flogen keilförmig, das heiBt keilförmig fliegen Flugzeuge und Kraniche.

An dem Schrei höre ich. daB meine Brust heil ist.

Sie flogen im Frühling.

Dorthin. wo es noch nicht warm ist. wo der Faulbeerbaum bluht.

Das Zimmer ist voll von dem Prasseln und Rascheln der Federn.

Wachst, ihr Federn.

Ich fliege hinauf.

Labt uns zusammen fliegen.

Genossen Zeitgenossen!

Bringen wir die Luft in Bewegung!

Bedecken wir den Himmel mit den Flügeln!

Es ist absolut nicht die Zeit. muide $z u$ werden.

Wir muissen Optimismus bewahren und Verantwortung vor der Zeit. ...

Diese Zeit blüht wie der Faulbeerbaum."114 


\section{Anmerkungen zu Tell II, Kap. 2: Die Stimme des Schriftatellerః}

1 V.Skklorakif. Carll Caplin. In: Carli Zaplin. (Hrag.) V.Sklovskij. L. 1929. S.77: vgl. A. Hensen-Löve. S.284. S.553: von thm Ubemehme lch die Ubersetzung der Bezelchnung "Zelovek ne na svoem meste" "deplaclerter" oder "ver-ruckter Mensch".

2 Zitate wie dleses aus Sklovskifs "Tret'ja ..." werde tch in den folgenden Kapitein nicht durch gesonderte Anmerkungen. sondern durch Seltenangaben in ecklgen Klammern kenntlich machen.

3 Vi.Lenin. Blbllografizeskaja chronika. Sobr. aoz. tom 12 (Dez. 1921 - Jan. 1924). M. 1982. S.293. 572

4 L. Trockif. Literatur und Revolution. S.14S

5 ebd. S.149

6 ebd. S.152

7 A.Lunatarskl). Formallzm $v$ nauke ob lakusatve. In: Pecat' 1 revolfucija. 5 (1924): zit. nach Marxismus und Formalismus. S.95

8 G.LeleviC. Gippokratovo Ilco. In: Krasnaja nov'. 1 (192S). S.299

9 F.Stepun. Rezension zu Sklorsklls "Sentimentale Relse". In: Sorremennye zeplak1. 16 (1923). S.411/412

10 V.Percov, Sklovakif I ego raznovidnost'. In: Zizn' lakusatva. \$1 (1925). S.8

11 M.Bulgakov, Dle WelBe Garde. S.257/S.305

12 ebd.. S.130/S.151

13 ebd., S.129-130/S.150

14 Vgl. V.Sklorakll. Sentimental'noe .... S.220-233/S.221-232

is val. M.Bulgakov, S.12S/S.1sS und V. Sklovskil. S.79/S.80-81

$16 \mathrm{rgl}$. M.Bulgakor. S.130/S.150 und V. Sklorsk1). S.223/S.223-224

17 vgl. M.Bulgakov. S.125-126/S.146: dag Sklovskll unter Frounden den SpltzSpltznamen Onegln trug. erfuhr ich von selnem letzten Sekretar Alexander Galuskin.

18 M. Bulgakor. S.126/S.146

19 ebd.. S.127/ebd.

20 ebd./ebd.. S.147

21 vgl. V.Sklovaklf. Treile .... de Muschelmetapher S.t0/41. die in einem ahnlichen Sinn gebrauche wird: vgl. auch de Metapher des Warmedquivalents S.102

22 vgl. dazu ders.. Trei'le .... S.52: Uber Jakublnsklf und die Zaghaftigkelt selner FuBe: S.86: "'Weshalb hast du dir den FuB wundgestoBen?' fragte Freud selnen Sohn". S.28: "So offenbare slch die Kunat. mit den FuBen nach oben zu leben."

23 Nach selner Rlickkehr aus dem Berliner Exll verfabie Sklovsklf alnige Reportagen uber diese Arbelt. Aus seinen elgenen veratreuten Ausangen daruber labe slch nicht elndeutig schlleBen. wie es dazu kam. dab er dor arbeltete. Vgl. V. Sklorakl). Motalka. M.-L. 1927. S.37 ff.

24 R. Sheldon, Lterary theory .... S.277

25 Vgl. auch V. Sklorskll. Tret'je .... S.49

26 vgl. dle Dlakusslonabeltrïge L.Trock1js. A. Lunazarakils. N. Bucharine in dieser Debatte. abgedruckt in: Marxismua und Formalismus

27 A.Platonova Romane "Cevengur" (1926-29 entatanden) und "Dle Baugrube" (Dez. 1929-April 1930) alnd in der Sowjetunion ble heute nlcht erschlenen: vel. H. Gunther. Die Veratentllchung der Literatur. Stutggart 1984. S.112

28 berelts 1925 veröffentlichte Reportagen Sklovaklla Uber selne Relsen aufa Land: V.Sklovak11. Derevnje akuzaet po gorodu. In: Zumalist, 8-9 (1925): 
ders.. Ne anmolete “llcom k derevne". In: Ogonek. 30 (1925), S.12: alle in: Gamburgakif acet; ders.. Polet 1 posadka, In: Vaemimaja IIIjuatracija 7-8 (1925). S.23-25

29 vgl. B. Ejchenbaum. Molodol Tolatol. Peteraburg/Berlin 1922. reprint: Slaviache Propylien Bd.53, 1968. S.130 f.: rgl. dazu Hansen-Love. S.280 f.: Ejchenbeum atudiert an dem Erzuhler Tolatol verachledene Verfahren der Verfremdung. Inabesondere das der Stllisierung der AuBenselterposition z.B. des Erzahlera rom Krlegageachehen in den Sevacopoler Erzihlungen: rel.V.Sklovakil. Iakuastro kak prïm. S.7-23

vgl. R. Sheldon. Llterery theory .... S.272/273; rgl. Sklovakif, Tret'je .... S.40.62,70

31 vgl. S.Tretjakor. Noryl Lev Tolstoj, In: NL 1 (1927). S.34; deutach: Der neue Ler Tolatoj. In: Die Arbelt des Schriftacellera. S.94: Vgl.V. Sklovakl\}. Gamburgakl] .... S.194

32 L.Tolatoj. Metel' (1855). Poln. sobr. sox., M. 1932-1958, t.3. S.118-144; deutach: Der Schneesurm. Sumellche Erzthlungen (U.: G.Drohla) in 8 Bden.. Ffm. 1961. S.5- 43

ebd.. S.124/S.14

ebd.. S.139/S.35

V. Sklovakl]. Lev Tolatoj. S.171/S.180

bbd. S.179

ebd.. S.94-95/S.100-101

ebd.. S.95/S.101: In V.Sklorakila Tret'le fabrike let ron Pugazer auch an enderer Stelle - alerdings ohne themetiachen Zusammenhang - dle Rede (S.so)

ebd.. S.95-96/5.101-102

V.Sklorakif. Gamburgakif .... S.194

41 A. Puxkin. Kapleanskaje docka. sobr. soz.. Moskre 1975. e.S. S.253: deuesch: Die Haupemannatochter. In: Erzählungen und Anekdoten. (Hrag. u. U.) J. . Guenther. Munchen 1964. S.204

42 Brlef V. Sklovaktja an B.Ejchenbaum rom 16.1.1928, In: Iz pereplakl Ju. Tynjenore I B. Ejchenbeume a V.Sklovakim 1925-2959. In: Voprosy literacury 12 (1984).S.189

43 Brtef B.Ejchenbaume an V.Sklovskif rom 28.4.1929. In: Iz perepisk1. S.201

44 Brief V.Sklovakifa an B. Ejchenbeum rom 25. Sepe. 1958. In: Iz pereplaki. S.216

45 Bol'seje Soretskaje Enciklopedije 1955

46 rgl. V. Sklorakil. Rozanor (1929/1966). S.226-245/S.163-185

$47 \mathrm{rgl}$. A.Crone. Rozanor and the End of Llterature. Wurzburg 1978

48 V. Skloraklf, ebd. . S.232/S.169-170

49 ebd.. S.234-235/S.173

so dera., Rozanor (1921). S.51

51 ebd.. 5.52

52 ebd.. 5.53

53 M. de Cervantes, Don Quijote. U.: L. Braunfela, Munchen $1983^{3}$, 5.34 ff.

54 vel. euch V.Sklovakij. Tretje .... S.16

55 dera.. Kak adelen Don-Klchot, In: 0 teorl prozy (1929). S.101; deutsch: Wie Don Quljote gemacht lat. In: Theorle der Prose, S.102

56 dera.. Zn sorok let. S.268

57 ders.. Kak adelan .... S.91-124/5.89-130 
58 H.Chr. Andersen. Der Flachs, Märchen Bd.II. S.162, 163

59 Platon. Das Geatmahl. S.51

60 ebd.. 5.53

61 V. Sklovakll. Carli Zaplin. S.75. 77

62 vgl. den Brief Sklovskifs an Jakobson. In: Knlżnyl ugol. 8 (1922), S.23-24: dazu anstelle elner Antwort Jakobsons Widmung an Sklovakif. in: 0 Zejukom stiche. Beriln 1923

63 V. Sklorsklf. Sentimentalnoe .... S.275/S.269: -ich bln auch ein Haiblude und ein Imitator."

64 vgl. V. Sklovakil. Tret'la .... S.60/S.67: Wahrend Sklovakll Chlebnikov mit der "Trompete des Marsianers" Identiflztert, bexelchnet er sich selbst als "durchlocherte Trompete"; ders.. Gamburgsktj .... S.5; ders.. Polakl .... S.83-119

65 H. Ch. Andersen. Dle alte Strabenleterne. Bd.II. S.96-101

66 ebd.. S.101

67 N. Gogor. Nevakif proapeke. Poln.sobr.aoc. M. 1937-1952, t.3 (1938). S.7-46: deutsch: in: Samtliche Erzahlungen. U.: J.Hahn. Munchen 1961. S.735-776

68 ebd.. S.15/S.741

69 ebd.. S.45/S.776

70 ebd.. S.46/ebd.

71 vgl. dezu Skloraklja Ansplelung in "Tretja...". S.7S auf de Publlkaclon dea Tarzanromana in Litauen: Sklovakll interasalerte slch auf der elnen Selte stark fur diese nichtkanonislerte Groschenheft-Literacur: er kannte keine Beruhrungadngate; er achrteb uber die Unschadilchkelt von Tarzan fur dle Sowjetunion (In: Russkil sovremennik. 3. 1924. S.253/254). zitlerte itn an den verschledensten Stellen und parodierte thn in dem gemeinaem mit Vsevolod Iranov verfabten Roman "Iprit". M. 1925

72 V. Sklovakl1. Zoo .... S.87/S.98

73 Sheldon welse die reale Existenz dieses Landes nach. In: (Hrsg.) G. Kern/ Chr.Collins. (U.) R. Sheldon. Envy Bay. In: The Sereplon Brochers. Ann Arbor 1975. S.48: vRl. V.Sklovakil. Z1ll byll. S.145/S.191

74 ebd.. S.72/5.93

75 ebd./ebd.. 5.92

76 Varianten 24 "Tret'ja ...”. Fond S62, sbom.statef, ockerkov. rasakazov 'Tret'ja fabrike' (okolo 1926) im CGAll

77 V.Sklorakif. Zoo .... S.87/S.98

78 ders.. Sentimental noe .... S.259/S.254

79 ders.. Polskl .... S.148

80 ders.. Zul byll. S.71-72/5.92

81 V.Percov, Sklovakl) 1 ego raznovidnost: S.8

82 B. Elchenbaum. Brief an V. Sklovakll rom 28.4.1929. in: Iz pereplakl .... S.201

83 V.Sklorskif, O Majakorakom. S.370/S.153

84 dera.. Zoo .... S.28/S.34

85 ebd. S.30: 5.36

86 R. KIpling, Die Katze .... S.599

87 ebd.. S.60s

$88 \mathrm{Vgl}$. H.Gunther. Utople nach der Revolution. In: Utopleforachung. Interdiaziplenare Studlen zur neuzeltlichen Utople. (Hrsg.) W. VoBkamp. Stutegart. Bd.1. 1982. S.379/380 
89 V.Šklovsklj. Podenxzina. S.227

90 ebd.. 5.227

91 Ju.Tynjanov. Entwurf zu einem Buch Uber Sklovakll ala Schriftateller neuen Typa. zit. nach Ju.N. Tynjanov. Potelka. latorija literatury. Kino. Anmerkungen zu: Vorwort zu: "Archalaty I novatory". S.570

92 H. Marcuse, Verauch Uber de Befrelung. U.: H.Reinicke. A.Schmidt. Ffm. 19692. S.6.3-65

93 A.Hansen-Love. S.S84

94 ebd., S.65

95 vel. II.Tell. Kap. 3.2 Sklovakifa Verhultenls zur kollektiven Arbelt: Vgl. selne Kritlk an der eesellachaftlichen Funktion der Famille. In: Tretja .... $5.67 / 68$

96 V. Sklovaklf, Sentlmental'noe .... S.270/S.264

97 ebd.. S.238/S.234

98 ebd.. S.266/S.260 f.

99 ders.. Zoo .... S.46 ff./S.49 ff.

100 ebd.. S.69/S.73

101 dera.. Tret'ja .... S.117: val. auch in dlesem Kapltel den Abachnitt "lat Sklovaklf ein Imitator oder ein Erfinder?"

102 vgl. E.A.Poe, Mellonta Tauta. Werke. Bd.II (4), S.624-648

103 vgl. H. Brugeemann. Zlvillaatlonskritlk und anthetlache Erfahrung. Zu Edgar Allan Poes Erzahlung 'Der Meseenmenech'. In: Akzente 3 (1980). S.272-287. Uberarbeltet abgedruckt in: ders.. "Aber schlckt ketnen Poeten nach London!-. Relnbek b. Hemburg 198S. S.188-205: vgl. auch F.H.Link. Edgar A.Poe. Eln Dichter 2 wischen Romantik und Moderne. Ffm. 1968. S.300 ff.

104 E.A. Poe. Mellonte Tauta. S.627

105 ebd., 5.629

106 dere.. Dialog 2 winchen Monos und Une. In Werke, Bd.ll (S), S.877

107 dera.. Mellonta Tauka, S.632

108 ebd.. S.635

109 V. Sklorakl1. Polskl.... S.83/8s: V.Chlebnlkor. Trube maralen. Werke in 2 Bden (deutsche Ausgabe): (Hrag.) P. Urban, U.: P.Urban. R.Zlegler: Bd. 2: Prose. Schriften. Briefe. Rainbek b. Hamburg 1972. S.250

110 dars.. Udazl 1 porażenlfa Maksime Gor'kogo. Titile 1926. S.8

111 dera.. EjzenXteln. M. 1973. S.293-295; U.: M.Dahlke. Relnbek b. Hamburg 1977. S.379/380

112 Sklovaklfa erstea Poem "Svincovyj Zreblj" (Peteraburg 1914) Ist elne Hymne ouf Velemir Chlebnikov: er zitiert Chiebnikov an rerschledenen Stellen setner Prosa.

113 dera.. Polakl .... S.114

114 ebd.. S.118/119 


\section{Kap. 3: Die Stimme des OPOJAZ-Mitarbelters}

Die Stimme des OPOJAZ-Mitarbeiters repräsentiert den Literaturtheoretiker Šklovskij. Sie steht nicht hinter den anderen zuriick und stellt sich dem Leser gleich zu Beginn des Einleitungskapitels im Verein mit dem Schriftsteller und dem Kinoarbeiter vor.

"Ich fixiere ein Stuick theoretischer Arbeit. So hält ein Soldat bei der Wachablösung sein Gewehr hoch." [7]

In der nun folgenden Passage übernimmt sie vorerst die Führung. Damit beginnt das Streitgespräch $z$ wischen den Stimmen in der "Dritten Fabrik" um die Hegemonie im Text. das eine ähnlich konstruktive Rolle spielt wie in "Zoo..." die Konkurrenz zwischen den Themen: die Liebe zu Alia. die Sehnsucht des Emigranten nach seiner Heimat und die Evolution der literarischen Sprache. Die Stimme des OPOJAZ-Mitarbeiters ist die Stimme des deplacierten Menschen. der hinter der Maske des Technikers seine Positionen und seine Arbeit zu rechtfertigen sucht. und zugleich die des Experimentators. der sich an den Petrograder OPOJAZ erinnert. an die Gespräche mit den Freunden über Probleme der Prosatheorie unter den abenteuerlichen Bedingungen der Revolutions- und Bürgerkriegsjahre, und der nach Methoden und Möglichkeiten ihrer Fortsetzung sucht.

\section{Die Maske des Technikers}

Eine Variation der Stimme des OPOJAZ-Mitarbeiters im Verwechselspiel der Selbststilisierungen ist der Techniker oder Handwerker Šklovskij. Diese Stımme stellt literarische Produktion als ein Handwerk und die OPOJAZ-Mitarbeiter als Handwerker vor.

\footnotetext{
Wir sind Handwerker. wir kennen uns aus in der Kunst. und wenn wir wollen. dann schreiben wir das Buch selbst ...” [88]

"Ich möchte meine Zeit wie ein Schicksal ausnutzen. Mich mit ihm mittels der Kultur meines Handwerks tretfen. wie sich zwei Herden treffen." [96]

"Aber ich weiB, daB das Handwerk klüger ist als ich." [97]
}

Sie weist es weit von sich. Kunstgewerbe zu betreiben - "Ich möchte nur nicht aus Steinen Wiener Stühle machen" [17] - oder zum Huiter traditioneller Kunst zu werden - "Wir haben nicht denselben Weg wie der in Goldschnitt gebundene A. Efros." [17] Die Meister des literarischen Handwerks planen. Strukturen der Unfreiheit zu studieren und zu sezieren, wie sie sich in das eigengesetzliche System der literarischen Sprache eingegraben haben. Das System der Literatur ist ihr Material, der Gegenstand ihrer handwerklichen Arbeit. Dieses Konzept einer handgreiflich faBbaren Wortding-Kunst richtet sich gegen überkommene Kunstvorstellungen der bürgerlichen Gesellschaft 
und zugleich gegen das Kunstverständnis der Marxisten-Leninisten. Es negiert die Vorstellung, Kunst sei Nachahmung der Natur oder geniale Schöpfung. die nur mimetisch nachempfunden werden könne, gleichermaBen wie die Lehre von der Kunst als Widerspiegelung der Wirklichkeit. [65] Uber die "proletarischen Schriftsteller" sagt der OPOJAZ-Mitarbeiter:

"Die Schwierigkeit der Position der proletarischen Schriftsteller liegt darin, daB sie Dinge auf die Leinwand schleifen wollen, ohne ihre Dimensionen verändert zu haben." [99]

Indem Šklovskij die Theorie der Formalen Schule von der Eigengesetzlichkeit der literarischen Sprache, deren Analyse die Arbeit eines Spezialisten erfordert. in der "Dritten Fabrik" so formuliert, daB die Literatur ein spezifisches Material sei und die Literaturwissenschaftler und Schriftsteller Handwerker und Techniker, versucht er den Formalismus und seine literatursoziologische Identität gegenuber der Kritik von Seiten der Marxisten-Leninisten, die dem Formalismus Subjektivismus. Dekadenz und Orientierung nach Westeuropa vorwarf, zu legitimieren. Die Stimme des Technikers in der "Dritten Fabrik" Ubernimmt hier eine ahnliche Funktion wie Sklovskijs These von der Notwendigkeit einer "Zweitprofession" für den Schriftsteller, wie er sie einige Jahre später in der "Literatura fakta" und in der Broschure "Die Technik des Schriftstellerhandwerks" vertrat. Aber es geht Šklovskij nicht nur um eine Legitimation, sondern auch darum, das Neue der formalistischen Konzeption verständlich 24 machen.

Ähnlich wie Poe macht sich Šklovskij die Konkretion technischer Begrifflichkeit zunutze, um auf eine Veränderung der Beziehungen zu den Dingen - seien es sprachliche, seien es auBersprachliche Dinge - hinzuarbeiten. Es geht ihm drum. die Konsumhaltung der Menschen den Dingen gegenuber in eine Produktionsbeziehung zu verwandeln. Fìr ihn als Spezialisten in der Literatur heiBt das in erster Linie, Literatur als Produktion vorzustellen. Diese Aufgabe erfullt in der "Dritten Fabrik" die Stimme des Technikers. Uber die Briks und ihre Wohnung sagt er:

"Man offnete die Tìr. Es war keine Tür, sondern ein Buchdeckel. Ich öffnete das Buch, das sich 'Die Lebensgeschichte Osip Briks und Lilja Briks' nennt.

In den Kapiteln dieses Buches wird manchmal auch mein Name erwähnt.

Ich blättere es zerstreut durch, wie Briefe, die man sich noch durchzulesen scheut.

Auf der ersten Seite stand Brik. Nicht jener, den ich kannte, ein Namensvetter. An den Wänden hingen turkestanische Stickereien. Auf dem Flügel stand ein Automobil aus Karten, in der GröBe eines Kubikmeters.

Natürlich leben die Menschen nicht dafür, daB man Bücher über sie schreibt. Aber trotzdem habe ich eine Produktionsbeziehung zu Menschen, ich möchte immer, daß sie irgend etwas machen." [57]

Der autobiographische Erzähler spricht von seiner "Produktionsbeziehung zu 
Menschen”. stellt sich einige Passagen weiter im gleichen Zusammenhang als Teil der Produktion dar (Suppen- bzw. Gemiisemetapher) und fordert, daB man sich der Kunst produktionsmäBig nähern solle [65]. Er läBt in dem Begriff "Produktion" verschiedene Stimmen zu Worte kommen: den Experimentator im OPOJAZ, der an ein zentrales Theorem der Formalen Methode erinnern und Brik zur Fortsetzung seiner literaturtheoretischen Studien bewegen will, den deplacierten Menschen, der sich in die marxistische Terminologie einibt und erkennt. daB er nur ein Teil im ProduktionsprozeB der Gesellschaft ist, und den Techniker, der die literarische Produktion als ein Handwerk betrachtet.

Die Mehrstimmigkeit des Produktionsbegriffs macht deutlich, daB der Techniker kein naiv technikgläubiger Mensch ist, der meint, die Welt planmäBig bauen zu können, ${ }^{1}$ sondern ein Literaturtheoretiker und Schriftsteller, dem seine eigene Technikbegeisterung und sein praktisches Technikverständnis es leicht machen, die allgemeine Technikeuphorie der Sowjetunion dazu zu benutzen. für verständnisvolles Interesse an einer Literaturkonzeption zu werben, die sich ohnehin mit der Technik des Industriezeitalters verbunden fühlt. Der Sachverstand des Technikers Šklovskij stellt sich in der "Dritten Fabrik" nicht nur in der bei der Avantgarde allgemein üblichen Uibernahme technischer Begriffe für literarische Verfahren wie "Montage" und "Konstruktion" und ihrer Anwendung in der literarischen Produktion unter Beweis, sondern auch in der Verwendung literarischer Bilder aus der Sprache der Technik, welche er mit Vorliebe einsetzt, um seine Freunde aus dem OPOJAZ zu charakterisieren. Jakubinskij vergleicht er mit einem Zirkel -

"Jakubinskij selbst hat einen zaghaften Schritt, wie ein Zirkel, der sich fürchtet, seine justierten Beine zu verbiegen." [52] -.

Brik mit einem "sich bewegenden Punkt" [59], und um die Beziehung zwischen Jakobson und sich selbst zur Zeit des OPOJAZ zu charakterisieren. sagt er: "Ich und du. wir waren wie zwei Kolben in einem Zylinder." [66]

\section{Der Experimentator im OPOJAZ}

\section{Erinnerungen an den OPOJAZ}

Der Experimentator des OPOJAZ präsentiert sich vor allen Dingen in den Briefen an die Formalistenfreunde Jakobson. Tynjanov. Ejchenbaum und Jakubinskij, in den Kapiteln über Brik. im Kapitel -Uber die Freiheit der Kunst", aber auch in den Erinnerungen an die Jugend, an Schule und Universität. Die Erinnerungen an die verschiedenen Schulen. die der Held durchlief, sind ebenso von den Projektionen des Experimentators bestimmt wie von denen des deplacierten Menschen. 
Šlovskij stellt sich als eigenwilliger Schüler, als Autodidakt vor, der die Schule und die Universität langweilig gefunden und dort während des normalen Unterrichts nichts gelernt hat. [23-25] Er habe bereits an der Theorie der Prosa gearbeitet, als es an der Universität dieses Spezialgebiet noch gar nicht gegeben habe. [27, 33] Methode habe ihm der Bildhauer Sherwood und der Futurismus beigebracht. [45] Als einzigen Universitätslehrer, von dem er etwas gelernt habe, bezeichnet er den Linguisten de Courtenay. Durch ihn habe er seinen späteren Freund. den Linguisten Jakubinskij, kennengelemt. [51/52]

In der Rekonstruktion der Erinnerungen erscheinen die Schulen, die der Held der "Dritten Fabrik" durchlief, als Vorschulen der Gesellschaft zur Erforschung der poetischen Sprache, aus denen der Experimentator hervorging.

Wenn eine schlechte Schule eine gute Schule ist, dann ist die erste Fabrik im Recht." [71]

Mit diesen Worten beschlieBt der Held die Erinnerungen an diese Vorschulen.

Die Oktoberrevolution bedeutete für die Formalisten Revolution in Kunst und Wissenschaft. Sie eröffnete ihnen die Möglichkeit. experimentell zu arbeiten. In der Erinnerung an die Arbeit im Petrograder OPOJAZ spielt eine Metapher, die Metapher vom Druck des Windes, der die Formalisten vorwärtstrieb. so, wie der Motor ein Auto antreibt, eine zentrale Rolle für ihr Revolutionsverständnis. Sie hat eine leitmotivische Funktion nicht nur in der "Dritten Fabrik". sondern in allen Prosatexten Šklovskijs. Im "Hamburger Vergleich" (1928) erinnert sie an die Jahre des Kriegskommunismus in der Hoffnung auf Erneuerung und Wiederbelebung der Revolution.

Wir lebten bis zur Revolution angekettet ans Schicksal, wie miBmutige griechische Schwämme an den Meeresgrund ... HäBlich gebaut ist in der kapitalistischen Gesellschaft eine solch interessante Sache wie das menschliche Schicksal. Ja. und während der Revolution gab es kein Schicksal. Wenn man sich nicht gerade um Fausthandschuhe bemiiht, dann hat man viel Zeit, man hat bereits eine Vorahnung von der Herrschaft der Freiheit: Sie ist unwägbar, aber schon räumlich vorhanden.

Fahre, wohin du willst, eröffne eine Schule für Souffleure für die Rote Flotte, lies die Theorie des Rhythmus im Krankenhaus - es werden sich Zuhörer finden. Die Menschen waren damals aufmerksam. Die Erde machte sich von den Ankern los.

Ich bin vierunddreiBig Jahre, und an viele von ihnen erinnere $\mathrm{kch}$ mich. Und ich wirde am liebsten die Erinnerungen an zwei, drei Jahre meines Lebens nach vorn umstellen und aufs neue das sehen. was wir Kriegskommunismus nennen. Sogar mit den nächtlichen Passierscheinen und den Patrouillen auf den Straßen war die Stadt hungrig, aber frei.

Wir sind jener Zeit als Erfinder verpflichtet, sie blies diesen Wind in alle Segel.

Dostcevskij, Jerome-Jerome (er ist jetzt verstorben) und der immer noch rastlose Merezkorskij sagten ubereinstimmend, daB der 
Sozialismus Langeweile bedeute.

Als Augenzeuge widerlege ich das. ${ }^{2}$

AnläBlich des 10. Jahrestags der Revolution erzählt Śklovskij mit Wehmut von jener Zeit des Kriegskommunismus, als die Bolschewiki noch keine rekonstruierende, ordnende oder gar verwaltende Staatsmacht. sondern eine sich gegen innere und äuBere Feinde wehrende politische Bewegung waren. dio sich als Stantsmacht eben zu konsolidieren begann. Šklovskij und seine Freunde im OPOJAZ und bei den Serapionsbruidern eriebten diese Zeit als Machtvakuum. in dem sich ihre experimentelle Arbeit frei von institutionellen Zwängen und von der Trägheit des Alltagslebens entfalten konnte. Sie wurden mitgerissen vom Sog der Revolution, die zunächst Umwälzung der Herrschaftsverhältnisse und Paradigmenwechsel der Ideologeme. keineswegs aber Festschreibung auf eine festumrissene neue politische Ordnung bedeutete, auch wenn sich - wie Šklovskij es in Texten jener Zeit bereits vorwegnahm ("Tausendfübler", "Sentimentale Reise" etc.) - die buirokratische und autoritäre Herrschattsform der Bolschewiki vorausahnen lieB. In dem Prosatext "Suche nach dem Optimismus" (1931), der in einer Zeit emeuter Desullusionierung entstand. stellt sich der autobiographische Erzähler als ziellos aut dem Meer herumtreibendes Hausboot dar.

"Wie ein kleiner, heiße Luft durch die Münder seiner trichtertörmigen

Schormsteine atmender Dampter schwimmt unser Haus.

Es schwimmt unter dem Himmel.

In der Schiffahrt nennt man das wahrscheinlich Abdritten.

Das Haus treibt uber die Erde.

Nichts ist entschieden. Ein Weg wurde nicht getunden.

Meine Schlüssel öffnen nicht alle Türen meiner Zeit. ${ }^{3}$

In Šklovskijs "Erinnerungen an Majakovskij" (1935) figuriert die Metapher als Symbol für die Synthese von gesellschartlicher Revolution in der Kunst, die die Dichtung der Futuristen bewerkstelligt hatte. Šklovskij nennt Majakovskij ein "thematisches Wortsegel der Revolution". das sich aber für den Wind der russischen Revolution als zu schnell erwies und am Leben zerschellte. Er mischt Verse von Majakovskij, die jener, kurz bevor er sich erschoB, verfabte. in seinen eigenen Text hinein.

"Das Meer wird schlaffer.

Das Meer geht schlafen!"

O Meer, so muide, aut das sich müde Regen goB.

O Meer um Norderney.

Vergangen sind die Azoren, und zu Ende jene groBe Liebe.

Zerflossen und verlaufen die Wellen.

Kein Wind fing sich im Segel.

Der Kampf um die zukünftige Liebe endete ohne Sieg. ${ }^{\text {.S }}$

Der neunzigiährige Šklovskij nimmt das Thema vom Erfinder und Experimentator, symbolisiert in der Metapher des Segels im Wind, noch einmal auf, um auf die konstruktive Funktion des Irrtums im ProzeB des Entdeckens, das für ihn 
der Struktur nach im Leben und in der Kunst das gleiche ist, hinzuweisen. Er entschluisselt auf diese Weise das energetische Zentrum seiner eigenen Arbeit.

"Wenn das Segel sich gegen den Wind richtet, scheint es, als ob es sich irt.

Es irgt sich nicht, es fängt den Wind und lenkt ihn auf seinen Weg um."

So wie sich beim Segeln der Könner darin erweist, inwieweit er die Kunst. gegen den Wind zu kreuzen, beherrscht, so will Šklovskij seine Kunst, dem Druck der Ideologie standzuhalten und ihn in einen Antriebsmotor für seine eigene Arbeit umzuwandeln. verstanden wissen: indem er sich querstellt. ohne zu blockieren und einfach "nein" zu sagen. behauptet er die Beweglichkeit des Subjekts bzw. die Beweglichkeit der Literatur in der kritischen Auseinandersetzung mit der alles beherrschenwollenden sowjetischen Ideologie und streitet für eine Unabhängigkeit. die sich ihrer eigenen Bedingtheit bewuBt ist. So wie der Segler kunstvoll den Gegenwind nutzt. um voranzukommen. so nutzt Šklovskij den Druck der Ideologie. um selbst produktiv zu werden, Eigenes zu sagen, d.h. experimentelle Literatur hersteilen zu können.

In der "Dritten Fabrik" erscheint die Metapher vom Druck des Windes mehrere Male. Sie rahmt den Prosatext in gewisser Weise ein. Sie verleiht der Selbststilisierung des OPOJAZ-Arbeiters in einem der ersten Kapitel Nachdruck und erinnert in der Form eines Verszitats des römischen Dichters Vergil am Ende des Buches an sie. Die Metapher vom Druck des Windes, der die Erfinder des OPOJAZ vorantrieb, fungiert in der "Dritten Fabrik" kontrastiv zu den Metaphem vom Gesetz der Schwerkraft und vom Menschen, der im Gleichschritt geht und imit beiden Beinen auf dem Boden der Realitat steht. Sie bezeichnet den Wunsch nach Befreiung von naturgesetzlich erscheinenden Zwangszusammenhängen und die Hoffnung. daB die Oktoberrevolution den ersten Schritt in diese Richtung getan haben möge. Was das Verständnis von revolutionären Entdeckungen anbetrifft, so sind sich der Erfinder im OPOJAZ. der Schriftstellererfinder der Flugmetaphern und der Revolutionïr Šklovskij einig: Ihre revolutionären Entdeckungen zielen darauf ab. Unfreiheiten aller Art - sei es im Leben, sei es in der Kunst - zu studieren, um sie zu bekämpfen und den Horizont der Wahmehmung zu erweitern.

Die Metapher hat den Status einer Erinnerung und die Funktion, auf die gesellschaftliche Veränderung, auf den Stillstand der Revolution hinzuweisen. Der Experimentator klagt uber die Windstille, die ihn umgibt. "... kein Druck des Windes, das Leben ist duinn gesät" [97], heiBt es in bezug auf die Arbeit in den Montageräumen der sowjetischen Kinofabrik. Der Experimentator beklagt die Erstarrung der Revolution - die "rote Restauration in der Kunst" [89], die Privatisierung und die Isolation seines Lebens. Seine Erzăhlung von der Familie [68], von der Alltagsarbeit im Kino, vom Morgentee [103] sowie die Selbststilisierung zum einsamen Kopfarbeiter, der sich hoch über dem Leben und Treiben der Menschen im Moskauer Altstadtviertel Arbat in einem Turm "ein Nest" baut, dort "ohne langen Atem" schreibt und bei dem die 
Komsomolzen, die $\mathrm{zu}$ ihm hinaufsteigen, atemlos vom langen Anstieg ankommen [106], stehen unter anderem für diese Klage. Auch die Briefe an die Formalistenfreunde handeln davon. Am Ende der "Dritten Fabrik" nimmt das Vergilzitat die Metapher noch einmal auf.

"Und der Südwind, leise in den Masten knarrend, ruft uns ins offene Meer." [138]

Im Unterschied zu den Klagen eröffnet die Metapher in dem Vers - wenn auch mit Worten. die Bedächtigkeit ("Der Südwind, leise in den Masten knarrend ...") und auch Unwissenheit über das Ziel ("Der Südwind ... ruft uns ins offene Meer.") verraten - erneut eine Perspektive in die Zukunft. Der Experimentator beläBt es nicht beim Klagen und bei der sentimentalen Erinnerung an die Tage der Revolution und an die Arbeit im OPOJAZ. sondern er belebt diese Metapher bzw. ihren Status in der "Dritten Fabrik" neu: Er beginnt mit der Flaute der Revolution. mit der gesellschaftlichen Bedingtheit der literarischen Produktion zu experimentieren, indem er die Auseinandersetzung $z$ wischen Material und Konstruktion. 2 wischen Untreiheit und Freiheit. zum Sujet der autobiographischen Prosa macht.

Ein metaphorisches Indiz dafür, daB der Held der "Dritten Fabrik" beharrlich an seinem Image als Erfinder festhäl. ist das poetische Vergilzitat am Ende der Schilderung der prosaischen Alltagsarbeit in den Filmateliers des Goskinos. Ein anderer. gewichtigerer Hinweis darauf ist, daB er Jakobson. Brik und Jakubinskif mit seinen neu gewonnenen Einsichten konfrontiert: daruber. mit welchem Selbstverständnis sie. die linken Intellektuellen. weiterhin in der Sowjetunion arbeiten könnten. woruber er im Kapitel -tuber die Freiheit der Kunst" ausführlich schreibt. Ein urittes Indiz für den Wunsch, die Arbeit des OPOJAZ fortzusetzen. ist. daB er in den Briefen mit Tymanov und Ejchenbaum fortgesetzt uber Fragen der Prosatheorie diskutiert.

Verfolgt und vergleicht man das Bild vom Wind quer durch Šklovskijs Prosa, dann lassen sich daran deutlich Veranderungen seines gesellschaftichen Selbstbewubtseins als Experimentator und Erfinder ablesen. Seinen MaBstab hat dieses Bild immer an dem Erlebnis der Jahre der Revolution und des Buirgerkriegs.

1926 ("Dritte Fabrik"): die Erinnerung an den Wind der Revolution hat einen komplizierten und verborgenen Status. Sie wird von der Erfahrung getragen. daB es für den Heimkehrer aus dem Berliner Exil unter den vom Staat diktierten Bedingungen schwer ist, seine Arbeit fortzusetzen. Der Autor literarisiert diese Erfahrung und legt sie einer der zahlreichen Masken der Selbststilisierung in den Mund: dem Experimentator des OPOJAZ.

1928 ("Hamburger Vergleich"): in der optimistischen Phase des Novyj LEF erfüllt sie die konstruktive Funktion, auf einen Neuantang kollektiver Arbeitsmöglichkeiten hinzuweisen.

1931 ("Suche nach dem Optimismus"): sie bezeichnet die Enttäuschung des 
Experimentators angesichts der drakonischen Politik des Stalinismus, die in jenen Jahren ihren Anfang nahm und von der auch der Selbstmord Majakovskijs 1930 nicht zu trennen ist.

1939 ("Erinnerungen an Majakovskij"): die Erinnerung an die Jahre der Revolution stellt den fü die damaligen Verhältnisse provokativen Versuch dar, das Leben Majakorskijs als die eigene Geschichte, die Geschichte der linken Avantgarde, zu lesen und den Selbstmord des Dichters als Reaktion auf den Tod der Revolution. 1981 rekapituliert und entschlüsselt der neunzigjährige Experimentator Šklovskij seine Methode. mit der sowjetischen Gesellschaft umzugehen. Er verfaBt ein Buch iber die "Energie des Irrtums" und schreibt darin beharrlich gegen den Stillstand der Revolution an, in dessen Vakuum sich der Druck der Ideologie des Marxismus-Leninismus breit macht. Er stellt erneut seine literarische Methode zur Diskussion. die in der Sowjetunion bis heute nicht offiziell anerkannt ist - die Methode. in einer verschieden verstehbaren Rede mit List das Tabu der Kritik an der hertschenden Ideologie zu brechen, ohne deren Realität bzw. die eigene Bedingtheit durch sie an Abrede zu stellen oder anzufechten. Die "Dritte Fabrik" kann als das erste Experiment dieser Methode gelten.

\section{Die Fortsetzung der Arbeit}

Der Experimentator des OPOJAZ spricht nicht nur von der Erinnerung an die Tage der Experimente im Petrograder OPOJAZ, seine Rede spielt häufig auch unf den Wunsch nach Fortsetzung dieser Arbeit, auf die Suche nach Methoden und Moglichkeiten ihrer Fortsetzung an. Er spricht kaum ausführlich und zusammenhängend uber seine Konzeption, seine Pläne und Projekte. sondern fragmentarisch und aphoristisch in Passagen mit Unterbrechungen und Abschweifungen, so daB der Leser inn nur innerhalb des Stimmengewirrs der Selbststilisierungen und ihrer Masken wahmehmen kann. Häufig spricht er sogar aus denselben Worten wie eine der anderen Selbststilisjerungen: zum Beispiel wie der deplacierte Mensch, der auf die Kritikerstimmen des "literarischen Lebens" eingeht (Gemiusemetapher, die Abhandlung über die Evolution der gesprochenen Sprache u.a.), wie der Schriftsteller-Erfinder in den Flugmetaphem oder der Kinoarbeiter, der von seinen Erfahrungen im Schneideraum der Kinofabrik spricht. Klar grenzt sich der Experimentator im OPOJAZ gegen den Typus des Akademikers ab, der die Forschung als Selbstzweck, als Buchstabengelehrsamkeit und reine $W$ issenschaft betreibt.

"Sie sind langweilig. Sie sind dreihundert Jahre alt. Ununterbrochene, Unsterbliche." [69]

Seine Freunde aus dem OPOJAZ Jakobson und Jakubinskij fungieren im Text als solche Kontrastfiguren zum Experimentator. Ihnen wirft er vor, daB sie sich vom OPOJAZ entfernt hätten, und daB sie sich zu Akademikem entwickeln 
würden. Während Jakobson nach Prag emigriert sei, dort als "tibersetzer der sowjetischen Botschaft" arbeite und Texte schreibe, in denen das Material für sich selber stehe [69], beschäftigt sich Jakubinskij mit der Geschichte der Zahlwörter, indem er allein die Veränderung der Wörter, nicht aber die Veränderung der Beziehungen der Menschen zu ihnen studiere [105]. Beide hofft der Experimentator in OPOJAZ für eine zukinftige Arbeit wiedergewinnen zu können.

"... Und Du bist ein solch nützlicher, solch kluger Mensch, und bist nicht da; statt dessen der dreihundertjährige Vinokur.

Zum 2 weiten Mal rufe ich Dich nach Haus. Ich komme nicht hinter Dir hergefahren." [69]

An seiner Stelle fuhr einige Jahre später Tynjanov von Berlin aus, wo er sich einer medizinischen Behandlung unterzog, nach Prag. Er traf dort mit Jakobson zusammen und schmiedete mit ihm gemeinsam Zukunftspläne für den neuen OPOJAZ, woruber er Šklovskij nach Moskau ausfiuhrlich in Briefen Bericht erstattete und wovon das Manifest der Formalisten in der letzten Nummer des Novyj LEF kündet. Aber Jakobson kehrte nicht wieder in die Sowjetunion zurïck, und der neue OPOJAZ wurde niemals gegrindet. Auch seine Erwartungen an Jakubinskij, codifiziert als weise Erkenntnis iber die Arbeit als energetischen ProzeB -

-Die Kurve der Ermuidung ist eine gute Sache, zuerst mindert sie die Arbeit, aber nach der Ermuidung, vor der Erschöpfung. kommt der schöpferische Aufschwung. Ich glaube an Deinen schöpferischen Aufschwung. Ich warte auf Briefe." [106] -

erfüllen sich nicht. Der Experimentator stimmt ebensowenig in den Chor der Apologeten des Ende-der-Kunst-Theorems mit ein, den Tret'jakov. Arvatov. Brik und andere innerhalb der sowjetischen künstlerischen Avantgarde anstimmten. An Brik gewandt. sagt er:

"Du sagst Dich los von der Kunst. Sagst, sie sei am Ende. Doch sie hat sich nur verändert.

Ich schreibe ein Buch. Und einstweilen arbeite ich am Goskino. Viel hat sich verändert. Schnee ist gefallen." [63]

Dagegen präsentiert er den Typus des Essayisten und homme de lettre. dessen theoretisches wie praktisches Interesse den Bereichen $\mathrm{g}$ ilt, die zwischen den klassischen Disziplinen - $z$ wischen Theorie und Praxis, zwischen Wissenschaft, Literatur und Publizistik. zwischen Linguistik. Literaturwissenschaft und Filmtheorie - liegen. Im Mittelpunkt seiner Thesen zu einer Theorie der Prosa, die die methodischen Engpässe des frühen Formalismus zu überwinden sucht, steht das Problem der literarischen Produktion. Es sind keine wissenschaftlichen Uberlegungen im engen Sinne des Wortes, sondern essayistische Entwürfe eines grenzenuiberschreitenden Experimentators. Er begreift seine 
Arbeit als eine Forschungsarbeit iber - wie er sagt - "die Unfreiheiten des Schriftstellers" [66 f.] bzw. "Untreiheiten verschiedener Art" [89]. Sein Interesse gilt dem Studium von Strukturen, die unterschiedlichen Formen der Unfreiheit gleichermaBen zugrunde liegen. Denn erst auf der Basis der Erkenntnis solcher Gesetze, die eine Verallgemeinerung zulassen, könne man eine Wissenschaft aufbauen. Mit diesem Plan setzt der Experimentator in der "Dritten Fabrik" das Projekt des Leningrader OPOJAZ, Literaturwissenschaft nicht länger in der geisteswissenschaftlichen Fakultät zu belassen. sondern sie in eine $W$ issenschaft von der Sprache, von der Evolution und vom System der Sprache zu uberfuhren. fort und erweitert die Formale Methode durch Fragen nach der gesellschaftlichen Bedingtheit der Literatur, danach, wie sich die gesellschaftliche Funktion im Kunstwerk manifestiert, und wie sie auf die Evolution der Literatur einwirkt. Das Projekt. die Unfreiheiten der schrifststellerischen Arbeit zu untersuchen. präsentiert sich dem Leser der "Dritten Fabrik" in doppelter Weise: als Thema des Experimentators des OPOJAZ und, dem ibergeordnet, als Sujetkonstruktion des gesamten Buches.

\section{Unfreiheiken verschiedener Art}

Der Experimentator thematisiert die Untreiheit des Wissenschaftlers gegeniber der Wissenschaft (Jakobson. Jakubinskij). die Unfreiheit des Schriftstellers gegenuber der Kunst (das betrifft die Traditionalisten unter den Künstlem) und seine Unfreiheit gegenuiber dem Leben (das betrifft die "Utilitaristen" unter den sowjetischen Avantgardekijnstlern: Tret'jakov. Brik u.a). Er spricht davon. daB die Erfahrang der Revolution in der Kunst zur Zeit der gesellschatilichen Revolution im Bewubtsein derjenigen. die sie erlebten, zu einer Verknupfung der Bereiche Kunst. Wissenschaft und Gesellschaft geführt habe. die nicht wieder rückgängig zu machen sei. so dab man davon ausgehen muisse. daB sich diese Bereiche nicht unabhängig voneinander entwickeln könnten. bzw. daB man im Rückblick ihre jeweilige Geschichte als sich gegenseitig bedingende begreifen und darstellen misse [62 f.]. Der Experimentator argumentiert - marxistische Theorie aufgreifend - deutlich gegen die bürgerliche Konzeption einer autonomen Literatur. Auf der anderen Seite wehr er sich gegen das deterministische Modell von Basis und Uberbau. das der Widerspiegelungstheorie zugrunde liegt. Denn er stellt sich die Verkettung der semantischen Systeme - das der Kunst. der Wissenschaft und des Lebens nicht als eine kausale oder gar statische, sondern als eine dynamische Verbindung vor, die sich dem Schriftsteller als die Notwendigkeit zur permanenten Auseinandersetzung zwischen dem Material, d.h. den gesellschaftichen Fakten, und der Kunst darstelle. Das Material bedränge die Kunst und verlange nach Interpretation [17]. Die Kunst tendiere dazu, sich von der Wirklichkeit zu entfernen, autonom aber irrelevant $2 u$ werden und, einmal kanonisiert. an Lebendigkeit $\mathbf{z u}$ verlieren. [86] Im Zwang zu dieser Auseinandersetzung ${ }^{7}$ liege, so Sklovskij, der Kern der Unfreiheit des Schriftstellers, die aber - 
und hierin bestehe ihre Hauptfunktion - von dem Wunsch nach Freiheit angetrieben werde. [81, 8S] Innerhalb dieses Bedingungsgeflechts spricht er der Kunst einige Freiheiten sowohl in bezug auf das Nltagsleben als auch in bezug auf den Schriftsteller zu:

die Freiheit, unkenntlich zu machen.

die Freiheit der Auswahl und

die Freiheit, modellhaft erleben zu lassen. was sich im Leben dem Erleben sperrt. [99, 100] Er warnt davor, den Wunsch nach Freiheit, der Ausdruck der Weltanschauung (im unmittelbaren Sinne des Wortes) und der Ethik des Schriftstellers sei, mit der Freiheit selbst zu verwechseln [85] und kritisiert die Vorstellung, da8 das Kunstwerk schon die Verwirklichung des Glücks sei. Es sei vielmehr die Organisation der Konstruktion, die diesem Wunsch Ausdruck verleihe und die dem unvermittelten Bild von Freiheit und Gluick. wie es sich in der Weltanschauung des Schriftstellers darstelle, seine vordergrindige. subjektive und intentionale Bedeutung nehme, es bearbeite und verändere.

An dieser Stelle wird sichtbar, daB die These von der Eigengesetzlichkeit nicht mit dem Autonomeanspruch der bürgerlichen Kunst gleichzusetzen ist. da sie die gesellschaftliche Bedingtheit der Kunst erkennt und anerkennt. Sie löst die unmittelbare Verknüpfung Schriftsteller/Werkobjekt als Grundlage der Textanalyse und betrachtet das Wort als ein Ding, das im System (synchron) und in der Evolution (diachron) der Literatur nach bestimmten Gesetzen geformt wird und analog und auf bis dahin ungeklarte Weise mit dem semantischen System der empirischen Wirklichkeit verknuipft ist. Der Experimentator geht davon aus, daB sich die Struktur der Verknijpfung der Systeme in der Kunstproduktion erst im nachhinein enträtsele, was den Schriftsteller aber nicht der Aufgabe enthebe, sie nach ihrer technischen Seite hin zu analysieren und $\mathrm{zu}$ bestimmen, da diese Seite eine konkrete und handgreiflich auszumachende sei, die der literarischen Sprache als einem sich eigengesetzlich entwickelnden System entspreche [64] - im Unterschied zur emotionalen oder geistesgeschichtlichen Dimension, die bis dahin im Zentrum der literarischen Betrachtung stand. Die Eigengesetzlichkeit der literarischen Sprache nötige den Schriftsteller dazu, sich dieser GesetzmäBigkeiten der Auseinandersetzung der beiden Seiten der Produktion (Material und Konstruktion bewruBt zu bedienen [ 65$]$ und sie in Gestalt von kilnstlerischen Verfahren ins Werk zu setzen. Denn für den Experimentator im OPOJAZ ist der produktionsmälige Zugang zum Kunstwerk [65], d.h. der operative und methodisch konkret durchdachte Umgang mit Material und Konstruktion von zentraler Wichtigkeit.

Der Experimentator unterscheidet drei Arten von Schriftstellern: denjenigen. der Literatur als Hobby und schöngeistige Beschäftigung betreibe. denjenigen. der das Leben beschreibe und seine schriftstellerische Arbeit ganz in den Dienst der Gesellschaft und ihrer Entwicklung stelle und den Essayisten, der eine permanente Auseinandersetzung $z$ wischen den verschiedenen Systemen 
nicht scheue. [84/85] Der Held der "Dritten Fabrik" entscheidet sich für den dritten und letzten Weg nicht nur, weil - wie es heiBt - "Der Kuinstler nicht entlang den StraBenbahngleisen gehen sollte" [84], sondern weil es der Prosakonzeption des Experimentators im OPOJAZ entspricht, daB die permanente Auseinandersetzung 2 wischen Kunst und Leben, Kunst und Wissenschaft und Wissenschaft und Leben den Motor der literarischen Produktion ausmacht. Der Experimentator des OPOJAZ spricht jeder der beiden Seiten der Literaturproduktion - dem Material und der Konstruktion - eine ähnlich gewichtige Funktion und Bedeutung zu - im Unterschied zu seinen Formalistenfreunden in Leningrad, Tynjanor und Ejchenbaum. mit denen er in den Briefen fortgesetzt über prosatheoretische Probleme diskutiert.

An Ejchenbaum kritisiert er, daB jener die Bedeutung des Materials für die literarische Produktion unterschätze, daB er versuche, aus der Psychologie des Autors auf sein Werk zu schlieBen (eine Anspielung auf Ejchenbaums Tolstoj-Monographie), und daB er einzelne Verfahren - vor allem den Kunstgriff des "skaz" (den Kunstgriff der muindlichen Rede) studiere. Dariber vernachlässige [100-102] er das einheitsstiftende Prinzip. die Sujet-Konstruktion. Er ibernimmt Tynjanovs Theorie der literarischen Evolution und erweitert sie. Im Postskriptum seines Briefes deutet er an, in weichem MaBe er den Widerstand des Materials gegenüber der Kunst anerkennt:

"Das persönliche Leben erinnert mich an die Anstrengung, eine Portion Eis zum Schmelzen zu bringen." [100]

Dementsprechend bezieht er - mehr als Tynjanov - die über das Werk hinaus und auf Veränderung des Materials "Altagsleben" abzielende Intention der Kunst in seine Prosakorzeption ein.

Die Theorie der Prosa des Experimentators in der "Dritten Fabrik" ist zugleich eine Reaktion auf die Kritik der Marxisten-Leninisten am Formalismus, insbesondere an Šklovskij, und eine Fortsetzung der formalistischen Prosatheorie. Mit der List der Ironie, der List des verschieden verstehbaren Wortes, erbringt der Held der "Dritten Fabrik" einerseits eine Anpassungsleistung, die andererseits die Anpassung der formalistischen Literaturtheorie an die Ideologie des Marxismus-Leninismus abwehrt und verhindert. Er bewahrt das Theorem der Eigengesetzlichkeit und die Forderung nach einem produktionsmäBigen Zugang zur Kunst und bezieht dabei die konstruktive Funktion und die gesellschaftliche Bedingtheit des Materials in seine Theorie mit ein, wie er scheinbar neutral und verallgemeinernd alle auBerliterarischen Fakten des gesellschaftlichen Lebens nennt - die materiell existierenden Dinge so wie die BewuBtseinsdinge des alltäglichen und politischen Lebens. Sheldon liest diese These im Rahmen der "Dritten Fabrik" einfach als ein Tăuschungsmanઠver Šklovskijs. in dem sich der alte Formalist Šklovskij hinter dem Šklovskij, der den Marxisten ein Lippenbekenntnis ablegt, versteckt.

"Despite his supreme efforts to abdicate from his former position. 
the dominant impression remains that he still discounts the role of social conditions in influencing literary change. Whenever Shklovsky pays lip-service to the ideas of Marxist critics. he instantly contradicts these ideas - usually in the succeeding paragraph. ${ }^{8}$

Im Unterschied dazu begreift Hansen-Löve diese Überlegungen zum Verhältnis von Kunst und Leben als den Anfang einer soziologisch fundierten formalistischen Prosatheorie. 9 Er versucht nachzuweisen. daB der Formalismus nicht erst unter dem Druck der gesellschaftlichen Verhältnisse bzw. des MarxismusLeninismus literatursoziologische Topoi in seine Theorie aufgenommen hatte. sondern daB die Erkenntnis vom EinfluB auBerliterarischer Fakten auf die Literatur in nuce bereits im fruihen Formalismus angelegt sei.

Einfluß auBerliterarischer Realitäten auf die Literatur heiBt fur den Experimentator Šklovskij, anders als fur die Verfechter der Widerspiegelungstheorie, nicht einfach, daB jene die Literatur okkupieren, sondern daB sie in das System der literarischen Sprache transformiert werden. Sich auf die Arbeiten seines Freundes Tynjanov stuitzend, behauptet er, daB das auBerliterarische Material, sowie es in die Literatur aufgenommen sei, seine urspriingliche Funktion und Bedeutung verliere, sich statt dessen den Gesetzen der Kunst unterwerfe und Funktion und Bedeutung in ihrem System zugesprochen bekomme.

Der Gesamttext der "Dritten Fabrik" ist, unter diesem Aspekt betrachtet, der Versuch der Literarisierung dieses Theorems. Die Erkenntnis des Experimentators, dab eine semantische Transformation des Materials im ProzeB der Ästhetisierung stattfindet, impliziert den EinfluB sozialer Fakten auf die Literatur, besteht aber darauf, daB es einen komplizierten tibertragungsmechanismus von einer Sprache in die andere gibt. Sie beschreibt nicht blob, wie die Kunst dem Leben Terrain raubt, um sich zu erneuem. sondem weist auch auf die Vielfalt und Dynamik der wechselseitigen referentiellen Bezüge hin der denotativen und der konnotativen -, die das Material im ProzeB seiner ästhetischen Bearbeitung realisiert. Denn im System der Kunst aufgehoben, verliert es den eindimensionalen Zweckrationalismus des Alltagslebens. Es wird zu einem Zeichen. das 2 war an seine urspringliche Bedeutung erinnert. gleichwohl aber eine neue Bedeutung gewinnt und auf diese Weise eine verschieden verstehbare Auseinandersetzung zwischen Material und Konstruktion evoziert, die nicht nur darauf abzielt. Kunst zu erneuern. sondern darauf, Dinge lebendig wahrmehmbar zu machen und aufs Leben zu wirken.

Die Kunstkonzeption des Experimentators in der "Dritten Fabrik" räumt weiterhin mit der aus der bürgerlichen Ideologie überkommenen Vorstellung auf, daB die Kunstproduktion der geniale SchaffensprozeB eines originellen Individuums sei. Er betrachtet die Kunstproduktion als einen Schnittpunkt verschiedener semantischer Systeme (Leben, Kunst und Wissenschaft), wobei sich dieser Schnittpunkt in einer dialektischen Bewegung von EntäuBerung und Aneignung ständig aufs neue konstituiert und wieder auflöst. Der Held der "Dritten Fabrik" beschreibt diesen ProzeB folgendermaBen: 
"Ich nehme an, daB sich das Sujet dialektisch entwickelt, sich von sich selbst abstöBt so, als ob es sich selbst parodiere - ... die Veränderung der Kunstproduktion kann aus nichtästhetischen Ursachen entstehen und entsteht auch so ... So entsteht unbewuBt und ohne Blick auf ästhetische Kategorien in der Kunstproduktion eine neue Form, und erst später wird sie ästhetisch beurteilt und verliert dabei zugleich ihre urspriingliche Bedeutsankeit, ihre auBerästhetische Bedeutung." [94/95]

Dem Künstler kommt darin einerseits objektiv die Funktion zu, dieser um ihn herum und in ihm stattfindenden Auseinandersetzung zwischen den Systemen Ausdruck zu verleihen, andererseits hat er subjektiv die Aufgabe, sie als intentional handelndes Subjekt auf seine Weise zu bearbeiten. Der Experimentator betont im allgemeinen die rational erfaBbaren, konkret und objektiv existierenden Aspekte der Kunstproduktion. Er betrachtet die Kunst als Form, d.h. als ein System, das in seine Teile zerlegbar ist und dessen Konstruktionsprinzipien erforschbar sind. Aber er kennt auch die Bedeutung und Funktion des Unbewubten und des Subjektiven. des Imationalen und des Zufalligen für die Kunst. Formen, in denen sich die Gesetze und Mechanismen des Lebens eine Erscheinung geben. täuschen und leiten den Menschen - sei es als Produzenten, sei es als Rezipienten. Im konstruktiven künstlerischen Umgang mit diesen Gesetzen des Zufalls sieht der Experimentator einen Weg, eine Methode. sie vor Augen zu halten und zu studieren. Denn

"was der Zufall an Sinnfremdheit in jedes Gebilde hineinträgt. ahmt die des Zeitalters nach: indem er unbeschönigt die Sinnfremdheit des Zeitalters einbekennt, erhebt er Einspruch gegen sie."

In diesem Zusammenhang erfährt die künstlerische Intuition - ăhnlich wie im Surrealismus und in der konkreten Poesie - eine Aufwertung als konstruktiver Faktor für die Kunstproduktion. Während der Experimentator im OPOJAZ uber die Intuition spricht, verrätselt sie der Schriftsteller-Erfinder. Denn die Intuition, die den Gesetzen des UnbewuBten und Zufaligen gehorcht. macht das Geheimnis des einheitsstiftenden Prinzips der autobiographischen Prosa aus. Sie lenkt die Montage der verschiedenen Masken der Selbststilisierung zu einem mosaikartigen. facettenreichen Gesamtbild des Helden. zur literarischen Manifestation der "literarischen Persönlichkeit" Šklovskij und tritt in dem Augenblick auf den Plan, wenn der Klinstler die Illusion hat, frei $\mathbf{z w i s c h e n}$ Methoden und Gegenständen wählen zu können. Die künstlerische Intuition entzieht sich der bewubten Kontrolle des Kunstproduzenten, enthebt ihn aber nicht der selbstkritischen Kontrolle der Produktion. Einmal ins Werk gesetzt. gerinnt sie zu einer ästhetischen Form, die nach MaBgabe des Systems der Kunst "formal" beurteilt werden will. Zwischen solchen, an Paradoxa grenzenden Widersprichen. Widersprichen zwischen Anpassung und Verweigerung, 2 wischen Technik und Intuition, bewegt sich die künstlerische Produktion nach der Theorie des Experimentators Šklovskij in der "Dritten Fabrik". 
Der Experimentator tanzt mit der Wissenschaft

(dargestellt am Beispiel der Abschweifung liber die Evolution der Anekdote)

In der Rede des Helden der "Dritten Fabrik" iberschneiden sich verschiedene Diskurse. Literaturtheoretische Termini bzw. Reflexionen uber literaturtheoretische Fragen fungieren häufig als Metaphern für existentielle Probleme, und umgekehrt stehen existentielle Probleme als Motivation und Metapher fur die Realisierung der Formalen Methode. Hansen-Löve beschreibt und bestimmt diesen Vorgang in der "Dritten Fabrik" folgendermaBen:

\begin{abstract}
"Kern der metaphorischen Entwicklung in 'Tret'ja fabrika' ist die Überschneidung der gegenläufigen Prozesse der Existentialisierung und der Realisierung im Begriff der 'obrabotka', der - wie erwähnt - sowohl die künstlerische Transformierung der realen Fakten zu ästhetischen meint als auch die 'Umarbeitung'. Verwandlung und Deformation des Menschen durch die verdinglichende, deformierende. desintegrierende Wirkung der Zeit, der Gesellschaft, des 'byt' Im allgemeinen: Beide Transformationsprozesse entwickeln sich in parallelen metaphorischen oder metonymischen Reihen und iberschneiden einander in verschiedenen Stadien der metaphorischen Metamorphose, deren Subjekt der Autor personifiziert, der gleichzeitig der künstlerischen und der auBerkünstlerischen Reihe angehört. ${ }^{-11}$
\end{abstract}

Der Rede des Experimentators kommt dabei die Rolle zu, diesen TransformationsprozeB zu thematisieren und zu kommentieren, ohne daB er die metaphorische Ebene der Metamorphosen verläBt. Er behält den Status einer Stimme unter den Stimmen der Selbststilisierungen. Die Literarisierung der Erkenntnisse der Formalen Methode in der Stimme des Experimentators erlaubt ihre Selbstdarstellung und macht es gleichzeitig möglich. den theoretischen Diskurs als Kunstgriff der Verrätselung existentieller Probleme zu benutzen. Als Beispiele für die metaphorische Manifestation der Überschneidung von Realisierung und Existentialisierung in der Rede des Experimentators können 2.B. die Abschweifungen über die Evolution der Anekdote $[7 / 8]$ oder über die Evolution der gesprochenen Sprache [93/94] gelten.

In der Abschweifung über die Evolution der Anekdote führt der Held der "Dritten Fabrik" aus, daB man am Ende des 18./2u Beginn des 19. Jahrhunderts unter dem Begriff Anekdote eine interessante Mitteilung uber irgend etwas verstanden habe. Eine anekdotische Geschichte sei. vom Standpunkt jener Zeit aus betrachtet, eine Geschichte gewesen, die aus einzelnen miteinander nur schwach verbunden Mitteilungen besteht. Es habe sogar philosophische Anekdoten gegeben. Witze mit einer unerwarteten Pointe seien zu jener Zeit in Anekdoten undenkbar gewesen. In der heutigen Zeit bezeichne man eine kleine Novelle mit einer Pointe als Anekdote. Von seinem (Šklovskijs) Standpunkt aus betrachtet, sei die Frage am Ende eine Anekdotenerzählung "Und wie ging es weiter?" Unsinn, aber das sei der Standpunkt von heute. Früher habe man nach einer anekdotischen Mitteilung eine andere anekdotische Mitteilung erwarten dürfen. In der zeitgenössischen Anekdote fühle man hauptsächlich die Konstruktion, in der alten Anekdote sei vor allem der Reiz der Mitteilung - das Material fühlbar gewesen. Diese Verlagerung der Wahr- 
nehmung von dem einen Produktionsaspekt auf den anderen könne man leicht nachverfolgen. Die Zeit habe sich erneut verändert. und bald werde man nicht eine witzige Mitteilung. sondern jene Fakten, die man unter der Rubrik "Vermischtes" in der Zeitung abdrucke, als Anekdote bezeichnen. Jedes einzelne Moment eines Stuickes verwandele sich in gesonderte, sich selbst genügende Nummern. Die Konstruktion miBlinge entweder vollkommen oder aber sie werde, falls sie zufälig existiere, zerschlagen. wobei das Publikum das Vergehen nicht bemerke. [7/8]

Der Diskurs liber die Evolution der Anekdote in evolutionierenden System der Literatur, der auf die experimentelle Arbeit im OPOJAZ rekurriert und an sie erinnert. entbehrt in diesem Zusammenhang wie in allen anderen dieser Abschweifung ähnlichen Zusammenhängen im Text einer systematischen wissenschaftlichen Fundierung. Seine Realitätshaltigkeit verdankt er allein der Überzeugungskraft der Rede des Experimentators.

Genauso wie der Gesamttext der "Dritten Fabrik" als Konstruktion einer losen Verkettung von Anekdoten 12 die Realisierung des Diskurses über die Evolution der Anekdote ist, so ist die Rede des Experimentators ein Teil der Realisierung dieses Diskurses, jener Teil, in dem er sich selbst thematisiert. Gleichzeitig demonstriert sie die Existentialisierung des Diskurses. Die Erläuterungen zu seiner Legitimation sind nicht bloB verspielte Koketterie, sondern verweisen auf einen gesellschaftlichen Rechtfertigungszwang. wie ich in bezug auf die Abschweifung uber die Evolution der gesprochenen Sprache bereits an anderer Stelle ausführte. Sie machen zugleich eine Aussage iber die Zerrissenheit und Entfremdung im Leben des Helden. Die Abhandlung Uber die Evolution der Anekdote ist ihrer form nach wie eine Anekdote aufgebaut. Die Ernsthaftigkeit, mit der sie ihre Unemsthaftigkeit demonstriert. läBt sich am besten an dem Beispiel zeigen. das der Experimentator anführt. um das Verständnis des 18./19. Jahrhunderts von der Anekdote zu erläutern. zeigen. Da beiBt es:

"Die Mitteilung darüber, daB die Firma Krupp heute einen Diesel mit 2.000 Pferdestärken in einem Zylinder baut. wäre vom Standpunkt jener Zeit eine Anekdote gewesen." [7]

Diese anschauliche Erläuterung ist mehr. als sie vorgibt zu sein. Sie verwirt spielerisch die Zeiten bzw. ihre jeweiligen Perspektiven im Hinblick auf die Anekdote und verwandelt sich unter der Hand selbst in eine Art Anekdote: Die Einstellung des 18./19. Jahrhunderts zur Anekdote, verkniupft mit der in den 20er Jahren des 20. Jahrhunderts aktuellen Information. ergibt im Kontext der Reflexion iber die Evolution dieses Genres eine Anekdote, in der die Konstruktion fuhlbar wird. was ihren Witz ausmacht.

Liest man die Anekdote uber den Kruppschen Dieselmotor mit den Augen eines Menschen des 18./19. Jahrhunderts, so verwandelt sie sich in eine Anekdote des 20. Jahrhunderts. Liest man sie aber mit den Augen eines Menschen des 20. Jahrhunderts, so verwandelt sie sich in eine Anekdote des 18./19. Jahrhunderts. Das Sprachspiel, in das der Experimentator die Abhandlung iber die Evolution der Anekdote uberfuhrt. kann als Paradigma für 
seinen Umgang mit der Wissenschaft gelten, als Realisierung der Metapher "Ich tanze mit der Wissenschaft" [68] (Brief an R Jakobson). Hierin zeigt sich, daB es ihm nicht auf philologische Begriffsgeschichte ankommt, sondern daB es ihm neben literaturtheoretischen Erkenntnissen vor allen Dingen um eine listige Form der Darstellung seiner Kritik an der sowjetischen Kulturpolitik jener Jahre geht, die in der Prognose zum Ausdruck kommt, daB man bald jene Fakten als Anekdote bezeichne, die unter der Rubrik "Vermischtes" in der Zeitung stehen - ein Sprachspiel obendrein insofern, als das russische Wort für "Vermischtes" (meloč) auch "Kleingeld". "Kleinkram" heiBt. Hinter der quasiwissenschaftlichen These verbirgt sich ein ironischer Seitenhieb gegen die Tendenz der Utilitarisierung der Literatur, die mit dem Vorwurf. jegliche Auseinandersetzung mit Fragen der künstlerischen Konstruktion sei Formalismus, einhergeht - gegen eine Tendenz, die deutliche Parallelen zum althergebrachten Verständnis von der Anekdote als Mitteilung einer interessanten Neuigkeit aufweist und insofern methodisch einen Riucktall hinter das Erreichte bedeuten wirde. Auf diese Weise konstruiert der Experimentator die Abhandlung uber die Evolution der Anekdote zugleich als Anekdote iber diese Evolution und als Metapher fur die gesellschaftliche Bedingtheit der literarischen Produktion.

\section{Die Briefe an die Freunde im OPOJAZ - eine Erfindung des Experimentators}

Den Briefen an die Freunde Roman Jakobson. Jurij Tynjanov, Boris Ejchenbaum und Lev Jakubinskij aus dem Petrograder OPOJAZ, denen in gewisser Weise auch das Kapitel "O.M. Brik" zuzuordnen ist, kommt im Text der "Dritten Fabrik" eine besondere, die autobiographische Prosa Šklovskijs prägende Funktion und Bedeutung zu. Die Übergänge von der autobiographischen Erzählung zur Form des literarisierten Briefes innerhalb dieser Erzählung sind flieBend. Abgesehen von den explizit so benannten und dadurch vom lubrigen Text abgesetzten Briefen weist die Erzählung von Beginn an Spuren der Briefform auf, vor allen Dingen dadurch. daB der Erzähler im Textzusammenhang unvermittelt Freunde anspricht.

Wo seid thr. Freunde?

Wo bist Du. Klimoveckij? Wo ist Eniserskij? Man sagt: 'Getötet bei der Verteidigung von Caricyn.

Wo ist Tarasov? Uber Bruk weiB ich Bescheid.

Surovcev ist Flieger. Wenn wir uns treffen, dann werden wir betribt sein, daB wir so gealtert sind. Es ist 2 wecklos. daB wir uns versammeln. All das geschah wider das Lyzeum am Kamennoostrovskij Prospekt ..." [28]

Eine längere Textpassage, in der autobiographische Erzählung und literarisierter Brief stark miteinander vermischt werden, sind die vier aufeinander folgenden Kapitel uber Osip Brik [56-65]. Brik gehörte zwar nicht zum engen Kreis 
der Formalisten, aber er spielte für Šklovskij als Bindeglied zwischen den Futuristen und den Formalisten eine wichtige Rolle. Die Wohnung der Briks in der Žukovskaja Straße Nr. 7 war lange Zeit ihr Treffpunkt. thr literarischer Salon. In der "Dritten Fabrik" bezieht der autobiographische Erzähler Brik nicht nur als Folie seiner Selbstdarstellung mit ein, sondern er spricht ihn persönlich an und appelliert an ihn, seine literaturtheoretischen Studien fortzusetzen und sein Buch uber den Rhythmus zu Ende zu schreiben.

Die literarisierten Briefe und die briefähnlichen Passagen in der "Dritten Fabrik" können als eine literarische Innovation im System der Evolution der Literatur, als eine Erfindung des Experimentators $\breve{S}_{k}$ lovskij und als Statthalter der Erinnerung an die Arbeit des OPOJAZ gelten. Dringender und ausführlicher als in anderen Passagen der "Dritten Fabrik" erinnert der Autor in ihnen an die kollektive und experimentelle Arbeit der Gesellschaft zur Erforschung der poetischen Sprache und daran, daß sich diese Gruppe selbst als engagierter Teilnehmer an der öffentlichen Diskussion uber Revolution und Literatur verstand. Die Literarisierung des Briefes, seine Aufnahme in den autobiographischen Prosatext statuiert das Modell einer solchen experimentellen und kollektiven Arbeit bzw. das Modell dessen, was nach dem Verbor einer solchen Arbeit in der sowjetischen Öffentlichkeit davon ibbriggeblieben ist und zäh um sein Überleben kämpft. Die Briefe rekonstruieren jene Arbeit und erinnern zugleich an sie.

In seinem Aufsatz "Das literarische Faktum" entwickelt Tynjanor u.a. am Beispiel der Literarisierung des Briefes in der 2. Haltie des 18. Jahrhunderts - vor allen Dingen an den Briefen Karamzins - den KonstitutionsprozeB des literarischen Faktums in System der literarischen Evolution. ${ }^{13}$ Tynjanov begreift die Entstehung eines literarischen Faktums nicht als einen linearen, sondern als einen sich dialektisch entwickelnden ProzeB der Literarisierung von auBerliterarischem Material und in der umgekehrten Richtung als Entliterarisierung von literarischen Formen. Entsprechend beschreibt er die Art und Weise, wie sich die Literatur auf der Suche nach neuen, unverbrauchten Konstruktionsprinzipien zeitweilig der Briefform bemächtigt und sie für ihre Zwecke umfunktioniert, um sie später, nachdem sie sich etabliert und kanonisiert hat, wieder ins auBerliterarische Leben zu entlassen. a's einen in der Geschichte der Literatur in Variationen sich wiederholenden Vorgang. Die Tatsache, daB Tynjanov diese Abhandlung über das literarische Faktum "für Viktor Šklovskij” schrieb, ${ }^{14}$ deutet darauf hin, daß er auch dessen Prosa vor allem "Zoo..." - vor Augen hat, wenn er uber die Literarisierung des Briefes spricht. Denn jene Merkmale der Briefform, die Tynjanov als "die gefügigsten. leichtesten und am dringendsten efforderlichen Erscheinungen. die die neuen Konstruktionsprinzipien (der Karamzinzeit, V.D.) mit besonderer Kraft herauszustellen vermochten" bezeichnet - "das Nicht-zu-Ende-Sprechen. das Fragmentarische, die Anspielungen, und die 'häusliche' kleine Form des Briefes. ${ }^{-15}$ machte sich auch Šklovskij in seiner autobiographischen Prosa zunutze, um Literatursprache zu erneuern. 
Als Revolutionär in der Literatur feierte ihn nicht nur Tynjanov, sondern auch ihr gemeinsamer Freund Ejchenbaum, ihr Schiler Gric und der Theoretiker der literatura fakta Cužak: er habe Alltägliches und Intimes gleichermaBen wie die Theorie und die Kritik der Literatur Betreffendes als Material in die Literatur aufgenommen. ${ }^{16}$ Die Briefe an die Freunde aus dem OPOJAZ. die jeweils ein Kapitel im Text der "Dritten Fabrik" ausmachen und die mit Ausnahme des Briefes an Jakobson, der im zweiten Teil, in der "Zweiten Fabrik" steht, aufeinanderfolgend im dritten Teil des Buches der "Dritten Fabrik" zu finden sind, können als solch eine Innovation gelten.

Der Autor präsentiert sich hier als Experimentator in dem BewuBtsein, daB er das kompliziert geknuipfte System der Evolution eines Genres fortschreibt. Er weiB, daB die Literarisierung des Briefes nicht seine Erfindung ist. ${ }^{17} \mathrm{Er}$ stellt sich bewubt in die Tradition der Literatur, die, gegen den jeweils geltenden Kanon literarischer Formen anschreibend, das Alltägliche und Banale zum literarischen Thema erhebt, um das Gefühl für die Welt und fur das Leben zu erwecken und einer neuen Sensibilität das Wort zu reden. Insofern ist nicht die Idee der Literarisierung des Briefes schlechthin, sondern die Art und Weise seiner Literarisierung und die Spezifik des Briefmaterials das Neue und Revolutionäre der Textstruktur der "Dritten Fabrik". In diesem Text beziehen die Briefe ihre Intimität und Intensitilt nicht aus einem schlicht persönlichen Verhältnis zu einem Menschen, sondern aus der Sehnsucht nach einem Diskussions- und Arbeitszusammenhang mit den Freunden, an die diese Briefe gerichtet sind. Die Literarisierung des Briefes ermöglicht es dem Autor der "Dritten Fabrik", den wissenschaftlichen Diskurs mit der Intimitalt einer persönlichen Beziehung zu behandeln, ohne daB diese Verknüpfung zu einer vordergrilndigen Verwechslung oder Vermischung dieser in unserer Zeit so konträren Existenzformen miBrat. ${ }^{18}$

Das, was Šklovskij in bezug auf die Literarisierung des Materials in allgemeinen konstatiert, gilt gleichermaBen für den Brief im besonderen: die Literarisienung verändert den Brief, seine Funktion und Bedeutung. Innerhalb des autobiographischen Prosatextes erfüllt er nicht länger den Zweck, eine Form der schriftlichen Kommunikation zu sein, sondern er verwandelt sich in die Fiktion einer schriftlichen Kommunikation. Indem sich die Briefform ästhetisiert, wird sie zu einer Metapher.

Šklovskij hat diesen ProzeB der Transformation von Sprachformen aus dem semantischen System der Alltagssprache in das der Literatursprache nicht nur immer wieder studiert, er nutzt ihn auch bewuBt als ein konstruktives Sujetverfahren der Verfremdung. Einige seiner Kritiker lieBen sich davon täuschen. Sie erkannten den Kunstgriffcharakter des intimen Tons der "Dritten Fabrik", dessen sich der Erzähler insbesondere in den Briefen befleiBigt. nicht oder erkannten ihn nicht an. Gor'kij bemängelte, wie schnell Šklorskij sich in der "Dritten Fabrik" ausgeschwätzt habe. ${ }^{19}$ Die Kritiker Polonskij und Beskin beklagten den familiären Ton des Buches. ${ }^{20}$ Es gab wenige, die, wie seine Formalistenfreunde, diesen Kunstgriff als innovatives Verfahren goutierten. $^{21}$ 
Indem Sklovskij Briefe an Freunde mit all ihren charakteristischen Eigenschaften wie der persönlichen Anrede, zum Teil nur mit dem Vormamen, und dem intimen Ton von Botschaften, die nur dem am Briefwechsel Beteiligten verständlich sind, um ihren Zweck zu erfullen, in seine autobiographische Prosa aufnimmt, weicht er vom Gewohnten ab: er verletzt die Grenzen der Intimität. Dadurch verwirt er den Leser, macht den Unwissenden neugierig oder ärgerlich und vermittelt dem Wissenden das schmeichelhafte Gefuhl, zum Kreis der Eingeweihten 24 gehören. Er arbeitet bewuBt mit dem Trick der Ästhetisierung auBerliterarischen Materials und nicht, um das Material, in diesem Falle die Briefe an die Freunde, zu kompromittieren. Es ist deshalb weniger wichtig, herauszufinden, ob er diese Briefe an Jakobson. Tynjanov, Ejchenbaum und Jakubinskij wirklich jemals geschrieben hat, als zu konstatieren, daB der Briefwechsel mit den Formalistenfreunden fir ihn und fur seine Arbeit eine groBe Bedeutung hatte und daB er mit einigen von thnen. insbesondere nachdem sie getrennt waren, intensiven Briefkontakt hielt und auf diese Weise die Diskussionen in OPOJAZ fortzusetzen versuchte. Die Briefe an die Formalistenfreunde in der "Dritten Fabrik" fungieren als ein Symbol fur die kollektive und experimentelle Arbeit des OPOJAZ.

Abgesehen von zahireichen ÄuBerungen über den ProzeB der Literarisierung im allgemeinen, belegen auch Äuberungen iber den Brief im besonderen in der "Dritten Fabrik" oder aber die Tatsache, daB Variationen zu diesen Freundesbriefen existieren bzw. daB es (im Fall des Briefes an Jakobson) einen veröffentlichten Vorläufer $2 u$ einem dieser Briefe gibt, daB క̌klovskij sie nicht naiv, sondern mit Bedacht literarisierte. In dem Kapitel "Ich schreibe dariber, daB das Sein das BewuBtsein bestimmt, aber das Gewissen unstrukturiert bleibt" heiBt es gleich zu Beginn:

-Mark Twain schrieb sein Leben lang Briefe doppelt - einen schickte er weg und den anderen schrieb er für sich, und dort schrieb er das, was er dachte.

Auch Puškin schrieb seine Briefe mit Entwilrfen." [15]

Die Differenz, auf die క̌klovskij hier anspielt, zwischen einem ganz persönlichen, offenherzig geschriebenen und unzensierten Brief und einem Brief, der in seinen ÄuBerungen kontrolliert. dadurch gemäBigt und zur Veröffentlichung - und sei es nur der an den Adressaten - bestimmt ist, gilt auch fur die Briefe an seine Formalistenfreunde. Hier soll nicht 2 wischen den Entwiurfen und den tatsächlich abgesandten Briefen unterschieden werden, sondern zwischen den Entwiirfen und den letztlich gedruckt veröffentlichten. Der Unterschied $\mathbf{z w i s c h e n ~ d e n ~ j e w e i l i g e n ~ F o r m e n ~ i s t , ~ s o w o h l ~ w a s ~ i h r e ~ O f f e n t l i c h - ~}$ keit als auch was ihre Ästhetisierung anbetrifft, nicht bloB ein gradueller. sondern ein qualitativer. Um diesen ProzeB zu beleuchten, ist ein Textvergleich aufschluBreich. Die Varianten der Briefe an die Freunde im OPOJAZ sind im Vergleich zu denen, die in der "Dritten Fabrik" tatsächlich abgedruckt sind. worteich und thematisieren kulturpolitische Probleme offener als jene. Die Briefe in der "Dritten Fabrik" erscheinen gegen sie verschlusselt und zugleich 
kunstvoller konstruiert. Auffällig ist zum einen. daB der Brief an Jakubinskij im Manuskript wesentlich länger ist und völlig anders lautet als die gedruckte Fassung. zum anderen, daB ein weiterer Brief an Ejchenbaum vorgesehen war. der gar nicht in das Buch aufgenommen wurde. An dem Brief an Tynjanov wurde nur das Postskriptum geändert.

In der "Dritten Fabrik" erinnert lediglich ein Kalambour zu Beginn des Briefes an Jakubinskij wörtlich an das Thema, das in der Variante den meisten Raum einnimmt. Trotzdem handeln beide Fassungen - der gedruckte und der variante - von ebendemselben Thema. Der Kalambour in der gedruckten Fassung basiert auf einem Wortspiel.

"Freund, ich verwandele mich nicht in einen folgerichtigen (posledovatel'nyi) Marxisten und rate auch Dir davon ab. In unserem Bereich ist es besser. nicht nachzufolgen (posledovat'), sondern nachzuforschen (issledovat')." [104]

Der Briefschreiber spielt auf den Methodenstreit zwischen Marxismus und Formalismus an. der in der kulturellen Öfentlichkeit der Sowjetunion seit der Mitte der 20er Jahre zunehmend in einen Kampf um die Hegemonie unter den Methoden ausartete. Der Brieftext der Variante nimmt das Thema des Methodenstreits explizit und wortwörtlich auf, nenst Namen (Trockij, Plechanov) und Positionen -

"Es wird zum Beispiel behauptet, daB eine gute, für die Entwicklung des Proletariats geeignete Kunst von der aufsteigenden Klasse geschaffen wird und eine schlechte von der niedergehenden Klasse." -

und widerspricht ihnen:

Homer. Puškin und Lev Tolstoj hätten zum Beispiel niedergehenden Klassen angehört - warum sie dann keine dekadente Kunst geschaffen hätten. "Ich behaupte nicht. daß eine niedergehende Klasse immer eine hohe Literatur schafft. Ich behaupte nur, daB man nicht das Gegenteil behaupten darf."

Dagegen macht sich der Brieftext der "Dritten Fabrik". versteckt hinter einem Wortspiel, uber die Bomiertheit der sowjetischen Marxisten, iber ihr epigonenhaftes Verständnis und ihr autoritätsfixierte Auslegung der kritischen marxistischen Theorie, die sie auch der Kunst und Literatur iberstiilpen wollten. lustig und sucht daruber Einverständnis mit Jakubinskij herzustellen. Während der Briefschreiber der Variante den Linguisten auf der Basis dieses kritischen Einverständnisses gegenüber dem Sowjetmarxismus mit pragmatischen Appellen wie:

-Schreib, wenn Du nicht uiber Literatur schreiben willst, dann uber die Sprache, und wenn nicht dariber, dann kannst Du mit neuem Material anfangen ... Du bist ein Marxist. Lev, Du bist wirklich kein Naturwissenschaftler, sie sind Zitateklauber .... ${ }^{23}$.

zu einer Weiterarbeit in der sowfetischen Offentlickeit bewegen will, versucht es der Briefschreiber im gedruckten Text mit einer linguistischen Argumenta- 
tion, die sich einem Laien nur schwer entschlüsselt, aber der Sache, um die es geht, angemessen ist. Der Briefschreiber versucht Jakubinskij von der Notwendigkeit zu uberzeugen, die Evolution der Sprache unter dem Gesichtspunkt threr gesellschaftlichen Bedingtheit zu betrachten.

"Es ist nicht notwendig die Ursprache zu erforschen, nicht einmal die Sprache im allgemeinen, sondern die Sprache in ihrer Verbindung mit der Produktion, hauptsächlich dort, wo sie noch als lebendige in Erscheinung tritt." [105]

Er möchte das Interesse des Linguisten für solch eine Forschungsarbeit wecken. In beiden Fassungen warnt er seinen Freund davor, zum Akademiker und Zitateklauber zu werden - in der Variante ganz unverblumt und direkt und in der "Dritten Fabrik" in einer an einen asiatischen Weisheitsspruch erinnernden Metapher - in der Metapher uber die Kurve der Ermüdung. Der Vergleich der Variante mit dem gedruckten Text des Briefes an Ler Jakubinskij zeigt, daß sich der Text umso verschlusselter präsentiert, je gröBer der Grad an Offentlichkeit ist. Dabei arbeitet die Literarisierung der Verschlusselung in die Hand. Abgesehen von der allgemein in der Sowjetunion auch in der zweiten Häfte der 20er Jahre bereits geltenden Einschränkung der politischen Diskussionsfreiheit (es war die Zeit der Hetzkampagnen gegen die Trockisten. in der die Position Bucharins noch allgemeines Ansehen genoB) war es für den Formalisten Šklovskij mit seiner zwielichtigen und spektakulären Vergangenheit besonders schwer, seine Kritik an der Kulturpolitik der Bolschewiki offen und direkt öffentlich politisch darzustellen. Dariber hinaus spricht Šklovskijs Sprachkonzeption gegen eine solch unmittelbare form politischer Meinungsäußerung. Als Kritiker jeglicher form von automatisierter und ritualisierter Sprache traut er der konstruierten und erschwerten Sprache der Kunst weit mehr politische Aussagekraft zu als der politischen Sprache, die, wie er in einem Aufsatz uber die Sprache Lenins aufgezeigt hat. ${ }^{24}$ besonders anfallig für Ritualisierungen und Automatisierungen ist.

Der Autor der "Dritten Fabrik" macht sich sein eigenes Theorem ron der Ásthetisierung des Materials im ProzeB der Literarisierung, d.h. der Entlassung des Wortes aus seiner auBerliterarischen Funktion und seiner Einbindung ins Funktionssystem des literarischen Textes, als Kunstgriff der Verrätselung zunutze, um auf dlese Weise ein politisches Wort hörbar zu machen und um an seine Mitstreiter im OPOJAZ zu appellieren, sie möchten doch, allen Schwierigkeiten zum Trotz und die Erfahrungen und Entwicklungen der vergangenen Jahre bedenkend, gemeinsam die experimentelle Arbeit so offentlich wie möglich fortsetzen. Dies gilt auch für den Vergleich des Postskriptums im Brief an Tynjanor mit der entsprechenden Variante. Im gedruckten Text lautet es lakonisch:

"Das persönliche Leben erinnert mich an die Anstrengungen, die man braucht, um eine Portion Eis zum Schmelzen zu bringen." [100] 
Dagegen heiBt es in der Variante:

"Es ist interessant, daB Bucharin sich als Beispiel für revolutionäre Kunst auf die Marseillaise beruft, aber die Marseillaise ist nicht von einem Revolutionär geschrieben, ihre Musik ist aus einer katholischen Hymne entlehnt worden. Er hätte bei irgendjemandem lemen sollen, aber nicht gerade dort. Dein Viktor." ${ }^{25}$

Der Briefschreiber hat an dieser Stelle das Thema geändert. Im Drucktext verzichtet er auf die kritische Erörterung der sowjetmarxistischen Literaturtheorie und schlieBt statt dessen mit einem Aphorismus à la Rozanov. Auch der Entwurf zu einem weiteren Brief an Ejchenbaum bestätigt die These, daß Šklovskij das Theorem von der Ästhetisierung des Materials im ProzeB seiner Literarisierung in einen Kunstgriff der Verrätselung verwandelt. In dem Entwurf kommt der Briefschreiber, nachdem er in wenigen Sätzen die Entwicklung der Arbeit des OPOJAZ rekonstruiert hat. auf Ejchenbaums Projekt, eine Tolstoj-Monographie zu verfassen, zu sprechen, wovon auch in dem in der "Dritten Fabrik" abgedruckten Brief an Tynjanov die Rede ist. Aber während er in jenem Brief an Tynjanov seinen Freund Ejchenbaum dafür kritisiert, daB er zu unvermittelt von der Biographie und der Psychologie des Schriftstellers Tolstoj auf seine Literatur schlieBe und daB es ein Unding sei, die Monographie eines Schriftstellers schreiben zu wollen - man dürfe nicht über Tolstoj, sondern müsse uiber "Krieg und Frieden" schreiben [100] spricht er im Entwurf zunächst davon. daB man Ejchenbaum die Tageblicher und Konzepte Tolstojs nicht gab, so daB jener seine Arbeit an diesem Projekt vorläufig abbrechen muBte. Der Briefschreiber äuBert sich im Entwurf relativ lakonisch zu diesem Vorfall, der de facto einen enormen Eingriff und eine starke Behinderung der Arbeit des Literaturwissenschaftlers bedeutete. Aber er bringt dann seine ganze Utberzeugungskraft auf, um Ejchenbaum. dieser massiven Behinderung zum Trotz. zur Weiterarbeit zu bewegen. Er versucht ihn zu beschwichtigen. Ejchenbaum solle sich nicht so sehr auf das Tagebuchmaterial fixieren. Wenn es schwierig sei, irgendein beliebiges Material zu erlangen. müsse man ohne das auskommen. müsse man dieses Projekt auf anderem Material aufbauen. Die Tagebijcher seien wohl spannend, aber doch nur von beschränktem Nutzen. Sie führten leicht zu Psychologismus. ${ }^{26}$ Denn das Laboratorium des Schriftstellers sei nicht in den Tagebuichern, sondern in der Literatur zu suchen und selbst das Faktum, daB die literarische Produktion mit der Zeit und mit Tradition verbunden sei, sei ein Faktum der Form und nicht der Geschichte. Die literarische Produktion könne ihren gesellschaftlichen Hintergrund verändern. Deshalb sei es nötig, die Gesetze der Beziehung der Produktion zu ihrem Hintergrund, aber nicht die jeweilige historische Verbindung zu studieren. ${ }^{27}$

Vergleicht man den Text des Entwurfs zu einem weiteren Brief an Ejchenbaum mit jener Passage aus der Druckfassung des Briefes an Tymianov zum gleichen Thema, so stellt man fest, daB ăhnlich lautende Sätze verschiedene Bedeutungen haben, weil ihnen in dem einen Falle eine Information vorausgeht und 
als Voraussetzung der fortlaufenden Argumentation fungiert, die in dem anderen Falle verschwiegen wird. Während der Briefschreiber des Entwurfs seinen Brief auf der Information aufbaut, daB Ejchenbaum die Arbeit mit den Tagebiichern und Manuskripten Tolstojs untersagt worden ist, setzt der Schreiber des Briefes an Tynjanov unvermittelt mit der Rede uber "Boris' Fehler" ein:

"Er hat viele Fehler. Der erste - und den hat er mit meinen Arbeiten gemeinsam - ist, das AuBerachtlassen der Bedeutung der auBerasthetischen Reihen.

Es ist ebenfalls vollkommen falsch. Tagebiicher zur Klärung der Entstehungsgeschichte von Werken zu benutzen. Hier liegt die Lüge verborgen, der Schriftsteller schaffe und schreibe selbst und nicht zusammen mit seinem Genre, mit der ganzen Literatur, mit all ihren widerstreitenden Strömungen. Die Monographie eines Schriftstellers ist ein unmögliches Projekt. Abgesehen davon führen uns die Tagebiicher zur Psychologie des Schaffens und zur Frage nach dem Laboratorium des Genies. Aber wir brauchen das Werk. Die Beziehung zwischen dem literarischen Text und seinem Autor ist ebenfalls eine nichtfunktionale." [100]

Auch wenn es schwierig ist. genau zu differenzieren, welche der Textveränderungen schlicht auf stilistische Verfeinerungen abzielen, welche von ihnen eine kunstvolle Verrätselung politisch brisanter Informationen bezwecken und welche sich letztlich der tatsächlich vorgenommenen politischen Zensur verdanken. so zeigt der Textvergleich zwischen Varianten und gedruckter Fassung am Beispiel der Briefe doch so viel, daB die These. Šklovskij habe den Kunstgriff der Verrätselung im BewuBtsein der konstruktiven Möglichkeiten der Ubertragung des Wortmaterials aus auBerliterarischen Reihen in die literarische Reihe angewandt, aufrechtzuerhalten ist und daB sich die Behauptung oder gar der Vorwurf, Šklovskij befleiBige sich in der "Dritten Fabrik" eines intimen. schnodderigen Tones und einer nachlässigen Alltagssprache als falsch erweist. Denn bei genauerer Betrachtung entpuppt sich diese Sprache ebenfalls als ein Kunstgriff der Stilisierung zum Zwecke der Verrätselung.

Abgesehen von der vielstimmigen Rede der verschiedenen Masken der Selbststilisierungen des autobiographischen Erzählers und von den mannigfaltigen intertextuellen Bezijgen, die jeweils in einen Dialog mit der autobiographischen Erzählung treten. repräsentieren die Briefe an die Formalistenfreunde eine besondere Variante der dialogischen Rede in der "Dritten Fabrik". Die Form des Briefes kann a priori als eine dialogische Redeform gelten. Schon Aristoteles soll den Brief als die Hälfte eines Dialogs bezeichnet haben. denn der Brief impliziert - auch wenn er nur von Einem geschrieben wird - den Anderen - und zwar nicht nur als passiven Empfänger. sondern auch als aktiven Redeanteil des Empfangers, sei es vor- (als Vorgabe, auf die der Briefschreiber reagiert) oder nachzeitig (als Projektion auf dessen Antwort). Das heiBt, daB die Form des Briefes den Briefwechsel impliziert. 
Der Briefwechsel gilt als eine schriftliche Form der Kommunikation. an der mindestens zwei Personen beteiligt sind. Er setzt im allgemeinen die Ferne der Partner voraus. Die Briefe an die Freunde im OPOJAZ in der "Dritten Fabrik" stellen keinen Briefwechsel dar. Der autobiographische Erzähler ist der Brietschreiber und seine Freunde sind die Adressaten. Aber diese Briefe implizieren den Briefwechsel. Sie überschreiten die traditionell monologische Form der autobiographischen Erzählung. Denn. im Unterschied zum Beispiel zum Tagebuch, erheischen sie eine Antwort der Freunde und/oder stellen eine Replik auf ÄuBerungen von ihnen dar. Sie fordern durch Fragen. Provokationen und Appelle zu einer Antwort auf, und sie rekurrieren auf Äußerungen der Freunde, in diesem Fall auf veröffentlichte Arbeiten, bzw. darauf, daB diese ausblieben.

An Brik:

"'Brik. wo ist Dein Buch?' fragte Dich Larissa Rejsner.

Brik. man kann nicht auf Probe leben.

Selbst der Samovar kocht nicht ohne Zugluft. Die Zeit. Brik. ist taub.

Das Erdbeben ist vorbei. Der Deckel ist abgenommen. Die Suppe ist fertig.

Die Löffel sind ausgeteilt. - iB ...

Wir brauchen das Buch und Dich, Brik.

Haben sie Dich wirklich mit dem Tee geschluckt?

Dich per Telefon klein gekriegt?

In kleinen Siegen aufgezehrt?" [63]

An Jakobson:

"Zwei Jahre kein Brief von Dir. Auch ich schweige, als sei ich schuldig. Lieber Freund, das Buch 'Theorie der Prosa' ist herausgekommen.

Ich schicke es Dir." [66]

"Roman, warum schreibst Du mir nicht? Ich denke an Prag ..." [67]

"Richte mich. Roma ... Und ich richte Dich. Roma." [68]

"Und Du bist ein Imitator. Du Rotblonder. sag. warum bist Du ein Akademiker? Sie sind langweilig, sie sind dreihundert Jahre alt ... Ich rufe Dich zum zweiten Mal nach Hause. Ich fahre nicht hinter Dir her." [69]

\section{An Tymjanov:}

-Dein Aufsatz über das literarische Faktum gefält mir sehr. Es ist gut bemerkt. daB der Begriff der Literatur beweglich ist ... Utber die Schlubfolgerungen Deines Aufsatzes wirst Du mir selbst schreiben, und ich schreibe Dir liber meine Kunst, kärglich zu leben." [98]

"Zeige Boris den Brief, ich habe mit ihm ulber all das geredet. Antworte mir. nur zieh mich nicht in die Literaturgeschichte hinein ..." [100] 


\section{An Ejchenbaum:}

"Ich werde Dir uber den skaz schreiben. Du bestimmst den skaz als die Einstellung in der Erzählung auf das mündliche Wort ..." [101]

An Jakubinskij:

"Bei Euch (bei Marr) spricht man scheint's daruber (über Probleme der Etymologie der Wörter. V.D.), es ist scheint's möglich. Eure Idee so zu formulieren - das Dublett fördert die Begrïndung eines neuen Begriffs leine allgemeine GesetzmäBigkeit in der Geschichte der Sprachel. Antworte mir darauf. Aber ist es richtig. daB Ihr Euch mit Zahlwörtern beschäftigt? ... Worauf ich hinaus will? Darauf ..." [105]

"Ich warte auf Briefe." [106]

Die Briefe handeln, wie die Zitate zeigen, nicht von irgendwelchen persönlichen Erlebnissen oder alltäglichen Ereignissen, sondern von der Arbeit der Formalisten. Sie sind gleichsam als ein Symbol für das dialogische Prinzip ihrer kollektiven Arbeit im OPOJAZ zu verstehen. "Lieber Roman! Wozu arbeiten. wenn man es niemandem erzählen kann?" [67] schreibt Šklovskij im Brief an Jakobson in der "Dritten Fabrik". Die Gesellschaft zur Erforschung der poetischen Sprache in Petrograd war "ein Forschungsinstitut ohne Mittel, ohne Kader, ohne Hilfsarbeiter, freilich auch ohne den Kampf nach dem Motto: 'Das hast du gesagt, das habe ich gesagt.' Wir arbeiteten zusammen, gaben unsere Entdeckungen einander weiter. ${ }^{28}$ Damals waren es die Mitarbeiter des OPOJAZ gewohnt, kollektiv 24 arbeiten. Nach der räumlichen Trennung und nach der öffentlichen Diskriminierung ihrer Arbeit garantierte einzig der Briefkontakt die Möglichkeit der Diskussion iber Literatur. Theorie und Kulturpolitik. Eine umfangreiche. zu gröBten Teilen bisher unverötfentlichte Sammlung der Briefe im Zentralarchiv für Literatur und Kunst in Moskau (CGALI) und eine schmale, im Dezember 1984 in der Zeitschritit Voprosy literatury veröffentlichte Auswahl aus dem Briefwechsel zwischen Šklovskij, Ejchenbaum und Tynjanor können dies bezeugen. ${ }^{29}$ Die drei Freunde sollen nach Auskunft der Tochter Šklovskijs. Varvara Viktorovna, wöchentlich mindestens einmal Briefe gewechselt haben.

Indem Šklovskij Briefe an seine Formalistenfreunde in die "Dritte Fabrik" aufnahm, setzt er diesem Meinungsaustausch, der von der existentiellen Bedingtheit und den im Verhältnis zur Arbeit im Leningrader OPOJAZ stark reduzierten Möglichkeiten der Diskussion kündet, nicht nur ein Denkmal zur Erinnerung. sondern er demonstriert mit diesem Akt auch die Absicht, die Arbeit im Kollektiv, im Dialog mit den Freunden fortzusetzen - ein Unterfangen, das 1926. im Jahr der Veröffentlichung der "Dritten Fabrik". wieder möglich zu werden schien. Tatsächlich bot der Novyj LEF den Formalisten - in erster Linie Sklovskij und der zweiten Generation, den jungen Moskauer OPOJAZ-Anhängem Gric. Trenin und Nikitin - trotz interner Meinungsverschiedenheiten einen organisatorischen Schutz und die Möglichkeit zu veröffentlichen. 
Als sich der Novyj LEF auflöste, hoffte Šklovskij, unter der Schimherrschaft des Dachverbands FOSP den Moskauer OPOJAZ neu begrïnden zu können. Das Manifest der Formalisten, formuliert und unterzeichnet von Jakobson und Tynjanov, das in der letzten Nummer des Noryj LEF erschien, berichtete seinerzeit von diesem Plan. ${ }^{30}$ Die veröffentlichten Auszüge aus dem Briefwechsel zwischen Šklovskij, Ejchenbaum. Tynjanov und Jakobson beleuchten den Hintergrund der Situation, in der das Manifest entstanden ist.

Auszüge aus dem Briefwechsel zwischen Šklovskij. Tynjanov und Jakobson. die auf den Plan. den OPOJAZ neu zu gründen, Bezug nehmen: ${ }^{31}$

V. ̌̌klovskij an Ju. Tynjanov

(15.11.1928)

"Lisber Durigf ...

Dee LEZ ist serfallen ... Och teenne mich won den Restbestïnden des LEJ7. Wenn wie elne Geuppe beauchen. dann wä̈es es gut. unserer Freundschaft elnen Sntzungscharakter an geben und five uns einen plata un dee Fördecention wad ein Doweral an foederen. Wie seltsam es auch klingen mag. aber das kann klappen. DLe Sympachie dee beniten Mhasse Lot and unserere Selte. Merdoedeo hat das Buch

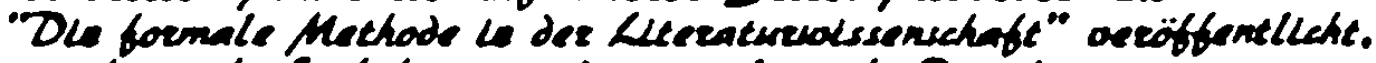

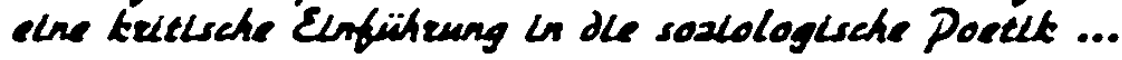

[R.Jakobson an V. ̌̌klovskij

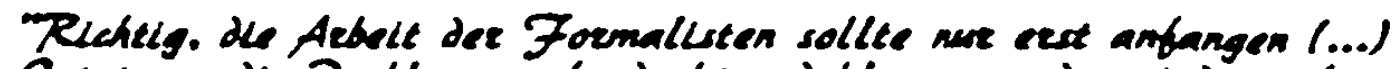
Breat. wo des Probleme anfgedectet und klare gewooeden sind - soforet Unstlmmigtelt. DLe Argst oor dem Problem, dee abewede Wunseh. de elne Reche aus dee anderen an cetclïen ..." ] (CGALI. f. 562, op.1. ed.che. 795)

v.Šklovskij an Ju.Tynjanov

(27. Nov. 1928)

"Lubere Dwely ...

Deh habe elnen Belef oon Roman Datobson echalten, cinen setie schönen Brief. er scheribt. dab steh nicht der Formalismues in einer Kelse beflendet. sonderen de Foemalleten - das Lot nicht otine Wits. abere Du werst Diah mit itm einigen. Wir sind wenige. und fene nicht. Wie müssen zusammen sein und zusammen arbelten, wie müsen einen Sammelband oon maximales Qheochetalthgteit und mit einem Maximum an gemelnsamen Positlonen herausgeben. Aupsätze flnden sich bel Die. bel Roman. bel mir und oielleleht bei Polioanoo. Mein Roman mit Osia (O.Brik. V.D.) Lst beendet ..."

V.Šklorskij an Ju. Tymjanov

"Lleber Dwris ...

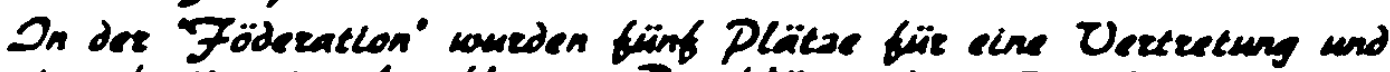
elne bestlmmite Araatil oon Dewekbögen (zur Berechnung eines 


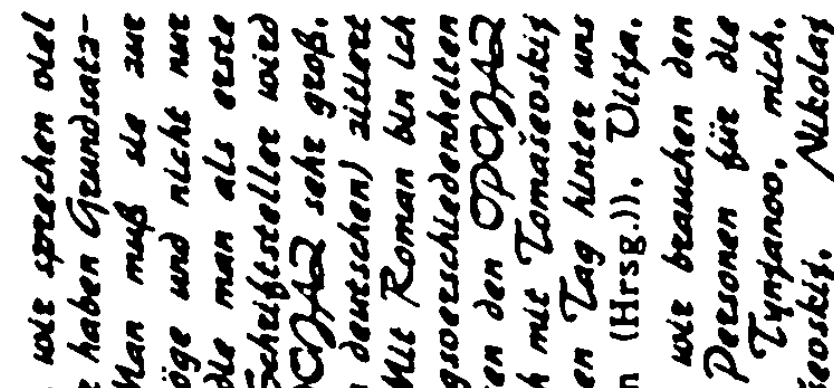
ช3 ०. ริ5

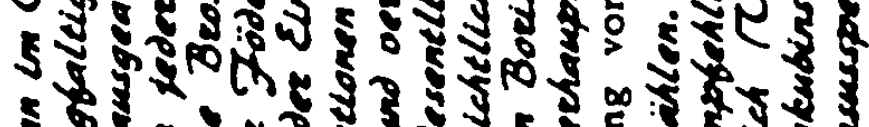
3. राร

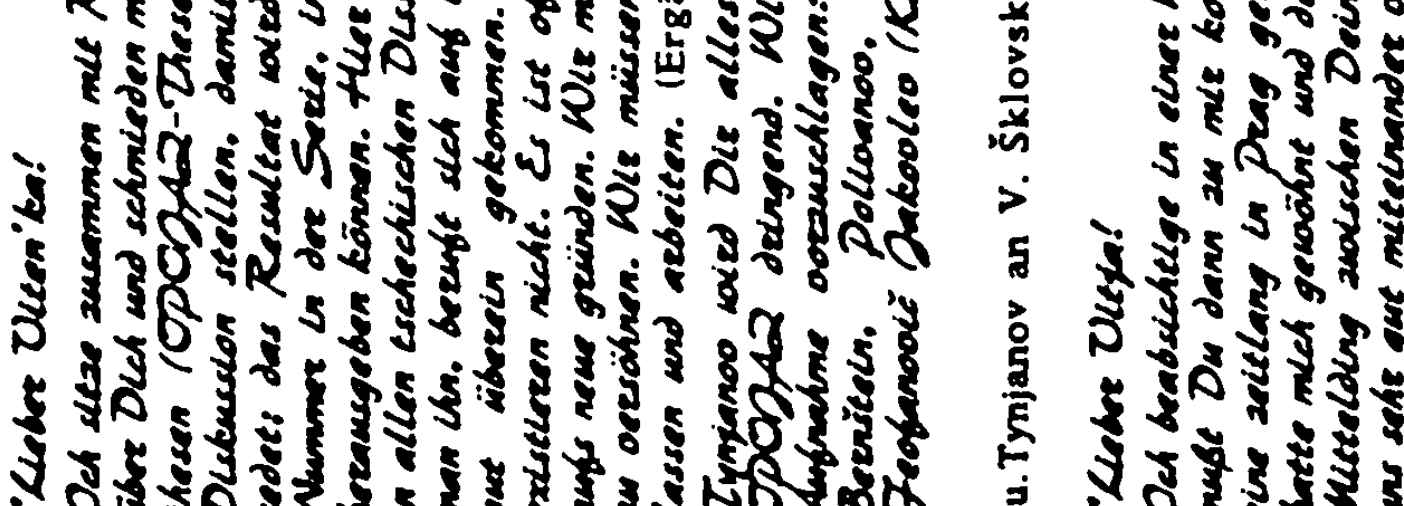

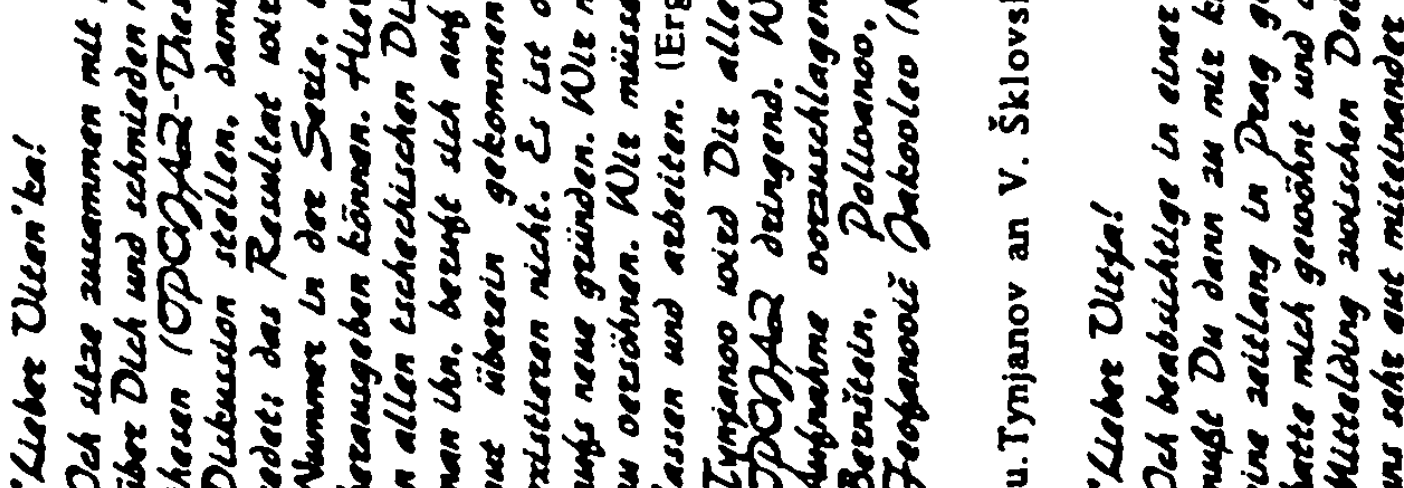
ริ

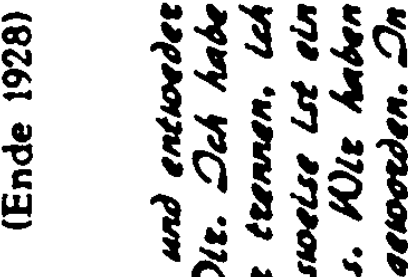

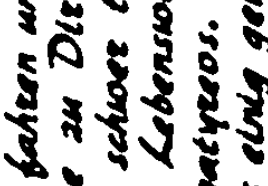
3 है है

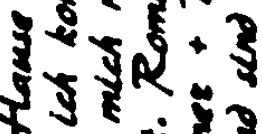
र ช है

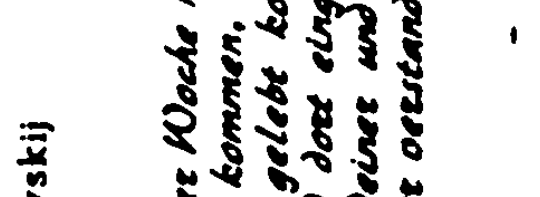

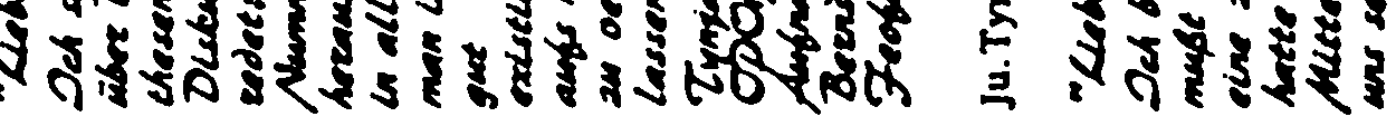




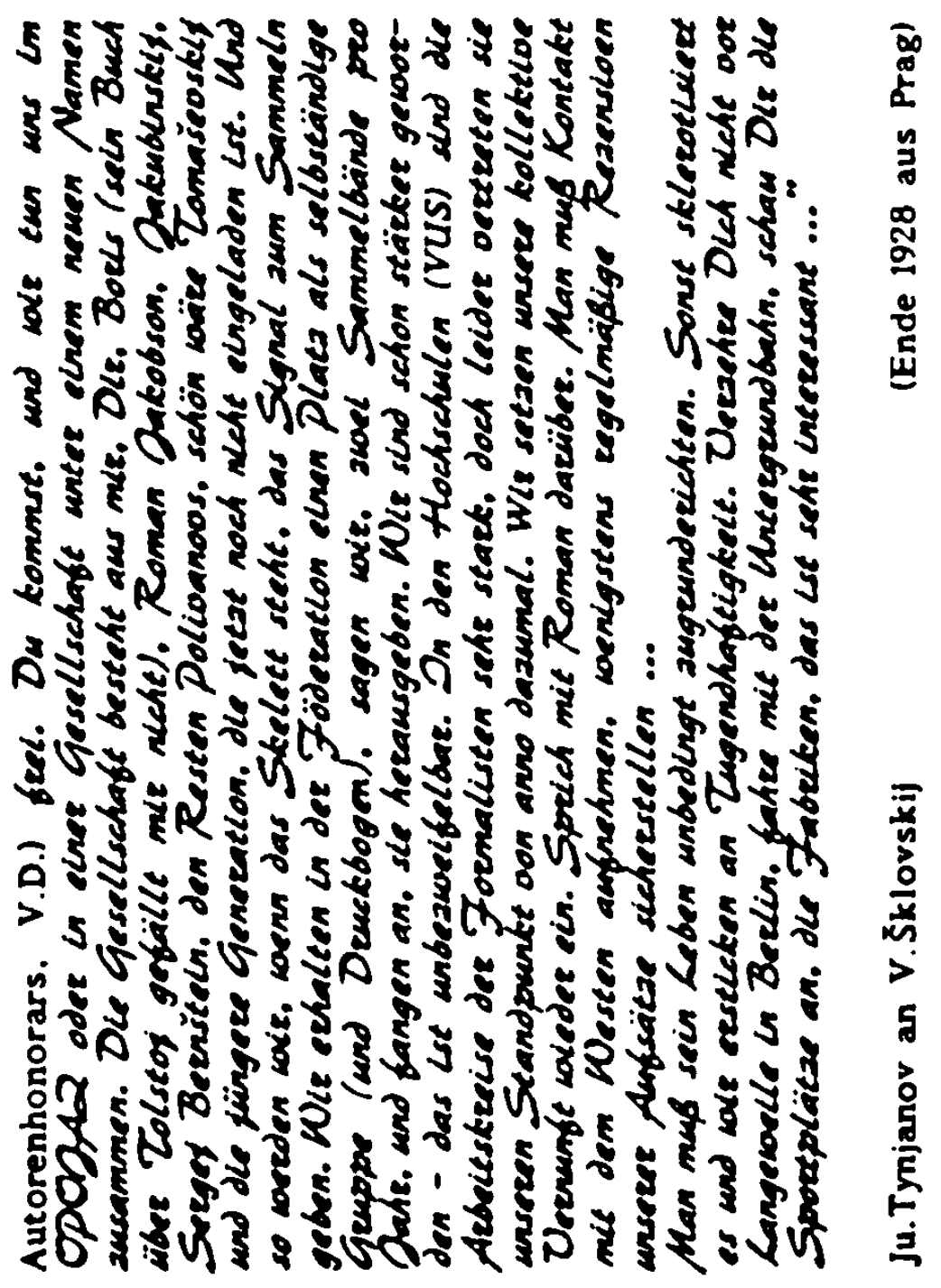

$\stackrel{0}{0}$
8
8
8 
den cokssenschioffllichen Feagen glbt es oölliges Verständnis und Einocenehmen. Ez oevechet sich nicht allausehe oor Langewoelle. Doch in thisblut awf unsere konstitutionelle Verschiedenheit sind seine Langeweile und seine Elegie füre mich oollkommenn Fröhlichtelt ... Ee Let eln großartlger und angenehmer Menuch.

Wir haben dout in aller Elle etwass sum wissenschatitlehen Toil

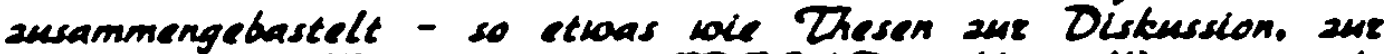
Ergänzung etc. Wie mü̈sen den OPODA2 ceöffren. Wenn es nicht die Geschichte und die Geographile gäbe. dans hätten. Du. er und lah schon ociel zusammen gemacht. Ee liebt DLet sehe. Ulbertaupet wat es sehe angenehm. nach sïb-sawren Lenten Euch in OpODA2 in crefffen .... Dch küsse Dich fest and oerbletbe, mach Retcung dürstend ... Onedis

[R. Jakobson an Ju.Tynjanov

"Telle mir ausfütrelleh mit. we Uitja und die anderen. jeder im

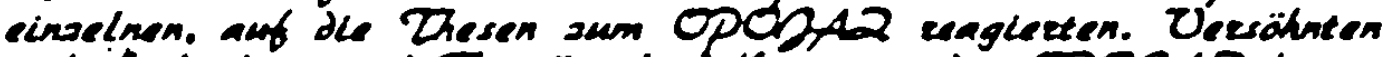
sich Elchenbaum und Tomašeoskit? Kann man den OpORA2 kitcen oder int es, wornn auch nicht auf dem Wege des geeingsten Widerstands. catsächlich hofferungslos? Spreach ef mit Uinogradoo?" ) (CGALI.f. 562, op. 1 ed.chr.964)

[V.Šklovskij an R. Jakobson

"Durly kam oon Die total aglthert zurëck und as Lst gans und gae

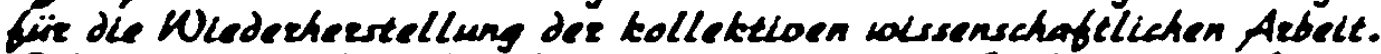
Och bln natïrllech auch dafüre. denn das lot die Sache melnes Lebens und leh bann allein nicht arbeiten (...) Dateubinskli bann ich in die

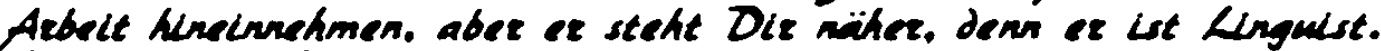
Leider aweh Dafetlt (d.h. Anhänger der von Stalin favorisierten Spracheheorie Marts, V.D.) ${ }^{32}$ Ez scheribt gerade elne Antwoet anf Deire Thesen. Tomaseostijy ist gano antgeregt. amch gerade am

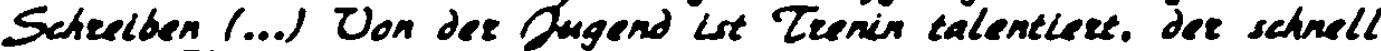
wächst. Für den Sammelband kännte der fufsats Meillets nütalleh sein (...). Facit: der OPCBA2 kann eest bei Deines Ankunft wiedertergestellt werden. denn der OPODA2. das sind unmee deri. (...) Wahescheinlich müssen wir uns mit Belletristlt beschäfftigen. Die Freunde lieben Dich. Und nemnen Dich genial. Volodja zürnt ein bibchen. bel chm häufen sich einige leichte Klagen über Dich an. abee leh dente. Ohe woredet Euch oeveöhnen. (...) Om Ausland kann das Leben woke die Azoren-Dnseln ocelauken. Wir haben unsere Uerantwoturg oor der 2eit. (...) Obwoth es mir unendlich sehwoerfiel. habe ich mich entschileden und berewe es nicht. Det schreibe Dir dees nichte, wall weh Diet llebe. sondern weil ich den OPODA2 metie llebe als was beide. (...) Dwrit ist in Dich oerllebt (....)." ] (CGAll, f. 562, op. 1 ed.chr. 477)

[V. Šklovskij an O.Brik

(26.2.1929)

"Mit dLesem Buch (demersten Sammelband des neuen OPOJAZ. in dem über die Thesen Tynjanovs und Jakobsons diskutiert werden sollte, V.D.) soll ein gano mewes Leben beginnen ..." 
an E.D. Polivanor

-Alle Kontwren der alten Theoulen haben sich oerschoben so woke oft dee Lthographile bet der Ubertragung oon einem Stein aut den anderen.

an B.l. Jarcho

"Wir wodlen ein Buch mit Thesen ausammenstellen. Das Buch woted nicht aus Antwooten bestehen. sondern sosusagen aus Proklamationen (...) Wie selbst haben begonnen. uns teïge 24 bewogen und müssen waser Geprick stecteen. "] (CGAll, f. 562. op.1, ed.chr. 478)

V.Šklovskij an Ju. Tynjanov

"Liebre Durigi!

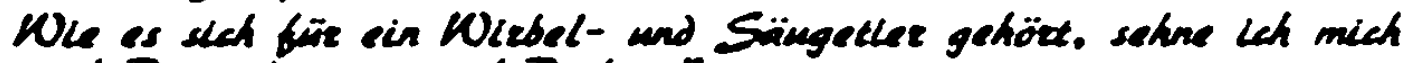
mach Dis und warete and DLet ..."

Ju.Tynjanov an V.Šklovskij

\section{"Llebere Fremond. sed gegriipt!}

Warewn scherelbst Du mis nichts? Roman sehweigt auch und ich stete allein and dem Platz. dessen Name Ruestecte Literature Lat. Kann es sein. dap Da mie böse diet? Westialb? ..."

v.Šklovskij an Ju.Tynjanor

(25.3.1929)

"Och habe Die lange nicht geschichben. Dm übelgen hast auch Dw mie Lange nicht geschtedeben. Det habe eiren Beief oon Roman cehalten und chm noch nicht geantwootet. Watescheinllet bedentet all

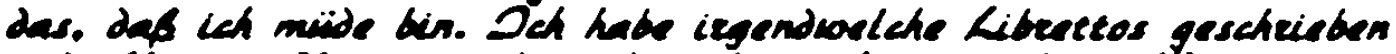
und alles in allem ocereter lat mich oor Langeworlle... Was int mit Bods? Was Lat mit Dureif Tynjanoo? that es die Lïftungstlapper in seinem Aebeitsaimmer geofffret. that ex elnen Stuht oor selnen Scherdberet gestellt? that of eine Scherebtischlampe? Kann er

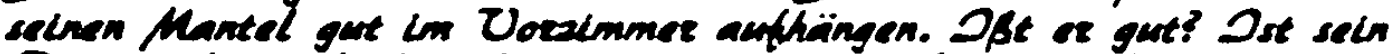

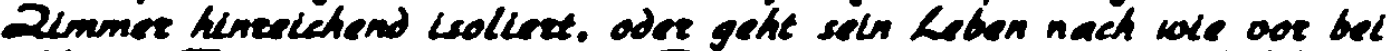
offenen Tiven oonstattent (...) Die Angelegenteiten des OpOPA2 aind in folgender Verfaseung: ein Beinf oon S. Beenstein ist angekommen. det besagt. dak ee sich un allgemeinen and dhe alten posithonen des OpOBA2 brenft und mativielich elnoerestanden Lst. mit

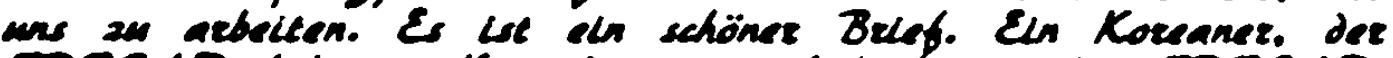

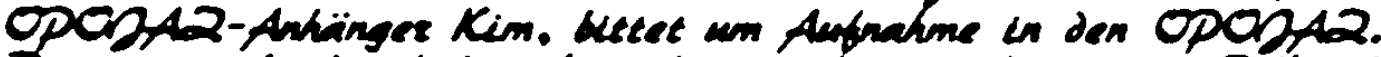

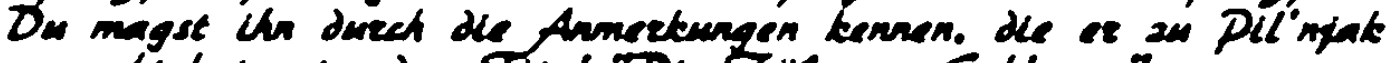
semacht hat unter dem Zitel "Ole Jü̈p ane Schlange".

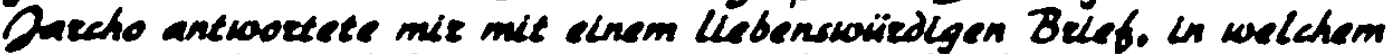

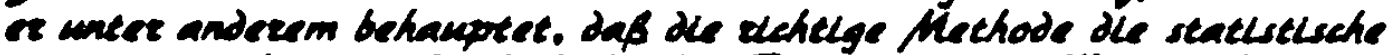

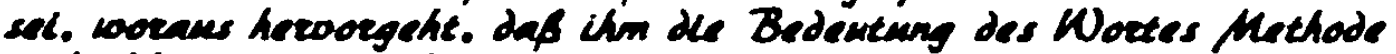
netie blate an sein setheint. 


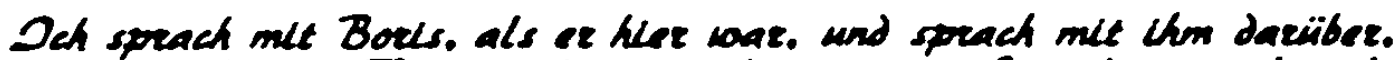
dak man chn mit Tomašeostily aussöhmen müsse. Ez wotderopeach nicht wnd sagte. dab dies oon allein geschetien solle. Es scheint mir. dak wie mit Tomašeostli genug sind.

Scherlb mir. Versuche leicht an leben. Enropoituleres das leben.

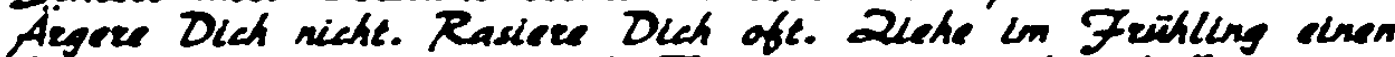
Frïhlingsmantel an wad baute Flleder, wern es ihn glbe."

[V.Šklovski] an Ju.Tynjanor

(10.4.1929)

"Ognacly Berniteln sehickte mir lange Antwooten aub Delur Zhesen. die leh gerade durechgetie. Deh fange awch bald $2 n$ schieelben an." J (CGALI, f.562, op.1, ed.chr.441)

Weder aus den Erläuterungen von Čudakova/Čudakov/Toddes zum Manifest -Probleme der Literatur- und Sprachforschung ${ }^{-33}$ noch aus den veröffentlichten Briefen erfahrt man etwas Genaueres dariber, woran die Griindung des neuen OPOJAZ letztlich scheiterte. Nach der anfänglichen Euphorie, mit der Šklorskij. Tynjanor und Jakobson den Plan. den OPOJAZ neu zu gründen. schmiedeten, klingen die letzten Briefe, in denen davon die Rede ist, merklich verhalten. Auch wenn offen bleibt, ob die Krise des Formalismus oder die Krise der Formalisten oder aber restriktive MaBnahmen einer autoritären staatssozialistischen Kulturpolitik die Gründung des neuen OPOJAZ vereitelten. so können wir auf jeden Fall davon ausgehen, daB - ungeachtet der Verständigungsschwierigkeiten und Meinungsverschiedenheiten zwischen den potentiellen OPOJAZ-Mitgliedern, von denen in den Briefen die Rede ist - letztlich das Scheitern der Verhandlungen mit der FOSP. die scheint's Šklovskij führe $^{34}$ und über deren Ausgang in dem veröffentlichten Briefwechsel nicht berichtet wird, ausschlaggebend dafür war, dab es nicht zu einer Neugriindung kam. Danach blieb den Formaisten nichts anderes ubrig, als auf eigene Initiative, über die Distanz zwischen Leningrad und Moskau hinweg. zusammenzuarbeiten. Die kollektive Arbeit reduzierte sich im wesentlichen auf briefliche Ratschläge.

Die Briefe in der "Dritten Fabrik" nehmen andeutungsweise vorweg, in welche Richtungen sich die einzelnen Beziehungen zwischen den Formalisten entwickeln sollten. Während die Briefe an Tynjanov und auch an Ejchenbaum im groBen und ganzen - auch wenn Šklovskij an Ejchenbaum, an seinem Plan, eine Tolstoj-Monographie zu schreiben, oder an seiner skaz-Theorie Kritik übt - in freundschaftlich kooperativem Ton gehalten sind und als ein Medium erscheinen, in dem fortgesetzt eine Diskussion über Fragen der Literaturtheorie geführt wird, muten die Briefe an Jakubinskij und Jakobson so wie auch die Ansprachen an Brik eher als Appelle an Abtrinnnige oder Abwesende an, die bekehrt werden sollen.

Abgesehen von einigen Buchpublikationen, die zumindest gemeinsam redigiert murden. ${ }^{35}$ blieb Tynjanov, Ejchenbaum und Šklovskij nur noch der Briefwechsel als Ort und Medium, um ihre Auseinandersetzungen zu führen. Als 
solche waren die Briefe eine private Angelegenheit und sie verbleiben so lange in der Sphäre des Privaten, bis sie in Zukunft irgendwann einmal veroffentlicht werden. Indem Šklovskij einige von thnen in die "Dritte Fabrik" aufnimmt, verwandelt er sie in ein exemplarisches Faktum öffentlicher Kommunikation und verschafft ihnen somit einen Status, der ihnen der Sache und der Tradition des OPOJAZ nach zusteht. Er literarisiert den Freundesbrief und macht sich die historische Erfahrung, die Habermas in bezug auf den Strukturwandel der bürgerlichen Offentlichkeit diskutiert, ${ }^{36}$ als Kunstgriff zunutze, daB die literarische Kultur der Ort ist, an dem Dialektik von Offentlichkeit und Privatheit offensichtlich wird: während Richardsons "Pamela" das Bügertum psychologisch emanzipierte und dern Intimen Eingang in die Öfentlichkeit der Salons verschaffte. eröffnet der sowjetische Avantgardeschriftsteller Šklovskij der experimentellen literarischen Diskussion der Formalisten Uber den Umweg des Rilckzugs in die Privatheit emeut ein Podium: die Rede in der Offentlichkeit. und umgeht auf diese Weise das liber die Formalisten verhängte Verbot, als selbständige Organisation öffentlich 24 arbeiten.

Im September 1919 veröffentlichte Šklovskif einen kurzen Arikel mit dem Titel "Kollektives Schaffen" in der Zeitschrift $Z_{i z n} n^{\prime}$ iskusstva, in dem er die Vorstellung, kollektive Abeit sei gleichzusetzen mit Gruppenproduktion, als naiv bezeichnet und kritisiert. Echte Kollektivitit im Schaffen liege tiefer, aber sei dafur auch umfassender. ${ }^{37}$ Dem naiven Verständnis von Kollektivităt entspreche die naive Vorstellung vom genialen Schðpfertum, d.h. Erfindungen nicht als Produkt einer Epoche bzw. einer bestimmten gesellschaftlichen Kultur zu betrachten, sondern der Genialität einzelner zuzusprechen.

-Die Epoche hat allmählich die Voraussetzungen fur eine Konstruktion geschaffen, und einige Menschen, die nicht miteinander in Verbindung stehen. fühlen sich als Schöpfer. Unter diesen Umständen ist der Mensch und das menschliche Hirn nichts anderes als der geometrische Ort der Schnittpunkte des kollektiven Schaffens. ${ }^{-38}$

Dieses Denken sei weit verbreitet und erstrecke sich auch auf die Betrachtung der Literatur. Es verhindere, einzusehen. dab "wir, hier und jetzt, umgehen mit traditionsgebundenen, kollektiven Schöpfungen" und daB "selbst revolutionäres künstlerisches Schaffen (...) traditionsgebunden ist." 39 Die Durchbrechung des Kanons sei nur möglich, wo ein Kanon lebendig sei, und die Gotteslästerung setze eine noch nicht abgestorbene Religion voraus. Der Mensch sei es so gewohnt, nicht in Prozessen, sondern in Rubriken zu denken. Deshalb orientiere er sich in seinem Denken an "Genies" und "Schöpfern"." Diese Kritik war gegen die Produktionskunstbewegung gerichtet, dagegen, die Kunstproduktion zu industrialisieren, d.h. zu taylorisieren. Skklovskij selbst hat stets in Gruppen gearbeitet und sich fü die Möglichkeit, kollektiv zu arbeiten, stark gemacht. Er hat die Arbeit in OPOJAZ und mit den Serapionsbriddern als solche empfunden. In seinem Buch "Zoo..." trauert er diesem Arbeitszusammenhang nach. 
"Ich bin an Berlin gebunden, aber wenn man mir sagen wiirde: 'Du darfst heim', dann wilrde ich, ich schwöre es beim OPOJAZ, heimgehen, ohne mich umzublicken, ohne meine Manuskripte einzustecken. Ohne telefoniert zu haben ...

In RuBland ist das 'Wir' fester gebaut."

"Zoo ..." wiederum weist in mancher Hinsicht - sowohl was das Thema der unglücklichen Liebe als auch was einzelne Metaphern für das Leid (die Tiere im Zoo. die Uiberschwemmung. das Telefon) anbelangt - Ahnlichkeiten zu Majakovskijs "tiber das besagte Thema" auf, ${ }^{42}$ die als Spuren einer gemeinsamen Auseinandersetzung uiber die jeweilige Textproduktion gedeutet werden können. Die Biicher wurden etwa zur gleichen Zeit geschrieben: Majakovskij hielt sich in jenem Jahr 1922 wie Šklovskij in Berlin auf; gemeinsam unternahmen die Freunde damals eine Reise nach Norderney. In den Büchern "tber das besagte Thema" und "Zoo ..." ist jeweils von der unglücklichen Liebe zu einer Frau die Rede: in Majakovskijs Text von der Liebe des Dichters zu Lilja Brik und in Sklovskijs Briefroman von der Liebe des Autors zu Liljas Schwester, Elsa Triolet. Das Erinnerungsbuch "Sentimentale Reise" verfaBte $\zeta_{k l o r s k i j}$ in seinem letzten Teil gemeinsam mit dem Aisoren ${ }^{43}$ Larzar Zervandov, den er aus Persien kannte. und den er nach dem Krieg in Petrograd zufallig wieder getroffen hatte. Ânnlich wie Tretjakor sein Bio-Interview "Den Ši-Chua" schrieb Šklovskij nach der Erzählung des Schuhputzers Lazar' die Leidensgeschichte der Aisoren, aus der Perspektive der persönlichen Erfahrungen Lazar's. ${ }^{44}$ Gemeinsam mit seinem Freund Vsevolod Ivanov verfaBte Sklovskij im Jahr 1925 in "sozialem Auftrag" den parodistischen Fortsetzungsroman "Senfgas". 45 Er arbeitete im Kollektiv des Noyy LEF und setzte alles daran, die Kinoarbeit zu einer kollektiven Arbeit zu machen. Auch die Idee, den OPOJAZ in Moskau 1929 neu zu gruinden, war mit der Vorstellung verknüpft. die "kollektive Vernunft" wieder in ihre alten Rechte einzusetzen. 46 SchlieBlich beteiligte er sich auch aktiv am Projekt "Geschichte der Fabriken und Industriewerke", in dessen Rahmen das skandalumwitterte, kollektiv geschriebene Buch "Weißmeerkanalbau" entstand. Im Zusammenhang mit diesem Projekt äuBerte sich Šklovskij mehrfach öffentlich zum Prinzip der kollektiven Arbeit. Seine Praxis aber bringt sein Verständnis von kollektiver Arbeit am besten zur Geltung. Urspringlich (z.Zt. des Petrograder OPOJAZ) verstand er darunter die Arbeit einer Gruppe von Individuen, die sich auf der Basis der tubereinstimmung von persönlichen Interessen und gemeinsamer Fragestellungen zusammentun, um selbständig, aber kooptrativ und parallel zur sozialen Revolution für die Revolutionierung der Kultur zu arbeiten. Später (z.Zt. des Novyj LEF) veränderte er seine Haltung insofern, als er die kollektive intellektuelle Arbeit zunehmend in die Verantwortung fur gesellschaftliche Prozesse, d.h. für die kollektive Rekonstruktion der Sowjetgesellschaft nach Revolution und Bürgerkrieg einbezogen sehen wollte.

"Wir erteilten der Bitterkeit des Lebenbauens und der Notwendigkeit. es wieder aufzubauen, damals eine Absage und waren, scheint's 
glücklich. Nur reichten die Kohlehydrate und die EiveiBe nicht dafür aus, um das Reich der intellektuellen Freiheit unter den Kanonen der 'Aurora' zu festigen."

In diesem Sinne arbeitete er als Faktograph und in diesem Sinne hoffte er. den OPOJAZ als selbständig arbeitende Gruppe innerhalb der FOSP in Moskau neu begriinden zu können. Aber angesichts der staatlichen Kollektivierungskampagnen, die zunehmend eine bedingungslose Unterordnung unter die propagierten Ziele verlangten, geriet die künstlerische Avantgarde mit ihren Vorstellungen von selbständiger, eigenverantwortlicher kollektiver Arbeit in Schwierigkeiten.

Šklovskij gehört nicht zu jenen Apologeten, die das Prinzip der Kollektivität als Ideologem gebrauchen und es vorschnell und naiv jeder gemeinsamen Aktion iberstülpen. Er registriert vielmehr kritisch, daB sich dieses Prinzip im Sowjetmarxismus in ein Ideologem verwandelt und erkennt, wie Kollektivität zum Ordnungs- und Kontrollprinzip verkommt und sein gegen das Individualitätsprinzip der bürgerlich-kapitalistischen Gesellschaft gerichtetes Kritikpotential ausgehöhlt wird, was sich in der Literatur daran zeigt, daß insbesondere die sogenannten proletarischen Schriftsteller "Helden" produzteren und Lev Tolstoj zum genialen Dichter kanonisieren, und daB die Kulturrevolution des ersten Fünfahresplans. eine von der Staatspartei lancierte Bewegung, den sowjetischen Scbriftstellem nicht nur das Thema "Helden der Arbeit" im Zusammenhang mit der Bewegung der StoBarbeiter nahelegt. sondern sie obendrein in diese Bewegung hineinzieht. In dem in diesem Zusammenhang einsetzenden, in der wissenschaftlichen Literatur schon häufig beschriebenen ProzeB der Anpassung an oder der Verweigerung der avantgardistischen Kunst gegenüber den staatlichen Forderungen entschied sich Šklovskij zu einer Gratwanderung zwischen deklamatorischer Anpassung und subversiver Arbeit flir seine nach wie vor guiltigen Vorstellungen von gemeinsamer Arbeit in der GewiBheit. daB kollektive Vernunft mehr vermag als die Vernunft einzelner - vorausgesetzt es handelt sich um eine kritische.

Auf der XVII. Parteikonferenz 1934 hielt Šklovskij eine Rede iber "Die Einzelbauernwirtschaft in der Literatur". 18 Hier entwirft er das Bild einer dialektischen Entwicklung der Geschichte der Arbeit: die Bourgeoisie habe das System der kapitalistischen Arbeit eingeführt, die dem Arbeiter seine Individualität genommen und ihn an die Maschine gekettet habe. wovon die kiinstlerische Arbeit aber ausgenommen worden sei, um den Preis, daß man sie nicht ernstgenommen habe; jetzt entwickele sich die Arbeit des Arbeiters zu einer "Autorenarbeit", die reproduktive Arbeit gehe auf die Maschine über, die Individualität der Arbeit nehme zu und gleichzeitig werde die geistige Arbeit zunehmend zu einer gemeinsamen Sache. Im Rahmen dieser Entwicklung beobachte er zwei einander gegenläufige Tendenzen: daB auf der einen Seite Wissenschaftler gemeinsam an groBartigen Erfindungen arbeiteten, aber daß es auf der anderen Seite zu Konkurrenz und Eigenbrödlertum in der Wissenschaft und in der Literatur komme. ${ }^{49}$ Gegen diese letztgenannte Tendenz 
setzt er seine Erfahrung mit kollektiver Arbeit, wie er sie beim "WeiBmeerkanalprojekt" gewonnen hat.

Wir arbeiteten am Buch 'WeiBmeerkanalbau'.

Bei dieser Arbeit war es verboten, an seinem eigenen Stil als einer interessanten Eigenheit zu hängen, es war verboten, sie mit der Arbeit des Nachbarn zu vergleichen, der Nachbar wurde zum Mitarbeiter. Ich sah, was ich konnte und was ich nicht konnte.

Und am Ende konnte ich dem Nachbarn helfen. konnte von ihm Hilfe annehmen. Wir hatten ein gemeinsames Arbeitsfeld.

Zusammenzuarbeiten, das ist für den Wissenschaftler und für den Arbeiter eine solch gewöhnliche Sache und eine so unerwartete für den Mann der Literatur.

Habt keine Angst. die Spezifität eures literarischen Schaffens zu verlieren. Nun, und jetzt schreiben wir wieder jeder selbst. aber ich fuhle, dab sich meine Stimme verändert hat, ich habe weniger alte Gewohnheiten, ich fühle mich literarisch jünger. Ich sah, was Agapov kann. was Dikovskij kann, welche Fehler ich habe, wie ich meine Sätze verwenden kann, wie Vsevolod Ivanov die Bewegung des Satzes verwendet, und ich bewertete die funktionale Rolle der Stilmittel neu.

Wir vergesellschafteten das Experiment. Und wir verschmolzen nicht miteinander. wie ihr seht, benutzen wir das Wort 'ich' oft genug. Wir entschieden die politischen Fragen gemeinsam. bewerteten unsere Beziehungen neu. dachten uber die Methoden des Klassenkampfes nach, über die spezifischen Besonderheiten der sowjetischen Technik und erkannten, Inwieweit sie vom neuen sozialen System nicht zu trensen ist.

Ja und so arbeiteten wir unerfahren. fröhlich und begeistert.

Die Unerfahrenheit geht voruber. "సึั

Die Kritik an der "Einzelbauernwirtschaft" in der Literatur, legitimiert durch die oben skizzierte Rekonstruktion der Geschichte der Arbeit, nimmt eine zentrale Forderung der forcierten Kollektivierungs- und Industrialisierungspolitik des Stalinismus auf und uberträgt sie auf die Literatur.

Vergleicht man die frühe, im Aufsatz "Kollektives Schaffen" (1919) dargelegte Position mit der späten. 1934 auf der XVII. Parteikonterenz geäuBerten, so zeigt sich, daB sie 2 war in der Argumentation Ahnlichkeiten aufweisen. daB aber der eine ein kritischer, hingegen der andere ein legitimatorischer Beitrag ist. Hier wie dort vertritt Šklovskij die Auffassung, daß geistige Arbeit kein genialer Schöpfungsakt ist und nicht wie Privatbesitz gehandelt werden darf. sondern daB man im BewuBtsein, daB das eigene Denken und seine Manifestationen ein Teil von gesellschaftlichen Prozessen sind, eine Distanz zur Projektion auf seine eigene Individualität und Originalität schaffen und auf dieser Basis mit anderen zusammen ohne Konkurrenz an gemeinsamen Projekten arbeiten kann. Hier wie dort begriindet er diese These mit hegelianisch anmutenden therlegungen Uber die Entwicklung der Arbeit in der Geschichte. Aber während die frihe Position eine offene Kritik an der Produktionskunst ist, die Šklorskij in einer für Auseinandersetzungen offenen kulturpolitischen Situation als Diskussionsbeitrag in einer literarischen Zeit- 
schrift darbot, ist die Rede auf der Parteikonferenz 1934 eine verschlüsselte Botschaft, die sich auf der Oberfläche affirmativ gibt, um die Zustimmung eines AuBenseiters zur Staatspolitik zu bekunden, und die auf einer zweiten Ebene, kaum hörbar, subversiv und kritisch spricht, um zu zeigen, daB der AuBenseiter an seine alten Positionen ankniupft.

Der Bericht über die kollektive Arbeit am Buch uber den Bau des WeiBmeerkanals enthält sich - wenn man die Worte genau betrachtet - einer eindeutigen Stellungnahme zur Industrialisierungspolitik der 30er Jahre. Er enthät sich sogar einer eindeutigen Beurteilung der Arbeit der Schriftstellergruppe. Er stellt einzig und allein heraus, daB die Erfahrung kollektiver Arbeit in diesem Zusammenhang lehrreich war und die schriftstellerische Arbeit Šklovskijs veränderte, d.h. "verjüngte", was nicht mehr besagt, als daB die Teilnahme an diesem Projekt ihm seine Fähigkeit zur lebendigen Auseinandersetzung mit der gesellschaftlichen Realität bestätigte. Darüber hinaus nennt er Namen von Schriftstellerkollegen und macht auf diese Weise indirekt eine Aussage iiber Fraktionen innerhalb des Kollektivs. Er spricht vom Freund und Nachbarn Vsevolod Ivanov und erwähnt Agapor und Dikovskij, zwei von den Konstruktivisten, die mit einer relatir groBen Gruppe an dem Kollektivprojekt beteiligt waren (Agapov, Dikovskij, Gabrilovič, Gauzner, Lapin, Zelinskij) und den Formalisten durch ihr Formverständnis näher standen als die proletarischen Schriftsteller, auch wenn sie sich seit dem Frihhjahr 1930 zur RAPP bekannt hatten. Von dem ideologischen Wortfithrer des Projekts und Literaturpolitiker der RAPP, Averbach, spricht er mit keinem Wort.

Šklovskij versuche, dem Zugriff des Systems dadurch zu entgehen, daß er sich im Rampenlicht der Offentlichkeit mit brillianter Rhetorik immer wieder des Kunstgriffs der offensiven Selbstdarstellung zur Selbstverteidigung bedient. Seine vorbehaltlose Fürsprache für das Prinzip der kollektiven schriftstellerischen Arbeit im Jahre 1934 wird verständlich. wenn man beruicksichtigt, daB die Art und Weise, wie sich der Formalist Šklovskij zur Politik der KPdSU (B) unter Stalin verhielt, zur Frage uber Leben und Tod werden konnte. Die linke Avantgarde war durch die ersten massenhaften Säuberungskampagnen gegen die sogenannte Industriepartei und im Zusammenhang mit der Slavistenaffäre. in deren Verlauf auch der Sprachwissenschaftler Viktor Vinogradov inhaftiert wurde, ${ }^{51}$ eingeschüchtert worden. Abgesehen davon soll Šklovskij, wie ich bereits an anderer Stelle erwähnte, deshalb an dem WeiBmeerkanalprojekt teilgenommen haben, um seinem dort internierten und zur Zwangsarbeit gezwungenen Bruder, dem Philologen Vladimir Šklovskij das Leben zu retten, was ihm nicht gelang. Sein Plädoyer fir die kollektive Arbeit von 1934 umreiBt weniger eine politische Position - eine solche muibte man als eine moralisch fragwiirdige, das Zwangssystem des Stalinismus legitimierende Haltung verwerfen -. sondern zeigt den Balanceakt eines Grenzgängers zwischen Anpassung und Verweigerung in einer extremen Situation: es zeigt die Gratwanderung $\mathbf{z w i s c h e n}$ Selbstverleugnung und der möglicherweise todbringenden Selbstbehauptung eines linken Intellektuellen in einem System, das die bedingungslose Unterwerfung eines jeden unter die Staatsmacht forderte. 
1 L. Ginzburg. (Tynjanor-uČenyj, In: Vospominanja o Ju.Tynjanove. M. 1983. S.1Si] vermitelt deaen Eindruck. Sle erinnert alch an die XuBerung Tynjenova: "Viktor lat eln Monteur, eln Mechanker ... und ein Chauffeur. Er glaubt an die Konatruktion. Er glaubt zu wiesen. wie ein Auto gemacht Iet ..."

2 V. Sklovakil. Gamburgaklj .... $5.58 / 59$

3 ders.. Polekt .... S.4

4 ders.. O Mejakovakom. S.355/S.132

S ebd.. S.409/S.204-205

6 dera.. Energlje zebluzdenlje. M. 1981. S.13

7 Von dem Zwang zur Auseinandersetzung zwischen dem gesellechafellchen Meterial und der Kunet in Schriftateller apreche schon L.Tolstol. weis Sklovaklf und zitiert thn: Brief L. Tolatola an L. Andreev. Tret'je .... S.82

8 R. Sheldon. Literary Theory .... S.263

9 A. Hansen-Love. S.369 ff.: S.386

10 T.W.Adorno. Noten zur Literatur II. Ffm. 1973. S.S8

11 A.Henaen-Lore. 5.555

12 vel. Munk. S.SS $f$.

13 Ju.Tynjanor. Dae llemerache Faktum. S.418/419

14 ebd.. S.393/394

15 ebd.. S. $\$ 18 / 419$

16 vel. I.Tell. Kap.l und Kap.2

17 vel. V. Sklorakil. Gemburgakil .... S.14

18 vgl. ders., Zoo .... S.48/S.S1: -Niemand kenn una krdnken. denn wir arbelien. Niemand kann une licherlich mechen. denn wir wiasen. wa wir wert alnd. Unsere liebe eber, die liebe von Munnern. de niemala Fritcke getragen haben: ketne von den Frauen, de nicht mit une gemelneam an der last unsere Lebene miterugen, kann das begreifen."

19 M.Gor'kll I sovetskaje pazez'. II. Archlv Gor'kogo. tom X. 2. M. 1965. S.44

20 Vj.Poloneklf. 'LEF Ull BLEF?', In: leveatlje. 27.Febr.1927; dazu: Protokol o Polonakom. In: NL 3(1927). S.42: O.Beskin. Rez. zu: Tret') ...: vgl. V. Majakorakif. Rede betm Dieput 'LEF lll BLEF?'. 2.12(1959), S.325-350: rel. V.Sklovaklj, Gamburgakij .... S.14

21 2.B. der Kritiker A.Kura in aeiner Rezension zum Buch -Sentimentale Relse". In: Knlgonole. 31(1924). S.S

22 Vartante zu Sklovaklle Brtef an L.Jakublnaklf. CGALI. Fond 562. opla' Nr.1. ed. chr. Nr. 46

23 ebd.

24 V.Šklorakll. Lenln kak deknnonizator, In: LEF, 1(5) 1924. deutech: Lenln d. Dekanonteator, In: Sprache und Stul Lenlns. (Hrsg. u. Vorwort) F. Mlerau. U.: J.Benoly, Leon Nebenzahl. G.Neuseer. B.Schroder. Berlin (DDR. Munchen 1970. S.29

Vartante zu Skloraklja Brief an Ju.Tynjanov, ebd.

Das russiache Wort Paychologlemus (palcholożeatro) kann auch ala "Paychoverlogenheli" gelesen werden.

27 Veriante zum Brief an B.Ejchenbaum. ebd.

28 V. Skloraklj. Zul byll. S.110/S.143 
29 Iz peroplakl ...; rel. auch de Anmerkungen von M. Cudakova. A. Eudakor und E.Toddea, In: Ju.Tynjanov. Pottlka .... S.S31 ff., hler zltieren dle Herauseeber auefuhrlich aus jenen Brtefen und kommenteren ale.

30 Ju.Tynjanor, R.jakobeon. Problemy lzukenija llteratury i jazyka. in: NL 12(1928). S.35-37; deutsch: Probleme der Literatur und Sprachforachung. In: TdF. Bd.2. S.386-391

31 Uberaetze und ausgewiblt aua: Iz pereplek1 .... S.192-198; Ergunzungen (jewelle durch Klammern und Lleeraturhinwete kenntllch gemecht) aus den Erikuterungen der Hrag.: O.Cudakova, A. Cudakov, E.Toddea. In: Ju. Tynjanov. Podeika .... S.531-534

32 Marr behauptet dan Primat der okonomischen Funktion der Sprache vor der kommuriktiven Funktion und gehe ron elner Homogenese aller Sprechen eus: de jephetischen Sprechen. d.h. die des Abendlandes, selen die Hitese Varlanie in der Chronologle der allemetnen Gloteogonle. (Vel. Sowjetlache Sozlolinguletik. (Hrag.) W.Glrke, H.Jachnor, Kronberg Ta. 1974. S.55 f.)

33 Erliuterungen der Hrag.: M.Cudakova. A.Cudakov. E.Toddes. S.531-534

34 In den Brtefen lat immer devon die Rede. das Skloraklf dle Verhondlungageapricho mit den Organiacuonen fuhree. wan aeiner Rolle ale "literartache Porsoblichkelt" in der sowjetischen Kultur der 20er Jahre durchaus entapriche. Auch die Tacasche, das Jakoboon und Tynjanor is Manifeat Siklorakif den Vorale im Moskeuer OPOJAz zugedncht haben. besurke dlese incerpretetion (Menifese. S. 390/391)

35 zB. V.Sklorakil. Metref Komarov: hlerbel halfen thm T.Gric. M.Nikiein und V.Trenin (rel. Vorbemerkung zu desem Buch); oder: T.Grtc. V.Trentn. M.Nlkikin. Slovenont 1 kommerclja. Sklovaklj und Ejchenbaum warn die Hermangebor diesea Buches.

36 J.Hrabermen. Strukturwandel der Offentlichkelt. Neuwled u. Berlin $1971^{5}$. S.60 ff.

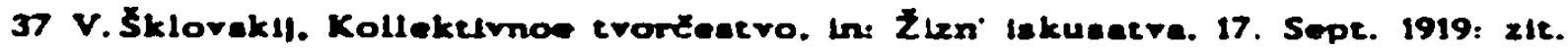
nach: dere.. Chod konja. S.68-73; deutech: U.: K.Maurer. In: Poetlke 1 (2967). $5.98-103$

38 ebd. S.69/5.98-99

39 ebd. 5.73/5.100-102

40 ebd. S.72-73/5.100-101

41 V. Sklorakly. Zoo .... S.58-59/5.62-63

42 Derauf wles echon Zdentk Metheuser in Nachwort zur techechechen Ubereetzung ron "Zoo ...” (VIkeor \$klovaki). Zoo. In: Zdenłk Machauser. Nepopulim! etudle. Z dXjin ruak eventgerdy. Prahe 1969. S.127) hin; J. Holthusen erolft diesen Gedanken euf und fuhrt inn in: Tiergeneleen und metamorphe Eracheinungen in der Llteratur der ruasiechen Arantgarde (1909-1923)". Munchon 1974. S.S4 ff. aua.

43 Die Aleoren and eine Volkeminderhelt mit altchreticher Tradition in Porsien. die ureprunglich in der Turkel und in Tranekaukasien bohelmatet war und ahnlich wie die Juden und Amenter unterdrucke, verfolgt und echlleblich helmatloe wurde.

44 V.Sklorakif. Sentimental'noe .... S.346 ff./S.340 ff.: dera.. Konec pochoda. M. 1925

4 V. Skloraklj/Va. Iranov. Iprit. M. 1925

46 V.Sklovak1f. Brief an Ju.Tynjanor rom 5.12.1928. In: Iz peroplakl .... S.194

47 V. Sklorakif. Gamburgaklf .... S.59

48 dere.. O edinollzente $\rightarrow$ literature. Pleatell XVII. parta-ezda. (Hrag.) P. Judin. M. 1934. S.233-235 
49 obd.. $5.233 / 234$

50 dera.. O edinollzeatve .... S.234/235

51 R. Medreder, Die Wahrhelt let uneere Stirke. (Hrsg.) D. Joraraky. G.Haupt, U.: G. Danehl. Ffm. 1973. S.156/157: rgl. R. Grubel. Ruselecher Konatruktiviemus. Opere Slevica, Neue Folge Bd.1. Wleabaden 1981. S.235 


\section{Kap. 4: Die Stimme des Klnourbelters}

\section{Der deplacierte Mensch im Kinoalltag}

"Die Laterne ging von Redaktion zu Redaktion: Nein, ich bin kein Kinematograph, ich bin ein Projektor!" [103]

Eine in "Dritte Fabrik" unüberhörbare Stimme ist die des Kinoarbeiters گ́klovskij. Sie präsentiert sich häufig als publizistischer Text und läßt sich zumeist durch eine bestimmte Thematik (Alltagsarbeit). Tonlage (gelangweilter Jammerton, ironischer Kritikerton) und Form (Montage einzelner, unzusammenhängender Stücke. ungewöhnliche Perspektive) von anderen unterscheiden: von der ihr entgegenhaltenden Stimme des OPOJAZ-Mitarbeiters oder von der beide überlagernden und sie ironisch transzendierenden Rede des Schriftstellers Šklovskij. Doch kommt es häufig zu Knotenpunkten. an denen sich die Stimmen so miteinander vermischen, daB der Leser sie nur mit Muihe entwirten kann. um der je einzelnen wieder zu folgen. In einem der ersten Kapitel sagt der Heid der "Dritten Fabrik":

Tch lecke wie ein abgenutzter Gummischlauch. Das Buch wird heiBen ' $\mathrm{r}$ it $t$ e $F$ a b r i $k$ '. Erstens. ich bin in der dritten Fabrik des Goskino angestellt. Zweitens. den Titel zu erklären ist nicht schwer. Die erste Fabrik war für mich die Familie und die Schule. Die zweite der 'OPOJAZ'. Und die dritte bearbeitet mich jetzt." [16]

Die in Anspielungen verrätselte resignierte Klage des Kinoarbeiters in "Dritte Fabrik" läßt sich erst auf dem Hintergrund der publizistischen Texte Šklovskijs vollends entschlüsseln. Die Differenz zwischen der Stimme des Kinoarbeiters im literarischen Text und den fraglichen publizistischen Texten, die sich dem vergleichenden Wissenschaftler wie auch dem zeitgenössischen Leser erschlieBt. der sowohl den Publizisten und Drehbuchautor als auch den Schriftsteller Šklovskij kannte. ist vom Autor der "Dritten Fabrik" als Kunstgriff der Verfremdung intendiert. Für die Stimme des Kinoarbeiters gilt, ähnlich wie fur die des Schriftstellers, daB sie sich eine fremde Rede leiht, in diesem Fall die des Szenaristen und Kritikers Šklovskij, sie dann deformiert und der Maske des deplacierten Menschen anpaßt.

Die Stimme des Kinoarbeiters zeigt den deplacierten Menschen Šklovskij in seinem Arbeitsalltag. Sie verrät, daB der Held sich nicht zuletzt aus dem Grunde für die Arbeit als Montagetechniker und Drehbuchautor entschied. um sich eine kontinuierliche Einnahmequelle flir den Broterwerb zu sichern. Denn er ist kein Mätyrer der reinen Kunst. Die Briefe an die Freunde, die die Stimme des Formalisten Sklovskij diktiert. deuten die finanzielle Not des Helden an. 
"Es ist wahr, in meinem Kopt sind $z$ wei Ziffern eingeschrieben wie in eine beleuchtete Hausnummer. Die eine ist eine einstellige - wieviel Geld ich brauche. Die andre ist eine zweistellige wieviel ich für die Wohnung haben muB." [98; vgl. auch Brief an Jakobson, 67]

Anders als Babel", der sich nur mit groBem Widerwillen als Drehbuchautor verdingte," wovon auch der Held in "Dritte Fabrik" in Andeutungen spricht [85, 86], oder auch anders als der Dichter Mandel'štam, der, obwohl Šklovskij ihm dazu geraten hatte, mit Drehbüchern seinen Lebensunterhalt zu sichern, diese Arbeit für sich verwarf. ${ }^{2}$ lieB sich Šklovskij auf die Alltagsarbeit am sowjetischen Kino ein. Davon erzählt die "Dritte Fabrik" mit der Stimme des Kinoarbeiters.

Als Šklovskij Ende 1923 aus dem Berliner Exil in die Sowjetunion zuriickkehrte, ging er nicht in seine Heimatstadt Petrograd zurick, sondern nach Moskau [76]. Dort begann er gewissermaBen ein neues Leben. Er heiratete. Er bewohnte zusammen mit seiner Frau ein Zimmer mit undichten Fenstern, feuchten Wänden und einem Ofen, der wohl rubte, aber nicht heizte. Dort verbrachten sie den ersten Winter in Moskau [77]. Seine Frau gebar ihm 1924 einen Sohn. Šklovskij suchte Arbeit - Arbeit, die seinen Interessen und Fähigkeiten entsprach und Arbeit, durch die er die Existenz seiner Familie sichern konnte. All das schien zunächst nicht miteinander vereinbar. Seine erste literansche Arbeit in Moskau. der parodistische Abenteuerroman "Sentigas". wurde ein Mißerfolg. Šklovskij hatte ihn als "soziale Auftragsarbeit" gemeinsam mit einem alten Schriftstellerfreund aus Petersburger Zeiten. Vsevolod Ivanov, verfaßt und sich mit ihm dariber zerstritten. ${ }^{3}$

Die Linke Kunstfront hate ihre offentliche Arbeit vorläufig eingestellt.

1926 begann Šklovskij am staatlichen sowjetischen Kino zu arbeiten. Zunächst schrieb er Untertitel für den Stummfilm und besserte miBlungene Filme aus. Später verfaßte er Drehbiicher, arbeitete mit namhaften Regisseuren wie Kulešov, Room. Barnet. Pudovkin und Tarič zusammen. wobei. wie noch zu zeigen sein wird. die Art der Zusammenarbeit. die Rolle und Kompetenz. die Šklovskij jeweils zukam. schwer zu erschlieBen ist, und schrieb filmpädagogische Broschüren und Artikel. Šklorskij begann ein Alltagsleben zu führen, das der Ruickkehr des Alltags in der sowjetischen Gesellschaft nach Revolution und Bürgerkrieg entsprach. Die Frage, warum Šklovskij sich der Kinoarbeit zuwandte, der er mehr als dreiBig Jahre treu bleiben sollte. läBt sich auf keinen Fall damit beantworten, daB seinen Entscheidungsprozessen jeweils eine innere Kausalität zugrunde liegt. Der Held der "Dritten Fabrik" spricht von der Arbeit am sowjetischen Kino wie von einer Natumotwendigkeit. der er. wie friher der Familie und der Schule, ausgesetzt ist. und dennoch weckt er die Neugierde des Lesers, nach den Grinden für diese Entscheidung zu fragen. Sicher ist, daß Šklovskijs eigene Erklärung, wie er sie in "Kindheit und Jugend" gibt, nicht aussagekräftig und detailliert genug Auskunft erteilt. 
"Die analytische Methode (des OPOJAZ) hatte sich erschöpft. Da wanderten die einen von uns in die reine Sprachwissenschaft ab, die andern in die Textologie, wieder andere in die künstlerische Prosa. Ich wandte mich dem Film zu."

Auf keinen Fall sei die Arbeit des OPOJAZ durch irgendwelche administrativen Verfügungen abgebrochen worden, heiBt es weiter; und einige Zeilen später weist er indirekt darauf hin, daB er durch die Arbeit am Kino "zum Marxismus gestoBen" sei. 5 Diese Erklärung im nachhinein verschweigt. daß zwischen der Arbeit in der Gesellschaft zur Erforschung der poetischen Sprache in Petrograd und dem Beginn der Arbeit am Goskino (später Sovkino genannt) in Moskau das durch staatliche Anklage und Verfolgung wegen Sabotage und Rebellion gegen den Sowjetstaat erzwungene Exil in Berlin lag, aus dem er nur durch Fursprache Gor'kijs und Majakovskijs in die Sowjetunion zuriickkehren durfte. Nun galt es, sein Image als gesellschaftlich verantwortungsbewuBter Kïnstler zu rehabilitieren.

Abgesehen davon. daß Šklovskij als Mitglled des OPOJAZ das Kino als ein seiner Qualifikation und seinen Interessen entsprechendes Arbeitsfeld betrachtete, gilt. daB das Kino zunächst auch miBliebig gewordenen Schriftstellem als Ausweichmöglichkeit und Rückzugsort diente. Dieser Kulturbereich hatte sich noch zu wenig etabliert, als dab sich dort staatliche Kontrolle schon hätte routiniert abwickeln lassen.

Die scheinbar liberale und auf Ausgleich bedachte Resolution des ZK der RKP (b) vom 18. Juni 1925 sah für den Bereich der Literatur bereits eine politische Kontrolle dergestalt vor, daB sie proletarische und bäuerliche Literatur zum allgemeinen Maßstab erhob, während die sogenannte Mitläuterliteratur zwar toleriert, aber allmählich verdrängt werden sollte. ${ }^{\circ}$ Noch schärfer formulierte dann im Dezember 1927 der XV. Parteitag die politische Linie der Literatur. Sie sollte sich ganz in den Dienst der neuen Wirtschaftspolitik. der Politik des ersten Fünfjahrplans stellen. ${ }^{7}$

Hingegen eröffnete die halboffizielle Konferenz des Sovkinos im Oktober 1927 bei den Kinoarbeitem noch die Hotfnung auf offene Diskussion und öfentliche Meinungsbildung über lange schon unter der Oberfläche schwelende Konflikte, in deren Zentrum die Kritik an der schwerfällig arbeitenden und unqualifizierten Administration des Kinos stand, die die künstlerische Produktivität und eine effektive Filmproduktion stark behinderte. ${ }^{8}$

Auch der XV. Parteitag gab für den Bereich des Kinos noch keine Direktiven aus. Erst im Mărz 1928 fand eine Allunions-Parteikonferenz zu Fragen des Films statt. Der englische Filmhistoriker J. Leyda berichtet, daB diese Konferenz "attempted to formulate the several directions taken by the discussion at the Fifteenth Congress, and party members in the film industry joined the larger number of lay critics and provincial delegates to talk about 'what's wrong with our films'." Es wurde ein allgemeiner BeschluB daruber gefabt. daB "ficitional films must be made in a way that can be appreciated by 
millions." ${ }^{10}$ Hierbei handelte es sich weniger um eine Frage nach filmischer Qualität, sondern um eine, angesichts der verschwindend geringen Anzahl der Kinos in der Sowjetunion zu jener Zeit - ca. 9000 an der Zahl, Wanderkinos und außerordentliche Vorführungen nicht eingerechnet -. beliebig auslegbare kulturpolitische Direktive. Die Filmzensur sah so aus, daB zunächst ungefähr 20 Leute darüber entschieden, ob der Film der kommunistischen Weltanschauung genüge. um ihn dann einer Gruppe von Arbeitern vorzustellen. die ubber seine Massenwirksamkeit entscheiden sollte. ${ }^{11}$ Entsprechend erörterte die Konferenz Fragen über die politische Zuverlässigkeit der Regisseure als Maßstab für die Güte ihrer Filme, über Verständlichkeit insbesondere auch für die ländliche Bevölkerung und über die politische und moralische Qualität der Filme.

Doch 1925/26 war von all dem zumindest in der allgemein verpflichtenden Form von Parteibeschluissen und die Filmproduktion bevormundenden ideologischen Richtlinien noch nicht die Rede. Verschiedene Freunde und Mitstreiter Šklovskijs aus dem LEF und dem OPOJAZ wie Majakovskij, Brik. Tynjanov und Tretjakov arbeiteten am sowjetischen Kino. Sie schrieben - wie auch §̌lovskij - vorwiegend Drehbilcher. Ihnen galt das Medium Film als ein progressiver Bereich der künstenschen Produktion. Aber sie hatten gleichermaBen auch Schwierigkeiten. mit ihren avantgardistichen Konzeptionen in der Sowjetunion der zu Ende gehenden 20er Jahre Anerkennung zu finden und suchten deshalb nach einem Broterwerb in dieser Branche. Letzteres galt auch für Schriftsteller wie I. Babel'. Ju. Oleša u.a., das heiBt für die "Mitläufer" bzw. "Weggenossen".

Die Kinoarbeit ist das politische Zugeständnis des deplacierten Menschen Šklovskij an die Gesellschaft. in der er lebt. Sie bearbeitet den Helden der "Dritten Fabrik" zuletzt. Auf die Frage: Wissen wur etwa, wie der Mensch bearbeitet werden muB?" antwortet der Kinoarbeiter, und der Schriftsteller mischt sich ein:

\footnotetext{
"Möglich. daß es richtig ist, ihn zu zwingen, vor der Kasse zu stehen. Möglich, daB es richtig ist, daB er nicht seiner Qualitikation entsprechend arbeitete.

Das sage ich mit meiner eigenen Stimme, nicht mit der des Elefanten. Die Zeit kann sich nicht irren, die Zeit kann vor mir nicht schuldig sein.

Es ist nicht richtig zu sagen: 'Die ganze Kompanie geht nicht in Gleichschritt, nur der Fähnrich geht in Gleichschritt.' Ich möchte mit meiner Zeit sprechen. ihre Stimme verstehen." [16]
}

Der Schriftsteller gibt den Ton an, in welchem der Kinoarbeiter künftig zu hören ist: die Arbeit am Kino ist keine, die Šklovskijs Qualifikationen entspricht, vielmehr ein Tribut, den er zahlt, um am gesellschaftlichen und kulturellen Leben in Moskau teilnehmen zu können. Der Kinoarbeiter hält dem Schriftsteller den Rijcken frei. Lange bleibt seine Stimme im Hintergrund 
und bringt sich nur durch die Konstruktion der Sätze und durch Metaphern in Erinnerung. Erst im dritten Teil spricht er uber seine Arbeit.

"Ich bin an der dritten Fabrik des Goskino angestellt und arbeite Filmstreifen um. Der ganze Kopf ist vollgestopft mit Fetzen von Filmstreifen. Wie der Papierkorb im Montageraum. Ein zufalliges Leben." [93]

Beinghe stereotyp wiederholt er einige Seiten später diese Sätze und charakterisiert dadurch die Monotonie dieser Arbeit.

"Unterdessen ist die Jugend halb ausgetrunken. Der Mund ist verbrannt. Da ist die Fabrik, an der du angestellt bist. Die Szenarien, die du liest. Und das Schicksal, das $2475 \times$ bestimmt ist. Gewöhne dich daran, ohne Ereignisse zu leben." [96]

Der Kinoarbeiter versucht sich iber die Monotonie seiner Arbeit mit der Erkenntnis hinwegzutrösten, dab auch Ereignisse den Menschen betrilgen. Er schweift ab und erzahlt. um diese Einsicht 24 veranschaulichen, eine Geschichte, die ihm eine Frau in der Kinofabrik zugetragen hat, und die von der Schicksalsgläubigkeit der Menschen handelt.

Auf der Wanderung von dem fermöstlichen Zeja uber das Stanovojgebirge und das Aldanhochland in das per Luftlinie mehr als $500 \mathrm{~km}$ entfernt liegende Aldan hatten sich fünfundachtzig Menschen in ihrer Not, um dem Hungertod zu entgehen, dazu entschlossen, einen von den thren zu töten und zu essen.

Sie warfen das Los. Es fiel auf einen junges Mann. Als unmittelbar auch dieser Entscheidung ein alter starb, verschonten sie das Leben des jungen und aBen den alten Die Gruppe erreichte später ihr Ziel, erhielt Land in Nidan und machte sich dort seBhaft. [97]

Die Kinoarbeit ist das Aldan des deplacierten Menschen, der seinen Platz in der sowjetischen Gesellschnft einzunehmen versucht. ${ }^{12}$

-Nun, und es liegt Staub in der Fabrik. SechsunddreiBig Jupiterlampen hàngen im Atelier. Vier Quecksilberplatten. Aufnahmen sind selten. Warten auf dem Korridor. Das Leben ist dunn gesät.

Kein Druck des Windes.

...

In der Fabrik im Montageraum riecht es nach Bonbons. Und es ist notwendig, das Schicksal der Filme ein ganz klein wenig zu verändern.

Der Bonbongeruch kommt von der Birnenessenz. damit klebt man die Filmstreifen. Kleben tun die Schnittechnikerinnen. Eine schädliche Produktionsweise. Sie wickeln den Film auf Spulen, er lauft. flimmert in den einzelnen Aufnahmen auf wie die Kiefern auf dem Weg zum Aldan.

Aber ich weiB - das Handwerk ist klüger als ich." [97]

Die Einsicht, daß auch Ereignisse den Menschen betrigen, leitet fragmentarisch und assoziativ die Rede uber Atmosphäre und Arbeitsbedingungen am sowjetischen Kino ein. Sie signalisiert de Bereitschaft des deplacierten 
Menschen, sich auf eine pragmatische Arbeit, eine Lohnarbeit. ${ }^{13}$ am Kino einzulassen. Der Kinoarbeiter erzählt nicht von Ereignissen, sondern montiert Fragmente sinnlicher Wahmehmung, auch der des Kinoalltags scheinbar ohne Verbindung zusammen. Seine Stimme - unterstuitzt, vorangetrieben aber auch hinterfragt von der des Schriftstellers - schildert den schmerzlichen ProzeB, sich selbst 24 verlieren und von der Alltagsarbeit am Kino ausgehöhlt zu werden.

"Ich habe lange nicht geschrieben, weil ich von der Arbeit betäubt war. Ich werde physisch taub auf dem rechten Ohr.

Das kommt von der fröhlichen Arbeit des Szenaristen. von der Anstrengung des Fisches, auf einem Asphaltfeld zu laichen." [123]

Diese Erfahrung versucht sie dadurch auszugleichen, daB sie sich die sinnliche Wahrnehmung dieses Alltagslebens erhält. So wie Proust ("Auf der Suche nach der verlorenen Zeit") dem Leser die Erinnerungen an die Atmosphäre seiner Kindheit sinnlich vergegenwärtigt, indem er den Duft der weißblühenden Schlehdomhecke und den Geschmack der auf dem Gaumen zergehenden Madeleines heraufbeschwört, so bringt der Kinoarbeiter Šklovskij dem Leser seine ambivalente Haltung gegenuiber der Kinoarbeit nahe, indem er die unscheinbaren Schönheiten des Alltags wahnehmbar macht. sich auf diese Weise seiner eigenen Möglichkeiten vergewissert und das Gewicht der schicksalhaft erscheinenden Ereignisse eindämmt.

Anders als in OPOJAZ. wo die Formalisten aus Interesse an bestimmten literaturtheoretischen Fragen zusammenkamen und gemeinsam diskutierten. und auch anders als der Schriftsteller Šklovskij, der sich im Kreise der Serapionsbrider oder auch zusammen mit Majakovskij oder Vsevolod Ivanov in der kollektiven literarischen Arbeit versuchte, bewegt sich der Kinoarbeiter altäglich inmitten des öffentlichen Geschehens einer bürokratisch verwalteten Institution. Er gibt sich den Anschein, halbherzig bei der Sache 24 sein. Scheinbar gleichguiltig und resigniert schildert er den biirokratischen Schlendrian, die veralteten Methoden und die Einfallslosigkeit der Administration.

Šklorskij arbeitete im staatlichen Kollektiv der Kinoarbeiter, aber die Arbeitsbedingungen, die er dort vorfand, entsprachen in keiner Weise seinen Vorstellungen von kollektiver Arbeit. wie er sie im OPOJAZ und bei den Serapionsbrïdem kennengelemt und vertreten hatte. Sein Arbeitsplatz war die kiinstlerische Abteilung der Kinofabrik, die streng von der Produktionsabteilung getrennt arbeitete. Esfir' Šub weiB zwar zu berichten, daß die Szenaristen mit den Regisseuren. Kameraleuten und Montagetechnikern im Kollektiv zusammenarbeiteten. aber sie verwechselt scheinbar den Ausnahmefall, den einzelne Szenaristen für sich durchsetzen konnten, bzw. den die Mežrabpomfil'm, die Filmgesellschaft der Internationalen Arbeiterhilfe, in gewisser Weise darstellt, mit der Praxis im Normalfall. ${ }^{14}$ In dem Aufsatz "Hütet euch vor der Musik" berichtet Šklovskij uber die schwierige Lage der 
Szenaristen, indem er das Problem literarisch verpackt als Anekdote präsentiert:

'Die unterirdischen 'Geister'

'Geister' nannte man in der alten Flotte die Leute, die irgendwo in der Tiefe des Schiffes, bei den Maschinen, hausten. Man behandelte die 'Geister' verächtlich, man spöttelte über sie. Die 'Geister' besaBen keinerlei Tradition; sie werden weder in der Geschichte der Ruderflotte noch in der der Segelflotte erwähnt.

In der zeitgenössischen Kinematographie wird die Rolle der auf allen Filmplakaten kleingedruckten 'Geister' von den Drehbuchautoren erfullt, deren miBachtete Arbeit darin besteht. die Mechanismen für einen Filmstreifen anzufertigen und $z u$ bedienen. Die Bewohner der oberen Etage hegen für die Geister weder kameradschatitliche Gefühle noch Dankbarkeit. Ab und zu wird sogar rorgeschlagen, die Geister abzuschaffen. wobei sich dann herausstellt. daB niemand Lust verspiurt, an Stelle der Geister in die Tiefe zy kriechen. Man nimmt an, der Dampfer werde schon allein fahren. 15

Šklorskij las Drehbulcher, die massenhaft eingeschickt wurden. ${ }^{16}$ Möglicherweise war auch die Geschichte von der Wanderung nach Aldan eine Idee zu einem Film, die ihm jemand angeboten hate. Er muBte sich mit zahllosen. dilettantisch geschriebenen Texten und mit den Autoren dieser Texte auseinandersetzen, was ihn später dazu veranlabte, bei verschiedenen Gelegenheiten Aufrufe an Szenarienschreiber und pädagogische Broschuiren zum Problem des Drehbuchschreibens, aber auch iber technische Probleme der Fulmproduktion zu rerfassen. ${ }^{17}$ Es war seine Aufgabe, annehmbare Librettos und Szenanen auszuwählen und zu iberarbeiten. Er schrieb selbst Szenarien und machte sich als Berater der Filmproduktion bei den Regisseuren unentbehrlich. Schon zu Beginn seiner Kinoarbeit schrieb Sklovskij Szenarien. Das Drehbuch "Die Tüte" entstand bereits 1925, wurde aber - soweit mir bekannt ist" ${ }^{18}$ niemals realisiert. Gemeinsam mit Lev Kulešov verfaßte er auBerhalb seiner regulären Arbeit in der dritten Fabrik $1925 / 26$ das Drehbuch zu dem Film "Nach dem Gesetz" nach einer Erzählung von Jack London über Goldsucher in Alaska. In diesem Film entwarfen Šklovskij und Kulešov eine exzentrische Filmsprache dafür, wie sich die Gesetze und Regeln der bürgerlichen Gesellschaft, symbolisiert durch die Bibel und ein Bild der englischen Königin, in die Psyche des Menschen hineingegraben haben. Wie sie noch in einer existentiellen Extremsituation, weit entfernt von der menschlichen Zivilisation und vom Arm des Gesetzes. die von Kampf um Leben und Tod gezeichnet ist. auf absurde Weise ihr Recht behaupten. Nach Verhandlungen mit dem Direktor der Filmfabrik gelang es Šklosvkij, die Produktion dieses Films dort unterzubringen. $^{19}$ In diese Zeit fiel auch die erste gemeinsame Arbeit mit dem Regisseur Abram Room an dem Film "Bucht des Todes", für den Šklorskij die Unter- und Zwischentitel schrieb. Dieser Film entstand im gleichen Jahr wie Ejzenštejns "Panzerkreuzer Potemkin". Beide Filme wurden in der Kritik häufig zusammen besprochen und miteinander verglichen. Das Sujet der Revolution verbindet sie, aber während Ejzenštejn die pathetische Linie der 
Revolution von 1905 darstellt, hält Room die alltäglichen Begebenheiten des Bürgerkriegs fest. ${ }^{20}$

Für Room schrieb Šklovskij im Jahre 1926 noch einige andere Drehbuicher: das Drehbuch zu dem Dokumentarfilm "Die Juden auf der Erde" (1927), einen Film über eine jüdische Neusiedlung auf der Krim" und das Szenarium "Der Verräter" (1926), einen Film aus dem Ganovenmilieu, der stark umstritten war. ${ }^{22}$ Des weiteren entstand aus der Zusammenarbeit zwischen Room und Šklovskij in Jenen Jahren "Bett und Sofa" (1927) und "Schlaglöcher" (1927) - beides Filme uber das Alltagsleben der 20er Jahre in der Sowjetunion, die in den Zeitungen lebhafte Diskussionen auslösten. ${ }^{23}$ "Bett und Sofa" hatte insbesondere im westlichen Ausland groBen Erfolg und wird hier auch noch heute in den Retrospektiven des historischen Avantgardefilms gezeigt. Die sowjetische Filmhistorikerin Irina Graščenkova schätzt die produktive Zusammenarbeit zwischen Room und Šklovskij besonders hoch ein. In ihrem Buch über Room wiirdigt sie wie niemand sonst in der Sowjetunion den Drehbuchautor und Regieessistenten Šklovskij. ${ }^{24}$ Šklovskijs Liebe zum Alltäglichen, zu der sinnlichen Wahrnehmung des Ungewöhnlichen im Gewohnlichen und umgekehr des Gewöhnlichen im Ungewöhnlichen, zeige sich auch in den Filmen, insbesondere in denen, die er gemeinsam mit Room gedreht habe.

In der Zeit, als Šklorskij an "Dritte Fabrik" arbeitete, fielen auch die Dreharbeiten 24 dem histonschen Film "Die Flügel des Nnechts" unter der Regie von Jurij Tarič. mit dem Šklovskij 1928 noch einmal an dem - ebenfalls historischen - Film "Die Hauptmannstochter" (nach Puškin) zusammenarbeiten sollte. ${ }^{25} \mathrm{Zu}$ "Flilgel des Knechts" schrieb Sklovskij nicht allein. sondern zusammen mit Karl Šild'kret. dem Autor der gleichnamigen Erzählung, ${ }^{26}$ Szenarienschreiber und Mitglied des künstlerischen Rats der dritten Fabrik. das Drehbuch, wobei anzunehmen ist, dab der eine die filmtechnischen Fähigkeiten und kïnstlerischen Einfälle, der andere dagegen die getragte politische Einstellung und eine günstige administrative Position einbrachte. ${ }^{27}$ Die Montage dieses Films besorgte Esfir' 'Sub. Ihr Name ist der einzige aus der Moskauer Filmszene, den Šklorskij in seinem Buch "Dritte Fabrik" erwăhnt. [137] Šklovskij wurde täglich mit den Huitern der offiziellen Linie in der Kulturpolitik konfrontiert, auch wenn diese Linie im Bereich des Kinos bis zur Parteikonferenz zu Fragen des Films im Frïhjahr 1928 noch nicht dogmatisch bestimmt war. Diese Wächter der Ideologie traten sowohl als Kritiker in den Zeitungen als auch als Mitarbeiter innerhalb der Kinoadministration auf. Šklovskij war eingebunden in eine unbewegliche, bürokratisch organisierte Kinoadministration, die - und daraus entstand ein weiteres Problem - im Rahmen der ohnehin wirtschaftlich in den Anfangen steckenden Sowjetgesellschaft der 20er Jahre nur uber geringe finanzielle Mittel verfügte. Im letzten Kapitel. benannt wie das garze Buch "Dritte Fabrik". eröffnet der Kinoarbeiter einen flichtigen Einblick in diese Dimensionen der Kinofabrik.

"Im ersten Stock befindet sich das Arbeitszimmer des Direktors. In einer Ecke zwei Trumeaus in Gold aus der Requisite. Barock. Ein 
Schreibtisch geschwungen - Jugendstil. Kronleuchter - Renaissance. Auf dem Boden ein - falscher - Perser. An den Wänden Portraits der fotogensten Regisseure. Hier laiche ich meinen Kaviar.

Ich wiurde das Leben gern anders filmen, um die Montage des Lebens $\mathrm{zu}$ verändern. Ich liebe die langen Sticke des Lebens. Gebt auch den Schauspielern zu spielen.

Weniger Tee, weniger Montage.

Doch wir geben uns Mühe. Er hört mir zu und spricht gleichzeitig am Telefon - der, wie ich, rosafarbene Direktor.

Manchmal ist der Film fehlerhaft. Nicht richtig aufgenommen. LäBt sich nicht montieren. Die Bewegungen passen nicht zusammen. Der Regisseur hat schlecht arrangiert. Dann sagt man: 'Der Film kommt auf den Dachboden:. - Das heiBt soviel wie auf den Friedhof. - In den Tagen des Filmhungers werden aut diesem Friedhof die Toten auferstehen.

Doch auf unseren Friedhöfen stehen die Toten niemals wieder auf. Wir alle sind Ware vor dem Antlitz unserer Zeit ... wir diriten nicht sterben: Weggenossen werden sich schon finden.

Der Direktor schaukelt leicht auf seinem amerikanischen Stuhl. Der Stuhl knart.

Ich erinnere mich an einen kleinen Vers von Vergil: 'Und der Südwind. leise in den Masten knarrend, rutit uns ins oftene Meer." [137/138]

Die Szenaristen hatten nicht allzuviel Bewegungsfreiheit. Da war die Administration, die Direktoren Kaptinskij. Trajnin. Bljachin und der Produktionsleiter Bljoch, um nur einige zu nennen Ihre Biographien sprechen für sich. Ulber Kapčinskij. einen der Direktoren der ersten Fabrik. schreibt Šklovskij in seinem Buch uber Ejzenštejn:

"KapXinskil hatte bei der Ammee angefangen, sich bis zu drei Balken an den Kragenlitzen hochgedient. war Vorsitzender des Soldatenkomitees gewesen, hatte ziemlich schlechte Theaterstilcke geschrieben und wurde dann Direktor der Ersten Moskauer Staatlichen Filmfabrik. 28

Bljachin, einer der Direktoren der dritten Fabrik, mit dem Šklovskij viel zu tun hatte. war - so erfahren wir von Esfir Šub ${ }^{29}$ - selbst auch Schriftsteller und Szenarist. Er arbeitete aber vorwiegend als Organisator, als Leiter der Kinoproduktion und Redakteur am Kino. Auch er gehörte zu jener Gruppe alter Bolschewiki, die die Partei in den 20er Jahren in die Kinoarbeit geschickt hatte, um sie ideologisch zu festigen. Über Trajnin berichtet Esflr Šub in ihrem Erinnerungsbuch "In GroBaufnahme", daB er, der Direktor der ersten Goskinofabrik, ein "Akademiker der alten Schule". ihr zunächst seine Hulfe fur die Produktion ihrer Chronikmontage uber die Romanovs und die Revolution von 1905 am Goskino versagt hatte. Erst dank der Fürsprache Šklovskijs und Bljachins war es gelungen. Trajnin von dem Film zu uberzeugen. ${ }^{30}$ In den Diskussionen der Kinoarbeiter zur Vorbereitung der Parteikonferenz zu Fragen des Films im Oktober 1927 ist in erster Linie der Direktor Trajnin die Zielscheibe der Kritik. Ihm wird ein autoritärer Führungsstil, fachliche Inkom- 
petenz und die Verantwortung für bürokratischen Schlendrian vorgeworfen. ${ }^{31}$ Utber Bljoch schreibt Šklorskij:

"Bljoch war einer der Kommissare der ersten Kavallerie gewesen; ein Organisator, der rasch Entscheidungen fallen konnte, der begriffen hatte, wie man mit dem einzelnen Menschen umgehen muBte. damit dieser unentbehrlich wiirde im Kampf, in der Abteilung, in der Attacke. ${ }^{\text {"32 }}$

Subtile Nuancen in der Beschreibung des Werdegangs der verschiedenen Administratoren weisen auf Abweichungen in deren Verhalten hin. Während Šklovskij dem Produktionsleiter des "Panzerkreuzer Potemkin" Bljoch ein effektives Management attestiert, stellt er Kapčinskij nicht eben ein gutes Zeugnis aus. Bljachin wiederum, der Direktor, den Šklovskij aller Wahrscheinlichkeit nach in "Dritte Fabrik" schildert. ${ }^{33}$ scheint $2 u$ den umgänglichen, gemäBigten Administratoren zu gehören. Der Kinoarbeiter skizziert den Direktor ironisch. Von seiner Person spricht er nur in zwei. drei Sätzen. Aber es gelingt ihm. den Raum, in dem er sich bewegt. so auszuleuchten, dab ein vielsagendes Bild von ihm vor dem Leser entsteht. Zunächst richtet er den Blick auf sein Zimmer, dessen Einrichtung auf die chaotischen und illustren Zustände in der Kinofabrik hinweist. Die Schilderung des Zimmers ist sicherlich aber auch beredter Ausdruck der Amtsgewalt des Direktors.

In der Kinozeitschrift prangert auch der Kritiker Šklovskij den Schlendrian am sowjetischen Kino an. ${ }^{34}$ Dekoration und Angestellte - das seien die teuersten Faktoren. Aber sie allein machten einen guten Film nicht aus. Kino-Fabrik sei kein passender Name für das, was man im Augenblick vorfände, die dritte Fabrik ähnele eher einem Wohnheim für Kinozauberer. Jeder arbeite für sich selbst und auf seine Weise. Dabei sei gerade das Kino die Kunst, die besonders mechanisch sei. "Sie verlangt Wissen und Berechnung ... Deshalb muissen viele Kino-Zauberer Schüler werden. ${ }^{35}$ Der Kinoarbeiter Šklovskij stellt den Direktor persönlich vor. Er erscheimt vor dem Leser als ein Manager, der verschiedene Dinge gleichzeitig zu erledigen vermag und mit ihm, dem Drehbuchautor, nebenbei verhandelt. In Andeutungen signalisiert er die pragmatische Geisteshaltung des Direktors, indem er ihm bestimmte. ideologisch belastete und darum um so aussagekräftigere Wortattribute wie "er ist rosa" (on rozovyj) im Kontrast zu den "Portraits der fotogensten Regisseure" (portrety naibolee krasnoreživych režisserov), die über seinem Schreibtisch hängen, zuordnet - ein Sprachspiel, das in der deutschen Ubersetzung gar nicht deutlich wird. ${ }^{36}$ Eine ähnliche Wirkung erzielt das kulturpolitische Reizwort "Mitläufer" oder "Weggenosse" (poputčik), das in unmittelbare Năhe zum Direktor gebracht wird, der - wie es weiter heiBt - "auf einem amerikanischen Stuhl schaukelt". Die Direktoren waren häufig damit iberfordert, zwischen der Künstlerischen Abteilung und der Produktion, zwischen den Szenaristen auf der einen Seite, den Regisseuren, den Kameraleuten und den Technikern auf der anderen $2 u$ vermitteln. Die zentralistische, iberaus birrokratische Organisation der Kinofabrik verhinderte eine flexible Zusammen- 
arbeit. Nach Abgabe der zumeist als Auftragsarbeit entstandenen Drehbuicher hatten die Szenaristen keinerlei EinfluB mehr auf sie. Aus diesem Dilemma entstanden zahlreiche Konflikte. Majakovskij beschwerte sich verschiedentlich daruber, daB seine Filme verunstaltet worden seien. ${ }^{37}$ Leyda weiB von seinen vergeblichen Bemulhungen, Filmdrehbiicher nach eigenen Vorstellungen an die staatlichen Filmgesellschaften Sovkino oder Mežrabpom-Rus' zu bringen, zu berichten. ${ }^{38}$ Möglicherweise resultiert auch Babel's Abneigung. Filmszenarien zu verfassen, u.a. daraus. daB die Möglichkeiten für Szenaristen. EinfluB auf die filmische Realisierung ihrer Filme zu nehmen, am sowjetischen Kino relativ gering waren. ${ }^{39}$

Im Laufe des Jahres 1926 und besonders konzentriert seit Oktober 1927, als im Zusammenhang mit dem XV. Parteitag die Vorbereitungen für die Parteikonferenz über Fragen des Films begannen, fanden immer wieder öffentliche Diskussionen über wirtschaftliche. organisatorische, politische und ästhetische Probleme des sowjetischen Kinos statt. Hier meldeten sich vor allen Dingen die Szenaristen zu Wort. Unter der Überschrift "Ich sitze am Meer und warte auf gutes Wetter" ergriff Šklovskij im Februar 1926 in "Kino" für die Szenaristen das Wort. ${ }^{40} \mathrm{um}$ über ihre Schwierigkeiten mit dem staatlichen Kino $\mathbf{z u}$ berichten und um an die Kinoadministration zu appellieren. Aseev, Babel', Tret'jakov, Šklovskij, Leonov sei es bisher nicht gelungen, auch nur ein Szenarium zu schreiben, das die Zustimmung der Künstlerischen Abteilung des Goskino gefunden hätte.

Wir haben eine Menge Zeit am Kino verloren. Das Kino greift nach wie vor zu Ausflüchten. Mag sein. dab wir daran schuld sind. Mag sein, daf die russische Literatur nicht fotogen ist. Aber die Mehrheit der Szenarien passierten den Künstlerischen Rat der Fabriken. Wir pabten blos nicht durch das zweite Sieb. "wl

Šklovskij beschwört, ironisch Legitimation erheischend. die Tradition der Arbeiter- und Bauernbewegung, um basisdemokratische Rechte für die Szenarien schreibenden Literaten geltend $z u$ machen. An ihrer Stelle würden solche Leute wie Gol'denvejzer, ein Szenarist und Administrator der Künstlerischen Abteilung des Goskino. die Entscheidung über Drehbücher, ihre Qualität und Eignung, treffen, obwohl an ihrer fachlichen Kompetenz durchaus zu zweifeln sei. Šklovskij selbst habe schlieBlich ein Szenarium Gol'denvejzers umarbeiten muissen. um es brauchbar zu machen. Jeder der Schriftsteller habe seinen eigenen Stil. Man dürfe sie nicht so einfach gängeln. mahnt Šklorskij.

"Ich bestehe nicht auf der völligen Freiheit der Kunst. Am Kino ist offensichtlich, daB es sie nicht gibt. Ich spreche von dem Recht Gleichwertiger und davon, daB die künstlerischen Sovets ihre Autorität nicht auf eine Tariftabelle stützen dürfen. Das künstlerische Schaffen ist dazu verpflichtet. sich zur Produktion, aber nicht zu den Kanzleien zu zählen. Gol'denvejzer schmiB mich nicht raus, er lobte mich sogar. Befahl. sich zu bemuihen. Aber sollte es mir etwa verboten sein. lieber mit Ejzenštejn. mit Room, mit Kulešov, meinet wegen mit Sabinskij zu reden, wenn es nur Leute vom Fach sind." 
Šklovskij betont, daß er nicht vom Kino weggehen, sich aber auch nicht auf bïrokratische Entscheidungsprozesse daruber, wessen Drehbuch wie realisiert werden soll, einlassen wolle.

"Reden wir in der ARK (Assoziation der revolutionären Kinoarbeiter. V.D.), in der Kinozeitschrift, aber nicht in den Kanzleien. Beweint die Antwort nicht in Form von Stempelmarken. Weil das Meer austrocknet. Und es uns langweilig zu werden beginnt." ${ }^{43}$

Die übermäBig bürokratisch organisierte Filmproduktion führte. vermischt mit ideologischer Kontrolle. zu Desorganisation und MiBwirtschaft. Denn sie beeinträchtigte ein flexibles Zusammenspiel und somit den effektiven Einsatz der jeweiligen qualifizierten Kräfte. Der Publizist und Drehbuchautor Šklovskij wehrt sich gegen diese Misere, indem er an der öffentlichen Diskussion über das sowjetische Kino teilnimmt. Im fulmkritischen Feuilleton bedient er sich der literarischen Sprache, um unangreifbar und rhetorisch wirksam zu sein. Die Stimme des Kinoarbeiters im Text der autobiographischen Prosa leiht sich die Stimme des Publizisten, aber sie verkürzt sie und verändert ihren Tonfall.

"Doch langsam ist das Leben. Die Schauspieler sitzen auf dem Kormdor. Sie lassen sich für die Fulmautnahmen Bärte wachsen. Trinken Tee." [136]

Beinahe den gleichen Wortlaut hat der Titel eines Artikels, den Šklovskij zu Beginn des Jahres 1926 in der Kinozeitschrift "Nino" veröffentlichte: "Kinoschauspieler auf dem Korridor". ${ }^{44}$ Aus diesen Worten spricht der Kritiker Šklovskij. In der "Dritten Fabrik" maskieren sie dagegen den deplacierten Menschen. der über das Nichtstun, über den Staub und die Dekoration. über das Warten und den ProduktionsausschuB in der Kinoarbeit räsoniert. Geschützt hinter dieser Narrenkappe kann der Held der autobiographischen Prosa seiner Enttäuschung dariber Ausdruck verleihen, daB kollektives und selbstbestimmtes Arbeiten. wie er es vor allen Dingen im OPOJAZ und im LEF kennengelemt hatte. am Kino für ihn keineswegs selbstverständlich herstellbar war. Im Artikel der Kinozeitung sind sie als ein kritischer Beitrag zu tagespolitischen Fragen der Filmproduktion zu verstehen, der sich durch eine zum Teil hermetische Sprache vor kulturpolitischen Attacken schuitzen möchte. Hier kritisiert Šklovskij den unaufmerksamen und unhöflichen Umgang mit den Schauspielern. Sie wïrien herumkommandiert, abgestellt und nicht in die Pläne der Regisseure miteinbezogen. Man behandle sie wie Waren. Allein um die Qualität der Filme zu heben. müsse man sich eines intensiven. menschlichen und einfühlsamen Umgangs mit ihnen befleiBigen. "Was das Verhältnis zu den Schauspielern betrifft. so haben wir kein Produktionskollektiv, sondern Durchgangskasernen" ${ }^{45}$ schreibt er bissig. Er macht sich zum Anwalt der Schauspieler, da er auch in ihrem Dilemma die Auswirkungen des Bürokratismus am sowjetischen Kino erkennt. 
Das Kollektiv Kulešov, zu dem neben den zukïnftigen Regisseuren Pudovkin und Bamet, neben den Schauspielern Fogel' und Komarov auch Aleksandra Chochlova gehörte, muBte sich in jenen Jahren gegen den Vorwurf, ihre Filmkunst sei Formalismus, zur Wehr setzen. Ihnen wurden keine Filmaufträge erteilt. Bamet hatte bereits begonnen, sich selbständig $2 u$ machen; nun verlieB auch Pudovkin das Team. Zwar wurde Kulešov 1925 bei der MežrabpomRus', der Produktionsgesellschaft der internationalen Arbeiterhilfe, eingestellt, doch wenige Monate darauf verlor er erneut seine Stelle, erinnert sich Chochlova. ${ }^{46}$ In dieser Zeit entstand der Film "Nach dem Gesetz", zu dem Šklovskij in intensiver Zusammenarbeit mit dem Regisseur Kulešov das Drehbuch schrieb. Chochlova spielte eine der drei Hauptrollen dieses Fllms. der auBerhalb der offiziellen Produktionspläne zustande gekommen und dank Šklovskijs Einflus an der dritten Fabrik dort produziert werden konnte. Namhafte Filmer wie Room und Ejzenštejn setzten sich für die Chochlova ein. Im April 1926 meldete sich Room in der Kinozeitschrift "Kino" mit einer Lobeshymne auf die Schauspielerin zu Wort. Man habe die Chochlova in ihren Fähigkeiten bisher nicht genügend beachtet und ihr ihrem Talent unangemessene Rollen gegeben. Sie sei besonders für dramatische und exzentrische Rollen geeignet. Ja, sie könne und müsse bei ihren kinematographischen Fähjgkeiten und Kenntnissen sogar Kinoregisseur werden. ${ }^{\$ 7}$ Ejzenštejn verfaßte zusammen mit Šklovskij eine Broschuire uber die Schauspielerin, die in einer Auflage von 10.000 Exemplaren 1926 in Moskau erschien. in der sie. im Sinne Rooms, auf das besondere Talent der Chochlova hinwiesen. $\$ 8$

Ein anderes Problem, mit dem Šklovskij sich am sowjetischen Kino konfrontiert sah. das der Kinoarbeiter in "Dritte Fabnk" verschiedentlich verrätselt und resigniert andeutet und mit dem sich der Drehbuchautor und Kritiker praktisch auseinandersetzte, war die permanente finanzielle Not der jungen sowjetischen Kinematographie. Der Film ist. in wesentlich stärkerem MaBe als die Buchproduktion, auf eine kostspielige Technik und einen aufwendigen Apparat angewiesen, die der Sowjetstaat angesichts der allgemeinen wirtschaftlichen Notlage nur in einem MindestmaB zur Verfügung stellen konnte. Dazu kam. daß den Kinoarbeitern häufig die Erfahrung im Umgang mit dem Medium fehlte. Im Zusammenhang mit der buirokratischen Organisation des Kinos einerseits und seinem politischen Anspruch. Basisaktivitäten (Szenarien. die die Arbeiterkorrespondenten massenhaft verfaBten) besonders $z u$ bericksichtigen und ins Produktionsprogramm aufzunehmen andererseits. führten diese Schwierigkeiten häufig zu MiBwirtschaft und AusschuBproduktion. was Šklovskij als Fachmann verärgerte und ihn als Kritiker auf den Plan rief, aber was den deplacierten Menschen in der "Dritten Fabrik" nur zu ironischen Andeutungen bewegen kann:

"Im Atelier hängen Dutzende von Lampen wie leuchtende Fledermäuse. Dekoration. aus Holzstämmen gebaut. Ein tausendfach durchgesprochenes Drehbuch.

Zusammengestiuckelte Dekorationen. Es kostet Muihe, was der Apparat zu sehen bekommt. Rundherum Breschen. 'Fertig', schreit 
der Regisseur, 'wir fangen an'. Zwei Minuten Autnahme ... Wenn der Chor der Lampen bloB keinen flirrenden Schatten wirft. Wenn die Schauspieler es bloB schaffen. Das Ergebnis ist ein Film und viel Verschnitt in den leinernen Abfallsäcken der Montage. Eddi Šub wird kleben. Auch wenn es nichts geworden ist. Sie wird montieren.

So ist es sogar bei den Amerikanern. Sie haben mehr Filmmaterial. und Mary Pickford liegt bei Durchsicht des Gefilmten auch im Schneidekorb. Und trinkt Tee in der Kantine. Als Fabrik ist die Fabrik in Ordnung. Als Leben ist sie ein Fehlschlag." [136/137]

Der Kinoarbeiter erwähnt Esfir' Šub und Mary Pickford, ohne ihre Bedeutung. sei es für sich selbst. sei es für das Kino im allgemeinen, zu erläutern. Nur der eingeweihte Leser weiB. daB Šklovskij beide, sowohl die Sowjetrussin als auch die Amerikanerin als Filmerinnen sehr schätzte, weil sie mit den Möglichkeiten des Films experimentierten. Hinter der Banalität der Worte des deplacierten Menschen versteckt sich der kritische Kenner, der den Schlendrian an sowjetischen Kino im ironischen Vergleich mit dem Experimentalfilm Amerikas kritisiert.

Sowohl der Kritiker Šklovskij als auch der Kinoarbeiter in "Dritte Fabrik" plädieren für eine Sparpolitik an sowjetıschen Kino. Beide bedienen sich einer Redefigur. einer Metonymie: sie sprechen vom Tee. Im Text der "Dritten Fabrik" erfillt das die Funktion, den Alltag, insbesondere den Alltag der Kinotabrik zu imaginieren. In der Kinozeitschritt appelliert der Kritiker Šklovskij unter dem Titel Tee mit Zucker" an die Filmemacher. billig und trozzdem gut. d.h. technisch gekonnt und überlegt zu filmen. In der Form eines humoristischen Vergleichs mit einem insbesondere für den russischen Alltag bedeutungsvollen Gegenstand - dem Tee, einem Vergleich. der in diesem Falle noch einen Exkurs in die Wirschaftsgeschichte nach sich zieht. will Šklovskij die Kinoarbeiter überzeugen. Die Kontinentalsperre, die Europa vom Rohrzucker abschnitt, habe Frankreichs Chemie dazu angeregt. den Zucker auf andere Weise zu gewinnen. So erfand man den Zucker aus Ruben. Ebenso muisse die sowjetische Kinematographie lemen, auf ihre Weise und mit ihren beschränkten Mitteln - ihren Zucker für den Tee - einfallsreich. technisch perfekt und billig zu produzieren. $\$$

Während der Kinoarbeiter, sich auf die in der Sowjetunion umstrittene und auch von Šklovskij selbst häufig ironisierte Psychoanalyse Freuds berufend, das Bild beschwört. um den gelangweilten Klageton des besserwisserisch kritischen AuBenseiters hervorzukehren - "Der Tee sublimiert hier die Zeit" [136] - verwendet der Publizist die gleiche Metapher konstruktiv kritisch und rhetorisch geschickt: besser einen Tee mit als ohne Zucker, besser einen Film mit einer den sowjetischen Bedingungen angepaßten Technik als ein schlechtes Hollywoodimitat. Der Film "Nach dem Gesetz" entstand unter diesem Anspruch. Er kann in der Tat als ein exemplarisches Beispiel für einen Film gelten, der streng nach dem Grundsatz aufgebaut ist: wie erzielt man den gröBtmöglichen Effekt mit dem geringsten Aufwand. ${ }^{\text {SO }}$ Auch andere 
Filme, vor allen Dingen "Bett und Sofa", zu dem Šklovskij 1927 das Drehbuch schrieb und den Room drehte, ${ }^{51}$ zeugen von dem Anspruch, mit den Mitteln sparsam umzugehen. Dieser Anspruch war zum einen eine Reaktion auf die finanzielle Not der Kinofabriken, er entsprach zum anderen aber auch dem künstlerischen Interesse des Formalisten. Šklovskijs Engagement für die Sparpolitik im besonderen ist ebenso wie sein Engagement in der Kinoarbeit im allgemeinen zunächst als eine pragmatische Haltung im Arbeitsalltag zu verstehen, aber auch als eine experimentelle, sich selbst reflektierende und den Alltag transzendierende Haltung, mit der er gegen die Anpassung an die kritisierte gesellschaftliche Realität streitet. Das pathetische Nachwort des Kinoarbeiters ist ein Täuschungsmanöver des deplacierten Menschen, um. geschüzt hinter einer Maske. die Spuren des Leidens an der Zeit zu zeigen. aber auch um mit listigem Mutwillen die Lust an der Auseinandersetzung mit eben dieser Zeit behaupten zu können.

"Nimm mich an. dritte Fabrik des Lebens!

Bring nur meine Zunft nicht in Verwirrung.

Und zur Sicherheit sei gesagt: ich bin gesund. solange das Herz sogar aushält. was ich hier nicht beschreibe.

Es ist nicht gebrochen, es hat sich nicht erweitert." [139]

Aus dieser Auseinandersetzung schöpfte S̆klovskij, solange es möglich war. Energie und Phantasie für die Drehbücher, die er verfaßte, für die filmpädagogischen Aufsätze. Broschüren und Bücher, die er schrieb. Er verstand es, seine eigenen theoretischen Interessen mit den gesellschaftlichen Anforderungen geschickt zu verkniłpfen. so daB niemand genau wuBte: plädiert er für die Sparsamkeit der Mittel, um die Kasse der staatlichen Filmgesellschaft zu schonen oder um mit künstlerischen Verfahren zu experimentieren. Šklovskij setzte sich innerhalb der Institution Kinofabrik auf verschiedenen Ebenen als Kritiker. Szenarist. Organisator und Techniker - listig zur Wehr. Er spielte die Rollen gegeneinander aus. schlüpfte in die eine. wenn sich die andere als unpassend erwies, genau so wie in "Dritte Fabrik" der Kinoarbeiter gegen den OPOJAZ-Mitarbeiter auftritt, der OPOJAZ-Mitarbeiter gegen den Schriftsteller, der Schriftsteller gegen den Kinoarbeiter. Auf diese Weise eroberte er sich eine zeitlang eine gewisse Bewegungsfreiheit und die Möglichkeit, gemeinsam mit Regisseuren wie Kulešov, Room. Tarič. Barnet und Pudovkin zu arbeiten und niche bloB als Drehbuchschreiber vor den verschlossenen Türen der Produktionsabteilung zu stehen. 
Auch der Kinoarbeiter ist nicht nur der deplacierte Mensch, sondern gleichermaßen der Experimentator Šlovskij, selbst wenn er sich thematisch im Hintergrund hält Sein Anteil im Text der "Dritten Fabrik" besteht darin, das Wortmaterial zu ordnen und miteinander zu verknipfen.

"Wie man im Film an den Anfang entweder ein Stück ron einem belichteten Negativ oder einen Ausschnitt aus einem anderen Filmstreifen klebt.

Ich hefte ein Stiuck theoretischer Arbeit daran ..." [7]

Der Experimentator verfaht in der literarischen Produktion mit dem Material ähnlich wie mit den Filmstreifen im Montageraum der Kinofabrik. Er weiB sich darin in der Nachfolge des Formalisten Šklorskij. Ihre Stimmen amalgamieren einige Sätze lang. um dann wieder auseinander zu gehen und der Stimme des deplacierten Menschen den Platz zu räumen: "Das Ding wird ganz und gar trocken werden. Das macht der Husten. [7]

Gravierender als denotative Verweise auf die Kooperation zwischen dem Schriftsteller, dem Formalisten und dem Experimentator am Kino sind die Spuren im Text der "Dritten Fabrik". die ihre Zusammenarbeit im Bau der Sprache, in der Konstruktion der einzelnen Textsequenzen hinterlassen hat. Der Kinoarbeiter legt dem Erzähler Worte aus der Filmsprache in den Mund (Montage. kleben. anheften. Grobaufnahme. schneiden etc.) und befähigt inn. in Metaphern zu sprechen. die Erfahrungen aus der Kinoarbeit zu sprachlichen Hilfskonstruktionen fuir in der Literatur bis dahin Unaussprechliches modeln. d.h. in Metaphern. die nicht einfach Bekanntes ungewöhnlich darsteilen. sondern die die Literatursprache durch die Konfrontation mit der Filmsprache erneuem und erweitern.

"Im gruinen Lichtkegel der Laternen vertaufen neben mir die Filmaufnahmen der Straßen." [15]

"Es kommt vor. daB man im Kino einen Fulm dreht. Man fumt. verschwendet, aber er wird nicht geklebt. nicht montiert.

Die Totalen stimmen nicht mit den GroBaufnahmen uiberein. Es gibt keine Handlung. - bloB Passagen." [71]

Ich würde das Leben gem anders filmen. um die Montage des Lebens $z u$ verändern. Ich liebe die langen Stiucke des Lebens." [137]

Das Medium des Films bot sich gewissermaBen dazu un. die unterbrochenen Arbeiten für eine experimentelle Kunstkonzeption fortzusetzen. Als neue. dem industriellen Zeitalter angemessene und in die Zukunft weisende Kunstform hatte der Film sowohl in den programmatischen tberlegungen und Kunstwerken des LEF als auch in den analytischen Arbeiten des OPOJAZ bereits eine Rolle gespielt. Der Film erwies sich für die Formanalysen des OPOJAZ als ein geeignetes Forschungsobjekt. da sich hier, noch exakter als 
in der Poesie, erst recht als in der Prosa, die Gesetze der Konstruktion isolieren und betrachten lassen. Im Film wird die ästhetische Produktivität der Form besonders offensichtlich. ${ }^{52}$ Für Šklovskij sei - so Wolfgang Beilenhoff - der Film gleichermaBen Technik und Kunst, industrielles Produkt und der Literatur kontrastierte ästhetische Konstruktion. Seine 1919 beginnende filmpublizistische Tatigkeit sei gleichsam eine Parallelmontage dieser beiden Perspektiven und ihrer Ausrichtung auf einen Punkt, in dem sich das Kino als System des Denkens abzeichne. ${ }^{53}$

Die Würdigung des Filmtheoretikers Šklovskij in der Sowjetunion, die ihm in Gestalt der immer noch repräsentativen Publikation einer Vielzahl seiner filmtheoretischen und feuilletonistischen Aufsätze unter dem Titel "Im Laufe von vierzig Jahren" 1965 zuteil wurde und die in Ausziugen ein Jahr später auch ins Deutsche uibersetzt erschien, verhalf zwar zu einem ersten Einblick in seine Kinoarbeit und hinterlie日 vor allen Dingen einen nachhaltigen Eindruck von seiner Bedeutung als Theoretiker des Films, aber sie vermochte nicht das gesamte Feld seiner Arbeit an sowjetischen Kino, vor allem nicht die kuturpolitische und existentielle Bedingtheit von Theorie und Praxis auszuleuchten, wovon der autobiographische Text "Dritte Fabrik" erzählt. In diesem Zusammenhang geben einige Bemerkungen M.Blejmans in seinem Vorwort zu Im Laufe von vierzig Jahren" eine erste Auskunft uiber die Rolle Šklovskijs am Gos-. später Sovkino, ${ }^{54}$ die Efim Levin, Redakteur der sowjetischen Kinozeitschrift Iskusstro kino im Bereich der Filmtheorie, in einem Aufsatz über den Kinotheoretiker $\check{S}_{k}$ lovskij $^{55}$ aufgreift und zum Ausgangspunkt seiner Ausfuihrungen macht Šklovskij sei als Schriftsteller und Wissenschaftler zur Kinematographie gekommen. Er habe dort von vorn angefangen und die Dreckarbeit nicht gescheut. Er habe Filmtitel erfunden. Szenarien uberarbeitet und geschrieben, schlechte filme gerettet und sei beharrich im Montageraum sitzengeblieben, um Filmstreifen zu schneiden und zu kleben. Für seine Arbeit am Kino habe er sich genauso leidenschaftlich engagiert wie für seine literarische Arbeit. Er sei ans Kino gekommen und dort geblieben. nicht um das kinematographische Sehvermögen zu beherrschen, sondern um in Gestalt des Films ein Medium zu gewinnen, das dazu verhilft. die Welt und die Kunst neu zu sehen. "Er verlangt, daB man sich in den Stil hineinfühlt, sich in die Manier hineinlebt ${ }^{\mathbf{m 5} 6}$, schreibt Levin, der - wie mir Il'ja Vajsfel'd. Professor am Moskauer Filminstitut, im Januar 1984 erzahlte - sich darauf vorbereitete, Šlovskijs Schriften zum Film neu zu veröffentlichen. "Im Laufe von vierzig Jahren" sollte in "Im Laufe von 60 Jahren" umbenannt und durch bisher unbekanntes Material ergänzt werden. 57 Levins vorläufige Interpretation der Kinoarbeit Šklovskijs, wie er sie 1970 in Iskusstvo kino dargelegt hat. erscheint mir um vieles ergiebiger für die Aufschlüsselung der Erzählung vom "Kino" in der autobiographischen Prosa "Dritte Fabrik" zu sein als der 1983 publizierte Aufsatz von Gennadij Maslovskij uber den Kinotheoretiker Šklovskij. ${ }^{58}$ der sich ausschlieBlich mit dessen Verfremdungstheorie, ihrer Geschichte und den ihr innewohnenden Unstimmigkeiten und Widerspriichen beschäftigt. 
Vor allem anderen rehabilitiert Levin Šklovskij als einen "last not least"-marxistischen Denker, "was sich nicht einfach und bei weitem nicht sofort entwickelte". sondern "zum Zeitpunkt seiner Reife". Der tief durchdachte Hegel und die marxistische Dialektik hätten es dem Wissenschaftler ermöglicht, die Produktion von Kunst nicht nur als ein Problem von Material und Stil zu begreifen. sondern vor allen Dingen als einen spezifischen Zusammenhang von Subjekt und Objekt, als einen ProzeB der subjektiven Aneignung der Wirklichkeit. 59

Mag diese Rehabilitation auch in erster Linie die Funktion der Rechtfertigung vor der immer noch doktrinär hertschenden Sowjetideologie haben. mag dem Autor die Legitimation für die, wie sich zeigen wird. positiv gestimmte Auseinandersetzung mit Šklovskij erst auf diesem Hintergrund gelingen, so erweist sie sich doch als mehr. Sie ist eine brauchbare Bestimmung elementarer Grundzuige der Denk- und Darstellungsmethode des Avantgardisten. Nachdem Šklovskij, so argumentiert Levin, die methodologisch verengte Perspektive des Petrograder OPOJAZ, die als Gegenbewegung gegen eine metaphysische Kunstauffassung durchaus sinnvoll gewesen sei. iberwunden gehabt habe. habe er sich dazu bekannt, daB "im Zentrum der Kunst nicht das Verfahren. sondern das menschliche Schicksal als ein Atom des historischen Prozesses ${ }^{\mathbf{6 0}}$ stehe - ein Gedanke, der als unhinterfragt moralische Prämisse wohl auch schon in der "Theorie der Prosa" zu finden sei und der sich in den folgenden Schriften als Widerspruch bemerkbar mache. Ungeachtet dessen habe Šklovskij an wesentlichen Grundannahmen der OPOJAZ-Konzeption zu einer neuen Theorie der Literatur festgehalten.

"Die Kunst wird als eine von einer besonderen Bildlichkeit organisierte ästhetische Reihe untersucht. die nicht identisch ist mit irgendeiner beliebigen anderen Reihe, mit einem beliebigen anderen Material der Wirklichkeit und die aus dem Zusammenprall des Materials und der Beziehung des Autors 24 ihm entsteht."

Dem Gedanken von der Eigengesetzlichkeit der Literatur ordnet Levin das in der Konzeption Šklovskijs grundlegende Theorem vom prozessualen Charakter der Literatur zu, das der Schriftsteller Šklovskij in seiner dialogischen Prosa selbst verwirkliche. Levin geht davon aus, daB der "Kinematograph" Šklovskij in seinem Denken stark beeinflußte.

"Der Kinematograph gab dem Forscher zum ersten $\mathrm{Mal}$ in solcher Fülle ein sinnlich-anschauliches, fühlbares Sehen der Produktion als eines minuitlich ablaufenden Prozesses. Im theoretischen BewuBtsein flihrte das Moment der inneren Dynamik der Produktion. der Effekt ihrer Bewegung zu einer ästhetischen Einheitlichkeit."

Šklovskij sei "mit dem Kopf" in die Kinoarbeit eingetreten und sei doch "Maddchen für alles" gewesen. Úber all das habe er geschrieben: uber Szenarien und die unendliche Unordnung in den Studios. die die Arbeit störte, uiber Schauspieler und die Qualen bei der Ausbesserung schlechter Filmstreifen. 
uber sowjetische und ausländische Regisseure, über Filme. Alle Aufsätze Šklovskijs seien wie "Eilbriefe" abgefaBt, "in den Intonationen äuBerst hartnäckig. Manchmal klingen darin beunruhigte und sogar verzweifelte Töne an, wie in einer letzten Warnung vor einer nahen Gefahr. ${ }^{.63}$

Auch wenn sich einige ÄuBerungen Levins über Šklovskij, über seine theoretische Konzeption und seine praktische Arbeit zu glatt lesen und konkrete - politische und existentielle Probleme verschweigen, die Šklovskij häufig eher zu bestimmten Haltungen und Einsichten zwangen als die Wahrheit gewisser Ubberzeugungen - es ging vielmehr um ihre BotmäBigkeit gegenüber einer repressiven Kulturpolitik - , so macht Levin an verschiedenen Stellen doch Andeutungen daruber, daß Šklovskij lange von der Öffentlichkeit verkannt wurde, daB er es lange Zeit sehr schwer hatte. Bedauerlicherweise neigt er gerade da zu legitimatorischen und glättenden Einschätzungen. wo konkrete Hinweise zum Verständnis der Entwicklung bestimmter literatur- bzw. filmtheoretischer Positionen nötig wären. Auf diese Weise schildert er Šklovskijs scheinbar so widerspruchslosen Weg von der theoretischen Präferenz subjektiver, assoziativer und fragmentarischer Formen in der Kunst hin zum Plädoyer für eine fast klassische Bildlichkeit, die man, wie ich denke, ohne die permanenten Fehden gegen das Westiertum und die Dekadenz der Formalen Methode und der linksavantgardistischen Kunst in der Sowjetpresse am Ende der 20er. stärker noch in den 30er Jahren, und ohne einen Blick auf die zum Teil entwirdigende Arbeitssituation der drehbuchschreibenden Schriftsteller am Sovkino zu werfen, nicht verstehen kann.

Es ist etwas anderes, wenn Šklovskij selbst sich listig und vital die Hegelsche Argumentation von der objektiven Wahrheit der Geschichte, die manchmal mit dem eisernen Besen kehrt und niedermacht, was sich ihr in den Weg stelt. ironisch zu eigen macht. als wenn fünfzig Jahre später ein Wissenschaftler und Kritiker mit ihm so verfährt. Aus seinem Munde klingt es zynisch.

"Hier frage ich mich selbst: Warum konnte Viktor Borisovič Šklovskij die Verbindung mit dem Lauf der Zeit nicht verlieren? ...

Und ich antworte so: Er wächst und entwickelt sich zusammen mit der Kunst vor allem deswegen. weil er die Bewegung der Zeit lebendig spiurt und ihre grundlegenden Forderungen erkennt, die letztendlich die Evolution der künstlerischen Kinoform bestimmen. ${ }^{.64}$

Doch sollte man mildernde Umstände walten lassen angesichts der in der Sowjetunion geltenden Praxis. Wissenschaft zu kontrollieren und zu zensieren. und sich einer den kulturellen Kontext des Textes berlicksichtigenden Lesart befleiBigen. In diesem Licht erscheint Levins Wirdigung der Konzeption des "neuen Sehens" bei Šklovskij besonders bemerkenswert. Mit dem Argument. Šklovskij vertiefe unablässig sein Verständnis von den künstlerischen Elementen als den Materialträgem der Ausdruckskraft und von den künstlerischen Strukturen als den Materialträgern der Buldlichkeit, rehabilitiert er dessen bereits in der "Theorie der Prosa" (1925) formuliertes, lange als Provokation 
gelesenes Theorem, indem er auf die Entwicklung dieser streitbaren Hypothese hinweist, die bei Šklovskij lautet:

"Das Ziel der Kunst ist, uns ein Empfinden für das Ding zu geben, ein Empfinden, das Sehen und nicht nur Wiedererkennen ist. Dabei benutzt die Kunst zwei Kunstgriffe: die Verfremdung der Dinge und die Komplizierung der Form, um die Wahrnehmung zu erschweren und ihre Dauer zu verlängern. ${ }^{-65}$

Im Unterschied zum "Wiedererkennen" - dem Stereotyp der Wahmehmung schliebe das "Sehen" - und darin liege der Kern der Konzeption - ein aktives. auf Erkenntris gerichtetes Moment in sich ein.

-Es ist der ProzeB der Analyse und der Synthese, die EntblöBung der Ähnlichkeit im Unähnlichen und der Unähnlichkeit im Ähnlichen. die Umgestaltung der Realität nach den Gesetzen des künstlerischen Denkens.

Sehen - das ist persönliches ästhetisches Erkennen, die Bearbeitung der individuellen Weltbetrachtung, des individuellen Weltbildes. ${ }^{.66}$

Levins Interpretation der Konzeption eines "neuen Sehens" darf in diesem Zusammenhang als die Andeutung eines Versuchs. die asthetische Theorie Šklovskijs als eine Verfremdungsästhetik zu begreifen. verstanden werden, in der subjektive Wahrnehmungs- und Darstellungsformen zu ihrem Recht kommen. Solche Worte wie "immerwährende Frische in den Ansichten". "Antidogmatismus". "Wilbegierde" und "eine nichtstereotype Wahmehmung ohne jegliche Trägheit ${ }^{-67}$ erhalten zur Umschreibung seiner Persönlichkeit einen besonders bedeutungsvollen Klang. wenn man sie mit den Klischees zur offiziellen Beschreibung verdienter Helden der Sowjetunion kontrastiert. Dasselbe gilt für Levins Rechtfertigung der "Vielseitigkeit" Šklorskijs.

"Sie ist keine Liederlichkeit, sondern eine unerläBliche Bedingung für Tiefgrundigkeit und Entschiedenheit. Natürlich ist sie eine Renaissance, rein psychologisch als Faktor des geistigen Lebens, als Charakteristik einer Persönlichkeit betrachtet. Aber hier ist Vielseitigkeit unerläßlich. Šklovskij so wie auch Ejzenštejn stellen den Typus des Denkers und Künstlers dar, der die Welt und ihre Wechselbeziehungen erkennt und alles daransetzt, das in sich abgeschlossene Bild der sich ereignenden Wechselwirkungen $z \mathrm{u}$ verstehen. ${ }^{.68}$

Šklovskijs eigenwillige Manier, entsprechend seinen vielfältigen Qualifikationen als Literaturtheoretiker, Kritiker, Kinotheoretiker, Drehbuchautor, Schriftsteller und Fahrlehrer ïber verschiedene Dinge in einem Atemzug zu reden, die in der kulturellen Öffentlichkeit der Sowjetunion !ange Zeit auf Widerstand stieB und deshalb dort einer besonderen Rechtfertigung bedarf, wird von Levin als ästhetische Konzeption rehabilitiert, obwohl sie mit den Dogmen des Sozialistischen Realismus nicht zu vereinbaren ist. Indem Levin Šklovskij in die Nähe des in der Sowjetunion zwar nur widerwillig, aber doch kanonisierten Ejzenštejn rilckt und ihm in gewissem Sinne Genialität zuspricht. verleiht er ihm eine Aura, die ihn unangreifbar machen soll. 
3. Sklorskijs Montagekonzeption und ihre Literarisierung in "Dritte Fabrik

Ohne an dieser Stelle die Diskussion über den Zusammenhang von Avantgarde und Montageprinzip in der Kunst rekonstruieren oder gar weitertreiben zu wollen, die im vorrevolutionären Futurismus (RuBland und Italien), in den Auseinandersetzungen um James Joyce "Ulysses". im Dadaismus, in den Theoriediskussionen des sowjetischen Kinos in den 20er und 30er Jahren und in der "Expressionismusdebatte" (Ernst Bloch und Bert Brecht contra Georg Lukacs) eine so wichtige Rolle spielte und bis heute fortdauert, möchte ich die Kooperation zwischen dem Experimentator am Kino und dem in der Literatur in dem Text der "Dritten Fabrik" am Beispiel der Montagetechnik aufzeigen. Denn die Montage ist - wie auch diese Theoriediskussionen beweisen - kein beliebiges technisches Mittel, sondern ein zentrales Prinzip in der Kunst, vor allem in der Filmkunst, von dem ausgehend man andere Spezifika wie die Frage der Einstellung oder der Bewegung im Film erschlieBen und mit dessen Hilfe man den Zeichencharakter der Filmsprache dingfest machen kann. Zwar gehörte die Montage seit alters her zum Arsenal der Kunst, aber erst die künstlerischen Avantgarden dieses Jahrhunderts - vor allen Dingen des sowjetischen Kino - erhoben sie in den Stand eines theoretisch fundierten Konstruktionsprinzips.

Es erscheint mir wenig ergiebig, definitorisch festzustellen. wer die konstruktiven Möglichkeiten dieses Prinzips wohl als erster erkannt und praktisch umgesetzt hat, denn - wie Šklovskij sagt - die Montage existierte im Leben der Avantgarde 69 und war keine Kopfgeburt eines Einzelnen. Es gab in der Sowjetunion. was den Kunstgriff der Montage betrifft, eine Bewegung der gegenseitigen EinfluBnahme - der der Formalen Schule auf den sowjetischen Avantgardefilm und umgekehrt der des sowjetischen Films auf die Formale Schule -, die ich am Beispiel von Šklovskijs früher Ejzenštejn-Rezeption einerseits und seiner praktischen Erfahrung mit Kulešov andererseits exemplarisch nachzeichnen möchte, um die Bedeutung der avantgardistischen

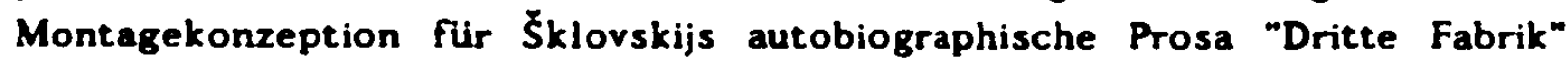
ermessen zu können.

Als Šklorskij die "Dritte Fabrik" schrieb, hatte er seine ersten praktischen Erfahrungen mit dem Kino bereits hinter sich. Er hatte Kulešor und dessen Kollektiv kennengelernt und möglicherweise ${ }^{70}$ mit ihm bereits die Arbeit zu dem Film "Nach dem Gesetz" begonnen. Er kannte die ersten Versuche Esfir' Subs. Chronik-Montagen zu kleben, die "Kinopravda"- und "Kinoglaz"-Filme Vertovs und die ersten Füme Ejzenštejns "Streik" (1924) und "Panzerkreuzer Poternkin" (1925). Dariber hinaus wissen wir, daB er die friihe Montagekonzeption Ejzenštejns, die "Montage der Attraktionen", positiv rezipiert hatte. ${ }^{71}$ die zunächst als theoretische Fundierung für die gemeinsam mit Tret'jakov an Ersten Arbeitertheater des Moskauer Proletkul't erarbeitete Inszenierung von Ostrovskijs "Eine Dummheit macht auch der Gescheiteste" konzipiert 
worden war. Alle diese Namen sind ein Inbegriff des sowjetischen Avantgardefilms der 20er Jahre, der in dem psychologischen Realismus der traditionellen Kunst und des in seiner Nachfolge stehenden kommerziellen Kinos (soweit es das in der Sowjetunion iberhaupt gab) seine Gegner sah und in dieser Abgrenzung eine Einheit bildete, aber nach innen in verschiedene Fraktionen zerfiel.

An den Arbeiten Vertovs und Šubs kritisierte Šklovskij die Dominanz des Materlals gegenuber der Konstruktion und die Ignoranz gegeniber dem bedeutungsbildenden Potential des Schnitts. d.h. der Montage der einzelnen Teile der Konstruktion, allerdings ohne die jeweilige Bedeutung Šubs und Vertovs für die Entwicklung des Genres Filmchronik, das sich seiner konstruxtiven Möglichkeiten im allgemeinen wohl bewuBt ist, zu leugnen. ${ }^{72}$ Während sich Šklovskij gegen diese Konzeptionen. vor allen Dingen in der aktuellen Situation abgrenzte, in der, wie er selbst später zugibt, der Streit zwischen den einzelnen Fraktionen der Avantgarde "nicht immer Baulärm war", 73 rezipıerte er Ejzenštejn, der nicht zum Kreis der Linksavantgardisten gehórte. mit Anerkennung, wenngleich mit leicht ironischem Unterton, der bei aller Achtung die Distanz zwischen dem Filmemacher und dem Formalisten markiert. $^{74}$ In der praktischen Zusammenarbeit mit Kulešov, aber auch in den Auseinandersetzungen mt Ejzenštejn, mit seiner Konzeption der Montage der Attraktionen (1923) und mit seinen Filmen erhöhte sich seine Aufmerksamkest für die Möglichkeiten dieses Kunstgriffs, und er konkretisierte und differenzierte seine Autfassung und erprobte sie als Drehbuchschreiber. Regieassistent und Montagetechniker.

Šklovskij suchte nicht nur nach Ubbertragungsmöglichkeiten von der literarischen Form in die Filmsprache, es genïgte ihm auch nicht, die Medien gegeneinander abzugrenzen. sondem er versuchte - im Rahmen seiner Bestrebungen. Literatur zu erneuern - auch Konstruktionsprinzipien des Films. z.B. die Montage, auf die Prosa zu ibbertragen. Auch wenn sich für seine ersten literarischen Texte nicht klar sagen läßt, inwieweit sie von der Auseinandersetzung mit dem Film geprägt sind, da er sie vor bzw. während dieser Auseinandersetzungen verfaBte ("Sentimentale Reise" und "Zoo ...") so ist doch evident. daß Šklovskij in dem Briefroman "Zoo ..." vor allem aber in seinem Kinobuch "Dritte Fabrik" bestimmte literarische Verfahren auf eine Weise realisiert. wie sie im Film durch das Verfahren der Montage realisiert werden und dadurch filmische. die literarischen Sprache verfremdende und ihr Kunstgriffsarsenal erweiternde Effekte erzielt. Der Parallelismus, die semantische Verschiebung, die Wiederholung und das Zitat, in der Literatur von je her übliche Kunstgriffe, sind hier wie in Fum als bewuBt überzeichnete, mechanisierte Tricks eingesetzt. Zusammenhang erscheint als ProzeB und wird, wie im Film durch die gedankliche Bewegung der Bilder in der Wahmehmung der Zuschauer, durch das Zusammenlesen abrupt montierter und rasch aufeinander folgender Zeichensequenzen hergestellt, die ohne sinnfäligen Zusammenhang. ja, in sich unabgeschlossen sind.

In seiner ersten umfangreicheren Arbeit zum Film "Literatur und Kinemato- 
graph". die er als Broschüre in Berlin. im Exil 1923, zwei Jahre bevor er in die Kinoarbeit eintrat, veröffentlichte, ${ }^{75}$ erkannte Šklovskij, daB das elementarste Geheimnis des Films in der Bewegung von Bildern besteht, die sich als eine diskontinuierliche, gebrochene Kurve erweist, da sie von den Schnittstellen zusammengeklebter Filmstreifen. die wiederum nichts anderes als die Abfolge einzelner Bilder mit Anfang und Ende sind, wie Šklorskij Im Rekurs auf Bergson und den griechischen Mathematiker Zenon nachweist. durchzogen und markiert ist. ${ }^{76}$ Das Verfahren der Montage - zunächst nicht mehr als eine technische Notwendigkeit in der Filmproduktion - war, wie Šklovskij. Ejzenštejn. Kulešov u.a. richtig erkannten. von den Pionieren des amerikanischen Kinos (Griffith. Fairbanks. Pickford u.a.) geschickt als ein wirkungsvoller Trick der Illusionierung eingesetzt worden, den es nun 24 analysieren galt. ${ }^{77}$

Šklorskij sah, daB dem technischen Vorgang der Bewegung der Bilder eine gedankliche entspricht, die er als eine zeichenhafte erkannte.

-Der Kinematograph kann nur mit der Bewegung als Zeichen, mit gedanklicher Bewegung zu tun haben. Nicht einfich Bewegung. sondern Bewegung als Handlung, dies ist die Sphäre des Kinos. Die gedankliche Bewegung des Kinos - das Zeichen - wird durch unser Erkennen aufgenommen. wird von uns zu Ende gezeichnet, ohne besondere Konzentration. Hierher rühren im Kino diese verabredete Mimik. diegerhobenen Augenbrauen, die groben Tränen. Bewegungen. Zeichen."

Šklovskij thematisiert, wenn zunidchst auch nur flüchtig. den Zeichencharakter der Fulmsprache, den Ejzenక̌tejn und Kulešov wenige Jahre später, jeder auf seine Weise, fuir den sowjetischen Film genauer analysierten und in ihrer Filmpraxis zu konstruktiven Verfahren ummiunzten und dessen Erkenntnis dem Strukturalisten Lotman Jahrzehnte später als Grundlage seiner Theorie des Films diente. ${ }^{79}$

Insbesondere am Beispiel Chaplin, den er dem sowjetischen Publikum u.a dadurch nàherbringen wollte. dab er eine Sammlung von Aufisätzen über den Komiker und seine Fulme zusammenstellte und der nicht nur als Kinoidol. sondern auch als Typus des deplacierten Menschen in der Kunst seine Aufmerksamkeit fesselte, konkretisierte Šklovskij seine ersten Erkenntnisse uber den Zeichencharakter der Filmsprache. Er vergleicht Chaplin mit den Masken der Commedia dell'arte: er fungiere als Handlungsträger. der einen bestimmten. in gewissem Rahmen festgelegten Ablauf der Bilder garantiere, dessen Spiel allerdings von den Gesetzen des Films regiert werde.

"Chaplins Bewregungen, Schritte, Gebärden. Mienen, ja seine Filme selber sind nicht vom Wort, nicht von der Zeichnung sondern vom Flimmern der schwarz-grauen Schatten her konzipiert ... Chaplin spricht nicht - er bewegt sich. Er arbeitet mit kinematographischem Material. statt sigh selber aus der Theatersprache in die Filmsprache zu ubersetzen. ${ }^{\text {"80 }}$ 
Šklovskijs Versuch, die Komik Chaplins aus der bewuBt uiberzeichneten Zeichenhaftigkeit der Filmsprache zu erklären, bleibt 1923 noch vage.

"Worin das Komische seiner Bewegungen besteht, kann ich noch nicht zureichend bestimmen; möglicherweise darin, daß sie mechanisiert sind. Sein Spiel kann man in einzelne Perioden zerlegen, wobei jede Periode gewöhnlich mit einem SchluBpunkt endet: mit einer Pose. Um eine Metapher zu gebrauchen: Chaplins Bewegung stellt eine Linie dar, die sich aus vielen Punkten zusammensetzt. Er ist sich selber vermutlich der Pas seiner Kunst sehr wohl bewuBt, und man kann sein Spiel als eine Folge 'ständiger Bewegungen' auffassen. die. mit wechselnder Motivierung, aus dem einen seiner Filme in den anderen ubergreifen und übergehen.

Die Filme Chaplins führten Šklovskij vor Augen. wie sich die Mechanik der Filmtechnik, d.h. die Bewegungen, mit deren Hilfe der Apparat automatisch einen Effekt erzielt, in ein bewuBtes Verfahren transformiert und auf die gedankliche Bewegung ibertragen werden kann. Der Kunstgriff des Zeitraffers. noch heute als komischer Effekt im Film eingesetzt, gibt ein anschauliches Beispiel dieser Transformationsmöglichkeit. Dieses rein technische Mittel. Filmzeit zu beschleunigen. erweist sich in der Anwendung als bedeutungsbildendes Potential. Aber es gewinnt erst dann kiinstlerische Qualität. wenn es auf das Tempo der gedanklichen Bilder übertragen und nicht nur als uberhöhte Abspulgeschwindigkeit eingesetzt wird. In dem BewuBtsein. daB "das Wichtigste wie in der Kinematographie zwischen den Zeilen steht". 82 baut der Experimentator Šklovskij den Text der "Dntten Fabrik" aus Zitaten. Notizzetteln. Briefen etc., die er wie belichtete Filmstreifen aneinandermontiert. Der Text, der insgesamt nur 139 Seiten umfaBt, besteht aus vierundvierzig kurzen Kapiteln, die im großen und ganzen zwar der Chronologie der Biographie des Autors - von der Kindheit bis ins Mannesalter - folgen, aber dennoch aus unzusammenhängenden Einzelteilen mit einem Anfang und einem Ende - aus Anekdoten zumeist ${ }^{83}$ - bestehen, wobei die kleinste Einheit nicht unbedingt ein Kapitel, auch nicht eine Passage, sondern manchmal nur ein einziges Wort umfaBt.

Der Experimentator zerschneidet die im allgemeinen als Einheit vorgestellte Autobiographie bis in das einzelne Wort hinein, so daB selbst aus ihm mehrere. Verschiedenes bedeutende Stimmen tönen und Geschichten erzählen. Zum Beispiel erzählt das Bild der StraBenlaterne zugleich Andersens Märchen und Gogol's "Nevskij Prospekt". sie erzählt von den Arbeitsschwierigkeiten bzw. der Arbeitsweise des Schriftstellers, des Kinoarbeiters und von den Uberlegungen des Formalisten Šklovskij [102/103]. Ähnliches gilt für zahllose andere Worte sowie Textpassagen. In dem Kapitel "Brief an Boris Ejchenbaum" [102-103] verknüpft Šklovskij eine Erörterung über den Kunstgriff der münlichen Rede (skaz) - ein zentraler Streitpunkt in den Diskussionen der beiden Formalisten und zugleich eine verrätselte Thematisierung der Sujetkonstruktion eben des Buches, an dem er schreibt - mit einer Nacherzählung von Andersens Märchen "Die alte StraBenlaterne", in die er ein Zitat aus Gogol's 
Novelle "Nevskij Prospekt" einläBt. montiert die Straßenlaterne dann in die Räume der sowjetischen Kinofabrik und verschiebt die Handlung auf diese Weise hin zu seiner eigenen Existenz: Die StraBenlaterne wird von seinem Gesicht uberblendet und spricht an seiner Stelle. Der Autor schlieBt das Kapitel mit einem ironischen Autorskaz a la Rozanov. Das Ganze steht qua Titel unter dem Etikett, ein Brief zu sein.

Die "Dritte Fabrik" ist eine Montage von Erinnerungsfetzen. publizistischem und literaturtheoretischem Text und aphoristischen Selbstreflexionen, die allein durch die Präsenz des in verschiedene Stimmen zerfallenden autobiographischen Helden zusammengehalten werden. In dem Brief an Ejchenbaum demonstriert der Formalist Šklovskij vor seinem Freund dieses Verfahren der Montage. um ihm die Uberlegenheit seiner Sujettheorie. die im wesentlichen eine Montagetheorie ist, gegenuber der "skaz"-Theorie seines Freundes zu beweisen. Das Verfahren der mündlichen Erzählung. von ihm selbst in "Dritte Fabrik" auch praktiziert. sei - so der OPOJAZ-Mitarbeiter - nur ein Kunstgriff neben anderen. entscheidend sei das Prinzip der Montage der einzelnen Verfahren zum Sujet. das die Einheit des Textes bilde. Anders als die amerikanischen Avantgardefilmer, die das lllusionspotential der Montage nutzten. macht Šklovskij das Verfahren der Montage sichtbar. Er entblößt es und weist zum Teil demonstratuv auf die Willkür dieses Vorgehens hin. das 2 war auch einen Zusammenhang herstellt. aber nicht als in sich geschlossene Einheit mit einem Anfang. einer Mitte und einem SchluB, sondern als fortwathrender. unruhiger ProzeB der Auseinandersetzung der Stimmen. als eine diskontinuierliche Bewegung von einzelnen Redesequenzen analog zu der Bewegung der Bilder im Film.

Die einzelnen Redesequenzen im Text sind - ahnlich wie Šklovskij es für den Film hypostasiert - in sich unabgeschlossene Zeichen, die vom Leser zu Ende gedacht werden sollen. Es sind elliptische Redefiguren. die die Fähigkeit der literarischen Sprache. Unaussprechliches durch Auslassungen zum Ausdruck zu bringen - wie Śklovskij es nennt - auf ganz spezifische Weise ausnutzen. indem sie häufig mut meist ironischen oder parodistischen Anspielungen auf andere Texte bzw. auf fremde Rede arbeiten.

Dadurch. daB diese Redefiguren miteinander verkettet werden. verdichtet sich die fragmentarische Redeweise: Der Leser hört den Kinoarbeiter, den Schriftsteller und den Formalisten aus ein und demselben Wort. um beim alten Beispiel zu bleiben, aus der Metapher "Laterne" und vermeint doch ganz Verschiedenes zu hören. Und dadurch. daB sie sich verdichtet. gewinnt sie an Tempo, ohne daB eine Handlung sie vorantriebe. Der Leser hat Mühe. den je einzelnen Stimmen gedanklich zu Ende zu folgen, die Stimmen zu entwirren. Das Stimmengewirr wirkt auf ihn.

In seinem Aufsatz "Über die Gesetze des Kinos" aus dem Jahre 1924 werden Šklovskijs Äußerungen über die Konstruktionsprinzipien der Filme Chaplins konkreter. Er stellt fest, daß Chaplin sehr stark mit dem Uberraschungseffekt 
arbeitet, einem Prinzip, das in komischen Filmen gewöhnlich häufig vorkomme, das aber Chaplin verfeinere.

"Ein ganzer Teil des Films 'Chaplin im Kino', zum Teil ein sehr schöner Film, besteht darin. daB die Feinde Charlys auf ein und derselben Gangway einstiurzen, die mittels eines Hebels bewegt wird. Sie fallen auf eine Art, auf zwei, auf drei Arten, - alle nur möglichen Kombinationen haben sich bis zum Ende erschöpft.

Hier lacht der Zuschauer nicht über denselben Trick. sondern iuber ihre Abfolge, er durchlebt das Gefühl des Unterschieds zwischen ähnlichen Fallarten." ${ }^{\text {84 }}$

Für den Literaturtheoretiker Šklovskij war es interessant, in den Filmen Chaplins GesetzmäBigkeiten zu entdecken, die er bereits am parodistischen Roman (Don Quijote. Tristram Shandy) studiert hatte und die er für seine Theorie der Verfremdung wirksam machen konnte. Der Kunstgriff, durch nuancierte Abweichung von der automatisierten Bewegung Uiberraschung zu erzeugen. den Chaplin nicht nur in komischen sondern auch in melodramatischen Situationen anwende, schaffe - so Šklovskij - eine Atmosphäre des Erstaunens, die sich kunstvoll zu einem Lachen entlade. ${ }^{\circ}$ Das Prinzip des Überraschungseffekts als ein Mittel. das Gefühl für den Unterschied zu wecken, fügt sich ohne Schwierigkeit in seine Prosatheorie (Theorie der Verfremdung) ein. Seine Erkenntnis vermittelt ihm daruber hinaus exaktes Wissen über technische Möglichkeiten ihrer Realisierung im Film. über die Möglichkeiten der Montage. In Gestalt der Montagetechnik sind dem Künstler vielfältige konstruktive Möglichkeiten an die Hand gegeben, in das Zeichensystem der Sprache - sei es die des Kinos, sei es die der Literatur - einzugreifen und es nach bewuBten Intentionen 24 verändern, wovon Šklovskijs Kinoarbeit, aber auch seine Prosa ein beredtes Zeugnis abgeben und woriber er viel später in seiner Monographie uiber Ejzenštejn ausführlich berichtet.

Entsprechend seiner Auffassung von der Kunst als einem dynamischen ProzeB von Produktion und Rezeption, in dem das eine aus dem anderen folgt und umgekehrt, bezieht Šklovskij den Zuschauer und seine Wahrnehmungsweise in seine Überlegungen zum Kino mit ein und kommt zu einem ähnlichen SchluB wie später Benjamin: daB die Rezeption im Kino eine zerstreute ist und daB der Zuschauer, ohne es eigentlich zu merken, die Zeichen weiterdenkt und mit Bedeutung füllt. ${ }^{86}$ Es erscheint Šklovskij so, als probiere der Zuschauer 2.B. mit Hilfe Chaplins auf diese Weise verschiedene Berufe und Verhaltensweisen aus, als versuche er sich in ihnen und verfremde sie dadurch. ${ }^{87}$ Diese Erkenntris motiviert inn landers als Benjamin, der daraus direkte politisch-pädagogische SchluBfolgerungen zieht und das Kino potentiell als Erzieher der Massen betrachtet), weitere Untersuchungen uber die Spezifik dieser Zeichenmechanismen anzustellen, wobei er sich allerdings, wie aus der Verfremdungskonzeption im allgemeinen, aber auch aus insbesondere das Kino betreffenden ÄuBerungen deutlich hervorgeht, von grundsätzlichen. kritisch-politischen und utopischen Überlegungen leiten läßt. In der Großstadt 
Berlin, im Nachtleben der Kinos in der Friedrichstraße hatte er das Geschäft mit der Phantasie zur Genüge kennengelernt. Deshalb ist ihm (ähnlich wie Benjamin, der vor einer Okkupation der Kinos durch die Faschisten warnt) ${ }^{88}$ die Gefahr wohl bewuBt, die zum einen von der illusionierenden Kraft. zum anderen von der Eigenschaft des Kinos ausgeht, nicht nur Kunst und Technik. sondern auch Industrie und Kommerz zu sein. Trotzdem betont er - und auch hier gibt es eine Affinität zum Denken Benjamins - die konstruktiven Möglichkeiten des Kinos, eben diese Entfremdung in der Wahrnehmung aufzudecken und abzuschuitteln. ${ }^{89}$ Im BewuBtsein der dem Kino inhärenten Dialektik von Emanzipationsmöglichkeit und kommerziellem Interesse äußert sich Šklovskij widersprüchlich: auf der einen Seite ist er über die einem naiven. spontanen und intuitiven Sehen der Dinge entgegenstehenden Bewegungsstrukturen des Kinos erbittert. denn der Zuschauer fällt einer Illusion zum Opfer, wenn er den Film naiv betrachtet. d.h. dem Schein kontinuierlicher Bewegung glaubt. Auf der anderen Seite hat er die Hoffnung, daB das Kino den Zuschauer lehrt. in Prozessen zu denken und den engen Horizont des Denkens in gerichteten Bahnen und abgesteckten Zonen zu entgrenzen und $z u$ dynamisieren.

"Der Kinematograph steht schon von seinen Grundlagen her auBerhalb der Kunst. Ich sehe mit Erbitterung die Entwicklung des Kinematographen und möchte glauben. daB sein Triumph von begrenzter Dauer sein wird. Es vergehen keine hundert Jahre. dann gibt es weder Dollars noch Mark. weder Visa noch Staaten. all das sind Bagatellen. Nichtigkeiten. Nein, hundert Jahre vergehen und der menschliche Gedanke wird iber die Grenzen dringen. die ihm von der Theorie der Grenzen gesetzt sind, er wird lemen in Prozessen zu denken und von neuem die Welt als Kontinuum aufzunehmen. Dann wird es kein Kino mehr geben. Wir sehen. daB dem Kinematographen als Material zur Schaffung von Form die Bewegung als Handlung zugrunde gelegt werden muB." 90

Dem Prinzip der Montage, der verfremdenden (unerwarteten. Wahrnehmung erschwerenden. den Kunstgriff entblöBenden) Verknupfung einzelner BilderZeichen als bewuBter Eingriff in die scheinbare Kontinuität des Sehens sichtbar gemacht, kommt in der Konzeption Šklorskijs eine elementar wichtige Funktion zu. Šklovskijs Auseinandersetzung mit diesem Konstruktionsprinzip läBt sich nicht nur auf ein technisch-philologisches Interesse zuruckführen. sondern verweist auf die utopische Dimension seiner Kunstkonzeption - auf die Möglichkeit, in der Kunst modellhaft der automatisierten Wahmehmung innezuwerden und im ProzeB der ästhetischen Wahrnehmung ein Gespür für die Sprache und für die Dinge zu entwickeln.

Die Montage der verschiedenen Stimmen und ihrer je nach Maskierung unterschiedlichen Tonlagen im Text der "Dritten Fabrik" soll keineswegs den Anschein erwecken, die autobiographische Rede sel Ausdruck der Integrität der Erzählerpersönlichkeit. Vielmehr schockt sie den Leser durch soviel 
Disparatheit, daB dieser geneigt ist, sie gar nicht emst zu nehmen. Der Erzähler jongliert mit verschiedenen Variationen zum Thema "Wie soll man in der Sowjetunion der 20er Jahre ein künstlerisch arbeitender linker Intellektueller sein?" und uberrascht den Leser durch ungewöhnliche Wechsel einander widersprechender Positionen. Um bei dem Zitat-Beispiel zu bleiben: In dem Kapitel "Brief an Boris Ejchenbaum" kehrt er zunächst den OPOJAZ-Mitarbeiter heraus, der die theoretische Diskussion, zu guter Letzt Legitimation erheischend, in der Terminologie der Techniker-Sprache fortsetzt. Dann unterbricht er abrupt und läBt, um sein Theorem unter Beweis zu stellen. den Schriftsteller zu Wort kommen, der im Kontrast zur Rede des experimentierenden Literaturtheoretikers der Avantgarde einen nostalgischen Ton anschlägt und Andersens Märchen "Die alte StraBernlaterne" wie ein Märchen nachzuerzählen beginnt. dann aber abrupt unterbricht. um auf die Parallelität der Motive 2 wischen Andersens Märchen und Gogol's Novelle "Nevskij Prospekt" hinzuweisen, was den Märchenerzähler stört und entblöBt. Plötzlich wechseln die Stimmen ermeut. und der Kinoarbeiter S̉klovskij spricht aus dem Märchen. das dadurch auf einmal ganz prosaisch und alltäglich klingt. Der Kinoarbeiter beginnt zu lamentieren und beruft sich dabei auf den Formalisten. Da sieht die Stimme des Schriftstellers die Chance, um aus dieser Klage für sich einen Vorteil zu ziehen und einen literarischen Stil daraus zu machen. Der Schriftsteller wiederholt mechanisch das Bekenntnis des deplacierten Menschen zur marxistisch-leninistischen Ideologie. läBt dann die Maske fallen und sucht sich einen unerwarteten Fluchtweg, indem er sich für die Chaplinsche AbschluBpose die Stimme des anrilchigen Rozanov leiht. Nach diesem Muster sind viele Passagen der "Dritten Fabrik" gebaut.

\section{"Brief an Boris Ejchenbaum}

Ich werde über den "skaz"91 schreiben. Du bestimmst den "skaz" als Einstellung auf das mündliche Wort in der Erzählung.

Auch wenn das stimmt - kann man den "skaz" etwa auberhalb des Sujets betrachten? Conan Doyles "Brigadier Gerard" hat zwei Ebenen: 1) die Erzählung über eine Heldentat. 2) die Parodie auf diese über den "skaz" motivierten Erzählungen. Sämtliche Heldentaten erweisen sich als Fehler. Den Erzähler braucht man für die Ironie. Dasselbe sehen wir in Leskovs "Floh". Die Geschichte ist abgehakt, der mit Hufen beschlagene Floh tanzt nicht mehr. Der "skaz" ermöglicht eine zweite, ironische Lesart des scheinbar patriotischen Werks. Aut diese Weise stellt er (häufig wenigstens) ein Sujetverfahren dar und kann nicht auBerhalb des Sujets betrachtet werden. Ebenso begrindet der "skaz" (häufig) das System der Bilder. Der "skar" bearbeitet das Sujet. indem er aus der primären Ebene eines der Sujetmomente herausarbeitet: es geht nicht um den "skaz". Nicht um die Grenzziehungen der Definitionen. Nicht die Metrik macht's. nicht der Reim, auch das Bild nicht. sondern der ProzeB. Ich dricke mich unklar aus. Aber all unsere Arbeit zielt auf die Zusammenbindung der Kunstgriffe. darauf, daB es nicht bloB Materie und Energie gibt, oder zumindest. anders gesagt. daB es ein Wärmeäquivalent für die Einheit der Arbeit gibt. Vinogradov versteht das nicht. 


\section{Eine Notiz zur Erläuterung}

Warum es diesen Brief hierher verschlagen hat.

In Dänemark gibt es die Stadt Kopenhagen. Dort lebte Andersen. Das Land ist so klein. daB man bei der Eisenbahn wahrscheinlich nur Billetts zum halben Preis ausgibt.

Einst wechselte man dort die Waltranlatermen gegen Gaslaternen aus. "Weg, um Gottes willen, weg von der Laterne!". schrieb Gogol" in seiner klassischen Erzählung "Nevskij Prospekt" ... - "und geht schnell. so schnell ihr könnt. an ihr vorbei. Ihr könnt noch von Gluick reden. wenn ihr damit davonkommt. dab sie euch den stutzerhaften Rock mit ihrem übelriechenden Ol betraufelt."

Doch andererseits zeigte die Laterne, wie man sieht. romantische Züge. Besonders als man sie gegen eine Gaslaterne auswechselte. Der ausrangierten Laterne machten die Sterne ein Geschenk. Wenn man in ihr ein Wachslicht anzïndete. dann verwandelte sie sich in eine Zauberlaterne (in eine Art Kinematograph).

Und der Regen machte ein anderes Geschenk ... "Wenn du alles satt hast". sagte er. "dann wuinsche es dir und du zerfällst $2 u$ Staub."

Die Laterne erhielt ein Nachtwächter - ein Held dor Arbeit in Rente. Die Laterne liebte den Nachtwächter und winschte sich. sein Kinematograph zu sein. Der Wächter liebte die Laterne und goB manchmal Waltran in sie hinein. Aber wozu in einer Strabenlaterne eine Kerze anzinden?

Die Laterne ging von Redaktion zu Redaktion ...

Sie sprach: "Nein. ich bin kein Kinematograph, ich bin ein Projektor." Ich vermag es nicht. ein Zimmer zu erleuchten. ich bin Forscher ...

Ich habe meinen Witz satt. Der Witz ist die Annaherung des Unähnlichen. Ich bin ein Ertinder in der Kunst ...

Ich habe keinen Ort. wo ich leuchten könnte. Und so zünde ich mir mitten im Buch ein Licht an.

Was ibrigens die Lebensweise betrifft. so bestimmt sie tatsächlich das Bewubtsein.

Aber in der Kunst leistet sie ihm oftmals Widerstand. Mein Kopf ist mit dem täglichen Einerlei beschätigt. Das Beste im Leben ist der morgendliche Tee.

BloB so geht es nicht: die einen vergieBen Blut und Samen in der Kunst. Die anderen urinieren.

Je nachdem." [101-103]

Im Kapitel "Goldenes Grenzland" des Buches "Suche nach dem Optimismus" bezeichnet der autobiographische Erzähler Ejzenštejn als Mitbegrïnder des barocken, elliptisch-fragmentarischen Stils.

"Die Menschen unserer Zeit. das sind die Menschen des interessanten Details. Menschen des Barock.

Sergej Michailovič Ejzenštejn. Autor ausgezeichneter Filmsequenzen. durchschaute das zusammen mit mir und mashte eine Theorie daraus. Die Theorie der Attraktionen."92

Was die Konzeption der Montage der Attraktionen anbelangt. sind sich Šklovskij und Ejzenštejn einig: beiden geht es um die Emeuerung kanonisierter 
Kunstformen durch die Übernahme konstruktiver Elemente aus auBerhalb der Kunst liegenden Bereichen. Ejzenštejn übernimmt Tricks aus dem Zirkus, der Estrade. der Music Hall. ${ }^{93}$ Šklovskij bezieht alltägliches und intimes, publizistisches, wissenschaftliches und abwegig erscheinendes literarisches Material in seine Prosa ein. Bei beiden spielt in diesem Zusammenhang das Komische eine zentrale Rolle. In der parodistischen Bearbeitung alter, uberlebter Werke setzen sie die Evolution der Künste bewubt in Szene. ${ }^{94}$ Dabei machen sie die Konstruktion durch das Verkettungsprinzıp der Montage von einzelnen Attraktionen sichtbar. ${ }^{95}$ In Ejzenštejns Überlegungen zur Schock-Wirkung der Attraktionen bzw. der unvermittelten Übergänge zwischen ihnen findet sich das Pendant zu Šklovskijs Konzeption der Kunst als Verfremdung. ${ }^{96}$

Dennoch gibt es eine kulturpolitische Distanz zwischen dem Regisseur Ejzen štejn und S̆klorskij, die sich auch in den Kunstformen, in der Montage niederschlägt. Das politische Pathos Éjzenštejns, das sich im Laufe der Zeit von Film zu Film verfestigt und dementsprechend die Gestalt einer tendenziell erstarten Bildlichkeit annimmt, ist Šklovskij fremd. Er erkennt seine unfreiwillige Komik und kritisiert es. ${ }^{97}$ Bei der Betrachtung der Filme Ejzenštejns im Vergleich mit jenen Filmen. zu denen Šklovskij das Drehbuch verfaßt oder bei deren Produktion er assistiert und beraten hat, vor allen Dingen aber bei der Lektiure der Schriften beider Kinoarbeiter, wird offensichtlich. dab man von einer Affinität zwischen ihnen nur bedingt sprechen kann. Šklovskij erkannte Ejzenštejn als einen genialen Experimentator, was Montageverfahren anbelangt. der - ähnlich wie er selbst - dem Konflikt. dem Zusammenprall einander unähnlicher Zeichen für die Konstruktion der Montage grundlegende Bedeutung beima8, der die dem Film analoge Montagestruktur der Bildzeichen in unserem altäglichen Denken, seine weitgehend auf automatischer Wahrnehmung beruhende Funktionsweise, erkannte und sie untersuchte, um in der konstruktiven Abweichung von ihr Effekte zu erzielen.

Auch wenn Šklovskij sich später in der Monographie nicht direkt von Ejzenštejns Montage-Konzept abgrenzt oder auf Differenzen in bestimmten Phasen hinweist, was zum Teil wohl als stillschweigende Vorwegnahme der sowjetischen Zensur zu verstehen ist. sich zum Teil aber auch der zeitlichen Distanz zum berichteten Geschehen verdankt, in der sich Probleme und Konflikte nivellieren. so fallen die Unterschiede zu Ejzenštejns Konzeption der intellektuellen Montage $(1929 / 30)^{98}$ und weit stärker zur "Montage 1938"99 doch deutlich ins Auge. Ejzenštejn geht mit dem Konflikt der Bildelemente. der aus dem Zusammenprall ihrer Verschiedenartigkeit resultiert, in der intellektuellen Montage so um: er löst ihn innerhalb einer Zeichensequenz zu einer neuartigen. Allgemeinheit erheischenden Aussage auf. undem er ein komplexes. in sich geschlossenes semantisches Geflecht zusammenstellt. das häufig auf mythische Urbilder zurückgeht - mit dem Plan, eine bestimmte ideologisch ausgerichtete intellektuelle Erkenntnis auf dem Wege sinnlicher Anschauung emotional nahezubringen, so wie die Hieroglyphe. wenn sie zu uns spricht.

Der Film "Die Generallinie" (Das Alte und das Neue) ${ }^{100}$ macht deutlich, wie 
Ejzenštejn in der Tradition des Arbeitskulturkonzepts Gastevs, des Proletkul'ts und des LEF die Montage als ein konstruktives Mittel der "rein ideologischen Bearbeitung des Menschen ${ }^{-101}$ einsetzt. Dem Film liegt die Idee zugrunde, die ersten Erfolge der Kollektivierung und der Industrialisierung der sowjetischen Landwirtschaft in den ersten Jahren der Stalinherrschaft zu zeigen. Ejzenštejn liegt offensichtlich mehr daran. die Landwirtschaftspolitik der Partei zu legitimieren, als den Konflikt 2 wischen Stadt und Land. 2 wischen Tradition und staatlich organisierter Kulturrevolution darzustellen. Dieser Konflikt wird zwar gezeigt, aber er dient vor allem dazu, den Effekt des Neuen um so stärker zur Geltung zu bringen. Das gluickselige Gesicht der Landarbeiterin Marfa Lapkina. der Heldin des Films, umgeben von dem aus zahllosen Disen milchspriuhenden Separator, und der kraftstrotzende Stier, der nach Sekunden der Stille plötzlich aus dem Stall heraussprengt und mit einem komisch wirkenden. aber wohl pathetisch gemeinten Blumenkranz um den Nacken in GroBaufnahme auf die Zuschauer, d.h. auf die Kamera zurast und gleichsam im Objektiv verschwindet. sind allzu deutliche metaphorische Signale - sowjetische Inkarnationen alter Fruchtbarkeitsmythen - dieser auf eine fixe. weltanschaulich fundierte Intention zielenden Filmmontagen.

Auch wenn Šklovskij die unfreiwillige Komik des Films, die meines Erachtens tatsächlich eine subversive Semantik konstituiert. erkennt und heraushebt. leider ohne sie näher zu erläutern, so schmäler sie die auf Agitation für die bestehende Macht ausgerichtete Aussage doch nicht. die "Die Generallinie" zu einem wenn auch kunstvollen Propagandakunstwerk macht. Schon vor diesem Film, in der theorerischen Aufarbeitung des "Oktober". deutet sich der Gedanke einer alle Konflikte in sich auflösenden Allgemeinheit an. die dem Zuschauer 2 war explosionsartig klar werden. selbst aber keine Explosion mehr auslösen soll.

"Als wir von dem intellektuellen Film sprachen. da dachten wir
vor allem an eine Bauform. die in der Lage sein sollte. das Denken
des Publikums $z u$ lenken (Hervorhebung durch den Verfasser. V.D.).
wobei sie hierbei eine konkrete Rolle für das emotionale Denken
spielen sollte."102

Ejzenštejns Hieroglyphenforschung muB man in diesem Sinne als eine Hilfskonstruktion verstehen, deren er sich bedient, um möglichst wirkungsvolle Bildkombinationen als Zeichenträger seiner ideologisch intellektuellen Intentionen zu finden.

In der "Montage 1938" nimmt Ejzenštejn den Gedanken der Attraktion des unerwarteten Zusammenpralls kontrastiver Zeichenelemente noch stärker zurick und betont statt dessen den Gedanken der Einheit. der alles umschliessenden Allgemeinheit und des Zusammenhangs. Sein Bestreben, angesichts der permanenten Repression des staatlich verordneten Sozialistischen Realismus, das Verfahren der Montage zu rehabilitieren, zwingt ihn einerseits dazu. der Montage der Attraktion vollends eine Absage zu erteilen und 
veranlaBt ihn andererseits, die systematische Ableitung fuir eine kunstvolle. der Tendenz nach klassisch-realistische Filmtheorie mit ideologischer Ausrichtung zu verfassen. ${ }^{103}$ In seiner Ejzenštejn-Monographie stellt Šklovskij das späte Montagekonzept des Regisseurs, das seiner Meinung nach auch schon den "Panzerkreuzer Potemkin" prägte, als das Verfahren des "ibbergangslosen Spiels” dar, ohne sein eigenes Konzept explizit dagegen abzusetzen.

"Das übergangslose Spiel ist ein Spiel des Regisseurs, ein Spiel mit der Montage, mit der Schneideschere. es ist architektonische Filmkunst. sehr typisch für den Architekten Ejzenštejn. Es sind Fresken. an denen der Mensch voribbergeht: die Fresken selbst existieren auBerhalb der Zeit. Die Zeit wird als Passage oder als Montage wiedergegeben; diese Passage führt verschiedene Menschen oder verschiedene, gleichsam ohne Vorbereitung gegebene Situationen des einzelnen Menschen zusammen." ${ }^{104}$

Während - um mit Šklovskij zu sprechen - Ejzenštejns Filme wie die griechischen Tragödien ${ }^{105}$ "mit einer Lösung und oft von einem einzigen Punkt aus gefilmt" sind, ${ }^{106}$ setzen sich Šklovskijs Schriften aus Montageketten zusammen. denen weder ein systematisch-intellektuelles noch ein positiv-weltanschauliches Konzept zugrundeliegt. das sie abrunden und sie schlieBen wïrde. Im Gegenteil - sie leben von einem MiBtrauen gegenüber jeglicher Geschlossenheit. sei es des Denkens, sei es der Anschauung. Ein Glied treibt das andere durch EntblöBung. Verschiebung. Abschweifung, durch Irritation und Negation voran und gewinnt auf diese Weise Dynamik. ohne allerdings ein leeres Formenspiel zu bleiben. Denn hinter diesem Spiel verbirgt sich das Konzept der Verfremdung. mit dem Ziel, ein BewuBtsein für die Methode und ein Gefühl für die Worte und für die Welt zu wecken.

Auch wenn Šklovskij kein Buch über Kulešov, sondern über Ejzenštejn schrieb, auch wenn der sowjetische Filmkritiker Levin in seiner Abhandlung ibber Šklovskij als Kinotheoretiker Kulešovs Einfluß auf jenen nicht für erwähnenswert hält. sondern nur auf Parallelen im Denken Ejzenštejns und Šklovskijs hinweist. so ist es doch unabdingbar festzuhalten. daß Šklorskij mehr als von Ejzenštejn von Kulešov lernte, der schon friiher als jener mit den Möglichkeiten der Montagetechnik im Film experimentierte und wohl als erster und ehe er diesen Gedanken in seiner Filmtheorie ausführte. ${ }^{107}$ die grundlegende Erkenntnis flir das exzentrische Kino nutzbar machte, daB die Montage zweier Bilder nicht ihre Summe, sondern eine neue Aussagequalität produziert (sog. Kulešov-Effekt). ${ }^{108}$ Im Unterschied 24 Ejzenštejn, der in den 20er Jahren heftig gegen Kulešov polemisierte, indem er ihn eines konzeptionslosen Umgangs mit der Montage bezichtigte. ${ }^{109}$ versucht Kulešov die Mikrostruktur der menschlichen Existenz bzw. ihrer subtilen Äußerungsformen in eine exzentrische Filmsprache zu übertragen. ${ }^{110}$ Seine Montageketten sind anders als Ejzenštejns geschlossene Metaphern, die sich als ewig gültige Schriftzeichen in die Filmsprache eingegraben haben (die Odessaer Treppe. 
die Löwen im "Panzerkreuzer Potemkin"), - auf Assoziationen bauende Bildimpulse, die in einem anderen Kontext ihre Funktion und Bedeutung wieder verändern. Sie sind keine Träger pathetisch politischer Intentionen, sondern Zeichen, die nach Äquivalenzen menschlichen Verhaltens in ganz verschiedenen Situationen ungeachtet einer moralischen oder ideologischen Bewertung suchen und die mit Substraten emotionalen Empfindens arbeiten. ${ }^{111}$

Für seine Montagekonzeption sind beispielsweise solche Entdeckungen von Bedeutung, daB der Gesichtsausdruck eines Menschen, der vor seiner Suppe sitzt, dieselbe Reaktion zeigt, wie wenn er Schmerzen hätte, und daB sein Gesichtsausdruck angesichts der Suppe sich ebenso stark verändert, wenn er plötzlich die Sonne erblickt, wie wenn er die Freiheit sähe. ${ }^{112}$ Mit ăhnlichen Phänomenen äquivalenten Verhaltens des Menschen experimentiert auch Šklovskij in der "Dritten Fabrik". Der Kinoarbeiter kennt keinen Respekt vor hierarchischem Denken: er montiert kanonisierte Literatur (Tolstoj, Gogol', Poel neben Alltagsrede und publizistischen Text neben die Theoriediskussion. und er zitiert nichtkanonisierte Literatur (Rozanov) und Kinderbuchliteratur (Andersen, Kipling) in der "Gelehrtenprosa". Er stellt Unfreiheiten verschiedenster Art nebeneinander, ohne einen Unterschied $z \mathbf{z}$ machen: die Unfreiheit gegenuber dem Verleger gleichermaBen wie die gegenuiber der Frau, die Unfreiheit gegeniber der Kulturpolitik gleichermaßen wie die gegenuber der Kunst. Er behauptet, daB der Morgentee die Lebensfreude des Helden genauso stärke wie die literarische Arbeit und läBt die Erzählung Uber existentielle Probleme eines sowjetischen avantgardistischen Intellektuellen mit der Stimme eines roten Spielzeugelefanten beginnen: der eine klingt genauso mechanisch und heiser wie der andere. Er sucht nach einem Aquivalent von Kunstgriffen. die sowohl Tragisches als auch Komisches zum Ausdruck bringen. ${ }^{113}$ und findet es in der Redemontage der Selbststilisierungen der Mliterarischen Persönlichkeit". die den deplacierten Menschen als komischen Charakter darstellt. um mit dieser Pose die "Versteifungen" der Gesellschaft (Bergson) zu entlarven und auf diese Weise der Rede des Experimentators Gehör zu verschaffen.

In seinem Buch "Die Kunst des Kinos" berichtet Kulešov von der Funktion der Montage in einem seiner Filme, ${ }^{114}$ an den auch Šklovskij sich in einem anderen Zusammenhang erinnert, von dem er erzăhlt, um Kulešovs Filmarbeit zu erläutern. ${ }^{115}$ In diesem Film geht es um die Suche eines Mannes nach einer Frau, die niemals ganz, sondern nur in ihren Teilen oder in der Form ihrer Accessoires (Puderdose, Schuhe etc.) zu sehen ist. Dieser Montagetrick ist nicht bloB spielerisches Beiwerk der Filmtechnik, sondern fungiert als Konstruktionsprinzip, das die Handlung vorantreibt. Die Frau - zerlegt in ihre Teile - wird zum Rätsel, das die Zuschauer zusammen mit dem Mann lösen müssen. Die Montagekonstruktion suggeriert, daB die Einzelteile nicht die Abwesenheit der Frau, sondern ihre - wenn auch splitterhafte - Präsenz bedeuten. Sie konzentriert die Aufmerksamkeit auf die Suche nach der Frau. Ähnlich wie jedes einzelne Ding - der Schuh, die Puderdose, die Handtasche 
etc. - im Fulm ein Teil der Frau ist, die der Mann sucht, so sind die einzelnen Stimmen und ihre Masken in der "Dritten Fabrik" ein Teil des Helden der autobiographischen Prosa Šklovskijs. Die Montage erweist sich in beiden Fälen als eine Möglichkeit, das Subjekt in seiner Zersplitterung darzustellen. Ohne ibber seine Disparatheit, uiber die vielfältige Bedingtheit der existierenden Perspektiven des Subjekts auf die Welt bzw. der Welt auf das Subjekt hinwegzutäuschen, konstruiert sie einen Zusammenhang des Nichtzusammenhangs. 
1 In elnem Brief an den Redakteur des Noryj mir. W.P.Polonally. rom 8.4.1929, in dem Babel um de Verlingerung aelnes Arbeltevertragea bel der Zeltung blteet, ale deren Autor er elne zelteleng etn becheldenes Einkommen bezog, beschrelbt er selne mleerable Arbelta- und Elnkommenaaltuation. In diesem Zusummenheng erwihnt Babel einge Zellen tefer. dab man thn eufgefordert habe, eln Szenarium zu echreiben. "Ich denke mit Entectzen daran. dab lch gezwungen eetn werde, auf den Vorschleg einer Organleation ... elnzugehen und eln Drehbuch zusammenzuachuetern. Mir graut devor, lch kann Ihnen gar nlcht eagen. wie sehr mir graut. Ea widre elundhaft. Wo man sich auf Hobheres elngestellt hat. Zelt und Kraft euf unnölges Gewlach zu vergeuden. debel wirde ea. zumal lch nicht pfuschen kans. unwahrecheinlich viel Kraft und Zelt beanepruchen. kostbarate Monete." U.Babel. Prose. (Hrag.) F. Mlerau. Berlin 1983. S.560). Der Herauegeber der eusgewthlien Prose J.Babel's. F.Mlerau, nimme in elinem Nachwort de AuBerung des Schrffetellers uber elch elbet - er sel eln "Martyrer der relnen Kunat" - euf. um den senatblen Odesaeer Kunatler zu beschrelben. Dle Arbelt am Kino ael - ao Mlerau - nur "Brotarbelt" geweeen. der Babel" "durch raffinderte Fluchten in unauffindbare Moskauer Wohnungen oder Provinz neater auBerhalb entgegenzuleben" verauchte. (F.Mlerau. Im Zelchen Babela. In: J.Babel. Prose. S.602)

O.Mendelitem. Je plixu acenarj, ebd.

3 rgl. Valinanor. Brtete en M.Gorkll aus dem Jahre 1925. Sobr.eod.. M. 1973-78, tom 8 (1978). S.S4s ff.

4. Vklorakll. Z111 byll. S.13/S.183

5 ebd./ebd.. S.184

6 K.Elmermacher, Die sowjetleche Literaturpolitik zwischen 1917 und 1932: In: Dokumente zur aowjetlachen Llteraturpolitik. (Hrag.) K.Elmermecher. Stutegart 1972. S.46/47: vgl. Dokument 77. Uber die Pollelk der Partel im Berelch der achönen Literatur. Resolution des ZK der RKP(b) rom 18. Jund 1925, ebd.. S.308 f.

7 Vgl. Dokument 90. J.Lexilan. Die Beachluses des XV. Parteltage und dle zeltgendselsche Literatur. ebd.. S.354 f.

8 J. Leyde. Klno. A Hietory of Russian and Sorlet Film.London 1960. S.245: rgl. Nachrtchten von der Verammiung der Kinourbelter des sowjetiachen Kinoa im Jan. 1928 zu dlesem Problem. In: Kino (M) \& (1928). S.4

9 J.Leyde. ebd.

10 ebd.. S.246

11 bod.

12 Vgl. V.Skloveklf. Gamburgaklf .... S.18: hler trite Sklovaklf in dle offenalve Verteldigung aeiner Arbele an sowfetischen Kino: Man mbchte mikh devon Uberzeugen. dap Ich in der Kinemacographle ruckwirte gehe. Man etelle sich des so vor: Wenn ldeologlach undiszlplinlerte Filme gedreht werden. dann helbe es. dab eln Ideologlach undiaziplinierter Mensch schuld daran sel. ... Unterdeseen achrelbe lch nicht nur Aufautze, sondern auch Szenaten: melne Szenarien lleat man in den Arbelterclube u.e.w. Offeneichelich hebe lch elinen Kopf mit der Vorderaelte an der richelgen Stelle."

13 rel. den Titel PodenjZlna" (Lohnurbelt in Tagewerk) jenee Buches. in dem Sklorakll Uber eclne Kinoarbalt echrelbe.

14 E. Jub. Krupnym plenom. S.73 (t Erläuterung). Samtliche mlr rerfugberen Zougntese. dif llbar die Organlantion der etantlichen Klnos. Inabesondere Uber die Lage der Szenarieten Auskunft geben, beheupten den Gegentell. Vgl. Kino (M) 40 (1927). S 2: “Gotortes' k perteorexzanifu'; Kino (M:) 45 (1928).S.3: "Plaetel" o kino"; hler bechwert elch u.a. Veevolod Iranov 
daruber, dab er kelnerlel Elnflub darauf nehmen konnte. wle selne Novalle -Ghaby" fllmiach umgesetxt wurde; alcherlich muB man berllckalchelgen. dab nur werige von den Schriftatellern, de Szenaten echrieben, abch technlech und politiach mit den Anforderungen an die spezifieche Arbelt des Drehbuchnutors vertraut gemecht hatten, so whe dae bel Sklovakif der Fall war. Diejenigen Drahbuchautoren. de in den Zeltungen Immer wleder genennt werden, ind nicht Majakovaklj. Babel'. Ivanov u.a., sondem Zarchl, Grobner. Nikulln, Leonldov. Tretjakov. Sklovaklj u.a. Inaofom haben de Beachwerden der Schriftateller uber thro Schwerlgkelten da Drehbuchnutoren im allgemeinen in mancher Hinalcht elnen anderen Hintergrund ale dle der Szenartaten, de alch uber zu geringen Elnflus euf die Fllmproduktlon beklagen. Trotzdem blelbe de StoBrichtung dieser Beschwerden die glelche: belden Gruppen ging es um atärkere Mitbeatimmung und Kooperation bel der fllmiachen Umeetzung threr Szenarten.

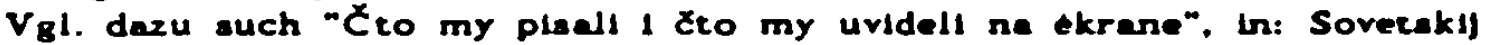
ukran 8 (1928), S.6-7

Abgesehen devon sollte man bedenken. daB Sub ale Beleplel kollektiver Zusammenarbelt zwiechen Szenaristen und Filmemechern ausdrucklich dle Mezrabpomfll'm nennt. de im Verhaltnle zum Goa- bzw. Sovklno schon allets durch thre Geachichte elne besondere Position innehatte. Die Metrabpomfil'm war eus der zu Tellen privaten Fllmgesellschaft Rue' der NEP-Zelt hervorgegangen, de sich 1924, als das Ende Jener Wirtachaftapertode in Sicht wer. unter den Schutz der Internationalen Arbelterhllfe begeben und den Namen Mežrabpom-Rus' angenommen hatte. Ende der 20er Jahre wurde der en reakitionire Verhultenisse erinnernde Ancell deses Namene getllgt und "Rug"w durch "fll'm" ersetze. Elnige sus der Truppe Kulesova. zeltwelse auch Kuleior selbat. fanden hler gunatge Arbeltsbedingungen: Pudorkin. Barnet. Komarov und Fogel'. (M. Kulnikov, Zizn' I fil'my Boriae Barnete. M. 1977, S.34-37; Vgl, euch Sklovakil. Plevatel'nyl puzyr. In: Soretsk1f ukran 39 (1928), S.6)

Auch Sklovakll arbeltete fur die Mekrabpom-Rua/-fil'm als Szenartat: 1927 achrteb er dea Drehbuch zu"Dom na Trubnol". 1928 zuasmmen mit Grebner und Leonidov dea Drehbuch zu "Ledjanof dom". 1932 zuammen mit Muntblit und Kulesor des Drehbuch zu "Gorizont" und im selben Jahr zusammen mit Fedorov das Drehbuch zu"Mertryl dom". Alle dese Fllme wurden in der Meźrabpom-Fllmgesellachaft produzlert. Aus der Rus: Ubernommene Umgangaformen und Mitarbelter und das Protektorat der von Deutachiand as geleiteten Internationalen Arbelterhilfe haten zur Folge. das die Fllmemacher in der Filmgesellachaft elnen groberen Fretraum fur die Gestaltung der Fllmproduktion zur Verfugung haten (vgl. auch Kulnikov. S.36 f.).Sie konnten unangefochtener im Kollektiv arbeiten als thre Kollegen In den Sorkinofabriken - elne Tatsache. de Sklovakly mit Neld sah. die er eber euch rugte, de dlese Arbeltaform - so Sklovakll - als verelnzelte Privetinltlative elner Gruppe begebter. Junger Reglsseure sich nicht auch auf dle obere Etage der literariachen Abtellung und der Buchhaltung der Fumgesellachaft eratreckte. sondern alch nur euf dle Produktionabbellung und einge von thr bevorzugte Szenarteten d. Belaplel wird Zarchl genannt - bezog. Da Skloavkif bekanntlich alch selbst auch nicht anders Elnlas in die Produktion. in die Montageriume verschaffe. Fichtet alch seine harsche Kritlk an den Meżrabom-Reglaseuren Bernet. Pudovkin etc.. denen er Prinxlplenlosigkelt vorwirft, letztlich gegen thn selbat. (vgl. V.Śklovaki). Plavatel'ny) puzyr', ebd.; vel. ders.. Ich nastojextee, M.-L. 1927. S.36 f.

15 V. Sklovsklj, Beregites' muzyki (1929), In: Podenzxina. S.134; deutach: Schrlften zum Film. S.110

16 vgl. ders., Kinofabrike, In: dera.: Mocalka, M.-L. 1927, S.22, S.58; deutach In: ders.. 'Schriften zum Fllm'. S.29/30

17 ders.. Llbretto 1 material. Klno (M) 39 (1926), S.3: dera.. Po povodu konkurae libretto. In: Sovetek1] ekran 21 (1927). S.10; ders.. Kak pleat ecenarij, M.-L. 1921: vel. ders.. Motalke 
18 CGNLI. Fond Šklovak1f. Nr.562. ople' Nr.1: ed.chr. 277. evtograf 'Funtlk'. ecenart) 1925, in 6 Tellen; vgl. auch die Nechrtcht in Kino (M) 20 (1926): Sklovaklj habe dae Szenerium zu elnem Fllm Don Quljote' geschrieben. zu dem Room und sein Aseletent Jutkevle die Dreharbelten begonnen hilten. Sortel ich weiB, lat auch dieser Fllm nlemale reallelert worden.

19 A.Chochlore L.Kulexor. 5.97 ff.

20 Vel. 1.Graxenkova. Abram Room. M. 1977. S.20 ff.; der Herauageber der Kinozeltachrift Sovetsklj ekran und Kritlker A. Kura beachrolbt die Difforenz 2 wlachen dlesen belden Fllmen noch auf elner anderen Ebene: "Ejzenrejejn aplelt mit den Menachen wle mit Objekten. Bel Room aplelen die Menachen mittele Dingen." (in: Sovetaklf ekran 8 (1926). S.2). Skloraki) trite hler zwar nur ala Autor der Unter und Zwischentitel in Eracheinung. aber I.Graxkenkova welat nach. daB Room und Sklovakll bel dleaem und mehr noch bel den folgenden gemelnaam produzlerten Fllmen intenaiv zusammenarbelteten.

21 Neben Room und Skloavklf arbelteten L. Brik (Drehbuch) und V1.Majakovaki) (Zwiechen- und Untertitel) an diesem FUm mit. der in Aufirag der judiechen Umalediungagesellachaft OZET (objzertro zemleustrofatra evreer-erudjaxichajal sedreht wurde. Vgl. V.Skloveklj. S tokkl zrenfja vetra. In: Sovetakif ekran 3 (1926). S.6/7; vgl. dera.. Tretje Mejkanekeja. In: dere.. Za sorok let. S.104 f.; vgl.V.Fevraligklf in: VI. Majakovaklf. Poln. sobr. sox.. t.11 (1936). S.292; vgl. J.Leyda. S.226

22 Der Fllm "Predatel" serlet schnell in den Verdache. In Ideologiach verwerflicher. kommerzleller Film zu eeln. vgl. S. Tretjakor. Linije namen lego soprotiviendja. In: Kino (M.) 40 (1926). S.3; Tretjekor war Drehbuchautor dieses Fume vor Sklovakif. geb dlese Arbelt aber wutend wheder ab. Vgl. Kritlk V.Pencora an deaem Fllm in: Kino (M.) 40 (1926). S.2: positir beapricht S. Gecht den Fllm In: Klno (M.) 29 (1926). S.2: er erwahnt lobend de Arbelt Sklovakifa ala Drehbucheutor: er habe den Fllm von achablonenhaften und unmotivierten Blldeequenzen befrelt und thm elne klare Sprache gegeben. Sklovaklj aelbat kommentert aelne Arbele an dem Fllm tronlach: "Ich wache meine Hinde in Unechuld ... aoger de hohe Technlk elnes Szenariaten kann elne schon auf de Letnwand eebannte Frau nicht bekleiden." (Soretakij •kran $\$ 2$ (1926),S.S)

23 Der Fllm "Klelnburgeratrabe Nr.3". auch "Llebe zu drite" oder auch "Bete und Sofe" genanne. lat etne Traglkomodle uber die Bazlehung zwinchen Mann und Frau. Uber elne neue Moral in der Sowjetunion der 20 er Jahre. in der gezelgt wird. wie elne Frau. zwiechen Minnern hin- und hergeriesen. zu neuem Selbatbembiesin gelange und lernt, threr elgenen Wege zu gehen. Beaprechungen in: Klno (M) \& (1927).S.3: 5 (1927). S.3: 7 (1927). S.2: 12 (1927) (Diakuasion): 13. 14. 15 (1927) etc.. Der Fllm "Schiaglbcher" nimmt atch eines im Sowjetallieg ebenso dringlichen. aber mordluch nicht so brisanten Themae an: des Problema elner jungen Arbeltertn. die die Doppelbeletung. Muteer und zugleich Arbeltertn zu seln. nicht auahile. woll thr Mann ale darln nicht unteratutze. aondern im Gegentell - aeiner elgenen Wege geht. A.Room/V.Sklovakil. Uchaby In: Iz letorll kino. Dokumenty 1 materialy. rypuak 9. M. 1974. S.96-122

24 1. Graxtenkova. ebd.. In threm Buch uber den Regleseur A. Room gibe ele der Endhlung uber Šklovaklj bzw. Uber dle produkelve Zusemmennrbelt zwlachen Room und Sklovakif sehr viel Rnum. Ste epriche mehr von dem Team Room/Skloraklj ale von Room alleln.

25 Fllmogrephle Sklovaklf. In: dera.. Za eorok let. S.446 ff.: dera., Motelka. S.36 ff.; dera.. Kapltanakeje dozka. M. 1929

26 K. Stldkret. Kryl'ja Cholope. M. 1928²: Sklorakif. Motalka. S.24. S.37-39: deutech: dera.. Schriften zum Fllm. S.31

27 vgl. de Schwlemgkelten bzw. die Rolle Sklovakije bel der Produktion ron "Der Verriter": Anmerkung 22 in diesem Kepltel: val. auch V. Sklovaklf. Stzu u morfe. Zdu pogody. In: Klno (M) 7 (1926), S.2 
41

42 bod

43 ebd.

44 ders.. Klnoschauepleler auf dem Korrldor, In: Klno (M) 3 (1926),S.2; abgedrucke auch in: dere., Podenktina. S.113-116

45 ebd.

46 A.Chochloral L. Kuletor. 50 let $\vee$ klno. M. 197S. S.96

47 A.Room. Kino (M) 11 (1926). S.2

48 S. EjzenXitejn V.Sklorek1\}. Nekeandra Chochlora. M. 1926

49 V. Skloveklf. Caf a secharom, In: Kino (L), 2.Nov. 1926: wiederabgedrucke In: Kino (M). 11. Dez. 1926

50 rgl. A.Chochlora/L.Kulexor. S.96: val. U.Cregor/E.Patalan. Geschlchte des Fllme in 2 Bden., Reinbek b.Hamburg 1976. Bd.1. S.102: Vgl. V. Sklovak1). Tret'ja mextannkaja, In: Za sorok lot, S.10S f., deutach: dore., Drite Kleinburgeratrabe, in: Schnifien zum Fum. S.147 f.; rel. J.Leydn. S.121 ff.: vel. E. Sub. S.71

51 vel. V. Sklorakil. Trat'ja mexzanakaja. abd./S.147-148

52 rel. Poitlke Kino. (Hrag.) B.Ejchenbaum, L. 1927

s3 W.Bellenhoff. Nachwort zu: Poetlk des Fllme. Texte ruselecher Formalleten. (Hres.) W.Bellenhoff. Munchen 1974, S.143

54 M.Blejman. Popreka portreta, ins V.Sklovekif. Za worok let. S.14 f.

55 E.Levin. Viktor Sklovaklf - kinoteoratlk. Ini Iakusatro klno 7 (1970). S.10S

56 ebd., S.106

57 desees Buch lat mittlerwelle erachlenens V. Sklovaklf, Zn 60 lot. M. 1985

58 G.Malorekdj. letortja odnof teorl. in: Inkunatro kino 2 (1983), S.113-123

59 E.Lavin. ebd., S.107

60 ebd., S.108

61 ebd. S.109

62 ebd., S.109

63 abd.

64 ebd.. S.115

65 V. Sklorakl1, O teorll prozy. M.-L. (1925), S.12; zlt. nach, E.Lorin. S.116; deutech: Theorte der Prose. S.14

66 E.Levin. S.116

67 ebd., S.119 
71 V. Sklovak1). EjzenXtejn (1927) in: dera.. Za sorok let. S.74 ff.

V.Skkloveklf. Vertor (1927) und dera.. Eaftr Sub (1940), belde in: ders., Za sorok let. S.70 und S.208: alehe auch dera., Dokumental'nyf Tolatof. NL 10 (1928). S.34

73 V.Skloraklj, Eafir' Sub. S.209. deutsch: dera.. Schriften zum Fllm. S.94: -Der LEF ging so welt, die Kunat zu negleren. Er kontratierte Montage und Schöpfertum und entschled elch fur die Montage. Doch der Lurm bease seine Loglk, die man veratehen kann. Metall lat das nicht, aber manchmal Erz."

74 dere.. Ejzenlitejn (1927). S.75/S.70: "E. verhult elch kelneewege so. dab Ejzentitejn mit den Kunatmiteln des Kombechen arbaltet: eelne Sechen alnd ernatgemelne. Allerdinge lat bel thm dae Gertlet der neuen Theoreme - von der Funktion solcher Geruste lat in den mathematischen Abhandlungen von Polncart de Rede - auf das 'humoriatache Gerus' gegrundet." Mit dleser Elnschibzung - whnliche folgen in der Kritlk an deseen Fumen (x.B. kritlelert or im welteren den unmotivierten. Uberfluselgen Gag mit dem Lumpenproletariat in den Tonnen im Film "Strelk- (S.83/S.85-86)) erhebe esch der Kritlker Sklovakll Uber den Regleseur Ejzenltejn.

75 dera., Literatura 1 klnematograf. Beriln 1923: deutach (In AuszUgen) In: Formaliemus. Serukturaliemus und Geschlchee. S.22-41: des Kap. "Sujet im Kenematographen" dieser Abhendlung. des nicht in der oben genannten Ubersetzung enthelten 1st. flndet elch in der Ausgabe "Schriften zum Fllm". S.17-25: die Kap. "Caplin". "Budurznost" klno" und. "Zakljuzenle" blleben unuberactze.

76 ebd. (da mir die ruas. Ausgabe unzugänglich blleb, zitiere ich im folgenden aus der deutschen Ausgabe). S.36: vgl. euch ders., Semantike kino. ARKJournal 8 (1925). S.S

77 ders.. Luk bez ochotnlke. In: Podentzine. S.127-131: vgl. ders.. Ejzendtejn (1927). S.71: vgl. S. Ejzenlitejn. Beis verglBt de Schere. Eleenateln. Schriften 2. Hrag. V. H.-J. Schlegel, Munchen 1973. S.134-140: vel. auch L.Kuletor. Iakuastro klno. M. 1929. das erate Kapltel

78 V. Sklovaklf. Literatur und Kinematograph. S.36

79 vel. Ju.Lotman. Probleme der Klnobiathetlk - Elnfuhrung in de Semlotik dea Fums. U.: Chriaclane Bobler-Auran. Ffm. 1977

80 V. Sklovaklj. Literatur und KInematograph: "Das Sujet im Klnematograph". S.23

81 ebd.. S.23/24

82 dere.. In: Kak my plaem. S.211

83 vel. Il.Tell. Kap.3.2. S.160 ff.

84 V.Sklovaklf. O zakonach kino. Ini Rusaklf sorremennlk 1 (1924), S.249

85 ders.. Llteratur und Klnematograph. 5.27 f.

86 W. Benjamin. Des Kunatwerk im Zeltalter seiner tochniachen Reproduzlerberkelt. Gesammelte Schriften. Bd.1. 2. S.SOS

87 V. Sklovakij. Literatur und Klnematograph: "Das Sujet im Kinematograph". S.22

88 rel. W.Bonjamin. obd.. S.506 f. und S. 488: "Dae Publikum fuhlt atch in den Darateller nur ein. Indem es elch in den Apperat einfuhlt: Ea Uber nimme also deseen Haltung: es testet." vel. auch S.493 den Gedanken dar 
tendenziellen Aufibaung dea Unterechleds zwlechen Autor und Publkum in den meseenhafe reproduzlerbaren. entauretilerten Medlen: -Die lltararteche Befugnis wird nlcht mehr in den epezialielerten. eondern in der polytechnlechen Ausblldung begrundet, und so Gemelngut." $N$ a Vorblld echwebt Benjamen de Sowjetunlon. de Arbelter- und Bauernkorteapondentenbewegung ror (ebd.). "Dle technische Reproduzlerberkelt des Kunstwerka verifindert des Verhillente der Masse zur Kunst. Aus dem rucketändlgeten, zum Beisplel elnem Picasao gegenuber. achlugt es in den fortachritichate. zum Bateplel angealchte elnes Chaplin, um. Dabel let des fortachritiche Verhalten dadurch gekennzelchnet, das die Luet am Scheuen und am Erleben in thm eine unmitcelbare und innlge Verbindung mit der Heltung des fachmïnnischen Beurtellers elnhergeht. Solche Verbindung ist eln wichtiges gestlechaftliches Indizium." (S.496/497)

89 V.Sklovakil. Literatur und Kinematograph. S.36

90 ebd.

91 De das Wort skex (mundliche Erzdhlung) zu etnem llteraturwissenschaftlichen Temlnue wurde. mochte ich auf eine Ubersetzung verzichten. Skloveklf selbst mache in diesem Brief etnen Unterachled zwiachen skax (mundliche Erzuhlung). we Ejchenbaum thn verwendet, und "akez" (Verfahren der Sujetblldung). wle er es veratanden wiasen mbehte. und kennzelchnet thn durch Antuhrungezelchen. Ich achlleBe mich thm an.

92 V. Skloraklf. Polaki optimizma. S.115

93 S.Ejzenitejn. Die Montege der Ateraktonen, In: LEF 3 (1923). S.70-75; zltiert nach der deutschen Ubersetzung ron $K$. Hlelecher. In: $X a t h e t 1 k$ und Kommunlketion 13 (1973). S.77: vel. auch V.Sklovakif. Ejzenxtefn (1927). S.76

94 Ejzenteln verfahre so in der Oetrovakif-Inazenlerung. Sklovakif in selner Prose, d.h. In selner ironischen Rozanov-, Sterne-, Cervantes- etc. -Verarbettung.

95 vgl. S.EjzenItefn. Die Montage .... S.77: val. V.Sklovakif. Literature me 'ejuxete'. S.226 ff./S.163 ff.

96 vgl. S.Ejzentefn. Die Montage .... S.76 f.: vgl. V.Skloraklf. lakuagro kak prièm. S.13/S.14

97 V.Šklovakif. Ich natojartee. S.107: Er apricht ron Elzenjtefn zwar mit Bewunderung. aber gerade aus dlesen Beschrelbungen aprechen auch dle Differenzen zu Sklovaklf in elinem elgenen Schaffen. -Der Ingenieur Ejzenzicein lat eln Erfinder und eln Sieger. dazu echarfainnig. Weltblickend. tronlech und jemend. der welB, we man Pathos produzlert - elner der beaten Menschen der heutgen Zelt." rgl. dene.. EjzenItejn (1927). S.70/S.75

98 S.Ejzentefn. Zur Theorle des Fllms "Oktober". Schriften zum Film 3; (Titel ecamme rom Herauseber Schlegel. Ihm alnd elne Rethe von Aufadtzen Ejzentiejne aubsumbert. In denen dleser die Theorle der intellektuellen Montege entwickelt.). S.169-264

99 S. Ejzendtejn. Montege 1938. In: Sergel Elsenateln. Ausgewahlte Aufadtze. Berlin (DDR 1960. S.325

100 Der Film. der uraprunglich den Titel "Die Generallinle" hatee. sollte "die in der Sowjetunion im Dez. 1925 beschlosene Generallinie' fur die soziale Umgeteltung des Dorfea propagleren helfen. Nach elner Intervention der Kulturburokraten Staline wurde der Titel 1929 in 'Das Alte und das Neue' abgeändert." (aue der Vorbemerkung des Hrag. H.-J. Schlegel zu: S.M.Elsenetein. Schriften \& (1984)

101 K. Hlelecher. Futuremus und Kulturmontage. In: aiternative 122/123 (1978). S.235

102 S. Eleenateln. Schriften 3. S.234

103 Zur Verdeutlichung melner Interpretetion verwelse ich auf die Auselnander- 
ectzung Uber Ejzentitejns Montagebegrtff zwischen C.MacCabe. H.-J. Schlegel und K.-M.Bodgal in: alternntive 117 (1977), wobel lch mich im Urtall und in der Argumentation watigehend K.-M.Bodgel ansechllaben mobhte.

Sklovaklj erkennt deea Entwicklung bel Ejzenteajn. wirdigt ale in eelnem Aufsatz 'Konec Barokko' (1932) ds eine Evolution der Konzeption und etellt sle den fragmentariechen formen der sog. ormamentalen Prose gegenuber. die er her - wle auch zu anderen Gelegenhelten - kritielert. Solche Ausagen mbchte ich - ohne ale an dleser Stelle zu diskuteren den "devices of ostenable surrender" (Sheldon, in: Sheldon. Viktor Shkloveky and the Device of Oatenalble Surrender. Slavic Review 1 (197S). S.86-108) zuordnen. Denn Šklovakl] selbat hat bla zu selnem Lebenaende - mit Elnechrankungen in selner Klnoarbelt, wo er vor allem ale Zubringer und Ghoetwriter funglerte und wenlg produktiven Splelraum hate sowohl in selner Prose ale euch in seinen liceratur und flimtheoretiachen Schrtften an der fregmentarischen Schrelbwelee featgehalten, um die Unithallchkelt dee Xhnlichen sichtber zu machen.

104 V.Skloraklf. Ejzenjteln (1973/1977). S.145/S.204

105 ebd.. $5.144 / 5.203$

106 ebd. S.146/S.205-206

107 L. Kulezor, lakuaetro kino, erates Kapitel

108 V. Sklovakl). Ejzenxtejn (1973/77). S.145/S.204; dera.. Ich natolaxkee. S.36 f.: "Melne Schule al Szenariat war, auber der Fabrik. de Kulexor-Kollektiv."

109 ders.. Ejzendeejn (1973/77). S.138. 140. 145/S.196. 198. 204

110 V.Sklorakll. Ich neetolaxkee. Kep. Kulexor/Po zakonu. S.45 ff. Hler beachmibt \$klorakll die Arbalt an dem gemeineam mit dem Kulexor-Kollektiv produzierten Flim.

111 bbd.. S.105: "Es gelang Kulexor. glelchxeltig an der Erklanng fur einen Heuptbatandtell dea kinemetographechen Verfiahrene in der Seche der Befrelung. der Verringerung der Zelchen des kinematographlechen Alphabets zu erbelten und den Weg elner anderen Montage. elses enderen Umgenge mit den Detalls zu betreten.-

112 L. Kulezor. Iakusetro ktno. S.28

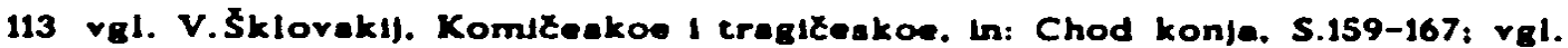
dera.. K teorll komlteakogo. In: Epopee 3 (1922). S.57-67

114 L. Kulezor. Iakuetro kino. S.28

115 V. Škloraklf. Ich neatojarzer. S.38 


\section{SchluBbemerkungen: Šklovakijs Llteraturfabrik}

\section{"Skklovskij: Und die Avantgarde?}

Born: Wer ist das? Was sich so nennt, produziert einen kurzatmigen Professorendadaismus, zuweilen unterhaitend, aber durchweg von einer hämischen Sprachbesserwisserei.

Cortázar: Und keiner denkt daruber nach, wie die Literatur in $z$ wanzig, vierzig, füntzig Jahren aussehen könnte?

Born: Doch, einer. Und der sagte neulich, es gehe darum, daB der. der schreibt. schreibend sich auslebt, statt das Leben zum Gegenstand von Literatur $\mathrm{zu}$ machen.

Cotazar: Seit wann schlieBt sich das aus?

Sklorskij: Ich sag's ja, die sind dekadent da im Westen, diese Angst vor der Annäherung an die Realitäten, der Verzicht auf jedes minimale Einmischen.

Born: Wirst du wieder nuichtern, Viktor?

Cortazar: Lab ihn, er hat recht: Freiwillig ins Reservat, das scheint die Devise der Literaten aller Richtungen zu sein.

Born: Man kann sich darauf berufen. Kunst sei immer Opposition und immer Negation des Bestehenden.

Cortazar: Ein bißchen eintach. finde ich. Die werden sich noch wundern. Wenn sie ihre Phantasie nicht schärfen und so feige bleiben. dann werden sie bald abgeschafft sein wie die Scheren.

Sklovskij: Ach. wiBt ihr, es hat auch sein Gutes. Solange die nichts Besseres produzieren, liest man wenigstens uns. ${ }^{-1}$

Šklovskijs Literaturfabrik weist einen Weg aus der Krise der Avantgarde: Der Schriftsteller möge die Dreckarbeit nicht scheuen, er solle nicht sich, sondern die Arbeit schonen, sich wieder und wieder mit den Dingen konfrontieren, sich permanent verändern und die Dinge erneut bearbeiten, bis endlich Literatur daraus werde. Das "Ende-der-Kunst"-Theorem stuirte Sklovskij weder in Verzweiflung noch in eine "Aufbau-des-Sozialismus"-Euphorie, sondern veranlabte ihn $z u$ der lapidaren Bemerkung, daB sich die Kunst verändert habe. Diese richtungsweisende Einschätzung scheint mir (ebenso wie Friedrich Christian Delius) nicht nur für die sowjetische Kunst von Bedeutung zu sein.

Die Arbeiten der Formalisten ïber die literarische Evolution und ihre Erkenntnis, daB sowohl der kulturelle Text als auch das Schriftstellersubjekt als Material und Konstruktion in die literarische Produktion eingehen und die Entwicklung der Literatur mitbedingen, haben nicht nur einen neuen wissenschaftlichen Zugang zu Fragen einer politischen Ästhetik eröffnet. sondem auch das Theorie-Praxis-Verhältnis im Bereich der Literatur in ein neues Licht getaucht: Theorie geht als Konstruktion und als Selbstreflexion der Kunst in die künstlerische Praxis ein. Sie erhält so die Chance, den Elfenbeinturm zu verlassen, von dem aus sie uiber die Literatur wacht und iber ihre ästhetische Qualität und Tugend urteilt. Die Aufhebung der dichotomischen Arbeitsteilung macht es ihr leichter, sich von Erfahrungen korrigieren zu lassen. 
Das Schriftstellersubjekt. Theoretiker und Praktiker in einer Person, gewinnt auf diese Weise an Handlungsspielraum, den es dazu benutzt, sich in kritischer Auseinandersetzung zu den Dingen der gesellschaftlichen Realität zu nähern - nicht, indem es sich absolut setzt und spontaneistisch von sich selbst redend agiert, sondern indem es, von seinen eigenen Erfahrungen ausgehend. den Blick neugierig wie ein Kind auf die Welt richtet und sie aus verschiedenen Perspektiven betrachtet. Ju. Tynjanov gab der Erkenntnis, dab das Schriftstellersubjekt ein literarisches Faktum, d.h. genauer der Schnittpunkt verschiedener semantischer Systeme sei - der der Kunst und der des Lebens -, den Namen "literarische Persönlichkeit" und machte sie an Viktor Sklovskij fest: er verkörpere einen neuen Typus von Schriftsteller.

Aber die sowjetische Kultur des beginnenden Stalinismus brachte diese Konzeption und mit ihr die "literarische Persönlichkeit" Šklovskij in Schwierigkeiten. Sie forderte eine Agitationskunst, die die politischen Ziele der kommunistischen Partei mit durchsetzen und ihre Errungenschaften illustrieren sollte. Eine solche Forderung lieb sich nicht mit einer Kunst vereinbaren, die ihre Eigengesetzlichkeit behauptet und auf dem Experiment behart. Šklovskij half sich aus diesem Dilemma, indem er die schwierige Existenz der "literarischen Persönlichkeit" eines Avantgardisten in der Sowjetunion der 20er Jahre literarisierte und - seiner Konzeption der Kunst als Vertremdung gemäl verrätselt darüber schrieb. wie man ein Schrifisteller in gesellschaftlicher Verantwortung sein könne. Sein fragmentarisch-essayistischer Stil erlaubte es ihm. mittels Auslassungen und durch die willkürliche Montage ganz heterogener Fakten eine verschieden verstehbare Rede zu konstruieren. um MiBliebiges oder gar Verbotenes zu Worte kommen zu lassen. Hierbei bediente er sich der literarischen Tradition: er zitierte kanonisierte Literatur, deren Provokationen den Leser nicht mehr erreichten. und benutzte ihre Rede, um Kritik an Gegenwärtigem zu äuBern. Er erinnerte an zu Unrecht in Vergessenheit geratene Literatur. um ihre Aktualität zu beweisen. Auf diese Weise setzte sich Šklovskij mit der Geschichte der Literatur auseinander, ohne in Ehrfurcht vor ihr zu erstarten, aber auch ohne sie einfach zu verwerfen. Er interpretierte sie neu, nahm sie als vorgefertigtes Material, das er in die eigene Rede einpaBte oder ihr entgegenhielt - in dem Wissen, daB sie ihre urspriingliche Funktion eingebüBt hatte, zumal die Oktoberrevolution von der Kunst gefordert hatte, ihren Standort in der Gesellschaft nicht bloB zu reflektieren. sondern auch aktiv und engagiert Position zu beziehen.

Der autobiographische Prosatext "Dritte Fabrik" ist in der Zeit einer (für Sklovskij) lebensgeschichtlichen und gesellschaftspolitischen Wende entstanden. Die Rekonstruktionsphase nach Revolution und Bürgerkrieg war abgeschlossen. Der Versuch. die sowjetische Wirtschaft durch Konzessionen an den privaten Kleinhandel $2 u$ stabilisieren. galt als gescheitert und wurde verworfen. Die staatlichen Planungskommissionen begannen - kontrolliert von der kommunistischen Partei - erste Rationalisierungs- und Kollektivierungsvorschläge zu unterbreiten. Noch stritten sich Bucharin. Trockij und Stalin Uber den "richtigen" Weg zum Sozialismus. Im Bereich der Literatur 
konnten die "proletarischen" Schriftsteller - unterstiutzt von der Partei ihren Hegemonieanspruch zunehmend offensiver geltend machen. Die "Dritte Fabrik" war die erste gröBere Arbeit, die Šklovskij in Moskau veröffentlichte. Das Buch markiert den Beginn eines neuen Lebensabschnitts nach mannigfaltigen abenteuerlichen Erfahrungen in der Revolution und im Exil. In "Dritte Fabrik" setzt sich die "literarische Persönlichkeit" intensiver als in "Sentimentale Reise" und in "Zoo ..." und offensiver als in den späteren autobiographischen Prosatexten mit der Situation des Avantgardekuinstlers auseinander. Der Erzähler der "Dritten Fabrik" streift sich das Kostüm einer in der Literatur seit alters her bekannten Heldenfigur iber: das des AuBenseiters, um die Rede des Experimentators und Erfinders in der Kunst 24 maskieren. Der Außenseiter - bei Šklovskij deplacierter oder ver-rlickter Mensch genannt spricht mit drei verschiedenen Stimmen: mit der des Schriftstellers, der des Literaturtheoretikers und der des Kinoarbeiters Šklovskij. Der Erzähler vermag auf diese Weise die vielfaltigen Wirklichkeitserfahrungen des Avantgardisten ins Blickfeld zu ruicken und $z u$ literarisieren. Daruber hinaus hat er sich damit einen zusätzlichen Kunstgriff der Verdichtung, d.h. der Verrätselung der Sprache geschaffen. Die Stimmen streiten sich, ergänzen oder bestätigen einander: sie spielen sich gegenseitig aus oder halten einander zuweilen auch den Rücken frei. Im Dialog vermischen sich die Stimmen derart. daB sie passagenweise unentwirtbar erscheinen und der Experimentator - geschützt hinter der Maske des deplacierten Menschen - um so auffäliger seine Sprachkunststücke vorführen kann.

"Dritte Fabrik" erzählt davon. wie sich das Schriftstellersubjekt den Gesetzen der Literaturfabrik unterwirft, um gegenüber dem Herrschaftsanspruch der gesellschaftlichen Wirklichkeit, dem es sich ausgesetzt sieht. Handlungsspielraum zu behalten. Das Theorem von der Eigengesetzlichkeit der Literatur gibe Šklovskij die Möglichkeit, sich des Arsenals ihrer Kunstgriffe als Schutzraum zu bedienen. um von der Feste der Literatur aus gegen Dogmen und Ideologeme anzureden und um nach Methoden zum Studium und zur Bekämpfung von Unfreiheiten jeglicher Art zu suchen. Der Erfahrung, dem gesellschaftlichen Alltag ohnmächtig ausgeliefert $2 u$ sein und von ihm, wie der Flachs in Andersens Märchen oder im sowjetischen Flachszentrum. geschlagen und gebrochen zu werden. setzt das Schriftstellersubjekt die bewubte literarische Bearbeitung in der Literaturfabrik entgegen. Es schaut auf sich selbst und betrachtet sich aus verschiedenen Perspektiven. Es betrachtet sich mit den Augen der Kritiker in der sowjetischen Öffentlichkeit ebenso wie mit den Augen der literarischen Vergangenheit und mit denen der fremden Kultur. Die Kritikerstimmen sprechen aus dem deplacierten Menschen, der sich mit dem "sozialen Auftrag" der Literatur konfrontiert sieht. Die Stimmen aus der literarischen Vergangenheit und aus der fremden Kultur liefern erprobte Muster. mit deren Hilfe die "literarische Persönlichkeit" das Problem der AuBenseiterexistenz experimentell bearbeiten kann. Sie stärken ihr Selbstbewubtsein und ermutigen sie, ein Anrecht auf einen Sonderstatus innerhalb der auf Egalität fixierten sowjetischen Kultur einzuklagen. Der Schriftsteller 
spricht zu dem Kinoarbeiter und beklagt seine Einsamkeit. Er lamentiert, es mangele ihm an Intuition und Einbildungskraft, um uber die sowjetische Wirklichkeit zu schreiben. Er leidet darunter, in seiner eigenen Kultur keine Anerkennung zu finden. Der Kinoarbeiter spricht zum Schriftsteller und klagt uber die Langeweile im Arbeitsalltag als Drehbuchautor und uber den bürokratischen Schlendrian in den sowjetischen Kinofabriken. Er ärgert sich darüber, daB er beim Film nicht seinen Fähigkeiten und Interessen gemäB arbeiten kann. Der Literaturtheoretiker erinnert den Kinoarbeiter und den Schriftsteller an die Zeit der experimentellen und kollektiven Arbeit in der Gesellschaft zur Erforschung der poetischen Sprache. Er ist voller Wehmut über den Verlust dieses Diskussionszusammenhangs, aber er setzt trotzdem alles daran, listig, im Verborgenen, diese Arbeit, so gut es eben geht. fortzusetzen.

Die Fähigkeit zur Auseinandersetzung mit sich selbst im Dialog der Stimmen ersetzt der "literarischen Persönlichkeit" die utopische Hoffnung, ein harmonisch in sich ruhendes Individuum werden 24 können. Šklovskij kann auf diese Utopie verzichten, ohne sich als handelndes Subjekt aufgeben zu muissen und ohne in einer determinierten Gesellschaftlichkeit zu verschwinden. Vielmehr schafft er sich im Spiel mit den Masken bzw. in dem verschieden verstehbaren Gespräch der Stimmen des Kinoarbeiters, des Literaturtheoretikers und des Schriftstellers die Möglichkeit. seine Identitätskrise als Künstler der Avantgarde literarisch zu bearbeiten.

Im Kampf der Literatur mit der Macht nimmt Šklovskij in seiner autobiographischen Prosa die Pose Chaplins und die tragikomische Gestalt eines Don Quijote an und fordert mit der Stimme eines Märchen- und Anekdotenerzählers die Literatur dazu auf, sich einzumischen und nicht davon abzulassen. wenn ihr das Leben lieb ist.

\section{Anmerkung zu den Schlubbemerkungen: Šloraklja Literaturfabrlk}

1 Literarische Tlechgespridche mit Corthar. Bom und Sklovaklf. aufgezelchnet von Frledrch Chriatian Dellue. In: Literaturmagezin 16. (Hreg.) M.Ludke. D. Schmidt, Reinbek b. Hambure 1986. S.17/18 


\section{Literaturverzelchnls}

1. Texte Šklovskijs (chronologisch geordnet)

a Veröf fentlichungen in Buchform

V.B.Šklovskij, Sobranie soł̌inenij v 3-ch tomach, M. 1973-1974

Svincovyj Żrebij, Petersburg 1914

Chod konja. Kniga statej, M., Berlin 1923

Sentimenta' noe putešestvie. Vospominanija 1917-1922. M.. Berlin 1923; Sentimentale Reise, U..: R.-E. Riedt unter Mitwirkung von G. Drohla, Ffm. 1964; 1974

Zoo. ili pis'ma ne o ljubvi ili Tret'ja Eloiza. Berlin 1923: Zoo oder Briefe nicht über die Liebe (U.: A. Kaempfe), Ffm. 1965; 1980: $1982^{2}$

O teoril prozy, M. 1925, $1929^{2}$, reprint: Zentralantiquariat der Deutschen Demokratischen Republik Leipzig 1977; Theorie der Prosa. Hrsg. u. U.: G.Drohla.Ffm. 1966, 1984²

(zus. mit Vse. Vjač. Ivanov) Iprit. M. 1925

(zus. mit S. Ejzenštejn) Aleksandra Chochlova. M. 1926

Tret'ja fabrika. M. 1926: reprint: Letchworth-Herts-England. 1978

Udači i poraženija M. Gor'kogo. Tiflis 1926

Putešestvie v stranu kino ("Zemlja | fabrika"), M.-L. 1926

Pjat' Zelovek znakomych. Tiflis 1927

Motalka. Knizka ne dlja kinematografov, M.-L. 1927

Ich nastojaščee, M.-L. 1927

Gamburgskij šet. L. 1928

Material I stil' v romane L'va Tolstogo 'Vojna i mir', M. 1928

Kapitanskaja dožka. Kommentamyj scenarij, M. 1929

Matvej Komarov, L. 1929

Podenక̌tina. L. 1930

Technika pisatel'skogo remesla. M.-L. 1930

Kak pisat' scenarij. Posobie dlja načinajuక̌čich scenaristov s obrazcami, scenariev raznogo tipa. M.-L. 1931 
Skazka o tenjach. M. 1931

Poiski optimizma, M. 1931

O Majakovskom (M. 1940), in: Žili byli, S.257-412; Erinnerungen an Majakovskij, U.: R. Reimar, Ffm. 1966

Lev Tolstoj, M. 1963, 1967²; Leo Tolstoi, U.: E. Panzig, Berlin (DDR) 1980, Wien 1981, Ffm. 1984

Żili-byli. Vospominanija. Memuarnye zapisi. Povesti o vremeni, M. 1964, $1966^{2}$; Kindheit und Jugend, U.: A. Kaempfe, Ffm. 1968

Za sorok let. Stat'i o kino, M. 1965; Schriften zum Film. Hrsg. u. U.: A. Kaempfe, Ffm. 1966

Povesti o proze, Razmyšlenija I razbory v 2-ch tomach, M. 1966

Tetiva. O neschodstve schodnogo. M. 1970; Von der Ungleichheit der Ähnlichkeit in der Kunst. Hrsg. u. U.: A. Kaempfe. München 1973

Ejzenštejn. M. 1973; Ü.: M. Dahlke. Hamburg 1977

Energija zabluždenija. Kniga o sjužete. M. 1981

O teorii prozy, M. 1983

Za 60 let. Raboty o Kino, M. 1985

b) Aufsätze und Manuskripte

V.B. Šklovskij: Voskrešenie slova (1914), in: TdF 2, S.3

Kollektivnoe trorčestro, in: Žizn' iskusstva (17. Sept.) 1919; U.: K. Maurer, in: Poetica 1 (1967), S.98

K teorii komičeskogo, in: Epopea (3. Dez.) 1922, S.57

Anna Achmatova Anno Domini MCXXI, in: Petersburg 2 (1922), S.18

Pis'mo k Romanu Jakobsonu, in: Knižnyj ugol 8 (1922), S.23

Literatur und Kinematograph (1923), in: Formalismus, Strukturalismus und Geschichte, S.22

O zakonach kino, in: Russkij sovremennik 1 (1924), S.245

Razdavlennaja strana (Germanija), in: Narodnyj učitel' 1 (1924), S.137 
Tarzan, in: Russkij sovremennik 3 (1924), S.253

Polet 1 posadka, in: Vsemirnaja illjustracija 7-8 (1925), S.23

Semantika kino, in: ARK-Journai 8 (1925), S.S

Caplin-policejskij. in: Carli Čaplin, Sbornik statej. (Hrsg.) V.Sklovskij, L. 1925, S.71

Funtik, scenarij, 1925. CGALl, f.562, opis' Nr.l, ed.chr. 277, avtograf

Tret'ja fabrika (Varianten), in: CGALI, f.S62, sb.statej, očerkov, rasskazov "Tret'ja fabrika" (Okolo 1926)

Kino-aktery $v$ koridore, in: Kino (M) 3 (1926), S.2

Sižu u morja, Żdu pogody, in: Kino (M) 7 (1926), S.2

Libretto i material, Kino (M) 39 (1926), S.3

Čaj s sacharom, in: Kino (M) (11. Dek.) 1926

S točki zrenija vetra. in: Sovetskij èkran 39 (1926), S.6

Ja umyraju ruki .... in: Sovetskij èkran 42 (1926), S.S

Po povodu konkursa libretto, in: Sovetskij èkran 21 (1927), S.10

Uchaby (1927), in: Iz istorii kino. Dokumenty i materialy, vypusk 9. M. 1974, S.96

60 dnej bez služby, in: NL 6 (1927), S.17

Dokumental'nyj Tolstoj, in: NL 10 (1928), S.34

Pod znakom razdelitel'nym (Protiv sozdanija "Živych klassikov"), in: NL 11 (1928), S.44

Plavatel'nyj puzyr', in: Sovetskij ekran 39 (1928), S.6

Togda 1 sejčas, in: Literatura fakta, S.122

O pisatele i proizvodstve, in: Literatura fakta, S.189

K technike vne-sjužetnoj prozy, in: Literatura fakta, S.222

Neskol'ko slov o 400 millionach, in: Literatura fakta, S.246

Est' ll krizis $v$ sovremennoj sovetskoj literature? in: Żizn' iskusstra 8 (1929), S.15

"V.Šklovskij", in Kak my pišem (1930)

1. "Strach", 2. "Mertvyj dom", 3. "Uchaby", 4. "Po zakonu", 5. "Troe", Literaturnye scenarii, 1 T. razd. pag. mašinopisi, ékz. (IMLI, M. o.J.) 
O ljudjach, kotorye idut po odnoj 1 toj Ze doroge 1 ob etom ne znajut - konec barokko, in: Literatumaja gazeta. (17.7) 1932

Kol'cov Michail prodol'nyj I poperečnyj, in: Literaturnaja gazeta. (11.7.) 1932

Jugo-zapad, in: Literaturnaja gazeta, (S.1.) 1933

Belomorstoj, in: Pioner 14 (1933), S.10

Sjužet i obraz, in: Literaturnaja gazeta. (16.11) 1934

O edinoličestve $v$ literature, in: Pisateli XVIl. part s-ezda. (Hrsg.) P. Judin, M. 1934, S.233

Redebeitrag: vtoroj plenum pravlenija sojuza sovetskich pisatelej SSSR, März 1935 (Stenograph.Bericht), M. 1935, S.305-307

Iz perepiski Ju. Tymjanova I B. Ejchenbauma s V.B. Šklovskim 1925-1959, in: Voprosy literatury 12 (1984). S.185

2. Literatur uber Šklovskif (alphabetisch geordnet)

Shklovsky Viktor. An International Bibliography of Works by and about him. Compiled By R Sheldon. Ann Arbor Ardis 1977

W.Beilenhoff. Nachwort, in: Poetik des Films, S.139

A. Belyj. Veter s Kavkaza. Vpečatlenija. M. 1928

O.Beskin. Kustarnaja masterskaja literaturnoj reakcii, in: Na literaturnom postu 7 (1927), S.18

M.Blejman, Popytka portreta, Vorwort in: V.Šklovski], Za sorok let, S.4

A.Chochlova/L.Kulešov, 50 let $v$ kino, M. 1975

M.Čudakova, E.Toddes, Prototipy odnogo romana, in: Al'manach bibliofila rypusk X. M. 1981

N.Čužak, Pisatel'skaja pamjatka, in: Literatura fakta, S.9

N.Čužak, Literatura Žiznestroenija, in: Literatura fakta, S.34

B.Ejchenbaum, Kniga o Kizni, in: Krasnaja gazeta (1S. Oktober) 1926

B.Ejchenbaum. Moj vremennik, L. 1929

S.Ejzenštejn, Družeskij šarž, 1936, CGALI f.S62, opis' Nr.1, ed.chr. Nr.971

II.Erenburg. Die russische Dichterkolonie im Café "Prager Diele" (1922-1923), In: Die Lachküche, S.40 
V.Erlich, Russischer Formalismus, U.: M.Lohner, München 1964, Ffm. 1973

O.Forక̌, Sumaş̌edર̌ij korabl'. L. 1930, reprint: Washington 1964

S.Gecht, Rez. zu "Predatel", in: Kino (M) 29 (1926), S.2

M.Gel'fand, Deklaracija carja Midasa, ili Zto slučlos's Viktorom Šklovskim? in: Pečat' i revoljucija 2 (1930), S.8

L.Ginzburg, O starom i novom. L. 1982

L.Ginzburg. Tynjanov - uČenyj, in: Vospominanija o Ju.Tynjanove. M. 1983. S.147

M.Gor'kij, Pis'mo K.Fedinu ot 3 marta 1925 g.. in: Gor'kij i sovetskie pisateli. Neizdannaja perepiska. Vol. LXX. Literaturnoe nasledstvo, M. 1963, S.492

M.Gor'kij i sovetskaja pežat'. Archiv M.Gor'kogo, X.1. kniga pervaja, M. 1965

Gotor'tes k partsoveščaniju, in: Kino (M) 40 (1927), S.2

I.Graščenkova. Abram Room (Reihe: Meister des sowjetischen Theaters und Kinos), M. 1977

T.Gric, Troř̌estro V.B.Šklovskogo. O tret'ej fabrike, Baku 1927

A.Hansen-Löve. Der russische Formalismus. Methodologische Rekonstruktion seiner Entwicklung aus dem Prinzip der Verfremdung. Wien 1978

A.Hansen-Löve, Wissenschaftliche Theoretisierung künstlerischer Modelle und kinstlerische Realisierung (Literarisierung) theoretischer Modelle dargestellt am Beispiel des Russischen Formalismus, in: Wiener Slavistisches Jahrbuch Bd.24. Beiträge österreichischer Slavisten zum VIll. Internationalen SlavistenkongreB, Zagreb. Ljubljana 1978. Wien. Köln. Graz 1978. S.60

J.Holthusen. Tiergestalten und metamorphe Erscheinungen in der Literatur der russischen Avantgarde (1902-1923), in: Bayrische Akademie der Wissenschatien. Philosoph.hist.Klasse. Sitzungsberichte 12 (1974), S.3

R.Jakobson, O Cešskom stiche, Berlin 1923

RJakobson, Co je poezie? (Was ist Poesie?) (1933-1934), In: TdF 2, S.392

V.Kaverin, Skandalist ili večera na Vasil'evskom ostrove, L. 1929, 1930²,1931 ${ }^{3}$. $1963^{4}$

V.Kaverin. Sobesednik. M. 1973

A.Kurs. Rez. zu "Sentimentale Reise", in: Knigonoša 31 (1924), S.S

A.Kurs, Rez. zu"Buchta smerti", in: Sovetskij ekran 8 (1926), S.2

A.Kurs. Samoe mogušestrennoe. M.-L. 1927

M.Kuక̌nikov, Žizn' i fil'my Borisa Bameta, M. 1977 
R.Lachmann, Die Verfremdung und das neue Sehen bel Viktor Šklovskij, in: Poetica 1-2 (1970), S.226

R.Lachmann. Faktographie und Formalistische Prosatheorie, In: Ästhetik \& Kommunikation 2 (1973), S.76

M.Lalee-Waller, Les Romans de V. Šklovskij, étapes d'une évolution: 1914-1930, Université Sorbonne Paris-IV, 1983-84

A.Lejtes. Pravo na optimizm. in: Literaturnaja gazeta (10.9.) 1931

G.Lelevið, Gippokratovo lico. in: Krasnaja nov I (192S), S.299

G.Leleviz, O formal'nych vlijanijach $v$ proletarskoj poèzii, in: Pečat' i revoljucija 5 (1927) S.124

Vl.I.Lenin. Bibliografi飞eskaja chronika. t.12 (Dek. 1921 - Jan. 1924), M. 1982

E.Levin, V.Šklovskij - kinoteoretik, in: Iskusstro kino 7 (1970). S.10S

A. Ležnev, Sorremenniki. M. 1927

N.Mandelstam. Das Jahrhundert der Wolfe, U..: E.Mahler, Ffm. 1973

O.Mandel'క̌tam. Ja pišu scenarij, in: Sovetskij êkran 25 (1927), S.4

H.Marcuse, Versuch über die Befreiung, U.: H.Reinicke, A.Schmidt. Ffm. 1969

G.Maslorskij, Istroija odnoj teorii, in: Iskusstro kino 2 (1983)

F.Mierau, Konzepte. Zur Herausgabe sowjetischer Literatur. Leipzig 1979

M.Munk. Fragmentation and Unity in the Prose of V.B.Šklovsky 1923-1964, Ann Arbor 1974

M.Osorgin. Rezension zu Šklovskij, "Zoo ...”. in: Sovremennye zapiski, 17 (1923), S.486

V.Percov, Šklovskij i ego raznovidnost', in: Žizn' iskusstra 41 (1925), S.8

V.Percov, Rez. zu "Predatel" , in: Kino (M) 40 (1926), S.2

Pisatel' i poligramota, in: Literaturnaja gazeta (14.10) 1929

Vj.Polonskij, LEF ili BLEF?, in: Izvestija (27.Febr.) 1927

Protokol o Polonskom, in: NL 3 (1927), S.42

R.Sheldon. Victor Shklovsky, Literary Theory and Practice 1914-30, Ann Arbor 1967

R.Sheldon, Viktor Shklovsky and the Device of Ostensible Surrender, in: Slavic Review 1 (1975), S.86

F.Stepun, Rez. zu Šklovskij, "Sentimentale Reise", in: Sorremennye zapiski 16 (1923), S.411 
E.Šub, Krupnym planom. M. 1959

S.Tret'jakov, Linija naimenł̌ego soprotivlenija, in: Kino (M) 40 (1926), S.3

L.Trotzki. Literatur und Revolution. Miinchen 1972

Ju.Tynjanov, Literaturnyj fakt (Das literarische Faktum) (1924), in: TdF 1, S.392

Ju.Tynjanov. O literaturnoj évoljucii (Ulber die literarische Evolution) (1927), in: $T d F$ 1, S.432

Ju.Tynjanov/R.Jakobson. Problemy izučenija literatury i jazyka (Probleme der Literatur- und Sprachforschung) (1928), in: TdF 2. S.386

V.Zalesskij, O knige V.Šklovskogo "Poiski optimizma", in: Molodaja gvardija, 21-22 (1931), S.156

K.Zeliniskij, Kak sdelan Viktor Šklovskij, in: Žizn'iskusstva, 14 (1924), S.13

F. Žic. Rezension zu Šklorskij. Sentimentale Rẹise, in: Krasnaja nov'. 2 (192S). S.283

M.Zoščenko. Družeskie parodii. in: Literaturnye zapiski 2 (1922), S.8

M.Zoščenko, O sebe. o kritikach i o svoej rabote. in: ders.. Stat'i, materialy. L. 1928. S.7

3. Sonstige Texte (alphabetisch geordnet)

a) Werkausgaben

Andersens Märchen in 3 Bden. Aus dem Dänischen: E.-M. Bluhm. Ffm. 1975

W.Benjamin. Gesammelte Schriften in V Bden., (Hrsg.) R.Tiedemann/H.Schweppenhäuser. Ffm. 1972-1982

M.Bulgakov, Belaja gvardija. Teatral'nyi roman. Master i Margarita, L. 1978

Vel. Chlebnikov, Werke 1 (Poesie) und 2 (Prosa, Schriften, Briefe). (Hrsg.): P.Urban. U.: P.Urban. R.Ziegler u. zahlr. bundesdeutsche Schriftsteller. Reinbek b. Hamburg 1972

Sergej M. Eisenstein. Schriften 1-4. (Hrsg.) H.-J.Schlegel, Muinchen 1974-1984

N.Gogol', Poln.sobr.soz. v 14-ti tomach, M. 1937-1952

N.Gogol’, Sämtliche Erzählungen. U.: Josef Halm, München 1961

Vse.Ivanov, Sobr.soč. v 8-i tomach. M. 1973-78

R.Kipling. Gesammelte Werke in 3 Bden., U.: E.A.Reinhardt. München 1965 
I.Ehrenburg. Menschen - Jahre - Leben (Memoiren) in 3 Bden. U.: H.Burck, F.Mierau, R.Schröder, Berlin (DDR) 1978, $1982^{2}$

Vl.Majakovskij, Poln.sobr.soč. v 13-ti tomach. M. 1957-59;

ders., ausgewählte Werke in 5 Bden., (Hrsg.) L.Kossuth. U.: H.Huppert, Berlin (DDR) 1973-1975

R.Musil, Gesammelte Werke in 9 Bden., (Hrsg.) A.Frisé, Reinbek b. Hamburg 1978

E.A.Poe, Das gesamte Werk in zehn Bänden, (Hrsg.) K.Schumann, H.D.Müller, U.: Arno Schmidt, H.Wollschläger, Olten 1966

A.Puškin. Sobr.soð. v 10-ti tomach, M. 1975

Vs. Rozanov, Izbrannoe. (Hrsg.) E. Žiglevič, München 1970;

ders., Solitaria. Ausgewählte Schriften. Hrsg. U. U.: J.v.Guenther, Hamburg und München 1963

Lev Tolstoi, Poln.sobr.soð. v 90-ta tomach. M. 1932-1958

L.Tolstoj, Sämtliche Erzählungen in 8 Bden., U.: G. Drohla, Ffm. 1961

b) Allgemeine Literatur

Veröffentlichungen in Buchform:

Th.W.Adorno, Der Essay als Form, Noten zur Literatur I, Ffm. 1961, S.9

Th.W.Adorno, Valèrys Abweichungen, in: Noten zur Literatur II. Ffm. 1973. S.42

B.Arvatov, Kunst und Produktion (M. 1926). Hrsg. U. U.: H.Günther u. K.Hielscher, München 1972

I.Babel, Prosa, (Hrsg.) F.Mierau. Berlin 1983

M.Bachtin. Probleme der Poetik Dostoevskijs, U.: A.Schramm. Munchen 1971

M.Bachtin. Literatur und Karneval. Zur Romantheorie und Lachkultur. U.: A.Kaempfe, Munchen 1969

Belomor, An Account of the Construction of the New Canal between the White Sea and the Baltic Sea. ed. by Maxim Gorky. L.Averbach and S.G.Firin, transl. by A.Williams-Ellis. New York 1935; reprint: Hyperion Press. Westport, Connecticut 1977

H.Bergson. Das Lachen, U.: R.Plancherel-Walter, Zürich 1972

K.-H. Bohrer, Plötzlichkeit. Zum Augenblick des ästhetischen Scheins, Ffm. 1981

M. de Cervantes, Don Quijote, Ubertr. v. L.Braunfels, München $1983^{3}$

A.Crone, Rozanov and the End of Literature, Würzburg 1978 
Dialog der Texte, (Hrsg.) W.Schmid, W.-D.Stempel, Wiener Slavistischer Nmanach, Sonderband 11. Wien 1983

Dokumente zur sowjetischen Literaturpolitik. (Hrsg.) K.Eimermacher. Stuttgart 1972

B.Ejchenbaum. Molodoj Tolstoj, Petersburg/Berlin 1922, reprint: Slavische Propyläen Bd.53, 1968

Chr.Enzensberger, Literatur und Interesse. Bd.l (Theorie), München/Wien 1977

Die Expressionismusdebatte. Materialien zu einer marxistisc.sen Realismuskonzeption. (Hrsg.) H.-J.Schmitt. Ffm. 1973

Formalismus. Strukturalismus und Geschichte. Zur Literaturtheorie und Methodologie in der Sowjetunion. CSSR. Polen u. Jugoslawien, (Hrsg.) A.Flaker, V.Żmegač, Kronberg/Ts. 1974

W.Girke, H.Jachnow, Sowjetische Soziolinguistik, Kronberg/Ts 1974

U.Gregor/E.Patalas, Geschichte des Films Bd.1. Reinbek b. Hanburg 1976

T.Gric. V.Trenin. M.Nikitin. Slovesnost' i kommercija. Knjžnaja lavka Smirdina (pod redakciej V.B.Šklovskogo i B.M.Ejchenbauma), M. 1929

R.Gribel, Russischer Konstruktivismus (opera Slavica, neve folge Bd.1). Wiesbaden 1981

H.Günther. Die Verstaatlichung der Literatur. Entstehung und Funktionsweisen des sozialistisch-realistischen Kanons in der sowjetischen Literatur der 30er Jahre. Stuttgart 1984

J.Habermas, Strukturwandel der Óffentlickeit. Neuwied und Berlin $1971^{5}$

Istorija zavodor 3-4 (11. 12), M. 1934

Kak my pišem. Andrej Belyj, M.Gor'kij. Evg. Zamjatin i.dr., L 1930, reprint: Benson. Vermont 1983

V.Kaverin. Chudožnik neizvesten I drugie prolzvedenija (1931), Jerusajem 1982; Unbekannter Meister, U.: G.Drohla. Ffm. 1967

J.Kristeva, U.Eco, M.Bachtin, u.a., Textsemiotik als Ideologiekritik, Ffm. 1977

Kolloquium Kunst und Philosophie 1. Ästhetische Erfahrung. (Hrsg.) W.Oelmuller, Paderborn, München, Wien, Zürich 1981

L.Kulešov, Iskusstvo kino, M. 1929

Die Lachküche. Eine Literaturenzyklopädie in Karikaturen und Selbstzeugnissen, gez. v. den Kukryniksy, zusammengetr. v. F.Mierau, Lespzig und Weimar 1981

J.Leyda, Kino, A History of the Russian and Soviet Film. London 1960 
F.H.Link, Edgar A. Poe. Ein Dichter zwischen Romantik und Moderne, Ffm. 1968

Literature fakta. (Hrsg.) N.Čužak, M. 1929

Ju.Lotman, Aufsätze zur Theorie und Methodologie der Literatur und Kultur. (Hrsg.) K.Eimermacher. Kronberg/Ts. 1974

Ju.Lotman. Probleme der Kinoästhetik. Einfuhrung in die Semiotik des Films. U.: Chr.Böhler-Auras. Ffm. 1977

G.Lukacs. Die Seele und die Formen. Neuwied \& Berlin 1971

G.Lukács. Ästhetik I, Darmstadt \& Neuwied 1972

Majakovskij, 20 Jahre Arbeit. Katalog zur Ausstellung im Künstlerhaus Bethanien vom 12.2. bis 27.3.1978. NGBK Berlin 1978

Manifesty i programmy russkich futuristov. Mit einem Vorwort v. VI.Markov, Slavische Propyläen 27. München 1967

K.Marx. Das Kapital. Kritik der politischen Ökonomie. Bd.I. MEW 23. Berlin 1971

Marxismus und Formalismus. (Hrsg.) H.Günther. München 1973

R.Medvedev. Die Wahrheit ist unsere Stärke. (Hrsg.) D.Joravsky. G.Haupt. U.: G.Danehl, Ffm. 1973

F.Mierau. Erfindung und Korrektur. Tretjakovs Ästhetik der Operativität. Berlin 1976

Platon: Das Gastmahl (griech./dtsch.). Hamburg 1960

Poetik des Films. Texte russischer Formalisten (1927). Hrsg. U. U.: W.Beilenhoff, U.: K.Hielscher, K.Maurer, Nachwort u. Anmerkg. v. Hrsg.. München 1974

Rabočie pišut istoriju zavodov. (Hrsg.) M.Gor'ki]. M. 1933

M.Schneider, Die operative Skizze Sergej Tret'jakovs. Futurismus und Faktographie in der Zeit des 1. Fünfjahrplans. Diss., Bochum 1983

Die Serapionsbruider von Petrograd, Hrsg. u. U.: G.Drohla,Ffm. 1963; $1982^{2}$

The Serapion Brothers, (Hrsg.) G.Kern. Chr.Collins, U.: R.Sheldon. Ann Arbor 1975

K.G.Šil'dkret, Kryl'ja cholopa, M. $1928^{2}$

A.Solschenizyn. Der Archipel Gulag, U.: A.Peturnig, Bern 1974

Sozialistische Realismuskonzeptionen. Dokumente zum 1. AllunionskongreB der Sowjetschriftsteller. (Hrsg.) H.-J.Schmitt. G.Schramm, Ffm. 1974 
Sprache und Stil Lenins, (Hrsg.) F.Mierau, München 1970

G.Struve, Geschichte der Sowjetliteratur, U.: H.Neerfeld, G.Schäfer, München 1958

Texte der russischen Formalisten Bd.1. Texte zur allgemeinen Literaturtheorie und zur Theorie der Prosa, (Hrsg.) J.Striedter, München 1969

Bd.2. Texte zur Theorie des Verses und der poetischen Sprache, (Hrsg.) W.-D.Stempel, München 1972

S.Tretjakow, Lyrik, Dramatik, Prosa, (Hrsg.) F.Mierau, Leipzig 1972

S.Tretjakov, Die Arbeit des Schriftstellers, (Hrsg.) H.Boehncke, U.: K.Hielscher, Reinbek b. Hamburg 1972

S.Tretjakov, Feld-Herren. Der Kampf um eine Kollektivwirtschaft. U.: R.Selke, Berlin (Malik) 1931, reprint: Amsterdam 1972

E. Triolet. Na Taiti, L. 1925

Ju.Tynjanov, Poètika. Istorija literatury. Kino, M. 1977

\section{Aufsätze:}

Ja.Bljoch, Akter i scenarij, in: Sovetskij ékran 16 (1926), S.3

K.-M. Bogdal, Montage und Sinnkonstituierung. Nachfragen, in: alternative 117. (1977), S.270

O.Brik.Ne teorija, a lozung, in: Pečat' i revoljucija 1 (1929), S.2S

H.Brijggemann, Zivilisationskritik und ästhetische Erfahrung. Zu Edgar Allan Poes Erzählung 'Der Massenmensch'. in: Akzente 3 (1980), S.272; uiberarbeitet abgedr. in: ders., "Aber schickt keinen Poeten nach London!". GroBstadt und literarische Wahrnehmung im 18. und 19. Jahrhundert, Texte und Interpretationen, Reinbek b. Hamburg 1985, S.188

Čto my pisali i čto my uvideli na ékrane 8 (1928). S.6

N.Čužak, K zadačam dnja, in: LEF 2 (1923), S.145

K.Eimermacher, Die sowjetische Literaturpolitik zwischen 1917 und 1932, in: Dokumente zur sowjetischen Literaturpolitik, S.13

S.Eisenstein. Die Montage der Attraktionen. U.: K.Hielscher, in: Ästhetik \& Kommunikation 13 (1973), S.76

S.Eisenstein, Montage 1938, in: Sergej Eisenstein. Ausgewählte Aufsätze, Berlin (DDR) 1960. S.325

B.Ejchenbaum, Illjuzija skaza (Die Illusion des "skaz") (1918), in: TdF 1, S.160 
B.Ejchenbaum, Kak sdelana "Šinel" Gogolja (Wie Gogol's "Mantel" gemacht ist) (1918), in: TdF 1, S.122

B.Ejchenbaum. Literaturnyj byt (Das literarische Leben) (1929), in: TdF 1. S.462

J.Gruzdev, Gesicht und Maske, in: Die Serapionsbrilder von Petrograd, Hrsg. u. Ü.: G.Drohla, Ffm. 1963, $1982^{2}$, S.272

H.Günther, Utopie nach der Revolution, in: Utopieforschung, Interdisziplinäre Studien zur neuzeitlichen Utopie, (Hrsg.) W.VoBkamp. Stuttgart Bd.1, 1982, S.379

H.Günther, Michail Bachtins Konzept als Alternative zum Sozialistischen Realismus, in: P.V.Žima (Hrsg.). Semiotics and Dialectics. Ideology and Text (Linguistic and Literary Studies in Eastem Europe 5), Amsterdam 1981, S.137

K.Hielscher, Futurismus und Kulturmontage, in: alternative 122/23 (1978), S.226

J.Kristeva. Wort, Dialog und Roman bei Bachtin, in: alternative 62/63 (1966)

S.Kovacs, Kuleshov's Aesthetics, in: Film quarterly, Spring 1976, XXIX, 3,S.34

RLachmann. Intertextualität als Sinnkonstitution, Andrej Belyjs "Petersburg" und die "fremden" Texte, in: Poetica 1-2 (1983), S.66

J.Lehmann. Ambivalenz und Dialogizität, Zur Theorie der Rede bei M.Bachtin. in: F.A.Kittler/H.Turk (Hrsg.), Urszenen, Ffm. 1977, S.355

G.Lelevič, Meždu formalizmom I socializmom. Pečat' 1 revoljucija 6 (1928), S.175

G.Lukaċs, Erzählen oder Beschreiben, in: Internationale Literatur 12 (1936), S.118

Pisatel' o kino, in: Kino (M) 45 (1928), S.3

A.Room. (Ửber Aleksandra Chochlova), in: Kino (M) 11 (1926), S.2

H.Schlaffer, Der kulturkonservative Essay im 20. Jahrhundert, in: Studien zum ästhetischen Historismus, Ffm. 1975, S.140

H.-J. Schlegel, Altes und Neues in der ideoästhetischen Generallinie S.M.Eisensteins. Eine Einführung in "Die Generallinie" ("Das Alte und das Neue"). in: Sergej M. Eisenstein 4, S.7

H.-J. Schlegel, Eisensteins Weg von der "Revolutionierung des Theaters" zum Revolutionsfilm. Eine Einführung in "Streik". In: Sergej M. Eisenstein 1. S.7

H.-J. Schlegel, Montage als dialektisches Verfahren, in: alternative 117 (1977), S.265 
Ju.Striedter, Transparenz und Verfremdung. Zur Theorie des poet. Bildes in: der russ. Moderne, in: Poetik und Hermeneutik II. Immanente Ästhetik Ästhetische Reflexion. Lyrik als Paradigma der Moderne. (Hrsg.) W.Iser,. Muinchen 1966, S.263

S.Tret'jakov, Obrazoboř̌estvo, in: NL 1928, XII, S.43

S.Tret'jakov, Skvoz' neprotertye očki, in: Literatura fakta, S.227. 